Departamento de Construcción y Tecnología Arquitectónicas

Escuela Técnica Superior de Arquitectura

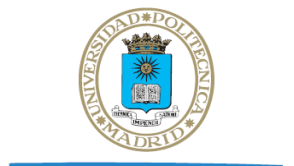

POLITÉCNICA

\title{
Optimización de la fachada de doble piel acristalada con ventilación natural. Metodología de diseño para el análisis de la eficiencia energética del sistema.
}

TESIS DOCTORAL

Edurne Sánchez Salcedo

Arquitecta 

Departamento de Construcción y Tecnología Arquitectónicas

Escuela Técnica Superior de Arquitectura

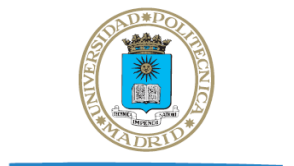

POLITÉCNICA

\section{Optimización de la fachada de doble piel acristalada con ventilación natural. Metodología de diseño para el análisis de la eficiencia energética del sistema.}

TESIS DOCTORAL

Edurne Sánchez Salcedo

Arquitecta

Directores:

Dr. Rodolfo Sant Palma

Dra. Consolación Acha Román 

Tribunal nombrado por el Sr. Rector Magfco. de la Universidad Politécnica de Madrid, el día... de. .de $20 \ldots$.

Presidente:

Vocal:

Vocal:

Vocal:

Secretario:

Suplente:

Suplente:

Realizado el acto de defensa y lectura de la Tesis el día.

de de $20 \ldots$ en la E.T.S.I. /Facultad

Calificación

EL PRESIDENTE

LOS VOCALES

EL SECRETARIO 



\section{AGRADECIMIENTOS}

A Antonio Rolando, por animarme a embarcarme en esta aventura, por su paciencia, por toda la ayuda que me ha prestado desde el principio, y por el cariño que me ha dado en todo momento.

A Rodolfo Sant, por su gran dirección, por su dedicación, por enseñarme y ayudarme tanto. Por estar siempre ahí para mí. Por todo y mucho más.

A Luis Ayuso, por su gran contribución a lo largo de la tesis, por enseñarme tanto, por su comprensión y por el ánimo y apoyo constante.

A Juan, por su ayuda y apoyo a lo largo del camino.

A la Escuela Técnica Superior de Ingeniería Aeronáutica y del Espacio, y en especial al Departamento de Aeronaves y Vehículos Espaciales, por acogerme y permitirme utilizar el laboratorio de aerodinámica donde tantas horas he pasado realizando las simulaciones necesarias para mi investigación. A mi compañero Jesús por sus consejos y los momentos que hemos pasado juntos.

A Chelo Acha, por su contribución al final de la tesis.

A mi padre Daniel, a mis hermanos Alaiz y Miguel, y a todos aquellos que están cerca de mí, por su confianza, apoyo, paciencia, ánimos y comprensión.

Muchas gracias. 


\section{ÍNDICE}

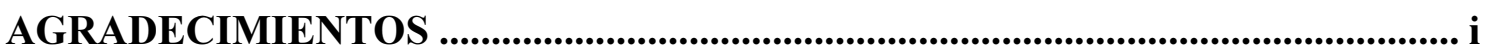

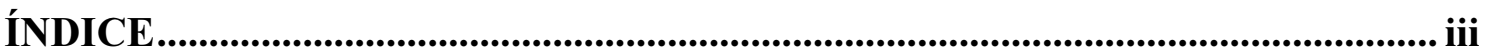

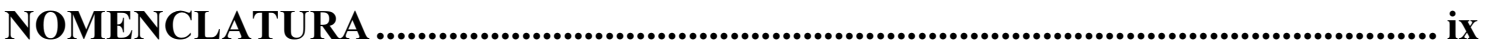

RESUMEN ........................................................................................................

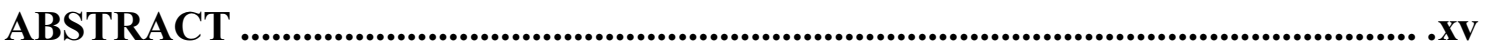

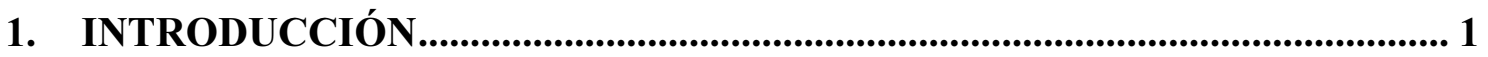

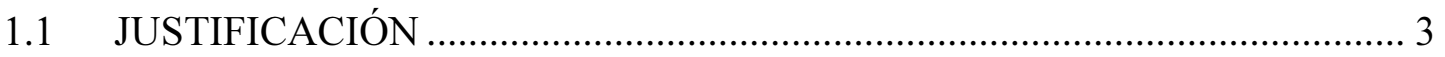

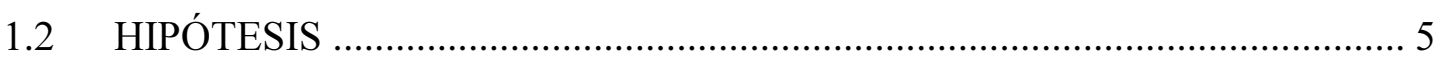

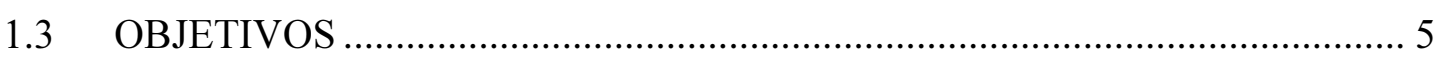

1.3.1 OBJETIVO PRINCIPAL …........................................................... 5

1.3.2 OBJETIVOS ESPECÍFICOS …...................................................... 5

1.4 METODOLOGÍA DE LA INVESTIGACIÓN ............................................. 6

2. ESTADO DE LA CUESTIÓN ................................................................ 11

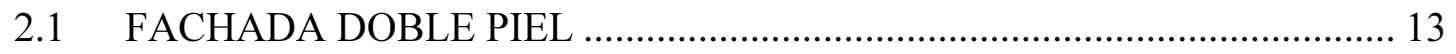

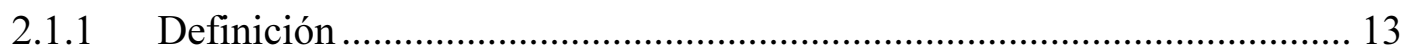

2.1.2 Ventajas y desventajas del sistema................................................... 13

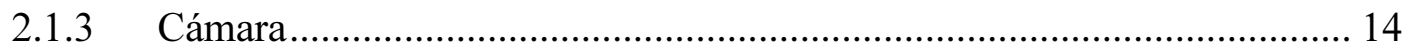

2.1.4 Dimensión y posición de las aberturas ..................................................... 14

2.1.5 Profundidad de la cámara ....................................................................... 15

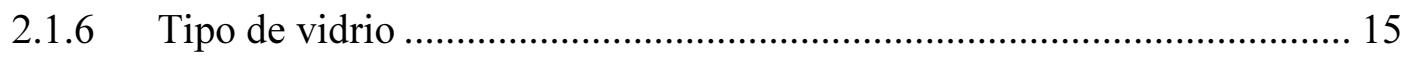

2.1.7 Definiciones presentes en la bibliografía............................................. 15

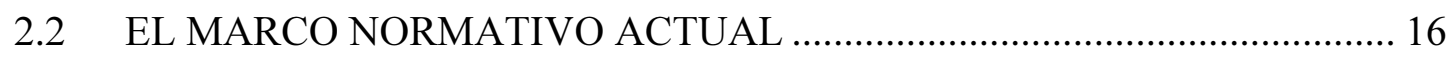

2.2.1 Características de las fachadas ligeras recogidas en las normas UNE ..... 16

2.2.2 Terminología ............................................................................... 17

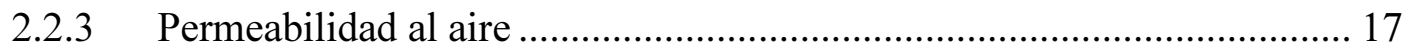

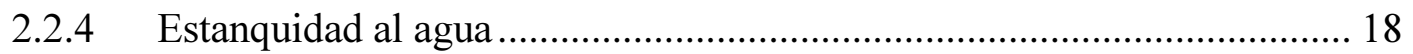

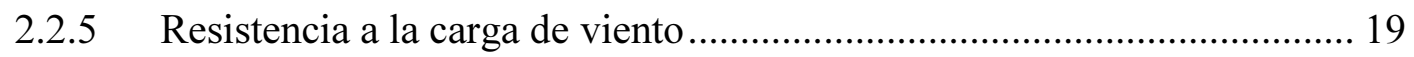

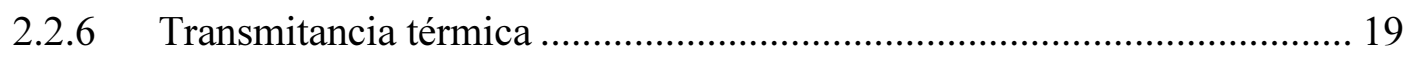




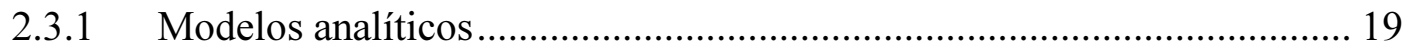

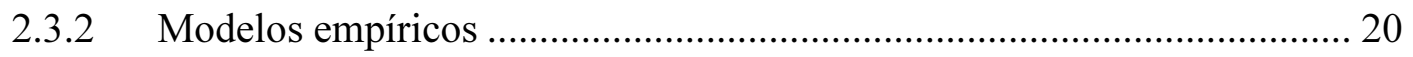

2.3.3 Modelos experimentales de pequeña escala ......................................... 20

2.3.4 Modelos experimentales a escala real .................................................. 20

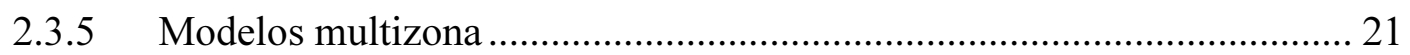

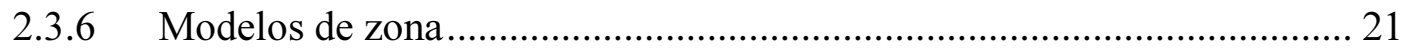

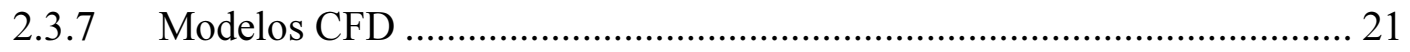

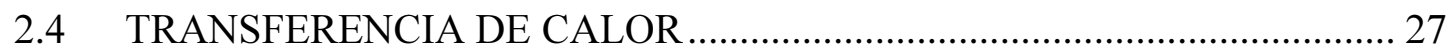

2.4.1 Propiedades térmicas de los vidrios. Mecanismos de transmisión de calor

2.4.2 Propiedades energéticas de los vidrios ................................................. 28

2.4.3 Comportamiento de la radiación solar incidente en un vidrio................. 29

2.4.4 Transferencia de calor en el sistema de fachada doble piel..................... 30

2.4.5 Normativa de aplicación..................................................................... 31

2.4.6 Métodos de cálculo que incorporan la radiación solar ........................... 32

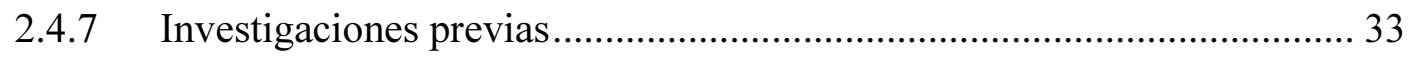

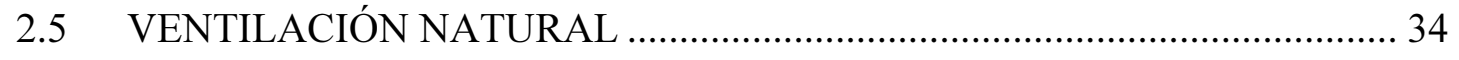

2.5.1 Tipologías de ventilación natural ....................................................... 34

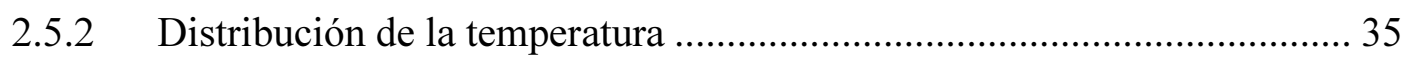

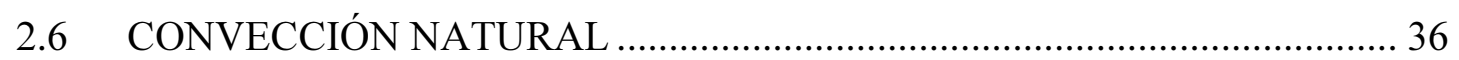

2.6.1 Números adimensionales ................................................................... 36

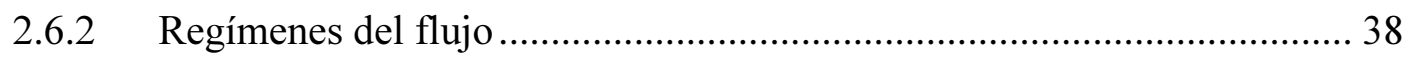

2.6.3 Investigaciones previas sobre convección natural y transferencia de calor 40

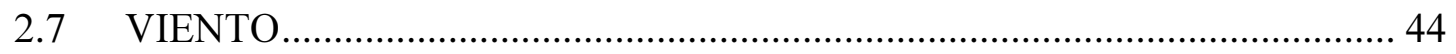

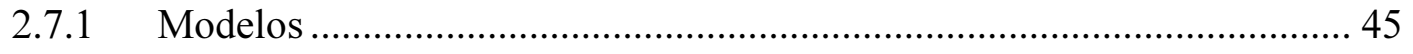

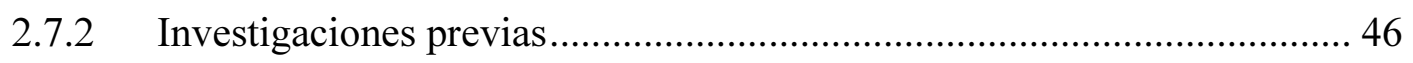

2.8 EFICIENCIA ENERGÉTICA DE LA FACHADA DOBLE PIEL ................ 48

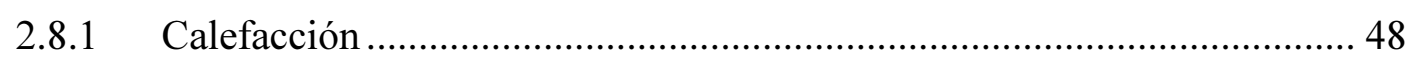

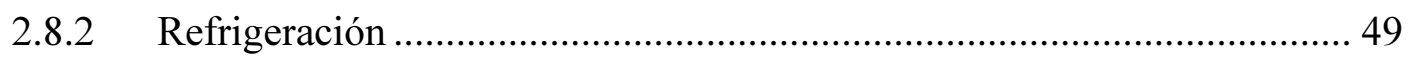

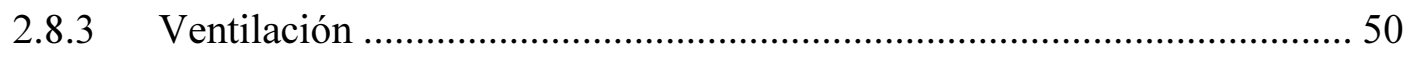

2.8.4 Comportamiento de la fachada doble piel frente a la fachada simple piel51

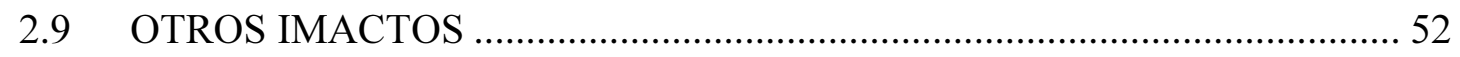

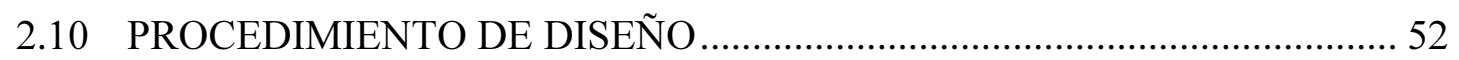

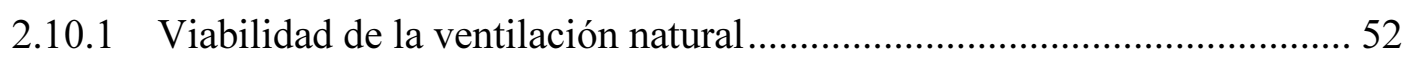

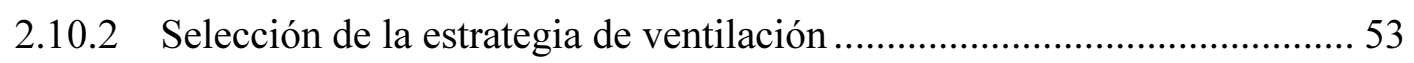




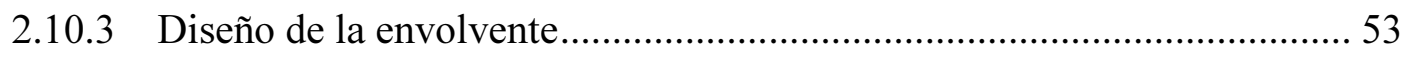

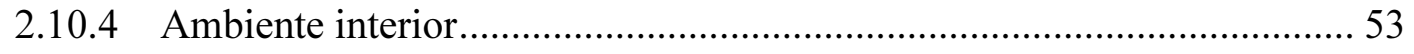

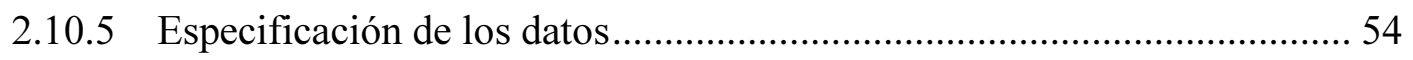

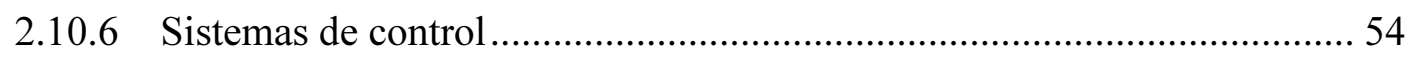

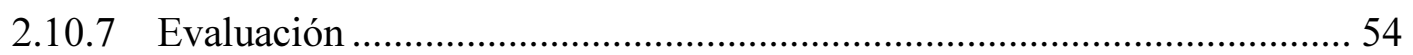

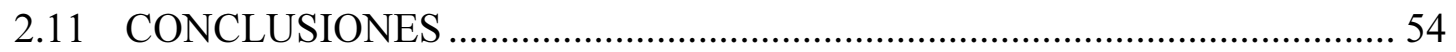

3. PLANTEAMIENTO DE LA INVESTIGACIÓN .......................................... 57

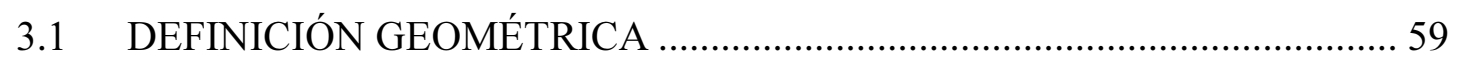

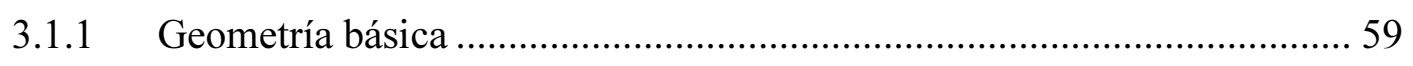

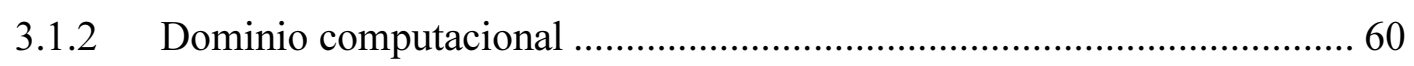

3.2 DETERMINACIÓN DE LA TEMPERATURA DE CONFORT ....................61

3.3 DETERMINACIÓN DE LA TEMPERATURA DEL AMBIENTE

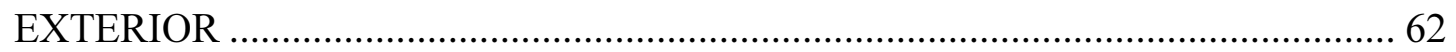

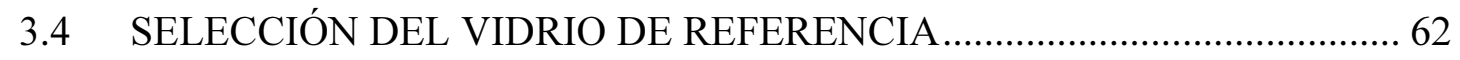

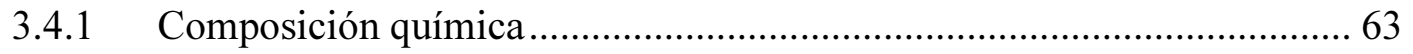

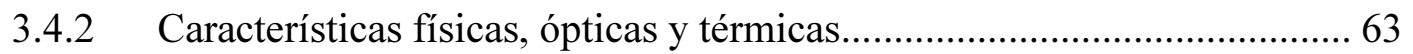

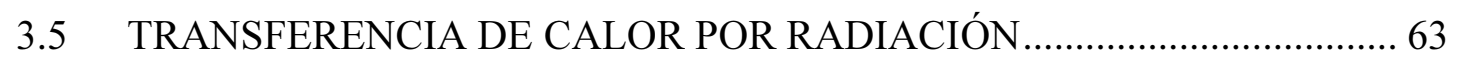

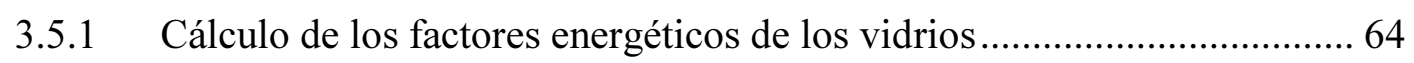

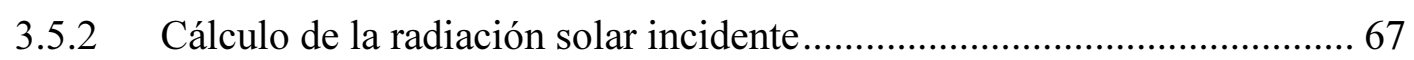

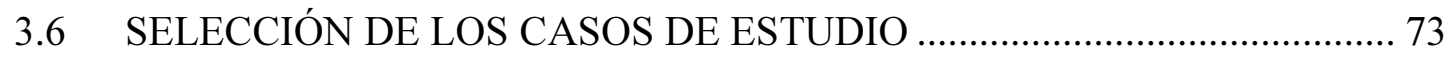

3.6.1 Flujo dominado por convección natural ................................................. 73

3.6.2 Optimización de las aberturas............................................................. 74

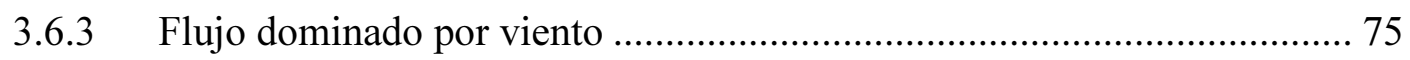

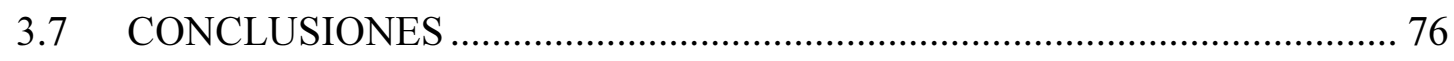

4. MODELIZACIÓN FLUIDODINÁMICA ......................................................... 81

4.1 VALIDACIÓN I. VALIDACIÓN INICIAL DEL MODELO DE

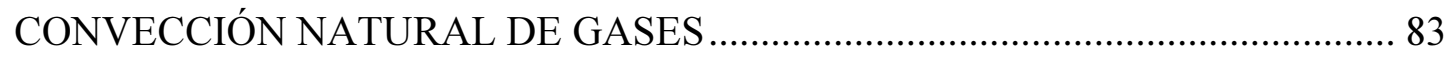

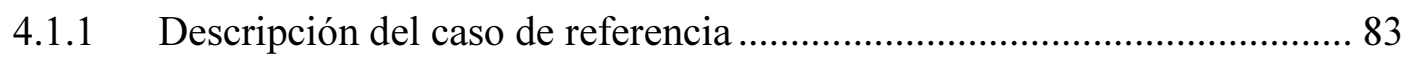

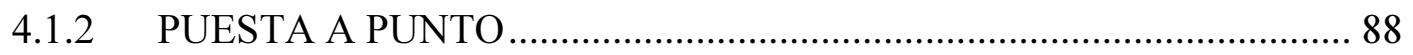

4.2 SOFTWARE DE SIMULACIÓN …....................................................... 102

4.2.1 Proceso de trabajo en ANSYS Fluent................................................. 102

4.3 FLUJO DOMINADO POR CONVECCIÓN NATURAL ............................ 103

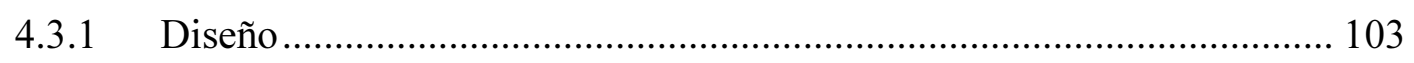

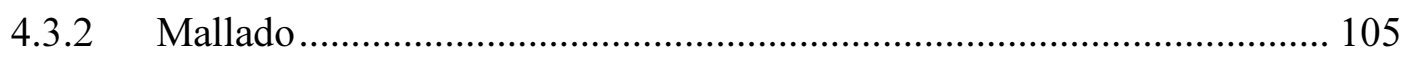




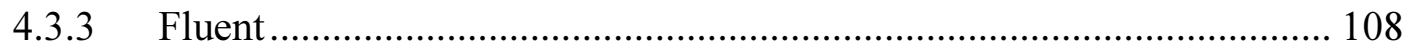

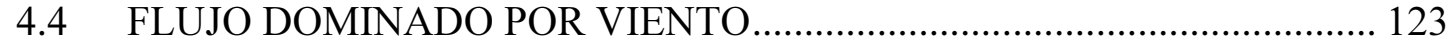

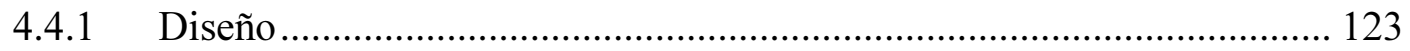

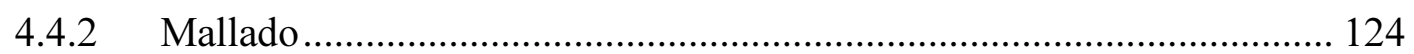

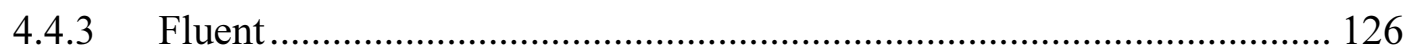

4.5 VALIDACIÓN II. VALIDACIÓN DEL MODELO NUMÉRICO DE FACHADA DOBLE PIEL ACRISTALADA INCLUYENDO LA RADIACIÓN

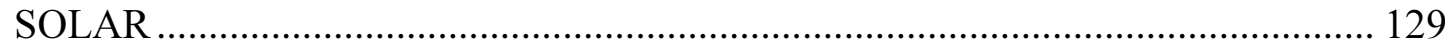

4.5.1 Descripción de la investigación de referencia ...................................... 129

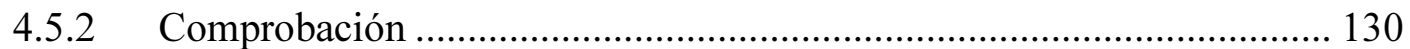

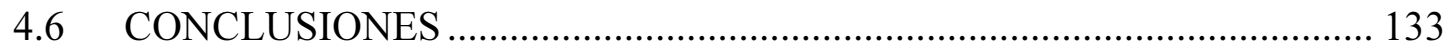

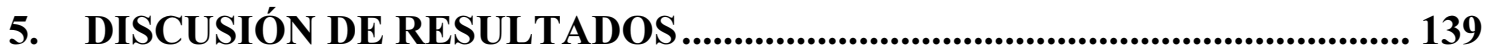

5.1 RESULTADOS DEL FLUJO DOMINADO POR CONVECCIÓN

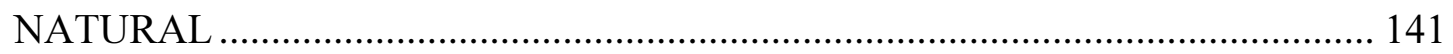

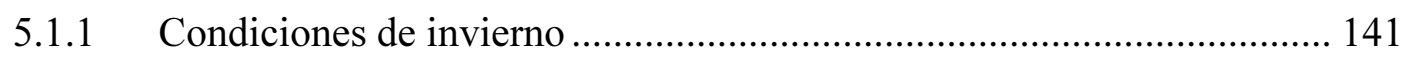

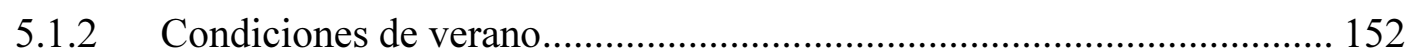

5.1.3 Optimización de las aberturas............................................................. 161

5.1.4 Análisis de eficiencia energética ........................................................ 163

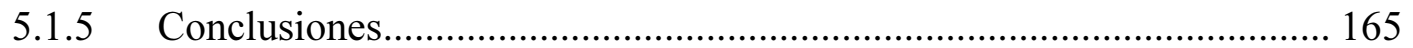

5.2 RESULTADOS DEL FLUJO DOMINADO POR VIENTO ......................... 166

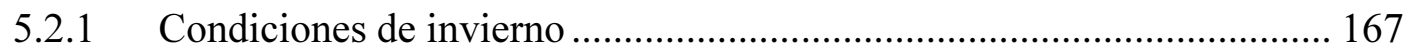

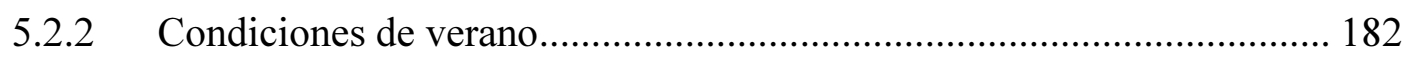

5.2.3 Análisis de eficiencia energética ........................................................ 196

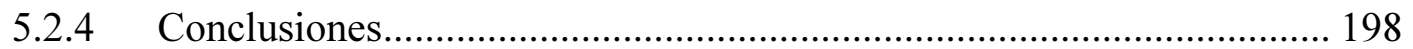

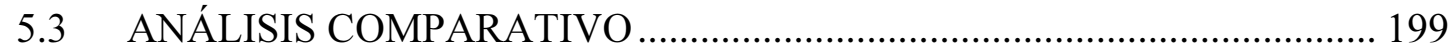

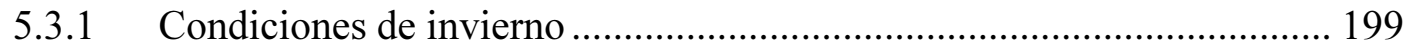

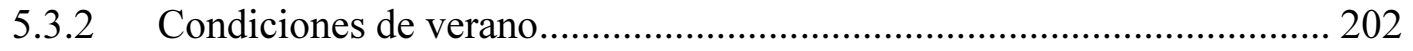

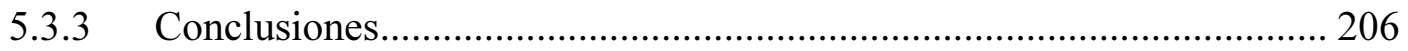

6. CONCLUSIONES FINALES Y TRABAJOS FUTUROS ............................. 207

6.1 CONCLUSIONES DEL ANÁLISIS DE RESULTADOS ............................ 209

6.1.1 Conclusiones del flujo dominado por convección natural ..................... 209

6.1.2 Conclusiones del flujo dominado por viento ...................................... 209

6.1.3 Conclusiones del análisis comparativo con la fachada simple piel ........ 210

6.2 CONCLUSIONES DEL CONJUNTO DE LA INVESTIGACIÓN .............. 212 
6.3 FUTURAS LÍNEAS DE INVESTIGACIÓN.............................................. 213

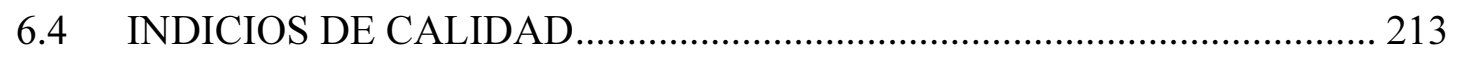

6.4.1 Contribuciones a congresos internacionales.................................... 213

6.4.2 Artículo científico ........................................................................ 213

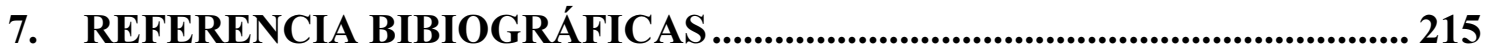

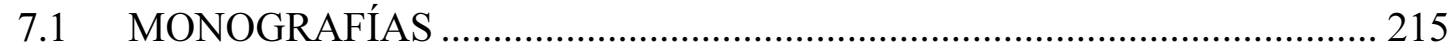

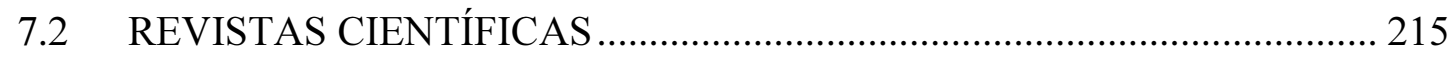

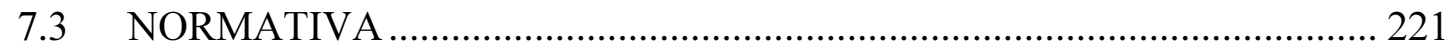

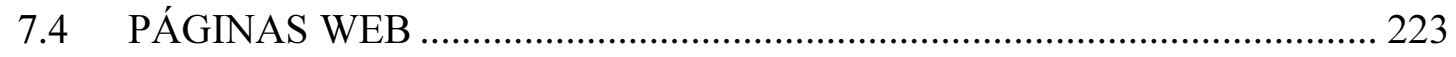

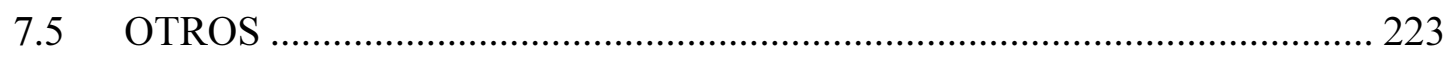

ANEXO I 


\section{NOMENCLATURA}

\section{SÍMBOLOS LATINOS}

$A$ esbeltez (adimensional)

$C_{p}$ calor específico $\left(\mathrm{Jkg}^{-1} \mathrm{~K}^{-1}\right)$

Gr número de Grashof (adimensional)

$g$ aceleración de la gravedad $\left(\mathrm{m} / \mathrm{s}^{2}\right)$

$H$ altura de la cámara $(\mathrm{m})$

$h$ coeficiente de transferencia de calor medio $\left(\mathrm{Wm}^{-2} \mathrm{~K}^{-1}\right)$

$h_{e}$ coeficiente de intercambio térmico exterior $\left(\mathrm{Wm}^{-2} \mathrm{~K}^{-1}\right)$

$h_{i}$ coeficiente de intercambio térmico interior $\left(\mathrm{Wm}^{-2} \mathrm{~K}^{-1}\right)$

$h_{n}$ altura del plano neutro (m)

$h_{v}$ altura de la abertura de entrada y de la abertura de salida (m)

$k 1$ coeficiente de la correlación de $\mathrm{Nu}$ en función de $\mathrm{Ra}_{\mathrm{L}}$

$k 2$ exponente de la correlación de $\mathrm{Nu}$ en función de $\mathrm{Ra}_{\mathrm{L}}$

$L$ ancho de la cámara (m)

$M_{w}$ peso molecular de un gas $\left(\mathrm{kgkg}^{-1} \mathrm{~mol}^{-1}\right)$

Nu número de Nusselt (adimensional)

$P$ presión del aire $(\mathrm{Pa})$

$P_{0}$ presión del aire del ambiente exterior $(\mathrm{Pa})$

$P_{i}$ presión del aire del recinto $(\mathrm{Pa})$

$P_{o p}$ presión operativa del aire $(\mathrm{Pa})$

Pr número de Prandtl (adimensional)

$Q$ flujo de calor $\left(\mathrm{W} / \mathrm{m}^{2}\right)$

$Q_{r}$ índice de generación de calor $\left(\mathrm{W} / \mathrm{m}^{3}\right)$

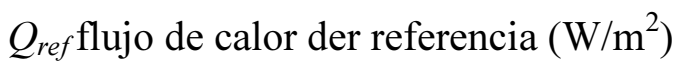


$Q_{s}$ irradiancia solar $\left(\mathrm{W} / \mathrm{m}^{2}\right)$

$q_{e}$ factor de reemisión térmica hacia el exterior (adimensional)

$q_{i}$ factor de reemisión térmica hacia el interior (adimensional)

$\mathrm{Ra}_{\mathrm{c}}$ número de Rayleigh crítico (adimensional)

$\mathrm{Ra}_{\mathrm{L}}$ número de Rayleigh (adimensional)

$\mathrm{R}_{\mathrm{g}}$ constante universal de los gases ideales (Jkg-1K-1)

$S_{\lambda}$ reparto espectral relativo de la radiación solar (adimensional)

$T$ temperatura media en el recinto $\left(\mathrm{K} \mathrm{o}{ }^{\circ} \mathrm{C}\right.$ según el contexto)

$T^{+}$temperatura media adimensional en el recinto (adimensional)

$T^{*}$ temperatura adimensional en la cámara de aire (adimensional)

$T_{c}$ temperatura del paño caliente $\left(\mathrm{K}\right.$ o ${ }^{\circ} \mathrm{C}$ según el contexto)

$T_{f}$ temperatura del paño frío ( $\mathrm{K}$ o ${ }^{\circ} \mathrm{C}$ según el contexto)

$T_{\text {ref }}$ temperatura de referencia ( $\mathrm{K}$ o ${ }^{\circ} \mathrm{C}$ según el contexto)

$t_{p}$ espesor del paño de vidrio (m)

$\Delta T$ incremento de temperatura media en el recinto ( $\mathrm{K}$ o ${ }^{\circ} \mathrm{C}$ según el contexto)

$V$ caudal de aire $\left(\mathrm{m}^{3} / \mathrm{s}\right)$

$v$ velocidad de viento $(\mathrm{m} / \mathrm{s})$

$v_{m}$ velocidad media del viento $(\mathrm{m} / \mathrm{s})$

$v_{m, r e f}$ velocidad media del viento de referencia $(\mathrm{m} / \mathrm{s})$

$X^{*}$ distancia horizontal en la cámara (adimensional)

$x$ distancia horizontal en la cámara $(\mathrm{m})$

$Y^{*}$ posición vertical en la cámara (adimensional)

$y$ posición vertical en la cámara $(\mathrm{m})$ 


\section{SÍMBOLOS GRIEGOS}

$\alpha$ difusividad térmica $\left(\mathrm{m}^{2} / \mathrm{s}\right)$

$\alpha_{e}$ factor de absorción directa de la energía solar (adimensional)

$\alpha_{e l}$ factor de absorción directa de la energía solar del vidrio exterior en el doble acristalamiento (adimensional)

$\alpha_{e 2}$ factor de absorción directa de la energía solar del segundo vidrio en el doble acristalamiento (adimensional)

$\alpha_{l}(\lambda)$ factor espectral de absorción directa del vidrio exterior, medido en el sentido de la radiación incidente (adimensional)

$\alpha_{1}^{\prime}(\lambda)$ factor espectral de absorción directa del vidrio exterior, medido en el sentido opuesto a la radiación incidente (adimensional)

$\alpha_{2}(\lambda)$ factor espectral de absorción directa del segundo vidrio, medido en el sentido de la radiación incidente (adimensional)

$\beta$ coeficiente de expansión térmica del aire $\left(\mathrm{K}^{-1}\right)$

$\gamma$ factor de transmisión total de la energía solar (factor solar) (adimensional)

$\eta$ índice de eficiencia energética

$K$ conductividad térmica $\left(\mathrm{Wm}^{-1} \mathrm{~K}^{-1}\right)$

$\Lambda$ conductancia térmica $\left(\mathrm{Wm}^{-2} \mathrm{~K}^{-1}\right)$

$\lambda$ longitud de onda (m)

$\Delta \lambda$ intervalo de longitud de onda (m)

$\mu$ viscosidad dinámica $(\mathrm{Pa} \cdot \mathrm{s})$

$v$ viscosidad cinemática $\left(\mathrm{m}^{2} / \mathrm{s}\right)$

$\rho$ densidad $\left(\mathrm{kg} / \mathrm{m}^{3}\right)$

$\rho_{e}$ factor de reflexión directa de la energía solar (adimensional)

$\rho_{l}(\lambda)$ factor de reflexión espectral del primer vidrio (exterior), medido en el sentido de la radiación incidente (adimensional)

$\rho_{l}^{\prime}(\lambda)$ factor de reflexión espectral del primer vidrio (exterior) medido en el sentido opuesto a la radiación incidente (adimensional) 
$\rho_{2}(\lambda)$ factor espectral de reflexión del segundo vidrio, medido en el sentido de la radiación incidente (adimensional)

$\tau_{e}$ factor de transmisión directa de la energía solar (adimensional)

$\tau_{l}(\lambda)$ factor de transmisión espectral del primer vidrio (exterior) (adimensional)

$\tau_{2}(\lambda)$ factor de transmisión espectral del segundo vidrio (adimensional) 


\section{RESUMEN}

En los últimos años, el interés por las fachadas de doble piel acristaladas ha aumentado por razones estéticas y por su uso como sistema pasivo para el ahorro de energía. Algunos autores han investigado su comportamiento en relación con el rendimiento térmico y con la eficiencia energética en comparación con la fachadas simple piel pero considerando solamente la cámara de aire.

El objetivo de esta tesis es identificar una configuración de fachada de doble piel acristalada que optimice la eficiencia energética del edificio y que permita unas condiciones interiores de confort óptimas estudiando su comportamiento tanto en el caso dominado por convección natural como por viento, y la transferencia de calor incluyendo la radiación solar, en comparación con una fachada simple piel.

Se ha desarrollado una metodología de diseño para analizar la eficiencia energética del sistema de fachada de doble piel acristalada con ventilación natural para el caso de un edificio de una planta, en dos dimensiones, con un tipo concreto de vidrio y en la zona centro de España, en particular en Madrid; pero esta metodología es extrapolable a un edificio de mayor altura, en tres dimensiones, con otros tipos de vidrios y en diferentes localizaciones.

Se simula un modelo simplificado utilizando un software de dinámica de fluidos para realizar una investigación más extensa en la que el modelo se analiza de forma más amplia: el ambiente exterior, la cámara de aire, el ambiente interior; variando la geometría: esbeltez de la cámara, cámara abierta y cerrada, tamaño de las aberturas; y bajo diferentes configuraciones: condiciones de invierno y verano, con radiación solar y sin ella, con viento en la fachada de barlovento y de sotavento bajo diferentes velocidades. En todas las situaciones se estudian y analizan los fenómenos que tienen lugar desde el punto de vista de la distribución de temperaturas, transferencia de calor y comportamiento del flujo de aire.

Los resultados muestran que existe una esbeltez óptima de cámara de aire que además aumenta la superficie útil por ser un ancho de cámara moderado. Los principales resultados obtenidos son que en invierno siempre es eficiente mantener la cámara cerrada alcanzándose hasta el $75 \%$ de ahorro de energía. En verano, mantener la cámara cerrada es eficiente en ausencia de radiación solar alcanzándose hasta el $65 \%$ de ahorro de energía, pero en presencia de radiación solar abrir la cámara es más favorable produciéndose un ahorro del $4 \%$ de energía respecto de la fachada de simple piel y de un 5,4\% respecto a mantenerla cerrada. En presencia de viento el ahorro de energía es, en general, mayor respecto a la fachada de simple piel, aunque, como era de esperar, el aislamiento térmico es algo menor respecto del caso sin viento.

Se concluye que la fachada doble piel acristalada reduce el consumo de calefacción y de refrigeración de un edificio siendo bastante más eficiente energéticamente en comparación con la fachada simple piel. 


\begin{abstract}
In recent years, the interest in double skin facades has increased because of aesthetic reasons and for its use as passive system to save energy. Some authors have investigated their behavior related to thermal performance and energy efficiency compared to single skin facades but only considering the air cavity.

The aim of this thesis is to identify a more efficient double glazed facade configuration that optimizes energy efficiency and indoor comfort conditions in buildings studying natural ventilation due to buoyancy-driven flow and wind pressure, and heat transfer including solar radiation compared to a single skin facade.
\end{abstract}

A design methodology for the energy efficiency analysis of the double skin glazed facade system with natural ventilation has been developed for the case of a 2D one-story building with a specific glass, in the center of Spain, in particular in Madrid; but this methodology can be extrapolated to a 3D multi-story building with others types of glass and at different locations.

A simplified model was simulated using a computational fluid dynamics software to perform a more extensive research where the model is broadly analyzed: outside environment, air cavity and inside environment; varying the geometry: cavity width with closed and opened cavity vents, vents size; and under different configurations: winter and summer conditions, with and without solar radiation, wind on the windward and on the leeward facade and with different wind speeds. In all situations, the phenomena that take place from the point of view of temperature distribution, heat transfer and airflow characteristics, are studied and analyzed.

Results show that an optimum aspect ratio exists which also increases the gross internal area for being a moderate air cavity width. The main results obtained are that in winter closed vents is always efficient reaching up to $75 \%$ of energy savings. In summer closed vents is efficient in the absence of solar radiation reaching up to $65 \%$ energy savings, but in its presence opened vents is more favorable producing an energy saving of 4\% compared to a single skin facade and a $5.4 \%$ compared to keep them closed. In the presence of wind the energy saving is greater in general compared to single skin facade, although, the thermal insulation is somewhat lower compared to the buoyancy-driven flow situation, as expected.

It was concluded that these double skin facades reduce the heating and cooling consumption of a building, being considerably more efficient compared to single skin facades. 


\section{INTRODUCCIÓN}

En este capítulo se presenta el contexto general en el que se lleva a cabo la presente tesis.

Se describe la importancia de la fachada doble piel acristalada como sistema pasivo para mejorar el rendimiento térmico y la eficiencia energética de los edificios.

Se describen las fuerzas que impulsan la ventilación natural y la importancia de la transferencia de calor a través de los paños de la fachada.

Se establece el enfoque en torno al que se desarrolla la investigación: convección natural, viento, radiación solar, eficiencia energética y condiciones interiores de confort.

Por último, se expone la hipótesis, se plantean los objetivos que se proponen para evaluar la hipótesis, y se describe la metodología seguida para la consecución de los objetivos mencionados. 
Optimización de la fachada de doble piel acristalada con ventilación natural. Metodología de diseño para el análisis de la eficiencia energética del sistema. 


\subsection{JUSTIFICACIÓN}

La fachada doble piel es una tipología de fachada que consiste en dos paños separados por una cámara de aire a través de la cual fluye el aire. Generalmente el paño exterior es completamente de vidrio, mientras que el paño interior puede ser parcialmente opaco. En la presente tesis los dos paños son de vidrio. Este tipo de fachadas pueden incorporar aberturas para ventilar la cámara de aire cuando están abiertas.
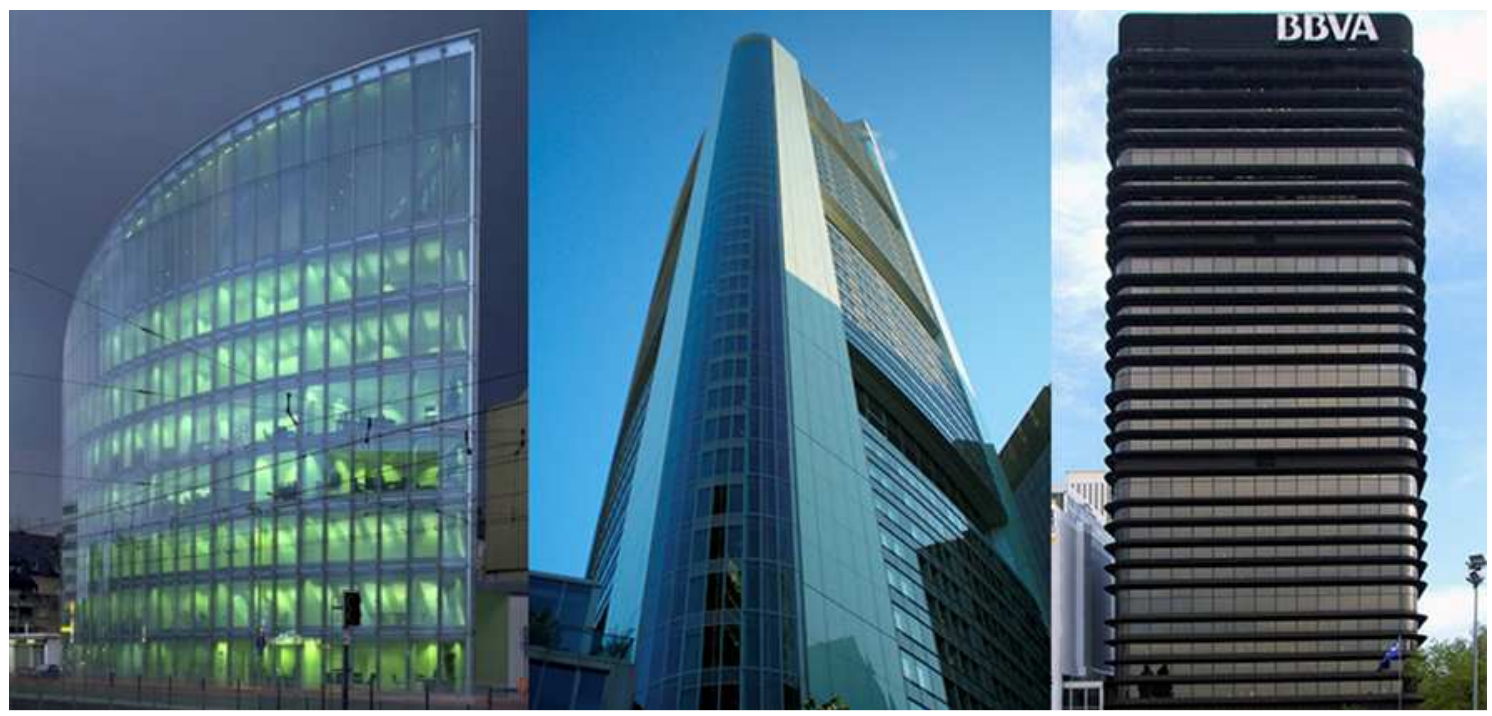

En los últimos años, el estudio y el interés por este tipo de fachadas ha aumentado. Normalmente se utilizan en edificios comerciales por razones estéticas. La ventaja de las fachadas doble piel es que admiten un grado alto de luz diurna por su gran área acristalada, sin embargo, puede tener pérdidas de calor en invierno y altas ganancias de calor en verano debido a la transmisión de energía solar hacia el interior con el posible sobrecalentamiento del edificio como consecuencia.

Las fachadas doble piel pueden utilizarse como sistema pasivo para mejorar el rendimiento térmico y la eficiencia energética de un edificio. Estas fachadas pueden utilizarse como una alternativa eficiente para reducir el uso de energía en los edificios.

Las fuerzas que impulsan la ventilación natural en las fachadas doble piel son: la convección natural, el viento o la combinación de ambas. En esta tesis se estudian ambas situaciones.

La convección natural en cámaras rectangulares con paredes a diferente temperatura se ha estudiado de forma analítica, empírica, numérica y experimental durante años. Se ha estudiado la transición de flujo laminar a flujo turbulento, las características del flujo, los fenómenos que tienen lugar en el interior de la cámara y las variables que intervienen en el proceso. La transferencia de calor en los flujos dominados por convección natural son de vital importancia en diversas aplicaciones arquitectónicas como las cámaras de las ventanas, las cámaras de fachadas ventilas y chimeneas solares, entre otras.

El viento es uno de los fenómenos más importantes que afectan a las fachadas doble piel acristaladas. Las variables que intervienen en la ventilación natural dominada por viento 
y que han sido investigas por varios autores son: presión, velocidad y dirección del viento, y la temperatura. A lo largo de los años se han realizado diversos experimentos, tanto a escala real como a pequeña escala en túnel de viento y modelos numéricos, para obtener información fiable relacionada con el flujo de aire y la distribución de presiones alrededor y en el interior de un edificio ventilado naturalmente.

En los últimos años se ha investigado el comportamiento de las fachadas simple piel en relación con el rendimiento térmico y la eficiencia energética en los edificios en comparación con el sistema de fachada simple piel. Algunos autores han utilizado programas de Dinámica de Fluidos Computacional o CFD (acrónimo de las palabras inglesas Computational Fluid Dynamics) para analizar el impacto de varios parámetros en la fachada doble piel, tales como orientación, viento, protección solar, profundidad de la cámara, tipo de acristalamiento, tamaño de las aberturas, condiciones climáticas y nivel de radiación solar, entre otros.

Otros autores llevaron a cabo experimentos a escala real para cuantificar el rendimiento térmico y la transmitancia de energía de las fachadas simple y doble piel. Se concluyó que si las fachadas doble piel se diseñan cuidadosamente, se conseguiría un comportamiento térmico mejor en comparación con las fachadas convencionales, y también reducirían el consumo de energía. Ésta es una tarea difícil por la complejidad de los fenómenos físicos involucrados.

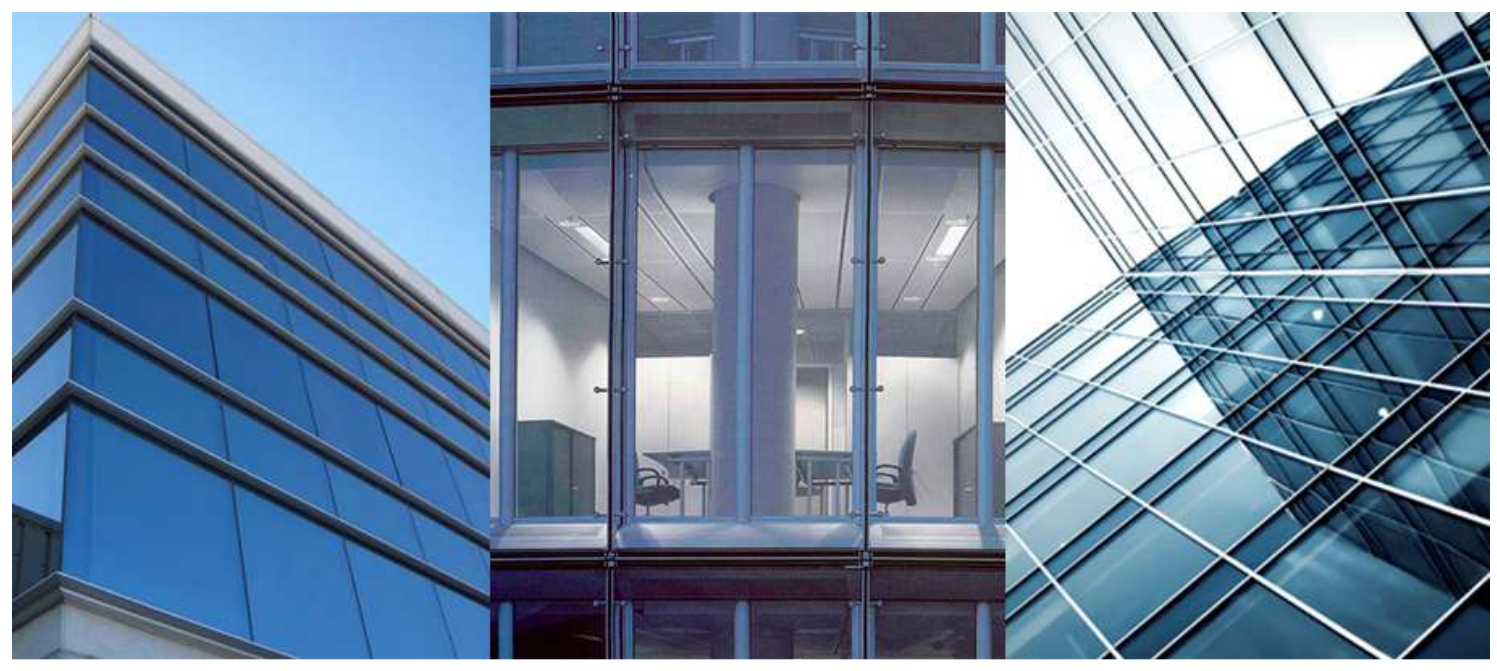

El propósito de esta tesis es estudiar la ventilación natural y la transferencia de calor en la fachada doble piel acristalada en comparación con la fachada simple piel convencional. Otras investigaciones sólo han estudiado los fenómenos que tienen lugar en la cámara de aire, y muchos de ellos no varían ni la geometría del modelo ni las condiciones de contorno ni tienen en cuenta la radiación solar.

Se utiliza un modelo CFD que incluye conducción, convección y radiación para estudiar de forma global el comportamiento de las fachadas doble piel. El objetivo es alcanzar una configuración de fachada doble piel acristalada que optimice la eficiencia energética del edificio, de tal forma que se reduzca el consumo de calefacción y refrigeración.

La novedad es que se realiza una investigación más extensa en la que el modelo se analiza de forma más amplia: el ambiente exterior, la cámara de aire, el ambiente 
interior; variando la geometría: ancho de cámara, cámara abierta y cerrada, tamaño de las aberturas; y bajo diferentes configuraciones: condiciones de invierno y verano, con radiación solar y sin ella, con viento en la fachada de barlovento y de sotavento bajo diferentes velocidades. En todas las situaciones se estudian y analizan los fenómenos que tienen lugar desde el punto de vista de la distribución de temperaturas, transferencia de calor, regímenes y comportamiento del flujo de aire.

El objetivo es alcanzar o identificar una configuración de fachada que mejore la eficiencia energética del edificio proporcionando unas condiciones interiores de confort óptimas.

\subsection{HIPÓTESIS}

Como ya es conocido, la fachada doble piel acristalada, tiene mayor resistencia térmica, y por tanto mejor grado de aislamiento térmico, frente a la fachada simple piel. Estoy convencida de que existe un valor de anchura de la cámara de aire, que unido a la posibilidad de abrirla al exterior, optimiza el ahorro de energía para mantener las condiciones de confort interior en una gran variedad de condiciones climáticas.

\subsection{OBJETIVOS}

\subsubsection{OBJETIVO PRINCIPAL}

Identificar una configuración de fachada doble piel acristalada que mejore la eficiencia energética del edificio y que permita unas condiciones interiores de confort óptimas estudiando la ventilación natural y la transferencia de calor e incluyendo la radiación solar en comparación con una fachada simple piel.

\subsubsection{OBJETIVOS ESPECÍFICOS}

1. Alcanzar el conocimiento necesario sobre mecánica de fluidos y del software que se va a utilizar para la investigación.

2. Analizar el conocimiento existente sobre el sistema y sobre los distintos aspectos que intervienen en las prestaciones de la fachada doble piel acristalada.

3. Generar un modelo numérico que permita variar:

- La geometría:

- Simple piel

- Doble piel: ancho de cámara, cámara abierta y cerrada.

- La configuración:

- Escenario: invierno y verano

- Radiación solar: con o sin 
- Viento: velocidad y dirección

4. Realizar un análisis comparativo del comportamiento térmico y energético de la fachada doble piel frente a la fachada simple piel considerando las siguientes variables y la sinergia entre ellas:

- Convección natural

- Viento

- Radiación solar

- Transferencia de calor

- Distribución de temperaturas

- Regímenes del flujo

- Comportamiento del flujo de aire

5. Analizar los resultados de forma más amplia teniendo en cuenta el ambiente exterior, la cámara de aire y el interior del modelo de estudio.

6. Alcanzar una configuración de fachada doble piel que mejore la eficiencia energética del edificio y que permita unas condiciones interiores de confort óptimas.

7. Generar una metodología para llevar a cabo el análisis numérico del índice de eficiencia energética del sistema de fachada doble piel frente al de fachada simple piel.

8. Evaluar la eficiencia energética, el ahorro o el gasto energético, en los meses que hay que calefactar o refrigerar un edificio con fachada doble piel acristalada en comparación con la fachada simple piel para determinar el sistema más eficiente.

\subsection{METODOLOGÍA DE LA INVESTIGACIÓN}

Para alcanzar estos objetivos, en primer lugar se realizan diversas investigaciones en distintos ámbitos: el marco normativo existente; técnicas teóricas, numéricas y experimentales; tesis doctorales; patentes; e investigaciones científicas relacionadas con el tema de la presente tesis publicadas en revistas científicas de impacto, monografías y en congresos nacionales e internacionales. De este punto se detecta la necesidad de:

- Investigar la fachada doble piel de una forma más amplia y desde el punto de vista de todos los aspectos que intervienen en la eficiencia energética del sistema $\mathrm{y}$ en el cumplimiento de las prestaciones.

- Desarrollar una metodología de diseño que evalúe el rendimiento y la eficiencia energética de la fachada doble piel acristalada dentro de unas condiciones de confort óptimas.

Tomando estas dos necesidades como punto de partida, se desarrolla la investigación que consta de cuatro fases siguiendo el siguiente esquema: 


\begin{tabular}{|c|c|c|c|c|c|c|c|c|}
\hline $\begin{array}{l}\text { FASE I. } \\
\text { Estado de la cuestión }\end{array}$ & & $\begin{array}{l}\text { Ventilación natural } \\
\text { en fachada doble piel } \\
\text { acristalada }\end{array}$ & $>$ & $\begin{array}{l}\text { Conclusiones } \\
\text { parciales }\end{array}$ & & $\begin{array}{l}\text { Relación de sistema, } \\
\text { eficiencia energética } \\
\text { y cond iciones de } \\
\text { confort óptimas }\end{array}$ & 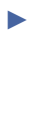 & $\begin{array}{l}\text { Metodología de diseño } \\
\text { para el análisis de la } \\
\text { eficiencia energética }\end{array}$ \\
\hline $\begin{array}{l}\text { FASE II. } \\
\text { Planteamiento de la } \\
\text { investigación }\end{array}$ & $\checkmark$ & $\begin{array}{l}\text { Definición modelo } \\
\text { y dominio } \\
\text { computacional }\end{array}$ & $>$ & $\begin{array}{l}\text { Determinación } \\
\text { de condiciones } \\
\text { de referencia }\end{array}$ & 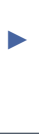 & $\begin{array}{l}\text { Cálculo de la } \\
\text { transferencia de } \\
\text { calor por radiación }\end{array}$ & $\checkmark$ & $\begin{array}{l}\text { Selección de los casos } \\
\text { de estudio }\end{array}$ \\
\hline $\begin{array}{l}\text { FASE III. } \\
\text { Modelización } \\
\text { fluidodinámica }\end{array}$ & & Validación I & $\checkmark$ & $\begin{array}{l}\text { Conclusiones } \\
\text { parciales }\end{array}$ & 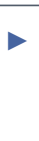 & $\begin{array}{l}\text { Diseño del modelo y } \\
\text { definición de los } \\
\text { parámetros de cálculo }\end{array}$ & 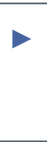 & Validación II \\
\hline $\begin{array}{l}\text { FASE IV. } \\
\text { Discusión de resultados }\end{array}$ & & $\begin{array}{l}\text { Tratamiento y } \\
\text { análisis de datos }\end{array}$ & $\checkmark$ & $\begin{array}{l}\text { Análisis } \\
\text { eficiencia } \\
\text { energética }\end{array}$ & $\checkmark$ & $\begin{array}{l}\text { Análisis } \\
\text { comparativo }\end{array}$ & 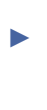 & $\begin{array}{l}\text { Conclusiones } \\
\text { parciales }\end{array}$ \\
\hline
\end{tabular}

Figura 1.1. Esquema de metodología.

Para ello, se han adquirido los conocimientos necesarios sobre mecánica de fluidos para abordar el tema de investigación planteado en la presente tesis, así como el aprendizaje de un software informático específico para modelar y simular los sistemas de fachada.

La tesis está dividida en 6 capítulos, siendo la introducción el capítulo 1 y las conclusiones y futuros trabajos el 6. A continuación se describe brevemente el contenido de los principales capítulos (capítulo 2 a capítulo 6):

\section{Capítulo 2: Estado de la cuestión}

En este capítulo se analiza el marco normativo actual en relación con la fachada ligera, a nivel de sus componentes y en relación con las prestaciones que cumple.

Se estudia el estado de la técnica mediante el análisis de los distintos métodos o herramientas existentes para la predicción de la ventilación natural en edificios con fachada doble piel.

Asimismo, se estudia el estado de la investigación de las fachadas doble piel en relación con la transferencia de calor y la ventilación natural (convección natural y viento). Se recogen diversos trabajos de investigación de ámbitos distintos seleccionados por su relevancia y relación con esta investigación.

Se analizan los aspectos relativos a la eficiencia energética del sistema prestando especial atención a aquellos factores de los que depende.

Finalmente, se analiza el procedimiento de diseño de la fachada doble piel considerando todos los factores que intervienen. 


\section{Capítulo 3: Planteamiento de la investigación}

En este capítulo se realiza el planteamiento geométrico y la determinación de algunas propiedades físicas y parámetros presentes en la investigación.

Se describen las características geométricas y el dominio computacional del modelo utilizado en las simulaciones CFD, así como la selección del tipo de vidrio utilizado.

Se definen algunas propiedades físicas de las condiciones de contorno del modelo como la temperatura de confort del ambiente interior y la temperatura media del ambiente exterior necesarias para el cálculo numérico en los diferentes escenarios.

Se establecen los parámetros que intervienen en la transferencia de calor por radiación en función del tipo de vidrio seleccionado, situación y orientación de la fachada, y escenario de estudio.

Por último se presentan los diferentes casos que se van a estudiar tanto para las situaciones de flujo dominado por convección natural como para las situaciones de flujo dominado por viento.

\section{Capítulo 4: Modelización fluidodinámica}

En este capítulo se describe el proceso de modelización de la fachada doble piel y del dominio para la simulación numérica de los diferentes casos de estudio desarrollados en la presente tesis.

En primer lugar, se realiza una validación inicial del modelo de convección natural de gases para definir el modelo y las condiciones de cálculo adecuadas. Para ello se utiliza una investigación publicada en revista científica de impacto como caso de referencia.

Se justifica la elección del software de simulación y se explica el proceso de trabajo en CFD.

Se define el diseño del modelo, del mallado y el modelo físico y numérico utilizado tanto para la simulación de los casos de flujo dominado por convección natural como para los casos de flujo dominado por viento.

Por último, se procede a la validación del modelo numérico de fachada doble piel acristalada incluyendo la radiación solar. Para ello se reproduce una investigación de similares características publicada en revista científica de impacto.

\section{Capítulo 5: Discusión de los resultados}

En este capítulo se presentan, analizan y discuten los resultados obtenidos de las simulaciones CFD.

Primero se muestran los resultados obtenidos para los casos de ventilación natural producida por convección natural bajo todas las variables y alternativas estudiadas. Se 
analizan los resultados obtenidos desde el punto de vista de la temperatura media en la habitación, la distribución de temperaturas y el comportamiento del flujo en la cámara de aire, y la transferencia de calor.

Se identifica la configuración de fachada doble piel óptima que mejora la eficiencia energética del edificio proporcionando unas condiciones interiores de confort adecuadas.

A continuación, se muestran los resultados obtenidos para los casos de ventilación natural producida por viento para el caso de la configuración de fachada óptima bajo todas las variables y alternativas estudiadas. Asimismo, se analiza la influencia del viento en el sistema de fachada doble piel.

Por último, se analiza la eficiencia energética de la fachada doble piel óptima en comparación con la fachada simple piel convencional en los distintos escenarios.

\section{Capítulo 6: Conclusiones finales y trabajos futuros}

En este capítulo se recogen las principales conclusiones de la aplicación del sistema de fachada doble piel acristalada como sistema pasivo para mejorar el rendimiento térmico y la eficiencia energética de los edificios frente al sistema de fachada simple piel, y se exponen las conclusiones finales de la integración del conjunto de esta investigación.

A continuación, se proponen futuras líneas de investigación en dos direcciones, la de dar continuidad y conclusión a los trabajos aquí realizados y la de abrir nuevos caminos.

Finalmente, se presentan los resultados científicos resultado de esta investigación. 
Optimización de la fachada de doble piel acristalada con ventilación natural. Metodología de diseño para el análisis de la eficiencia energética del sistema. 


\section{ESTADO DE LA CUESTIÓN}

En este capítulo se analiza el marco normativo actual en relación con la fachada ligera, a nivel de sus componentes y en relación con las prestaciones que cumple.

Se estudia el estado de la técnica mediante el análisis de los distintos métodos o herramientas existentes para la predicción de la ventilación natural en edificios con fachada doble piel.

Asimismo, se estudia el estado de la investigación de las fachadas doble piel en relación con la transferencia de calor y la ventilación natural (convección natural y viento). Se recogen diversos trabajos de investigación de ámbitos distintos seleccionados por su relevancia y relación con esta investigación.

Se analizan los aspectos relativos a la eficiencia energética del sistema prestando especial atención a aquellos factores de los que depende.

Finalmente, se analiza el procedimiento de diseño de la fachada doble piel considerando todos los factores que intervienen. 
Optimización de la fachada de doble piel acristalada con ventilación natural. Metodología de diseño para el análisis de la eficiencia energética del sistema. 


\subsection{FACHADA DOBLE PIEL}

\subsubsection{Definición}

La fachada doble piel es una tipología de fachada compuesta por múltiples capas: una piel exterior generalmente de vidrio, una cámara de aire en el espacio intermedio y una piel interior generalmente de vidrio también. Asimismo, esta tipología de fachadas doble piel con ambas fachadas de vidrio, se denominan muro cortina.

Estas fachadas se encuentran en edificios modernos sobre todo de oficinas.

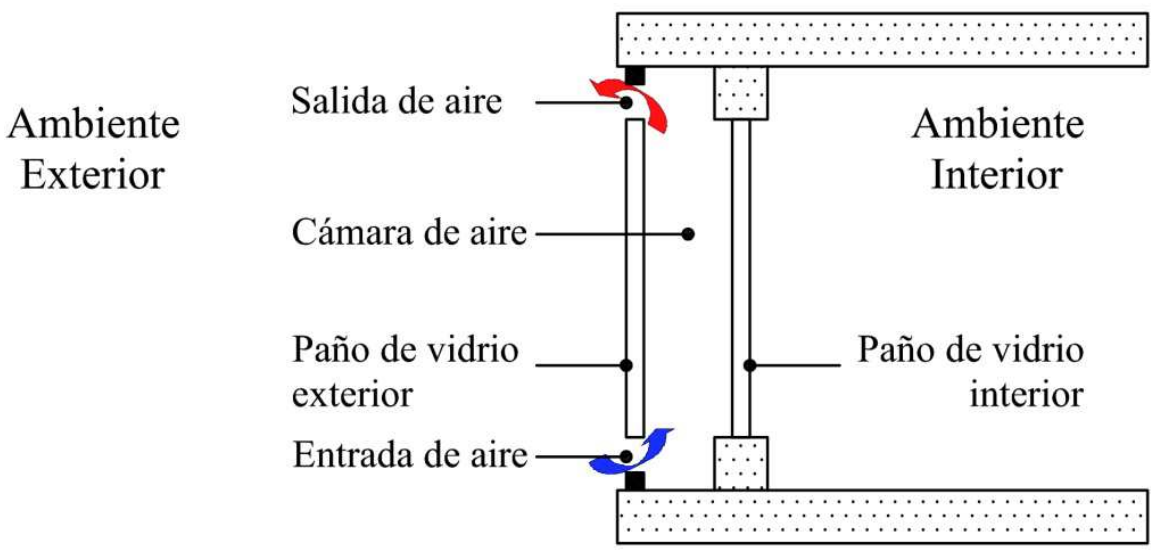

Figura 2.1. Geometría y composición esquemática del sistema de fachada doble piel de vidrio.

Los modos de ventilación de una fachada doble piel pueden ser natural, forzada y mixta. La ventilación natural de la fachada doble piel está basada en la convección natural producida por la diferencia de temperatura entre el exterior y el interior de la cámara. Este fenómeno se incrementa por el efecto de la radiación solar y por la transmitancia a través de los vidrios. El viento también puede influenciar la ventilación natural en la cámara.

En el diseño de la fachada doble piel hay que tener en cuenta: la geometría, condiciones climáticas, la orientación (generalmente a sur), dimensiones de la cámara (altura y profundidad), dimensión y posición de las aberturas, el tipo de vidrio de ambas pieles (simple, doble, laminar de seguridad, bajo emisivo, etc.), la carga de viento, la ventilación y el flujo de aire, el sombreamiento, y el sistema de control, entre otros.

La cámara ventilada se utiliza para acumular o evacuar la radiación solar absorbida por las fachadas de vidrio y realizar la ventilación natural del edificio, y de este modo mejorar el confort térmico y la calidad del aire interior mientras conserva la energía para calefactar y refrigerar.

La fachada doble piel puede ahorrar energía en el edificio cuidando su diseño. La cantidad de energía ahorrada depende del clima y del diseño escogido.

\subsubsection{Ventajas y desventajas del sistema}

$\underline{\text { Ventajas: }}$ 
- Buena estética.

- Admite una gran superficie.

- Transparencia, permite al edificio estar en contacto con el espacio exterior que le rodea.

- Aumento de la luz diurna.

- Acceso moderado al aire fresco.

- Control solar y reducción del deslumbramiento, admite gran cantidad de luz diurna sin reflejos.

- Temperatura moderada, confort.

- Ventilación natural.

- Reducción del consumo de energía, reducción del consumo de calefacción / refrigeración.

- Aislamiento acústico, reducción del ruido exterior.

- Se comportan térmicamente mejor que las fachadas convencionales simple piel.

\section{Desventajas:}

- Mantenimiento.

- Limpieza.

- Sobrecalentamiento en condiciones de verano, obligando a consumir más energía en refrigeración.

- Protección contra el fuego por propagación del mismo por la cámara.

- Coste mayor que el de las fachadas convencionales por: el nivel de sofisticación, situación, método constructivo y experiencia de las personas que lo montan.

\subsubsection{Cámara}

Existen dos tipos de cámaras:

- Dividirse a nivel de cada forjado, por lo que habrá aberturas de entrada y salida en cada planta.

- Extenderse a lo largo de toda la altura del edificio, por lo que habrá una sola entrada y una sola salida.

\subsubsection{Dimensión y posición de las aberturas}

La disposición de la cámara puede ser de diferentes maneras:

- Si la cámara está divida por plantas, habrá entradas y salidas cerca del techo y del suelo de cada sección.

- La configuración de una sola cámara en todo el edificio es la que crea un mayor flujo de aire debido a la gran altura de la cámara. Este es el denominado efecto chimenea, que consiste en un tiro de aire provocado por la existencia de un gradiente térmico considerable entre el interior y el exterior del edificio. Cuanto 
más alta es la cámara, más poderoso es el efecto chimenea. Si se combina con el viento, el efecto se ve reforzado.

\subsubsection{Profundidad de la cámara}

La mayoría de los estudios que han considerado diferentes anchos para las cámaras, han determinado que esta variable no tiene grandes efectos en el comportamiento térmico de la fachada doble piel.

\subsubsection{Tipo de vidrio}

Algunos estudios han demostrado que la selección del vidrio apropiado puede reducir la carga térmica del edificio considerablemente. Generalmente el vidrio exterior suele ser distinto del vidrio interior. La selección del vidrio más apropiado requiere un análisis térmico meticuloso para determinar el rendimiento energético de la fachada. Para ello es importante conocer la situación del edificio, orientación, condiciones medioambientales y posibles sombras. También requiere conocer la duración del periodo de invierno y de verano.

\subsubsection{Definiciones presentes en la bibliografía}

En la bibliografía existen varias definiciones para el sistema de fachada doble piel:

- Según Safer et al. (2005) la fachada doble piel es una tipología especial de fachada donde una segunda piel, generalmente de vidrio transparente, se coloca por delante de un edificio con una fachada convencional. La cámara de aire entre ellas puede ser bastante importante (hasta $0,8-1 \mathrm{~m}$ ). Generalmente, la cámara está ventilada naturalmente, mecánicamente o con un sistema híbrido para disminuir el problema de sobrecalentamiento en verano y para contribuir al ahorro de energía en invierno.

- Ding et al. (2005) declararon que la fachada doble piel está compuesta por una fachada externa, un espacio intermedio y una fachada interior. La fachada exterior de vidrio proporciona protección contra el clima exterior y mejora el aislamiento acústico contra el ruido exterior.

- Roth et al. (2007), Baldinelli (2009) declararon que en comparación con la fachada simple piel, la fachada doble piel consiste en un acristalamiento exterior desplazado del acristalamiento interior integrado en un muro cortina, y a menudo controlable por un sistema de sombreamiento posicionado en la cámara que se encuentra entre los dos sistemas de vidrio. El acristalamiento exterior es un paño simple de vidrio de seguridad o laminado, mientras que el acristalamiento interior consiste en un paño simple o doble con o sin ventanas practicables.

- Kim y Song (2007), expusieron que las fachadas doble piel son fachadas multicapa con una piel exterior, un espacio intermedio y una piel interior. Las 
pieles interior y exterior pueden ser de paños de vidrio simple o doble o de seguridad.

- Chan et al. (2009) afirmaron que las fachadas doble piel hacen referencia a la fachada de un edificio que está cubierta por múltiples pieles de vidrio. Estas pieles pueden estar ventiladas natural o mecánicamente. La piel exterior es generalmente de un paño de vidrio simple y la piel interior puede ser de un paño de vidrio doble. El ancho de la cámara de aire entre las dos pieles puede alcanzar desde $200 \mathrm{~mm}$ hasta $2 \mathrm{~m}$. La fachada doble piel puede aumentar el aislamiento térmico del edificio y reducir la pérdida de calor en invierno. Por otro lado, el movimiento de aire en el interior de la fachada doble piel ventilada puede absorber la energía procedente de la radiación solar absorbida por el vidrio y reducir la ganancia de calor así como el consumo de refrigeración del edificio.

\subsection{EL MARCO NORMATIVO ACTUAL}

\subsubsection{Características de las fachadas ligeras recogidas en las normas UNE}

La Norma UNE 13830: Norma de producto es una norma marco a partir de la cual cuelgan muchas otras de desarrollo más específico. Recoge los requisitos básicos de las fachadas ligeras y las características técnicas que deben medirse para cumplir dichos requisitos. La siguiente tabla muestra ambos conceptos.

\begin{tabular}{|c|c|c|c|}
\hline $\begin{array}{l}\text { Norma UNE-EN } 13830 \\
\text { Apartado }\end{array}$ & Requisitos de prestaciones & $\begin{array}{l}\text { Norma } \\
\text { de clasificación }\end{array}$ & $\begin{array}{l}\text { Norma de ensayo } \\
\text { y cálculo }\end{array}$ \\
\hline 4.1 & Resistencia a la carga de viento & EN 13116 & EN 12179 \\
\hline 4.2 & Peso propio & Valores declarados & EN 1991-1-1 \\
\hline 4.3 & Resistencia al impacto & EN 14019 & EN 12600 \\
\hline 4.4 & Permeabilidad al aire & EN 12152 & EN 12153 \\
\hline 4.5 & Estanquidad al agua & EN 12154 & $\begin{array}{l}\text { EN } 12155 \\
\text { EN } 13050\end{array}$ \\
\hline 4.6 & Atenuación al ruido aéreo & $\begin{array}{l}\text { Según lo requiera la } \\
\text { reglamentación }\end{array}$ & $\begin{array}{l}\text { EN ISO 10140-2 } \\
\text { EN ISO } 717-1\end{array}$ \\
\hline 4.7 & Transmitancia térmica & Valores declarados & EN ISO 12631 \\
\hline 4.8 & Resistencia al fuego & EN 13501-2 & $\begin{array}{l}\text { EN 1364-3 } \\
\text { EN 1364-4 }\end{array}$ \\
\hline 4.9 & Reacción al fuego & EN 13501-1 & EN 13501-1 \\
\hline 4.10 & Propagación del fuego & \multicolumn{2}{|c|}{ Según lo requiera la reglamentación } \\
\hline 4.11 & Durabilidad & \multicolumn{2}{|c|}{ Valores declarados } \\
\hline 4.12 & Permeabilidad al vapor de agua & \multicolumn{2}{|l|}{ Valores declarados } \\
\hline 4.13 & Equipontencialidad & \multicolumn{2}{|c|}{ Según lo requiera la reglamentación } \\
\hline 4.14 & Resistencia al choque sísmico & \multicolumn{2}{|c|}{ Según lo requiera la reglamentación } \\
\hline 4.15 & Resistencia al choque térmico & \multicolumn{2}{|c|}{ Según lo requiera la reglamentación } \\
\hline 4.16 & Movimiento del edificio y térmico & \multicolumn{2}{|c|}{ Valores declarados } \\
\hline 4.17 & $\begin{array}{l}\text { Resistencia a cargas vivas } \\
\text { horizontales }\end{array}$ & Valores declarados & EN 1991-1-1 \\
\hline
\end{tabular}

Tabla 2.1. Requisitos básicos y características técnicas de las fachadas ligeras. (UNE EN 13830) 
A continuación se describen algunas de las características de obligado cumplimiento de las fachadas ligeras de aplicación en la presente tesis.

\subsubsection{Terminología}

La Norma UNE 13119: Terminología define la terminología empleada en las normas relativa a los diferentes elementos constructivos de las fachadas ligeras.

\subsubsection{Permeabilidad al aire}

La permeabilidad al aire es la propiedad de una fachada ligera de dejar pasar el aire cuando está sometida a una presión positiva o negativa. Se mide en $\mathrm{m}^{3} / \mathrm{h}$, esta propiedad está relacionada con la superficie total de la fachada ligera. De forma alternativa, la proporción puede estar relacionada con la longitud en metros de junta.

La Norma UNE 12152: Permeabilidad al aire. Requisitos de funcionamiento y clasificación especifica y clasifica los requisitos de la permeabilidad al aire de los elementos, tanto fijos como de apertura, de una fachada ligera, sometida a la presión del aire.

Según la norma UNE 12152, la fachada ligera con elementos fijos puede ser clasificada como se indica a continuación:

\begin{tabular}{|c|c|c|}
\hline $\begin{array}{c}\text { Presión máxima } \\
\boldsymbol{P}_{\text {máx. }}(\mathbf{P a})\end{array}$ & $\begin{array}{c}\text { Permeabilidad al aire } \\
\mathbf{m}^{3} / \mathbf{m}^{2} \cdot \mathbf{h}\end{array}$ & Clase \\
\hline 150 & 1,5 & $\mathrm{~A} 1$ \\
300 & 1,5 & $\mathrm{~A} 2$ \\
450 & 1,5 & $\mathrm{~A} 3$ \\
600 & 1,5 & $\mathrm{~A} 4$ \\
$>600$ & 1,5 & $\mathrm{AE}$ \\
\hline
\end{tabular}

Tabla 2.2. Clases de permeabilidad al aire (A) basada en la superficie total. (UNE EN 12152)

\begin{tabular}{|c|c|c|}
\hline $\begin{array}{c}\text { Presión máxima } \\
\boldsymbol{P}_{\text {máx. }}(\mathbf{P a})\end{array}$ & $\begin{array}{c}\text { Permeabilidad al aire } \\
\mathbf{m}^{\mathbf{3}} / \mathbf{m}^{2} \cdot \mathbf{h}\end{array}$ & Clase \\
\hline 150 & 0,5 & $\mathrm{~A} 1$ \\
300 & 0,5 & $\mathrm{~A} 2$ \\
450 & 0,5 & $\mathrm{~A} 3$ \\
600 & 0,5 & $\mathrm{~A} 4$ \\
$>600$ & 0,5 & $\mathrm{AE}$ \\
\hline
\end{tabular}

Tabla 2.3. Clases de permeabilidad al aire (A) basada en la longitud de junta fija. (UNE EN 12152)

El método para determinar la permeabilidad al aire de una fachada ligera se define en la norma UNE 12153: Permeabilidad al aire. Método de ensayo donde se describe como debe ser ensayada la muestra bajo la presión del aire. 


\subsubsection{Estanquidad al agua}

La estanquidad al agua es la capacidad de la fachada ligera para resistir la penetración de agua.

La Norma UNE 12154: Estanquidad al agua. Requisitos y clasificación define los requisitos y la clasificación de prestaciones de estanquidad al agua, tanto de las partes fijas como de las móviles, de una fachada ligera bajo la presión del aire.

La muestra debe ser ensayada de acuerdo con el método que define la Norma UNE 12155: Estanquidad al agua. Ensayo de laboratorio bajo presión estática para determinar la estanquidad al agua de la fachada ligera.

Según la norma, se definen cinco clases con la finalidad de cubrir adecuadamente todas las condiciones a experimentar:

\begin{tabular}{|c|c|c|}
\hline Clases & $\begin{array}{l}\text { Escalones de presión Pa y duración del ensayo en minutos } \\
\qquad \mathrm{Pa} / \mathrm{T}\end{array}$ & $\begin{array}{l}\text { Proporción de } \\
\text { rociado } \\
\text { de agua } \\
\mathrm{l} / \mathrm{min} \cdot \mathrm{m}^{2}\end{array}$ \\
\hline $\mathrm{R} 4$ & $0 / 15 ; 50 / 5 ; 100 / 5 ; 150 / 5$ & 2 \\
\hline R5 & $0 / 15 ; 50 / 5 ; 100 / 5 ; 150 / 5 ; 200 / 5 ; 300 / 5$ & 2 \\
\hline R6 & $0 / 15 ; 50 / 5 ; 100 / 5 ; 150 / 5 ; 200 / 5 ; 300 / 5 ; 450 / 5$ & 2 \\
\hline R7 & $0 / 15 ; 50 / 5 ; 100 / 5 ; 150 / 5 ; 200 / 5 ; 300 / 5 ; 450 / 5 ; 600 / 5$ & 2 \\
\hline RE $x x x$ & $\begin{array}{c}0 / 15 ; 50 / 5 ; 100 / 5 ; 150 / 5 ; 200 / 5 ; 300 / 5 ; 450 / 5 ; 600 / 5 \\
\text { por encima de } 600 / 5 \text { en escalones de } 150 \text { Pa y de } 5 \text { minutos de } \\
\text { duración }\end{array}$ & 2 \\
\hline
\end{tabular}

Tabla 2.4. Escalones de presión. (UNE EN 12154)

De acuerdo con los resultados, la fachada ligera puede ser clasificada como se indica a continuación:

\begin{tabular}{|c|c|}
\hline Máxima presión de ensayo $\mathbf{P}_{\max }$ en Pa & Clasificación \\
\hline 150 & $\mathrm{R} 4$ \\
300 & $\mathrm{R} 5$ \\
450 & $\mathrm{R} 6$ \\
600 & $\mathrm{R} 7$ \\
Por encima de 600 & $\mathrm{RE}$ xxx \\
\hline
\end{tabular}

Tabla 2.5. Clasificación. (UNE EN 12154)

Existen otros ensayos suplementarios, no requeridos para la clasificación, que se pueden emplear cuando sea necesario. Como el método definido en la Norma UNE 13051 para identificar los puntos de fugas de agua en las fachadas ligeras, o el método de ensayo definido en la Norma UNE 13050 utilizado para evaluar la estanquidad al agua. 


\subsubsection{Resistencia a la carga de viento}

La acción del viento sobre una fachada provoca presiones positivas y negativas sobre ella, y deben ser soportadas sin que se deforme.

La Norma UNE 13116: Resistencia a la carga de viento. Requisitos y prestaciones define los requerimientos de prestación estructural de fachadas ligeras bajo la carga de viento bajo una presión de aire estática positiva y negativa.

La muestra debe ser sometida a ensayo de acuerdo con la Norma UNE 12179: Resistencia a la carga de viento. Método de ensayo.

El DB SE AE fija las condiciones para características específicas. De estos cálculos se obtiene la presión de diseño requerida.

\subsubsection{Transmitancia térmica}

La transmitancia térmica es la medida del calor por unidad de tiempo y superficie transferido a través de un sistema constructivo formado por una o más capas de material de caras planas y paralelas cuando hay un gradiente térmico de $1{ }^{\circ} \mathrm{C}$ entre los dos ambientes que éste separa. Se mide en $\mathrm{W} / \mathrm{m}^{2} \mathrm{~K}$ ó en $\mathrm{Wm}^{2 \circ} \mathrm{C}$.

El cálculo de la transmitancia térmica de las fachadas ligeras es complicado porque están formadas por distintos tipos de materiales y uniones y variaciones en su geometría.

La Norma UNE 12631: Prestaciones térmicas de las fachadas ligeras. Cálculo de la transmitancia térmica especifica un método para el cálculo de la transmitancia térmica de las fachadas ligeras. El cálculo incluye diferentes tipos de acristalamiento, marcos y paneles; pero no incluye los efectos de la radiación solar ni la transferencia de calor causada por pérdidas de aire, entre otros.

\subsection{MÉTODOS PARA LA PREDICCIÓN DE LA VENTILACIÓN NATURAL EN EDIFICIOS}

Existen varios métodos para estudiar la ventilación natural: modelos analíticos, modelos empíricos, modelos experimentales de pequeña escala, modelos experimentales a escala real, modelos multizona, modelos de zona y modelos de Dinámica de Fluidos Computacional o CFD (acrónimo de las palabras inglesas Computational Fluid Dynamics).

\subsubsection{Modelos analíticos}

Se derivan de las ecuaciones fundamentales como la masa, momento y conservación de la energía. Los modelos analíticos utilizan simplificaciones tanto en la geometría como en las condiciones de contorno para alcanzar una solución. Son los métodos más antiguos de predicción de la ventilación. Hoy en día se siguen utilizando mucho por su 
simplicidad, su significado físico y porque requiere pocos recursos computacionales. La contribución de los modelos analíticos a la investigación es mínima ya que se lleva desarrollando desde hace mucho tiempo.

\subsubsection{Modelos empíricos}

$\mathrm{Al}$ igual que los modelos analíticos, los modelos empíricos se desarrollan a partir de las ecuaciones de conservación de la masa, el momento y la energía. Los modelos analíticos y empíricos no difieren mucho, simplemente que los modelos empíricos utilizan más aproximaciones que los modelos analíticos. Los típicos modelos empíricos predicen la velocidad y la temperatura del aire en problemas de ventilación.

\subsubsection{Modelos experimentales de pequeña escala}

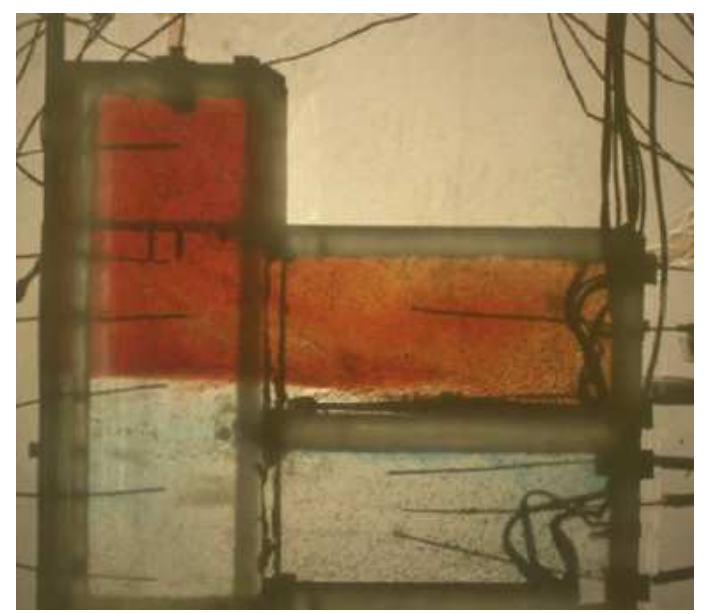

Figura 2.2. Modelo de pequeña escala. Tanque lleno de agua para la visualización del flujo en un edificio de dos plantas con un atrio. "Ventilation performance prediction for buildings: A method overview and recent applications". Chen, 2009.
Los modelos experimentales de pequeña escala utilizan técnicas de medición para predecir o evaluar la ventilación en edificios o habitaciones de pequeña escala. Es mucho más económico utilizar un modelo de pequeña escala que un modelo a escala real. Para alcanzar unos valores similares con el modelo de pequeña escala que con el de escala real, se tienen que utilizar los parámetros adimensionales del flujo. Cuando interviene la transferencia de calor, es difícil obtener los mismos valores.

Los modelos experimentales de pequeña escala proporcionan una visualización del flujo excelente y se utilizan principalmente para validar los modelos analíticos, empíricos o numéricos.

\subsubsection{Modelos experimentales a escala real}

Los modelos experimentales a escala real son un método ampliamente utilizado para predecir la ventilación en edificios. Se utilizan principalmente para generar datos para validar los modelos numéricos, especialmente los modelos CFD.

Pueden clasificarse en dos categorías: experimentos de laboratorio y mediciones in-situ para evaluar el comportamiento de edificios existentes. Si hay que tener en cuenta el viento, la cámara debe colocarse en un túnel de viento, lo que incrementa el coste del experimento. Estos experimentos proporcionan las predicciones más realistas de ventilación en edificios, pero también tienen errores. Los equipos de medición necesitan calibrarse con frecuencia y tienen sus limitaciones. Además, conllevan mucho tiempo. 


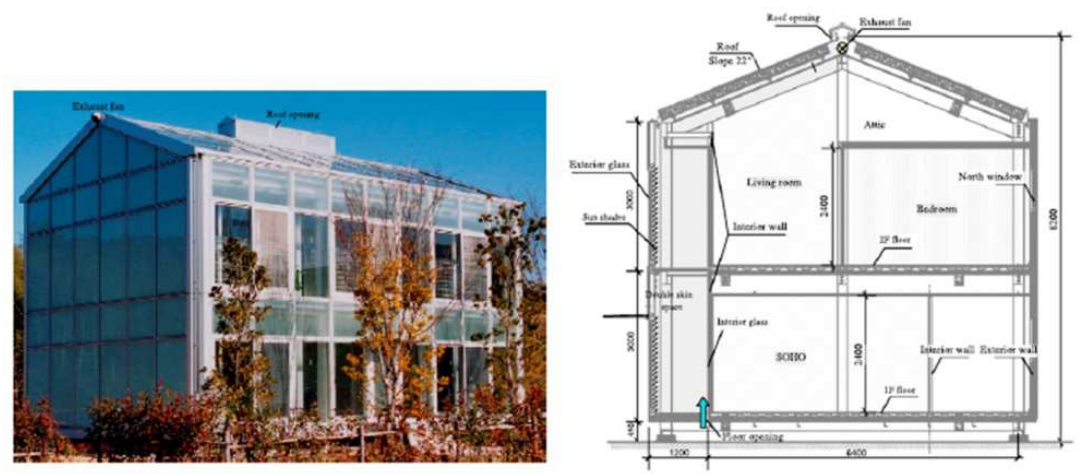

Figura 2.3. Experimento a escala real de un edificio de dos plantas con fachada doble piel. "Field experiments on natural energy utilization in a residential house with a double skin façade system". Xu et al., 2007.

\subsubsection{Modelos multizona}

Los modelos multizona se utilizan generalmente para predecir la tasa de intercambio de aire y la distribución del flujo en edificios con o sin sistemas de ventilación mecánica. También pueden utilizarse para calcular la eficiencia de la ventilación y el consumo de energía.

\subsubsection{Modelos de zona}

Los modelos multizona no pueden utilizarse para espacios interiores grandes con sistema de ventilación estratificada. Para ello se utilizan los modelos de zona, para predecir la distribución de temperatura mediante la división del espacio en celdas. Este método no es sencillo y conlleva bastante tiempo, más que para las simulaciones CFD.

\subsubsection{Modelos CFD}

La simulación CFD es uno de los métodos más importantes para el estudio de la ventilación natural. Puede predecir simultáneamente el flujo de aire y la transferencia de calor en el interior de los edificios y en el espacio exterior a su alrededor. Proporciona una distribución espacial detallada de la temperatura, presión, velocidad y turbulencia del aire. Modelar en CFD es muy útil para el diseño de edificios confortables térmicamente y eficientes energéticamente.

Los modelos CFD resuelven numéricamente una serie de ecuaciones diferenciales de conservación de la masa, momento (ecuaciones de Navier-Stokes), energía y turbulencia.

Inicialmente era un proceso complejo, largo y caro que sólo se utilizaba en ingeniería aeronáutica y nuclear. Actualmente algunos arquitectos lo utilizan en el diseño de edificios para mejorar la ventilación natural y la eficiencia energética. 
Los modelos CFD se han hecho muy populares en la predicción de la ventilación debido al rápido aumento de la capacidad de los ordenadores y por el desarrollo de programas con interfaces más sencillos.

Hay que tener en cuenta que este método requiere conocimientos de mecánica de fluidos, un equipo de gran capacidad, la especificación de muchos parámetros, mucho tiempo de ejecución del modelo y de cálculo. Hasta los pequeños cambios de la geometría requieren de mucho esfuerzo por tener que volver a repetir gran parte del trabajo. Por todo ello, es muy importante hacer un análisis previo en el que se definan los objetivos, el grado de precisión y los resultados concretos que se requieren del modelo CFD.

Hoy en día se puede afirmar que es una herramienta fiable para la evaluación térmica del ambiente interior y para optimizar los sistemas de fachada. Sin embargo, la predicción del confort térmico de edificios ventilados naturalmente sólo con CFD no es una tarea sencilla, y hay que tener en cuenta, entre otros, los siguientes aspectos:

- El dominio computacional debe ser lo más grande posible para evitar la interacción entre las zonas de recirculación y los extremos.

- Introducir en las condiciones de contorno parámetros para considerar las condiciones climáticas como la temperatura ambiente, la radiación solar, el viento y la humedad. La predicción del ambiente interior depende en gran medida de las condiciones del exterior.

- La transferencia de calor y la dinámica de fluidos están implicadas en el cálculo para la predicción del ambiente térmico interior. La simulación del ambiente exterior, las condiciones climáticas de viento y la radiación solar, necesitan un dominio grande y un tamaño de malla grande. Dentro de la habitación, la malla tiene que ser pequeña para describir de forma adecuada el ambiente interior; y tiene que ser todavía más pequeña para poder apreciar la transferencia de calor en el sistema de fachada.

- Conforme aumenta el tamaño de la malla, aumenta el tiempo de cálculo.

- Para las investigaciones de fachadas ventiladas naturalmente, se recomienda un modelo 2D ya que el campo de la velocidad es prácticamente bidireccional, con lo que no es necesario un modelo 3D.

La simulación CFD es un método adecuado y muy preciso para investigar el diseño de un edifico ventilado naturalmente. Puede realizar la simulación térmica y el flujo de aire del ambiente exterior, del sistema de fachada y del ambiente interior.

El modelo CFD se puede utilizar para realizar las siguientes investigaciones:

- Validación del modelo CFD: Se han realizado diversos estudios a lo largo de los años con CFD validando los resultados con modelos analíticos, empíricos o experimentales. 
- Acoplamiento de modelos CFD con otros modelos de simulación de edificios: Algunos investigadores acoplaron CFD a otros programas para mejorar la predicción del flujo, para determinar unas estrategias de diseño óptimas o para estudiar el confort térmico.

- Investigaciones sobre la calidad del ambiente interior.

- Diseño de sistemas de ventilación natural: Actualmente la aplicación de modelos CFD para el diseño es de gran interés por el uso de la ventilación natural para reducir el consumo de energía y mejorar la calidad del aire interior.

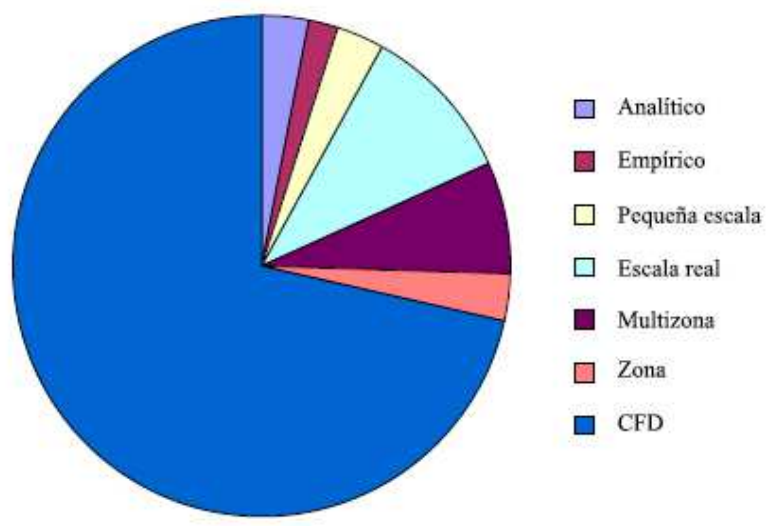

Figura 2.4. Proporción de los diferentes modelos utilizados en 2007 para la predicción de la ventilación en edificios. "Ventilation performance prediction for buildings: A method overview and recent applications". Chen, 2009.

\subsubsection{Investigaciones con CFD}

A continuación se enumeran algunas investigaciones realizadas con CFD en los últimos años:

- Zollner et al. (2002) propusieron una investigación sobre los coeficientes de transferencia de calor para flujos turbulentos en cámaras verticales y transparentes.

- Balocco (2004) utilizó el análisis dimensional para describir el rendimiento energético de diferentes diseños de fachada doble piel. Propuso un análisis que tenía en cuenta la energía y las propiedades térmicas para la fachada doble piel. Los resultados fueron validados con métodos experimentales y con simulación CFD. Este método puede utilizarse en todas las tipologías de fachadas ventiladas naturalmente.

- Saelens et al. (2004) estudiaron la importancia de la temperatura de entrada para una modelización correcta de una fachada ventilada compuesta por varias capas. Los resultados demostraron que el supuesto de una temperatura de entrada igual a la temperatura del aire interior o del aire exterior, generalmente no es válida. $\mathrm{Su}$ estudio de sensibilidad ilustra el significado de la temperatura de entrada como condición de contorno para los modelos numéricos de fachadas multi- 
capa. Finalmente, utilizaron el modelo de entrada de temperatura en una simulación energética de un edificio completo para indicar la importancia de la temperatura de entrada en el comportamiento energético.

- Manz (2005) presentó un modelo basado en el acoplamiento de tres tipos diferentes de simulación que es económico en términos de tiempo de cálculo, y por lo tanto, adecuado para fines de diseño. Los modelos fueron: modelo óptico espectral, modelo computacional de dinámica de fluidos y el modelo de simulación energética del edificio. El método se demostró en un edificio comercial con fachadas doble piel y además, la ventilación nocturna. El método propuesto mejora considerablemente la fiabilidad de la predicción.

- Jiru y Haghighat (2008) estudiaron el flujo de aire y la temperatura en una fachada doble piel ventilada.

- Hanby et al. (2008) utilizaron CFD para simular la transferencia de calor y la convección natural en el interior de una cámara de aire de forma simultánea.

- Cen et al. (2008) utilizaron CFD para simular diferentes modelos de la fachada doble piel y analizar diferentes fenómenos dentro de la cámara. Calcularon el coeficiente de transferencia de calor y la eficiencia energética. Utilizan estos dos parámetros para evaluar y diseñar las fachadas doble piel.

- Pappas y Zahai (2008) investigaron el rendimiento energético y los posibles factores que afectan la fachada doble piel. Desarrollaron un proceso iterativo e integrado con CFD y con un programa de simulación energética de edificios para analizar el comportamiento térmico de la fachada. Lo realizaron sólo por convección natural. Desarrollaron una correlación para el flujo de aire de la cámara, la estratificación de la temperatura y el coeficiente de convección interior que puede proporcionar un análisis más preciso de la fachada doble piel dominada por convección natural dentro del ahorro energético anual de un edificio.

- Kim et al. (2009) examinaron la contribución en el ahorro de calefacción de la fachada doble piel ventilada naturalmente en edificios de oficinas. Realizaron estudios experimentales y simulaciones por ordenador. Los resultados mostraron que para todas las variables, la temperatura del aire exterior era el factor que más influenciaba la temperatura del aire de la cámara.

\subsubsection{Programas de simulación energética para edificios}

En los últimos 50 años se han desarrollado una gran variedad de programas de simulación energética para edificios. A continuación se enumeran algunas de estas aplicaciones: DOE, ECOTECT, Energy Plus, HAP, eQUEST, ESP-r, IES, TRNSYS, entre otros.

Sus características y capacidades se pueden clasificar en las siguientes categorías para poder compararlos entre sí: características de modelado, zonas de carga, envolvente del edificio, luz diurna, radiación solar, infiltración, ventilación y flujo multizona, sistemas 
de energía renovable, sistemas y equipos eléctricos, sistemas y equipos HVAC, emisiones medioambientales, evaluación económica, disponibilidad de datos climáticos, resultados, validación, interface, acoplamientos con otros programas, y disponibilidad.

\subsubsection{Modelos turbulentos}

CFD ha jugado un papel muy importante en evaluar y diseñar varias distribuciones de aire en espacios cerrados donde importa el confort térmico y la calidad del aire. Hay muchos factores que influyen en las aplicaciones CFD para el estudio de la distribución del aire, y algunos de los más importantes son la selección del programa CFD apropiado y la selección del modelo de turbulencia apropiado.

El estudio de la ventilación natural requiere información tanto del flujo interior como del exterior. Es esencial controlar la distribución del aire en el ambiente interior cerrado. Los parámetros de distribución del aire incluyen: velocidad del aire, temperatura, humedad relativa, temperatura de la superficie de la habitación e intensidad de la turbulencia del aire, entre otros. Normalmente, en el espacio interior la velocidad del aire es menor que $0,2 \mathrm{~m} / \mathrm{s}$.

Generalmente, CFD predice el flujo turbulento mediante tres tipos de aproximaciones: simulación numérica (DNS), large-eddy simulation (LES), y por las ecuaciones de Reynolds-averaged Navier-Stokes (RANS).

DNS calcula el flujo turbulento resolviendo directamente las ecuaciones de NavierStokes sin aproximaciones. Resuelve todo el rango de escalas espaciales y temporales de la turbulencia. Requiere una malla muy fina.

RANS son ecuaciones con modelos turbulentos que pueden predecir distribuciones de aire rápidamente. Calcula estadísticamente las variables Reynolds para el estado estacionario y simula el efecto de fluctuación de la turbulencia utilizando diversos modelos turbulentos.

La Tabla 2.6 presenta los modelos turbulentos que predicen el flujo de aire en ambientes cerrados. Los modelos están organizados en ocho sub-categorías: 


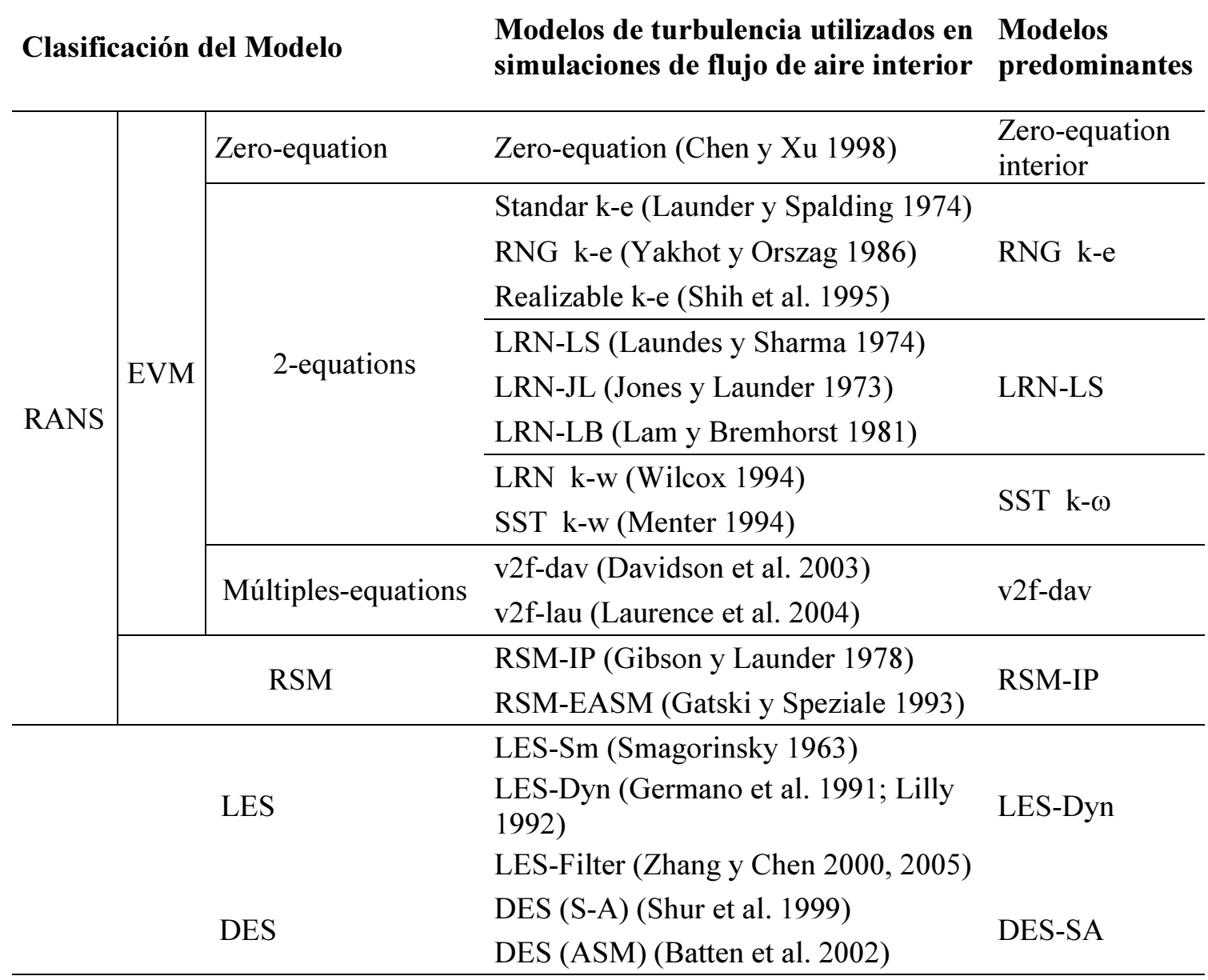

Tabla 2.6. Evaluación de diferentes modelos turbulentos para predecir el flujo de aire en ambientes cerrados. "Evaluation of various turbulence models in predicting airflow and turbulence in enclosed environments by CFD: Part 1-Summary of prevalent turbulence models" Zhai et al., 2007.

Muchos autores han investigado los distintos modelos de turbulencia, a continuación se muestran unas observaciones generales de los modelos turbulentos de distribución de aire en espacios interiores cerrados:

- El modelo k-e estándar (Launder y Spalding 1974) proporciona resultados aceptables, especialmente para flujo global y para patrones de temperatura, en un tiempo bastante aceptable. Tiene problemas con la convección natural y con altos gradientes de temperatura.

- $\quad$ El modelo RNG k-e (Yakhot y Orszag 1986) proporciona resultados similares o ligeramente mejores que el modelo k- $\varepsilon$ estándar. Recomiendan un mallado fino para una mejor predicción y resultados más precisos para simulaciones del flujo de aire interior.

- Los modelos zero y de una ecuación son apropiados para casos con características del flujo similares. 
- Los modelos LRN k- $\varepsilon$ y los modelos RANS no lineales proporcionan mejores predicciones pero tienen problemas de estabilidad y necesitan mucho tiempo de cálculo.

- Los modelos Reynolds stress pueden capturar algunos detalles del flujo. Estas pequeñas mejoras no justifican el gran tiempo de cálculo que necesitan.

- El modelo k- $\omega$ (Wilcox 1988) presenta un nuevo potencial de modelos de flujo de aire en espacios cerrados con resultados precisos y estables. Muchos estudios indican que el modelo SST k- $\omega$ (Menter 1994) funciona mejor que los modelos k- $\varepsilon$ estándar y RNG k- $\varepsilon$, por una evaluación sistemática especial para modelar flujos de aire interiores.

- El modelo v2f (Durbin 1995) parece muy prometedor pero tiene que resolver algunos problemas numéricos y de evaluación.

- El modelo LES proporciona predicciones más detalladas y más precisas para flujos de aire en espacio interior, que podría ser importante para la comprensión del mecanismo del flujo. Necesitan un gran tiempo de cálculo.

- El modelo DES puede ser un modelo valioso pero necesita más estudio y validación antes de ser utilizado para predecir flujos de aire.

\subsection{TRANSFERENCIA DE CALOR}

\subsubsection{Propiedades térmicas de los vidrios. Mecanismos de transmisión de calor}

Según la Segunda Ley de la termodinámica, la transferencia de calor es el paso de energía térmica desde un cuerpo a mayor temperatura a otro de menor temperatura. En el caso de los vidrios, se produce el mismo proceso físico. Generalmente, un paño acristalado separa dos ambientes que se encuentran a diferente temperatura, y por lo tanto, la transferencia de calor se produce del ambiente más caliente al más frío hasta que alcancen el equilibrio térmico.

Los intercambios térmicos a través de una pared se producen según tres modos de propagación:

1. Conducción: Es el proceso de transmisión de calor dentro de un mismo cuerpo o entre dos cuerpos en contacto directo. La transferencia de calor se efectúa sin intercambio de materia, y el calor fluye desde un cuerpo a mayor temperatura a otro a menor temperatura que está en contacto con el primero. El flujo de calor entre las dos caras de un acristalamiento depende de la diferencia de temperatura entre dichas caras y de la conductividad térmica del material, ya que es la propiedad física de los materiales que determina su capacidad para conducir calor. La conductividad térmica del vidrio es igual a $K=1 \mathrm{~W} / \mathrm{m} \cdot \mathrm{K}$. La transferencia de calor por conducción depende principalmente de las propiedades del material y de su espesor. 
2. Convección: Es una forma de transmisión de calor que se caracteriza porque se produce por medio de un fluido que transporta el calor entre zonas con diferentes temperaturas. La convección se produce únicamente por medio de materiales fluidos, es decir, líquidos y gases. Es la transferencia entre la superficie de un sólido y un fluido líquido o gaseoso. La diferencia de temperatura provoca diferencias de densidad que dan lugar a movimientos en el fluido, de manera que el más caliente sube y es sustituido por otro más frío.

3. Radiación: Es la transferencia de calor procedente de un intercambio por radiación electromagnética entre dos cuerpos que se hallan a temperaturas diferentes. Este mecanismo no precisa de medio material, sino que se da incluso en el vacío. A temperatura ambiente, esta radiación se sitúa en la zona de infrarrojos con longitudes de onda superiores a $5 \mathrm{~mm}$. Es proporcional a la emisividad de estos cuerpos. La transferencia de calor por radiación depende de las propiedades de la superficie del elemento.

La transferencia de calor a través de la fachada de un edificio depende de la radiación solar, de la conducción y de la convección del flujo de aire que pasa a través de la abertura. La convección en la cámara depende del flujo de aire. También está influenciada por las condiciones exteriores de viento y la presión que genera en la fachada del edificio.

\subsubsection{Propiedades energéticas de los vidrios}

Las propiedades ópticas expresan el comportamiento del vidrio a la luz diurna y a la radiación. Entre las más importantes se encuentran la transmitancia, la reflectancia y la absortancia.

\subsubsection{Transmitancia}

La transmitancia es un valor que expresa la cantidad de radiación solar que puede atravesar un vidrio, comparada con la radiación solar que incide sobre él.

La transmitancia se puede establecer para cualquier ángulo de incidencia, pero lo más común es indicar valores para una incidencia normal, es decir, con los rayos perpendiculares a la superficie del vidrio.

\subsubsection{Reflectancia}

La reflectancia es un parámetro que indica la cantidad de radiación solar que es reflejada por un vidrio, comparada con la radiación solar que incide sobre él.

Se puede indicar la reflectancia tanto para la superficie frontal (exterior) como para la superficie posterior (interior) del vidrio. Esto generalmente se hace para posibilitar el cálculo de las inter-reflexiones, considerando que en determinados tipos de vidrio ambos valores pueden ser bastante diferentes entre sí. 
Cuanto más se desvíe de la normal el ángulo de incidencia de la radiación solar, mayor será la cantidad reflejada por el vidrio. Los valores de reflectancia se suelen indicar para una incidencia normal a la superficie del vidrio.

\subsubsection{Absortancia}

La absortancia representa la cantidad de radiación solar que no es reflejada ni transmitida, sino absorbida por un vidrio, comparada con la radiación solar que incide sobre él.

Se trata de un parámetro que puede calcularse a partir de la reflectancia y la transmitancia de cada vidrio en particular:

\section{Radiación absorbida $=$ incidente - reflejada - transmitida}

En algunos ámbitos, tanto la transmitancia como la reflectancia y la absortancia se indican como valor porcentual del $0 \%$ al $100 \%$, mientras que en otros se emplean valores fraccionales entre 0,0 y 1,0 . Este valor se indica para todo el espectro de radiación solar.

\subsubsection{Comportamiento de la radiación solar incidente en un vidrio}

A continuación, se explica el comportamiento de la radiación solar incidente sobre un vidrio, ver Figura 2.5.

Cuando la radiación solar incide en un paño de vidrio, varios fenómenos tienen lugar. Una parte de la radiación solar se refleja instantáneamente $\left(\rho_{e}\right)$, por lo que ni penetra en el vidrio ni lo calienta. Otra parte de la radiación solar penetra en el vidrio pero es absorbida internamente $\left(\alpha_{e}\right)$, promoviendo su calentamiento. Parte de esta energía absorbida, se retransmite hacia el interior $\left(q_{i}\right)$ y otra parte hacia el exterior $\left(q_{e}\right)$ en cantidades variables, dependiendo de las características del vidrio y de la temperatura interior o exterior. Por último, la parte de radiación que ni se refleja ni se absorbe, pasa a través del vidrio y se transmite directamente al interior $\left(\tau_{e}\right)$.

La energía total que pasa a través del vidrio se denomina factor solar $(\gamma)$, y es la suma de la energía solar que entra directamente por transmisión $\left(\tau_{e}\right)$ y la energía retransmitida por el vidrio hacia el interior después de su calentamiento por absorción de la energía $\left(q_{i}\right)$.

Los factores de transmisión, reflexión y absorción de energía expresan las relaciones de los flujos energéticos transmitidos, reflejados o absorbidos en relación al flujo energético incidente. 
Optimización de la fachada de doble piel acristalada con ventilación natural. Metodología de diseño para el análisis de la eficiencia energética del sistema.

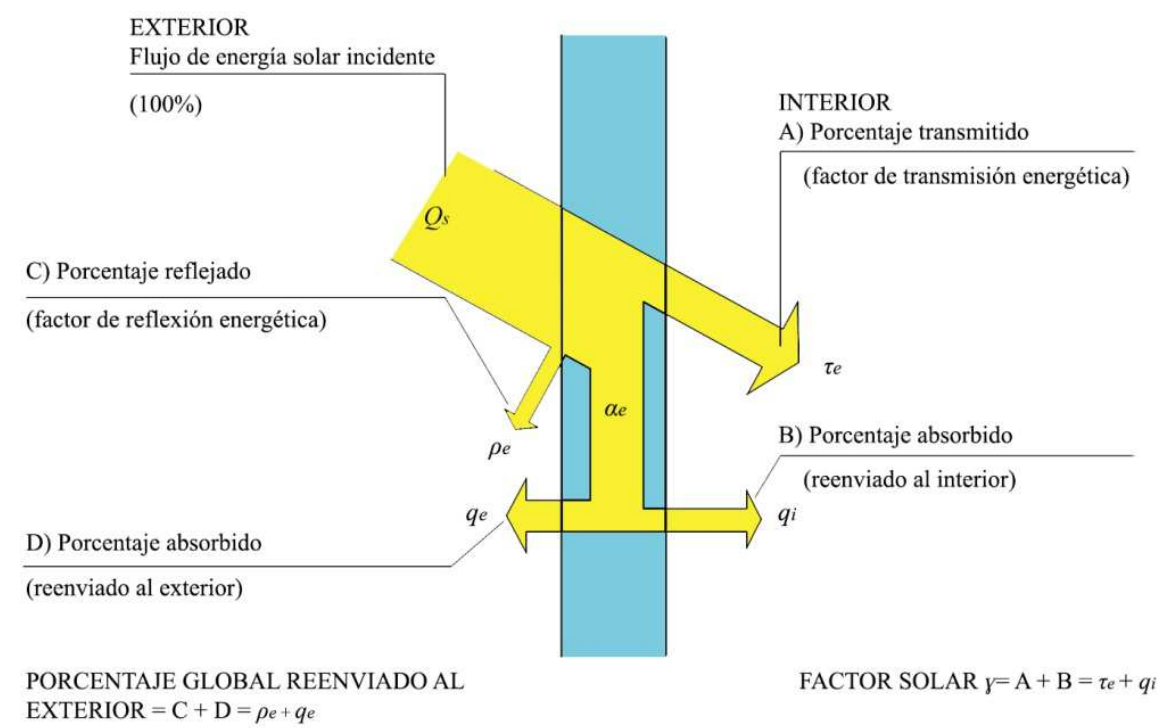

Figura 2.5. Comportamiento de la radiación solar en el paño de vidrio. Manual vidrio Saint-Gobain Glass.

A través de un análisis óptico es posible determinar las componentes de transmisión, reflexión y absorción de la radiación solar.

\subsubsection{Transferencia de calor en el sistema de fachada doble piel}

Una vez explicados los mecanismos de transmisión de calor, las propiedades ópticas de los vidrios y su comportamiento cuando la radiación solar incide sobre ellos, se procede a explicar de forma gráfica el proceso de transferencia de calor en el sistema de fachada doble piel acristalada tanto con cámara cerrada como abierta.

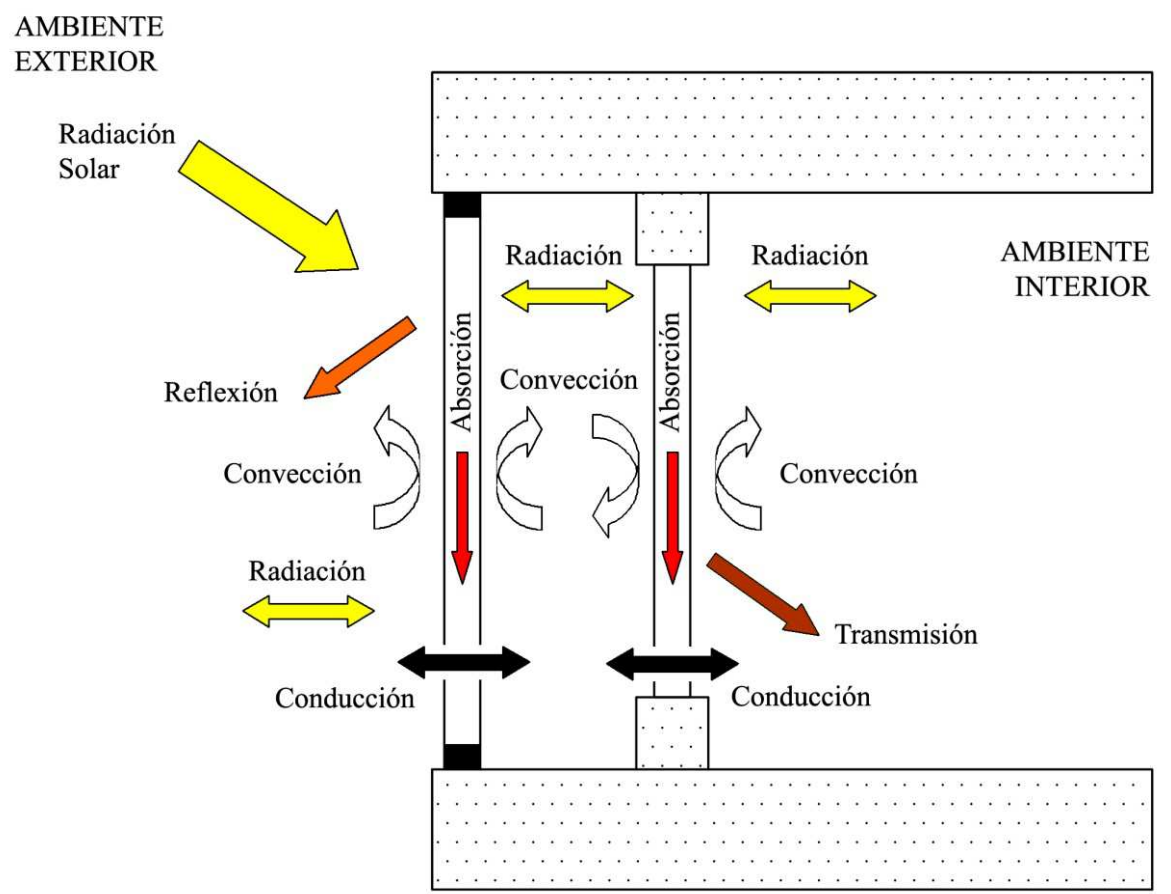

Figura 2.6. Esquema de proceso de transferencia de calor en el sistema de fachada doble piel acristalada con cámara cerrada. 
En el caso de fachada doble piel acristalada con cámara cerrada, el aire sube por la pared caliente, baja por la fría y gira alrededor de la cámara produciéndose la convección. También se aprecia que una parte de la radiación solar se transmite al interior y que se produce la conducción entre las dos caras de cada vidrio.

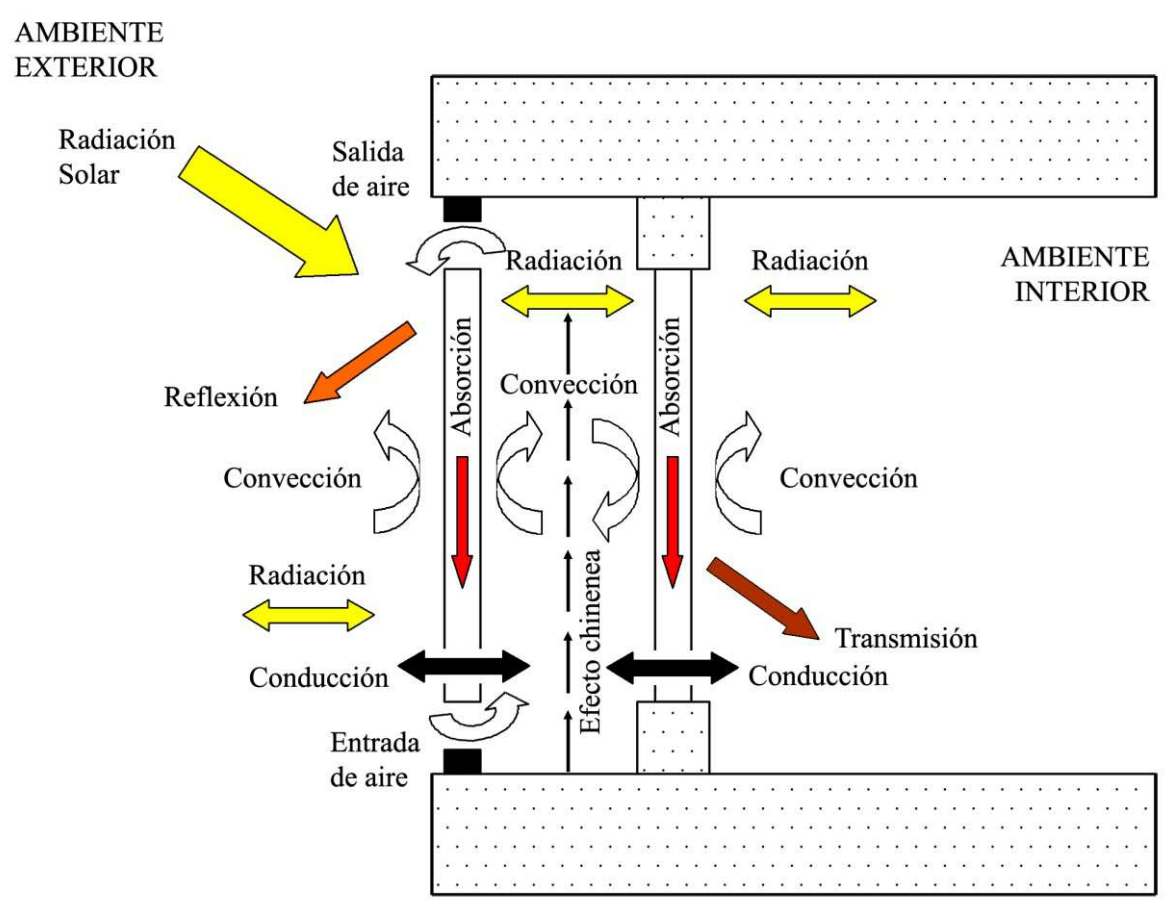

Figura 2.7. Esquema de proceso de transferencia de calor en el sistema de fachada doble piel acristalada con cámara abierta.

En el caso de fachada doble piel acristalada con cámara abierta, el aire entra por una de las aberturas y sale por la otra produciéndose la convección natural y el efecto chimenea.

\subsubsection{Normativa de aplicación}

La Norma UNE 572-1: Vidrio para la edificación especifica y clasifica los productos vítreos básicos e indica su composición química y sus principales características físicas y mecánicas.

La Norma UNE 10456: Materiales y productos para la edificación especifica métodos para la determinación de los valores térmicos y de diseño de materiales y productos de edificación. También proporciona tablas con valores ya calculados para casos genéricos.

La Norma UNE 410: Vidrio para la edificación especifica métodos para la determinación de las características luminosas y solares de los acristalamientos tanto convencionales como de control solar, sencillos y dobles, en edificios.

La Norma UNE 673: Vidrio en la construcción especifica un método de cálculo para determinar el coeficiente de transmitancia térmica del acristalamiento para casos concretos de vidrio y algunas tablas con valores ya calculados para casos genéricos. 


\subsubsection{Métodos de cálculo que incorporan la radiación solar}

La radiación solar térmica transmitida a través de un vidrio dependerá de:

1. Las propiedades ópticas y térmicas del vidrio.

2. El emplazamiento: latitud y longitud geográfica.

3. Datos climáticos: temperatura del aire exterior y radiación solar mensual.

4. Orientación del vidrio.

Los datos de los puntos 2, 3 y 4 se necesitan para calcular la radiación solar que incide en el vidrio.

Los métodos utilizados para resolver la cuestión de la transferencia de calor por conducción, convección y radiación son los siguientes:

1. Calcular de forma analítica el calor absorbido por cada paño de vidrio de acuerdo con la normativa existente.

2. Utilizar un software independiente para resolver la transferencia de calor por radiación.

3. Utilizar un modelo CFD acoplado con un modelo BS (Building Simulation). BS modela el proceso de transferencia de calor y la radiación, y CFD predice el flujo de aire.

4. Utilizar un modelo óptico-solar combinado con un modelo CFD que incluya conducción, convección y radiación.

\subsubsection{Modelo óptico-solar para sistemas acristalados}

Un área acristalada en la fachada de un edificio puede producir ganancias solares e influenciar el consumo de energía y la carga máxima. La ganancia solar de la carpintería puede ser ignorada en la mayoría de los casos.

Algunas investigaciones definen un método para determinar la ganancia de energía solar de los sistemas de acristalamiento complejos. El primer paso en el análisis térmico de una fachada de vidrio es conocer la radiación solar incidente para determinar los porcentajes de reflexión, absorción y transmisión; y en segundo lugar, hay que asignar propiedades óptico-energéticas u óptico-solares a las capas que componen la fachada de vidrio.

El coeficiente de ganancia solar puede combinarse con las propiedades óptico-solares como la transmitancia y la absorción de las capas determinadas por métodos no calorimétricos para producir coeficientes de ganancia solar de sistemas complejos de fenestración. Este método en dos pasos se ha denominado separación solar-térmica. 
El principio físico es simple, pero su aplicación no: la energía solar absorbida por un sistema acristalado eleva la temperatura de sus capas y esto causa la transferencia de calor por el proceso normal de conducción, convección y radiación hacia el interior y hacia el exterior. La temperatura de cada capa es fija hasta el punto en el que el flujo que va hacia el interior y el que va hacia el exterior se igualan, lo que da como resultado la tasa de absorción de energía solar. Este resultado depende de la temperatura de la capa en cuestión, de las capas adyacentes, del aire circundante y de la velocidad del flujo de aire; y a su vez, todos estos parámetros dependen del nivel de radiación solar.

\subsubsection{Modelo CFD acoplado con un modelo de simulación energética}

Algunos autores han desarrollado un método acoplado en el que se integra un modelo de simulación energética (BS) con un modelo CFD para analizar la transferencia de calor solar pasiva y la ventilación natural. El objetivo es poder incluir los efectos de la radiación, conducción y convección para poder analizar el consumo de calefacción y refrigeración en un edificio, así como estudiar el flujo hacia el interior y hacia el exterior del mismo.

\subsubsection{Investigaciones previas}

A continuación se describen algunas investigaciones que consideraron el efecto que tiene la radiación solar en la convección natural. Estos estudios combinan la transferencia de calor por convección natural, conducción y radiación:

- Ismail y Heríquez (2004) presentaron un modelo matemático y los resultados de simulaciones numéricas de una ventana de doble hoja ventilada. Obtuvieron resultados de temperatura en la cámara para diferentes separaciones entre las hojas de vidrio y en condiciones de radiación solar. También presentaron y discutieron los efectos sobre el coeficiente de ganancia de calor.

- Manz (2004) utilizó un modelo óptico y un modelo CFD para simular la energía solar total transmitida al interior. La influencia de la secuencia de capas y las propiedades de la ventilación en el comportamiento térmico fueron discutidas en detalle. Recomienda un modelo óptico combinado con un modelo CFD que incluya convección, conducción y radiación para analizar y optimizar la fachada doble piel de vidrio.

- Pérez-Grande et al. (2005) estudiaron la influencia de las propiedades del vidrio en el comportamiento de las fachadas doble piel acristaladas. La tasa total de calor que pasaba al interior del edificio, se calculó para 10 fachadas diferentes formadas por diferentes combinaciones de vidrio. Se estudió la masa de flujo de aire y el aumento de la temperatura del aire que pasaba a través de la cámara. Concluyeron que una selección apropiada del vidrio puede reducir la carga térmica del edificio.

- Chow et al. (2007) afirmaron que las fachadas de vidrio tienen la ventaja de ahorrar una gran cantidad de energía en invierno porque estos materiales reducen tanto la iluminación como los costes de calefacción haciendo uso de la radiación solar y de la luz natural. También concluyeron que los paneles 
pequeños de vidrio se comportaban mejor que los paneles grandes en las construcciones reales. Además, en paneles grandes de vidrio, hay una gran diferencia de temperatura entre los extremos y el centro. El factor clave es elegir vidrios de alta calidad.

- Coussirat et al. (2008) llevaron a cabo varias pruebas de modelización de casos experimentales bien documentados de la bibliografía con el fin de obtener un modelo adecuado de los efectos térmicos de dinámica de fluidos. Se obtuvieron las temperaturas de una fachada doble piel para tres modelos con diferente radiación y cinco modelos de turbulencia diferentes, se compararon con los resultados experimentales de la literatura, y se validaron de acuerdo con metodologías de verificación y validación numéricas. Utilizaron CFD para modelar el flujo y la transferencia de calor de una fachada doble piel de vidrio. El modelo incorpora convección, conducción y radiación para la transferencia de calor.

\subsection{VENTILACIÓN NATURAL}

Los edificios deben proporcionar una ventilación adecuada.

La ventilación se utiliza para diferentes propósitos. El principal es la renovación de aire, pero también es importante crear un espacio sin problemas de corrientes de aire y con ligeros cambios de temperatura.

La fachada doble piel se categoriza, de acuerdo con su función, por el tipo de ventilación de la cámara. Puede ser natural, mecánica o híbrida. La ventilación será de un tipo u otro según el clima, la orientación, la situación y el tipo de edificio.

Los beneficios de la ventilación natural están cada vez más reconocidos. La ventilación natural en un edificio ayuda a crear un ambiente interior confortable mejorando la calidad del aire interior y proporcionando un alto nivel de confort térmico. Asimismo, la ventilación natural es una alternativa eficiente energéticamente para reducir el uso de energía en los edificios.

Las fuerzas dominantes de la ventilación natural son la convección natural, el viento o la combinación de ambos. Las diferencias de presión del viento a lo largo de la fachada y la diferencia de temperaturas entre el interior y el exterior genera un intercambio natural de aire entre el interior y el exterior. El aire elimina el calor de la cámara reduciendo las cargas de calefacción en invierno y de refrigeración en verano de un edificio.

\subsubsection{Tipologías de ventilación natural}

\subsubsection{Convección natural}

En un espacio con una abertura superior e inferior, la diferencia de temperaturas entre el ambiente interior y el exterior causa una diferencia de densidad, donde el aire caliente es menos denso que el aire frío. Como resultado, se produce una diferencia de presión 
entre el aire interior y el exterior. La convección natural también es denominada efecto chimenea. Al equilibrarse las temperaturas del interior y del exterior, la presión se aproxima a cero hasta que no pueda producirse la ventilación.

La disposición de las aberturas determina la distribución de la temperatura en el espacio interior. El aire frío entrará por la abertura inferior y el aire caliente saldrá por la abertura superior.

\subsubsection{Viento}

La ventilación natural también puede darse por diferencia de presiones a través de las aberturas por el efecto del viento. Resultados experimentales han mostrado los efectos fluctuantes del viento atribuidos a las características turbulentas del viento que entra o producidas por el propio edificio. La turbulencia del flujo de aire a lo largo de las aberturas produce simultáneamente presiones positivas y negativas del aire interior.

\subsubsection{Convección natural combinada con viento}

En la mayoría de los casos, la convección natural y el viento se producen simultáneamente. La influencia simultánea de la temperatura y el viento en el proceso de ventilación es complicado porque el viento y la convección se refuerzan o se contrarrestan la una a la otra.

\subsubsection{Distribución de la temperatura}

Es importante conocer la diferencia de temperaturas a las que da lugar un sistema de ventilación.

La diferencia más importante de temperaturas se produce en la dirección vertical. La ventilación producida por convección natural, es un caso extremo que funciona generando una diferencia de temperaturas en sentido vertical.

Predecir el perfil de distribución de temperaturas no es sencillo. Generalmente, la temperatura del aire que entra se conoce y está controlada, sin embargo, la temperatura a la que sale depende de varios factores:

- Magnitud de la carga de calefacción y refrigeración

- Tasa de flujo de ventilación

- Situación de las cargas

- Propiedades térmicas de las paredes de la habitación

- Suministro de aire positivo o negativo

- Ración solar incidente

- Intercambio térmico entre las diferentes superficies

CFD puede resolver este tipo de problemas en los que simula el flujo de aire y la transferencia de calor. 


\subsection{CONVECCIÓN NATURAL}

La convección natural en cámaras verticales con paredes calentadas es un tema que se ha estudiado extensamente a lo largo de los años tanto experimental como analíticamente.

Casi todas las investigaciones consideran las paredes verticales isotérmicas bajo condiciones de contorno simples, y considerando las paredes horizontales adiabáticas, es decir, con un flujo de calor igual a cero.

La transferencia de calor en los flujos dominados por convección natural tiene gran importancia en aplicaciones tanto de arquitectura como de ingeniería. Los patrones del flujo en todos estos casos son extremadamente sensibles a los cambios en la configuración de la cámara y en las condiciones de contorno.

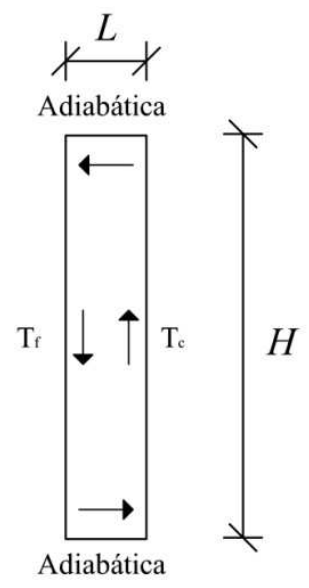

La Figura 2.8 muestra una cámara cerrada típica con una altura $H$ y un ancho $L$. La temperatura de las paredes derecha e izquierda se mantiene constante, aunque están a diferente temperatura. La pared derecha está a una temperatura superior $T_{c}$ a la de la pared izquierda $T_{f}$.

$H$ Debido a que el gradiente de temperatura aumenta entre la pared izquierda y la derecha, el fluido sube a lo largo de la pared caliente, baja por la pared fría y gira alrededor de la parte inferior de la cámara para producir convección unicelular.

Figura 2.8. Esquema de una cámara rectangular cerrada con paredes a diferente temperatura.

\subsubsection{Números adimensionales}

Se cuantifica el coeficiente de transferencia de calor entre paredes verticales en función de varias variables independientes en un formato adimensional.

\subsubsection{Número de Rayleigh}

El número de Rayleigh $\left(\mathrm{Ra}_{\mathrm{L}}\right)$ de un fluido es un número adimensional asociado con la transferencia de calor en el interior del fluido. Cuando el número de Rayleigh está por debajo de un cierto valor crítico, la transferencia de calor se produce principalmente por conducción; cuando está por encima del valor crítico, la transferencia de calor se produce principalmente por convección.

Para el caso de convección natural en una cámara vertical el número de Rayleigh se calcula en función del ancho de la cámara y de la diferencia de temperatura entre el paño caliente y el frío: 


$$
\mathrm{Ra}_{\mathrm{L}}=\frac{g L^{3} \beta\left(T_{c}-T_{f}\right)}{v \alpha}
$$

donde $g\left(\mathrm{~m} / \mathrm{s}^{2}\right)$ es la aceleración de la gravedad; $L(\mathrm{~m})$ es el ancho de la cámara de aire; $\beta\left(\mathrm{K}^{-1}\right)$ es el coeficiente de expansión térmica del aire; $T_{c}(\mathrm{~K})$ es la temperatura del paño caliente; $T_{f}(\mathrm{~K})$ es la temperatura del paño frío; $v\left(\mathrm{~m}^{2} / \mathrm{s}\right)$ es la viscosidad cinemática del aire; y $\alpha\left(\mathrm{m}^{2} / \mathrm{s}\right)$ es la difusividad térmica del aire.

Según la bibliografía, el régimen del flujo puede clasificarse en conducción, transición y convección según el número de Rayleigh que tengan:

- Para valores de $\mathrm{Ra} \leq 10^{4}$, el calor se transfiere por conducción.

- Para valores de $10^{4}<\mathrm{Ra}>10^{7}$, el régimen del flujo es de transición.

- Para valores de $\mathrm{Ra} \geq 10^{7}$, el calor se transfiere por convección.

\subsubsection{Número de Prandtl}

El Número de Prandtl (Pr) es un número adimensional proporcional al cociente entre la viscosidad cinemática y la difusividad térmica del aire. Se define como:

$$
\operatorname{Pr}=\frac{v}{\alpha}=\frac{C_{p} \mu}{K}
$$

donde $v\left(\mathrm{~m}^{2} / \mathrm{s}\right)$ es la viscosidad cinemática del aire; $\alpha\left(\mathrm{m}^{2} / \mathrm{s}\right)$ es la difusividad térmica del aire; $C_{p}\left(\mathrm{Jkg}^{-1} \mathrm{~K}^{-1}\right)$ es el calor específico a presión constante; $\mu(\mathrm{Pa} \cdot \mathrm{s})$ es la viscosidad; $\mathrm{y} K\left(\mathrm{Wm}^{-1} \mathrm{~K}^{-1}\right)$ es la conductividad térmica.

El número de Prandtl para los gases es en torno a $\mathrm{Pr}=0,70$.

\subsubsection{Número Nusselt}

El número de Nusselt $(\mathrm{Nu})$ es un número adimensional que mide la relación entre la transferencia de calor producida por convección y la producida por conducción, ambas en la dirección perpendicular al flujo.

Se utiliza el número de Nusselt $(\mathrm{Nu})$ para cuantificar el coeficiente de transferencia de calor debido a la convección natural entre las paredes de la cámara que están a diferente temperatura. La teoría muestra que $\mathrm{Nu}$ es función del número de Rayleigh $(\mathrm{Ra})$, del número de Prandtl (Pr) y de la relación entre el alto y el ancho de la cámara $(A)$. Por lo tanto hay una correlación dependiente: $\mathrm{Nu}=\mathrm{Nu}(\mathrm{Ra}, \mathrm{Pr}, A)$. El número de Prandtl se considera constante, así que la función se simplifica como: $\mathrm{Nu}=f\left(\mathrm{Ra}_{\mathrm{L}}, A\right)$.

Como el número de Nusselt está en función del número de Rayleigh, cuando la transferencia de calor se produzca por conducción, el número de Nusselt tomará un valor bajo; y cuando se produzca por convección tomará un valor alto. 
En resumen, tres parámetros adimensionales describen el flujo:

1. Número de Rayleigh $\left(\mathrm{Ra}=g \beta \Delta T L^{3} / v \alpha\right)$ : ratio de flotabilidad de las fuerzas viscosas.

2. Número de Prandlt $(\mathrm{Pr}=C p \mu / K)$ : ratio del momento de la difusividad térmica.

3. Esbeltez $(A=H / L)$ : Relación entre la altura y el ancho de la cámara.

\subsubsection{Regímenes del flujo}

Los flujos se clasifican en 3 regímenes: el régimen de conducción, el régimen de transición y el régimen de la capa límite (convección).

Según diversos autores que estudiaron el comportamiento del flujo en cámaras verticales, conforme el número de Rayleigh aumenta, el flujo va pasando por diferentes estados desde que está en estado laminar hasta que llega a estado turbulento:

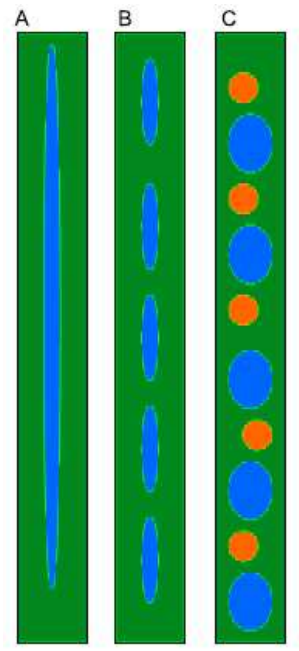

1. Flujo laminar. Patrón unicelular. Células primarias. Régimen de conducción.

2. Flujo laminar. Patrón multicelular. Células secundarias. Régimen de transición.

3. Flujo laminar. Patrón multicelular. Células terciarias. Régimen de capa límite (convección).

4. Flujo turbulento. Patrón irregular.

Figura 2.9. Esquema de las diferentes estructuras celulares: A) células primarias, B) células secundarias, C) células terciarias. "Numerical predictions on flow patterns due to natural convection in a vertical slot" Ganguli et al., 2007.

En el régimen de conducción, la temperatura varía linealmente a través de la cámara. El gradiente de temperatura horizontal $\Delta T / L$ da lugar a una circulación lenta en el sentido horario, sin embargo, la contribución de la transferencia de calor al flujo es insignificante.

En el régimen de la capa límite, se forman capas verticales térmicas a lo largo de las paredes que están a distinta temperatura. Las paredes horizontales adiabáticas se alinean en diferentes capas térmicas. La mayor parte del centro de la cámara está estancada y tiene temperatura uniforme. Sin embargo, en el régimen de transición, las capas límite en la pared caliente y fría se encuentran las unas con las otras.

Resumiendo, el régimen de conducción está gobernado por la conducción, el régimen de transición por conducción cerca de las paredes y por convección en el centro, y el régimen de la capa límite está gobernado por convección en el centro y conducción 
limitada en la capa de contorno. En la región dominada por convección (el centro) se forman múltiples células.

La Figura 2.10 muestra diferentes patrones de flujo obtenidos por diferentes autores en sus investigaciones.

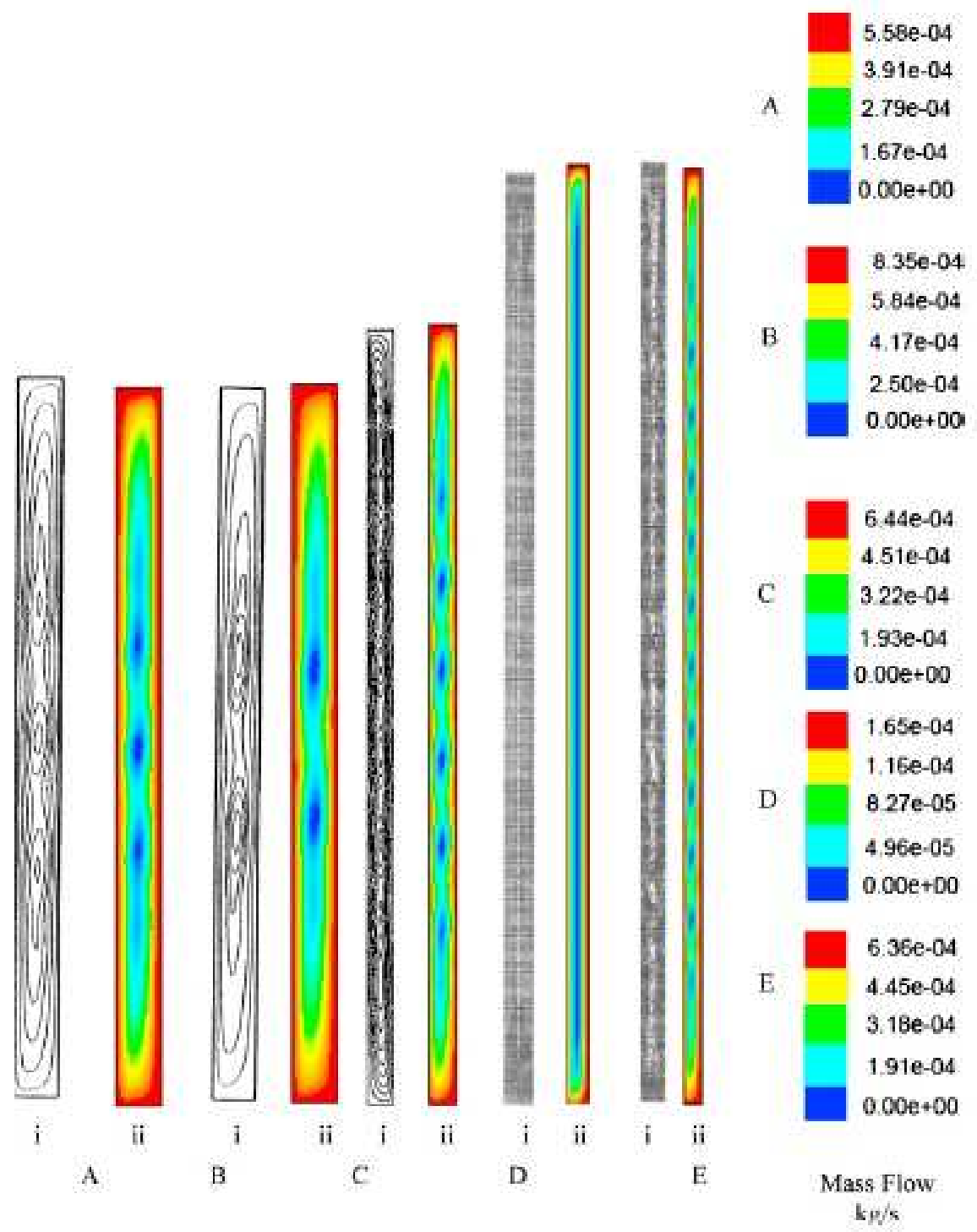

Figura 2.10. Patrones de flujo de diferentes autores. A) $A=16, \mathrm{Ra}=12.000$ : i) Le Quéré (1990), ii) Ganguli (2009). B) $A=16, \mathrm{Ra}=20.000$ : i) Le Quéré (1990), ii) Ganguli (2009). C) $\mathrm{A}=25, \mathrm{Ra}=10.100: \mathrm{i}$ ) Zhao et al. (1997), ii) Ganguli (2009). D) $A=40, \mathrm{Ra}=3.550$ : i) Lartigue et al. (2000), ii) Ganguli (2009). E) $A=16, \mathrm{Ra}=14.200$ : i) Lartigue et al. (2000), ii) Ganguli (2009). "CFD simulation of heat transfer in a two dimensional vertical enclosure" Ganguli et al., 2009. 


\subsubsection{Investigaciones previas sobre convección natural y transferencia de calor}

El flujo en dos dimensiones y su efecto en la transferencia de calor es un tema que se lleva investigando durante varias décadas.

Las investigaciones realizadas tenían dos objetivos principales:

1. Desarrollar correlaciones entre la geometría y la tasa de transferencia de calor.

2. Comprender el efecto de la transferencia de calor en los patrones de flujo inducidos por convección natural.

Las investigaciones se pueden clasificar en cuatro grupos:

1. Aproximación analítica

2. Estudios experimentales

3. Estudios numéricos

4. Estudios experimentales y numéricos: Investigaciones en las que se realiza un experimento y después se validan los resultados obtenidos experimentalmente con predicciones numéricas.

La Tabla 2.7 resume el tipo de investigaciones realizadas por los diferentes autores a lo largo del tiempo en materia de patrones de flujo en cámaras verticales. También se investiga el efecto de los tres parámetros adimensionales ( $\mathrm{Ra}, \operatorname{Pr}$ y $A)$ en la transferencia de calor en las cámaras. Asimismo, se describen las hipótesis que consideraron, las conclusiones que alcanzaron y las limitaciones de su trabajo. 


\begin{tabular}{|c|c|c|c|c|c|c|c|c|}
\hline Autor & Aproximación & Fluido & $\begin{array}{l}\text { Geometría } \\
\text { (rango de } A \text { ) }\end{array}$ & Rango de Ra / Gr & Correlaciones propuestas & ${ }^{*}$ Hipótes is & " Conclusiones & ${ }^{* \star *}$ Limitaciones \\
\hline $\begin{array}{l}\text { Jakob } \\
(1946)\end{array}$ & Analitica & Aire & $3.12-42.2$ & $2 \times 10^{4}<\mathrm{Gr}_{\mathrm{L}}>2 \times 10^{5}$ & $\begin{array}{l}\mathrm{Nu}=0.18(\mathrm{Gr})^{0.25} \\
(A)^{-0.111} \\
\mathrm{Nu}=0.065(\mathrm{Gr})^{0.333} \\
(A)^{-0.111}\end{array}$ & - & - & - \\
\hline $\begin{array}{l}\text { Eckert } \\
(1961)\end{array}$ & Analitica & Aire & - & $8 \times 10^{4}<\mathrm{Gr}_{\mathrm{L}}<2 \times 10^{5}$ & $\begin{array}{l}\mathrm{Nu}=0.119\left(\mathrm{Gr}_{\mathrm{L}}\right)^{0.3} \\
(A)^{-0.1}\end{array}$ & - & 19 & - \\
\hline $\begin{array}{l}\text { Yin et al. } \\
\text { (1978) }\end{array}$ & Experimental & Aire & $4.9<A<78.7$ & $\begin{array}{l}1000<\mathrm{Ra}<10^{7} \\
1500<\mathrm{Ra}<7 \times 10^{6}\end{array}$ & $\begin{array}{l}\mathrm{Nu}=0.091 \mathrm{Gr}_{\mathrm{L}}{ }^{0.307} \\
0.21 \mathrm{Gr}^{0.269} A^{-0.131}\end{array}$ & - & - & 12 \\
\hline $\begin{array}{l}\text { Seki } \\
(1978)\end{array}$ & Experimental & $\begin{array}{l}\text { Diferentes } \\
\text { fluidos }\end{array}$ & $5-47.5$ & $10^{6}<\mathrm{Ra}<10^{12}$ & $\begin{array}{l}\mathrm{Nu}_{\mathrm{H}}=0.039 \mathrm{Ra}_{\mathrm{H}}^{1 / 3} \\
2 \times 10^{2}<\mathrm{Ra}_{\mathrm{H}}\end{array}$ & 14,15 & 23 & - \\
\hline $\begin{array}{l}\text { EISherbiny et al. } \\
(1982)\end{array}$ & Experimental & Aire & $5<A<110$ & $1000<\mathrm{Ra}<10^{7}$ & $\begin{array}{l}\mathrm{Nu}_{1}=0.0605 \mathrm{Ra}^{1 / 3} \\
\mathrm{Nu}_{2}=[1+\{0.104 \mathrm{Ra} \\
\left.\left.+(6310 / \mathrm{Ra})^{1.36}\right\}^{3}\right]^{1 / 3} \\
\mathrm{Nu}_{3}=0.242(\mathrm{Ra} / A)^{0.272} \\
\mathrm{Nu}=\left[\mathrm{Nu}_{1}, \mathrm{Nu}_{2}, \mathrm{Nu}_{3}\right]_{\max }\end{array}$ & - & 20 & 15 \\
\hline $\begin{array}{l}\text { Wright } \\
(1996)\end{array}$ & Experimental & Aire & $A \geq 40$ & $\mathrm{Ra}<10^{6}$ & $\begin{array}{l}\mathrm{Nu}=0.0673838 \cdot \mathrm{Ra}^{1 / 3} \\
\mathrm{Ra}>5 \times 10^{4} \\
\mathrm{Nu}=0.028154 \cdot \mathrm{Ra}^{0.4134} \\
10^{4}<\mathrm{Ra} \leq 5 \times 10^{4} \\
\mathrm{Nu}=1+1.75967 \times 10^{-10} \cdot \mathrm{Ra}^{2.2984755} \\
\mathrm{Ra} \leq 10^{4}\end{array}$ & - & - & - \\
\hline $\begin{array}{l}\text { UNE EN } 673 \\
(2011)\end{array}$ & Experimental & Aire & & & $\mathrm{Nu}=\max \left(0.035 \times \mathrm{Ra}_{\mathrm{L}}^{0.38}, 1\right)$ & - & - & - \\
\hline $\begin{array}{l}\text { Batchelor } \\
\text { (1954) }\end{array}$ & Numérica & Aire & - & $10^{3}<\mathrm{Ra}>10^{7}$ & - & $1,2,5,8,9,10$ & $1,7,18$ & $1,3,5,17$ \\
\hline $\begin{array}{l}\text { Gill } \\
(1966)\end{array}$ & Numérica & Parafina & $A>1$ & $10^{3}<\mathrm{Ra}>10^{7}$ & - & $\begin{array}{l}1,2,3,4,5,7,8 \\
9,10\end{array}$ & 1 & 3,17 \\
\hline $\begin{array}{l}\text { Newel y Schmidt } \\
\text { (1970) }\end{array}$ & Numérica & Aire & $\begin{array}{l}A=1 \\
A=5\end{array}$ & $\begin{array}{l}4 \times 10^{3} \leq \mathrm{Gr} \leq 1.4 \times 10^{6} \\
10^{6}\end{array}$ & $\begin{array}{l}\mathrm{Nu}=0.0547(\mathrm{Gr})^{0.3947} \\
\mathrm{Nu}=0.155(\mathrm{Gr}) 0.315(A)^{-0.265}\end{array}$ & $\begin{array}{l}1,2,3,4,5,6,7 \\
8,9,10\end{array}$ & $4,5,6$ & 11,12 \\
\hline $\begin{array}{l}\text { Lee y Korpela } \\
\text { (1983) }\end{array}$ & Numérica & Aire & $5<A<60$ & $9.23 \times 10^{2}<\mathrm{Ra}<1.78 \times 10$ & 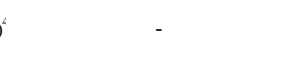 & $\begin{array}{l}1,2,3,4,5,6,7 \\
8,9,10\end{array}$ & $6,7,10,11$ & 4,14 \\
\hline $\begin{array}{l}\text { Le Quéré } \\
(1990)\end{array}$ & Numérica & Aire & $A=16$ & $6 \times 10^{3}<\mathrm{Ra}<4 \times 10^{4}$ & - & $\begin{array}{l}1,2,3,4,5,6,7 \\
8,9,10\end{array}$ & $8,11,12$ & 3,9 \\
\hline $\begin{array}{l}\text { Zhao et al. } \\
\text { (1997) }\end{array}$ & Numérica & Aire & $10<A<110$ & $\begin{array}{l}3550<\mathrm{Ra}<5 \times 10^{6} \\
\operatorname{Ra}_{\mathrm{L}}<10^{4}\end{array}$ & $\begin{array}{l}\mathrm{Nu}=\left[1-0.00813277\left(\mathrm{Ra}_{\mathrm{L}} / A\right)+\right. \\
\left.0.00723291\left(\operatorname{Ra}_{\mathrm{L}} / A\right)^{1.08597}\right]^{0.279072}\end{array}$ & $\begin{array}{l}1,2,3,4,5,6,7 \\
8,9,10\end{array}$ & 15 & $1,9,10$ \\
\hline $\begin{array}{l}\text { Lartigue et al. } \\
(2000)\end{array}$ & Numérica & Aire & $A=40$ & $3550<\mathrm{Ra}<2 \times 10^{4}$ & 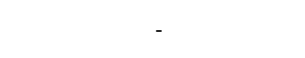 & - & 16 & $1,2,9,10,11$ \\
\hline $\begin{array}{l}\text { Xamán } \\
(2005)\end{array}$ & Numérica & Aire & $\begin{array}{l}A=20 \\
\mathrm{~A}=40 \\
\mathrm{~A}=80\end{array}$ & $\begin{array}{l}10^{3} \leq \mathrm{Ra} \leq 10^{6} \\
10^{4} \leq \mathrm{Ra} \leq 10^{8}\end{array}$ & $\begin{array}{l}\mathrm{Nu}=0.0857 \mathrm{Ra}_{\mathrm{L}}^{0.3033} \\
\mathrm{Nu}=0.0635 \mathrm{Ra}_{\mathrm{L}}^{0.323} \\
\mathrm{Nu}=0.054 \mathrm{Ra}_{\mathrm{L}}^{0.3335}\end{array}$ & $\begin{array}{l}1,2,3,6,7,12 \\
13\end{array}$ & 22 & - \\
\hline $\begin{array}{l}\text { Ganguli et al. } \\
(2009)\end{array}$ & Numérica & Aire & $20<A<120$ & & $\begin{array}{l}\mathrm{Nu}=0.171(\mathrm{Ra})^{0.265}(A)^{-0.205} \\
\mathrm{Nu}=0.151(\mathrm{Ra})^{0.3}(A)^{-0.164}\end{array}$ & $\begin{array}{l}1,2,3,6,7,8,9 \\
11\end{array}$ & $13,17,21$ & - \\
\hline $\begin{array}{l}\text { Elder } \\
(1965)\end{array}$ & $\begin{array}{l}\text { Experimental } \\
\text { y Numérica }\end{array}$ & Parafina & $1<A<60$ & $\begin{array}{l}10^{3}<\mathrm{Ra}>10^{5} \\
\mathrm{Ra}<10^{3} \\
\mathrm{Ra}<10^{8}\end{array}$ & $\begin{array}{l}\mathrm{Ra}_{\mathrm{c}}>=1700 A \\
\mathrm{Nu}=0.46\left((\mathrm{Ra} / \mathrm{Pr}) A^{3}\right)\end{array}$ & $1,2,5,8,9,10$ & $1,2,3$ & $1,3,5,17$ \\
\hline $\begin{array}{l}\text { Wakitani } \\
(1994-1997)\end{array}$ & $\begin{array}{l}\text { Experimental } \\
\text { y Numérica }\end{array}$ & Aire & $A=16$ & $9 \times 10^{3}<\mathrm{Ra}<3 \times 10^{5}$ & - & $\begin{array}{l}1,2,3,4,5,6,7 \\
8,9,10\end{array}$ & 14 & $2,9,10$ \\
\hline $\begin{array}{l}\text { Chan } \\
(2004)\end{array}$ & $\begin{array}{l}\text { Experimental } \\
\text { y Numérica }\end{array}$ & Agua, Aire & $A=15$ & - & - & $\begin{array}{l}1,2,3,4,5,6,7 \\
8,9,10\end{array}$ & 17 & - \\
\hline
\end{tabular}

Tabla 2.7. Investigaciones realizadas por diferentes autores. Hipótesis, conclusiones, limitaciones y correlaciones propuestas. "Numerical predictions of flow patterns due to natural convection in a vertical slot" A. A. Ganguli et al., 2007; "CFD simulation of heat transfer in a two-dimensional vertical enclosure" A. A. Ganguli et al., 2009.

\section{* Hipótesis:}

1. Superficies horizontales adiabáticas.

2. Utiliza Boussinesq como modelo de densidad.

3. No considera la radiación.

4. Las propiedades del fluido, excepto la viscosidad, no cambian significativamente en el rango de temperaturas $T_{c}<T_{m}<T_{f}$.

5. Considera la variación de la viscosidad. 
6. Modelo 2D.

7. Propiedades constantes excepto la flotabilidad.

8. Fluido Newtoniano e incompresible.

9. Flujo laminar y 2D.

10. Condiciones de contorno térmicas.

11. Considera diferentes temperaturas.

12. Considera flujo laminar y turbulento

13. Modelo de turbulencia k- $\varepsilon$ para resolver las ecuaciones.

14. Ancho de cámara $L$ y temperaturas constantes, varía la altura $H$. Estudia $\mathrm{Ra} \mathrm{y} \mathrm{Nu}$ en función de $H$.

15. Variación del número de Prandtl.

** Conclusiones:

1. El flujo es laminar $(A>5)$ hasta un número de Grashof crítico que está restringido a la capa de contorno.

2. Por encima de Ra $>1 \times 10^{5}$ se observan flujos secundarios (células múltiples), y por encima de $\mathrm{Ra}>1 \times 10^{7}$ se observan células terciarias (se mueven en sentido horario).

3. Posibilidad de que el flujo terciario se produzca por inestabilidad del flujo secundario.

4. Una malla más fina da mejores predicciones para el flujo.

5. El método de elementos finitos sirve como herramienta para predecir los patrones del flujo en geometrías complejas con cierta exactitud.

6. Para números de Prandtl bajos las células se bajan rápido y no se produce el comportamiento cuasi-periódico.

7. Alta transferencia de calor cerca de la parte inferior de la pared caliente y cerca de la parte superior de la pared fría pueden causar irregularidades locales en la temperatura de la pared en estas regiones. Esta puede ser una razón para la discrepancia entre experimentos y teoría.

8. Las células aumentan debido a la inestabilidad en el tiempo y después de un período de tiempo específico retorna al patrón unicelular.

9. El número de células aumenta paso a paso y cada cambio se caracteriza por histéresis.

10. La condición inicial es muy importante en casos de soluciones numéricas.

11. Se pueden realizar predicciones certeras cuando las simulaciones numéricas se hacen gradualmente aumentando el número de Rayleigh.

12. Con el aumento del número de Ra se forma un número de células diferente que pueden regresar al estado estacionario o permanecer cuasi-periódicas.

13. Cuando el número de Rayleigh aumenta se produce el comienzo de la formación de las células terciarias dependiendo del número de Prandtl (Pr).

14. Las observaciones experimentales muestran células fusionándose y moviéndose.

15. Existen unas particulares esbelteces y números Rayleigh en el régimen laminar en el que se forman células múltiples. Se le denomina régimen multicelular.

16. El uso de instrumentos sofisticados para realizar experimentos sirve como herramienta para validar el patrón de flujo obtenido por los resultados numéricos y proporciona un mejor entendimiento de las propiedades físicas del flujo.

17. La presión es el principal factor en la formación y fusión de las células.

18. Analizó la convección natural en el régimen laminar y definió los regímenes de conducción y capa límite. 
19. Definió el régimen de transición. Consideraba los tres regímenes del flujo a mitad de altura de la cámara y con unos valores de $\operatorname{Pr}$ y $A$ constantes.

20. Para $\mathrm{Ra}>6 \times 10^{3}$ el flujo dejaba el régimen de conducción y es función de $A$.

21. Se establece el balance energético relacionando las fuerzas viscosas, la flotabilidad y la presión.

22. En el flujo turbulento, $\mathrm{Nu}$ aumenta si $A$ aumenta, mientras que en el flujo laminar Nu disminuye si $A$ aumenta.

23. El flujo turbulento se alcanza fácilmente cuando Pr es pequeño, por lo que éste afecta significativamente al flujo. El flujo turbulento se genera en la parte superior de la pared caliente.

*** Limitaciones:

1. No investiga en cámaras con alta esbeltez $A>40$.

2. El artículo se restringe a un rango particular del número de Rayleigh.

3. Se utilizaron las ecuaciones de corriente de vórtice para eliminar la presión que juega un papel importante en la inestabilidad del análisis.

4. El flujo multicelular desaparece sólo para flujos entre 12,5 y 15, y entonces el flujo se convierte en turbulento.

5. Se hicieron aproximaciones considerando análogas la convección natural y la convección forzada.

6. Se consideró que las condiciones de transferencia de calor locales en las esquinas son independientes de la altura $\mathrm{H}$ de las paredes.

7. No se estudió la formación de las células debido a la inestabilidad.

8. No se consideró la variación de la viscosidad para el régimen de la capa límite donde la diferencia de temperaturas es alta.

9. Las razones físicas por las que hay un límite superior y un límite inferior de $\mathrm{Ra}$ donde el flujo multicelular puede existir, aún son indeterminadas.

10. Se necesita simular más esbelteces a diferentes Ra basados en límites laminares y turbulentos actualizados, para alcanzar el número de Rayleigh crítico $\left(\mathrm{Ra}_{\mathrm{c}}\right)$ sobre el cual hay inestabilidad, y el número de Rayleigh en el que las células múltiples desaparecen.

11. La esbeltez considerada era baja, de tal forma que la diferencia en el número de Nusselt no dependía de las condiciones iniciales.

12. La esbeltez considerada es muy pequeña, y la mayor parte del calor se transporta por convección a través de la cámara en la zona superior e inferior. Sin embargo, los números de Nusselt en función de un número de Rayleigh con flujo transitorio, difiere muy poco. No se observó el efecto de la inestabilidad del flujo en la transferencia de calor.

13. La razón por la que el número de Nusselt aumenta después de un número de Rayleigh particular donde se produce la inestabilidad hidrodinámica se desconoce para esbelteces $(A)$ altas. Las posibles razones pueden ser porque el flujo se convierte en turbulento.

14. Los coeficientes de transferencia de calor mal predichos, se atribuyen a la necesidad de una malla más fina, y por ello, no se capta lo que ocurre en la capa límite.

15. Se realizó una cámara experimental para alta conducción en la parte superior y en la inferior debido a lo cual la validación de los datos con condiciones adiabáticas puede estar sobreestimada o subestimada. 
16. Se consideró que la razón de que la temperatura fluctúe para esbelteces altas en cámaras de $A>40$ era el flujo inestable o la turbulencia. No se explicó la razón correcta. Esto sugiere que sería necesario un análisis del patrón del flujo para un rango particular de $A$ considerado, con el objeto de poder tener un mayor conocimiento de las propiedades físicas del flujo.

17. Las ecuaciones se resolvieron analíticamente.

\subsection{VIENTO}

La ventilación natural se produce por convección natural, por viento o por la combinación de ambas.

El viento es uno de los fenómenos más importantes que afectan a las fachadas doble piel acristaladas. Es tan importante porque afecta a tres superficies: a la cara exterior e interior de la hoja exterior, y a la cara exterior de la hoja interior.

El viento crea presiones altas y bajas en las diferentes caras del edificio y crea corrientes de aire que dependen en gran medida del gradiente de presión del viento.

El flujo del viento alrededor del edificio es completamente turbulento. Las fluctuaciones del viento dificultan su medición. La distribución del viento en la fachada de un edificio se describe mediante coeficientes adimensionales.

Las variables que intervienen en la ventilación natural dominada por viento y que han sido investigadas por varios autores son: presión, velocidad y dirección del viento, y la temperatura.

Los coeficientes de presión del viento $\left(C_{p}\right)$ están influenciados por un amplio rango de parámetros: condiciones climáticas, topografía, entorno del edificio, geometría del edificio, situación del edificio, tipo y posición de la fachada, grado de exposición, velocidad y dirección del viento, turbulencia. Todos estos parámetros hacen que sea difícil obtener un coeficiente de presión fiable.

La diferencia de temperaturas y la velocidad del viento es un factor que afecta a la ventilación natural. El aumento de la temperatura tiende a incrementar los coeficientes de transferencia de calor por radiación, mientras que el aumento de la diferencia de temperaturas incrementa los efectos de la convección. Si la temperatura del vidrio aumenta y la temperatura del interior permanece constante, la resistencia de la capa interior disminuye y tendería a incrementar el flujo hacia el interior. Por otro lado, si la velocidad del viento aumenta, la resistencia de la capa exterior disminuye, lo que disminuye el flujo hacia el interior.

Un diseño correcto de un edificio ventilado naturalmente es una tarea difícil por la complejidad de los fenómenos físicos involucrados. En particular, el flujo de aire a través de una abertura depende de la diferencia de presión entre ambos lados de la abertura, así como de la resistencia que oponga la propia abertura al flujo de aire (que es función de la forma y dimensión de la abertura). 
En edificios en altura, una fachada doble piel con un diseño apropiado de los elementos de abertura puede controlar las fuerzas del viento. El efecto chimenea se determinará por la diferencia entre la temperatura interna y externa y por la altura de la cámara. Dependiendo de la posición de las aberturas de entrada y de salida en el edificio, el viento podría ayudar al efecto chimenea, reducir su influencia o producir el efecto contrario, como forzar la entrada de aire por la abertura de salida.

\subsubsection{Modelos}

A lo largo de los años se han realizado muchos experimentos para investigar la velocidad del aire en la cámara según la velocidad y dirección del viento, y las diferencias de presión y temperatura a ambos lados de la fachada.

Estas investigaciones han mostrado la importancia tanto del viento como de la convección natural como las fuerzas que dominan la ventilación en la cámara.

Para obtener información fiable relacionada con el flujo de aire y la distribución de presiones alrededor y en el interior de un edificio ventilado naturalmente, se pueden realizar investigaciones de diferentes tipos:

- Experimentos a escala real: generalmente se utilizan para validar.

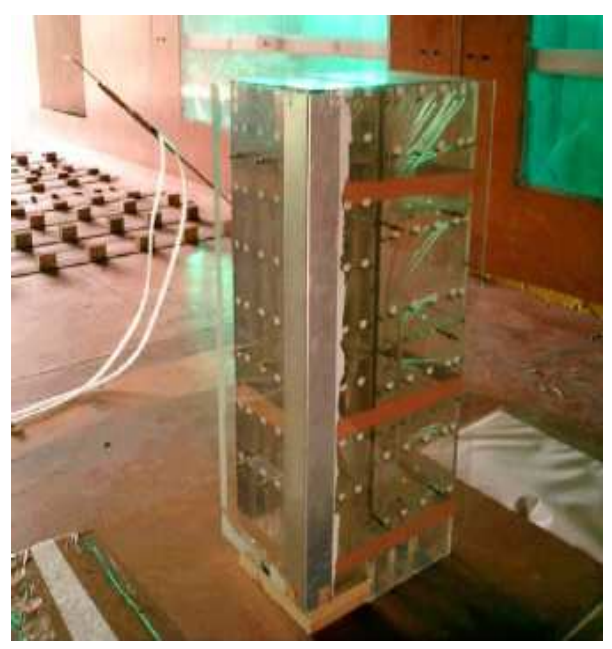

- Experimentos a pequeña escala en túnel de viento: permiten controlar la dirección y velocidad del viento, así como el estudio de diferentes configuraciones de fachada. Sin embargo, tienen una serie de desventajas porque las condiciones climáticas del exterior $\mathrm{y}$ la posible combinación de viento $\mathrm{y}$ convección natural son complicadas y difíciles de controlar.

Figura 2.11. Experimento de un edificio en túnel de viento. "Gap inner pressures in multi-storey double skin facades". Da Silva et al., 2008.

- Modelos CFD: solución numérica gracias a una serie de ecuaciones que describen el flujo. Es una herramienta muy útil para el estudio de la ventilación natural dominada por viento que puede reemplazar los experimentos de túnel de viento en términos de coste y tiempo.

La simulación CFD puede calcular el coeficiente de presión del viento. Para considerar la presión y velocidad del viento, el dominio computacional debe ser lo más grande posible para evitar la interacción entre las zonas de recirculación y los extremos. Con este modelo se puede determinar la distribución de la 
velocidad y temperatura del flujo de aire en el interior y alrededor del edificio así como la tasa de ventilación y los coeficientes de presión en todas las superficies del edificio.

Las simulaciones pueden ser de dos tipos: acopladas o desacopladas. En las simulaciones acopladas se consideran simultáneamente el patrón de flujo alrededor del edificio y el flujo de aire en la cámara dentro del mismo dominio computacional. En las simulaciones desacopladas se realizan dos simulaciones CFD: una del flujo de viento alrededor del edificio (con las aberturas cerradas) para determinar las presiones en la superficie, y otra del flujo de aire en la cámara producida por las presiones en la superficie.
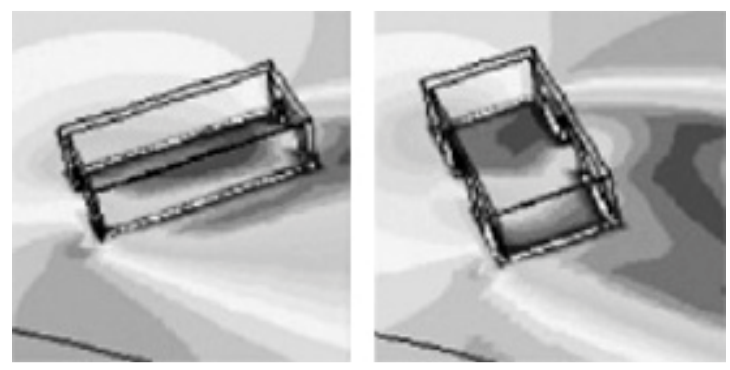

Figura 2.12. Modelo CFD. "A comparison between CFD and Network models for predicting wind-driven ventilation in buildings". Asfour et al., 2006.

\subsubsection{Investigaciones previas}

La ventilación natural dominada por viento es un campo que ha sido investigado por varios autores desde diferentes puntos de vista como:

- La distribución del flujo y la presión en el edificio.

- La interacción entre la ventilación natural por convección natural y por viento.

- Presión en el edificio para diferentes ángulos de incidencia del viento y para diferentes ambientes que rodean el edificio.

- Influencia del edificio y de la topografía en el flujo del viento.

A continuación se describen algunas investigaciones previas relacionadas con este tema:

- Según Grabe (2002) el viento crea diferencias de presión que estimulan el flujo de aire en el edificio. La diferencia de los valores de la presión en una fachada dependen de la dirección del viento, de la forma y de la altura del edificio. En particular, el coeficiente de presión del viento depende en primer lugar de la dirección del viento y según el tipo de edificio, se aplican unas fórmulas u otras.

- Eftekhari et al. (2003) investigó los patrones del flujo producidos por el viento en una fachada doble piel y la distribución de temperatura y confort térmico en el interior de una habitación durante los períodos de verano e invierno. Para ello utilizó distintas velocidades del viento y consideró la temperatura exterior y la presión, velocidad y dirección del viento. La investigación fue realizada mediante ensayos en túnel de viento y mediante modelos CFD. 
- Larsen et al. (2003) realizaron un estudio con el objetivo de encontrar una conexión entre la tasa de renovación de aire y la dirección, velocidad y temperatura del viento. Concluyeron que la renovación de aire depende de la velocidad y temperatura del viento a través de la abertura, así como de la dirección del viento.

- Allocca et al. (2003) estudiaron los efectos combinados de la convección natural $\mathrm{y}$ el viento en la ventilación natural en sistemas con una entrada y una salida. Para ello utilizaron un programa CFD cuyos resultados se compararon con modelos empíricos y analíticos. La investigación reveló que el viento y el efecto chimenea pueden reforzarse u oponerse entre sí.

- Lou et al. (2005) estudiaron la distribución de la presión del viento en cada superficie de las fachadas doble piel utilizando ensayos en túnel de viento. También estudiaron en 2008 la distribución media de la presión del viento en fachadas doble piel utilizando ensayos de túnel de viento. Los resultados mostraron que la presión del viento actúa principalmente en la fachada externa y es mayor que en la fachada interna. Por otra parte, para determinar la carga de viento en la fachada doble piel y predecir la diferencia entre la fachada simple piel y la fachada doble piel, realizaron ensayos en túnel de viento. Se concluyó que la carga de viento recibida por la fachada interior, es la misma que la recibida por una fachada simple piel.

En 2012 realizaron una serie de experimentos de diferentes configuraciones de fachadas doble piel con CFD y validaron los resultados con ensayos en túnel de viento. El método CFD es una buena alternativa para investigar la presión del viento sobre la fachada de un edificio.

- Asfour et al. (2007) validaron el uso de CFD para investigaciones de modelos con ventilación natural dominada por viento. Para ello utilizaron un modelo matemático apropiado y compararon los resultados obtenidos por ambos métodos. Obtuvieron una buena concordancia entre los resultados obtenidos matemáticamente y los de CFD.

- Da Silva (2008) realizó una serie de ensayos de la fachada doble piel en túnel de viento bajo diferentes perfiles de velocidad, diferentes ángulos de incidencia, y diferentes tamaños de aberturas con el objetivo de obtener las distribuciones de la presión del viento en la piel interior de la fachada doble piel. Los datos obtenidos mostraron que la distribución de presiones de la piel interior de la fachada doble piel es considerablemente diferente de la distribución de presiones sobre una fachada simple piel. Asimismo, los resultados mostraron que la distribución de presiones también depende de la dimensión del hueco y de la profundidad de la cámara. 


\subsection{EFICIENCIA ENERGÉTICA DE LA FACHADA DOBLE PIEL}

El sector de la construcción es responsable de una proporción significativa del consumo de energía primaria, emisiones de gas y agotamiento de recursos naturales. Debido a la preocupación medioambiental y al alto coste de la energía de los últimos años, ha generado un gran interés en edificios sostenibles.

En los edificios, el consumo de energía puede reducirse adoptando estrategias de eficiencia energética, que pueden ser activas o pasivas. Las fachadas doble piel pueden ayudar a reducir el consumo de energía del edificio. Es uno de los mejores sistemas pasivos para la gestión eficiente de la interacción entre el espacio exterior e interior.

El uso de la fachada ventilada puede ayudar a reducir las cargas térmicas del verano e invierno, y por tanto, el consumo de los sistemas de calefacción y refrigeración. Hay que controlar cuidadosamente el flujo y la temperatura del aire de la cámara para mejorar los efectos de la ventilación natural en el ahorro de energía.

Para asegurar un consumo de energía bajo y un buen confort térmico en el interior, es muy importante hacer un buen diseño de la fachada doble piel. La eficiencia energética del edificio depende en gran medida del diseño y construcción de la fachada.

Hay parámetros que son cruciales para el comportamiento del edificio: geometría, localización, orientación y ocupación. El diseño de la fachada doble piel también implica decisiones de geometría, tipo de vidrio, estrategia de ventilación, elementos de sombreamiento, cantidad de luz diurna, carga de viento, costes de mantenimiento y limpieza.

\subsubsection{Calefacción}

La reducción de las cargas de calefacción es uno de los argumentos que justifican el uso de la fachada doble piel. La radiación solar entra en la cámara cerrada a través del vidrio y se transforma en calor. El calor permanece en la cámara y calienta el aire creando patrones de flujo de aire de convección. Este mecanismo es beneficioso para el invierno ya que reduce las pérdidas de calor a través de la piel interior del edificio.

Investigaciones previas en relación con este tema:

- Yoon et al. (1997) evaluaron los efectos de una fachada simple piel orientada a sur y un intercambiador de calor en el consumo anual de energía de un edificio de oficinas de tres plantas. Los resultados mostraron que el ahorro de energía debido a la fachada doble piel y al intercambiador de calor es del 12 al 23\%.

- Yilmaz y Cetintas (2005) analizaron las pérdidas de calor de una fachada simple piel y de una doble piel en un edificio de oficinas para mostrar el efecto de la fachada doble piel en el consumo de energía en condiciones de invierno en Estambul. Los resultados mostraron que el consumo de energía de calefacción se reducía significativamente. 
- Pappas et al. (2006) utilizaron dos software informáticos para modelar la fachada doble piel. Obtuvieron un ahorro anual del 1\% en refrigeración y del 3\% en calefacción en comparación con el sistema convencional de distribución de aire.

- Gratia y Herde (2007) estudiaron el efecto invernadero en la fachada doble piel. Analizaron el impacto en la distribución de temperaturas en la cámara de aire. Observaron que se alcanza el efecto invernadero en la fachada orientada a sur. Sin embargo, no se produce en el resto de fachadas.

- Kim y Song (2007) examinaron la contribución de la fachada doble piel en el ahorro de energía en edificios de oficinas. Realizaron un estudio experimental en las fachadas este y oeste de un edificio de tres plantas y también con CFD. Los resultados mostraron que la fachada oeste contribuía al ahorro de energía cuando la ventilación natural del espacio interior se producía a través de la cámara de la fachada. La fachada este no se recomienda para el ahorro de energía por su pequeña exposición a la radiación solar.

- Chou et al. (2009) presentó un método sistemático para investigar la efectividad de la fachada doble piel en reducir las ganancias por radiación solar. Realizaron diversos estudios para obtener el valor del coeficiente de ganancia solar en los sistemas de ventanas.

\subsubsection{Refrigeración}

La ganancia solar se ha convertido en un aspecto importante y complejo para desarrollar sistemas más eficientes. La estrategia de reducir la carga de refrigeración en verano limitando la ganancia solar se ha vuelto complicado por el interés del uso de la luz diurna con un control adecuado en edificios comerciales. Investigaciones previas en relación con este tema:

- Stec y Paasen (2005) compararon el rendimiento de nueve sistemas diferentes de fachada y concluyeron que el sistema de doble piel era competitivo. También expresaron la importancia de tratar la fachada doble piel como un sistema integrado en el sistema HVAC.

- E. Gratia y De Herde (2004-2007) realizaron varios estudios para analizar el efecto de la orientación de la fachada doble piel y del viento en un día de verano soleado en un edificio de oficinas. Compararon el comportamiento y el consumo de energía de la fachada doble piel respecto a una fachada convencional. También estudiaron el impacto de estos parámetros: nivel de radiación solar, orientación y color de los elementos de sombreamiento, proporción de huecos y macizos de la fachada interior, velocidad del viento, ancho de la cámara, tipo de acristalamiento de la fachada interior, y temperatura en el interior de la cámara. Concluyeron que la fachada doble piel siempre causa un incremento de la carga de refrigeración y proponen la aplicación de estrategias de refrigeración natural para reducir el coste de la energía utilizada en un edificio con fachada doble piel. 
- Balocco (2004) definió 14 variables adimensionales para describir el comportamiento térmico y energético de diferentes diseños de fachadas.

- $\quad \mathrm{Xu}$ (2007) propuso una investigación de una fachada doble piel en un edificio de dos plantas en Japón. Obtuvo la distribución de temperaturas, el comportamiento térmico de la fachada doble piel y su impacto en la carga de aire acondicionado. Los resultados mostraron que la fachada doble piel ahorra entre un 10 y un 15\% en refrigeración en verano por la evacuación del calor por ventilación natural, y entre un 20 y un $30 \%$ en invierno por el efecto invernadero.

\subsubsection{Ventilación}

La ventilación se utiliza para diferentes propósitos. Las siguientes investigaciones consideran la posibilidad de suministrar aire fresco de buena calidad al interior a través de la fachada doble piel. También es importante crear un ambiente interior donde haya intercambios de temperatura suaves.

Investigaciones previas en relación con este tema:

- Pasquay (2004) hizo una investigación acerca del rendimiento térmico de tres edificios con fachada doble piel. Observó que la temperatura interior estaba ligeramente afectada por el clima exterior. Las fachadas defectuosas pueden introducir aire caliente en el interior de las oficinas lo que puede ser una situación muy negativa y perjudicial.

- Ding et al. (2005) sugirieron la adición de un espacio de almacenamiento térmico denominado chimenea solar sobre la fachada doble piel para mejorar el efecto chimenea de la misma. Realizaron experimentos a pequeña escala y análisis con CFD para evaluar el comportamiento de la fachada doble piel en un prototipo de edificio. El sistema mejoró notablemente el efecto chimenea de la fachada doble piel a pesar de necesitar una chimenea que alcanzase los $11 \mathrm{~m}$ por encima del edificio. Esta es una limitación desde el punto de vista estético.

- Ballestini et al. (2005) analizaron e investigaron la posibilidad de aplicar sistemas solares pasivos en el clima Mediterráneo. El estudio se realizó en una fachada doble piel ventilada naturalmente. Utilizaron dos programas de simulación. Se demostró cómo puede obtenerse la ventilación natural por medio de flujos de aire internos recorriendo toda la altura del edificio a través de pequeños huecos entre plantas. Demostraron que la fachada doble piel puede ser una solución valiosa para la renovación de aire en el edificio, y que puede ahorrar hasta el $12 \%$ del consumo de energía.

- Las fachadas doble piel son una técnica desarrollada para climas fríos, pocos investigadores piensan que también pueden servir para veranos calurosos. Zhou et al. (2010) lo estudiaron para verano e invierno en una zona de China. Llegaron a la conclusión de que puede utilizarse este tipo de fachada en verano siempre y cuando se utilicen sistemas de sombreamiento controlado. 


\subsubsection{Comportamiento de la fachada doble piel frente a la fachada simple piel}

Los autores comenzaron a estudiar el comportamiento de la fachada doble piel en comparación con la fachada simple piel en relación con la mejora térmica y la eficiencia energética del edificio.

Investigaciones previas en relación con este tema:

- Faggembauu et al. (2003) presentó un código para la simulación numérica de fachadas ventiladas. Permitió evaluar el comportamiento de las fachadas a lo largo de un año e introducir elementos avanzados en la composición. Era una herramienta útil para optimizar el diseño de fachadas con el fin de integrar diferentes materiales, orientaciones, geometrías y para hacer frente a diferentes condiciones climáticas. Se concluyó que si las fachadas de doble piel se diseñaban cuidadosamente, mostrarían un comportamiento mejor que las fachadas acristaladas convencionales y que permitirían recoger la energía en forma de aire caliente para reducir el consumo de energía en invierno.

- Hien et al. (2005) investigaron los efectos de una fachada doble piel ventilada en el consumo de energía, el confort térmico y la condensación en comparación con un sistema de simple piel. Utilizaron CFD para hacer los cálculos. Los resultados de la simulación mostraron que la fachada doble piel era capaz de minimizar el consumo de energía así como mejorar el confort térmico.

- Cetiner et al. (2005) investigaron la fachada doble piel en términos de eficiencia energética y de coste en comparación con la fachada simple piel. Concluyeron que la fachada doble piel es más eficiente energéticamente, pero la fachada simple piel es más eficiente en coste.

- Zerefos (2007) comparó las cargas de calefacción y de refrigeración entre una fachada doble piel y una simple piel en diferentes climas. Calculó las propiedades térmicas y luminosas de ambos tipos de fachadas basadas en la hipótesis de una oficina de orientación sur. Los resultados mostraron que los climas con muchas horas de radiación solar las cargas de calefacción y de refrigeración eran menores en una fachada doble piel en comparación con una fachada simple piel.

- Eicker et al. (2008) cuantificaron el comportamiento térmico de fachadas doble y simple piel en condiciones de verano utilizando experimentos en laboratorio y en edificios a escala real. Los resultados experimentales fueron utilizados para la validación de modelos y estudios utilizando herramientas de simulación dinámica de edificios. Se concluyó que las fachadas simple piel con un elemento de sombreamiento en la cara exterior y que las fachadas doble piel con un elemento de sombreamiento en la cámara pueden reducir de forma eficaz la transmisión de energía en un edificio en verano.

- Chan et al. (2009) estudiaron el comportamiento de la fachada doble piel en un edificio de oficinas en Hong Kong. Primero simularon un modelo utilizando un programa CFD y después realizaron un modelo experimental para verificar los resultados obtenidos en la simulación. Los resultados mostraron que el sistema 
de fachada doble piel con un vidrio simple en la cara interior y un vidrio doble reflectante en la cara exterior podía proporcionar un ahorro anual en la carga de refrigeración del edificio del $26 \%$ en comparación con una fachada simple con un vidrio simple estándar.

Asimismo, también hay investigaciones sobre la eficiencia de la fachada doble piel en cuanto a iluminación natural y seguridad frente al fuego, entre otros, que no se mencionan porque no son objeto de la presente tesis.

\subsection{OTROS IMPACTOS}

Las fachadas doble piel tienen otros impactos como la optimización, el deslumbramiento, el coste y la durabilidad de la fachada. Las fachadas doble piel influencian las propiedades térmicas de la fachada y el mantenimiento del interior de la cámara.

La fachada doble piel también es una manera de relacionar el exterior con el espacio interior, y proporciona flexibilidad al diseño.

Gratia y Herde, Hoseggen et al. y Poirazis creen que el ahorro de energía justifica el alto coste de la fachada doble piel. La eficiencia energética de una fachada doble piel depende de todos los factores mencionados en apartados anteriores.

\subsection{PROCEDIMIENTO DE DISEÑO}

\subsubsection{Viabilidad de la ventilación natural}

Factores a considerar cuando se tiene que decidir si la ventilación natural es un sistema de ventilación viable o no. Hay que considerar:

- Condiciones climáticas: viento, temperatura, humedad.

- Confort térmico de los ocupantes: los ocupantes tienen que intervenir en el control del sistema abriendo ventanas, reduciendo la ganancia solar, etc.

- Diseño del edificio.

- Ganancias de calor internas.

- Geometría del edificio y ambiente exterior: según su situación se determinará el flujo de aire y las presiones de viento generadas en su superficie. La orientación del edificio en relación con la dirección del viento es un factor que debe considerarse en el diseño.

- Fachada del edificio: es muy importante en el diseño de la ventilación natural. Además de contener las aberturas, tiene una gran influencia en el almacenamiento térmico y en las ganancias solares. 


\subsubsection{Selección de la estrategia de ventilación}

A continuación se enumeran algunos ejemplos de estrategias de ventilación básicas:

- Espacios aislados: se considera que una pared de la habitación tiene una abertura directa al exterior, así que la ventilación se produce por un solo lado. Puede ser por convección natural, por viento o por la combinación de ambas.

- Espacios conectados: para mejorar la ventilación cruzada del edificio utilizando la ventilación por convección natural y por viento. Puede utilizarse una chimenea o un atrio.

- Fachada doble piel: es una manera de acondicionar el aire antes de que entre en el edificio. Proporciona un efecto buffer entre el exterior y el interior.

- Edificios en altura: utilizan la ventilación natural como parte de un sistema mixto. Tienen problemas con el sistema puro de ventilación natural por la diferencia de presiones generadas por la convección natural y por el viento, por el número de aberturas que se requieren, etc.

- Ventilación nocturna: utiliza el flujo de ventilación nocturna con el objetivo de disipar el calor que la fachada ha absorbido durante el día.

\subsubsection{Diseño de la envolvente}

- Determinar los tamaños y la posición de las aberturas necesarias para generar la magnitud de flujo requerida según la estrategia elegida.

- Diseño de las condiciones de invierno: asegurar que no hay muchas pérdidas de calor por la ventilación.

- Diseño de las condiciones de verano: impedir que haya un sobrecalentamiento.

- Determinar las tasas de ventilación mínimas requeridas.

- Condiciones de diseño: velocidad y dirección del viento, diferencia de temperaturas, selección apropiada de las aberturas.

\subsubsection{Ambiente interior}

- Determinar la velocidad del aire y la temperatura interior.

- Determinar las condiciones de confort.

- Sólo viento: especificar la velocidad del viento según la situación del edificio. 
- Sólo convección natural: el movimiento del aire interior está dominado por los efectos de la convección natural. Generalmente se consideran las paredes adiabáticas.

\subsubsection{Especificación de los datos}

- Presión del viento de las superficies.

- Temperatura exterior.

- Características del flujo.

\subsubsection{Sistemas de control}

El sistema de ventilación natural está controlado por los ocupantes del edificio, para el caso de edificios residenciales, y por un sistema de gestión del edificio, para el caso de edificios no domésticos.

\subsubsection{Evaluación}

Los ocupantes del edificio son los que evaluarán el sistema de ventilación natural. Es importante para mejorar el sistema y para futuros diseños.

\subsection{CONCLUSIONES}

Del estado de la cuestión se pueden obtener las siguientes conclusiones en relación con las investigaciones previas:

- La mayoría de los autores investigan la fachada doble piel opaca, de panel opaco. La fachada doble piel del presente estudio es de vidrio.

- La mayor parte de los autores investigan sólo lo que ocurre en el interior de la cámara. La presente tesis estudia lo que ocurren en el ambiente exterior, en la cámara y en el ambiente interior.

- La mayoría se centran en los efectos de la convección natural. Hay poca información sobre la combinación de los efectos del viento con la convección natural y aún menos que tengan en cuenta la dirección del viento.

- Pocas incorporan convección, conducción y radiación en el modelo CFD para estudiar la transferencia de calor.

- Generalmente no estudian en detalle la combinación de la transferencia de calor y la convección natural. 
- Pocas incorporan la radiación solar en el modelo.

- Hay pocos estudios que tengan en cuenta la dirección del viento.

- De forma general no suelen estudiar el problema de forma más extensa teniendo en cuenta la transferencia de calor, el flujo de aire, la distribución de la temperatura y los regímenes del flujo.

De la investigación llevada a cabo en este punto se detecta la necesidad de:

- Investigar la fachada doble piel de una forma más amplia y desde el punto de vista de todos los aspectos que intervienen en la eficiencia energética del sistema y en el cumplimiento de las prestaciones.

- Desarrollar una metodología de diseño que evalúe el rendimiento y la eficiencia energética de la fachada doble piel acristalada dentro de unas condiciones de confort óptimas. 
Optimización de la fachada de doble piel acristalada con ventilación natural. Metodología de diseño para el análisis de la eficiencia energética del sistema. 


\section{PLANTEAMIENTO DE LA INVESTIGACIÓN}

En este capítulo se realiza el planteamiento geométrico y la determinación de algunas propiedades físicas y parámetros presentes en la investigación.

Se describen las características geométricas y el dominio computacional del modelo utilizado en las simulaciones CFD, así como la selección del tipo de vidrio utilizado.

Se definen algunas propiedades físicas de las condiciones de contorno del modelo como la temperatura de confort del ambiente interior y la temperatura media del ambiente exterior necesarias para el cálculo numérico en los diferentes escenarios.

Se establecen los parámetros que intervienen en la transferencia de calor por radiación en función del tipo de vidrio seleccionado, situación y orientación de la fachada, y escenario de estudio.

Por último se presentan los diferentes casos que se van a estudiar tanto para las situaciones de flujo dominado por convección natural como para las situaciones de flujo dominado por viento. 
Optimización de la fachada de doble piel acristalada con ventilación natural. Metodología de diseño para el análisis de la eficiencia energética del sistema. 


\subsection{DEFINICIÓN GEOMÉTRICA}

\subsubsection{Geometría básica}

Para la realización del estudio de la presente tesis se utiliza un modelo simplificado. Para ello se modeló en Fluent un modelo 2D, en dos dimensiones, y se consideró un flujo estacionario. La razón por la que se decidió realizar un modelo simplificado y estudiarlo sólo en dos dimensiones es porque resulta un caso representativo de lo que ocurre en una sección transversal de la geometría que se desea analizar y así se reduce mucho el tiempo de cálculo, lo que permite analizar más casos; y además se comprobó que haciendo un mallado fino del modelo en dos dimensiones, los resultados obtenidos eran óptimos.

La geometría básica utilizada para las simulaciones CFD está ilustrada en las Figuras 3.1 y 3.2. Se trata de una habitación con una fachada doble piel orientada a sur, compuesta por una fachada interior, una cámara de aire y una fachada exterior. La tipología de la fachada es de una planta, es decir, va de forjado a forjado.

Las dimensiones de la habitación son de $3 \mathrm{~m}$ de alto $(H)$ y $6 \mathrm{~m}$ de ancho $(2 H)$. La cámara discurre a lo largo de toda la altura del modelo. Hay una entrada de aire $\left(h_{v}\right)$ próxima a la base y una salida de aire cerca de la parte superior de la sección, ambas de $6 \mathrm{~cm}$ de alto. Los vidrios son de $6 \mathrm{~mm}$ de espesor $\left(t_{p}\right)$. La cámara de aire está completamente cerrada al interior del recinto. Se estudian diferentes configuraciones de fachada, por lo que el ancho de la cámara $(L)$ varía.

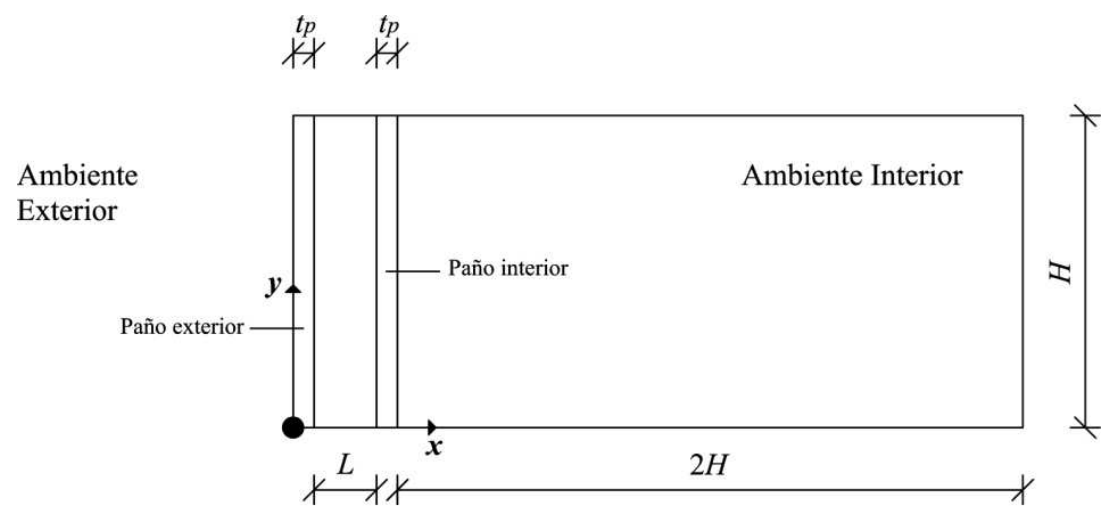

Figura 3.1. Sección esquemática de la cámara de aire con aberturas cerradas. Dimensiones en metros (m).

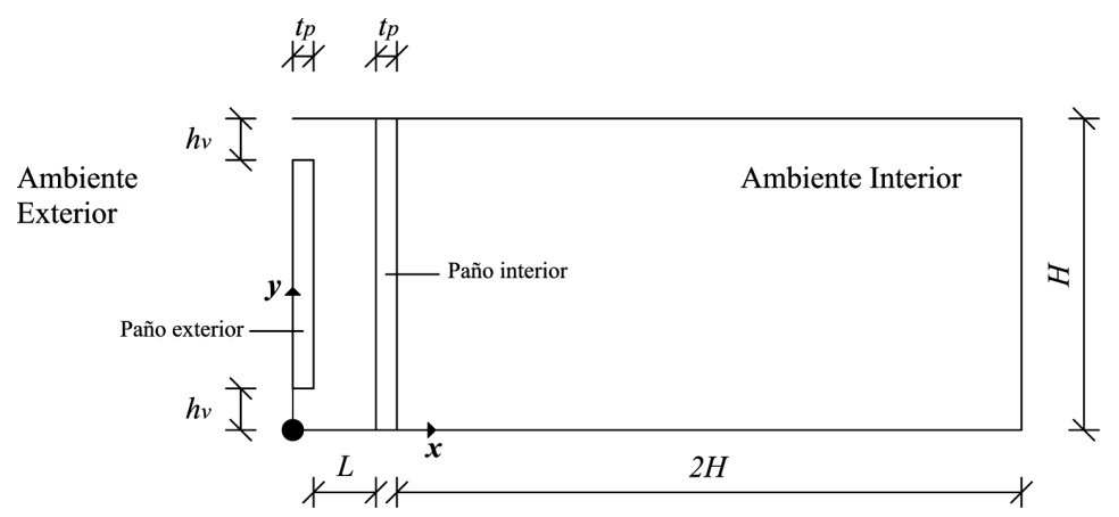

Figura 3.2. Sección esquemática de la cámara de aire con aberturas abiertas. Dimensiones en metros (m). 


\subsubsection{Dominio computacional}

\subsubsection{Casos de flujo dominado por convección natural}

Con el objetivo de estudiar el impacto de las diversas configuraciones de fachada bajo diferentes condiciones, se ha tenido que ampliar el dominio de cálculo CFD para incluir un ambiente exterior que rodea el modelo de estudio. El dominio se modela con una geometría sencilla y sus dimensiones son de $21 \mathrm{~m}$ de ancho y $10 \mathrm{~m}$ de alto. La Figura 3.3 muestra de forma esquemática el dominio computacional (ambiente exterior) utilizado para la simulación CFD y la situación del modelo de la habitación de estudio dentro del mismo.

La modelización del espacio exterior es importante para la calidad de la simulación, sobre todo si se quieren incluir los efectos del viento y de la radiación solar. Es importante utilizar un dominio grande para una simulación precisa del flujo de aire y de la transferencia de calor en la ventilación natural de edificios, así como para la predicción del ambiente térmico interior.

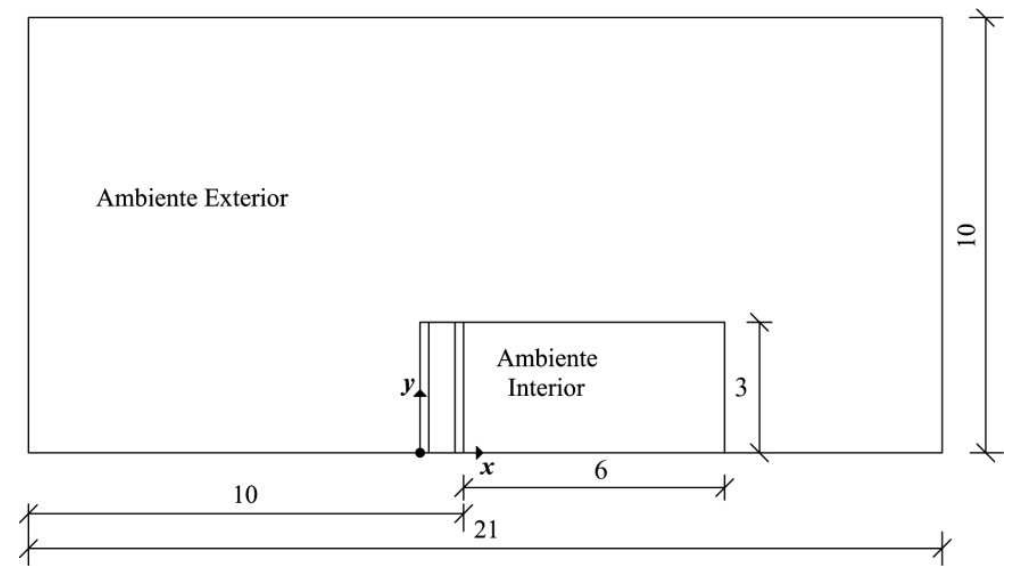

Figura 3.3. Sección esquemática del dominio computacional y de la geometría utilizada para la simulación CFD de los casos de flujo dominado por convección natural. Dimensiones en metros (m).

\subsubsection{Casos de flujo dominado por viento}

La simulación CFD puede calcular el coeficiente de presión del viento. Para considerar la presión y velocidad del viento, el dominio computacional debe ser lo más grande posible para evitar la interacción entre las zonas de recirculación y los extremos.

La geometría del ambiente exterior varía respecto a los casos de estudio del apartado anterior. Se ha tenido que ampliar considerablemente el dominio de cálculo CFD para poder incluir los efectos del viento en el modelo. El dominio se modela con una geometría sencilla de dimensiones de $126 \mathrm{~m}$ de ancho y $30 \mathrm{~m}$ de alto. La Figura 3.4 muestra de forma esquemática el dominio computacional utilizado para la simulación CFD del viento. Asimismo, muestra la situación de la habitación en el mismo. 


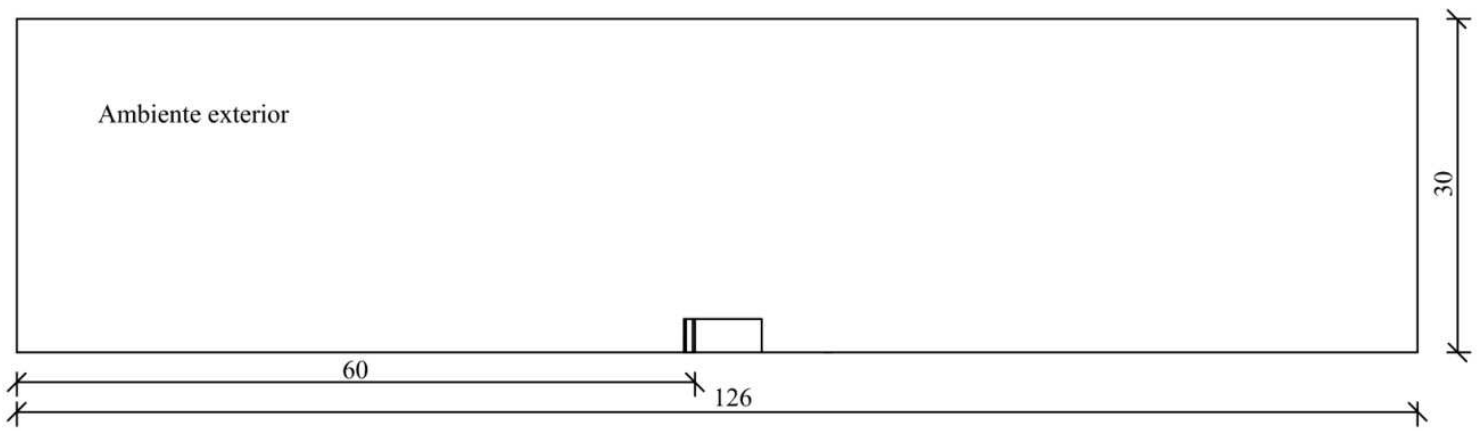

Figura 3.4. Sección esquemática del dominio computacional y de la geometría utilizada para la simulación CFD de los casos de flujo dominado por viento. Dimensiones en metros (m).

\subsection{DETERMINACIÓN DE LA TEMPERATURA DE CONFORT}

La norma UNE-EN 15251: Parámetros del ambiente interior a considerar para el diseño y la evaluación de la eficiencia energética de edificios incluyendo la calidad del aire interior, condiciones térmicas, iluminación y ruido establece que el consumo de energía de los edificios depende significativamente de los criterios usados para el ambiente interior (temperatura, ventilación e iluminación) y para el diseño y funcionamiento del edificio (incluyendo los sistemas).

Esta norma define cómo establecer y definir los principales parámetros para usarse como datos de partida para el cálculo energético del edificio y para la evaluación a largo plazo del ambiente interior.

Para la ejecución de las simulaciones de los casos de estudio de la presente tesis, es necesario especificar la temperatura de confort en el interior de la habitación para el diseño del ambiente interior y los cálculos. La temperatura de confort será diferente para el escenario de invierno que para el de verano.

De acuerdo con la Tabla I.1 Clasificación basada en los criterios para los cálculos energéticos de dicha norma, la temperatura interior para el cálculo energético en edificios residenciales, oficinas y espacios con actividades similares para la categoría II (nivel normal de expectativa para edificios nuevos y renovados), los criterios de diseño del ambiente interior son los siguientes:

- Condiciones térmicas en invierno: $20-24^{\circ} \mathrm{C}$

- Condiciones térmicas en verano: $22-27^{\circ} \mathrm{C}$

De acuerdo con los criterios de diseño utilizados en esta norma, se establecen las condiciones térmicas de confort del ambiente interior que se utilizarán en las simulaciones CFD:

- Condiciones térmicas de confort en invierno: $20^{\circ} \mathrm{C}$

- Condiciones térmicas de confort en verano: $26^{\circ} \mathrm{C}$

La temperatura de confort establecida es la temperatura de consigna que se encuentra dentro del intervalo definido por la norma $U N E-E N 15251$. 


\subsection{DETERMINACIÓN DE LA TEMPERATURA DEL AMBIENTE EXTERIOR}

Para la ejecución de las simulaciones es necesario especificar una temperatura como condición de contorno del ambiente exterior. Esta temperatura será diferente para el escenario de invierno y para el de verano.

Para poder justificar el valor de la temperatura media establecida en el ambiente exterior, se consultó el registro histórico de temperaturas en la zona centro de España, en particular en Madrid, en la base de datos de AEMET (Agencia Estatal de Meteorología). Ver Anexo I. Histórico de temperaturas en Madrid. Se observó que:

- el sistema de calefacción se utiliza durante 5 meses al año (enero, febrero, marzo, noviembre y diciembre), meses de invierno.

- el sistema de refrigeración durante 4 meses (junio, julio, agosto y septiembre), meses de verano.

- Durante 3 meses no es necesario utilizar ningún sistema de acondicionamiento térmico.

Según el registro, la temperatura media mínima en los meses de invierno oscila entre 0 y $5{ }^{\circ} \mathrm{C}$; y la temperatura media máxima en los meses de verano entre 30 y $35^{\circ} \mathrm{C}$. El valor de la temperatura se refiere a la temperatura seca, es decir, no se ha estudiado el efecto de la humedad en el aire.

Basándose en los datos registrados en la base de datos de AEMET, las condiciones térmicas del ambiente exterior para la realización de las simulaciones se establecen en:

- $\quad 4{ }^{\circ} \mathrm{C}$, temperatura media seca para el escenario de invierno (temperatura mínima media de los meses de invierno)

- $\quad 32{ }^{\circ} \mathrm{C}$, temperatura media seca para el escenario de verano (temperatura máxima media de los meses de verano)

\subsection{SELECCIÓN DEL VIDRIO DE REFERENCIA}

Para la realización de las simulaciones de la presente tesis, se escoge un vidrio común, convencional y sin tratar, por ser el más sencillo y por ser el que puede servir para un estudio más completo. Se elige el vidrio sodocálcico plano, que además viene bien definido en las diferentes normas.

Según la norma EN 572-1:2012, un vidrio plano es un "vidrio de silicato sodocálcico, plano, transparente, incoloro o coloreado, de caras paralelas y pulidas, que se obtiene por colada continua y solidificación sobre un baño de metal". 


\subsubsection{Composición química}

Según la norma EN 572-1:2012, las proporciones en masa de los componentes principales de los vidrios de silicato sodocálcico son los siguientes:

- Dióxido de silicio $\left(\mathrm{SiO}_{2}\right)$

- Óxido de calcio $(\mathrm{CaO})$

- Óxido sódico $\left(\mathrm{Na}_{2} \mathrm{O}\right)$

- Óxido de magnesio $(\mathrm{MgO})$

- Óxido de aluminio $\left(\mathrm{Al}_{2} \mathrm{O}_{3}\right)$

- Otros

$$
\begin{gathered}
69 \% \text { a } 74 \% \\
5 \% \text { a } 14 \% \\
10 \% \text { a } 16 \% \\
0 \% \text { a } 6 \% \\
0 \% \text { a } 3 \% \\
0 \% \text { a } 5 \%
\end{gathered}
$$

Además de los componentes anteriormente indicados, estos vidrios también pueden

\begin{tabular}{|c|c|c|c|c|}
\hline PROPIEDADES & $\begin{array}{l}\text { UNE-EN ISO } \\
10456: 2012\end{array}$ & $\begin{array}{l}\text { Paño simple } \\
\text { (6 mm) } \\
\text { UNE-EN } \\
\text { 410:2011 }\end{array}$ & $\begin{array}{c}\text { Paño doble } \\
(6+L+6) \mathrm{mm} \\
\text { UNE-EN } \\
\text { 410:2011 }\end{array}$ & $\begin{array}{l}\text { UNE-EN } \\
673: 2011\end{array}$ \\
\hline Densidad, $\rho\left(\mathrm{kg} / \mathrm{m}^{3}\right)$ & 2.500 & & & \\
\hline Calor específico, $C_{p}(\mathrm{~J} / \mathrm{kg} \cdot \mathrm{K})$ & 750 & & & \\
\hline Conductividad térmica, $K(\mathrm{~W} / \mathrm{m} \cdot \mathrm{K})$ & 1 & & & \\
\hline $\begin{array}{l}\text { Transmitancia, } \tau_{e}(\%) \\
\text { Reflectancia, } \rho_{e}(\%)\end{array}$ & & $\begin{array}{c}82 \\
7\end{array}$ & $\begin{array}{l}68 \\
13\end{array}$ & \\
\hline $\begin{array}{l}\text { Coeficiente de intercambio térmico } \\
\text { exterior, } h_{e}\left(\mathrm{Wm}^{-2} \mathrm{~K}^{-1}\right) \\
\text { Coeficiente de intercambio térmico } \\
\text { interior, } h_{i}\left(\mathrm{Wm}^{-2} \mathrm{~K}^{-1}\right)\end{array}$ & & & & $\begin{array}{l}25 \\
7,7\end{array}$ \\
\hline
\end{tabular}
contener pequeñas cantidades de otras sustancias.

\subsubsection{Características físicas, ópticas y térmicas}

Se utilizó un vidrio sodocálcico cuyas propiedades físicas se tomaron de la norma europea 10456:2012. La Tabla 3.1 muestra los valores generales de las características físicas, ópticas y térmicas del vidrio sodocálcico plano.

Tabla 3.1. Propiedades físicas, ópticas y térmicas de los paños de vidrio sodocálcico. (UNE-EN ISO 10456, UNE-EN 410, UNE-EN 673).

Las características de los productos básicos de vidrio de silicato sodocálcico pueden considerarse constantes en el tiempo.

\subsection{TRANSFERENCIA DE CALOR POR RADIACIÓN}

Los mecanismos de transmisión del calor son: conducción, convección y radiación.

ANSYS Fluent cuenta con dos métodos para introducir la radiación solar que se podrían adaptar al modelo: el modelo de radiación solar DO (discrete ordinates) y el modelo de 
carga solar. En un principio se hicieron pruebas con estas dos herramientas ya que se quería introducir la radiación solar utilizando el mismo software, pero ni se obtuvieron los resultados esperados ni se consiguió que el calor se transmitiese tanto por conducción como por convección. Finalmente, se decidió buscar otro método para introducir la radiación solar en el programa menos complejo, que funcionase y que no requiriese tanto tiempo de cálculo. Además, un modelado muy preciso de la radiación solar no es el objeto de esta tesis.

Se investigó en la bibliografía las diferentes soluciones para introducir la radiación solar utilizadas por otros autores, ya descritas en el Capítulo 2. Estado de la cuestión.

Tras el análisis y estudio de las diferentes opciones, se decidió realizar una aproximación desacoplada: resolver por CFD el flujo de calor que se transfiere por conducción y por convección, mientras que la radiación solar se calcula de forma independiente.

Para simplificar el modelo de radiación solar y para reducir el tiempo de cálculo, el flujo de calor debido a la radiación solar fue representado por una fuente de calor uniformemente distribuida y perpendicular a la superficie del paño de vidrio. El flujo de calor fue calculado con la radiación solar $\left(Q_{s}\right)$ y teniendo en cuenta las propiedades ópticas y térmicas de los paños de vidrio.

Para ello, es necesario saber la cantidad de radiación solar que incide y las propiedades del vidrio utilizado para poder calcular la radiación solar que pasa al interior de la habitación una vez que se ha producido la transmisión, reflexión y absorción de la energía.

Una vez realizados los cálculos, se obtiene el índice de generación de calor $\left(Q_{r}\right)$. Este valor es el que se introduce en Fluent a modo de fuente de calor en representación de la radiación solar que atraviesa cada vidrio.

De esta forma, se pudo calcular la temperatura media en el interior de la habitación para las condiciones de invierno y de verano incluyendo la transferencia de calor por radiación solar en el modelo.

El valor correspondiente para cada caso es introducido en las condiciones de contorno térmicas del software CFD. Ambas caras de los paños de vidrio fueron acopladas para considerar el efecto de la conducción entre el aire y los paños de vidrio.

\subsubsection{Cálculo de los factores energéticos de los vidrios}

\subsubsection{Cálculo mediante el software Calumen ${ }^{\circledR}$ II}

El tipo de vidrio utilizado en todos los casos de estudio es un vidrio sodocálcico plano de $6 \mathrm{~mm}$ de espesor $\left(t_{p}\right)$.

Para poder realizar las simulaciones incluyendo la radiación solar, hay que saber qué cantidad de radiación solar incidente pasa a través de cada uno de los vidrios para poder poner su valor en Fluent. 
Para ello es necesario conocer los factores energéticos del vidrio. Los factores de transmisión y reflexión se toman de un fabricante de vidrio. En este caso, se ha escogido el producto Planilux de $6 \mathrm{~mm}$ de espesor de la casa Saint-Gobain Glass, ya que es un tipo de vidrio que tiene las mismas características que el utilizado en las simulaciones.

La casa comercial Saint-Gobain Glass dispone de un software verificado que proporciona los valores energéticos del vidrio en función del tipo de vidrio seleccionado. Este software se denomina Calumen ${ }^{\circledR}$ II (versión 1.2.5), y es un programa de cálculo de las principales prestaciones espectro-fotométricas y térmicas de los acristalamientos como pueden ser la transmisión luminosa, el factor solar y la transmitancia térmica. Estos valores están calculados según las normas EN 410:2011 y EN 673:2011 con las tolerancias definidas en EN 1096-4. Los procedimientos de cálculo y los resultados de Calumen II han sido validados por TÜV Rheinland Quality / TNO Quality Report 11923R-11-33705.

La Figura 3.5 muestra los factores energéticos de un vidrio sencillo:

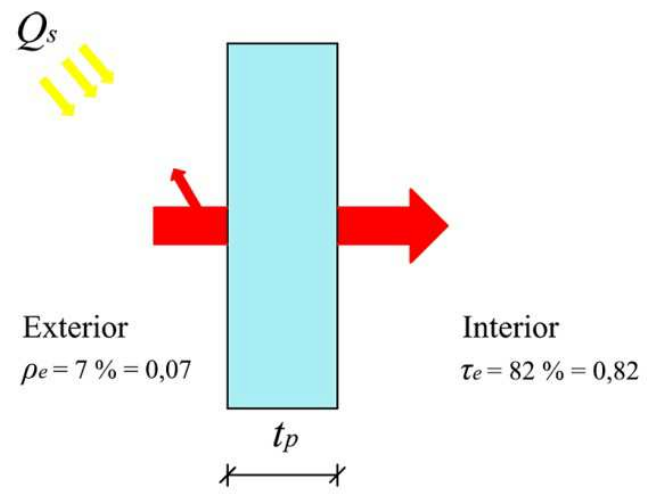

Figura 3.5. Factores energéticos del vidrio sencillo. Calumen ${ }^{\circledR}$ II (versión 1.2.5). Saint-Gobain Glass.

El valor del factor de absorción y del factor solar se han calculado a partir de las ecuaciones de la norma EN 410:2011. Lo que resulta en que el factor de absorción para el vidrio sencillo es del $11 \%$, es decir, $\alpha_{e}=0,11$. El valor del factor solar es $\gamma=0,84$.

La Figura 3.6 muestra los factores energéticos de un vidrio doble:

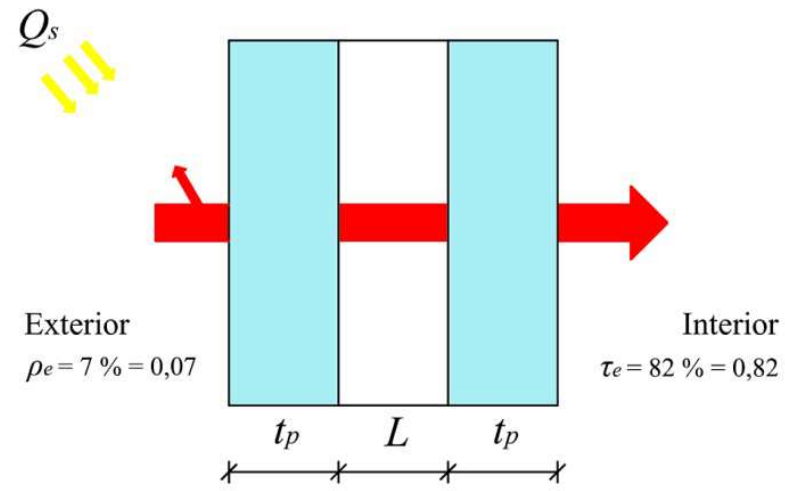

Figura 3.6. Factores energéticos del vidrio doble. Calumen® II (versión 1.2.5). Saint-Gobain Glass. 
El factor de absorción y el factor solar calculados a partir de las ecuaciones de la norma EN 410:2011, resulta que $\alpha_{e 1}=0,11$, absorción del vidrio exterior, y $\alpha_{e 2}=0,08$, absorción del vidrio interior. El valor del factor solar es $\gamma=0,74$.

Es importante tener presente que aunque los valores de reflexión y transmisión se han tomado de un fabricante de vidrio, y se han introducido en el software Calumen II, todos estos valores se han comprobado realizando los cálculos de acuerdo con las ecuaciones de las normas EN 410:2011 Y EN 673:2011, y se ha verificado que los resultados concordaban.

En el próximo aparatado se exponen detalladamente las ecuaciones de donde proceden los resultados.

\subsubsection{Cálculo mediante la normativa}

De acuerdo con la norma europea EN 410: 2011, el factor de transmisión de la energía solar total $\gamma$ se define como la porción de la energía solar incidente transmitida al interior de la habitación a través del vidrio. Se calcula como la suma del factor de transmisión directa de la energía solar $\tau_{e} \mathrm{y}$ del factor de reemisión térmica del acristalamiento hacia el interior $q_{i}$.

$$
\gamma=\tau_{e}+q_{i}
$$

El flujo energético solar incidente se divide en tres partes: trasmitida $\left(\tau_{e}\right)$, reflejada $\left(\rho_{e}\right)$, y absorbida $\left(\alpha_{e}\right)$. La relación entre estas tres características es la siguiente:

$$
\tau_{e}+\rho_{e}+\alpha_{e}=1
$$

La parte absorbida se divide a su vez en dos partes $q_{i}$ y $q_{e}$ que son las energías remitidas respectivamente hacia el interior y hacia el exterior:

$$
\alpha_{e}=q_{i}+q_{e}
$$

Para el acristalamiento sencillo, $q_{i}$ se calcula mediante la fórmula:

$$
q_{i}=\alpha_{e} \frac{h_{i}}{h_{e}+h_{i}}
$$

$h_{e} \mathrm{y} h_{i}$ son los coeficientes de transferencia de calor hacia el exterior y hacia el interior respectivamente. De acuerdo con la norma europea EN 673:2011, $h_{e}=25 \mathrm{Wm}^{-2} \mathrm{~K}^{-1}$ y $h_{i}=$ $7,7 \mathrm{Wm}^{-2} \mathrm{~K}^{-1}$. Ver Tabla 3.1. Tras la aplicación de estas fórmulas para el acristalamiento sencillo, se concluyó que la absorción del vidrio exterior es de $\alpha_{e l}=0,11$.

Para el doble acristalamiento, $q_{i}$ se calcula mediante la fórmula: 


$$
q_{i}=\frac{\frac{\alpha_{e 1}+\alpha_{e 2}}{h_{e}}+\frac{\alpha_{e 2}}{\Lambda}}{\frac{1}{h_{i}}+\frac{1}{h_{e}}+\frac{1}{\Lambda}}
$$

donde $\alpha_{e 1}$ y $\alpha_{e 2}$ son los factores de absorción directa de la energía solar del vidrio exterior y del vidrio interior en el doble acristalamiento, y $\Lambda$ es la conductividad térmica entre la superficie externa y la más interna del doble acristalamiento.

$$
\begin{gathered}
\alpha_{e l}=\frac{\sum_{\lambda=300 \mathrm{~nm}}^{2500 \mathrm{~nm}} S_{\lambda}\left\{\alpha_{l}(\lambda)+\frac{\alpha_{l}^{\prime}(\lambda) \tau_{1}(\lambda) \rho_{2}(\lambda)}{1-\rho_{l}^{\prime}(\lambda) \rho_{2}(\lambda)}\right\} \Delta \lambda}{\sum_{\lambda=300 \mathrm{~nm}}^{2500 \mathrm{~nm}} S_{\lambda} \Delta \lambda} \\
\alpha_{e 2}=\frac{\sum_{\lambda=300 \mathrm{~nm}}^{2500 \mathrm{~nm}} S_{\lambda}\left\{\frac{\alpha_{2}(\lambda) \tau_{l}(\lambda)}{1-\rho_{l}^{\prime}(\lambda) \rho_{2}(\lambda)}\right\} \Delta \lambda}{\sum_{\lambda=300 \mathrm{~nm}}^{2500 \mathrm{~nm}} S_{\lambda} \Delta \lambda}
\end{gathered}
$$

donde $\alpha_{l}(\lambda)$ y $\alpha_{2}(\lambda)$ son los factores de espectrales de absorción directa del vidrio exterior y del vidrio interior medidos en el sentido de la radiación incidente; $\alpha_{l}^{\prime}(\lambda)$ es el factor espectral de absorción directa del vidrio exterior medido en el sentido opuesto a la radiación incidente; $\tau_{l}(\lambda)$ y $\tau_{2}(\lambda)$ son los factores de transmisión espectral del vidrio exterior e interior respectivamente; $\rho_{l}(\lambda)$ y $\rho_{2}(\lambda)$ son los factores de reflexión espectral del vidrio exterior e interior respectivamente medidos en el sentido de la radiación incidente; $\rho_{l}^{\prime}(\lambda)$ es el factor de reflexión espectral del vidrio exterior medido en el sentido opuesto a la radiación incidente; $\lambda$ es la longitud de onda; $S_{\lambda}$ es el reparto espectral relativo de la radiación solar; y $\Delta \lambda$ es el intervalo de longitud de onda.

Después de la aplicación de estas fórmulas para el doble acristalamiento utilizando las propiedades físicas del vidrio sodocálcico plano, resultó que la absorción del vidrio exterior es de $\alpha_{e l}=0,11$ y que la absorción del vidrio interior es de $\alpha_{e 2}=0,08$.

Una vez calculada la absorción solar de cada paño de vidrio, es necesario conocer el valor de la radiación solar para poder obtener el índice de generación de calor.

\subsubsection{Cálculo de la radiación solar incidente}

\subsubsection{Objeto}

A continuación se explica de dónde se han tomado los datos de radiación solar y cómo se ha calculado la cantidad de radiación solar que pasa a través de ambos vidrios.

Como ya se ha explicado anteriormente, la radiación solar se introduce en Fluent como una fuente de calor uniformemente distribuida en la superficie exterior del vidrio. El 
valor será diferente para el vidrio exterior que para el vidrio interior. Este valor debe ser calculado utilizando las propiedades ópticas y térmicas de los vidrios. Para poder realizar los cálculos, se necesita tener como dato de partida la radiación solar incidente media, que será diferente para las condiciones de invierno que para las de verano.

\subsubsection{Radiación solar incidente media}

A continuación se explica de donde se ha tomado el valor de la radiación solar necesario para el cálculo del índice de generación de calor, valor que se coloca en la superficie de cada vidrio a modo de fuente de calor uniformemente distribuida.

Los datos necesarios se toman de la base de datos climáticos desarrollada por el Instituto Alemán Passive House Institute como referencia climática para Centro Europa. Se trata de un instituto de investigación independiente que ha asumido una posición de liderazgo en lo que respecta a la investigación y desarrollo de conceptos y componentes de construcción, herramientas de planificación y control de calidad de los edificios eficientes energéticamente. Ha desarrollado el estándar Passivhaus, un procedimiento exhaustivo en el desarrollo del proyecto y de la ejecución que da lugar a edificaciones con una demanda energética baja.

Dentro de la base de datos de esta herramienta, los datos que se necesitan para este trabajo se encuentran disponibles en la hoja de "Datos Climáticos", donde figuran los valores medios mensuales de las temperaturas exteriores y de la radiación solar sobre superficies horizontales y verticales en los principales puntos cardinales de todos los emplazamientos disponibles. Para algunos lugares están listados los datos anuales o pueden ser deducidos de los datos mensuales.

El conjunto de datos climáticos estándar ha sido desarrollado como referencia climática para lugares de Europa Central. Los datos climáticos regionales sólo se deberían usar para los lugares de referencia del conjunto de datos climáticos regionales y en regiones comparables.

En el Estándar Passivhaus están incluidos un conjunto de datos climáticos estándar que está adaptado a las condiciones típicas de Europa Central.

El caso de estudio se ha centrado en el clima típico de la zona centro de la península ibérica, en particular se han tomado los datos de Madrid, así que se selecciona en el menú de la hoja de Datos Climáticos los siguientes datos:

- Clima estándar: Datos climáticos regionales

- Región: Europa-Sur

- Conjunto de datos climáticos regionales: E-Madrid, Madrid D3

Además de los datos de temperatura y de radiación, la Tabla 3.2 indica la latitud y longitud geográfica, así como la altitud de la estación climática: 


\begin{tabular}{|l|l|}
\hline Localización & Madrid \\
\hline Zona Climática & $\mathrm{D} 3$ \\
\hline Altitud & $657 \mathrm{~m}$ \\
\hline Latitud & $40^{\circ} 24^{\prime} 30^{\prime \prime} \mathrm{N}$ \\
\hline Longitud & $3^{\circ} 41^{\prime} 15^{\prime \prime} \mathrm{O}$ \\
\hline
\end{tabular}

Tabla 3.2. Características geográficas correspondientes a la zona climática de Madrid.

Para cada conjunto de datos climáticos se requiere como mínimo:

- Los datos mensuales de la temperatura de aire exterior.

- Los datos mensuales de la radiación solar (como sumas mensuales en $\mathrm{kWh} / \mathrm{m}^{2}$ ) en superficies horizontales, así como en superficies verticales en los cuatro puntos cardinales.

- La latitud geográfica del lugar (unidad: número decimal en grados).

La Tabla 3.3 muestra la radiación global anual por orientación de acuerdo con el Estándar Passivhaus:

\begin{tabular}{|l|l|}
\hline Norte & $138 \mathrm{kWh} / \mathrm{m}^{2}$ \\
\hline Este & $326 \mathrm{kWh} / \mathrm{m}^{2}$ \\
\hline Sur & $657 \mathrm{kWh} / \mathrm{m}^{2}$ \\
\hline Oeste & $330 \mathrm{kWh} / \mathrm{m}^{2}$ \\
\hline
\end{tabular}

Tabla 3.3. Radiación global anual por orientación. Passive House Institute.

Se toma la orientación sur por ser la más desfavorable. Por lo tanto, la fachada de estudio se encuentra orientada a sur y se toman los valores de radiación de esta orientación para calcular el índice de generación de calor que habrá que colocar en el vidrio.

La Tabla 3.4 muestra los valores de la radiación global mensual para la orientación sur, se indican en $\mathrm{kWh} / \mathrm{m}^{2}$ por mes:

\begin{tabular}{|c|c|}
\hline Enero & $101 \mathrm{kWh} / \mathrm{m}^{2}$ por mes \\
\hline Febrero & $111 \mathrm{kWh} / \mathrm{m}^{2}$ por mes \\
\hline Marzo & $128 \mathrm{kWh} / \mathrm{m}^{2}$ por mes \\
\hline Abril & $101 \mathrm{kWh} / \mathrm{m}^{2}$ por mes \\
\hline Mayo & $92 \mathrm{kWh} / \mathrm{m}^{2}$ por mes \\
\hline Junio & $89 \mathrm{kWh} / \mathrm{m}^{2}$ por mes \\
\hline Julio & $100 \mathrm{kWh} / \mathrm{m}^{2}$ por mes \\
\hline Agosto & $117 \mathrm{kWh} / \mathrm{m}^{2}$ por mes \\
\hline Septiembre & $126 \mathrm{kWh} / \mathrm{m}^{2}$ por mes \\
\hline Octubre & $113 \mathrm{kWh} / \mathrm{m}^{2}$ por mes \\
\hline Noviembre & $97 \mathrm{kWh} / \mathrm{m}^{2}$ por mes \\
\hline Diciembre & $90 \mathrm{kWh} / \mathrm{m}^{2}$ por mes \\
\hline
\end{tabular}

Tabla 3.4. Radiación global mensual para la orientación sur. Passive House Institute. 
En base a los datos observados, se decide tomar los siguientes valores de radiación solar media como valores representativos de las condiciones de invierno y de verano respectivamente:

- $Q_{s}=101 \mathrm{kWh} / \mathrm{m}^{2}$ por mes, que es la radiación global correspondiente al mes de enero.

- $Q_{s}=117 \mathrm{kWh} / \mathrm{m}^{2}$ por mes, que es la radiación global correspondiente al mes de agosto.

\subsubsection{Cálculo del índice de generación de calor para un vidrio sencillo}

En la presente tesis, se utiliza el vidrio sencillo, es decir, un sólo vidrio, en los casos de fachada simple en los que el modelo no tiene cámara de aire. De forma que hay que calcular el índice de generación de calor para un vidrio.

En este caso se trata de un vidrio que por la cara exterior está en contacto con el aire del ambiente exterior, y por la cara interior está en contacto con el aire de la habitación.

\section{- Datos de partida}

- Radiación media mes de enero: $Q_{s}=101 \mathrm{KWh} / \mathrm{m}^{2}$ por mes

- Radiación media mes de agosto: $Q_{s}=117 \mathrm{KWh} / \mathrm{m}^{2}$ por mes

- Un mes $=30$ días.

- Un día $=24$ horas (h).

- Espesor del vidrio: $t_{p}=0,006 \mathrm{~m}$

- Factor de absorción de un vidrio: $\alpha_{e l}=11 \%=0,11$

- Condiciones de invierno

A continuación se realizan las siguientes operaciones:

$$
\begin{gathered}
\frac{101.10^{3} \mathrm{kWh} / \mathrm{m}^{2} \text { por mes }}{24 \mathrm{~h} .30 \text { días }}=140,27 \mathrm{~W} / \mathrm{m}^{2} \\
\frac{140,27 \mathrm{~W} / \mathrm{m}^{2}}{0,006 \mathrm{~m}}=23.379,62 \mathrm{~W} / \mathrm{m}^{3} \\
23.379,62.0,11=2.571,75 \mathrm{~W} / \mathrm{m}^{3}
\end{gathered}
$$

Resultado:

Índice de generación de calor (heat generation rate): $\boldsymbol{Q}_{\boldsymbol{r}}=\mathbf{2 . 5 7 1 , 7 5} \mathrm{W} / \mathbf{m}^{3}$ 
- Condiciones de verano

A continuación se realizan las siguientes operaciones:

$$
\begin{gathered}
\frac{117.10^{3} \mathrm{kWh} / \mathrm{m}^{2} \text { por mes }}{24 \mathrm{~h} .30 \text { días }}=162,5 \mathrm{~W} / \mathrm{m}^{2} \\
\frac{162,5 \mathrm{~W} / \mathrm{m}^{2}}{0,006 \mathrm{~m}}=27.083,3 \mathrm{~W} / \mathrm{m}^{3} \\
27.083,3.0,11=2.979,16 \mathrm{~W} / \mathrm{m}^{3}
\end{gathered}
$$

Resultado:

Índice de generación de calor: $\boldsymbol{Q}_{r}=\mathbf{2 . 9 7 9 , 1 6} \mathrm{W} / \mathbf{m}^{3}$

Estos valores son los que se introducen en Fluent en las condiciones de contorno térmicas para el caso de invierno y para el caso de verano respectivamente. Este vidrio estará acoplado para que Fluent tenga en cuenta el efecto de la conducción entre el vidrio y el aire exterior, y entre el vidrio y el aire de la habitación.

\subsubsection{Cálculo del índice de generación de calor para vidrio doble}

Se utiliza el vidrio doble, es decir, dos vidrios, para los casos en los que el modelo tiene fachada doble piel con una cámara de aire entre ambos vidrios. De forma que hay que calcular el índice de generación de calor para cada uno de los vidrios.

En este caso, el vidrio exterior está en contacto con el aire del ambiente exterior por su cara exterior y en contacto con el aire de la cámara por su cara interior; y el vidrio interior está en contacto con el aire de la cámara por su cara exterior y con el aire de la habitación por su cara interior.

\section{- Datos de partida}

- Radiación media mes de enero: $Q_{s}=101 \mathrm{KWh} / \mathrm{m}^{2}$ por mes

- Radiación media mes de agosto: $Q_{s}=117 \mathrm{KWh} / \mathrm{m}^{2}$ por mes

- Un mes $=30$ días.

- $\quad$ Un día $=24$ horas (h).

- Espesor del vidrio: $t_{p}=0,006 \mathrm{~m}$

- Factor de absorción del vidrio exterior: $\alpha_{e l}=11 \%=0,11$

- Factor de absorción del vidrio interior: $\alpha_{e 2}=8 \%=0,08$

\section{- Condiciones de invierno}

A continuación se realizan las operaciones pertinentes para el cálculo del índice de generación de calor en el vidrio exterior: 


$$
\begin{gathered}
\frac{101.10^{3} \mathrm{kWh} / \mathrm{m}^{2} \text { por mes }}{24 \mathrm{~h} .30 \text { días }}=140,27 \mathrm{~W} / \mathrm{m}^{2} \\
\frac{140,27 \mathrm{~W} / \mathrm{m}^{2}}{0,006 \mathrm{~m}}=23.379,62 \mathrm{~W} / \mathrm{m}^{3} \\
23.379,62.0,11=2.571,75 \mathrm{~W} / \mathrm{m}^{3}
\end{gathered}
$$

Resultado:

Índice de generación de calor del vidrio exterior: $\boldsymbol{Q}_{r}=\mathbf{2 . 5 7 1 , 7 5} \mathrm{W} / \mathbf{m}^{3}$

Este valor es el que se introduce en Fluent en las condiciones de contorno térmicas del vidrio exterior. Este vidrio estará acoplado para que Fluent tenga en cuenta el efecto de la conducción entre el vidrio y el aire exterior, y entre el vidrio y el aire de la cámara.

A continuación se realizan las operaciones pertinentes para el cálculo del índice de generación de calor en el vidrio interior:

$$
\begin{gathered}
\frac{101.10^{3} \mathrm{kWh} / \mathrm{m}^{2} \text { por mes }}{24 \mathrm{~h} .30 \text { días }}=140,27 \mathrm{~W} / \mathrm{m}^{2} \\
\frac{140,27 \mathrm{~W} / \mathrm{m}^{2}}{0,006 \mathrm{~m}}=23.379,62 \mathrm{~W} / \mathrm{m}^{3} \\
23.379,62.0,08=1.870,37 \mathrm{~W} / \mathrm{m}^{3}
\end{gathered}
$$

Resultado:

Índice de generación de calor del vidrio interior: $\boldsymbol{Q}_{r}=\mathbf{1 . 8 7 0 , 3 7} \mathrm{W} / \mathbf{m}^{\mathbf{3}}$

Este valor es el que se introduce en Fluent en las condiciones de contorno térmicas del vidrio interior. Este vidrio estará acoplado para que Fluent tenga en cuenta el efecto de la conducción entre el vidrio y el aire de la cámara, y entre el vidrio y el aire de la habitación.

\section{- Condiciones de verano}

A continuación se realizan las operaciones pertinentes para el cálculo del índice de generación de calor en el vidrio exterior:

$$
\frac{117.10^{3} \mathrm{kWh} / \mathrm{m}^{2} \text { por mes }}{24 \mathrm{~h} .30 \text { días }}=162,5 \mathrm{~W} / \mathrm{m}^{2}
$$




$$
\begin{aligned}
& \frac{162,5 \mathrm{~W} / \mathrm{m}^{2}}{0,006 \mathrm{~m}}=27.083,3 \mathrm{~W} / \mathrm{m}^{3} \\
& 27.083,3.0,11=2.979,16 \mathrm{~W} / \mathrm{m}^{3}
\end{aligned}
$$

Resultado:

Índice de generación de calor del vidrio exterior: $\boldsymbol{Q}_{\boldsymbol{r}}=\mathbf{2 . 9 7 9 , 1 6} \mathrm{W} / \mathrm{m}^{\mathbf{3}}$

Este valor es el que se introduce en Fluent en las condiciones de contorno térmicas del vidrio exterior. Este vidrio estará acoplado para que Fluent tenga en cuenta el efecto de la conducción entre el vidrio y el aire exterior, y entre el vidrio y el aire de la cámara.

A continuación se realizan las operaciones pertinentes para el cálculo del índice de generación de calor en el vidrio interior:

$$
\begin{gathered}
\frac{117.10^{3} \mathrm{kWh} / \mathrm{m}^{2} \text { por mes }}{24 \mathrm{~h} .30 \text { días }}=162,5 \mathrm{~W} / \mathrm{m}^{2} \\
\frac{162,5 \mathrm{~W} / \mathrm{m}^{2}}{0,006 \mathrm{~m}}=27.083,3 \mathrm{~W} / \mathrm{m}^{3} \\
27.083,3.0,08=2.166,66 \mathrm{~W} / \mathrm{m}^{3}
\end{gathered}
$$

Resultado:

Índice de generación de calor del vidrio interior: $\boldsymbol{Q}_{r}=\mathbf{2 . 1 6 6 , 6 6} \mathrm{W} / \mathrm{m}^{3}$

Este valor es el que se introduce en Fluent en las condiciones de contorno térmicas del vidrio interior. Este vidrio estará acoplado para que Fluent tenga en cuenta el efecto de la conducción entre el vidrio y el aire de la cámara, y entre el vidrio y el aire de la habitación.

\subsection{SELECCIÓN DE LOS CASOS DE ESTUDIO}

\subsubsection{Flujo dominado por convección natural}

Inicialmente, se estudian los fenómenos que tienen lugar en el modelo sólo desde el punto de vista de la convección natural, es decir, por el movimiento del aire producido por el cambio en la densidad del aire debido al cambio de su temperatura. Se decide no tener en cuenta los efectos del viento en esta primera serie de simulaciones porque se cree conveniente comenzar por casos sencillos donde no intervengan muchos fenómenos al mismo tiempo. 
Se simulan diferentes geometrías desde la fachada simple piel hasta la fachada doble piel variando el ancho de la cámara con esbelteces $(A)$ desde 6 hasta 600 , donde $A=H / L$ siendo $H$ la altura de la cámara y $L$ el ancho de la cámara, y con cámara abierta y cerrada. Se simulan condiciones de invierno y de verano, considerando radiación solar o no. Esto hace un total de 116 casos.

En el estudio no se ha tenido en cuenta ni la humedad relativa del aire ni la lluvia.

Los casos sin radiación solar se refieren a un día nublado o a horas sin sol, de noche.

La siguiente tabla muestra todas las alternativas de geometría y de configuraciones de fachada estudiadas:

\section{FLUJO DOMINADO POR CONVECCIÓN NATURAL}

\begin{tabular}{|c|c|c|c|}
\hline & Variables & Alternativas & Rango \\
\hline \multirow{4}{*}{ Geometría } & Simple piel & & 1 \\
\hline & \multirow{3}{*}{ Doble piel } & $\begin{array}{l}\text { Esbeltez } A \\
\text { (desde } A=6 \text { a } A=600 \text { ) }\end{array}$ & 14 \\
\hline & & $\begin{array}{l}\text { Abertura } \\
\text { (abierto / cerrado) }\end{array}$ & 2 \\
\hline & & & 29 \\
\hline \multirow{3}{*}{ Configuración } & Escenario & invierno / verano & 2 \\
\hline & Radiación solar & $\operatorname{con} / \sin$ & 2 \\
\hline & & & 4 \\
\hline Casos de estudio & & & 116 \\
\hline
\end{tabular}

Tabla 3.5. Número total de casos estudiados en función de las alternativas de geometría y de configuraciones de fachada posibles para los casos de flujo dominado por convección natural.

\subsubsection{Optimización de las aberturas}

Tal y como se explica más adelante en el Capítulo 5, apartado 5.1.3. Optimización de las aberturas; una vez obtenida la cámara óptima, se estudia la dimensión de abertura óptima $\left(h_{v}\right)$.

Se estudia en el escenario de verano, con cámara abierta y con radiación solar, ya que es el único caso en el que abrir la cámara resulta más eficiente, como se explicará más adelante en el Capítulo 5. Se estudian dimensiones de aberturas desde 0,01 m hasta $1 \mathrm{~m}$. Esto hace un total de 12 casos.

La siguiente tabla muestra todas las alternativas de geometría y de configuraciones de fachada estudiadas: 


\section{OPTIMIZACIÓN DE LAS ABERTURAS}

\begin{tabular}{|c|c|c|c|}
\hline \multirow{4}{*}{ Geometría } & Variables & Alternativas & Rango \\
\hline & \multirow{3}{*}{ Doble piel } & $\begin{array}{l}\text { Esbeltez } A \\
(A=30)\end{array}$ & 1 \\
\hline & & $\begin{array}{l}\text { Abertura } \\
\text { (abierto) }\end{array}$ & 1 \\
\hline & & & 1 \\
\hline \multirow{4}{*}{ Configuración } & Escenario & verano & 1 \\
\hline & Radiación solar & con & 1 \\
\hline & $\begin{array}{l}\text { Dimensión aberturas } \\
\text { entrada = salida }\end{array}$ & $\left(\right.$ desde $h_{v}=0,01$ a $\left.1 \mathrm{~m}\right)$ & 12 \\
\hline & & & 12 \\
\hline Casos de estudio & & & 12 \\
\hline
\end{tabular}

Tabla 3.6. Número total de casos estudiados en función de las alternativas de geometría y de configuraciones de fachada posibles para la optimización de las aberturas.

\subsubsection{Flujo dominado por viento}

Una vez concluidas con éxito las simulaciones del flujo dominado por convección natural, que son más sencillas ya que no intervienen tantos fenómenos a la vez, se procede a estudiar los fenómenos que tienen lugar por el efecto del viento.

Para los casos de flujo dominado por viento, sólo se estudiará la configuración de fachada que resulte más eficiente según los resultados obtenidos en las simulaciones de flujo dominado por convección natural, es decir, sin variar el ancho de la cámara, una sola esbeltez. Se estudiará con cámara abierta y cerrada, en condiciones de invierno y de verano, con radiación solar y sin ella, con las dos direcciones del viento (en la fachada de barlovento y de sotavento), y con 5 velocidades de viento $v=1 ; 2,5 ; 5 ; 10 ;$ y $20 \mathrm{~m} / \mathrm{s}$. Esto hace un total de 120 casos diferentes.

Barlovento es cuando se estudia la fachada que da hacia el lado de donde viene el viento, mientras que sotavento es cuando la fachada está en el lado opuesto del edificio de donde viene el viento.

La siguiente tabla muestra todas las alternativas de geometría y de configuraciones de fachada estudiadas: 
Optimización de la fachada de doble piel acristalada con ventilación natural. Metodología de diseño para el análisis de la eficiencia energética del sistema.

FLUJO DOMINADO POR VIENTO

\begin{tabular}{|c|c|c|c|}
\hline & Variables & Alternativas & Rango \\
\hline \multirow{4}{*}{ Geometría } & Simple piel & & 1 \\
\hline & \multirow{3}{*}{ Doble piel } & $\begin{array}{l}\text { Esbeltez } A \\
(A=30)\end{array}$ & 1 \\
\hline & & $\begin{array}{l}\text { Abertura } \\
\text { (abierto / cerrado) }\end{array}$ & 2 \\
\hline & & & 3 \\
\hline \multirow{5}{*}{ Configuración } & Escenario & invierno / verano & 2 \\
\hline & Radiación solar & $\operatorname{con} / \sin$ & 2 \\
\hline & Dirección viento & barlovento / sotavento & 2 \\
\hline & Velocidad viento & $v=1 ; 2,5 ; 5 ; 10 ; 20 \mathrm{~m} / \mathrm{s}$ & 5 \\
\hline & & & 40 \\
\hline Casos de estudio & & & 120 \\
\hline
\end{tabular}

Tabla 3.7. Número total de casos estudiados en función de las alternativas de geometría y de configuraciones de fachada posibles para los casos de flujo dominado por viento.

\subsection{CONCLUSIONES}

Se estudia la ventilación natural dominada por convección natural y por viento.

La geometría básica simplificada que se va a utilizar en las simulaciones en la siguiente:

- $\quad$ Modelo 2D

- Flujo estacionario

- Localización: zona centro España, Madrid

- Fachada doble piel acristalada orientada a sur

- Tipología de fachada: de forjado a forjado, una planta

- Dimensiones:

- Ambiente exterior: Convección natural: dominio $21 \times 10 \mathrm{~m}$

Viento: dominio $126 \times 30 \mathrm{~m}$

- Cámara de aire: $\quad$ Esbeltez $A=6$ - 600

$$
h_{v}=0,06 \mathrm{~m}
$$

- Ambiente interior: Dimensiones: 3 x $6 \mathrm{~m}$

El vidrio de referencia seleccionado con el que se han realizado todas las simulaciones es el vidrio sodocálcico plano con espesor $t_{p}=0,006 \mathrm{~m}$.

Según el intervalo definido por la norma $U N E-E N$ 15251, la temperatura de confort en el interior de la habitación se determina en:

- Condiciones térmicas de confort en invierno: $20^{\circ} \mathrm{C}$

- Condiciones térmicas de confort en verano: $26^{\circ} \mathrm{C}$ 
La temperatura media seca del ambiente exterior se establece en:

- $\quad 4{ }^{\circ} \mathrm{C}$ para el escenario de invierno

- $\quad 32^{\circ} \mathrm{C}$ para el escenario de verano

Se han realizado 116 casos para estudiar la ventilación natural dominada por convección natural. Se estudia la fachada simple piel y la fachada doble piel en los escenarios de invierno y de verano, con cámara abierta y cerrada, con radiación solar y sin ella, para esbelteces de la cámara de $A=6$ hasta $A=600$.

Se simulan 12 casos para estudiar la optimización de las aberturas del modelo. Se estudia para el caso de cámara óptima en el escenario de verano, cámara abierta y con radiación solar; ya que es el único caso en el abrir la cámara resulta eficiente tal y como se justifica en el Capítulo 5. Se estudian dimensiones de aberturas desde 0,01 hasta $1 \mathrm{~m}$, siendo la abertura de entrada de igual dimensión que la de salida.

Se han simulado 120 casos para estudiar la ventilación natural dominada por viento. Se estudia la fachada simple piel y la fachada doble piel para la configuración óptima obtenida en las simulaciones de convección natural. Todas ellas se estudian en los escenarios de invierno y verano, con cámara abierta y cerrada, con radiación solar y sin ella, para las dos direcciones del viento (viento en la fachada de barlovento y de sotavento) y bajo cinco velocidades diferentes $v=1 ; 2,5 ; 5 ; 10 ;$ y $20 \mathrm{~m} / \mathrm{s}$.

En el estudio no se ha tenido en cuenta ni la humedad relativa del aire ni la lluvia.

Los casos sin radiación solar se refieren a un día nublado o a horas sin sol, de noche.

Para introducir la radiación solar en el modelo se realiza una aproximación desacoplada. Se introduce el flujo de calor debido a la radiación solar como una fuente de calor uniformemente distribuida y perpendicular a la superficie del paño del vidrio.

Valores de radiación solar media representativos de las condiciones de invierno y de verano:

$$
\begin{aligned}
& Q_{s}=101 \mathrm{kWh} / \mathrm{m}^{2} \text { por mes, radiación global correspondiente al mes de enero. } \\
& Q_{s}=117 \mathrm{kWh} / \mathrm{m}^{2} \text { por mes, radiación global correspondiente al mes de agosto. }
\end{aligned}
$$

El índice de generación de calor que se introduce en cada vidrio para cada escenario es el siguiente:

Condiciones de invierno:

- Vidrio exterior: $Q_{r}=2.571,75 \mathrm{~W} / \mathrm{m}^{3}$

- Vidrio interior: $Q_{r}=1.870,37 \mathrm{~W} / \mathrm{m}^{3}$

Condiciones de verano:

- Vidrio exterior: $Q_{r}=2.979,16 \mathrm{~W} / \mathrm{m}^{3}$

- Vidrio interior: $Q_{r}=2.166,66 \mathrm{~W} / \mathrm{m}^{3}$ 
Para los casos con viento es necesario conocer la velocidad media del viento para realizar las simulaciones CFD en los diferentes escenarios. Tal y como se explica en los apartados 5.2.1.5 y 5.2.2.5 del Capítulo 5, la velocidad media del viento de referencia $\left(v_{m, r e f}\right)$ es de $5,8 \mathrm{~m} / \mathrm{s}$ en el escenario de invierno y $6,3 \mathrm{~m} / \mathrm{s}$ en el escenario de verano.

Tal y como se explica más adelante en el Capítulo 5, apartados 5.1.1.1 y 5.1.2.1, la fachada simple piel se utiliza como caso de referencia con el que comparar los resultados obtenidos. Para los casos de ventilación natural dominada por convección natural, se calcula el calor que es necesario aportar en el escenario de invierno para que la temperatura del ambiente interior se mantenga en $20^{\circ} \mathrm{C}$ (temperatura de confort para las condiciones de invierno), y resulta que los flujos de calor de referencia $\left(Q_{\mathrm{ref}}\right)$ son de $17,9 \mathrm{~W} / \mathrm{m}^{2}$ y $22 \mathrm{~W} / \mathrm{m}^{2}$ para los casos de con y sin radiación solar, respectivamente. También se calcula el calor que es necesario extraer en el escenario de verano para que la temperatura del ambiente interior se mantenga a $26^{\circ} \mathrm{C}$ (temperatura de confort para las condiciones de verano), y resulta que los flujos de calor de referencia $\left(Q_{r e f}\right)$ son de $-10,50 \mathrm{~W} / \mathrm{m}^{2}$ y $-4,6 \mathrm{~W} / \mathrm{m}^{2}$ para los casos de con y sin radiación solar, respectivamente.

Para los casos de ventilación natural dominada por viento, también se calcula el flujo de calor de referencia $\left(Q_{r e f}\right)$ que hay que aportar para el caso de $A=30$ para que la temperatura del ambiente interior se mantenga en $20^{\circ} \mathrm{C}$ en condiciones de invierno y en $26{ }^{\circ} \mathrm{C}$ en condiciones de verano, tal y como se explica en el Capítulo 5, apartados 5.2.1.5 y 5.2.2.5. En el escenario de invierno, el flujo de calor de referencia es de 34,4 $\mathrm{W} / \mathrm{m}^{2}$ con el viento en la fachada de barlovento y de sotavento sin considerar la radiación solar; y de $30,6 \mathrm{~W} / \mathrm{m}^{2}$ con el viento en la fachada de barlovento y de sotavento con radiación solar. En el escenario de verano, el flujo de calor de referencia es de -10,5 $\mathrm{W} / \mathrm{m}^{2}$ con el viento en la fachada de barlovento y de sotavento sin considerar la radiación solar; y de $-12,5 \mathrm{~W} / \mathrm{m}^{2}$ con el viento en la fachada de barlovento y de sotavento con radiación solar.

La siguiente tabla muestra de forma resumida todos los parámetros utilizados para el estudio de la presente tesis:

PARÁMETROS DE ESTUDIO DE LA FACHADA ACRISTALADA

\begin{tabular}{lll}
\hline Variables & Alternativas \\
\hline Ventilación & Natural & $\begin{array}{l}\text { Convección natural } \\
\text { Viento }\end{array}$ \\
\hline Modelo & $2 \mathrm{D}$ & $\begin{array}{l}\text { sección transversal simplificada } \\
\text { estacionario }\end{array}$ \\
\hline Localización & Flujo & Madrid \\
\hline Orientación & Zona Centro España & Sur \\
\hline Tipología & Fachada & de forjado a forjado \\
\hline \multirow{2}{*}{ Dimensiones } & 1 planta & $\begin{array}{l}\text { convección natural: } 21 \times 10 \mathrm{~m} \\
\text { viento: } 126 \times 30 \mathrm{~m}\end{array}$ \\
\hline Vidrio & Ambiente Exterior & $\begin{array}{l}\text { Esbeltez } A=6 \text { - } 600 \\
h_{v}=0,06 \mathrm{~m}\end{array}$ \\
\cline { 2 - 3 } & Cámara Aire & $6 \times 3 \mathrm{~m}$ \\
\cline { 2 - 3 } & Ambiente Interior & $t_{p}=0,006 \mathrm{~m}$ \\
\hline
\end{tabular}




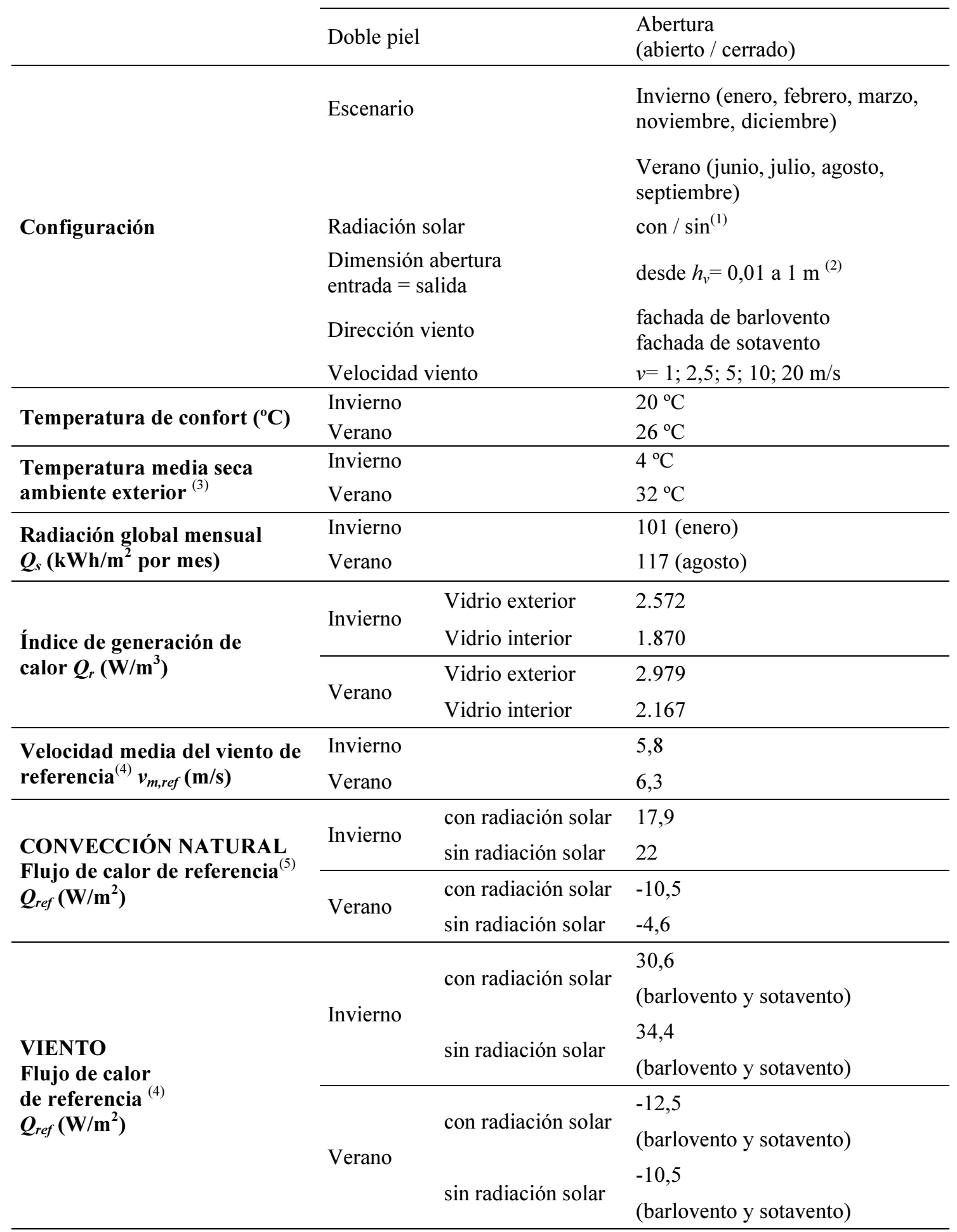

\footnotetext{
${ }^{(1)}$ Los casos sin radiación solar se refieren a un día nublado o a horas sin sol, de noche.

(2) Ver apartado 5.1.3 Capítulo 5.

${ }^{(3)}$ No se ha considerado ni la humedad relativa del aire ni la lluvia.

(4) Ver apartado 5.2.1.5 y 5.2.2.5 Capítulo 5.

(5) Ver apartado 5.1.1.1 y 5.1.2.1 Capítulo 5.
}

Tabla 3.8. Resumen de parámetros de estudio de la fachada doble piel acristalada. 
Optimización de la fachada de doble piel acristalada con ventilación natural. Metodología de diseño para el análisis de la eficiencia energética del sistema. 


\section{MODELIZACIÓN FLUIDODINÁMICA}

En este capítulo se describe el proceso de modelización de la fachada doble piel y del dominio para la simulación numérica de los diferentes casos de estudio desarrollados en la presente tesis.

En primer lugar, se realiza una validación inicial del modelo de convección natural de gases para definir el modelo y las condiciones de cálculo adecuadas. Para ello se utiliza una investigación publicada en revista científica de impacto como caso de referencia.

Se justifica la elección del software de simulación y se explica el proceso de trabajo en CFD.

Se define el diseño del modelo, del mallado y el modelo físico y numérico utilizado tanto para la simulación de los casos de flujo dominado por convección natural como para los casos de flujo dominado por viento.

Por último, se procede a la validación del modelo numérico de fachada doble piel acristalada incluyendo la radiación solar. Para ello se reproduce una investigación de similares características publicada en revista científica de impacto. 
Optimización de la fachada de doble piel acristalada con ventilación natural. Metodología de diseño para el análisis de la eficiencia energética del sistema. 


\subsection{VALIDACIÓN I. VALIDACIÓN INICIAL DEL MODELO DE CONVECCIÓN NATURAL DE GASES}

Se utiliza ANSYS Fluent ${ }^{\circledR}$ (versión 15.0.7) como software para realizar las simulaciones necesarias en la presente tesis.

En primer lugar se realiza una validación inicial del modelo de convección natural de gases reproduciendo casos ya resueltos con el fin de determinar qué parámetros hay que introducir y con qué opciones se alcanza una mejor solución.

Para ello se escoge un artículo publicado en una revista científica de gran impacto y con un alto índice JCR para asegurarse de que es una investigación que está validada y revisada por un comité científico.

Se empieza por un caso con una geometría sencilla en el que sólo intervienen las fuerzas de convección natural. Se elige la investigación de Li et al. (2007) publicada en el artículo "Buoyancy-driven natural ventilation of a room with large openings" como caso a reproducir con el objetivo anteriormente descrito.

A continuación se describe el caso estudiado en dicho artículo, en adelante caso de referencia.

\subsubsection{Descripción del caso de referencia}

Se investiga, utilizando un modelo analítico y un modelo CFD, la ventilación natural producida por convección natural de una habitación con una abertura inferior (entrada) y una abertura superior (salida). Se desarrollan fórmulas basadas en la presión para la predicción de la altura del plano neutro $\left(h_{n}\right)$ y del caudal de aire $(V)$. Asimismo, se realiza la simulación con CFD para cotejar la validez de las fórmulas derivadas.

\subsubsection{Modelo analítico}

El estudio sólo tiene en cuenta el flujo de aire producido por convección natural, por lo tanto, el aire se mueve sólo por diferencia de densidad de aire. El plano neutro es el plano donde la presión del aire de la habitación $\left(P_{i}\right)$ y la presión del aire del ambiente exterior $\left(P_{0}\right)$ se igualan, $P_{i}=P_{0}$. Se pueden producir dos situaciones:

- cuando $P_{i}<P_{0}$, el aire entra en la habitación,

- cuando $P_{i}>P_{0}$, el sale de la habitación.

Según el modelo analítico, la posición del plano neutro controla generalmente el régimen del flujo en la habitación. Como consecuencia, se pueden definir tres modos del flujo según la posición del plano neutro:

I. Cuando el plano neutro interseca con la abertura inferior.

II. Cuando el plano neutro no interseca con ninguna abertura.

III. Cuando el plano neutro interseca con la abertura superior.

La Figura 4.1 muestra la distribución de presiones y los tres modos del flujo. 


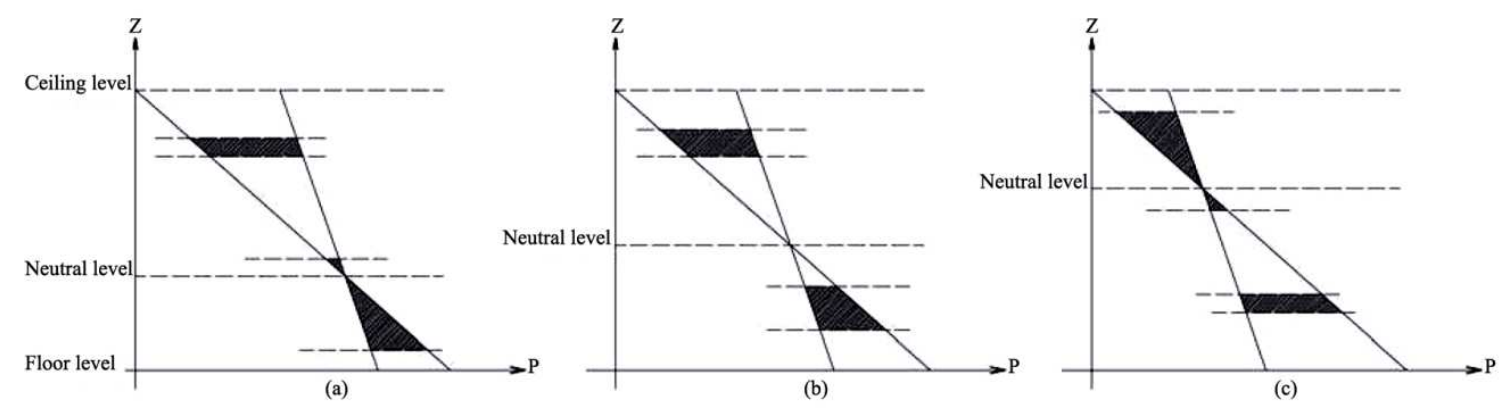

Figura 4.1. Distribución de la presión en el interior y en el exterior de una habitación con grandes aberturas (a: modo de flujo I; b: modo de flujo II; c: modo de flujo III). "Buoyancy-driven natural ventilation of a room with large openings". Li et al., 2007.

En el caso en el que el plano neutro interseca con la abertura inferior, el aire no sólo entra en la habitación por esta abertura, sino que también sale. El aire entra en la habitación por la zona que se encuentra debajo del plano neutro, donde $P_{i}<P_{0}$, y sale de la habitación por la zona que se encuentra por encima del plano neutro, donde $P_{i}>P_{0}$.

En el caso en el que el plano neutro no interseca con ninguna abertura, el aire entra en la habitación por la abertura inferior y sale por la abertura superior.

En el caso en el que el plano neutro interseca con la abertura superior, el aire no sólo sale de la habitación por esta abertura, sino que también entra. El aire sale de la habitación por la zona que se encuentra por encima del plano neutro, donde $P_{i}>P_{0}, \mathrm{y}$ entra en la habitación por la zona que se encuentra debajo del plano neutro, donde $P_{i}<$ $P_{0}$.

La Figura 4.2 muestra de forma esquemática los tres modos del flujo explicados anteriormente.
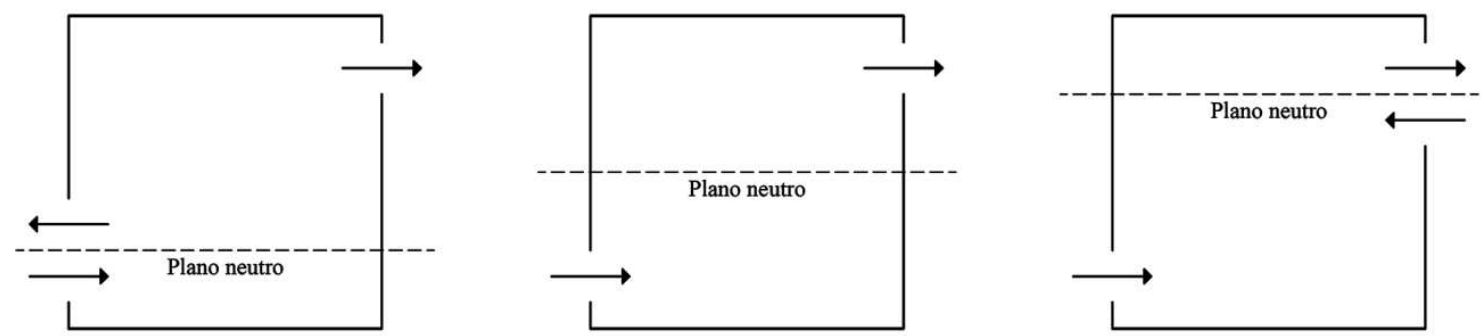

Figura 4.2. Ilustración esquemática de los tres modos de flujo según la posición del plano neutro y el movimiento del aire en cada uno de ellos. (a: plano neutro interseca con la abertura inferior; b: plano neutro no interseca con ninguna abertura; c:plano neutro interseca con la abertura superior). "Buoyancydriven natural ventilation of a room with large openings". Li et al., 2007.

Li et al. desarrollan expresiones analíticas basadas en la presión para predecir la altura del plano neutro y el caudal de aire. Estas fórmulas sugieren que la altura del plano neutro está determinada sobre todo por la distancia entre las aberturas. El caudal aumenta con el aumento de las aberturas. Para calcular el caudal de aire, primero calculan el nivel del plano neutro para determinar el modo del flujo, y así escoger la ecuación apropiada. 


\subsubsection{Modelo CFD}

Se realiza la simulación CFD para validar los resultados del método analítico y viceversa.

\section{- Geometría}

Utilizan ANSYS Fluent ${ }^{\circledR}$ (versión de 1996) para realizar las simulaciones CFD del caso de estudio. Se trata de una habitación de $12 \mathrm{~m}$ de ancho y $12 \mathrm{~m}$ de altura, y sólo se realiza la simulación en dos dimensiones (2D). Para poder estudiar el impacto de las características de las aberturas y su interacción entre los diferentes modos de flujo, se establece un ambiente exterior y se modela también con una geometría sencilla de $60 \mathrm{~m}$ de largo y $24 \mathrm{~m}$ de altura. La habitación de estudio se encuentra en el centro del mismo. Las Figuras 4.3 y 4.4 muestran de forma esquemática el modelo de estudio y el dominio computacional utilizados para la simulación CFD.

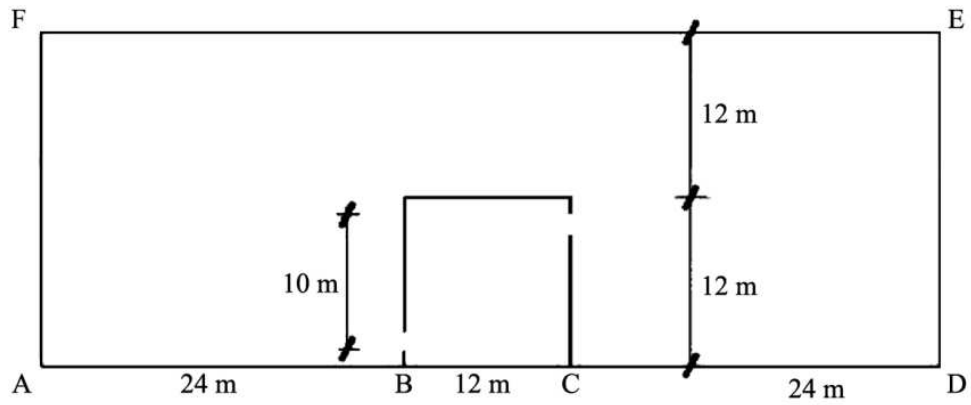

Figura 4.3. Detalle del dominio computacional y de la geometría utilizada para la simulación CFD. "Buoyancy-driven natural ventilation of a room with large openings". Li et al., 2007.

Se estudian dos tipos de casos:

1. Cuando la abertura superior es fija e igual a $1 \mathrm{~m}$ y la abertura inferior varía de 1 a $7 \mathrm{~m}$.

2. Cuando la abertura inferior es fija e igual a $1 \mathrm{~m}$ y la abertura superior varía de 1 a $7 \mathrm{~m}$.

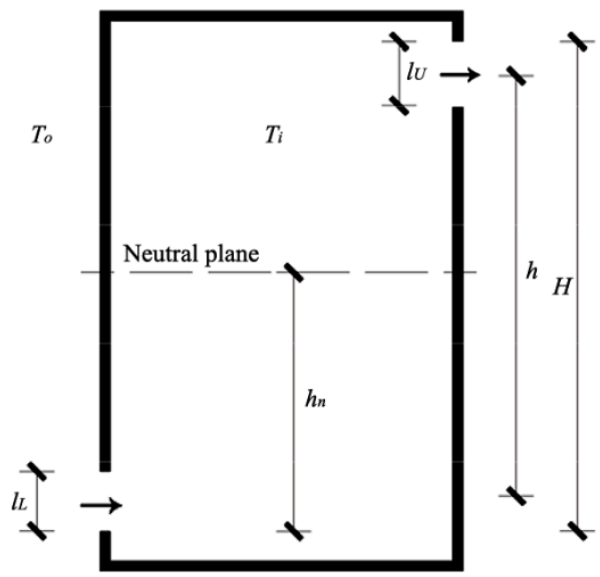

Figura 4.4. Figura esquemática del modelo físico considerado en el estudio. "Buoynacy-driven natural ventilation of a room with large openings". Li et al., 2007. 


\section{- Condiciones de contorno}

Sólo se tienen en cuenta las fuerzas de convección natural, es decir, que el movimiento del aire se produce gracias a la diferencia de densidad del aire producida por una variación de temperaturas.

En este caso, la diferencia de densidades las produce la diferencia de temperatura entre el interior de la habitación que se encuentra a $32{ }^{\circ} \mathrm{C}(305 \mathrm{~K})$, gracias a una fuente de calor uniforme situada en el suelo de la misma, y la temperatura del exterior que es constante e igual a $17^{\circ} \mathrm{C}(290 \mathrm{~K})$.

La fuente de calor calienta el aire interior que asciende y provoca una mayor presión en la zona superior y una menor presión en la zona inferior. Como consecuencia, el aire exterior entra por la abertura inferior y sale por la abertura superior.

Como se muestra en la Figura 4.3, las paredes ficticias del ambiente exterior (AF y DE) se especifican como placas planas sin rozamiento y con la temperatura igual a la temperatura del aire exterior. La pared del extremo superior (EF) se especifica con presión cero a la temperatura del aire exterior. El suelo del ambiente exterior (AB y CD) se especifica como adiabático, es decir, que no intercambia calor con su entorno.

En resumen, las condiciones de contorno son las siguientes:

- AF y DE: Tipo pared, sin rozamiento, Temperatura $17^{\circ} \mathrm{C}$

- AB y CD: Tipo pared, Adiabático

- EF: Tipo salida de presión, Temperatura $17^{\circ} \mathrm{C}$

- BC: Tipo pared, Temperatura $32{ }^{\circ} \mathrm{C}$

- Demás paredes: Adiabáticas

\section{- Modelo utilizado en la simulación}

Se utiliza el modelo de Boussinesq para aproximar la relación entre la densidad y el cambio de temperatura.

Las ecuaciones de continuidad, momento y energía, se resuelven utilizando el modelo de turbulencia k- $\varepsilon$ (2 ecuaciones). Las ecuaciones son discretizadas con el modelo de volúmenes finitos. Se utiliza PRESTO! como método de discretización espacial. Se utilizan aproximaciones de segundo orden para resolver las ecuaciones diferenciales.

\section{- Resultados}

Las Figuras 4.5 y 4.6 muestran los resultados del caudal y de la altura del plano neutro obtenidos por los autores utilizando el modelo analítico y el modelo CFD. 


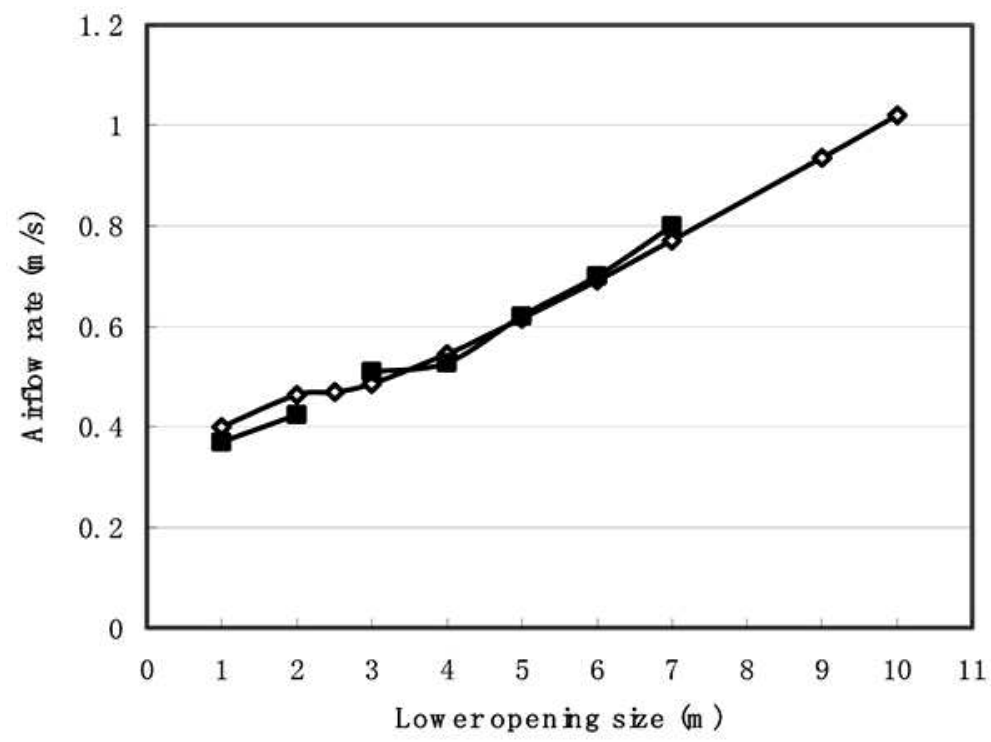

$\multimap$ Theoreticalcalubtion $\longrightarrow$ CFD sin uhtion

Figura 4.5. Caudal calculado mediante modelo analítico y por simulación CFD. "Buoyancy-driven natural ventilation of a room with large openings". Li et al., 2007.

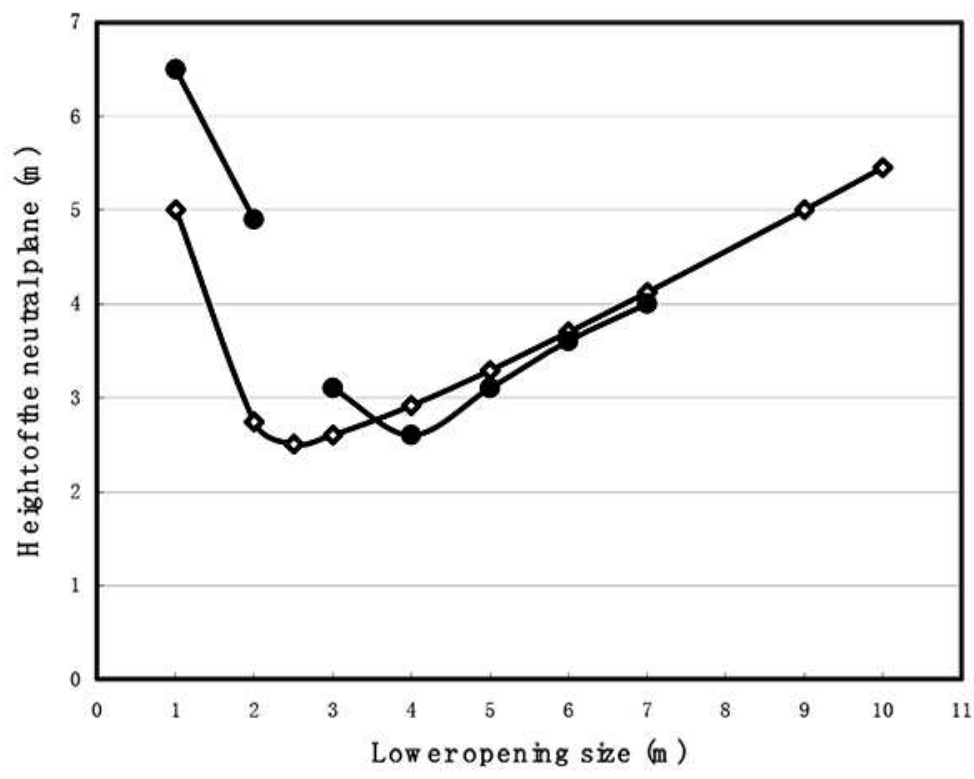

$\multimap$ Theoreticalcalculation $\longrightarrow$ CFD sin ubtion

Figura 4.6. Plano neutro calculado mediante modelo analítico y por simulación CFD. "Buoyancy-driven natural ventilation of a room with large openings". Li et al., 2007. 


\section{- Conclusiones}

Se obtienen las siguientes conclusiones:

- Concuerdan en el modo de flujo I, cuando el plano neutro interseca con la abertura inferior. Se llega a una buena concordancia cualitativa y cuantitativamente en la solución, con una discrepancia de menos del 18\% para el plano neutro y un $7 \%$ para el caudal de aire.

- Discrepan con un 30\% en algunos puntos en el modo de flujo III, aunque coinciden en el caudal y en el nivel neutro cuando varía la abertura superior. Esto puede ser causado por un fuerte momento vertical que se produce en la abertura superior debido a la fuerza de la convección natural.

- Aumentar el área de la abertura inferior es más eficiente que aumentar la de la abertura superior; sin embargo se reduce el nivel del plano neutro.

\subsubsection{PUESTA A PUNTO}

El software CFD que se utiliza en los casos de estudio de la presente tesis, es ANSYS Fluent ${ }^{\circledR}$ (versión 15.0.7). En primer lugar, hay que poner a punto el programa y asegurarse de que funciona correctamente con los parámetros que se le introduzcan. Para ello, se va a utilizar el caso del artículo expuesto anteriormente. El objetivo es reproducirlo e introducir variaciones hasta conseguir los mismos resultados o mejores que los obtenidos por los autores del mismo.

\subsubsection{Mallado}

Se realiza un estudio exhaustivo del mallado con el fin de observar la influencia del tamaño de la malla en los resultados obtenidos. Para ello se realizan pruebas con diferentes tipos de mallado para poder comparar tanto los resultados como el tiempo de cálculo invertido.

\section{- Malla 1}

Malla inicial muy burda, simplemente para comprobar que el modelo funciona bien y que el aire entra por la abertura inferior y sale por la abertura superior.

- Mallado generado automáticamente por el programa.

- Tamaño en las caras: $0,5 \mathrm{~m}$

- Tamaño de malla: grosero

- Suavizado: medio

- Tasa de crecimiento: 1,20

- Resto de valores: por defecto

- Número de nodos: 1.309

- Número de celdas: 1.268 
Las Figuras 4.7 y 4.8 muestran el mallado de las celdas del aire de la habitación de estudio y del entorno que la rodea.

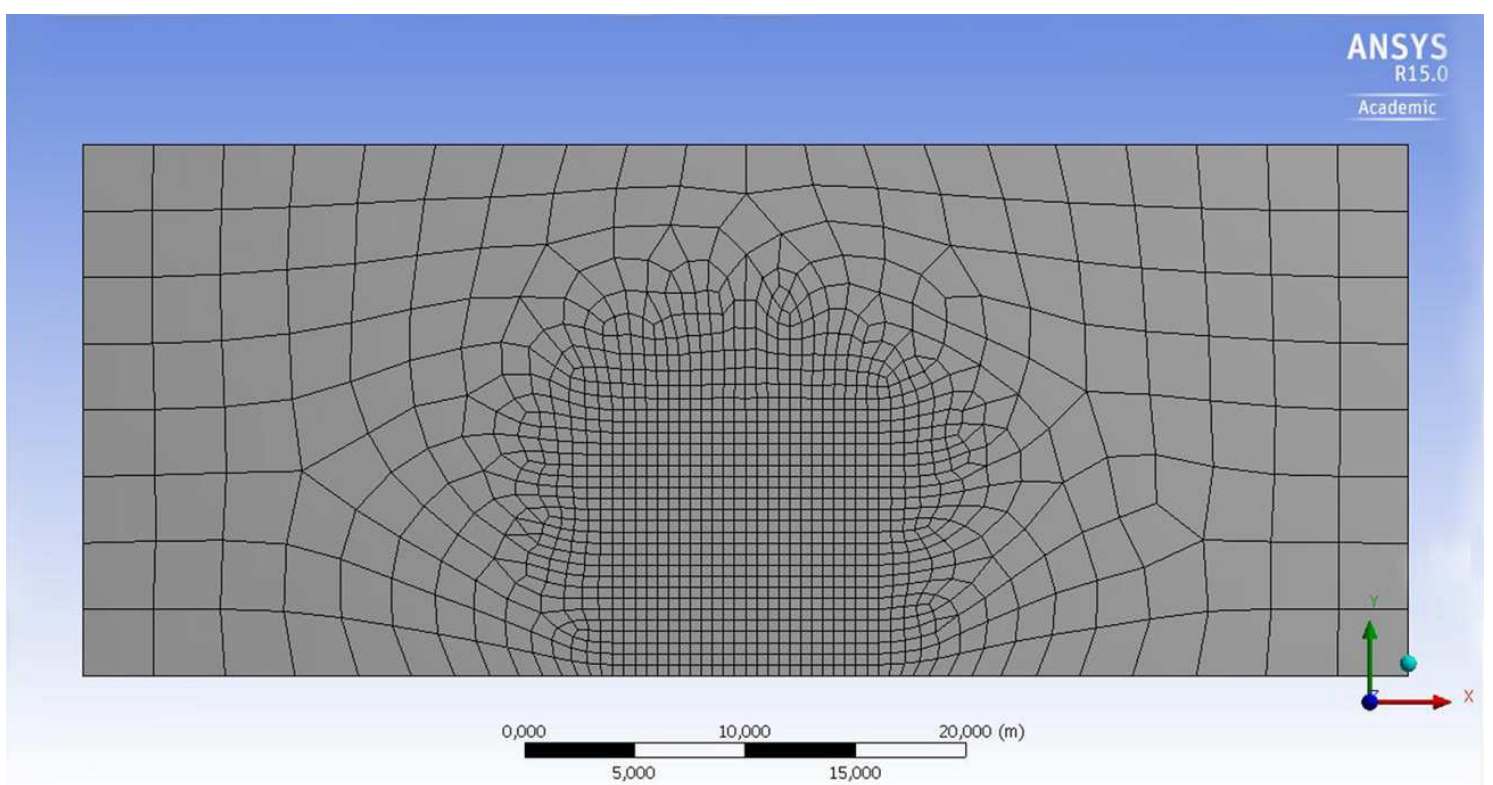

Figura 4.7. Caso de estudio mallado con la malla del tipo 1.
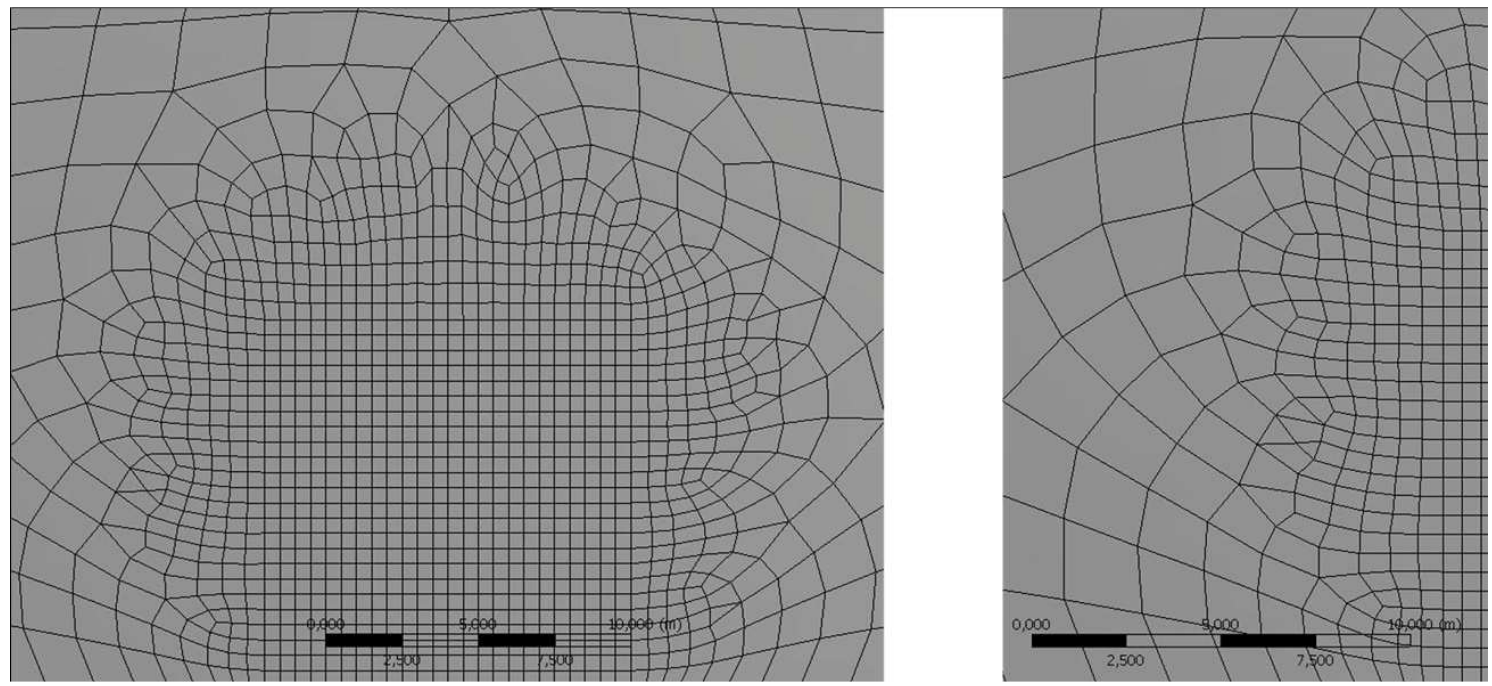

Figura 4.8. Detalle de la malla tipo 1.

\section{- Malla 2}

Se mejora el mallado del interior de la habitación. El mallado del exterior permanece sin cambios respecto a la malla 1, Figuras 4.9 y 4.10.

- Mallado generado automáticamente por el programa.

- Tamaño en las caras: $0,1 \mathrm{~m}$

- Tamaño de malla: fino

- Suavizado: medio

- Tasa de crecimiento: 1,20 
- Resto de valores: por defecto

- Número de nodos: 19.650

- Número de celdas: 19.522

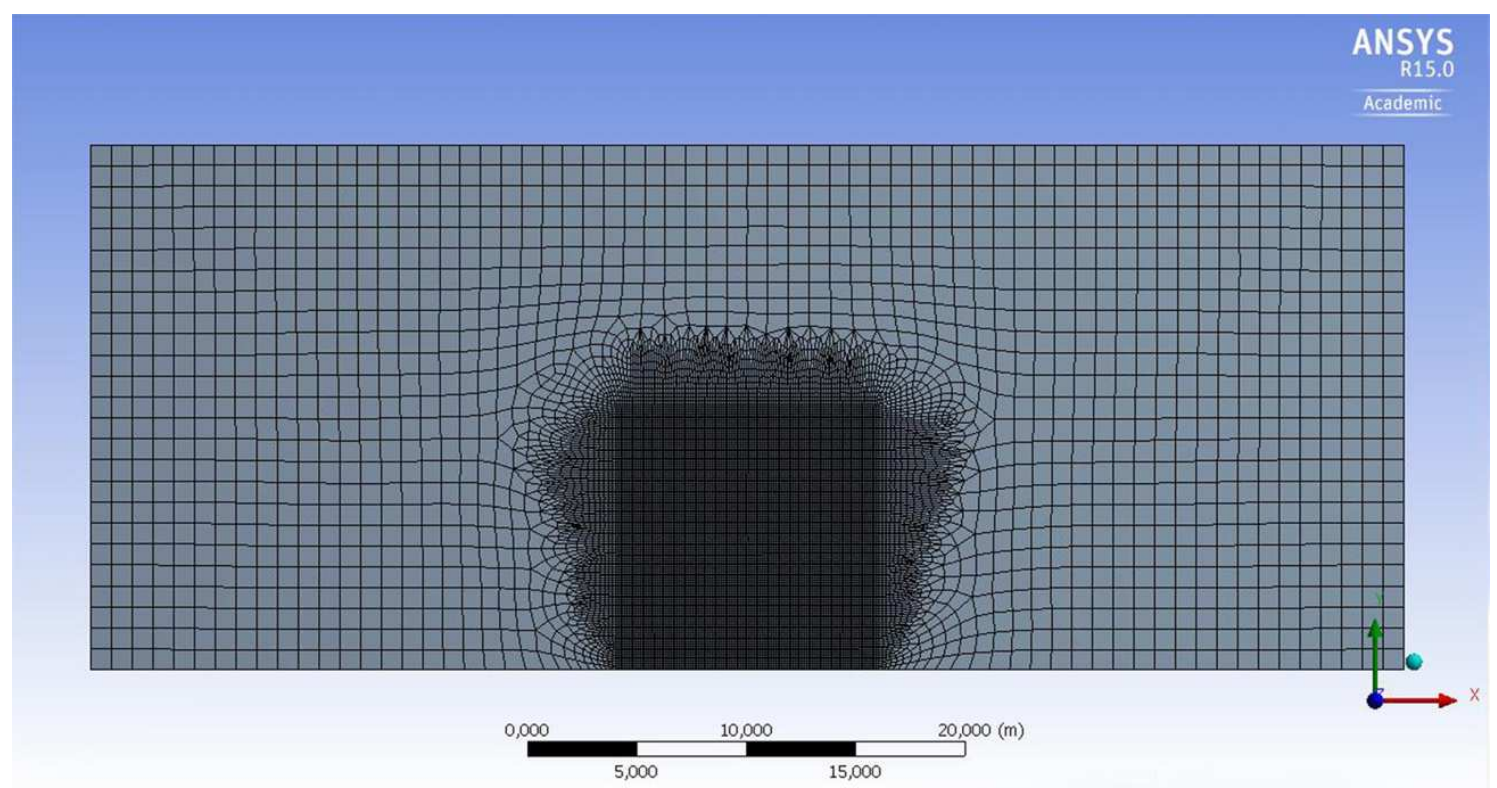

Figura 4.9. Caso de estudio mallado con la malla del tipo 2.
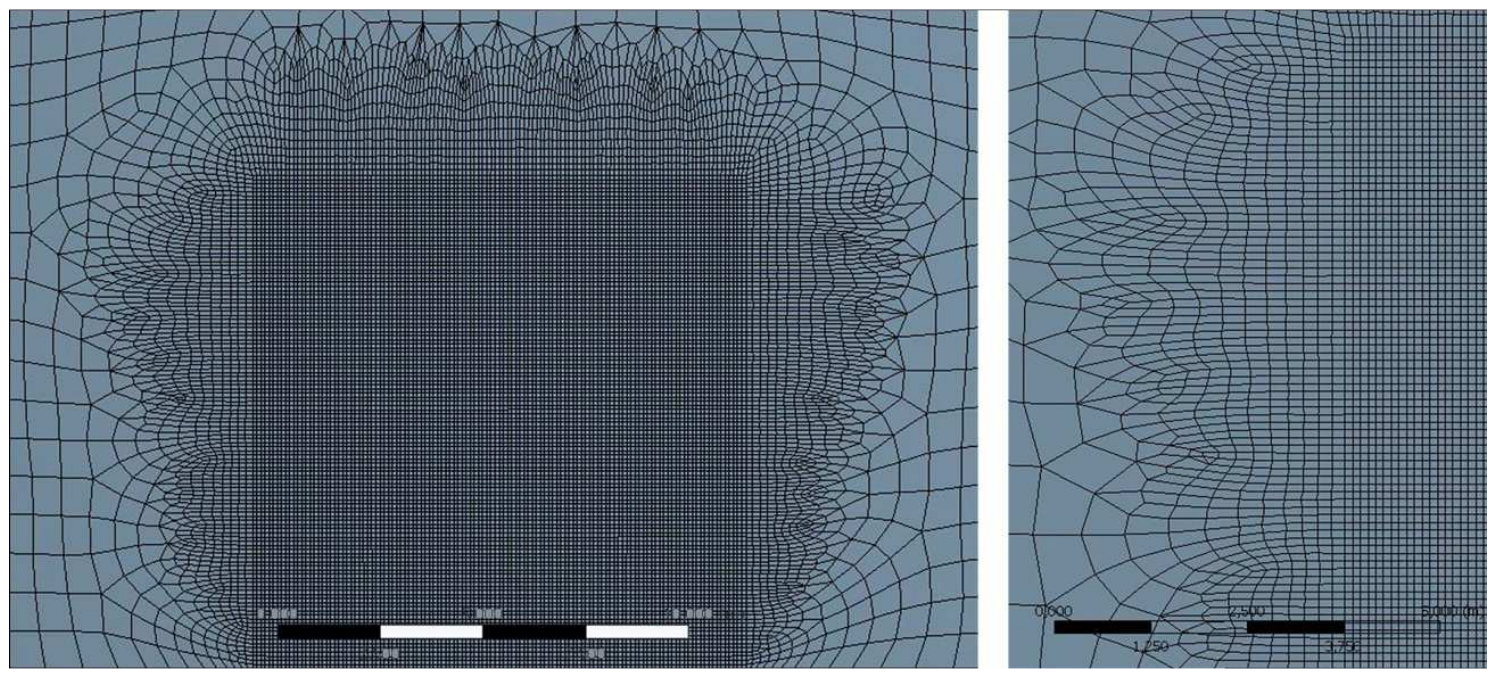

Figura 4.10. Detalle de la malla tipo 2.

\section{- Malla 3}

Se mejora el mallado del ambiente exterior para que haya mayor número de celdas y sea más densa. El mallado del interior de la habitación permanece sin cambios respecto a la malla 2, Figuras 4.11 y 4.12.

- Tamaño en las caras: 0,1 m

- Tamaño de malla: fino

- Suavizado: fino 
- Tasa de crecimiento: 1,03

- Número de nodos: 30.774

- Número de celdas: 30.581

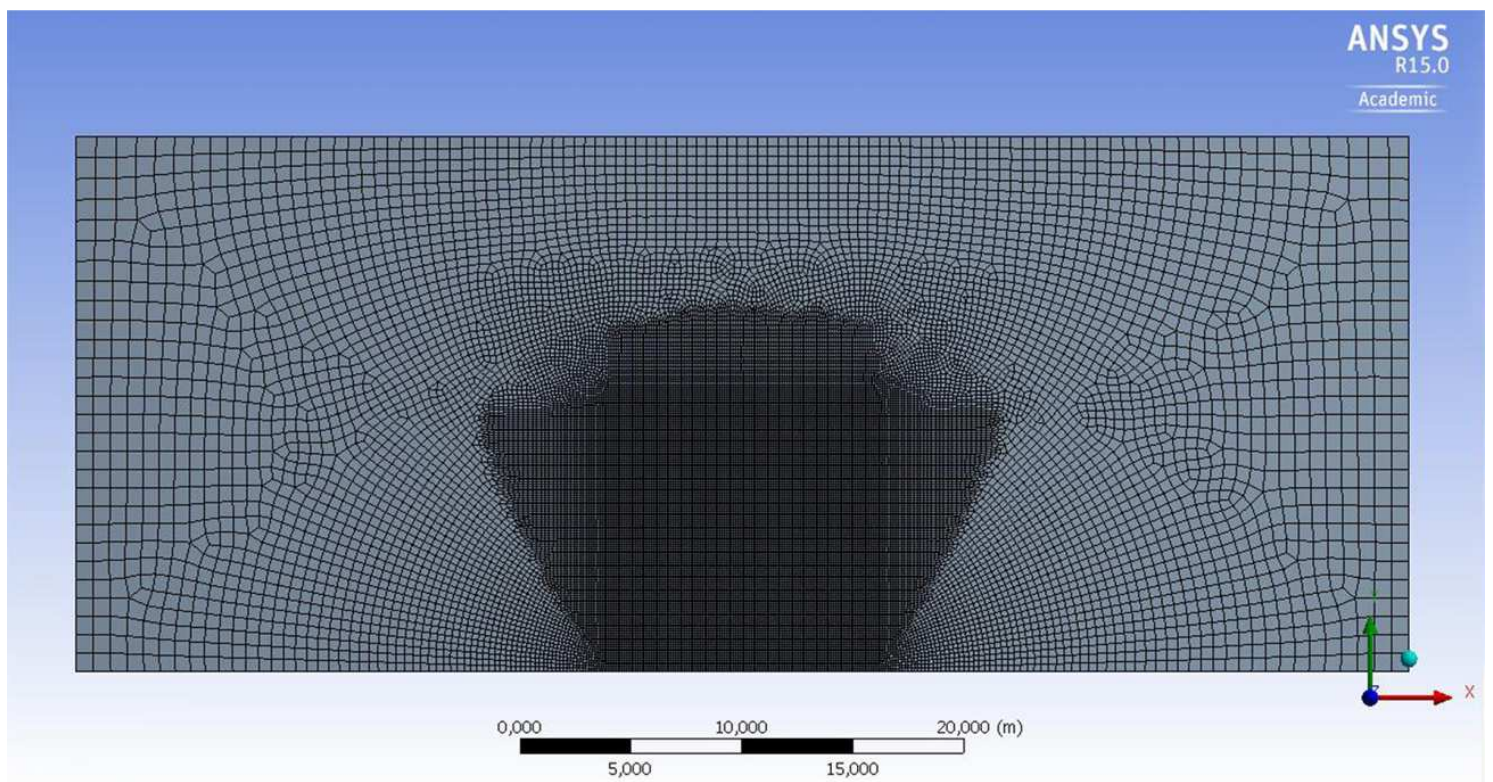

Figura 4.11. Caso de estudio mallado con la malla del tipo 3.
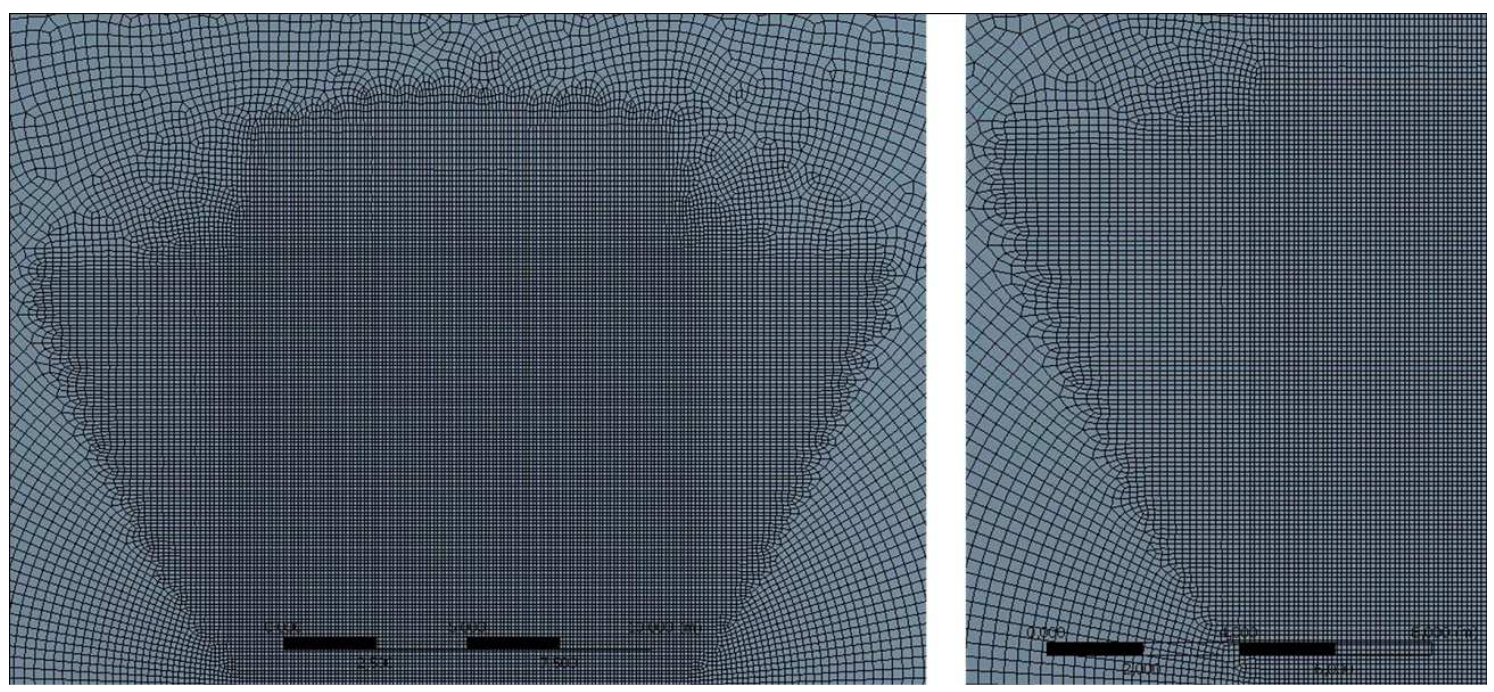

Figura 4.12. Detalle de la malla tipo 3.

El mallado de tipo 1 no es una opción, es un mallado muy burdo que se utiliza simplemente para comprobar que el modelo funciona correctamente en Fluent.

Se decide estudiar la influencia del tamaño de la malla con los tipos 2 y 3 . Para ello se escoge el caso 1.4 (abertura superior fija e igual a $1 \mathrm{~m}$, y abertura inferior igual a $4 \mathrm{~m}$ ) como caso de estudio comparativo entre los dos tipos de mallas. Se elige este caso porque es un caso intermedio en el que el aire no sólo entra por la abertura inferior, sino que también sale. El objetivo es ver la influencia del mallado en los resultados. 
Los resultados obtenidos son los siguientes:

Malla 2:

$V=0,424 \mathrm{~m}^{3} / \mathrm{s}$ (caudal neto)

$h_{n}=4,225 \mathrm{~m}$ (altura del plano neutro)

\section{Malla 3:}

$V=0,428 \mathrm{~m}^{3} / \mathrm{s}$ (caudal neto)

$h_{n}=4,2 \mathrm{~m}$ (altura del plano neutro)

Los resultados obtenidos muestran que con las mallas 2 y 3 se obtienen unos resultados muy similares. La ventaja de la malla 2 respecto a la malla 3 , es que el tiempo de cálculo es inferior.

Se concluye que en los próximos casos se puede utilizar una malla menos densa, del tipo de la malla 2, ya que los resultados obtenidos son muy similares y el tiempo invertido es menor. De esta forma se reduce el tiempo de cálculo, lo que permite analizar más casos.

\subsubsection{Modelo}

Se resuelven las ecuaciones de turbulencia utilizando el modelo de turbulencia RNG k- $\varepsilon$ ( 2 ecuaciones) con funciones de pared de no equilibrio. Dentro de este modelo, da como opción activar o no la corrección de curvatura. Para tomar la decisión, se realizó la simulación de un caso primero con la corrección de curvatura desactivada y posteriormente activada. Una vez que el caso hubo convergido, se observó que el valor del caudal era el mismo tanto si se activaba como si no, así que se decidió activarlo siempre.

Otra opción que da el modelo es la posibilidad de activar o no la opción de incluir los efectos de la convección natural. Para poder tomar una decisión correcta, se realizaron varias simulaciones en las que se compararon los resultados obtenidos y el comportamiento del modelo. En el próximo apartado se explican las simulaciones que se realizaron, los resultados obtenidos y la conclusión extraída.

\subsubsection{Método de cálculo}

Al estudiar y analizar los estudios y la bibliografía existente en relación con el tema de la presente tesis, se observó que la mayoría de los estudios realizados mediante simulación CFD utilizan como modelo de aproximación de la densidad el modelo de Boussinesq, que se utiliza para aproximar la relación entre la densidad y el cambio de temperatura. Sin embargo, se creyó conveniente realizar también el estudio con el modelo de Gas Ideal Incompresible ya que también era un modelo factible. Así que se llevó a cabo un análisis en paralelo del caso mediante el modelo de Boussinesq y mediante el de Gas Ideal Incompresible con el objetivo de comprobar cuál se acercaba más a los resultados obtenidos por los autores del caso de referencia y poder justificar el uso de un modelo u otro para los futuros ensayos. 
En la bibliografía, las simulaciones CFD que utilizaban Boussinesq como modelo de aproximación de la densidad utilizaban PRESTO! como esquema de discretización de la presión. Sin embargo, para el modelo de Gas Ideal Incompresible recomendaban utilizar Body Force Weighted como esquema de discretización. Así que al mismo tiempo que se realizaba el análisis comparativo entre el modelo de Boussinesq y el de Gas Ideal Incompresible, también se realizó un estudio comparativo entre utilizar el esquema de discretización de presión PRESTO! y el de Body Force Weighted.

Los casos estudiados fueron los siguientes:

- Boussinesq y PRESTO!

- Boussinesq, PRESTO! y Full Buoyancy Effects

- Gas Ideal Incompresible y Body Force Weighted

- Gas Ideal Incompresible, Body Force Weighted y Full Buoyancy Effects

- Gas Ideal Incompresible, PRESTO! y Full Buoyancy Effects

Para realizar el estudio comparativo entre los métodos utilizados, se escogió el caso 1.2 en el que la abertura inferior era igual a $2 \mathrm{~m}$ y la superior igual a $1 \mathrm{~m}$. La Tabla 4.1 muestra los resultados obtenidos en el caso de referencia para el caso 1.2:

\begin{tabular}{|l|c|c|}
\hline \multicolumn{1}{|c|}{ Método Aplicado } & $\begin{array}{c}\text { Caudal } \\
\boldsymbol{V}\left(\mathbf{m}^{\mathbf{3}} / \mathbf{s}\right)\end{array}$ & $\begin{array}{c}\text { Altura Plano } \\
\text { Neutro } \\
\boldsymbol{h}_{\boldsymbol{n}}(\mathbf{m})\end{array}$ \\
\hline CFD & 0,425 & 4,9 \\
\hline Método Analítico & 0,46 & 2,75 \\
\hline
\end{tabular}

Tabla 4.1. Resultados del caso de referencia para el caso 1.2.

La Tabla 4.2 muestra los resultados obtenidos mediante diferentes métodos para el caso 1.2:

\begin{tabular}{|l|c|c|}
\hline \multicolumn{1}{|c|}{ Método Aplicado } & $\begin{array}{c}\text { Caudal } \\
\boldsymbol{V}\left(\mathbf{m}^{\mathbf{3}} / \mathbf{s}\right)\end{array}$ & $\begin{array}{c}\text { Altura Plano } \\
\text { Neutro } \\
\boldsymbol{h}_{\boldsymbol{n}}(\mathbf{m})\end{array}$ \\
\hline Boussinesq, PRESTO! & 0,372 & 4,3 \\
\hline Boussinesq, PRESTO!, Full Buoyancy Effects & 0,155 & 1,4 \\
\hline Gas Ideal Incompresible, Body Force Weighted & 0,451 & Fuera* $^{*}$ \\
\hline Gas Ideal Incompresible, Body Force Weighted, Full Buoyancy Effects & 0,453 & 3,75 \\
\hline Gas Ideal Incompresible, PRESTO!, Full Buoyancy Effects & 0,469 & 3,75 \\
\hline
\end{tabular}

(*) El plano neutro se sale fuera de los límites de la habitación.

Tabla 4.2. Resultados mediante diferentes métodos de cálculo para el caso 1.2.

A continuación se realiza un análisis de los resultados obtenidos:

- Los casos resueltos mediante el modelo de Boussinesq, quedan totalmente descartados porque el valor del caudal no se acerca a los valores obtenidos 
en el caso de referencia. Así que hay que fijarse en los casos resueltos mediante Gas Ideal Incompresible.

- En el caso en el que se utiliza PRESTO!, el valor del caudal se aleja de los valores del caso de referencia, así que también queda descartado.

- En el caso de Gas Ideal Incompresible utilizando como esquema de discretización de la presión Body Force Weighted, el resultado del caudal es el mismo tanto si se activan los efectos de la convección natural como si no. Sin embargo, activándolos se consigue que el plano neutro quede dentro de la habitación y desactivándolos no. Así que se decide activarlo.

Al mismo tiempo se analizó el comportamiento del movimiento del aire en la habitación para todos los métodos aplicados. Para ello se analizaron los gráficos de vectores velocidad, líneas de corriente y presión estática en la sección central de la habitación. Se observa un comportamiento adecuado del aire para el caso de Gas Ideal Incompresible, Body Force Weighted y Full Buoyancy Effects.

De esta forma, se concluye que se utilizará el modelo de Gas Ideal Incompresible con el esquema de discretización de presión Body Force Weighted y activando Full Buoyancy Effects para resolver todos los casos. Asimismo, se decide resolver también todos los casos mediante el modelo de Boussinesq y el esquema de discretización de presión PRESTO! con el objeto de tener otro modelo para comparar calculado por otro método que también se aproxima bastante a los valores obtenidos en el caso de referencia. Todos los casos se resuelven con el mallado tipo 2 como ya se ha comentado en el apartado anterior.

\subsubsection{Simulación}

Se simulan dos tipos de casos, que son los mismos que los estudiados en el caso de referencia:

1. Casos 1.1 a 1.7: Abertura superior fija e igual a $1 \mathrm{~m}$ y abertura inferior variable de 1 a $7 \mathrm{~m}$.

2. Casos 2.1 a 2.7: Abertura inferior fija e igual a $1 \mathrm{~m}$ y abertura superior variable de 1 a $7 \mathrm{~m}$.

\subsubsection{Resultados}

A continuación se muestran los resultados del caudal de aire y de la altura del plano neutro obtenidos del Caso 1 y del Caso 2.

\section{- $\quad$ Caso 1}

La Figura 4.13 muestra los resultados del caudal de aire obtenidos por simulación mediante diferentes métodos. 


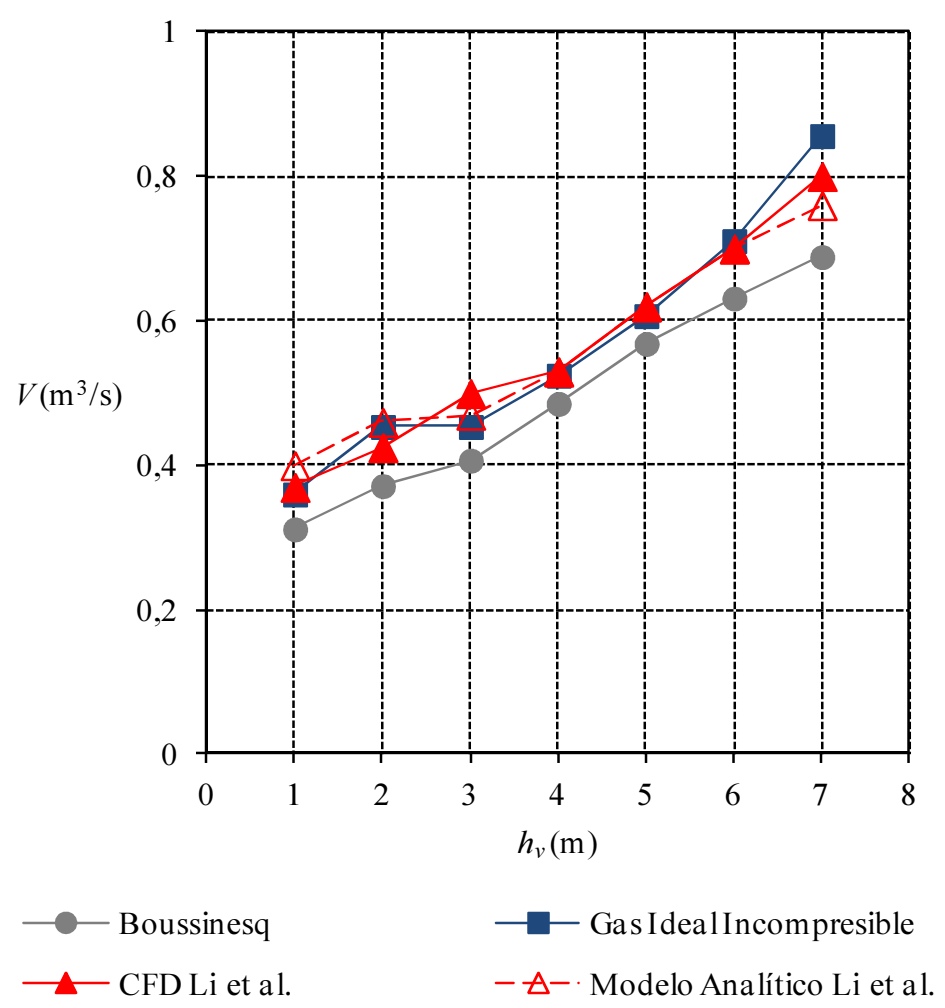

Figura 4.13. Caudal de aire $V\left(\mathrm{~m}^{3} / \mathrm{s}\right)$ que entra en el modelo calculado por diferentes métodos.

La Figura 4.14 muestra los resultados para la altura del plano neutro obtenidos por simulación mediante diferentes métodos.

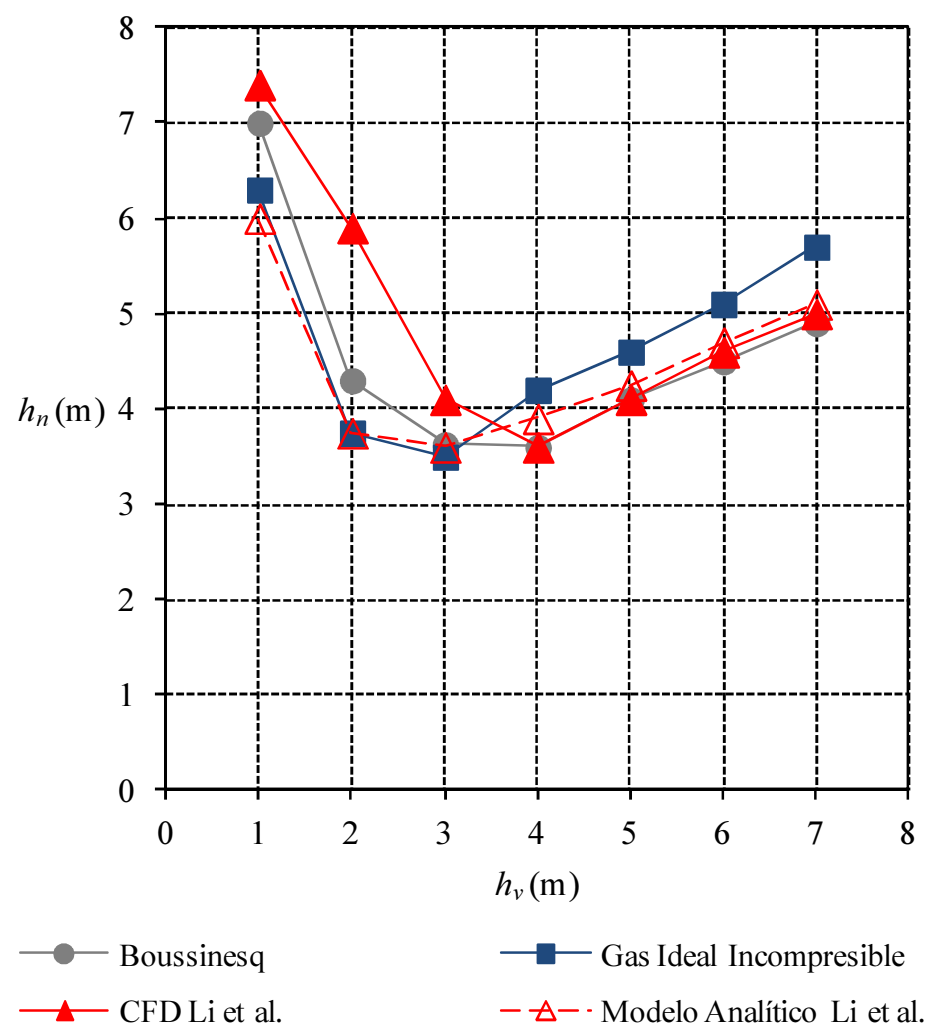

Figura 4.14. Altura del plano neutro $h_{n}(\mathrm{~m})$ calculado por distintos métodos. 
Se analizan los resultados obtenidos desde el punto de vista del caudal en la entrada:

- En los casos 1.1 y 1.2, el aire sólo entra por la abertura inferior a la habitación tanto con el modelo de Gas Ideal Incompresible como por el de Boussinesq.

- En el caso 1.3, para el caso de Gas Ideal Incompresible, el aire sólo entra por la abertura inferior, sin embargo para el caso de Boussinesq, el aire entra por la abertura inferior pero también sale.

- A partir del caso 1.4, el aire entra y sale por la abertura inferior por ambos métodos.

- En todos los casos se comprobó que el caudal que entraba por la abertura inferior fuese igual al caudal que salía por la abertura superior.

- En los casos en los que el aire entraba pero también salía por la abertura inferior, es decir a partir del caso 1.4, se calculó el caudal de aire que sólo entraba, por debajo del plano neutro, y no salía. Éste es el denominado caudal de aire de renovación, e interesa para ver la capacidad de renovación de aire que se produce según el tamaño de la abertura.

Desde el punto de vista de la altura del plano neutro, el análisis de los resultados obtenidos es el siguiente:

- En los casos de aberturas pequeñas (1.1 y 1.2), el aire sólo entra, así que la velocidad en la entrada es distinta de cero. En estos casos, la altura del plano neutro se calcula como la altura en la habitación en la que la presión del aire de la habitación es igual a la presión del ambiente exterior $\left(P_{i}=P_{0}\right)$.

- En los casos en los que el aire entra por la abertura de entrada pero también sale, se calcula la altura del plano neutro como el punto donde la velocidad es igual a cero, tal y como lo resuelven los autores del artículo de referencia.

\section{- $\quad$ Caso 2}

Después de analizar los resultados obtenidos en el caso 1, se decide realizar las simulaciones para el caso 2 sólo con el modelo de Gas Ideal Incompresible, utilizando el esquema de discretización de presión Body Force Weighted y activando Full Buoyancy Effects.

La Figura 4.15 muestra los resultados del caudal de aire obtenidos por simulación mediante diferentes métodos. 


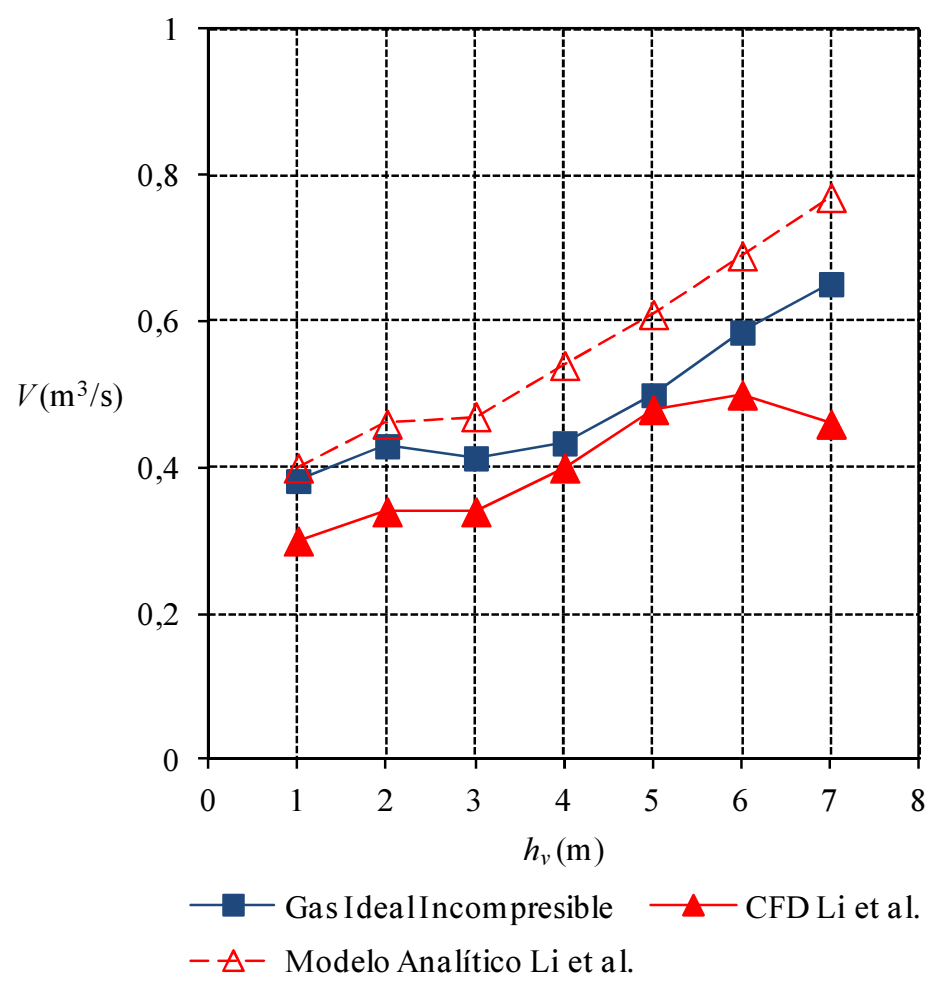

Figura 4.15. Caudal de aire $V\left(\mathrm{~m}^{3} / \mathrm{s}\right)$ que sale del modelo calculado por diferentes métodos.

La Figura 4.16 muestra los resultados para la altura del plano neutro obtenidos por simulación mediante diferentes métodos.

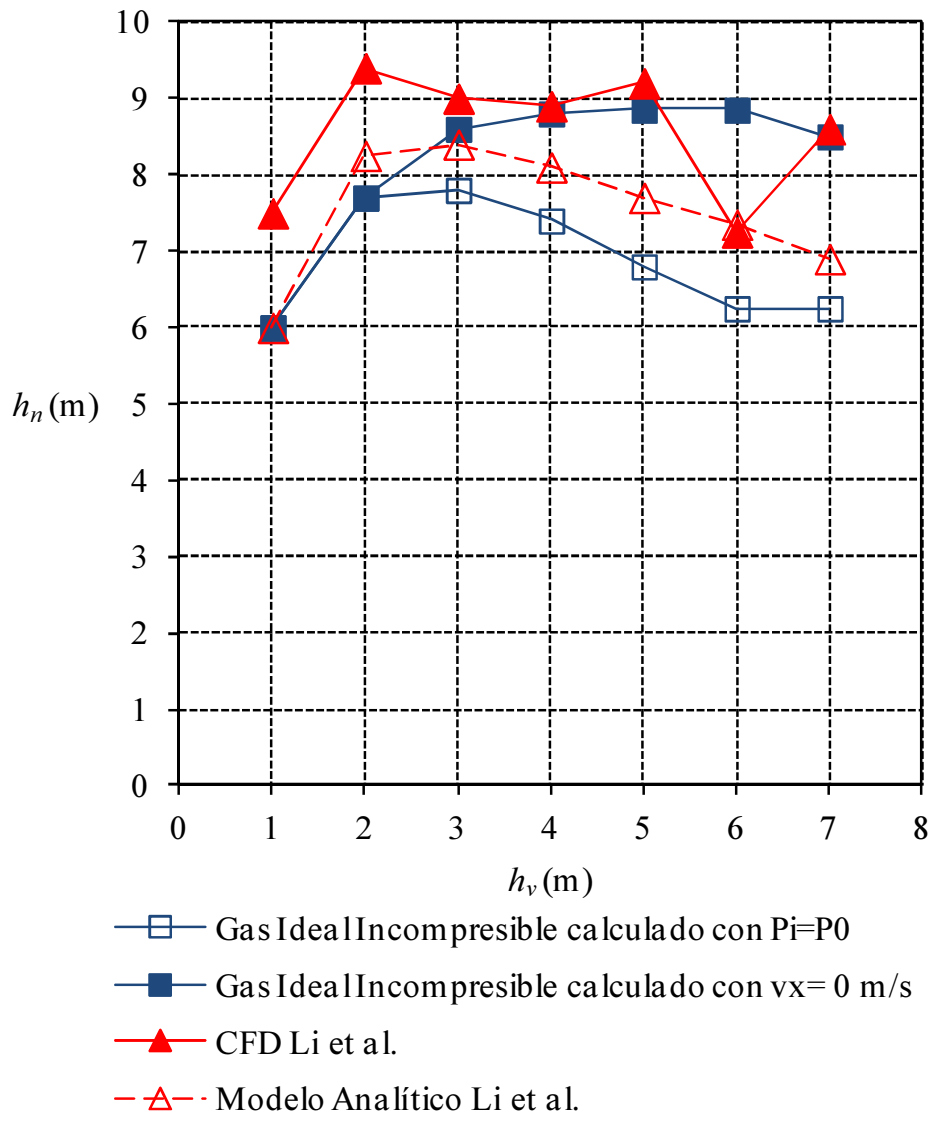

Figura 4.16. Altura del plano neutro $h_{n}(\mathrm{~m})$ calculado por distintos métodos. 
A continuación se analizan los resultados obtenidos desde el punto de vista del caudal en la salida:

- En los casos 2.1 y 2.2, el aire sólo sale por la abertura superior de la habitación tanto con el modelo de Gas Ideal Incompresible como por el de Boussinesq.

- A partir del caso 2.3, el aire sale y entra por la abertura superior.

- En los casos 2.1 a 2.7, el aire sólo entra por la abertura de entrada.

- Se calculó todo el caudal que entra, es decir, el que entra por la abertura inferior (entrada) más el que entra por la abertura superior (salida).

- Asimismo, también se calculó el caudal que sólo sale por la abertura superior.

Desde el punto de vista de la altura del plano neutro, el análisis de los resultados obtenidos es el siguiente:

- En los casos de aberturas pequeñas (2.1 y 2.2), el aire sólo sale, así que la velocidad en la salida es distinta de cero. Esto implica que el plano neutro no interseca con la abertura de salida, y por lo tanto el aire sólo sale, no entra nada. En estos casos, la altura del plano neutro se calcula como la altura en la habitación en la que la presión del aire de la habitación es igual a la presión del ambiente exterior $\left(P_{i}=P_{0}\right)$.

- En los casos en los que el aire sale por la abertura de salida pero también entra, implica que el plano neutro interseca con la abertura superior y que el aire también entra por la abertura de salida, por debajo del plano neutro. En estos casos, se calcula la altura del plano neutro como el punto en la abertura de salida donde la velocidad es igual a cero.

Asimismo, también se analizó el comportamiento del movimiento del aire en la habitación. Para ello se analizaron los gráficos de presión manométrica, vectores velocidad, líneas de corriente y presión estática en la sección central de la habitación. Se observa un comportamiento adecuado del aire para el caso de Gas Ideal Incompresible, Body Force Weighted y Full Buoyancy Effects.

Las Figuras 4.17 - 4.21 muestran el comportamiento del aire en el modelo para el caso 2.4 (abertura inferior fija e igual a $1 \mathrm{~m}$, y abertura superior igual a $4 \mathrm{~m}$ ) simulados mediante el modelo de Gas Ideal Incompresible, Body Force Weighted y Full Buoyancy Effects. 


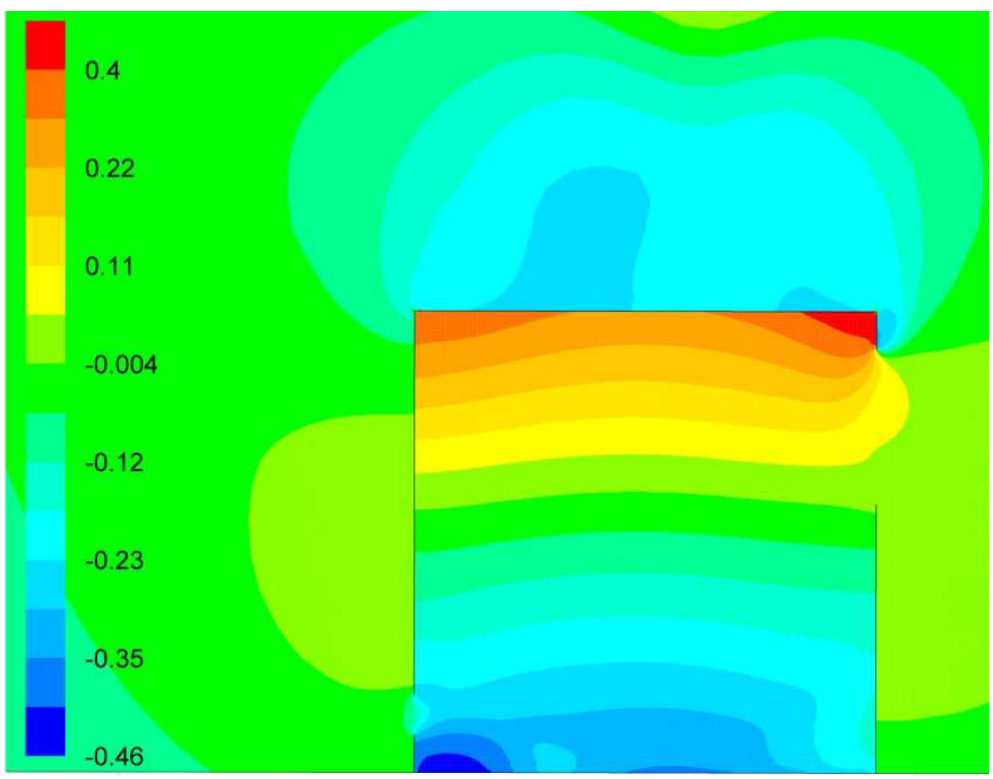

Figura 4.17. Contorno de presión manométrica $(\mathrm{Pa})$ del caso 2.4.

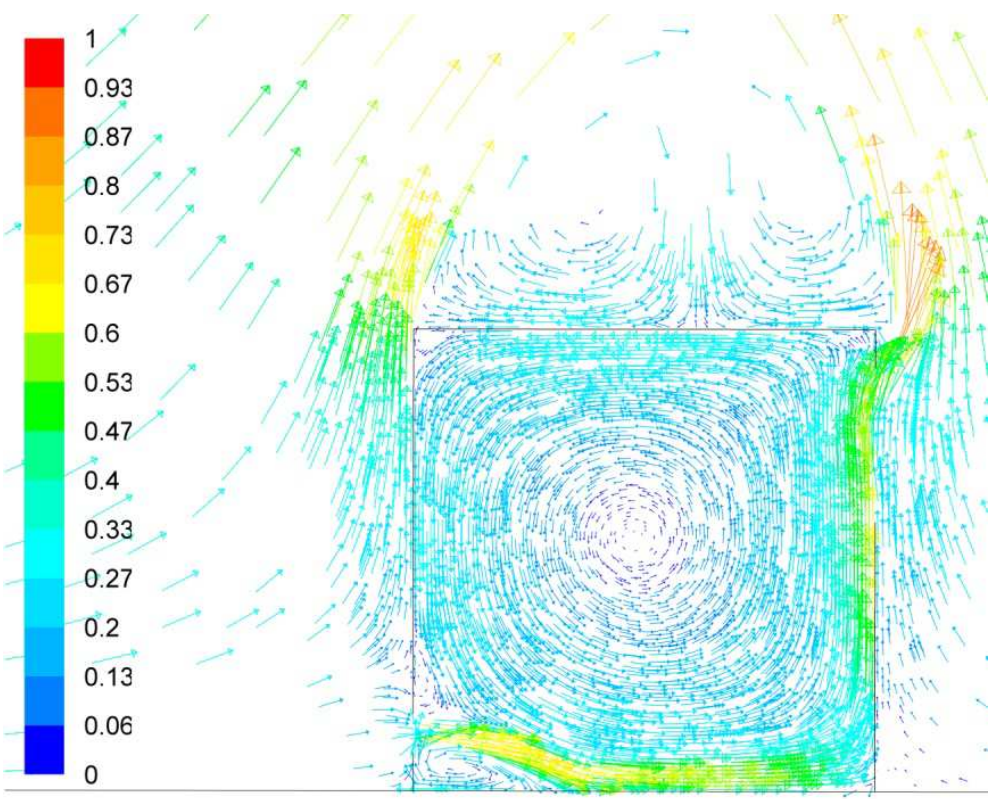

Figura 4.18. Vectores velocidad coloreados por velocidad $(\mathrm{m} / \mathrm{s})$ del caso 2.4. 


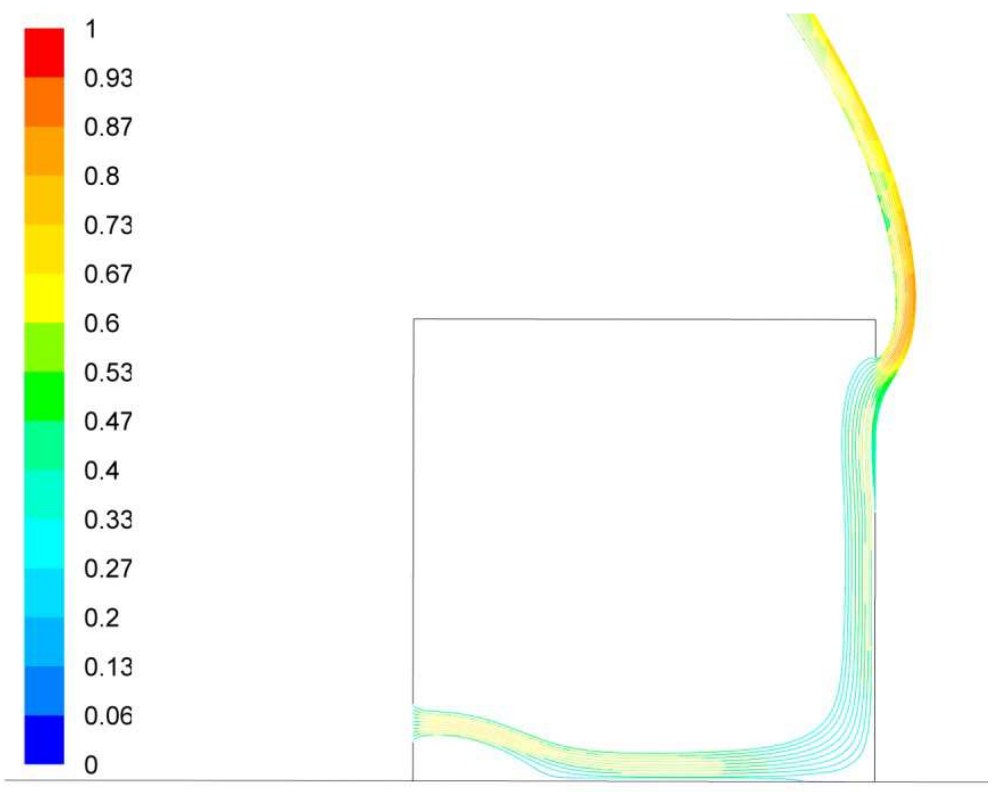

Figura 4.19. Líneas de corriente coloreadas por velocidad $(\mathrm{m} / \mathrm{s})$ del caso 2.4 .

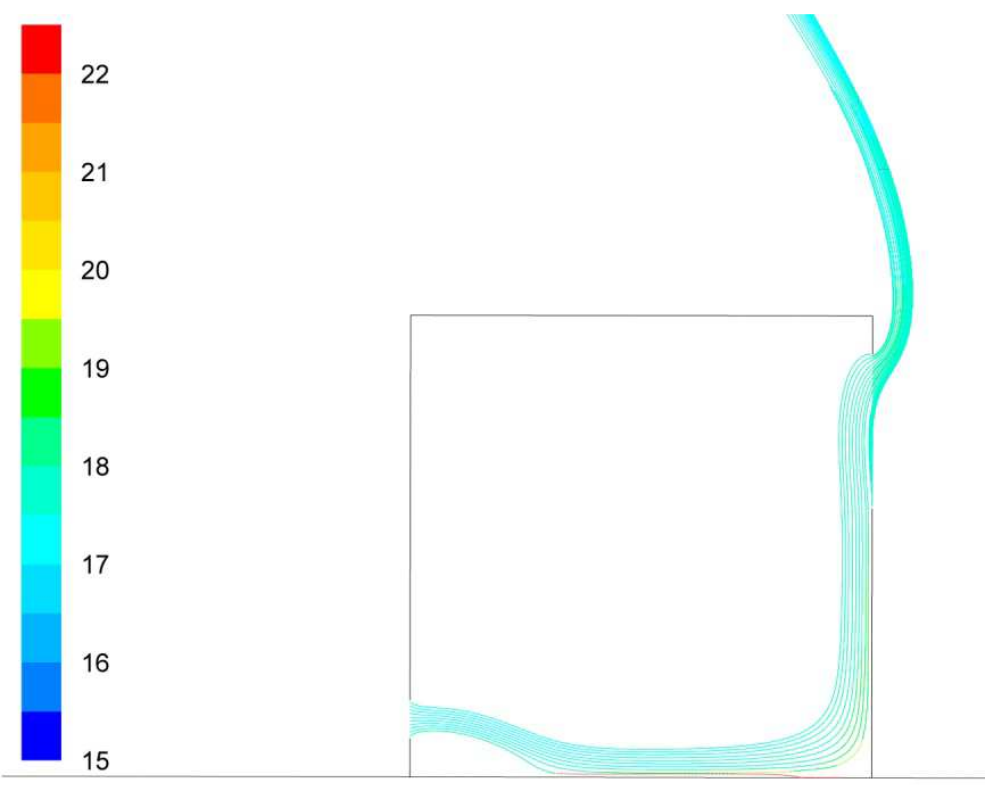

Figura 4.20. Líneas de corriente coloreadas por temperatura $\left({ }^{\circ} \mathrm{C}\right)$ del caso 2.4 . 


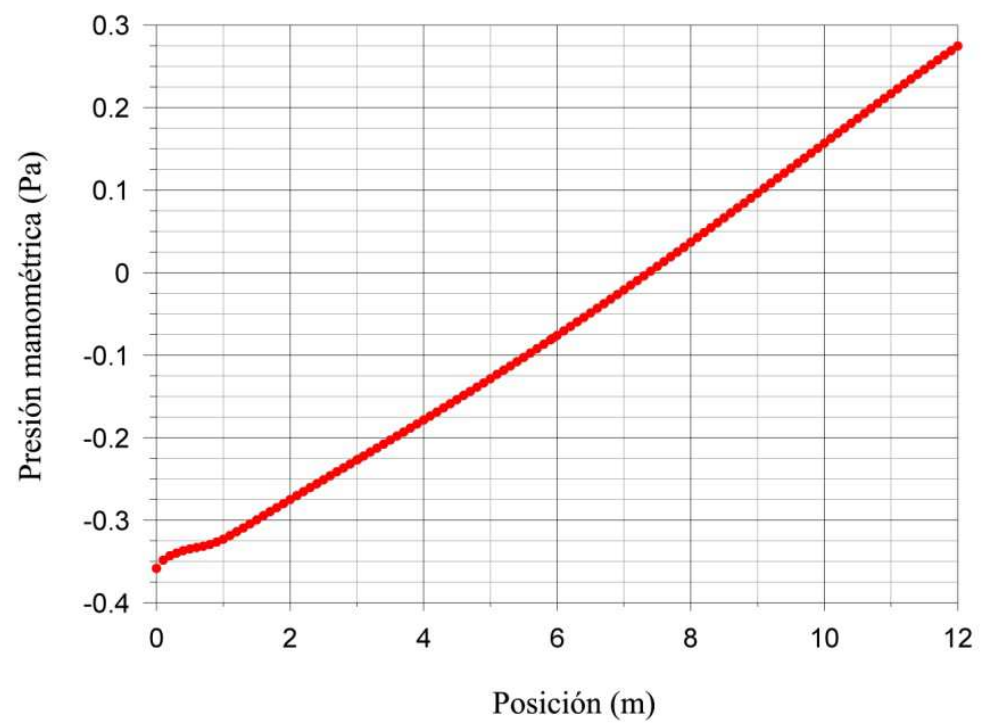

Figura 4.21. Presión manométrica $(\mathrm{Pa})$ en la sección central de la habitación del caso 2.4.

\subsubsection{Conclusiones}

De las simulaciones del Caso 1 pueden extraerse las siguientes conclusiones:

- El modelo de Gas Ideal Incompresible es el que mejor se comporta. Se obtienen unos resultados que se aproximan mucho a los del artículo de referencia, tanto a los obtenidos por simulación CFD como a los del análisis teórico.

- Con el modelo de Boussinesq no se obtienen unos resultados tan buenos como con el Gas Ideal Incompresible, aunque este sea el modelo utilizado en el artículo de referencia.

- En relación a la altura del plano neutro, el modelo de Gas Ideal Incompresible también es el que da mejores resultados. Como método de cálculo, parece que al calcular la altura del plano neutro como el punto donde $P_{i}=P_{0}$, se obtienen mejores resultados que calculándolo como el punto donde $v_{\mathrm{x}}=0 \mathrm{~m} / \mathrm{s}$.

De las simulaciones del Caso 2 pueden extraerse las siguientes conclusiones:

- Todo el aire que entra en la habitación debe ser igual a todo el aire que sale.

- Para el cálculo del plano neutro parece mejor calcularlo en la sección central de la habitación donde $P_{i}=P_{0}$, es decir, se llega a misma conclusión que en el caso 1.

Como conclusiones generales que se obtienen en este ejercicio y que van a servir para las próximas simulaciones, se extraen las siguientes:

- Mallado: muy fino cerca de las superficies acristaladas, tamaño medio de los elementos en el resto. 
- Modelo de turbulencia: RNG k-E (2 ecuaciones); activar corrección de curvatura.

- Modelo: Gas Ideal Incompresible.

- Método de discretización espacial: Body Force Weighted (2ºrden).

- Activar efectos de convección natural (full buoyancy effects).

- Plano neutro calculado en la sección central de la habitación donde $P_{i}=P_{0}$.

\subsection{SOFTWARE DE SIMULACIÓN}

Como ya se ha explicado anteriormente, en la presente tesis se utiliza ANSYS Fluent como software para predecir el flujo de aire, la turbulencia, la transferencia de calor y las reacciones que se producen en el modelo de estudio, ya que contiene las características de modelado físico que se necesitan.

Este software comercial es una de las herramientas más potentes en dinámica de fluidos computacional disponibles en el mercado. Además, incluye una buena validación de las capacidades de modelado físico para entregar resultados rápidos y precisos a través de una amplia gama de aplicaciones de CFD y multifísicas. Asimismo, fue validado previamente en la literatura.

\subsubsection{Proceso de trabajo en ANSYS Fluent}

La siguiente figura muestra de forma esquemática el proceso de trabajo que se va a seguir desde el planteamiento del modelo hasta la solución final. Es una manera sencilla de entender lo que se va a explicar detalladamente en los próximos apartados. 


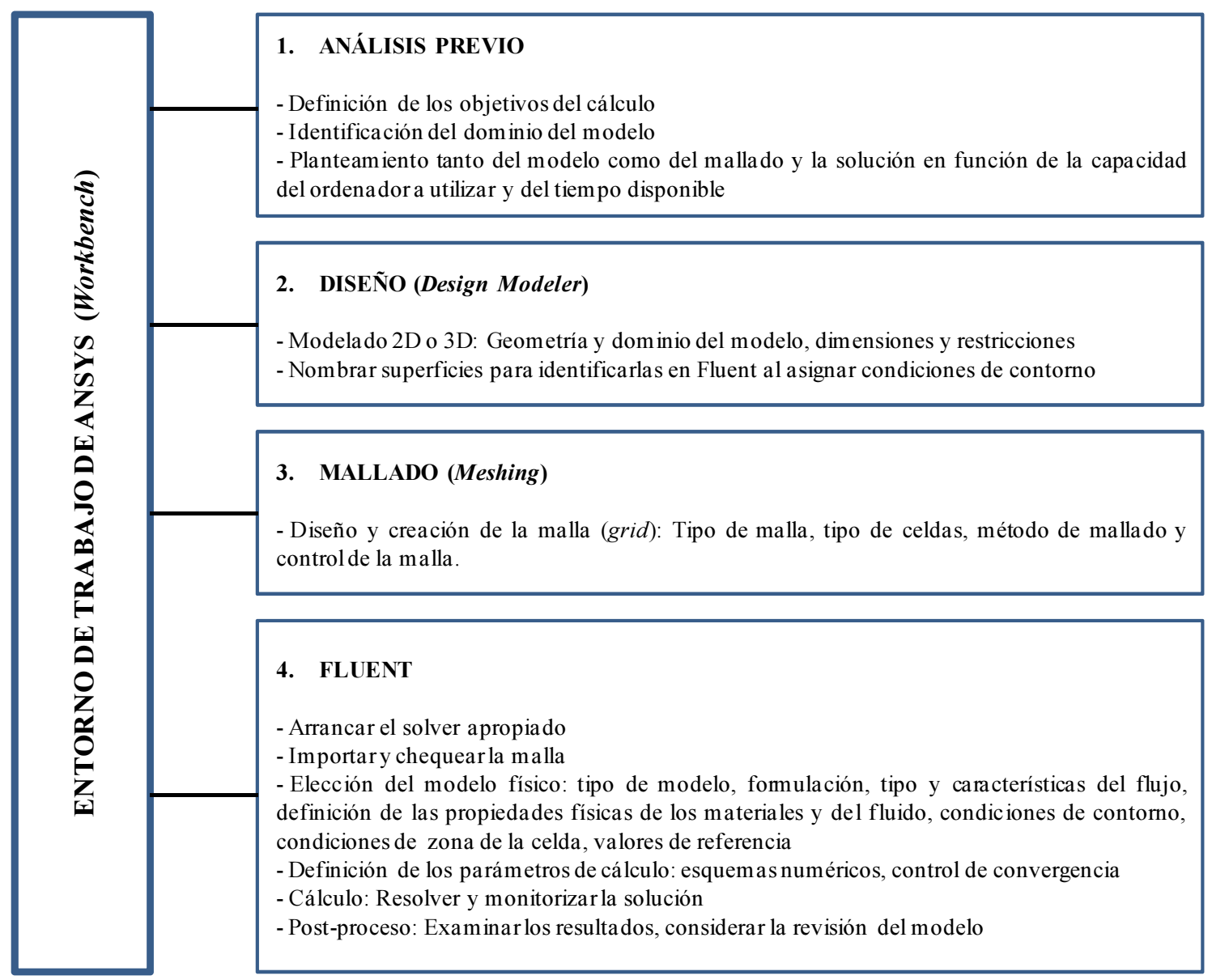

Figura 4.22. Esquema de procedimiento de trabajo en CFD.

\subsection{FLUJO DOMINADO POR CONVECCIÓN NATURAL}

\subsubsection{Diseño}

En primer lugar se crea la geometría 2D en el programa de diseño (design modeler). Para ello se van creando las geometrías en varios sketch. Se recomienda trabajar en un plano perpendicular para que sea más cómodo de dibujar.

A continuación se desarrolla y explica el proceso de diseño:

1. Se dibuja el ambiente exterior como líneas sueltas con la dimensión correspondiente definida en la geometría de 21 x $10 \mathrm{~m}$, y se crea una superficie del ambiente exterior.

2. Se dibuja la habitación (ambiente interior) con líneas con la dimensión que le corresponde de 6 × $3 \mathrm{~m}$, y se genera una superficie de la habitación.

3. Se dibuja el vidrio interior, el que está en contacto con el aire de la habitación por una cara y con el aire de la cámara por la otra, con una doble línea que serán 
las caras con $6 \mathrm{~mm}$ de separación entre ellas. Se genera una superficie del vidrio interior.

4. Se dibuja la cámara de aire con líneas en todo su perímetro. Hay que tener en cuenta que en esta tesis se estudian diferentes configuraciones de fachada, por lo que el ancho de la cámara variará en función del caso. Esto implica que habrá que modificar la geometría para cada caso, y como consecuencia el mallado y los datos de partida para realizar la simulación CFD. Se genera una superficie de la cámara de aire.

5. Se dibuja el vidrio exterior, el que está en contacto con el aire del ambiente exterior por una cara y con el aire de la cámara por la otra. Se dibuja con una doble línea que representan las dos caras del vidrio con una separación de $6 \mathrm{~mm}$ entre sí. Se genera una superficie del vidrio exterior.

6. De forma adicional, se genera una superficie auxiliar próxima a las paredes del vidrio de dimensión arbitraria. Es necesaria para poder hacer celdas más pequeñas y más concentradas en la zona cercana a la pared de los vidrios y poder obtener así resultados más precisos y fiables. Es en esta zona donde se van a dar los fenómenos de transferencia de calor, entre otros, e interesa que haya un mayor número de celdas.

Resumiendo, se han generado seis zonas en total: el ambiente exterior, la habitación (ambiente interior), el vidrio interior, la cámara de aire, el vidrio exterior y la superficie auxiliar. Se necesita dar un nombre a estas superficies para poder identificarlas más adelante en Fluent en el momento de asignar las condiciones de contorno o para analizar algo concreto en un punto o superficie. No es necesario especificar un nombre a la superficie auxiliar ya que va a ser fluido. Las Figuras 4.23 y 4.24 muestran el diseño de la geometría.

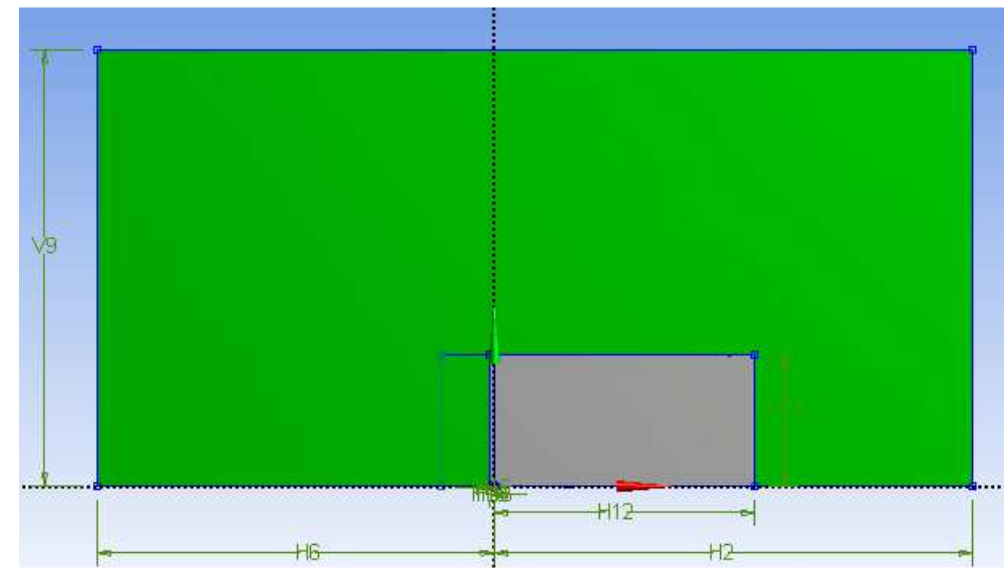

Figura 4.23. Diseño de la geometría del dominio computacional. 


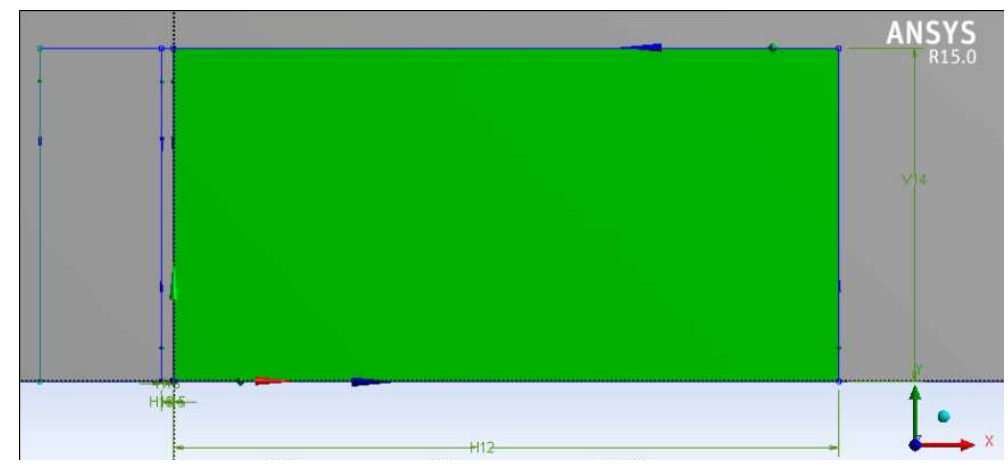

Figura 4.24. Detalle del diseño de la geometría de la habitación y de la fachada doble piel.

Una vez diseñada la geometría 2D, se exporta al programa de mallado (meshing) para diseñar y crear la malla.

\subsubsection{Mallado}

Una vez dibujada la geometría del modelo de estudio en el Design Modeler, tanto de la habitación como la del espacio exterior que la rodea, se procede al mallado del mismo.

La malla se realiza con la herramienta Meshing que es la que genera las celdas en el modelo. Una celda es el volumen elemental en el que se discretiza el dominio. Es necesario mallar el modelo para generar celdas y así poder dar características a la zona de las mismas y para poder establecer las condiciones de contorno posteriormente. Asimismo, es necesario el mallado para que Fluent pueda realizar la simulación y resolver el problema.

Cuando se inicia el meshing, lo primero es comprobar que la geometría se ha importado correctamente. Para ello, se comprueba que están las seis superficies creadas en el design modeler, que están bien nombradas y que el nombre de cada una se corresponde con la superficie que se selecciona.

Se crea una malla bidimensional, ya que el diseño del modelo también es en 2D como ya se ha explicado en el apartado anterior. Se malla el campo fluido, es decir, el aire de la habitación, el aire de la cámara y el aire del ambiente exterior. También se mallan los vidrios que posteriormente serán especificados como sólidos.

Había que resolver el problema de modo que Fluent tuviese en cuenta la transferencia de calor por conducción entre el aire del modelo y los vidrios. Para ello, se decidió diseñar los paños de vidrio en el design modeler como superficies de $6 \mathrm{~mm}$ de espesor $\left(\mathrm{t}_{p}\right)$ para poder mallarlos después en el meshing. De esta forma se pudo conseguir que hubiese diversas celdas entre ambas caras de los vidrios y así poder estudiar los fenómenos físicos que tenían lugar en el interior de los vidrios y en el fluido a su alrededor. Posteriormente, en Fluent se clasificarán las celdas del interior de los vidrios con la condición de sólido para que resuelva el problema de la conducción del calor, y también se especificará el tipo de material sólido con las propiedades físicas del vidrio. Esto último se explicará detenidamente en el apartado 4.3.3.4. Condiciones de la zona de celdas, y en el apartado 4.3.3.5. Condiciones de contorno de los vidrios. 
De todos los tipos de mallas que dispone el meshing, se decide realizar una malla no estructurada, que es más irregular y hay menos control de disposición de las celdas, pero se adapta muy bien a zonas complicadas como las esquinas y supone un ahorro de elementos. Por ello, para el tipo de celdas 2D se elige el método de mallado de los cuadriláteros, que es habitualmente estructurado, uniforme.

Antes de proceder a diseñar y crear la malla, se define en el cuadro de condiciones base del mallado que la configuración física es CFD y que se va a resolver mediante el solver de Fluent. A continuación, se detallan las propiedades de la celda en el cuadro de control de la malla:

- Tamaño de los elementos. Es el valor que se utiliza para mallar los bordes, caras y cuerpos.

- Tamaño de malla: medio

- Tamaño mínimo: $10^{-3} \mathrm{~m}$

- Tamaño máximo: valor por defecto en m

- Tasa de crecimiento: 1,20 (valor por defecto)

- Longitud mínima del borde: $6 \cdot 10^{-3} \mathrm{~m}$

- Suavizado: medio

- Transición: suave.

Controla el ritmo de crecimiento de las celdas.

- Grado de refinamiento: fino (de $12^{\circ}$ a $36^{\circ}$ ).

Establece el grado de refinamiento de los bordes basado en la curvatura.

- Funciones de tamaño avanzadas: basado en curvatura y proximidad

- Ángulo normal de curvatura: $18^{\circ}$ (valor por defecto)

Como ya se ha concluido en el apartado 4.1.2, no es necesario realizar un mallado muy fino. Se comprobó que utilizando una malla menos densa, se obtienen unos resultados muy similares a los de una malla más fina y el tiempo de cálculo invertido es menor.

Una vez definidos los detalles de la malla, se procede a dar tamaño a las celdas de las diferentes superficies:

1. Aire del ambiente exterior. El mallado se genera automáticamente con el tipo de mallado que se especifique.

2. Aire del interior de la habitación, los dos vidrios y el aire de la cámara. Se seleccionan las superficies y se inserta un mallado estructurado de cara de 6 divisiones. Este tipo de mapeado permite generar mallas estructuradas en las caras. La cara es el contorno de la celda definida por los bordes. Se escoge el método de los cuadriláteros.

3. Vidrios. Se procede a dar tamaño a los bordes de los vidrios, contorno de una cara definida por dos nodos. Se seleccionan el extremo superior e inferior de los vidrios, bordes cortos, y se inserta un tamaño con 6 divisiones. A continuación, se seleccionan las caras interior y exterior de cada vidrio, bordes largos, y se inserta un tamaño a los mismos con 80 divisiones. 
4. Cámara de aire. Se seleccionan los extremos superior e inferior, bordes cortos, y se da un tamaño con 19 divisiones. A continuación, se seleccionan ambas caras, bordes largos, y se inserta un tamaño con 80 divisiones.

5. Habitación. Se seleccionan los bordes derecho, superior e inferior y se inserta un tamaño con 80 divisiones.

6. Superficie auxiliar. Como ya se ha explicado anteriormente, para conseguir que en el mallado haya más celdas cerca de las caras del vidrio, se realiza una superficie auxiliar. A ésta se le inserta un mallado mapeado de cara por el método de los cuadriláteros y también se le da un tamaño al borde izquierdo de 80 divisiones. De esta forma, se consigue un mayor número de celdas en el entorno cercano de los vidrios sin que ello afecte al número de celdas del ambiente exterior. El aumento del número de celdas en esta zona es importante para la resolución del problema, para que la predicción sea satisfactoria y obtener resultados más precisos.

Una vez que se le ha dado tamaño a las celdas de las diferentes superficies, se genera la malla. La Figura 4.25 muestra el resultado del mallado. Se pueden realizar las siguientes observaciones:

- Las celdas del espacio exterior son más pequeñas en el entorno próximo del volumen de control y van aumentando de tamaño a medida que se van alejando.

- Las celdas del interior de la habitación son más pequeñas que las del espacio exterior.

- En la región cercana a las paredes de los vidrios y en la cámara de aire hay mayor número de celdas ya que es la región que interesa estudiar y se necesita una predicción satisfactoria.

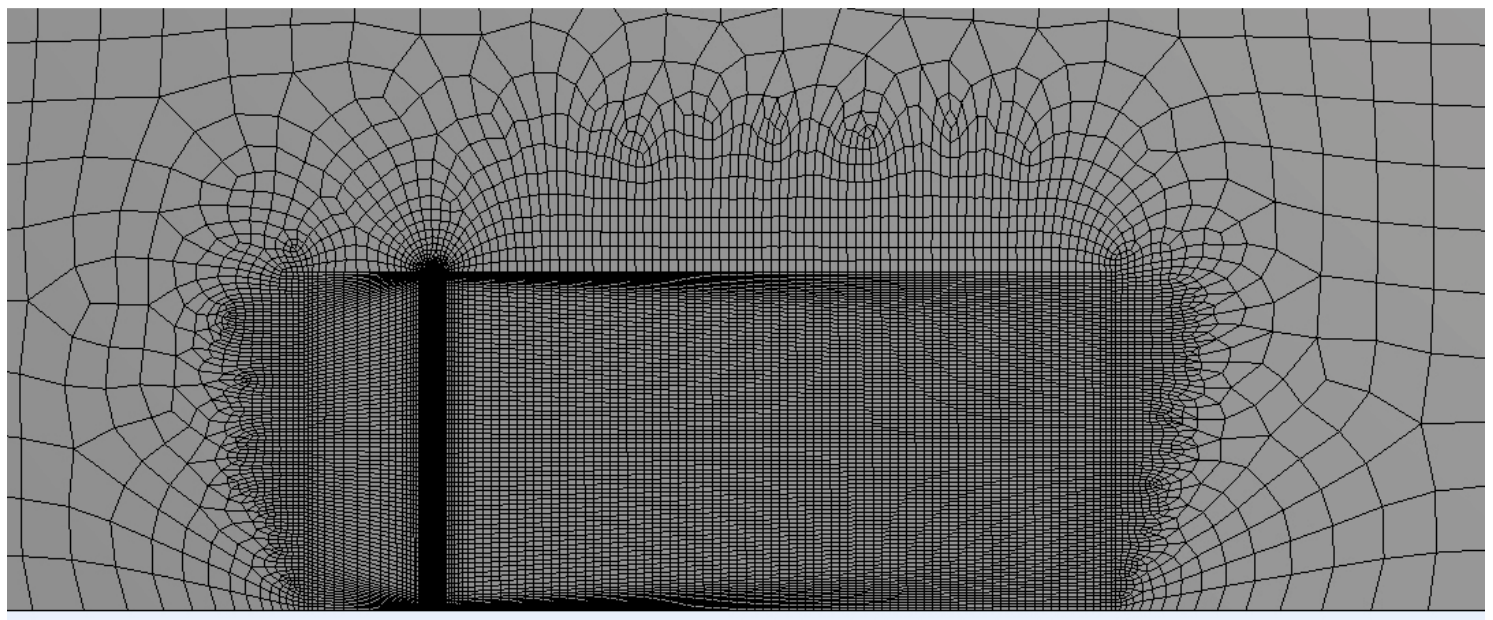

Figura 4.25. Mallado del volumen de control.

Una vez realizado el mallado se comprueba la calidad del mismo, que el aspecto sea bueno y que se ajuste bien a las esquinas. La Figura 4.26 muestra el detalle del mallado en la región cercana a los vidrios y de las esquinas. Se observa cómo las celdas se van 
concentrando y aumentando en número en las proximidades de ambos vidrios. Asimismo, se observa un mayor número de celdas en la zona de la cámara de aire. La malla es más refinada en esta zona, con una distribución más densa de celdas, porque es la zona donde se va a producir el intercambio de calor y el movimiento del flujo de aire e interesa obtener resultados más exactos.
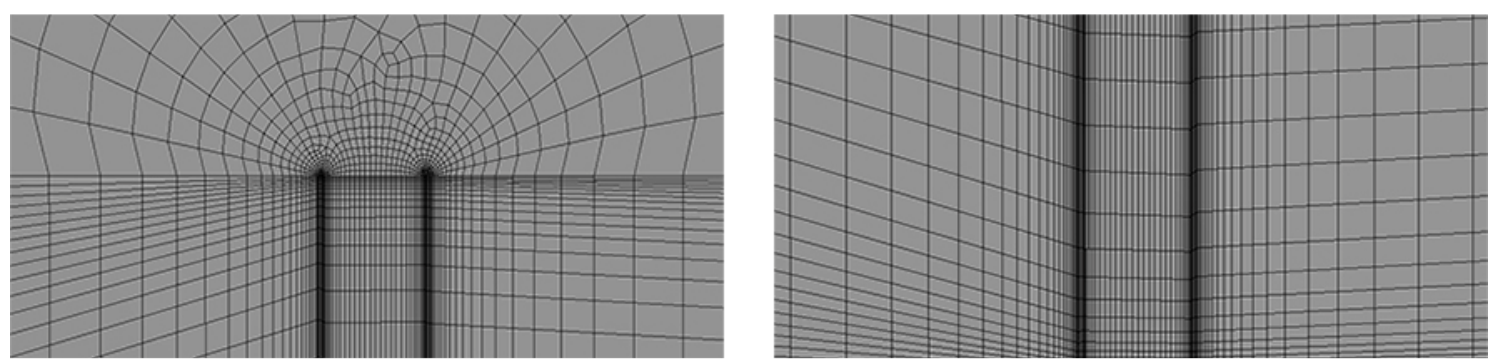

Figura 4.26. Detalle del mallado de los vidrios y de la cámara de aire.

Después se analizan los resultados obtenidos en el apartado de datos estadísticos:

- Número de nodos: 20.446

- Número de elementos: 20.315

- Deformación (skewness):

- Mínimo: $1,3 \cdot 10^{-10}$

- Máximo: 0,8451

- Valor medio: 0,0702

- Desviación típica: 0,1131

La calidad de la malla es muy importante para conseguir que la solución converja. Se recomienda que el valor máximo de la deformación esté por debajo de 0,95. Si la calidad de la malla es inaceptable, es mejor remallar antes de continuar con la definición física y numérica del problema.

A continuación se exporta la malla a Fluent para poder introducir las condiciones de partida (set up) y así poder calcular para obtener una solución.

\subsubsection{Fluent}

\subsubsection{General}

En primer lugar se visualiza el mallado, se chequea y se comprueba la escala del mismo para cerciorarse de que Fluent ha importado correctamente las características de la malla.

ANSYS Fluent dispone de dos solver, uno basado en presión, y otro basado en densidad. Ambos pueden utilizarse para una amplia gama de flujos, pero en algunos casos una formulación puede funcionar mejor que la otra al resolver ciertas características del flujo mejor o más rápido. La aproximación basada en presión y la 
basada en densidad difieren en la forma en que se resuelven las ecuaciones de continuidad, cantidad de movimiento y, en su caso, la de energía.

En este caso se ha utilizado el solver basado en presión. La ecuación de la presión se deriva de las ecuaciones de continuidad y de cantidad de movimiento, de tal forma que la velocidad, corregida por la presión, satisface la continuidad. Puesto que las ecuaciones que rigen son no lineales y están acopladas entre sí, el proceso de solución implica iteraciones de todas las ecuaciones hasta que la solución converge.

Existen dos algoritmos en Fluent para el solver basado en presión: un algoritmo segregado y un algoritmo acoplado. En el algoritmo segregado las ecuaciones se resuelven de forma secuencial, mientas que en el algoritmo acoplado las ecuaciones de momento y de continuidad se resuelven de forma acoplada.

Se escoge el algoritmo segregado, de forma que las ecuaciones se resuelven una tras otra. Cada ecuación, mientras se resuelve, se desacopla o segrega de las otras ecuaciones, de ahí su nombre. La solución debe ser llevada a cabo de forma iterativa con el fin de obtener una solución numérica convergente. La convergencia de la solución es relativamente lenta, ya que las ecuaciones se resuelven de una manera disociada. Fluent dispone de los siguientes algoritmos segregados: SIMPLE, SIMPLEC y PISO.

En resumen :

- Tipo: basado en presión

- Formulación de la velocidad: absoluta

- Tiempo: estacionario

- Espacio 2D: plano

- Gravedad: $X=0 \mathrm{~m} / \mathrm{s}^{2} ; \mathrm{Y}=9,8 \mathrm{~m} / \mathrm{s}^{2}$

- Unidades: Temperatura $\left({ }^{\circ} \mathrm{C}\right)$

El flujo de aire del interior de la cámara fue considerado en estado estacionario.

\subsubsection{Modelo}

\section{- $\quad$ Ecuación de la Energía}

La transferencia de calor es el proceso por el que se intercambia energía en forma de calor entre distintos cuerpos o entre diferentes partes de un mismo cuerpo que está a distinta temperatura. La transferencia de calor puede darse por tres mecanismos: conducción, convección y radiación. Los modelos físicos que incluyen sólo conducción y/o convección son los más simples, mientras que los que incluyen convección natural o flujo dominado por convección natural son más complejos.

ANSYS Fluent permite incluir la transferencia de calor dentro de las regiones fluidas y sólidas del modelo, pero para ello se debe activar el modelo físico y especificar las condiciones de contorno térmicas y las propiedades de los materiales para que se tengan en cuenta en las ecuaciones que gobiernan la transferencia de calor. 
Para resolver un problema de transferencia de calor, hay que activar la ecuación de la energía en el apartado correspondiente del cuadro de diálogo de Modelo.

Cuando se añade calor a un fluido y la densidad del fluido varía con la temperatura, puede inducirse un flujo debido a la actuación de la fuerza de la gravedad en la variación de la densidad. Este flujo se denomina convección natural.

Cuando se modela la convección natural en el interior de un dominio cerrado, la solución dependerá de la masa dentro del dominio.

\section{- Modelo de turbulencia}

La turbulencia está descrita por las ecuaciones de Navier-Stokes, que son un conjunto de ecuaciones en derivadas parciales no lineales que describen el movimiento de un fluido. Estas ecuaciones gobiernan cualquier fenómeno en el que se involucren fluidos newtonianos.

Las tres ecuaciones fundamentales son: la ecuación de conservación de la masa, la ecuación de continuidad, y la ecuación de la conservación de la energía. Estas ecuaciones pueden darse en su formulación integral o en su forma diferencial, dependiendo del problema. A este conjunto de ecuaciones dadas en su forma diferencial también se le denomina ecuaciones de Navier-Stokes.

En la mayoría de las situaciones no es factible resolver la amplia gama de escalas en tiempo y espacio por Simulación Numérica Directa (DNS). Por esta razón, hay que hacer promedios en los procedimientos para aplicar a las ecuaciones de Navier-Stokes con el objetivo de filtrar partes del espectro turbulento. El procedimiento de promedio que está más extendido para todas las ecuaciones es el Reynolds Averaged NavierStokes (RANS). Por este proceso, se eliminan del flujo todas las estructuras turbulentas (no se resuelven las escalas menores de la turbulencia) y se obtiene el valor medio en cada punto de los valores de velocidad y presión. Sin embargo, el proceso de promedio introduce términos desconocidos adicionales en las ecuaciones que tienen que ser proporcionados por los modelos de turbulencia adecuados.

La calidad de la simulación puede depender del modelo de turbulencia seleccionado. De los diferentes tipos de modelos de turbulencia que proporciona Fluent, se selecciona el modelo RNG k- $\varepsilon$ (2 ecuaciones).

El modelo de turbulencia RNG k- $\varepsilon$ se deriva de las ecuaciones de Navier-Stokes utilizando una técnica estadística llamada teoría de grupo de renormalización. Sus características son las siguientes:

- Tiene un término adicional en su ecuación $\varepsilon$ que mejora la precisión para los flujos tensos.

- El efecto de remolino en la turbulencia está incluido en el modelo RNG.

- La teoría RNG proporciona una fórmula analítica para los números de Prandtl turbulentos. 
- La teoría RNG proporciona una fórmula diferencial derivada analíticamente para la viscosidad efectiva que tiene en cuenta los efectos de bajo número de Reynolds. El uso eficaz de esta característica depende de un tratamiento adecuado de la región cercana a la pared.

Estas características hacen que el modelo RNG k- $\varepsilon$ sea más preciso y fiable para una clase más amplia de los flujos que el modelo estándar.

Los modelos de dos ecuaciones son históricamente los modelos de turbulencia más utilizados en CFD. El modelo k- $\varepsilon$ se utiliza mucho en las simulaciones del flujo y en la transferencia de calor por su robustez, economía y precisión razonable para una amplia gama de flujos turbulentos. Este modelo es el recomendado por varios autores para la simulación de edificios.

El modelado de cerca de la pared interfiere significativamente la fiabilidad de las soluciones numéricas. Es en la región cercana a la pared donde las variables de solución tienen grandes gradientes y el momento es mayor. Por lo tanto, la representación precisa del flujo en la región próxima a la pared determina predicciones satisfactorias de flujos turbulentos.

Para todos los modelos de k- $\varepsilon$, se debe seleccionar un tratamiento cerca de las paredes. Se selecciona la función de pared de no equilibrio. Las funciones de pared de no equilibrio tienen en cuenta el efecto del gradiente de presión en la distorsión de los perfiles de velocidad, efectos que no se tienen en cuenta en las funciones de pared estándar. Debido a la capacidad para tener en cuenta los efectos de los gradientes de presión, la función de pared de no equilibrio es recomendable para flujos complejos que implican la separación, reinserción y el impacto en el que el flujo y la turbulencia están sometidos a gradientes de presión y a cambios rápidos. En estos flujos se pueden obtener mejoras en la transferencia de calor.

Dentro del modelo k- $\varepsilon$, se elige la opción RNG. Al elegir este modelo se encuentran disponibles varias opciones, de las cuales hay que activar las siguientes en el cuadro de diálogo del modelo viscoso:

- inclusión de los efectos de convección natural en $\varepsilon$

- inclusión de la corrección de la curvatura

Fluent no incluye por defecto los efectos de la convección natural en $\varepsilon$, por ello deben activarse.

Algunos modelos viscosos muestran una falta de sensibilidad para agilizar la curvatura y el sistema de rotación que desempeñan un papel importante en muchos flujos turbulentos de interés práctico. Los modelos de turbulencia RNG $(\mathrm{k}-\varepsilon)$ tienen sus propios términos para incluir los efectos de rotación y de turbulencia.

Asimismo, hay que introducir algunas constantes en el modelo como es el número de Prandtl (Pr), que es un número adimensional proporcional al cociente entre la viscosidad cinemática y la difusividad térmica del aire. Se define como: 


$$
\operatorname{Pr}=\frac{v}{\alpha}=\frac{C_{p} \mu}{K}
$$

donde $v\left(\mathrm{~m}^{2} / \mathrm{s}\right)$ es la viscosidad cinemática del aire; $\alpha\left(\mathrm{m}^{2} / \mathrm{s}\right)$ es la difusividad térmica del aire; $C_{p}\left(\mathrm{Jkg}^{-1} \mathrm{~K}^{-1}\right)$ es el calor específico a presión constante; $\mu(\mathrm{Pa} \cdot \mathrm{s})$ es la viscosidad; y $K\left(\mathrm{Wm}^{-1} \mathrm{~K}^{-1}\right)$ es la conductividad térmica.

El número de Prandtl para los gases es de 0,709 y se considera constante.

Las ecuaciones son discretizadas con el método de volúmenes finitos.

En resumen, se seleccionó como modelo viscoso el modelo turbulento k- $\varepsilon$ (2 ecuaciones), y se activaron las siguientes opciones:

- $\quad$ Modelo k- $\varepsilon:$ RNG

- Tratamiento cercano a la pared: función de pared de no equilibrio

- Efectos de convección natural en $\varepsilon$

- Corrección de la curvatura

- Número de Prandtl constante e igual a 0,709

\subsubsection{Materiales}

ANSYS Fluent proporciona varias opciones para la definición de la densidad del fluido: constante o dependiente de la temperatura.

De todas las opciones que da Fluent, se elige el modelo de Gas Ideal Incompresible para aproximar la relación entre la densidad y el cambio de temperatura (convección natural térmica). Se utiliza la ley de los gases ideales incompresibles, cuando las variaciones de presión son lo suficientemente pequeñas que el flujo es totalmente incompresible pero se quiere utilizar la ley de los gases ideales para expresar la relación entre la densidad y la temperatura, para un problema de convección natural.

Al definir la densidad utilizando la ley del gas ideal incompresible para un flujo incompresible, el solver calculará la densidad como:

$$
\rho=\frac{P}{\frac{R_{g}}{M_{w}} T}
$$

donde $R_{g}$ es la constante universal del gas; $M_{w}$ es el peso molecular del gas; y $P$ es la presión operativa. De esta forma, la densidad sólo depende la presión operativa y no del campo de presión relativa local.

Otros autores utilizan generalmente el modelo de Boussinesq para resolver problemas de convección natural, pero ya ha quedado justificado en el apartado 4.1.2 de este capítulo el uso del modelo de Gas Ideal Incompresible, ya que se concluyó que éste 
modelo mostraba unos mejores resultados que el modelo de Boussinesq utilizado habitualmente.

Se selecciona el modelo de Gas Ideal Incompresible en el apartado de la densidad en el cuadro de diálogo de Materiales. Asimismo, hay que especificar las propiedades físicas del aire y del vidrio para que Fluent pueda tomar los valores necesarios para la resolución de las ecuaciones.

La Tabla 4.3 muestra las propiedades físicas del aire. ANSYS Fluent utilizará estos valores establecidos en sus simulaciones. Las propiedades del aire se consideraron constantes.

\begin{tabular}{|c|c|c|c|c|c|c|c|}
\hline $\begin{array}{c}\text { Calor } \\
\text { específico } \\
C_{p}(\mathrm{~J} / \mathrm{kg} \cdot \mathrm{K})\end{array}$ & $\begin{array}{c}\text { Conductividad } \\
\text { térmica } \\
K(\mathrm{~W} / \mathrm{mK})\end{array}$ & $\begin{array}{c}\text { Coef. } \\
\text { Expansión } \\
\text { térmica } \\
\beta\left(\mathrm{K}^{-1}\right)\end{array}$ & $\begin{array}{c}\text { Coef. de } \\
\text { viscosidad } \\
\mu(\mathrm{kg} / \mathrm{ms})\end{array}$ & $\begin{array}{c}\text { cte. } \\
\text { universal } \\
\text { gases ideales } \\
R g\left(\mathrm{Jkg}^{-1} \mathrm{~K}^{-1}\right)\end{array}$ & $\begin{array}{c}\begin{array}{c}\text { Peso } \\
\text { Viscosidad } \\
(\mathrm{kg} / \mathrm{m} \cdot \mathrm{s})\end{array} \\
\begin{array}{c}\text { Molecular } \\
M_{w} \\
(\mathrm{~kg} / \mathrm{kg} \cdot \mathrm{mol})\end{array}\end{array}$ & $\begin{array}{c}\text { Presión } \\
P(\mathrm{~Pa})\end{array}$ \\
\hline 1006,43 & 0,0242 & 0,00316 & $1,7894 \cdot 10^{-5}$ & 287 & Sutherland & 28,966 & 101.325 \\
\hline
\end{tabular}

Tabla 4.3. Propiedades físicas del aire.

La Tabla 4.4 muestra las propiedades físicas del vidrio sodocálcico plano utilizado en las simulaciones. Sus características fueron tomadas de la Norma Europea 10456:2012 y se consideraron constantes.

\begin{tabular}{|c|c|c|}
\hline $\begin{array}{c}\text { Densidad } \\
\rho\left(\mathrm{kg} / \mathrm{m}^{3}\right)\end{array}$ & $\begin{array}{c}\text { Calor específico } \\
C_{p}(\mathrm{~J} / \mathrm{kg} \cdot \mathrm{K})\end{array}$ & $\begin{array}{c}\text { Conductividad térmica } \\
K(\mathrm{~W} / \mathrm{m} \cdot \mathrm{K})\end{array}$ \\
\hline 2.500 & 750 & 1 \\
\hline
\end{tabular}

Tabla 4.4. Propiedades físicas del vidrio. (UNE-EN ISO 10456).

\subsubsection{Condiciones de la zona de celdas}

ANSYS Fluent permite definir el material de cada zona, ya sea fluido o sólido.

Se clasifican las zonas de las celdas del modelo de la siguiente forma:

- $\quad$ Aire del ambiente exterior: Fluido

- Aire de la cámara: Fluido

- Aire de la habitación (ambiente interior): Fluido

- Vidrio 1 (interior): Sólido

- Vidrio 2 (exterior): Sólido

Para las condiciones de fluido, la única entrada requerida es el tipo de material fluido que contiene la zona para que se puedan utilizar las propiedades adecuadas del material. 
En este caso, el tipo de material fluido es el aire, cuyas propiedades físicas se especifican en el cuadro de diálogo de materiales.

La condición de sólido, implica que en ese grupo de celdas sólo se va a resolver el problema de la conducción del calor, no se resuelven las ecuaciones de flujo. Se supone que no se va a producir la transmisión de calor por convección. Se requiere que se indique el tipo de material que contiene la zona sólida para que se puedan utilizar las propiedades adecuadas del material. En este caso, el tipo de material sólido es el vidrio, y sus propiedades físicas se especifican en el cuadro de diálogo de materiales.

En las condiciones de zona de celdas se abre un cuadro de diálogo en el que da la opción de activar o no la densidad operativa $(\rho)$. Se recomienda especificar la densidad operativa en este caso, ya que se va a resolver un problema de convección natural y se está resolviendo mediante un solver basado en presión. Especificando la densidad operativa se obtienen mejores resultados y una convergencia más rápida. El valor que se introduce es la densidad operativa calculada de la siguiente manera:

$$
\rho=\left(\frac{P}{R_{g} T}\right)
$$

donde $P$ es la presión del aire, $R_{g}$ es la constante universal de los gases ideales, y $T$ es la temperatura del ambiente exterior expresada en grados Kelvin $(\mathrm{K})$.

Cuando se calcula la densidad con la ley de los gases ideales, es importante introducir un valor distinto de cero para la presión operativa. Por defecto la presión operativa es de 101.325 Pa. Para un dominio cerrado, puede utilizarse la ley de los gases ideales incompresibles sólo con una presión operativa fija.

\subsubsection{Condiciones de contorno}

Una vez que se han establecido las condiciones de zona de celdas, se pasa a establecer las condiciones de contorno para cada zona. Para ello se va al cuadro de diálogo de condiciones de contorno donde aparece un listado de las diferentes zonas que contiene el modelo. Además, es muy sencillo identificar las condiciones de contorno visualmente ya que Fluent las muestra de un color diferente para cada una de ellas.

Como en las condiciones de zona de celdas se ha especificado como fluido el aire del ambiente exterior, el aire de la cámara y el aire de la habitación, Fluent los considera como tipo "interior" de zona de la cara interna, y no requiere ninguna especificación adicional. Además, se muestran en color verde para poder identificarlos rápidamente.

Lo mismo ocurre con los vidrios 1 y 2, que al haberlos especificado como sólidos en las condiciones de zona de la celda, Fluent las considera como tipo interior y también se muestran en color verde. 


\section{- Condiciones de contorno del ambiente exterior}

Se estudia el problema en condiciones de invierno y de verano, por lo que hay que introducir unas condiciones distintas para cada caso, y por lo tanto, las condiciones de contorno del ambiente exterior serán diferentes. En primer lugar se especifican las condiciones de contorno del ambiente exterior en condiciones de invierno.

Los límites laterales del modelo se especifican como entrada de presión. Esta condición de contorno se utiliza para definir la presión del fluido en las entradas de flujo. Esta condición puede utilizarse cuando se conoce la entrada de presión pero no la tasa del flujo ni la velocidad. Esta situación puede darse en flujos producidos por convección natural y es adecuada para los cálculos de flujos incompresibles. Fluent las muestra en color azul para poder reconocerlas rápidamente.

En el cuadro de diálogo de la condición de contorno de entrada de presión, aparecen varias pestañas con diversas opciones. En la pestaña del momento se especifica la presión como constante e igual a $0 \mathrm{~Pa}$, y se especifica como método turbulento el de k- $\varepsilon$ en el que se introduce la energía cinética turbulenta constante e igual a $0,01 \mathrm{~m}^{2} / \mathrm{s}^{2}$, y la tasa de disipación constante e igual a $0,01 \mathrm{~m}^{2} / \mathrm{s}^{3}$. En la pestaña térmica se especifica la temperatura total constante e igual a la temperatura del ambiente exterior en ${ }^{\circ} \mathrm{C}$. Como en la presente tesis se estudia el problema tanto para condiciones de invierno como de verano, la temperatura media seca del ambiente exterior será una u otra según el caso que se esté simulando en cada momento. Para establecer la temperatura del ambiente exterior, se toman temperaturas medias en el centro de España tal y como ya se ha explicado en el Capítulo 3, de tal forma que se especifica en $4{ }^{\circ} \mathrm{C}(277 \mathrm{~K})$ para condiciones de invierno, y de $32{ }^{\circ} \mathrm{C}(305 \mathrm{~K})$ para condiciones de verano.

El límite superior se especifica como salida de presión. Esta condición requiere la especificación de una presión estática en el límite de salida. En el cuadro de diálogo de las condiciones de contorno de salida de presión, en la pestaña del momento, se especifica la presión constante e igual a $0 \mathrm{~Pa}$. El software informático da la opción de especificar un conjunto de condiciones de reflujo por si el flujo invirtiese la dirección en el límite de salida de presión durante el proceso de la solución. Así que se especifican las mismas que en la entrada. En la pestaña térmica se especifica la temperatura total constante e igual a la temperatura del ambiente exterior en ${ }^{\circ} \mathrm{C}$, que será distinta según sean condiciones de invierno o de verano. Además, Fluent lo visualiza en color rojo para reconocerlo rápidamente.

El límite inferior del ambiente exterior se especifica como condición de contorno de tipo pared. Esta condición se utiliza para regiones de fluidos y sólidos consolidados. Se quiere calcular la transferencia de calor entre el fluido y la pared, y para ello hay que introducir información adicional para la condición de contorno de pared. En la pestaña del momento se introducen los siguientes parámetros:

- Condiciones de movimiento de pared: se especifica como estacionaria, fija.

- Condiciones de cortante: se especifica sin deslizamiento. Esta es la opción por defecto, e indica que el fluido se pega a la pared y que se mueve con la misma velocidad que ella, aunque en este caso no se mueve. 
- Rugosidad de la pared: constante e igual a 0,5. Es para flujos turbulentos.

En la presente tesis se están resolviendo problemas de transferencia de calor, y como ya se ha explicado anteriormente, la ecuación de la energía debe estar activada. Cuando se está resolviendo la ecuación de la energía, es necesario definir las condiciones de contorno térmicas en las fronteras de la pared. Las condiciones térmicas se introducen en la pestaña térmica del cuadro de diálogo de condiciones de contorno. Existen cinco tipos de condiciones térmicas:

- flujo de calor fijo

- temperatura fija

- transferencia de calor por convección

- transferencia de calor por radiación externa

- transferencia de calor por radiación y convección externa combinada

Para el caso del límite inferior del ambiente exterior, se quiere establecer la condición de adiabático, es decir, que no se produzca la transferencia de calor, que no haya intercambio de calor por este límite. Para ello se elige la condición de flujo de calor fijo y se establece un valor igual a cero. Fluent visualiza en color blanco las condiciones de contorno de tipo pared, de esta forma se reconocen rápidamente.

En condiciones de verano, las condiciones de contorno del ambiente exterior serán justo las inversas a las de invierno porque se introducirá un flujo de calor negativo que se explicará más adelante.

En resumen, las condiciones de contorno del ambiente exterior son las siguientes:

- Límites laterales: Entrada de presión en condiciones de invierno.

Salida de presión en condiciones de verano.

- Límite superior: Salida de presión en condiciones de invierno. Entrada de presión en condiciones de verano.

- Límite inferior: Adiabático, tanto en condiciones de invierno como de verano.

La Figura 4.27 muestra la visualización por colores que da Fluent a las condiciones de contorno para poder identificarlas de forma rápida. 


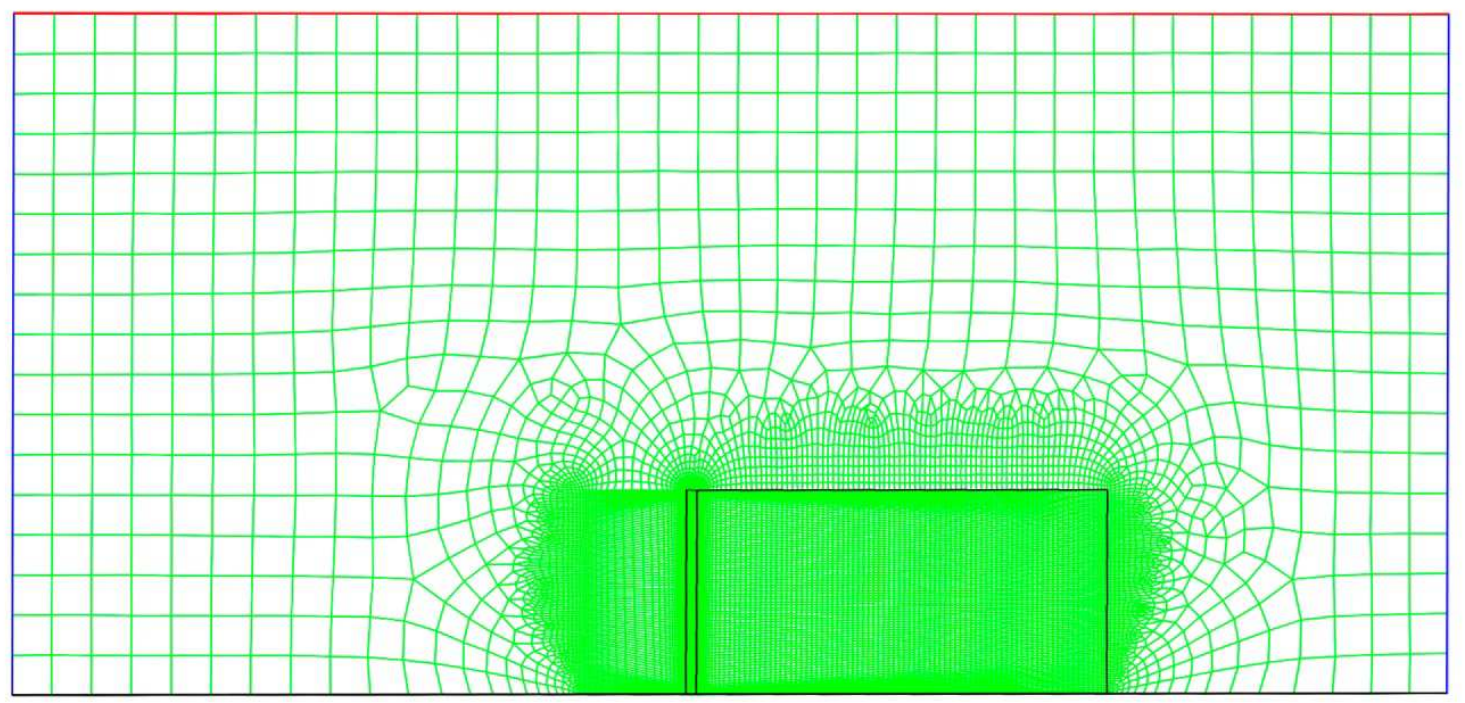

Figura 4.27. Visualización por colores de las condiciones de contorno en Fluent en el escenario de invierno: verde (interior), azul (entrada de presión), rojo (salida de presión), y blanco (pared).

\section{- Condiciones de contorno del ambiente interior}

En la primera parte de la tesis, se estudia la ventilación natural producida por convección natural, es decir, que el movimiento del aire se produce por diferencia de presiones. La diferencia de presiones se produce por diferencia de temperaturas, donde la temperatura es mayor, la presión es mayor; y donde la temperatura es menor, la presión es menor. De tal forma que el flujo de aire va de donde hay menor presión a donde hay mayor presión, produciéndose así el movimiento del aire.

Para poder realizar las simulaciones utilizando Fluent como software informático, hay que provocar el movimiento del aire. Para ello se establecen diferentes temperaturas en el interior de la habitación y en el ambiente exterior, de esta manera se produce un intercambio de calor desde la superficie caliente a la fría provocando así el movimiento del aire del modelo.

Las pequeñas variaciones de temperatura son importantes porque hacen que se consuma más o menos energía para mantener las condiciones de confort en el ambiente interior, y son las que provocan el cambio de densidad del aire que son el origen del movimiento de éste en la habitación, del movimiento del aire en el interior de la cámara cuando está cerrada, y del movimiento del aire exterior cuando no hay viento.

Como se quiere estudiar el problema en condiciones de invierno y de verano, hay que introducir unas condiciones distintas para cada caso. Para ello las condiciones de contorno tienen que ser diferentes, tanto las del ambiente exterior como las del interior de la habitación. Como ya se ha explicado anteriormente, las temperaturas medias secas del ambiente exterior se especifican como $4{ }^{\circ} \mathrm{C}$ para condiciones de invierno, y de $32{ }^{\circ} \mathrm{C}$ para condiciones de verano. Para establecer las condiciones de la habitación, se considera que la temperatura de confort en el interior de la habitación para el caso de invierno es de $20{ }^{\circ} \mathrm{C}(293 \mathrm{~K})$, y de $26{ }^{\circ} \mathrm{C}(299 \mathrm{~K})$ para el caso de verano. 
Para que se produzca el movimiento del aire en Fluent, se simula una fuente de calor en el interior de la habitación. Para ello se especifica un límite de la habitación con la condición de contorno de tipo pared y se introduce una condición térmica. De todas las opciones que da Fluent para definir las condiciones térmicas, se decide utilizar la condición de flujo de calor fijo y a continuación establecer el valor apropiado para el flujo de calor en la superficie de la pared.

Para las condiciones de invierno se considera una fuente de calor uniformemente distribuida en el límite inferior de la habitación que aporta un flujo de calor, mientras que para las condiciones de verano se considera una fuente de calor uniformemente distribuida en el límite superior de la habitación que extrae calor o que aporta un flujo de calor negativo.
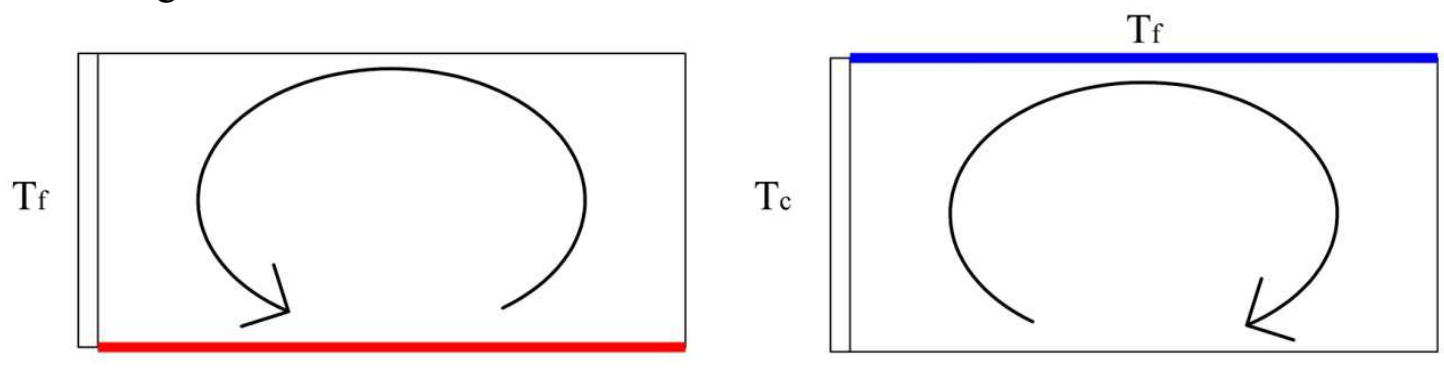

$T_{c}$

Figura 4.28. Fuente de calor uniformemente distribuida en el suelo (condiciones de invierno) y en el techo (condiciones de verano), respectivamente, donde $\mathrm{T}_{\mathrm{f}}$ es la superficie fría y $\mathrm{T}_{\mathrm{c}}$ la superficie caliente.

Para saber qué valor de flujo de calor hay que introducir en las condiciones de contorno, se utiliza la fachada simple piel como caso de referencia. Se calcula el calor necesario a aportar o a extraer para que la temperatura de la habitación se mantenga a $20{ }^{\circ} \mathrm{C}$ (temperatura de confort para las condiciones de invierno) y a $26{ }^{\circ} \mathrm{C}$ (temperatura de confort para las condiciones de verano) tanto para los casos con radiación solar como para los casos sin radiación solar.

El límite derecho de la habitación se especifica con la condición de contorno de tipo pared, y se consideró adiabática. Para ello se especifica con una condición térmica de flujo de calor fijo e igual a cero.

Todos los límites de la habitación fueron especificados con una condición de contorno de tipo pared. En todos ellos se estableció el movimiento de la pared como estacionaria, sin deslizamiento, y con una rugosidad constante e igual a 0,5 . Fluent visualiza en color blanco las condiciones de contorno de tipo pared, de esta forma se reconocen rápidamente.

En resumen, las condiciones de contorno de la habitación son las siguientes:

\section{$\underline{\text { Condiciones de invierno }}$}

- $\quad$ Límite inferior: Pared. Flujo de calor $Q=22 \mathrm{~W} / \mathrm{m}^{2}$

Flujo de calor $Q=17,9 \mathrm{~W} / \mathrm{m}^{2}$, casos con radiación solar

- Límite superior: Pared. Flujo de calor $Q=0 \mathrm{~W} / \mathrm{m}^{2}$. 
- Límite derecho: Pared. Adiabático.

\section{Condiciones de verano}

- Límite inferior: Pared. Flujo de calor $Q=0 \mathrm{~W} / \mathrm{m}^{2}$

- Límite superior: Pared. Flujo de calor $Q=-4,6 \mathrm{~W} / \mathrm{m}^{2}$.

Flujo de calor $Q=-10,5 \mathrm{~W} / \mathrm{m}^{2}$, casos con radiación solar

- Límite derecho: Pared. Adiabático.

\section{- Condiciones de contorno de los vidrios}

Las superficies verticales de vidrio se especifican como paredes sin deslizamiento. Esto indica que el fluido se pega a la pared y que se mueve con la misma velocidad que ella, si está en movimiento.

Al tratarse de un problema en el que también se quiere resolver el problema de la transferencia de calor en el modelo, la ecuación de la energía debe estar activada. Cuando se está resolviendo la ecuación de la energía, es necesario definir las condiciones de contorno térmicas en las fronteras de la pared.

La transferencia de calor puede ocurrir mediante tres mecanismos: conducción, convección y radiación. Dependiendo del problema, ANSYS Fluent resolverá una variante de la ecuación de la energía que tiene en cuenta el método de transferencia de calor especificado.

Fluent puede tener en cuenta la transferencia de calor por conducción en el modelo dentro de las condiciones de contorno de pared. Permite modelar de forma conveniente la conducción de calor en paredes donde el espesor de las mismas es pequeño en relación con la geometría general. Como ya se ha explicado anteriormente, las paredes de vidrio fueron malladas con $6 \mathrm{~mm}$ de espesor y se especifican como sólidas, lo que conduce a mallas con alta esbeltez y a un aumento significativo del número total de celdas.

La habitación se encuentra dentro de un ambiente exterior definido, esto implica que los dos paños de vidrio tienen regiones fluidas a ambos lados. Si la zona de la pared tiene una región fluida o sólida a cada uno de los lados, se denomina "pared de dos lados". Cuando Fluent detecta una malla con este tipo de zona de la pared, crea automáticamente una zona de "sombra", de modo que cada lado de la pared es una zona de pared distinta. La Figura 4.29 muestra de forma esquemática el concepto de pared de dos lados. 


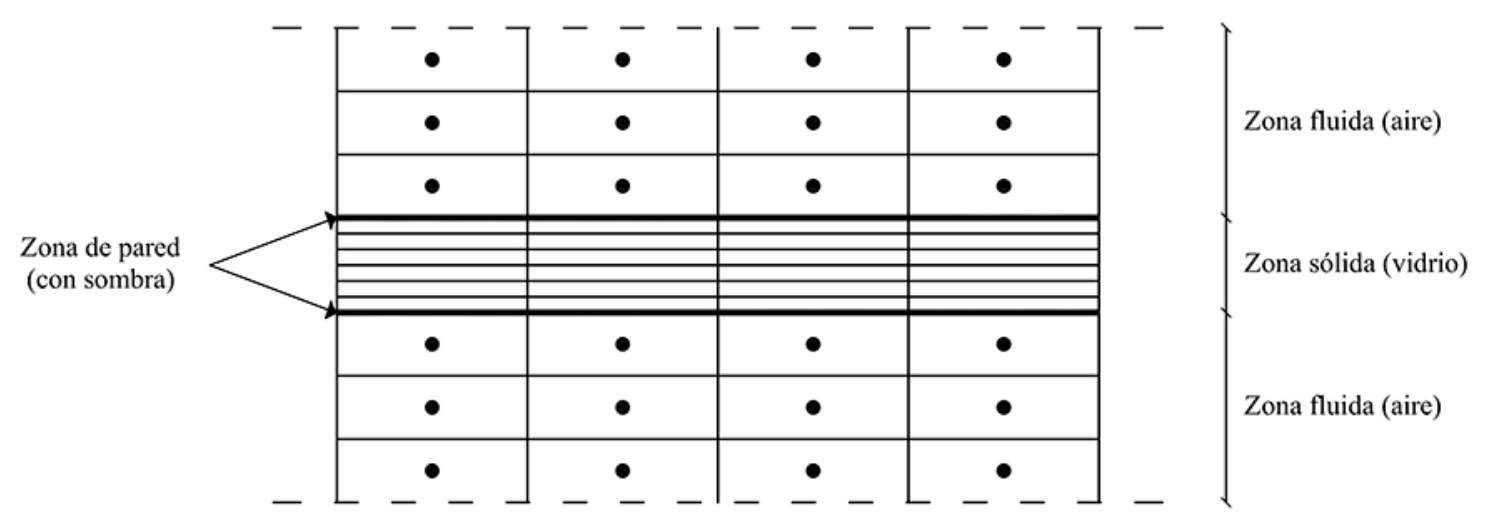

Figura 4.29. Detalle del vidrio como pared de dos lados.

En el listado de las diferentes superficies, aparecerá esta nueva pared de zona de sombra, y en el cuadro de diálogo de la pared se mostrará el nombre de la zona de sombra. Se pueden especificar diferentes condiciones térmicas en cada zona, o acoplar las dos zonas.

En este caso, para que el calor se transmitiese por conducción de un lado a otro de las superficies del vidrio, hubo que acoplar los dos lados de la pared. Asimismo, al acoplar ambas paredes, también calculará la distribución de temperaturas en el espesor del vidrio. Para ello, se selecciona la opción de acoplamiento en la pestaña de condiciones térmicas. Esta opción sólo aparece cuando la pared es de dos lados. Si se acoplan ambos lados, ya no se requieren condiciones de contorno térmicas adicionales, ya que el solucionador calculará la transferencia de calor directamente de la solución en las celdas adyacentes.

Sin embargo, puede especificarse el tipo de material de la pared, el espesor, y la tasa de generación de calor para los cálculos de resistencia térmica de la pared delgada. Los parámetros que se establezcan para un lado de la pared se asignarán automáticamente a su zona de sombra correspondiente por estar acopladas.

En este caso, el material de la pared de vidrio ya se ha especificado en el apartado de materiales, de esta forma, en la pestaña de condiciones térmicas de los vidrios del apartado de las condiciones de contorno, Fluent los entiende como materiales sólidos con unas propiedades físicas concretas.

En los casos que no se considera la radiación solar, como los vidrios ya están mallados con un espesor de $6 \mathrm{~mm}$, no hay que especificar el espesor de la pared y se deja con valor igual a cero. También se puede especificar la tasa de generación de calor, aunque en este caso es igual a cero.

Sin embargo, en los casos en los que sí se considera la radiación solar, hay que especificar que el espesor de la pared es igual a $t_{p}=6 \mathrm{~mm}$ para que Fluent tenga en cuenta el índice de generación de calor. El cálculo de los valores de índice de generación de calor ya se ha explicado anteriormente en el Capítulo 3.

En resumen, los valores de índice de generación de calor que hay que introducir en cada vidrio son los siguientes: 
Invierno:

- Vidrio 1(interior): $Q_{r}=1.870,37 \mathrm{~W} / \mathrm{m}^{3}$

- Vidrio 2 (exterior): $Q_{r}=2.571,75 \mathrm{~W} / \mathrm{m}^{3}$

$\underline{\text { Verano: }}$

- Vidrio 1 (interior): $Q_{r}=2.166,66 \mathrm{~W} / \mathrm{m}^{3}$

- Vidrio 2 (exterior): $Q_{r}=2.979,16 \mathrm{~W} / \mathrm{m}^{3}$

Todas las demás superficies horizontales de vidrio se consideraron adiabáticas, para ello se establece una condición de flujo de calor igual a cero.

\subsubsection{Valores de referencia}

El cuadro de diálogo de valores de referencia permite establecer las cantidades de referencia utilizadas para calcular las variables de campo de flujo normalizadas. También permite especificar la zona de referencia para el post-proceso de velocidades relativas en problemas con zonas en movimiento.

Se dejan todos los valores de referencia por defecto a excepción de los siguientes:

- Densidad:

$\rho=1,20494 \mathrm{~kg} / \mathrm{m}^{3}$, calculada con la temperatura de confort en condiciones de invierno $\left(20^{\circ} \mathrm{C}\right)$.

$\rho=1,18076 \mathrm{~kg} / \mathrm{m}^{3}$, calculada con la temperatura de confort en condiciones de verano $\left(26^{\circ} \mathrm{C}\right)$.

- Longitud característica: $L(\mathrm{~m})$, ancho de la cámara de aire. Varía según el caso.

- Presión: $\mathrm{P}=101.325 \mathrm{~Pa}$

- Temperatura:

$20{ }^{\circ} \mathrm{C}$, temperatura de confort en condiciones de invierno.

$26^{\circ} \mathrm{C}$, temperatura de confort en condiciones de verano.

- Zona de referencia: fluido de la cámara de aire. Para los flujos relacionados con múltiples zonas en movimiento, hay que seleccionar la zona de referencia para el post-proceso de velocidades relativas y cantidades relacionadas. En este caso, se selecciona el aire de la cámara.

\subsubsection{Método de solución}

Permite especificar diversos parámetros asociados con el método de la solución que va a ser utilizado en el cálculo. 
Para el acoplamiento de presión-velocidad se elige el esquema SIMPLE, ya que al elegir el solver basado en presión, se decide resolverlo mediante el algoritmo segregado, es decir, que las ecuaciones se resuelven una tras otra. SIMPLE es uno de los algoritmos segregados que dispone Fluent.

Como esquema de discretización espacial se elige el gradiente basado en celdas de mínimos cuadrados (least squares cell based). El gradiente es necesario para la construcción de los valores escalares en las caras de las celdas y también para el cálculo de términos de difusión secundarios y derivadas de la velocidad.

Como ya se ha justificado anteriormente, se escoge el esquema de discretización de presión de body force weighted. Este esquema calcula la presión de la cara asumiendo que el gradiente de la diferencia entre la presión y las fuerzas másicas es constante. Este esquema funciona bien si las fuerzas másicas se conocen a priori en las ecuaciones del momento, como para casos de convección natural.

Además, Fluent permite elegir el esquema de discretización para cada ecuación y también la precisión de primer o de segundo orden. Cuando el flujo está modelado con una malla de cuadriláteros, la discretización de primer orden es aceptable y además converge de forma rápida; pero para obtener resultados más precisos, se recomienda la discretización de segundo orden, especialmente para flujos complejos. A menudo, inicialmente se utiliza la de primer orden para que la solución comience a converger, y después se utiliza la de segundo orden para la solución final.

\subsubsection{Control de la solución}

Permite establecer los parámetros comunes de la solución. Contiene los factores de relajación para todas las ecuaciones que se van a resolver mediante el solver basado en presión. Por defecto Fluent otorga unos valores de relajación que van de 0 a 1 a las siguientes variables: presión, densidad, fuerzas másicas, cantidad de movimiento, energía cinética turbulenta, tasa de disipación turbulenta, viscosidad turbulenta y energía. Generalmente, se comienza con los valores por defecto, pero al cabo de varias iteraciones es necesario bajar algún factor de relajación para que la solución termine de converger.

\subsubsection{Monitores}

El cuadro de diálogo de monitores permite configurar la herramienta para realizar el seguimiento de la convergencia de la solución de forma dinámica chequeando los residuos, las estadísticas y las integrales de volumen y superficie, entre otros.

La convergencia global se alcanza cuando se verifica el balance de transferencia de calor total, es decir, cuando el flujo de calor proporcionado es el mismo que sale a través del paño del vidrio interior. También cuando el valor de los residuos son como mínimo menores que los siguientes: $10^{-3}$ para las ecuaciones de continuidad, velocidad en $\mathrm{x}$, velocidad en $\mathrm{y}, \mathrm{k}$ y $\varepsilon ; \mathrm{y} 10^{-6}$ para la ecuación de la energía. Este criterio de convergencia se realiza con el fin de asegurar buenas soluciones convergentes. 
En la presente tesis interesa conocer el valor de la temperatura media en la habitación, así que se crea un monitor de superficie en el centro de la habitación y se le dice a Fluent que muestre la temperatura media en ese punto a medida que va calculando. De esta forma, se puede ir controlando la solución.

\subsubsection{Inicialización}

Antes de empezar a calcular, se inicializa el caso. Se realiza una inicialización manual con los siguientes valores:

- Presión: $0 \mathrm{~Pa}$

- Velocidad en x: $0 \mathrm{~m} / \mathrm{s}$

- Velocidad en y: $0 \mathrm{~m} / \mathrm{s}$

- Energía cinética turbulenta: $1 \mathrm{~m}^{2} / \mathrm{s}^{2}$

- Tasa de disipación turbulenta: $1 \mathrm{~m}^{2} / \mathrm{s}^{3}$

- Temperatura:

- $\quad 4{ }^{\circ} \mathrm{C}$ (temperatura media seca del ambiente exterior en condiciones de invierno)

- $\quad 32{ }^{\circ} \mathrm{C}$ (temperatura media seca del ambiente exterior en condiciones de verano)

\subsubsection{Cálculo}

Este cuadro de diálogo permite iniciar las iteraciones del solver. Para los cálculos de flujo estacionario se establece el número de iteraciones a realizar, que generalmente rondan entre las 100.000 y las 150.000 iteraciones.

Se chequea el caso, y si no hay ninguna recomendación, se empieza el cálculo. Se puede parar el cálculo en cualquier momento del proceso.

\subsection{FLUJO DOMINADO POR VIENTO}

\subsubsection{Diseño}

Se utiliza la geometría del estudio anterior por convección natural, pero hay que realizar algunos cambios en el ambiente exterior, así que se utiliza el programa de diseño design modeler para dibujar la geometría 2D.

Lo único que cambia en el proceso de diseño son las dimensiones del dominio computacional, así que se dibuja el ambiente exterior como líneas sueltas con la dimensión correspondiente definida en la geometría de 126 × $30 \mathrm{~m}$, y se crea una superficie del ambiente exterior.

El resto de superficies, la geometría de la habitación, los vidrios, la cámara de aire y la superficie auxiliar próxima a las paredes de los vidrios, no varían, permanece igual y sin cambios. 
Resumiendo, hay seis superficies en total: el ambiente exterior, la habitación, el vidrio interior, la cámara de aire, el vidrio exterior y la superficie auxiliar. A todas ellas se les ha dado un nombre para poder identificarlas más adelante en Fluent. La Figura 4.30 muestra el nuevo diseño de la geometría del ambiente exterior.

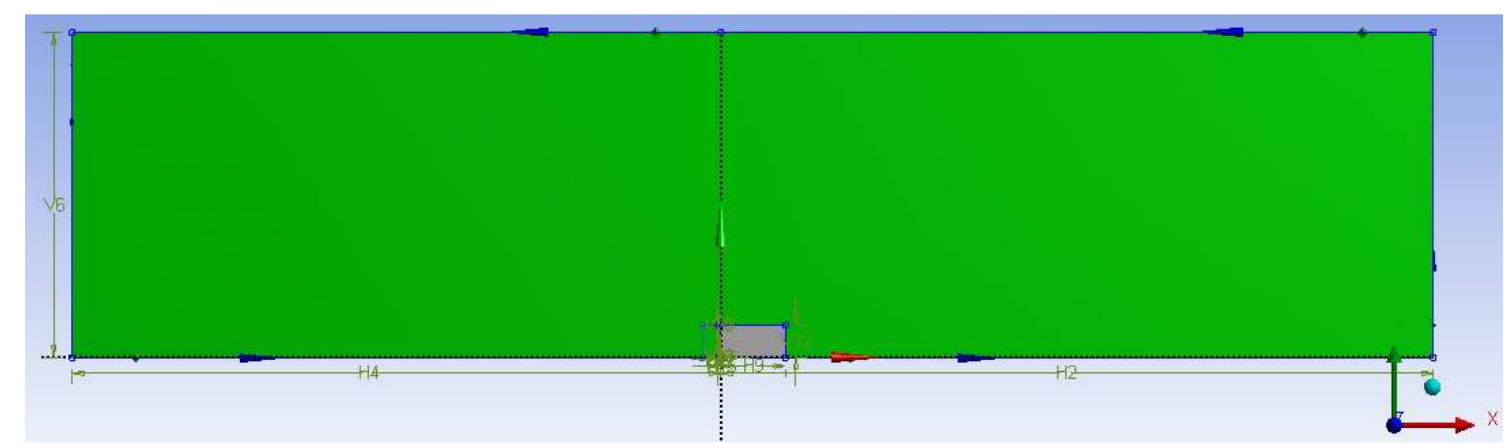

Figura 4.30. Diseño de la geometría del dominio computacional.

Una vez diseñada la geometría 2D, se exporta al programa de mallado (meshing) para diseñar y crear la malla.

\subsubsection{Mallado}

Una vez modificada la geometría del modelo de estudio en el Design Modeler, la del espacio exterior que la rodea, se procede al mallado del mismo.

Primero se comprueba que la geometría se ha importado correctamente, y que las seis superficies creadas en el design modeler están con su nombre correspondiente.

Como ya se ha explicado anteriormente, se crea una malla bidimensional. Se malla el campo fluido, es decir, el aire de la habitación, el aire de la cámara y el aire del ambiente exterior; y también se mallan los vidrios que se especificarán como sólidos.

Las características de la malla son las mismas que en los casos de estudio anteriores:

- Tipo de malla: No estructurada

- Método de mallado: Cuadriláteros

- Configuración física: CFD

- Solver: Fluent

- Tamaño de los elementos:

- Tamaño de malla: fino

- Tamaño mínimo: $10^{-3} \mathrm{~m}$

- Tamaño máximo: valor por defecto en $m$

- Tasa de crecimiento: 1,20 (valor por defecto)

- Longitud mínima del borde: $6 \cdot 10^{-3} \mathrm{~m}$

- Suavizado: medio

- Transición: suave. 
Controla el ritmo de crecimiento de las celdas.

- Grado de refinamiento: fino (de $12^{\circ}$ a $36^{\circ}$ ).

Establece el grado de refinamiento de los bordes basado en la curvatura.

- Funciones de tamaño avanzadas: basado en curvatura y proximidad.

- Ángulo normal de curvatura: $18^{\circ}$ (valor por defecto)

Una vez definidos los detalles de la malla, se procede a dar tamaño a las celdas de las diferentes superficies:

1. Aire del ambiente exterior. El mallado se genera automáticamente con el tipo de mallado que se especifique.

El tamaño de las celdas del resto de superficies: aire del interior de la habitación, vidrios, aire de la cámara, cámara de aire, habitación y superficie auxiliar; no varían, permanecen igual y sin cambios.

Una vez que se le ha dado tamaño a las celdas de las diferentes superficies, se genera la malla y se comprueba la calidad del mismo. La Figura 4.31 muestra el resultado del mallado.

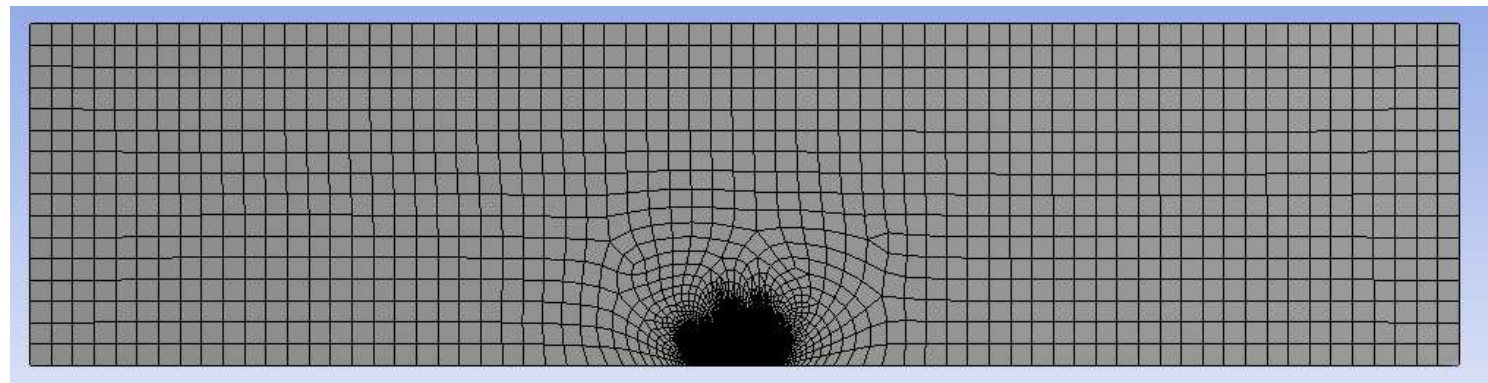

Figura 4.31. Mallado del volumen de control.

Después se analizan los resultados obtenidos en el apartado de datos estadísticos:

- Número de nodos: 22.512

- Número de elementos: 22.349

- Deformación (skewness):

- Mínimo: $1,3 \cdot 10^{-10}$

- Máximo: 0,9059

- Valor medio: 0,1382

- Desviación típica: 0,2082

A continuación se exporta la malla a Fluent para poder introducir las condiciones de partida (set up) y así poder calcular. 


\subsubsection{Fluent}

Todos los parámetros que hay que introducir en Fluent son los mismos que los introducidos en los casos de flujo dominado por convección natural, sólo van a variar las condiciones de contorno y los valores de referencia.

Por lo tanto, no se explicarán los siguientes parámetros ni condiciones de partida ya que son los mismos explicados anteriormente en el apartado de flujo dominado por convección natural: general, modelo, materiales, condiciones de zona de la celda, método de solución, control de la solución, monitores, inicialización y cálculo.

A continuación se explican las condiciones de contorno introducidas en el nuevo modelo para que tenga en cuenta los efectos del viento.

\subsubsection{Condiciones de contorno}

Se establecen diferentes condiciones de contorno para cada zona respecto al caso de convección natural. El objetivo es establecer unas condiciones de contorno en las paredes del ambiente exterior que simulen el viento dentro del dominio computacional.

En el cuadro de diálogo de condiciones de contorno aparece un listado de las diferentes zonas que contiene el modelo.

Como en las condiciones de zona de celdas se ha especificado como fluido el aire del ambiente exterior, el aire de la cámara y el aire de la habitación, Fluent los considera como tipo "interior" de zona de la cara interna, y no requiere ninguna especificación adicional. Además, se muestran en color verde para poder identificarlos rápidamente.

Lo mismo ocurre con los vidrios 1 y 2 , que al haberlos especificado como sólidos en las condiciones de zona de celdas, Fluent las considera como tipo interior y también se muestran en color verde.

\section{- Condiciones de contorno del ambiente exterior}

Se estudia el problema en condiciones de invierno y de verano. Las condiciones de contorno serán exactamente las mismas, simplemente se cambia el valor de la temperatura del exterior que será de $4^{\circ} \mathrm{C}(277 \mathrm{~K})$ para las condiciones de invierno, y $32^{\circ} \mathrm{C}(305 \mathrm{~K})$ para las condiciones de verano.

La pared izquierda se especifica como entrada de velocidad (velocity-inlet). Esta condición de contorno se utiliza para definir la velocidad del flujo en la entrada del mismo. Esta condición es aplicable a flujos incompresibles. Fluent la muestra en color azul para reconocerla rápidamente.

Se define la entrada de velocidad especificando la magnitud de la velocidad en $\mathrm{m} / \mathrm{s}$ y la dirección del flujo. Al tratarse de un modelo en dos dimensiones, sólo hay que definir la velocidad en los ejes $\mathrm{X}$ e $\mathrm{Y}$, que será $\mathrm{X}=1, \mathrm{Y}=0$. En el caso de viento en la fachada de barlovento se indicarán unos valores en $X$ positivos, y en el caso de viento en la fachada 
de sotavento unos valores de $\mathrm{X}$ negativos, para que el viento vaya en una dirección y en la contraria.

Para establecer la temperatura media seca del ambiente exterior, se especificarán en la pestaña térmica $4{ }^{\circ} \mathrm{C}(277 \mathrm{~K})$ para las condiciones de invierno, y $32{ }^{\circ} \mathrm{C}(305 \mathrm{~K})$ para las condiciones de verano.

La pared superior también se especifica como entrada de velocidad.

La pared derecha se especifica como salida de presión (pressure-outlet). Esta condición de contorno requiere la especificación de una presión estática en el límite de salida. En el cuadro de diálogo de las condiciones de contorno de salida de presión, en la pestaña de cantidad de movimiento, se especifica la presión manométrica (gauge pressure) constante e igual a $0 \mathrm{~Pa}$, y se selecciona como método turbulento el de k-E. El programa da la opción de especificar un conjunto de condiciones del flujo reverso en el caso de que entrase fluido en las iteraciones iniciales. Así que se especifican las mismas que en la entrada. En la pestaña térmica se especifica la temperatura total constante e igual a la temperatura media seca del ambiente exterior en ${ }^{\circ} \mathrm{C}$, que será de $4^{\circ} \mathrm{C}(277 \mathrm{~K})$ para las condiciones de invierno, y $32^{\circ} \mathrm{C}(305 \mathrm{~K})$ para las condiciones de verano. Fluent lo visualiza en color rojo para reconocerlo rápidamente.

La pared inferior se especifica como condiciones de contorno de tipo pared. En la pestaña del momento se introducen los siguientes parámetros:

- Condiciones de movimiento de pared: se especifica como estacionaria, fija.

- Condiciones de cortante: se especifica sin deslizamiento. Esta es la opción por defecto, e indica que el fluido se pega a la pared y que se mueve con la misma velocidad que ella, aunque en este caso no se mueve.

- Rugosidad de la pared: constante e igual a 0,5. Es para flujos turbulentos.

Se considera adiabático, es decir, que no hay transferencia de calor por ese límite. Para ello se elige la condición de calor fijo y se establece un valor igual a 0 . Fluent visualiza en color blanco las condiciones de tipo pared.

En resumen, las condiciones de contorno del ambiente exterior son las siguientes:

- Pared izquierda: Entrada de velocidad

- Pared superior: Entrada de velocidad

- Pared derecha: Salida de presión

- Pared inferior: Adiabática

La Figura 4.32 muestra la visualización por colores que da Fluent a las condiciones de contorno para poder identificarlas de forma rápida. 


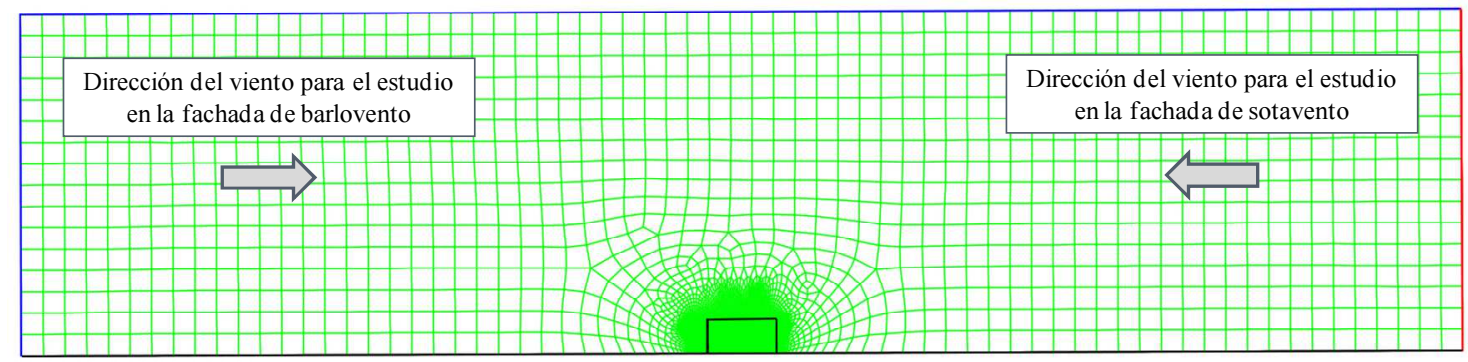

Figura 4.32. Visualización por colores de las condiciones de contorno en Fluent: verde (interior), azul (entrada de velocidad), rojo (salida de presión), y blanco (pared).

\section{- Condiciones de contorno del ambiente interior}

Las condiciones de contorno de la habitación son las mismas que las introducidas para las simulaciones de flujo conducido por convección natural. Recordar que el movimiento del aire en el interior de la habitación se produce por diferencia de temperaturas, por lo que se simula una fuente de calor en el interior de la habitación, que estará en la pared inferior en las simulaciones de invierno y en la pared superior en las simulaciones de verano.

\section{- Condiciones de contorno de los vidrios}

Las condiciones de contorno de los vidrios son las mismas que las introducidas para las simulaciones de flujo conducido por convección natural. Recordar que como también se quiere resolver el problema de la transferencia de calor en el modelo, la ecuación de la energía debe estar activada. Para que Fluent tenga en cuenta la transferencia de calor por conducción en el modelo, hay que acoplar ambas paredes de cada vidrio y especificar que el espesor de la pared es de $t_{p}=6 \mathrm{~mm}$ en los casos en los que se considera la radiación solar.

\subsubsection{Valores de referencia}

Se dejan todos los valores de referencia por defecto a excepción de los siguientes:

- Densidad:

$\rho=1,20494 \mathrm{~kg} / \mathrm{m}^{3}$, calculada con la temperatura de confort en condiciones de invierno $\left(20^{\circ} \mathrm{C}\right)$.

$\rho=1,18076 \mathrm{~kg} / \mathrm{m}^{3}$, calculada con la temperatura de confort en condiciones de verano $\left(26^{\circ} \mathrm{C}\right)$.

- Longitud característica: $L=0,1 \mathrm{~m}$

- Presión: $\mathrm{P}=101.325 \mathrm{~Pa}$

- Temperatura:

$20^{\circ} \mathrm{C}$, temperatura de confort en condiciones de invierno.

$26^{\circ} \mathrm{C}$, temperatura de confort en condiciones de verano. 
Velocidad: varía según el caso. Puede ser $v=1 ; 2,5 ; 5 ; 10 ;$ ó $20 \mathrm{~m} / \mathrm{s}$.

- Zona de referencia: fluido de la cámara de aire.

\subsection{VALIDACIÓN II. VALIDACIÓN DEL MODELO NUMÉRICO DE FACHADA DOBLE PIEL ACRISTALADA INCLUYENDO LA RADIACIÓN SOLAR}

Una vez realizado el modelo numérico de fachada doble piel acristalada incluyendo la radiación solar para el estudio con CFD, se procede a la validación del mismo. Para ello, se localizó una investigación de similares características publicada en una revista científica de impacto para asegurarse de que ya estuviese validada y revisada por un comité científico.

El objetivo era reproducirla en Fluent con el modelo CFD creado incluyendo la radiación solar. Si se alcanzaban los mismos resultados que los obtenidos por los autores y se observaba un buen comportamiento del flujo de aire, esto implicaría que quedaba validado el modelo y que las simulaciones podían continuar.

Se utiliza la investigación de He et al. (2011) publicada en el artículo "Double skin facades in the hot summer and cold winter zone in China: Cavity open or closed?" como caso de referencia con el objetivo anteriormente descrito. A continuación se describe dicha investigación.

\subsubsection{Descripción de la investigación de referencia}

El modelo numérico fue validado utilizando los resultados de $\mathrm{He}$ et al. (2011) que investigaron, tanto por análisis teórico como por simulaciones CFD, la ventilación natural debida a la convección natural y a la transferencia de calor en un sistema de fachada de un edificio en Hangzhou (China) incluyendo la radiación solar.

Se escogió esta investigación como caso de referencia para el modelo de validación porque es un caso de convección natural con una geometría sencilla y en un entorno similar al del presente estudio. Para la validación se utiliza el modelo de gas ideal incompresible porque da mejores predicciones del modelo de Boussinesq, tal y como ya se había demostrado anteriormente.

La Figura 4.33 muestra el diseño de la ventana doble que consiste en un panel de vidrio simple en el exterior y un panel de vidrio doble en el interior separados por una cámara de aire de 0,20 $\mathrm{m}$ de ancho. El aire del interior de la cámara no fue considerado. El modelo tenía 3,07 $\mathrm{m}$ de altura y tenía una abertura en el extremo superior y otra en el extremo inferior del paño simple de $0,06 \mathrm{~m}$ de altura. 


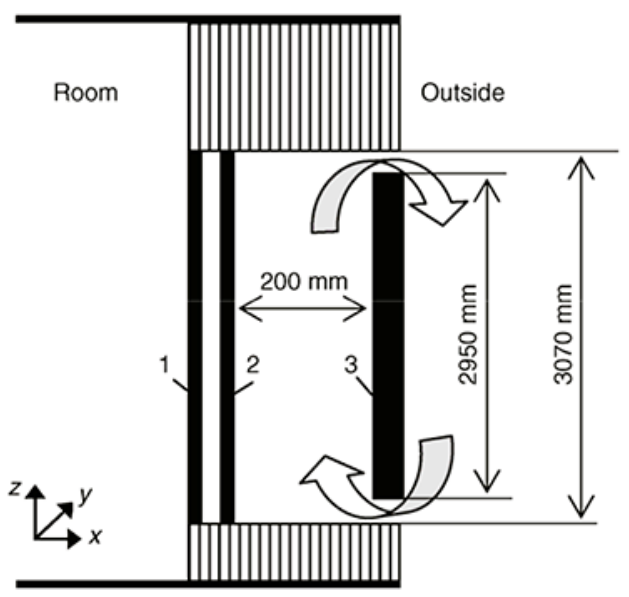

Figura 4.33. Esquema de la ventana doble. "Double skin facades in the hot summer and cold winter zone in China: cavity open or closed?". He et al., 2011.

Se simularon 12 casos. Se examinó la diferencia de rendimiento entre la fachada doble piel y la ventana doble en diferentes escenarios, como el de invierno y el de verano, y con y sin radiación solar. Examinaron numéricamente el comportamiento térmico de las ventanas dobles en condiciones de verano $\left(>30^{\circ} \mathrm{C}\right)$ y en condiciones de invierno (alrededor de $4{ }^{\circ} \mathrm{C}$ ). Se simularon cuatro casos adicionales para examinar la influencia de la ventilación en el rendimiento térmico.

A continuación analizaron los beneficios energéticos de la fachada doble piel y de la ventilación en el diseño de la cámara. Los resultados de la simulación mostraron que la fachada doble piel era más eficiente energéticamente que la ventana doble en condiciones de verano independientemente de si la cámara está abierta o cerrada. Estas ventajas energéticas se debían más bien al paño adicional que reducía la transmisión solar que a la ventilación de la cámara. Las simulaciones mostraron que la ventilación podía ahorrar energía en un $8 \%$ anual bajo las condiciones climáticas de Hangzhou.

\subsubsection{Comprobación}

Con el propósito de validar el modelo, se utilizó la geometría creada en la presente tesis con ancho de cámara de aire de 0,20 m (como en el caso de referencia), se malló y se exportó a Fluent.

Se reprodujo un caso en condiciones de invierno, con cámara cerrada y con radiación solar, así que se especifica una temperatura exterior de $4{ }^{\circ} \mathrm{C}$. Como ya se ha explicado anteriormente, se considera que la temperatura de confort en el interior de la habitación para el caso de invierno es de $20^{\circ} \mathrm{C}$.

La simulación sólo se realiza por convección natural, así que para que se produjese el movimiento del aire por diferencia de temperaturas, había que simular una fuente de calor uniformemente distribuida en el límite inferior de la habitación que aportase calor.

A continuación se describen las condiciones de contorno introducidas en cada superficie: 
Ambiente exterior

- Límites laterales: entrada de presión

- Límite superior: salida de presión

- Límite inferior: pared. Adiabático

$\underline{\text { Ambiente interior }}$

- Límite inferior: pared. Flujo de calor $Q=10 \mathrm{~W} / \mathrm{m}^{2}$

- Límite superior: pared. Adiabático

- Límite derecho: pared. Adiabático

- Vidrios interior y exterior: pared. Como ya se ha explicado anteriormente, ya están mallados con un espesor de $6 \mathrm{~mm}$, tienen las propiedades físicas del vidrio, y se acoplan ambas caras para que pueda producirse la transferencia de calor por conducción.

- Todas las demás superficies son adiabáticas.

Se calcula, y una vez que la solución converge, se analizan los resultados:

- Los resultados demuestran un movimiento del flujo estable.

- Se produce la transferencia de calor tanto por radiación como por conducción entre los vidrios y convección.

- La cantidad de energía aportada es igual a la que sale por el vidrio.

- El flujo de calor que hay que aportar para que la temperatura interior permaneciese a la temperatura de confort, concordaba con la del artículo con un error inferior al $2 \%$.

También se analizan los diferentes tipos de gráficos como: contorno de presión y temperatura, vectores velocidad coloreados por velocidad y por temperatura, XY Plot de temperatura media en el centro de la habitación y en las caras de los vidrios, y el Wall Yplus en el entorno de los vidrios, entre otros.

Se puede comprobar que el modelo funciona bien y que se produce la transferencia de calor observando los siguientes gráficos:

- Gráfico de vectores velocidad coloreados por temperatura (Figura 4.34): se observa mayor temperatura en el límite inferior de la habitación porque está la fuente de calor, menor temperatura en el ambiente exterior $\left(4^{\circ} \mathrm{C}\right)$, la temperatura media a la que se estabiliza la habitación $\left(20,68^{\circ} \mathrm{C}\right)$, y el aumento progresivo de la temperatura en la cámara de aire. 


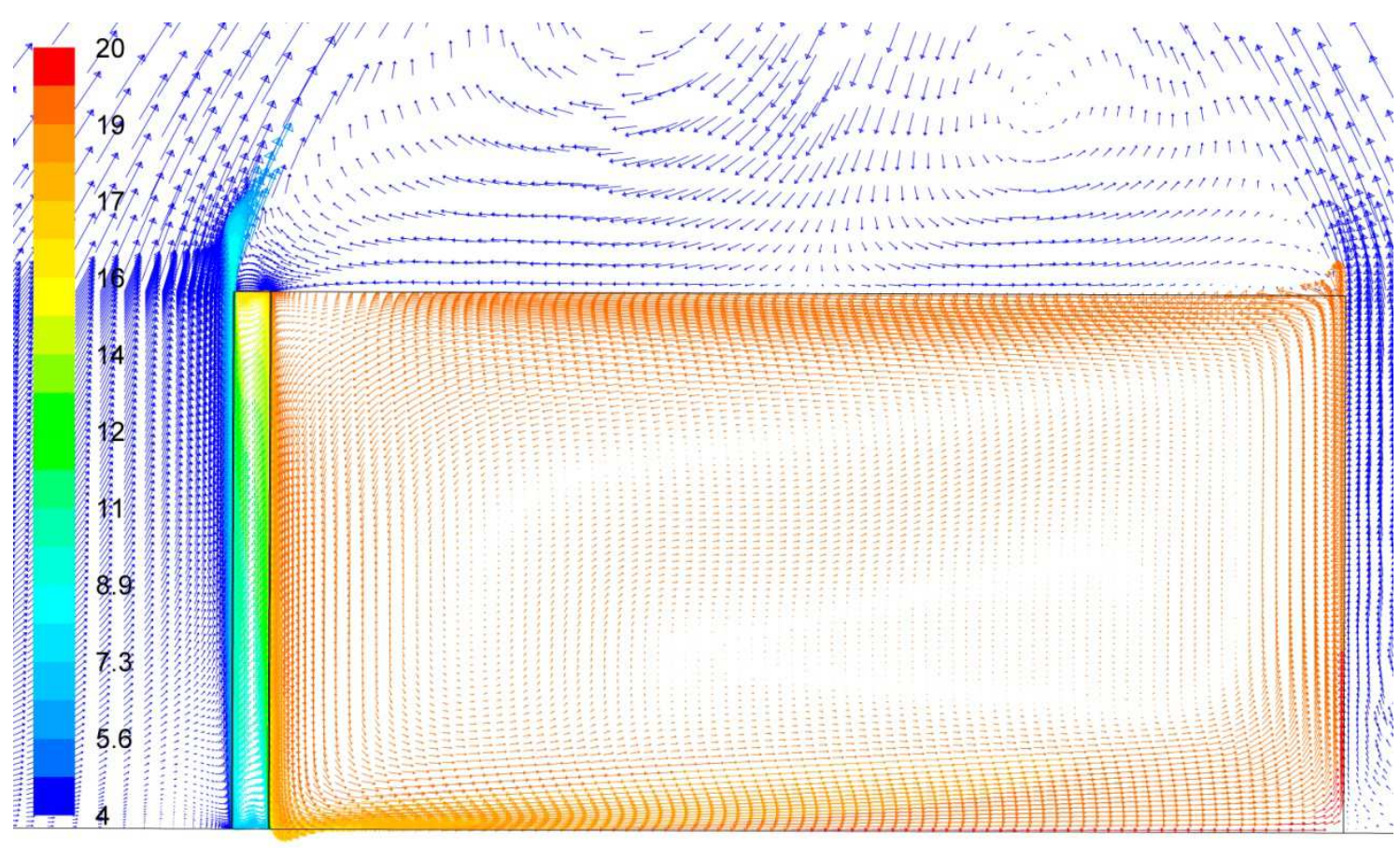

Figura 4.34. Vectores velocidad coloreados por temperatura $\left({ }^{\circ} \mathrm{C}\right)$.

- Gráficos de vectores velocidad coloreados por velocidad (Figura 4.35): se observa que la solución ha convergido porque no hay remolinos ni burbujas de aire. También se aprecia que el movimiento del aire es el adecuado porque sube por la pared caliente y baja por la fría tanto en el interior de la habitación como en la cámara.

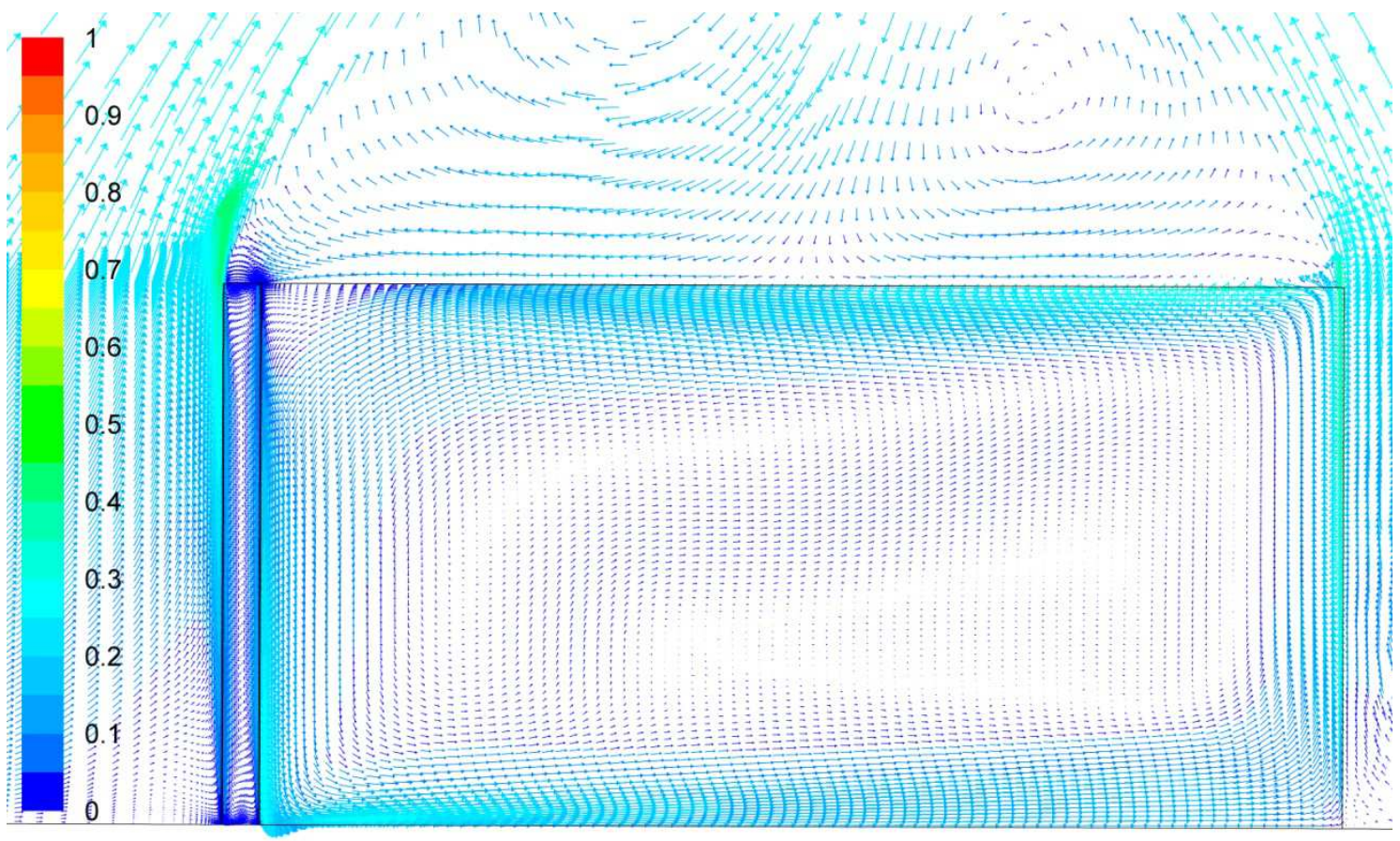

Figura 4.35. Vectores velocidad coloreados por velocidad $(\mathrm{m} / \mathrm{s})$. 
Por todo lo anterior, queda comprobado que los resultados concuerdan con los de la investigación de referencia y queda justificada la validación del modelo, de manera que las simulaciones pueden continuar.

\subsection{CONCLUSIONES}

En primer lugar se realiza una validación inicial del modelo de convección natural de gases utilizando una investigación científica publicada en revista de impacto de geometría sencilla y en la que sólo interviene la convección natural. Se reproduce este caso de referencia con Fluent, se estudia la influencia del mallado y se analiza el comportamiento del flujo de aire y los resultados para los distintos métodos de cálculo.

De la modelización fluidodinámica de la fachada doble piel para el cálculo numérico se concluye lo siguiente:

- Se utiliza como software de simulación ANSYS Fluent ${ }^{\circledR}$ (versión 15.0.7).

- Creación de la geometría 2D en el programa de diseño (design modeler).

- Mallado del modelo con la herramienta meshing. Se crea una malla bidimensional y se malla el campo fluido (el aire de la habitación (ambiente interior), de la cámara y del ambiente exterior), y los vidrios como sólidos para que se resuelva la transferencia de calor por conducción entre el aire y los vidrios.

Las características generales de la malla son las siguientes:

- Tipo de malla: No estructurada

- Método de mallado: Cuadriláteros

- Configuración física: CFD

- Solver: Fluent

- Tamaño general de las celdas: medio

Hay mayor número de celdas en la región cercana a las paredes de los vidrios y en la cámara para poder estudiar de forma más precisa la transferencia de calor y el movimiento del flujo de aire en esa zona.

- Convección Natural: Los parámetros que se han empleado para el cálculo con Fluent de las simulaciones de flujo dominado por convección natural son los siguientes:

\section{Solver :}

- Tipo: basado en presión

- Formulación de la velocidad: absoluta

- Tiempo: estacionario

- Espacio 2D: plano

- Gravedad: $X=0 \mathrm{~m} / \mathrm{s}^{2} ; Y=9,8 \mathrm{~m} / \mathrm{s}^{2}$ 
- Unidades: Temperatura $\left({ }^{\circ} \mathrm{C}\right)$

Modelo:

- Activar la ecuación de la energía para resolver la transferencia de calor.

- Se seleccionó como modelo viscoso el modelo turbulento k- $\varepsilon$ (2 ecuaciones), y se activaron las siguientes opciones:

- Modelo k- $\varepsilon$ : RNG

- Tratamiento cercano a la pared: función de pared de no equilibrio

- Efectos de convección natural en $\varepsilon$

- Corrección de la curvatura

- Número de Prandtl constante e igual a 0,709

Materiales:

- Gas Ideal Incompresible

- Se especifican las propiedades físicas del aire y del vidrio

\section{Zona de celdas:}

- Aire del ambiente exterior: Fluido

- Aire de la cámara: Fluido

- Aire de la habitación: Fluido

- Vidrio 1 (interior): Sólido

- Vidrio 2 (exterior): Sólido

Condiciones de contorno:

Se establecen condiciones de contorno para el ambiente exterior, para el ambiente interior y para los vidrios.

- Las condiciones de contorno del ambiente exterior son las siguientes:

- Límites laterales: Entrada de presión en condiciones de invierno.

Salida de presión en condiciones de verano.

- Límite superior: Salida de presión en condiciones de invierno.

Entrada de presión en condiciones de verano.

- Límite inferior: Adiabático, tanto en condiciones de invierno como de verano.

- Las condiciones de contorno del ambiente interior en condiciones de invierno son las siguientes:

- Límite inferior: Pared. Flujo de calor $Q=22 \mathrm{~W} / \mathrm{m}^{2}$

Flujo de calor $Q=17,9 \mathrm{~W} / \mathrm{m}^{2}$, con radiación solar 
- Límite superior: Pared. Adiabático.

- Límite derecho: Pared. Adiabático.

- Las condiciones de contorno del ambiente interior en condiciones de verano son las siguientes:

- Límite inferior: Pared. Adiabático

- Límite superior: Pared. Flujo de calor $Q=-4,6 \mathrm{~W} / \mathrm{m}^{2}$

Flujo de calor $Q=-10,5 \mathrm{~W} / \mathrm{m}^{2}$, con radiación solar

- Límite derecho: Pared. Adiabático.

- Las condiciones de contorno de los vidrios son las siguientes:

- Acoplar las dos zonas

- Para los casos con radiación solar:

- $t_{p}=6 \mathrm{~mm}$

- Introducir el índice de generación de calor correspondiente según el escenario de estudio

Valores de referencia:

- Se dejan todos los valores de referencia por defecto a excepción de los siguientes:

- Densidad: $\rho=1,20494 \mathrm{~kg} / \mathrm{m}^{3}$ en condiciones de invierno $\left(20^{\circ} \mathrm{C}\right)$; $\rho=1,18076 \mathrm{~kg} / \mathrm{m}^{3}$ en condiciones de verano $\left(26^{\circ} \mathrm{C}\right)$.

- Longitud característica: $L(\mathrm{~m})$, ancho de la cámara de aire. Varía según el caso.

- Presión: $P=101.325 \mathrm{~Pa}$

- Temperatura: $20^{\circ} \mathrm{C}$, temperatura de confort en condiciones de invierno.

$26^{\circ} \mathrm{C}$, temperatura de confort en condiciones de verano.

- Zona de referencia: fluido de la cámara de aire

\section{Método de solución}

- Esquema SIMPLE

- Esquema de discretización espacial basado en celdas de cuadrados mínimos

- Esquema de discretización de presión: Body Force Weighted 
- Viento: Los parámetros que hay que introducir en Fluent para el cálculo de las simulaciones de flujo dominado por viento son los mismos que los introducidos en los casos de flujo dominado por convección natural, sólo se van a variar las condiciones de contorno y los valores de referencia.

\section{Condiciones de contorno:}

- Las condiciones de contorno del el ambiente exterior son las siguientes:

- Pared izquierda: Entrada de velocidad

- Pared superior: Entrada de velocidad

- Pared derecha: Salida de presión

- Pared inferior: Adiabática

- Las condiciones de contorno del ambiente interior y de los vidrios son las mismas que las introducidas para las simulaciones de flujo conducido por convección natural.

\section{Valores de referencia:}

- Densidad: $\rho=1,20494 \mathrm{~kg} / \mathrm{m}^{3}$ en condiciones de invierno $\left(20^{\circ} \mathrm{C}\right)$. $\rho=1,18076 \mathrm{~kg} / \mathrm{m}^{3}$ en condiciones de verano $\left(26^{\circ} \mathrm{C}\right)$.

- Longitud característica: $L=0,1 \mathrm{~m}$

- Presión: $P=101.325 \mathrm{~Pa}$

- Temperatura: $20^{\circ} \mathrm{C}$, temperatura de confort en condiciones de invierno. $26^{\circ} \mathrm{C}$, temperatura de confort en condiciones de verano.

- Velocidad: varía según el caso. Puede ser $v=1 ; 2,5 ; 5 ; 10 ;$ ó $20 \mathrm{~m} / \mathrm{s}$.

- Zona de referencia: fluido de la cámara de aire.

Una vez creado el modelo y definidos los parámetros de cálculo, se realiza la validación del modelo numérico incluyendo la radiación solar para comprobar el funcionamiento del modelo diseñado y del mallado con las condiciones físicas y numéricas introducidas en Fluent. Para ello se utiliza una investigación científica ya publicada y se reproduce con el modelo CFD creado. Se analizan los resultados obtenidos y se comprueba que concuerdan con los de la investigación de referencia con un error inferior al $2 \%$. De esta manera queda justificada la validación del modelo y las simulaciones pueden continuar.

La Tabla 4.5 muestra de forma resumida todos los parámetros utilizados tanto para la modelización fluidodinámica de la fachada doble piel acristalada como para el cálculo numérico: 
PARÁMETROS PARA LA MODELIZACIÓN FLUIDODINÁMICA Y PARA EL CÁLCULO NUMÉRICO DE LA FACHADA ACRISTALADA

\begin{tabular}{|c|c|c|c|}
\hline & \multicolumn{2}{|l|}{ Variables } & Alternativas \\
\hline Software simulación & \multicolumn{2}{|l|}{ ANSYS Fluent } & versión 15.0 .7 \\
\hline Geometría & \multicolumn{2}{|l|}{ 2D } & design modeler \\
\hline \multirow{6}{*}{ Mallado } & \multicolumn{2}{|l|}{ Bidimensional } & meshing \\
\hline & \multicolumn{2}{|l|}{ Tipo } & no estructurada \\
\hline & \multicolumn{2}{|l|}{ Método } & cuadriláteros \\
\hline & \multicolumn{2}{|l|}{ Configuración física } & CFD \\
\hline & \multicolumn{2}{|l|}{ Solver } & Fluent \\
\hline & \multicolumn{2}{|l|}{ Tamaño elementos } & $\begin{array}{l}\text { medio (convección natural) } \\
\text { fino (viento) }\end{array}$ \\
\hline \multirow{6}{*}{ Solver } & \multicolumn{2}{|l|}{ Tipo } & basado en presión \\
\hline & \multicolumn{2}{|c|}{ Formulación velocidad } & absoluta \\
\hline & \multicolumn{2}{|c|}{ Tiempo } & estacionario \\
\hline & \multicolumn{2}{|l|}{ Espacio 2D } & plano \\
\hline & \multicolumn{2}{|l|}{ Gravedad } & $\mathrm{X}=0 \mathrm{~m} / \mathrm{s}^{2} ; \mathrm{Y}=9,8 \mathrm{~m} / \mathrm{s}^{2}$ \\
\hline & \multicolumn{2}{|c|}{ Unidades } & temperatura $\left({ }^{\circ} \mathrm{C}\right)$ \\
\hline & \multicolumn{2}{|c|}{ Ecuación de la Energía } & Transferencia de calor \\
\hline & \multicolumn{2}{|c|}{ Modelo turbulento } & RNG k- $\varepsilon$ (2 ecuaciones) \\
\hline T & \multirow{2}{*}{\multicolumn{2}{|c|}{$\begin{array}{l}\text { Tratamiento cercano a pared } \\
\text { Efectos de convección natural }\end{array}$}} & función de no equilibrio \\
\hline Modelo & & & en $\varepsilon$ \\
\hline & \multicolumn{2}{|c|}{ Corrección de curvatura } & activada \\
\hline & \multicolumn{2}{|c|}{ Número de Prandtl } & constante e igual a 0,709 \\
\hline \multirow{3}{*}{ Materiales } & \multirow{2}{*}{\multicolumn{2}{|c|}{ Aire }} & fluido \\
\hline & & & densidad: Gas Ideal Incompresible \\
\hline & \multicolumn{2}{|l|}{ Vidrio } & sólido \\
\hline & \multicolumn{2}{|c|}{ Aire ambiente exterior } & fluido \\
\hline & \multicolumn{2}{|c|}{ Aire cámara } & fluido \\
\hline Zona de celdas & Aire ambiente inter & & fluido \\
\hline & Vidrio 1 (interior) & & sólido \\
\hline & Vidrio 2 (exterior) & & sólido \\
\hline & & Invierno & $\begin{array}{l}\text { Límite lateral: entrada de presión } \\
\text { Límite superior: salida de presión } \\
\text { Límite inferior: adiabático }\end{array}$ \\
\hline & Ambiente Exterior & & Limite lateral: salida de presión \\
\hline & & Verano & Límite superior: entrada de presión \\
\hline & & & Límite inferior: adiabático \\
\hline & & & Límite derecho: pared. Adiabático \\
\hline CONVECCIÓN & & & Límite superior: pared. $Q=0 \mathrm{~W} / \mathrm{m}^{2}$ \\
\hline NATURAL & & Invierno & $\begin{array}{l}\text { Límite inferior: pared. } Q=22 \mathrm{~W} / \mathrm{m}^{2} \\
Q=17,9 \mathrm{~W} / \mathrm{m}^{2}, \text { con radiación solar }\end{array}$ \\
\hline Condiciones de contorno & Ambiente Interior & & Límite derecho: pared. Adiabático \\
\hline & & & Límite inferior: pared. $Q=0 \mathrm{~W} / \mathrm{m}^{2}$ \\
\hline & & Verano & $\begin{array}{l}\text { Límite superior: pared. } Q=-4,6 \mathrm{~W} / \mathrm{m}^{2} \\
Q=-10,5 \mathrm{~W} / \mathrm{m}^{2} \text {, con radiación solar }\end{array}$ \\
\hline & Vidrios & $\begin{array}{l}\text { Acoplar } \\
\text { Radiación } \\
\text { solar }\end{array}$ & $Q_{r}$ según escenario \\
\hline
\end{tabular}


Optimización de la fachada de doble piel acristalada con ventilación natural. Metodología de diseño para el análisis de la eficiencia energética del sistema.

\begin{tabular}{|c|c|c|}
\hline \multirow{7}{*}{$\begin{array}{l}\text { CONVECCIÓN } \\
\text { NATURAL } \\
\text { Valores de referencia }\end{array}$} & \multirow[t]{2}{*}{ Densidad $\rho$} & $1,20494 \mathrm{~kg} / \mathrm{m}^{3}$, invierno $\left(20^{\circ} \mathrm{C}\right)$ \\
\hline & & $1,18076 \mathrm{~kg} / \mathrm{m}^{3}$, verano $\left(26^{\circ} \mathrm{C}\right)$ \\
\hline & Longitud característica $L(\mathrm{~m})$ & según el caso \\
\hline & Presión $P$ & $101.325 \mathrm{~Pa}$ \\
\hline & Temperatura & $20^{\circ} \mathrm{C}$ (invierno) \\
\hline & & $26^{\circ} \mathrm{C}$ (verano) \\
\hline & Zona de referencia & fluido de la cámara de aire \\
\hline \multirow{6}{*}{$\begin{array}{l}\text { VIENTO } \\
\text { Condiciones de contorno }\end{array}$} & \multirow{4}{*}{ Ambiente Exterior } & Límite izquierdo: entrada de velocidac \\
\hline & & Límite derecho: salida de presión \\
\hline & & Límite superior: entrada de velocidad \\
\hline & & Límite inferior: adiabático \\
\hline & Ambiente Interior & (igual que en convección natural) \\
\hline & Vidrios & (igual que en convección natural) \\
\hline \multirow{4}{*}{ VIENTO } & \multirow[t]{2}{*}{ Densidad $\rho$} & $1,20494 \mathrm{~kg} / \mathrm{m}^{3}$, invierno $\left(20^{\circ} \mathrm{C}\right)$ \\
\hline & & $1,18076 \mathrm{~kg} / \mathrm{m}^{3}$, verano $\left(26^{\circ} \mathrm{C}\right)$ \\
\hline & Longitud característica $L$ & $0,1 \mathrm{~m}$ \\
\hline & Presión $P$ & $101.325 \mathrm{~Pa}$ \\
\hline \multirow[t]{4}{*}{ Valores de referencia } & Temperatura & $20^{\circ} \mathrm{C}$ (invierno) \\
\hline & & $26^{\circ} \mathrm{C}$ (verano) \\
\hline & Velocidad $v$ & $1 ; 2,5,5 ; 10 ; 20 \mathrm{~m} / \mathrm{s}$ \\
\hline & Zona de referencia & fluido de la cámara de aire \\
\hline
\end{tabular}

Tabla 4.5. Resumen de parámetros utilizados para la modelización fluidodinámica y para el cálculo numérico de la fachada doble piel acristalada. 


\section{DISCUSIÓN DE RESULTADOS}

En este capítulo se presentan, analizan y discuten los resultados obtenidos de las simulaciones CFD.

Primero se muestran los resultados obtenidos para los casos de ventilación natural producida por convección natural bajo todas las variables y alternativas estudiadas. Se analizan los resultados obtenidos desde el punto de vista de la temperatura media en la habitación, la distribución de temperaturas y el comportamiento del flujo en la cámara de aire, y la transferencia de calor.

Se identifica la configuración de fachada doble piel óptima que mejora la eficiencia energética del edificio proporcionando unas condiciones interiores de confort adecuadas.

A continuación, se muestran los resultados obtenidos para los casos de ventilación natural producida por viento para el caso de la configuración de fachada óptima bajo todas las variables y alternativas estudiadas. Asimismo, se analiza la influencia del viento en el sistema de fachada doble piel.

Por último, se analiza la eficiencia energética de la fachada doble piel óptima en comparación con la fachada simple piel convencional en los distintos escenarios. 
Optimización de la fachada de doble piel acristalada con ventilación natural. Metodología de diseño para el análisis de la eficiencia energética del sistema. 


\subsection{RESULTADOS DEL FLUJO DOMINADO POR CONVECCIÓN NATURAL}

Después de simular todas las configuraciones de fachada bajo diferentes condiciones, se procede a analizar una amplia gama de parámetros relevantes para este estudio.

Los resultados obtenidos se presentan mediante gráficos adimensionales. La teoría muestra que para derivar expresiones generales basadas en el análisis dimensional para la transferencia de calor y para el flujo de aire en cámaras ventiladas, se pueden introducir números adimensionales incluyendo el número de Nusselt $(\mathrm{Nu})$ para la tasa de transferencia de calor y el número de Rayleigh $\left(\mathrm{Ra}_{\mathrm{L}}\right)$ asociado al tamaño de la cámara y a las condiciones de contorno. Etheridge (2002) señaló una serie de beneficios de la utilización de gráficos adimensionales generados a partir de modelos numéricos sofisticados para el diseño de la ventilación natural.

\subsubsection{Condiciones de invierno}

\subsubsection{Temperatura media en el ambiente interior}

Se utiliza la fachada simple piel como caso de referencia con el que comparar los resultados obtenidos. Se calcula el calor que es necesario aportar para que la temperatura de la habitación se mantenga a $20{ }^{\circ} \mathrm{C}$ (temperatura de confort para las condiciones de invierno) tanto para los casos con radiación solar como para los casos sin radiación solar.

De esta manera resulta que los flujos de calor de referencia $\left(Q_{r e f}\right)$ son de $17,9 \mathrm{~W} / \mathrm{m}^{2}$ y 22 $\mathrm{W} / \mathrm{m}^{2}$ para los casos con radiación solar y sin radiación solar, respectivamente. Para las simulaciones del escenario de invierno, el flujo de calor se simula mediante una fuente de calor uniformemente distribuida en el límite inferior del ambiente interior.

La Figura 5.1 muestra el incremento de la temperatura media en la habitación en relación con la esbeltez $A$, relación entre el alto y el ancho de la cámara, en el escenario de invierno bajo diferentes condiciones: cámara abierta y cerrada, con y sin radiación solar. 
Optimización de la fachada de doble piel acristalada con ventilación natural. Metodología de diseño para el análisis de la eficiencia energética del sistema.

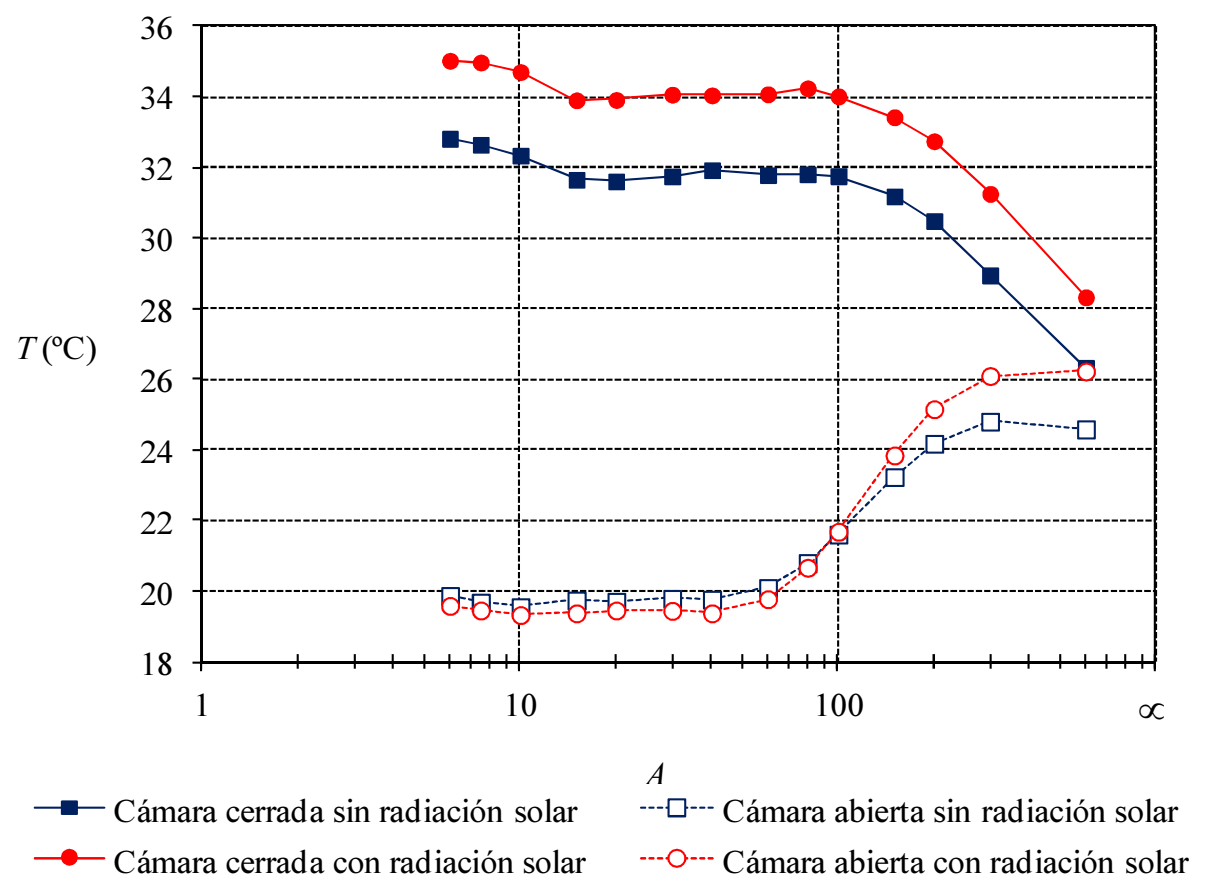

Figura 5.1. Temperatura media en la habitación en el escenario de invierno.

La Figura 5.2 representa el incremento de la temperatura media adimensional $T^{+}$en la habitación respecto de la fachada simple piel (caso de referencia) en función de la esbeltez $A$ en el escenario de invierno bajo diferentes condiciones. La temperatura adimensional se calcula mediante la fórmula:

$$
T^{+}=\left(T-T_{r e f}\right) / T_{r e f}
$$

donde $T$ es la temperatura media en la habitación; y $T_{\text {ref }}$ es la temperatura de referencia, la temperatura media en la habitación para el caso de fachada simple piel.

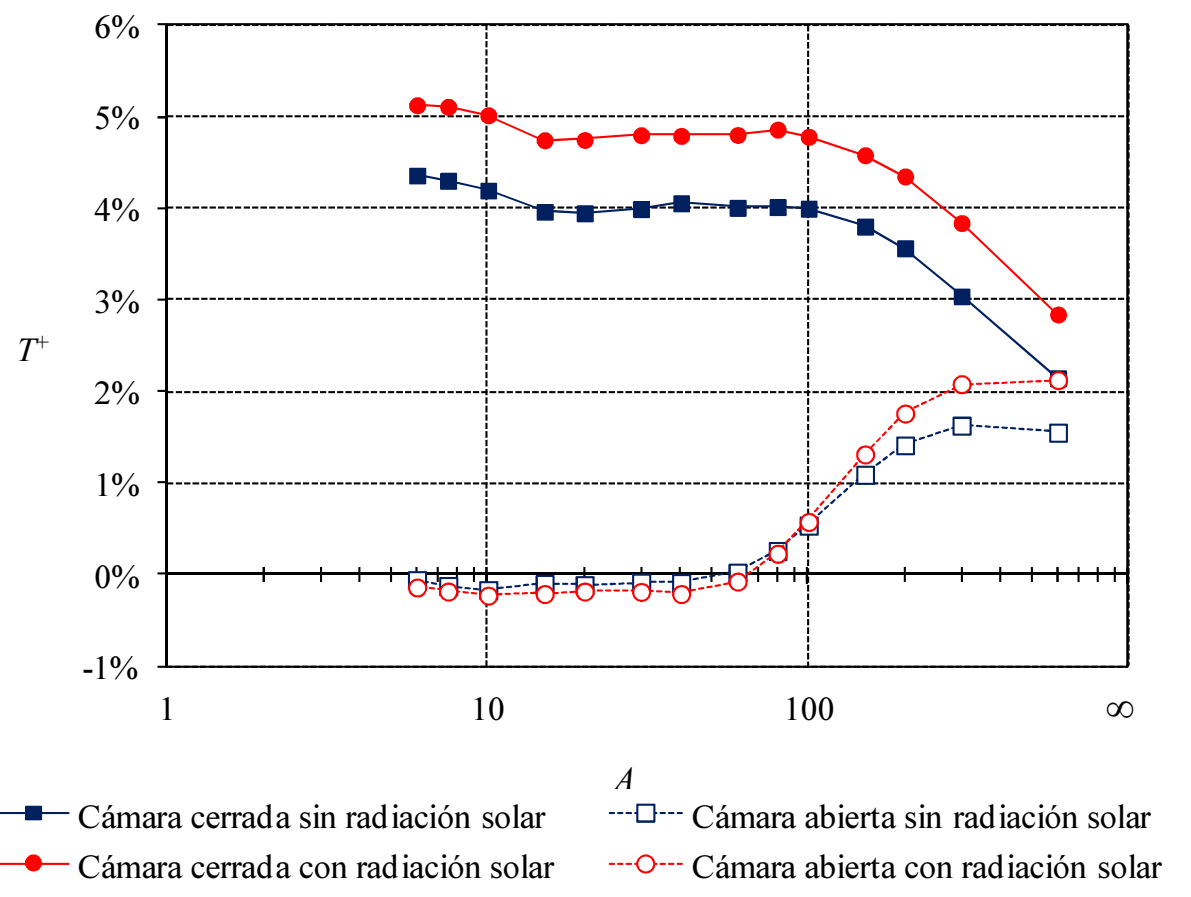

Figura 5.2. Temperatura media adimensional en la habitación en el escenario de invierno. 
Desde el punto de vista de la esbeltez de la cámara, se obtuvieron los siguientes resultados:

- En el caso de la cámara cerrada, con y sin radiación solar, se pueden observar tres secciones distintas:

- Para $A<15$, se observa una ligera disminución de la temperatura con el aumento de $A$. Esto se debe a que la disminución del ancho de la cámara provoca una disminución de la resistencia térmica del sistema. Este hecho se conoce generalmente como efecto invernadero. En presencia de la radiación solar el efecto es mayor, disminuyen las pérdidas por transmisión e incluso proporciona ganancias. Por tanto, se demuestra que la cámara de aire continúa aislando térmicamente. En esta sección, como se explica más adelante, domina el régimen de la capa límite (convección).

- Para $15 \leq A \leq 80$, la temperatura permanece constante o sin grandes variaciones, domina el régimen de transición.

- Para $A>80$, la temperatura media en la habitación disminuye con $A$, domina el régimen de conducción.

- En el caso de la cámara abierta, con y sin radiación solar, también se pueden observar tres zonas distintas:

- Para $A<60$, la temperatura permanece constante, domina la convección.

- Para $60 \leq A \leq 300$, la temperatura media en la habitación aumenta con $A$ y el flujo de aire es uniforme en la cámara.

- Para $A>300$, la temperatura media en la habitación aumenta al aumentar $A$, domina el régimen de conducción y el flujo de aire es uniforme en la cámara.

\subsubsection{Distribución de la temperatura en la cámara de aire}

En este estudio se realiza un análisis exhaustivo de la relación entre la tasa de flujo de aire y la diferencia de temperatura entre los paños de vidrio para diferentes esbelteces y condiciones del entorno. Los dos paños de vidrio de la fachada doble piel separan dos ambientes que se encuentran a diferente temperatura, por lo tanto, se produce la transferencia de calor entre el paño caliente y el frío.

Como ya se ha explicado anteriormente, el intercambio de calor a través de la cámara de aire se produce de acuerdo a tres modos de propagación: conducción, convección y radiación. El modo en el que se produce el intercambio de calor depende del número de 
Rayleigh $\left(\mathrm{Ra}_{\mathrm{L}}\right)$, que se calcula en función del ancho de la cámara y de la diferencia de temperatura entre el paño caliente y el paño frío.

$$
\mathrm{Ra}_{\mathrm{L}}=\frac{g L^{3} \beta\left(T_{c}-T_{f}\right)}{v \alpha}
$$

donde $g$ es la aceleración de la gravedad; $L$ el ancho de la cámara de aire; $\beta$ el coeficiente de expansión térmica del aire; $T_{c}$ la temperatura del paño caliente; y $T_{f}$ la temperatura del paño frío.

De acuerdo con investigaciones anteriores sobre convección natural y transferencia de calor en cámaras de aire, el régimen del flujo puede clasificarse en conducción, transición y capa límite, dependiendo del número de Rayleigh y de la esbeltez de la cámara de aire.

En esta investigación, se estudian esbelteces desde 6 hasta 600 y se obtuvieron números de Rayleigh, basados en el ancho de la cámara, entre 10 y $10^{8}$.

Las Figuras 5.3 y 5.4 muestran la distribución de temperatura adimensional $T^{*}$, en función de la distancia horizontal adimensional en la cámara $X^{*}$, desde la pared caliente de la cámara hasta la pared fría, para esbelteces de 150,30 y 7,5 y para los casos sin y con radiación solar, respectivamente. Se traza el perfil de temperatura adimensional en la cámara de aire para una sección horizontal dada para diferentes posiciones verticales adimensionales en la cámara $Y^{*}$ que son 0,$0065 ; 0,0374 ; 0,5 ; 0,9681 ;$ y 0,9935 .

$$
\begin{gathered}
T^{*}=\left(T-T_{f}\right) /\left(T_{c}-T_{f}\right) \\
X^{*}=x / H
\end{gathered}
$$

donde $x$ es la distancia horizontal en la cámara $(\mathrm{m})$.

$$
Y^{*}=y / H
$$

donde $y$ es la posición vertical en la cámara $(\mathrm{m})$.

Los perfiles de temperatura se validaron con los perfiles obtenidos por Xamán (2005), que investigó numéricamente la convección natural en régimen turbulento en una cámara alta y de sección rectangular para esbelteces de 20, 40 y 80 . 

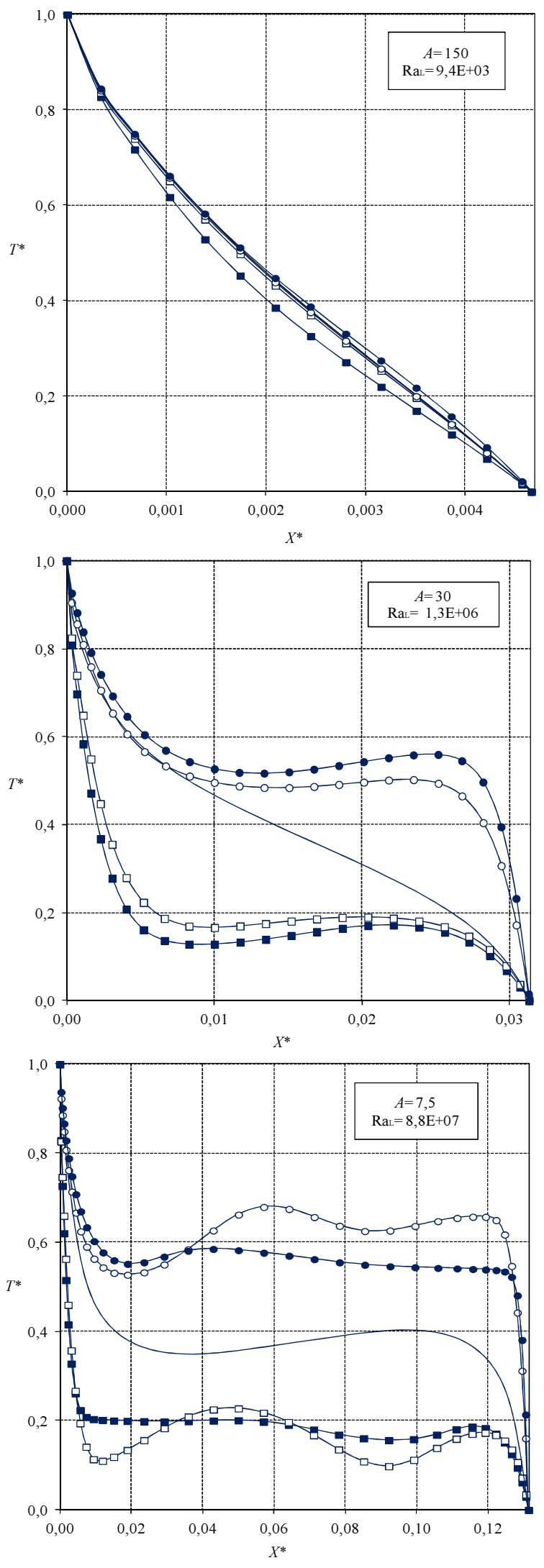

Figura 5.3. Perfil de temperatura en la cámara de aire para una sección horizontal dada para diferentes posiciones verticales: $A=150$, Régimen de Conducción; $A=30$, Régimen de Transición; $A=7,5$, Régimen de la Capa Límite, en condiciones de invierno, cámara cerrada y sin radiación solar. 
Optimización de la fachada de doble piel acristalada con ventilación natural. Metodología de diseño para el análisis de la eficiencia energética del sistema.
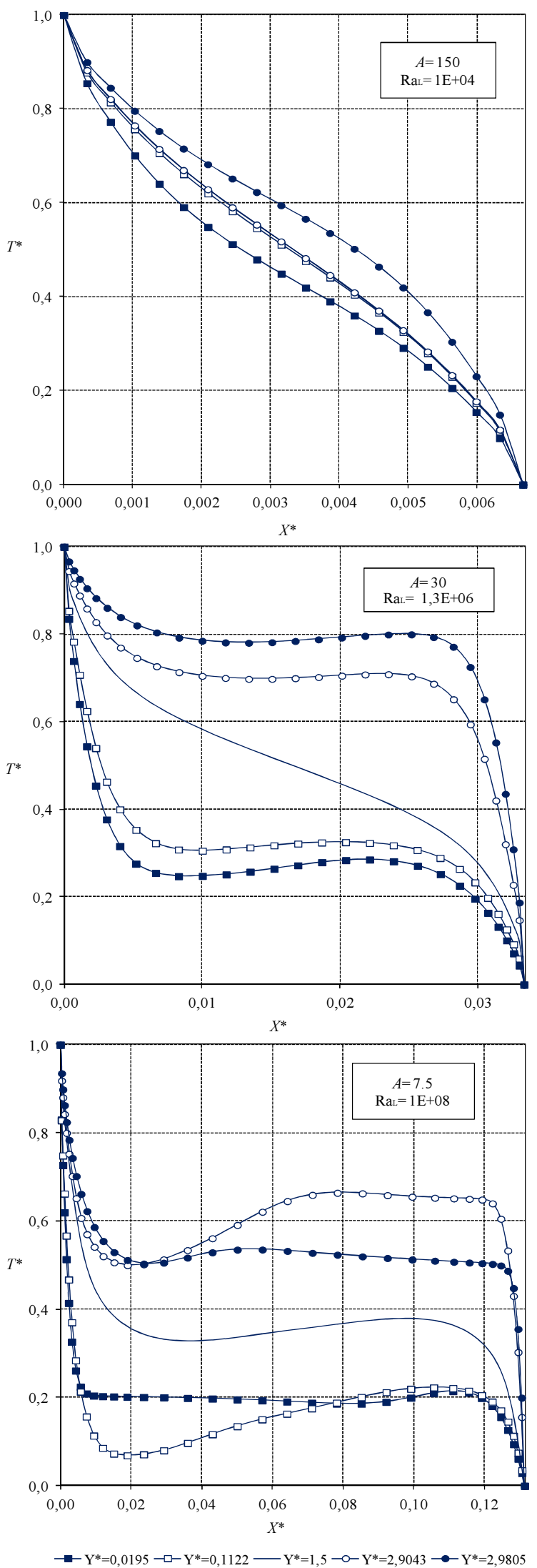

Figura 5.4. Perfil de temperatura en la cámara de aire para una sección horizontal dada para diferentes posiciones verticales: $A=150$, Régimen de Conducción; $A=30$, Régimen de Transición; $A=7,5$, Régimen de la Capa Límite, en condiciones de invierno, cámara cerrada y con radiación solar. 
En el caso de los números de Rayleigh por debajo de $10^{4}$, la distribución de temperatura en la cámara es lineal. Indica que el calor es transportado principalmente por conducción a través del núcleo central de la cámara. Este perfil lineal de la temperatura se denomina régimen de conducción.

Para los números de Rayleigh comprendidos entre $10^{4}$ y $10^{7}$, el calor se transporta por convección en la zona próxima a la superficie de los paños, y en el núcleo central se transporta por conducción. Como consecuencia del aumento del número de Rayleigh, el transporte convectivo del calor gana importancia y el perfil lineal de la temperatura desaparece. Este régimen del flujo se denomina régimen de transición.

Para los números de Rayleigh mayores que $10^{7}$, el calor se trasporta principalmente por convección desde el paño caliente al frío. En este caso, elevados gradientes de temperatura tienen lugar cerca de la superficie de los paños, pero la temperatura es prácticamente constante en el núcleo central de la cámara. Este régimen del flujo se denomina régimen de la capa límite porque está dominado por la circulación de aire a través de dos superficies verticales.

En el caso de la cámara cerrada, se dan los siguientes regímenes de flujo en términos de la esbeltez y del número de Rayleigh:

- Régimen de la capa límite, hasta $A=15, \mathrm{Ra}_{\mathrm{L}} \geq 10^{7}$

- Régimen de transición, desde $A=15$ hasta $A=80,10^{4}<\mathrm{Ra}_{\mathrm{L}}<10^{7}$

- Régimen de conducción, a partir de $A=80, \mathrm{Ra}_{\mathrm{L}} \leq 10^{4}$

En todas las situaciones, la temperatura media en la cámara de aire siempre es menor que la temperatura media en la habitación.

\subsubsection{Transferencia de calor}

El número de Nusselt $(\mathrm{Nu})$ es un número adimensional que mide la relación entre la transferencia de calor por convección y la transferencia de calor por conducción a través de la cámara de aire.

$$
\mathrm{Nu}=\frac{h L}{K}
$$

donde $h$ es el coeficiente de transferencia de calor medio a través de la cámara; $L$ es el ancho de la cámara de aire; y $K$ es la conductividad térmica del aire.

La tasa de transferencia de calor y las correlaciones obtenidas se muestran en la Figura 5.5, y se analiza en función de los siguientes parámetros independientes: el número de Rayleigh y la esbeltez. Cuando se considera la transferencia de calor por convección natural dentro de las cámaras, la bibliografía, en general, establece que la transferencia de calor puede determinarse en notación funcional como: $\mathrm{Nu}=f\left(\mathrm{Ra}_{\mathrm{L}}, \operatorname{Pr}, A\right)$. El número de Prandlt se considera constante. Por lo tanto, la relación funcional se reduce a: $\mathrm{Nu}=f\left(\mathrm{Ra}_{\mathrm{L}}, A\right)$. 
Se observó que la tasa de transferencia de calor obtenida concordaba con varias correlaciones de los números de Nusselt convectivos presentados en la literatura que eran similares a la expresión $\mathrm{Nu}=k 1 \mathrm{Ra}_{\mathrm{L}}{ }^{k}$, donde $k 1$ y $k 2$ son constantes que dependen del valor de $A$ y del rango de $\mathrm{Ra}_{\mathrm{L}}$ estudiado, y donde $k 1<1$ y $k 2$ son del orden de 0,3 como los resultados obtenidos por Wright (1996) y por Elsherbiny (1982).

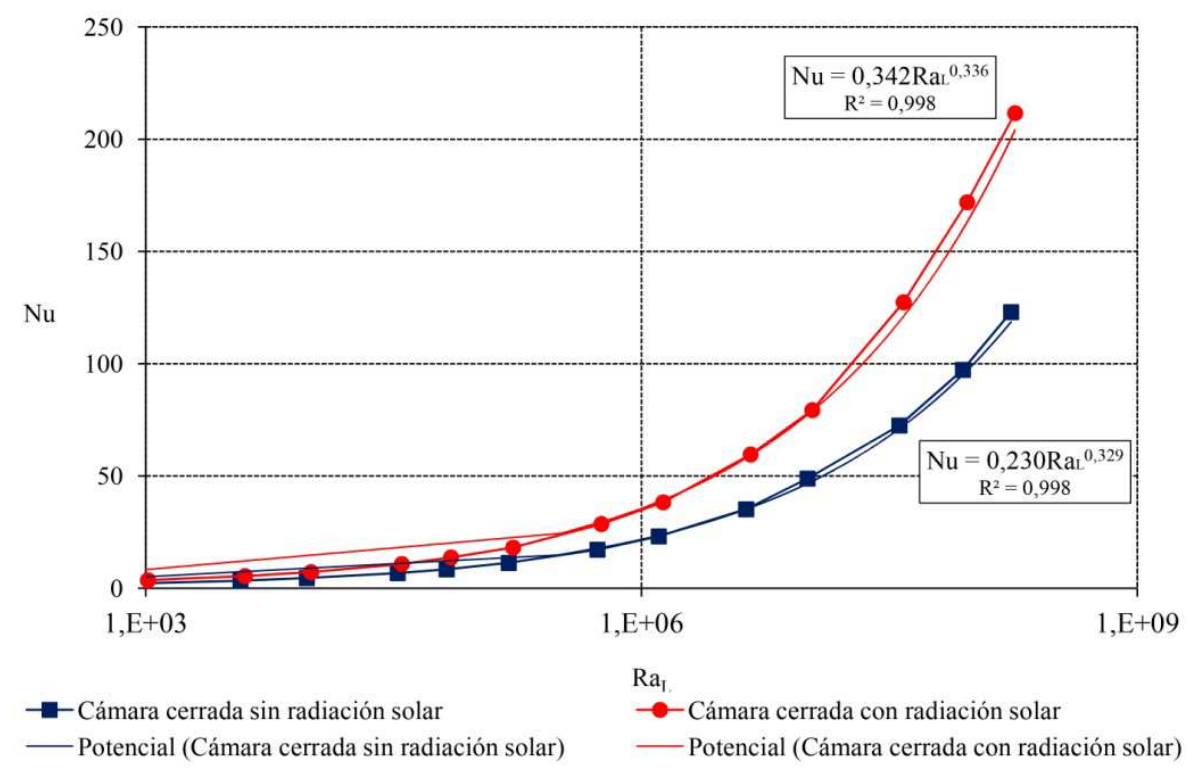

Figura 5.5. Tasa de transferencia de calor en el escenario de invierno.

Se observa que el número de Nusselt aumenta con el aumento del número de Rayleigh.

\subsubsection{Comportamiento del flujo de aire en el ambiente interior}

Las siguientes figuras muestran el comportamiento del aire en el ambiente interior para el caso de convección natural. Para ello se han escogido los gráficos de contorno de distribución de temperatura y líneas de corriente coloreadas por temperatura.
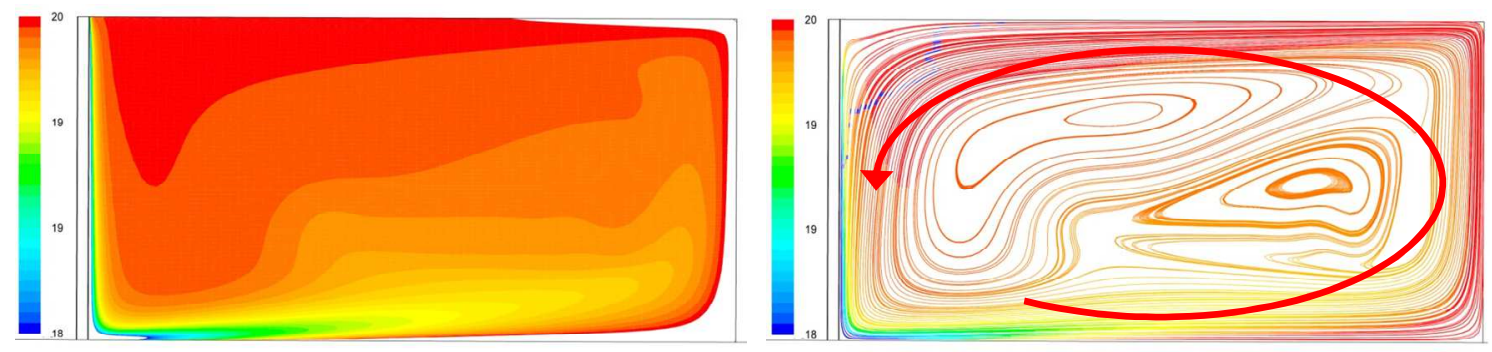

Figura 5.6. Contorno de distribución de temperatura y líneas de corriente coloreadas por temperatura en el escenario de invierno.

Se observa que en el escenario de invierno el ambiente exterior está más frío que el ambiente interior, con lo que el aire se enfría en contacto con el vidrio de la izquierda, que está más frío, por lo que aumenta su densidad y desciende por el vidrio hasta alcanzar el suelo donde se encuentra la fuente de calor. Allí se calienta, y al dilatarse disminuye su densidad por lo que asciende por el lado derecho de la habitación y se 
acumula en la parte superior de la misma, donde vuelve a entrar en contacto con el vidrio, se enfría de nuevo y se repite el proceso.

\subsubsection{Comportamiento del flujo de aire en el interior de la cámara}

El movimiento del aire en el interior de la cámara y en el interior de la habitación es debido a la diferencia de temperatura entre el ambiente interior y el exterior, con flujo ascendente cerca de la superficie caliente y con flujo descendente cerca de la superficie fría. Las siguientes figuras representan, de izquierda a derecha, el movimiento del flujo de aire en el interior de la cámara mediante vectores velocidad coloreados por temperatura en el extremo superior, zona media y extremo inferior de la cámara. Representan la situación de cámara cerrada y abierta, sin y con radiación solar en el escenario de invierno para el caso de $A=30$.
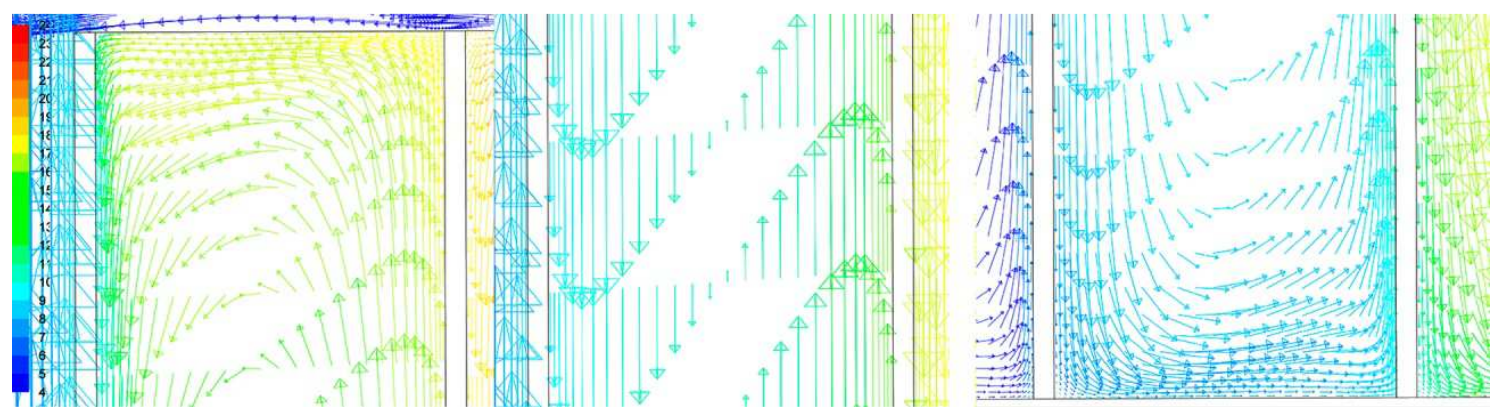

Figura 5.7. Vectores velocidad coloreados por temperatura $\left({ }^{\circ} \mathrm{C}\right.$ ) en el extremo superior (imagen izquierda), zona media (imagen central) y extremo inferior (imagen derecha) de la cámara de aire, para el caso de $A=30$ en condiciones de invierno cámara cerrada y sin radiación solar.
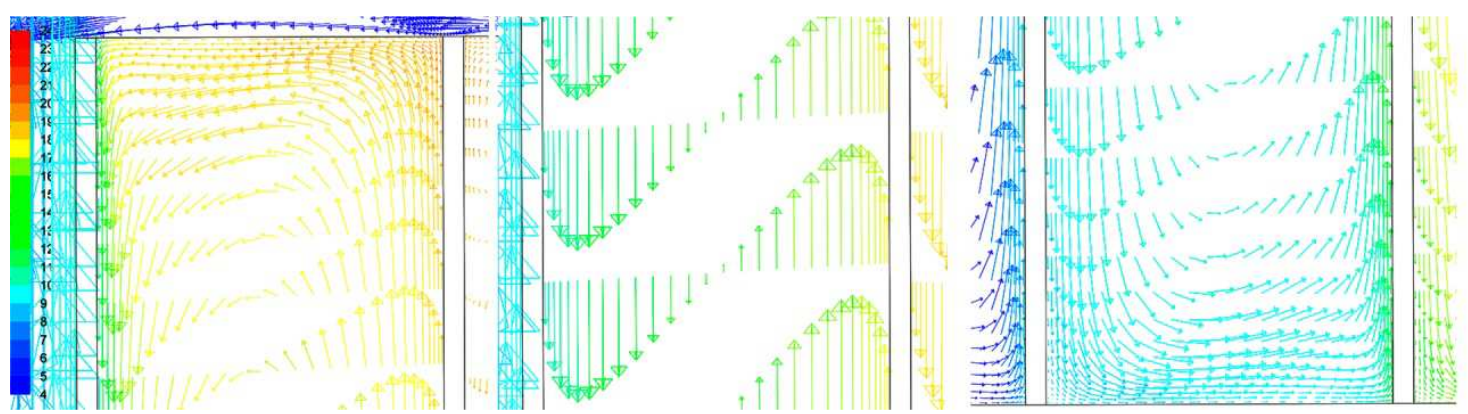

Figura 5.8. Vectores velocidad coloreados por temperatura $\left({ }^{\circ} \mathrm{C}\right)$ en el extremo superior (imagen izquierda), zona media (imagen central) y extremo inferior (imagen derecha) de la cámara de aire, para el caso de $A=30$ en condiciones de invierno cámara cerrada y con radiación solar.
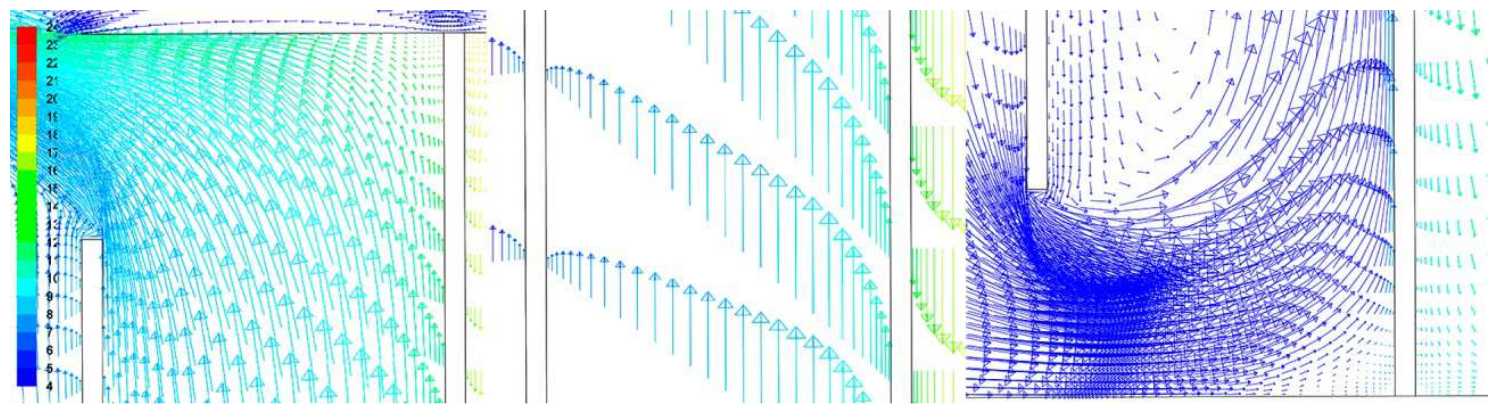

Figura 5.9. Vectores velocidad coloreados por temperatura $\left({ }^{\circ} \mathrm{C}\right)$ en el extremo superior (imagen izquierda), zona media (imagen central) y extremo inferior (imagen derecha) de la cámara de aire, para el caso de $A=30$ en condiciones de invierno cámara abierta y sin radiación solar. 


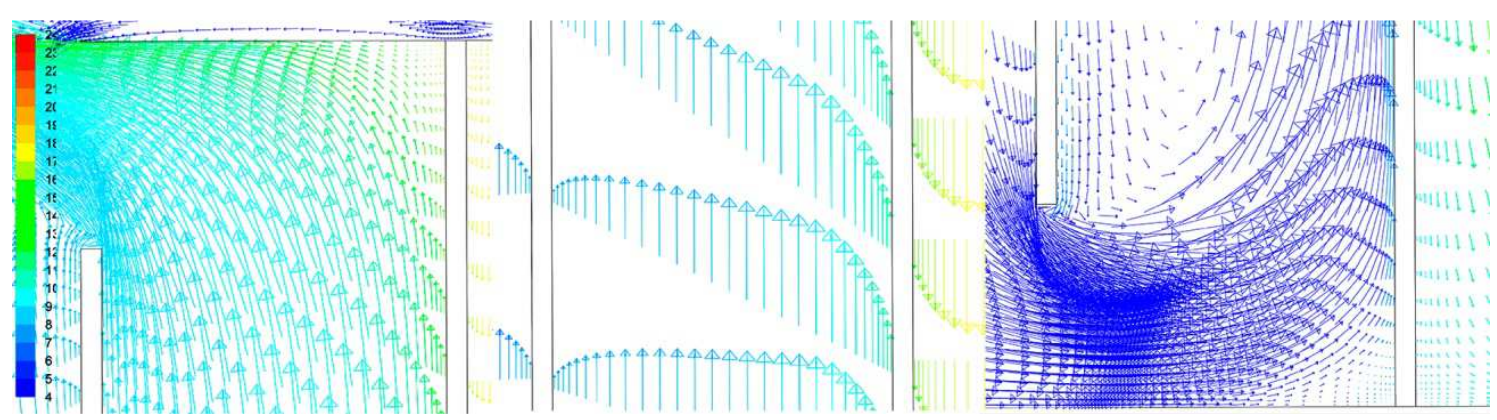

Figura 5.10. Vectores velocidad coloreados por temperatura $\left({ }^{\circ} \mathrm{C}\right.$ ) en el extremo superior (imagen izquierda), zona media (imagen central) y extremo inferior (imagen derecha) de la cámara de aire, para el caso de $A=30$ en condiciones de invierno cámara abierta y con radiación solar.

Cuando la cámara está cerrada, el gradiente de temperatura entre los paños de vidrio provoca que el aire gire de forma cíclica en el interior de la cámara. Se observan torbellinos de recirculación de aire en los extremos superior e inferior de la cámara.

Cuando la cámara está abierta, el aire entra a través de la abertura inferior y sale por la abertura superior creando un flujo de aire mayor debido a una fuerza de convección natural mayor. Se observa un torbellino importante en el extremo inferior de la cámara.

En todas las situaciones, se observa un pico de temperatura en el extremo superior de la cámara. La temperatura media en la cámara es menor que la temperatura media en el ambiente interior.

La única diferencia entre los casos con y sin radiación solar, es que la temperatura media en la cámara es mayor en los casos con radiación solar.

La Figura 5.11 muestra la relación entre el caudal de aire $(V)$ y la esbeltez en el caso de la cámara abierta.

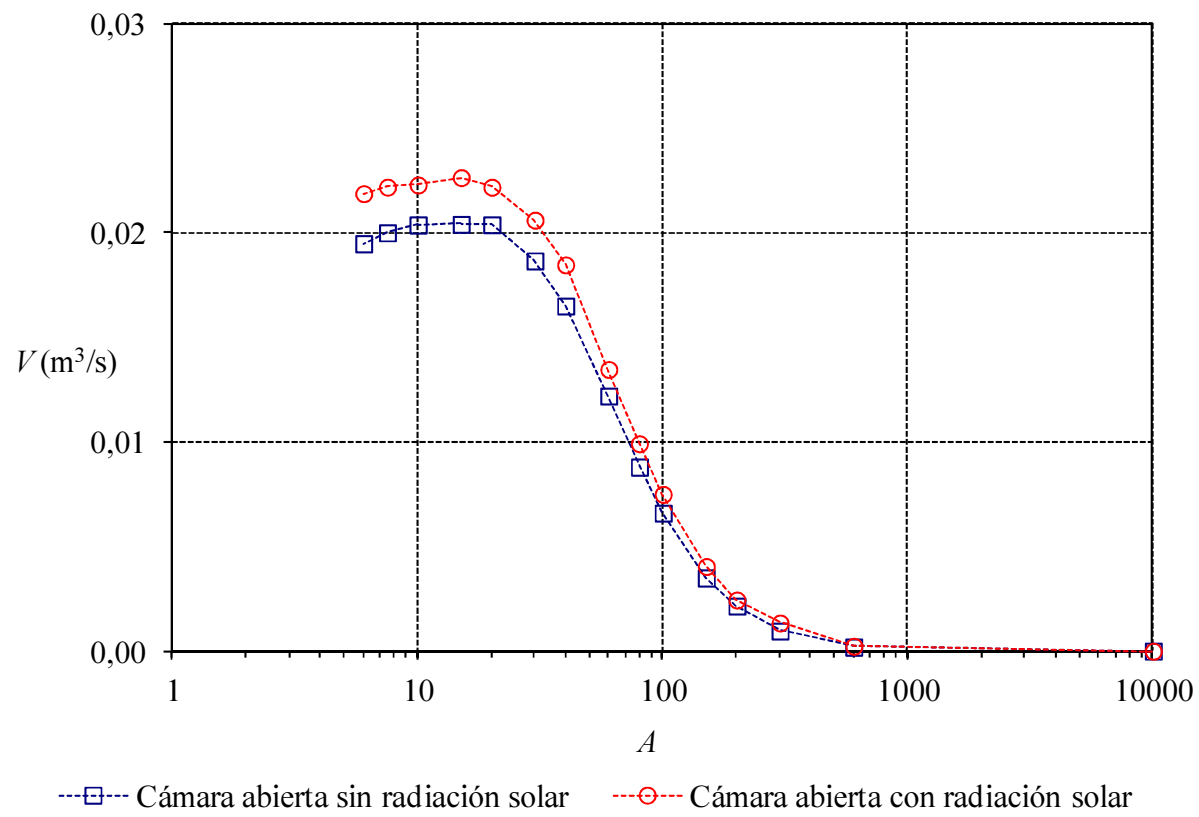

Figura 5.11. Flujo de ventilación en el escenario de invierno para el caso de cámara abierta. 
Se obtienen las siguientes conclusiones:

- El caudal de ventilación en la cámara disminuye en general con el aumento de la esbeltez.

- El caudal de ventilación aumenta ligeramente con la esbeltez de $A=6$ a $A=20$. A partir de ahí, disminuye de forma importante hasta $A=300$, y permanece prácticamente constante con el ancho de la cámara.

- En cámaras con esbelteces altas $(A>500)$, el aire apenas se mueve, domina la conducción.

- La simulación muestra que el caudal de ventilación provocado por convección natural en las cámaras abiertas aumenta con la presencia de la radiación solar, del orden del 15\% sobre los casos sin radiación solar.

\subsubsection{Cámara de aire óptima}

En la presente tesis se estudian diferentes configuraciones de fachada doble piel, variando el ancho de la cámara y bajo diferentes condiciones de contorno. Después de analizar los resultados obtenidos desde el punto de vista de la temperatura media en la habitación, la temperatura media en la cámara, la distribución de temperaturas y la tasa de transferencia de calor; se concluye que el ancho de cámara óptima es del orden de la esbeltez $A=30$ porque en el escenario de invierno valores menores no mejoran el aislamiento para el caso de cámara cerrada, que es la más eficiente, y valores más altos aíslan significativamente menos. El valor de $A=30$ también es adecuado para el escenario de verano como se explica más adelante en el apartado 5.1.2.6. Además, esta esbeltez supone un ancho de cámara moderado.

Ahora se calcula el flujo de calor que es necesario aportar para cada situación en el caso de $A=30$, para que la temperatura en la habitación sea de $20^{\circ} \mathrm{C}$. La Figura 5.12 muestra los resultados obtenidos.

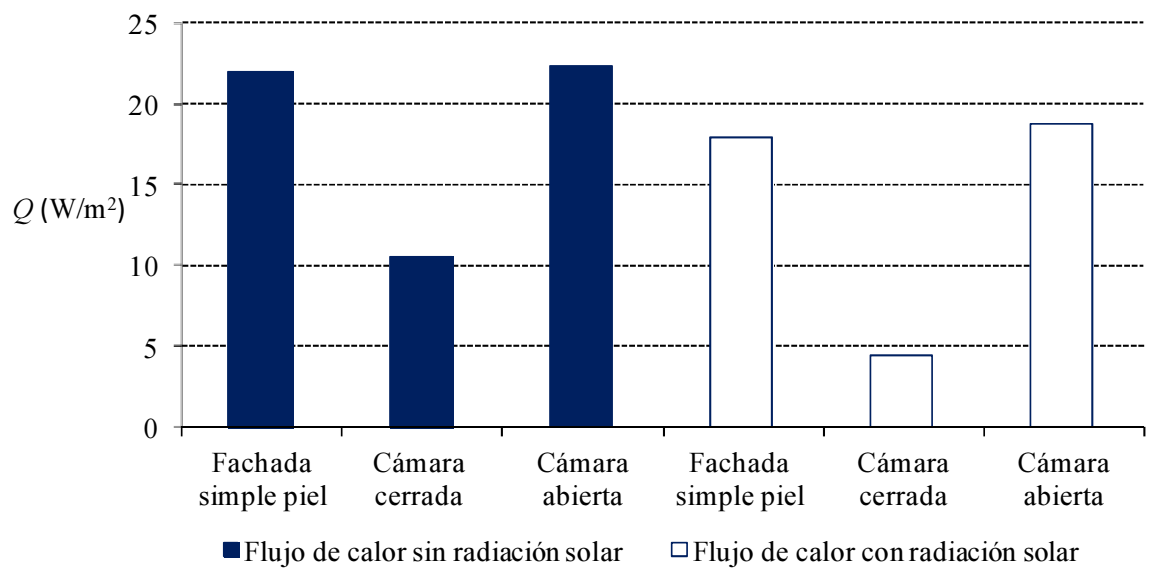

Figura 5.12. Flujo de calor para la fachada simple piel y para $A=30$ para mantener la temperatura de la habitación a $20^{\circ} \mathrm{C}$ en invierno. 
Por un lado se agrupan los casos con radiación solar, y por otro los casos sin radiación solar. Se observa que en ambas situaciones, el flujo de calor que es necesario aportar para la fachada doble piel es menor que el necesario para la fachada simple piel, a excepción de los casos de cámara abierta.

\subsubsection{Condiciones de verano}

\subsubsection{Temperatura media en el ambiente interior}

Se utiliza la fachada simple piel como caso de referencia con el que comparar los resultados obtenidos. Se calcula el calor que es necesario extraer para que la temperatura de la habitación se mantenga a $26{ }^{\circ} \mathrm{C}$ (temperatura de confort para las condiciones de verano) tanto para los casos con radiación solar como para los casos sin radiación solar.

De esta manera resulta que los flujos de calor de referencia $\left(Q_{r e f}\right)$ son de $-10,50 \mathrm{~W} / \mathrm{m}^{2}$ y $-4,6 \mathrm{~W} / \mathrm{m}^{2}$ para los casos con radiación solar y sin radiación solar, respectivamente. Para las simulaciones del escenario de verano, el flujo de calor se simula mediante un sumidero de calor uniformemente distribuido en el límite superior del ambiente interior.

La Figura 5.13 muestra la variación de la temperatura media en la habitación en función de la esbeltez $A$ en el escenario de verano bajo diferentes condiciones: cámara abierta y cerrada, con y sin radiación solar.

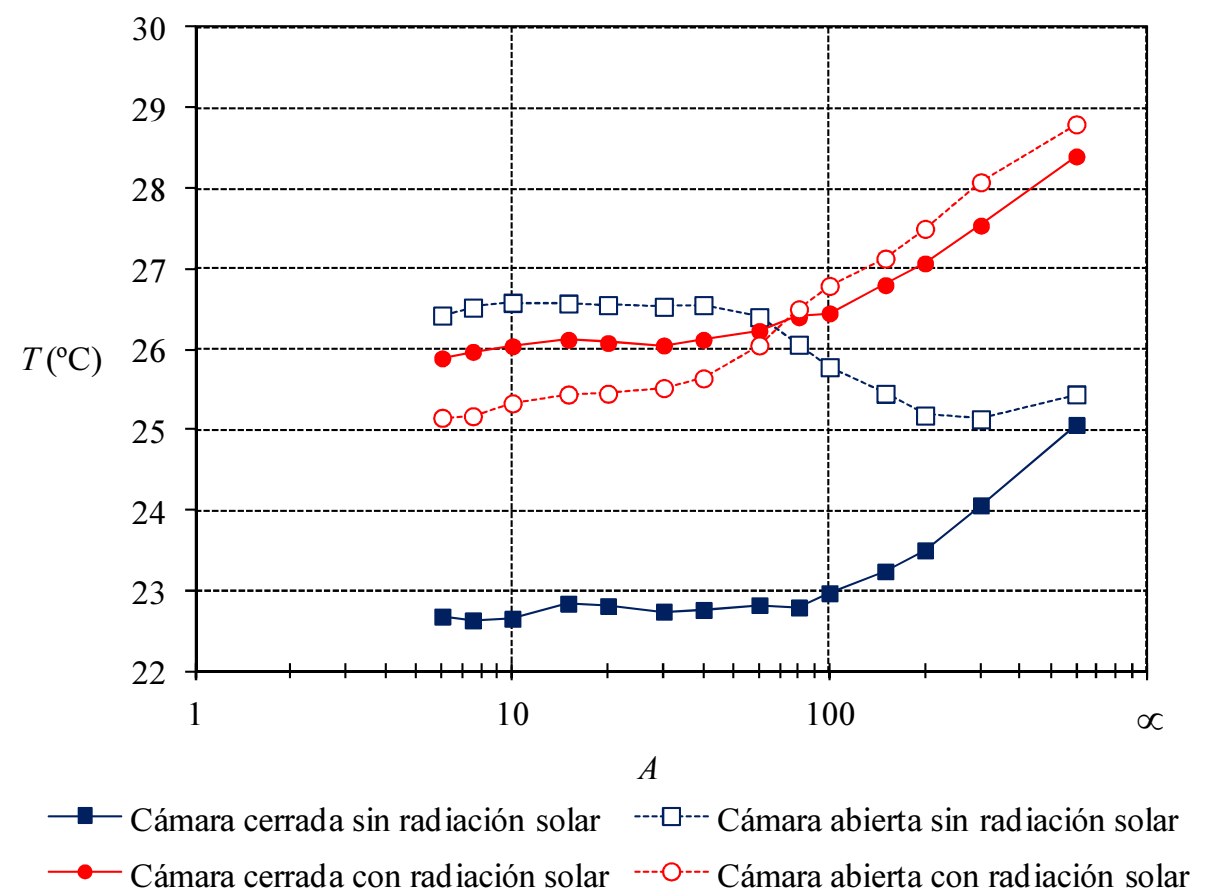

Figura 5.13. Temperatura media en la habitación en el escenario de verano.

La Figura 5.14 representa la variación de la temperatura media adimensional $T^{+}$en la habitación respecto de la fachada simple piel (caso de referencia), en función de la esbeltez $A$ en el escenario de verano y bajo diferentes condiciones. 


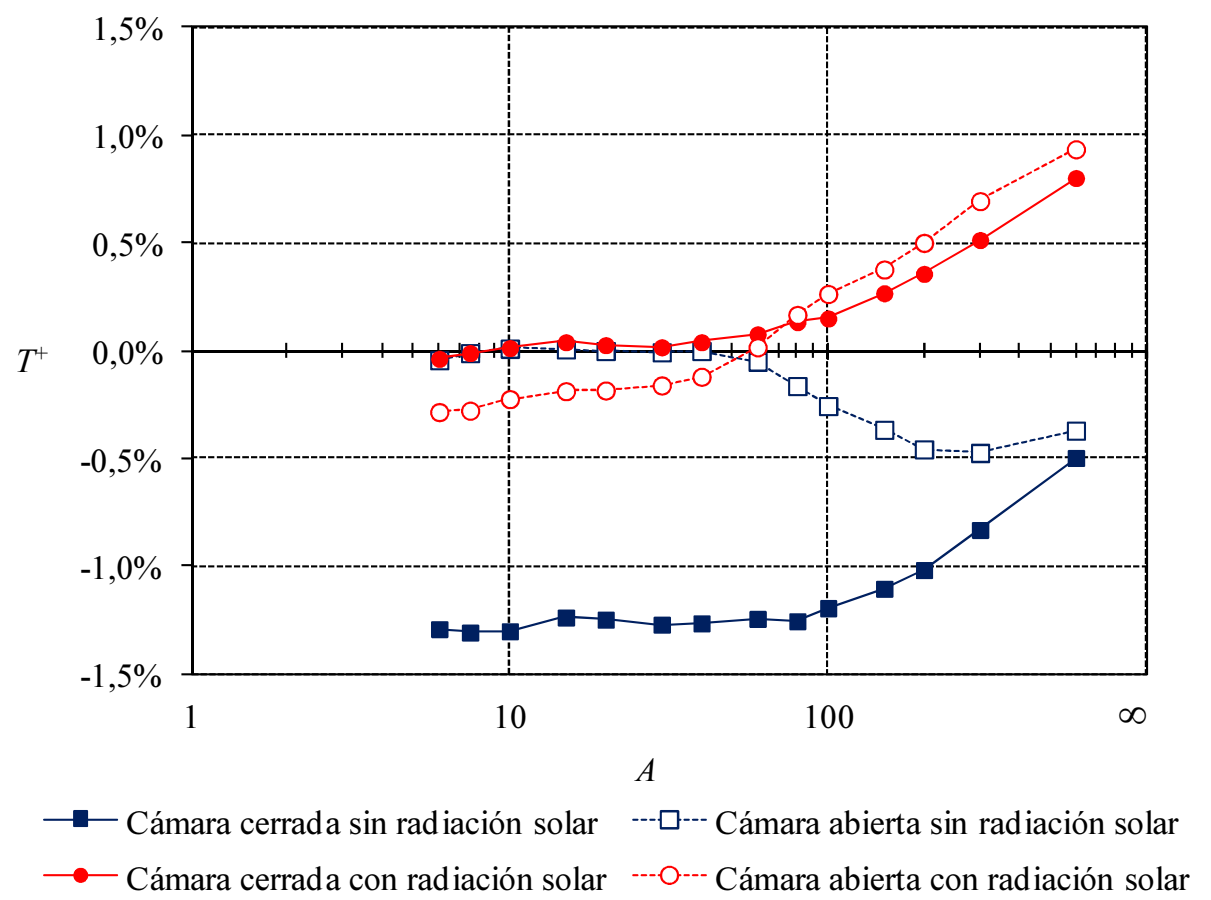

Figura 5.14. Temperatura media adimensional en la habitación en el escenario de verano.

Por un lado, se obtuvieron los siguientes resultados desde el punto de vista de la esbeltez de la cámara:

Para la situación de cámara cerrada:

- Sin radiación solar:

- Para $A<15$, la temperatura media permanece prácticamente constante con $A$. En esta sección domina el régimen de la capa límite.

- Para $15 \leq A \leq 80$, la temperatura permanece constante y domina el régimen de transición.

- Para $A>80$, la temperatura media en la habitación aumenta con $A$, domina el régimen de conducción.

- Con radiación solar:

- Para $A \leq 15$, se observa un ligero aumento de la temperatura con $A$. En esta sección domina el régimen de la capa límite.

- Para $15 \leq A \leq 60$, la temperatura permanece constante y domina el régimen de transición. 
- Para $A>60$, la temperatura media en la habitación aumenta con $A$ y domina el régimen de conducción.

En el caso de cámara abierta:

- Sin radiación solar:

- Para $A<40$, la temperatura permanece constante a prácticamente la temperatura de referencia que se obtiene con el sistema de fachada simple piel.

- Para $40 \leq A \leq 200$, la temperatura media en la habitación disminuye con $A$.

- Para $A>200$, la temperatura aumenta ligeramente con $A$, pero siempre por debajo de la temperatura de referencia.

- Con radiación solar:

- Para $6 \leq A \leq 600$, la temperatura media en la habitación siempre aumenta con $A$. Este hecho es debido al aumento del efecto chimenea en presencia de la radiación solar. La fachada doble piel es lo suficientemente eficaz para extraer la ganancia de calor solar del interior de la cámara y mantener la temperatura de la superficie interior baja, gracias al efecto chimenea. Sin embargo, la temperatura de la superficie exterior de la fachada doble piel es muy elevada por la absorción de calor por parte del vidrio.

\subsubsection{Distribución de temperatura en la cámara de aire}

Como se explicó anteriormente, el régimen del flujo puede clasificarse en conducción, transición y capa límite, dependiendo del número de Rayleigh y de la esbeltez.

Las Figuras 5.15 y 5.16 muestran la distribución de temperatura adimensional $T^{*}$, en función de la distancia horizontal adimensional en la cámara $\left(X^{*}=x / H\right)$, desde la pared caliente de la cámara hasta la pared fría, para esbelteces de 150,30 y 7,5 y para los casos sin y con radiación solar, respectivamente. Se traza el perfil de temperatura adimensional en la cámara de aire para una sección horizontal dada para diferentes posiciones verticales adimensionales en la cámara $\left(Y^{*}=y / H\right)$, que son $Y^{*}=0,0065$; 0,$0374 ; 0,5 ; 0,9681 ; \mathrm{y} 0,9935$. 

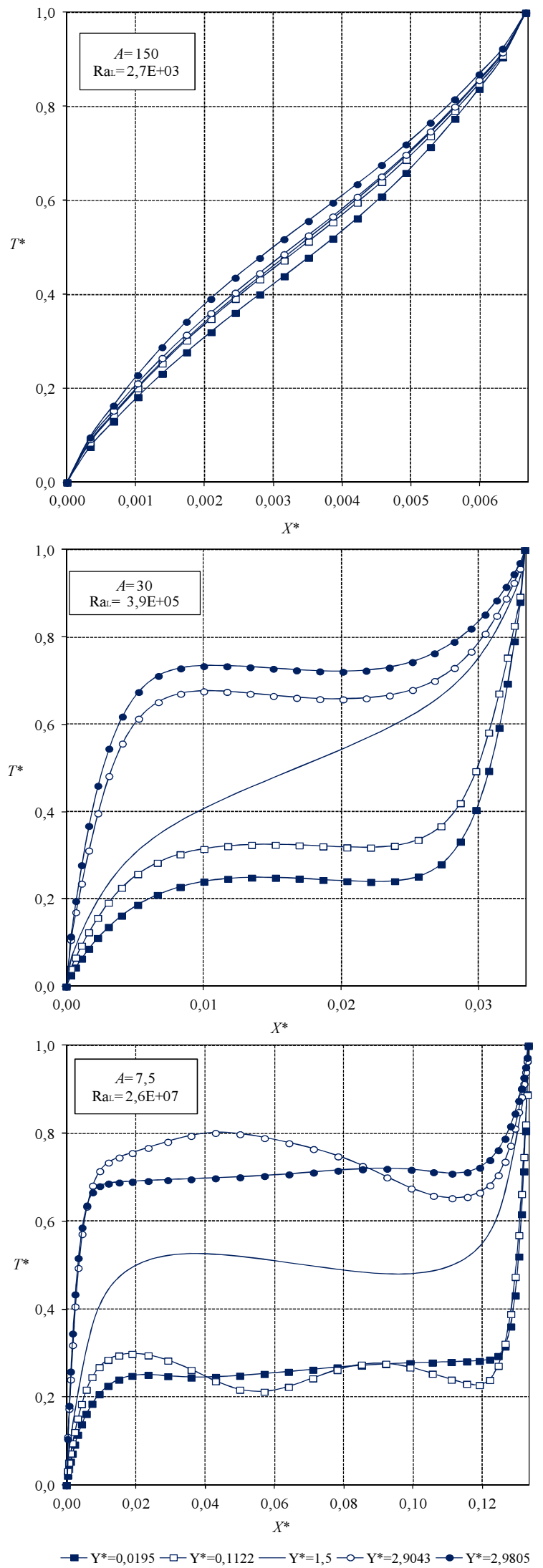

Figura 5.15. Perfil de temperatura en la cámara de aire para una sección horizontal dada para diferentes posiciones verticales: $A=150$, Régimen de Conducción; $A=30$, Régimen de Transición; $A=7,5$, Régimen de la Capa Límite, en condiciones de verano, cámara cerrada y sin radiación solar. 
Optimización de la fachada de doble piel acristalada con ventilación natural. Metodología de diseño para el análisis de la eficiencia energética del sistema.
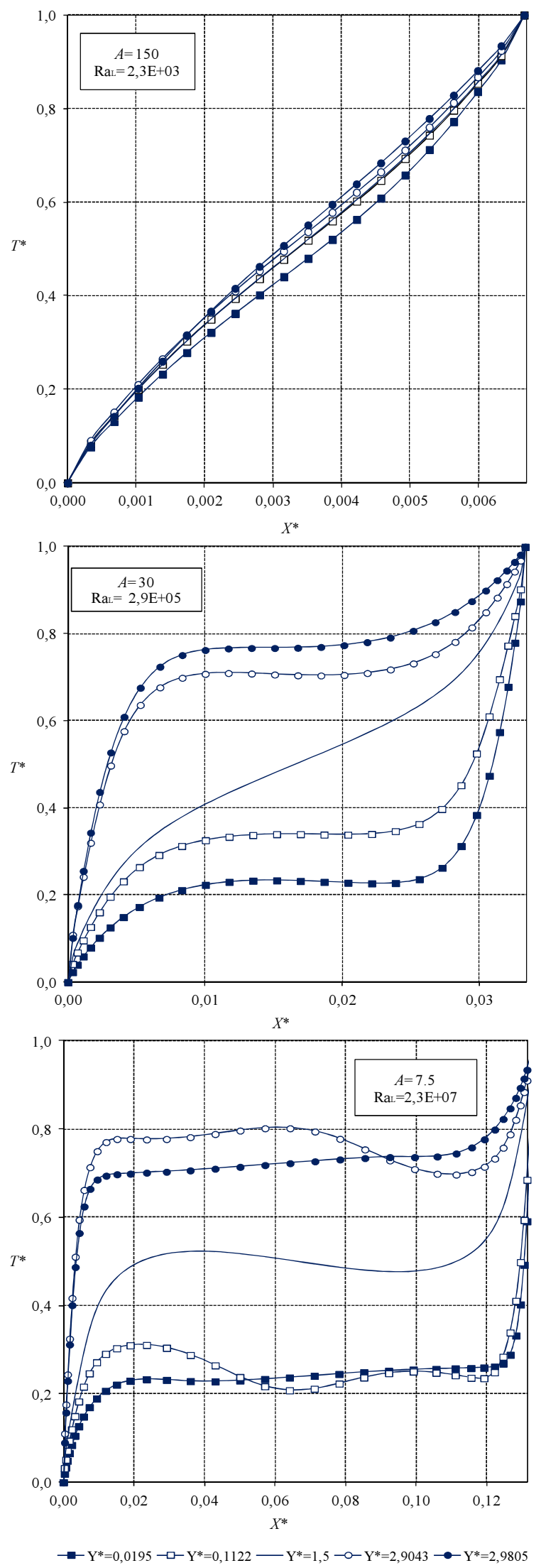

Figura 5.16. Perfil de temperatura en la cámara de aire para una sección horizontal dada para diferentes posiciones verticales: $A=150$, Régimen de Conducción; $A=30$, Régimen de Transición; $A=7,5$, Régimen de la Capa Límite, en condiciones de verano, cámara cerrada y con radiación solar. 
En todas las situaciones, estando la radiación solar presente o no, así como si la cámara de aire está abierta o cerrada, la temperatura media en la cámara de aire siempre es mayor que la temperatura media en la habitación. La temperatura media en la cámara de aire aumenta por la radiación solar absorbida.

En la situación de la cámara de aire cerrada sin radiación solar, se obtienen los siguientes regímenes:

- Régimen de la capa límite, hasta $A=15, \mathrm{Ra}_{\mathrm{L}} \geq 10^{7}$

- Régimen de transición, desde $A=60$ hasta $A=15,10^{4}<\mathrm{Ra}_{\mathrm{L}}<10^{7}$

- Régimen de conducción, a partir de $A=60, \mathrm{Ra}_{\mathrm{L}} \leq 10^{4}$

En la situación de la cámara de aire cerrada con radiación solar, se obtienen los siguientes regímenes:

- Régimen de la capa límite, hasta $A=15, \mathrm{Ra}_{\mathrm{L}} \geq 10^{7}$

- Régimen de transición, desde $A=40$ hasta $A=15,10^{4}<\mathrm{Ra}_{\mathrm{L}}<10^{7}$

- Régimen de conducción, a partir de $A=40, \mathrm{Ra}_{\mathrm{L}} \leq 10^{4}$

\subsubsection{Transferencia de calor}

La Figura 5.17, representa la tasa de transferencia de calor en las cámaras de aire cerradas y las correlaciones obtenidas tanto con radiación solar como sin ella, en el escenario de verano.

La transferencia de calor obtenida se comparó con varias correlaciones de los números de Nusselt de la bibliografía y se observó que concordaban con los resultados obtenidos por Wright y Elsherbiny, como ya se ha explicado anteriormente en el apartado 5.1.1.3.

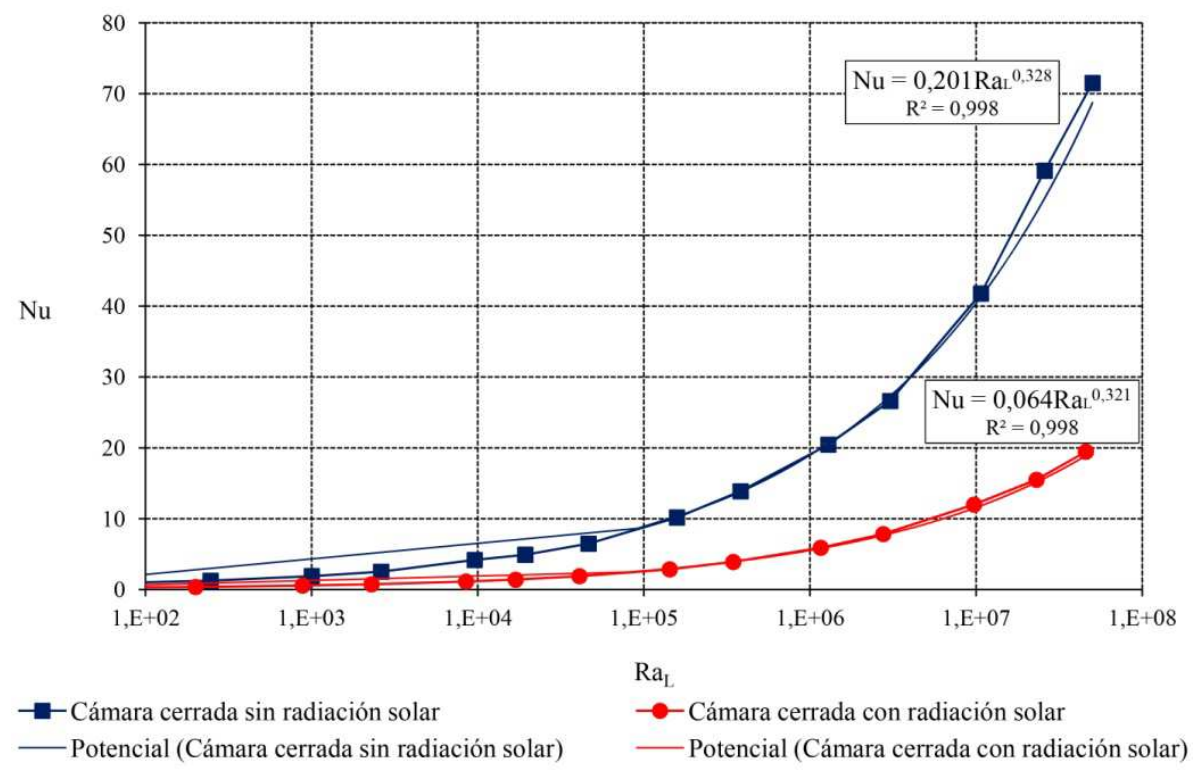

Figura 5.17. Tasa de transferencia de calor en el escenario de verano. 


\subsubsection{Comportamiento del flujo de aire en el ambiente interior}

Las siguientes figuras muestran el comportamiento del aire en el ambiente interior para el caso de convección natural. Para ello se han escogido los gráficos de contorno de distribución de temperatura y líneas de corriente coloreadas por temperatura.

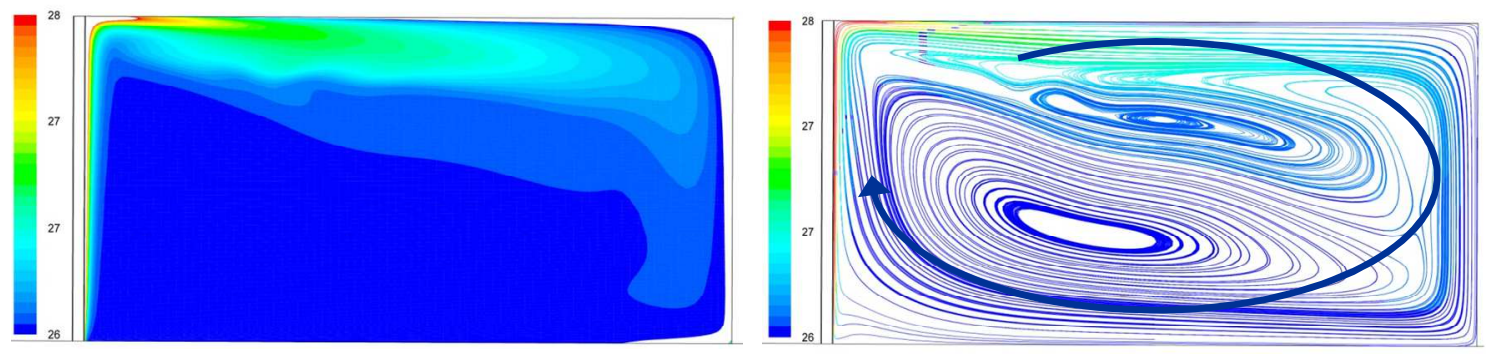

Figura 5.18. Contorno de distribución de temperatura y líneas de corriente coloreadas por temperatura en el escenario de verano.

Se observa que en el escenario de verano el ambiente exterior está más caliente que el ambiente interior, con lo que el aire se calienta en contacto con el vidrio de la derecha, que está más caliente, por lo que disminuye su densidad y sube por el vidrio hasta alcanzar el techo donde se encuentra con la fuente de calor. Allí se enfría, disminuye su densidad por lo que desciende por el lado derecho de la habitación y se acumula en la parte inferior de la misma, donde vuelve a entrar en contacto con el vidrio, se calienta y se repite el proceso.

\subsubsection{Comportamiento del flujo de aire en el interior de la cámara}

Las siguientes figuras muestran el movimiento del flujo de aire en el interior de la cámara para el caso de $A=30$ con y sin radiación solar, y con cámara cerrada y abierta, en el escenario de verano, representado mediante vectores velocidad coloreados por temperatura.
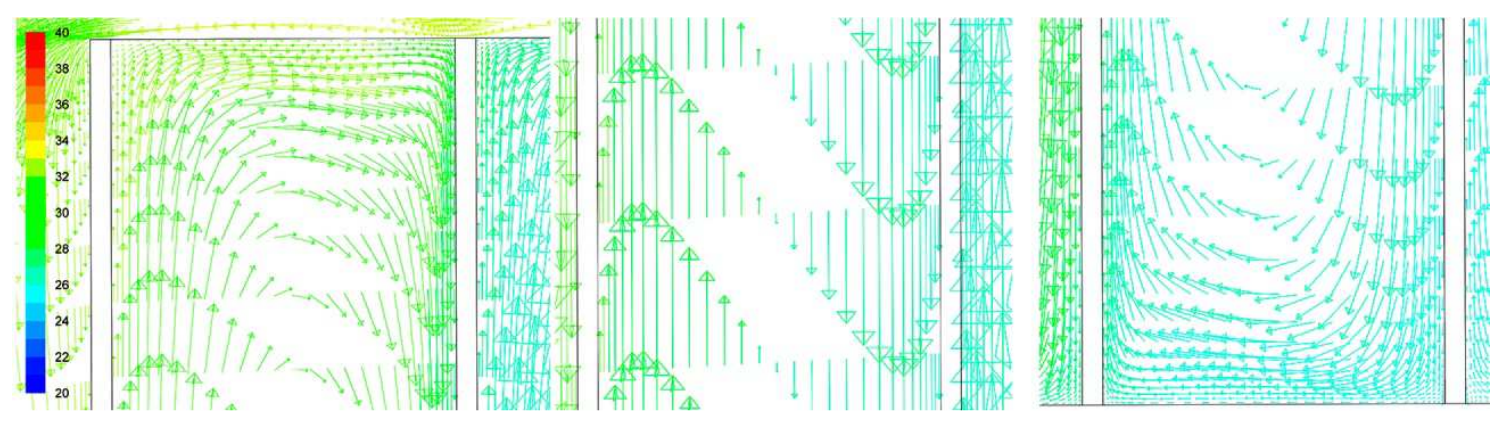

Figura 5.19. Vectores velocidad coloreados por temperatura $\left({ }^{\circ} \mathrm{C}\right.$ ) en el extremo superior (imagen izquierda), zona media (imagen central) y extremo inferior (imagen derecha) de la cámara de aire, para el caso de $A=30$ en condiciones de verano cámara cerrada y sin radiación solar. 


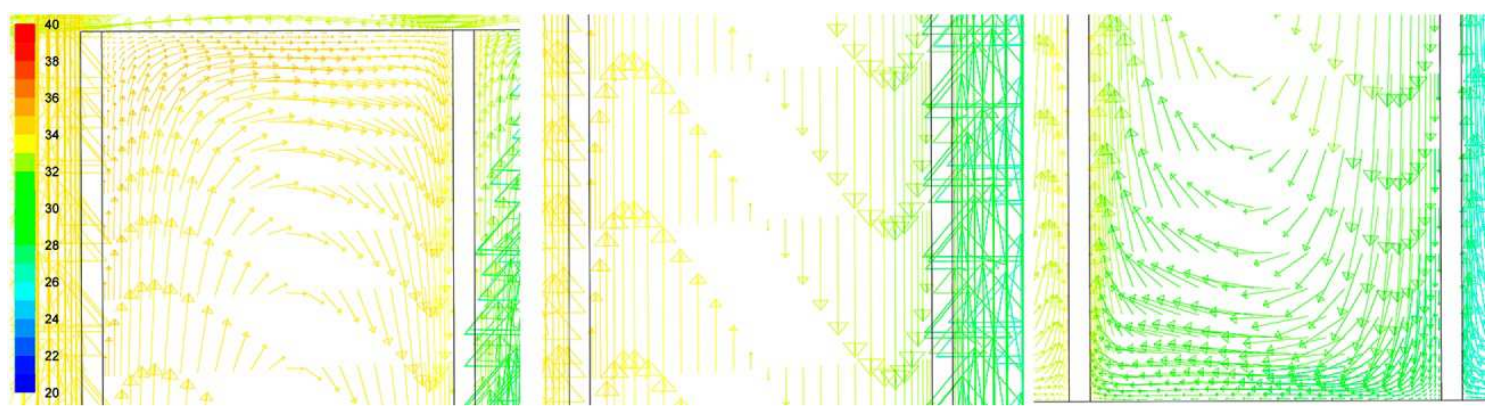

Figura 5.20. Vectores velocidad coloreados por temperatura $\left({ }^{\circ} \mathrm{C}\right)$ en el extremo superior (imagen izquierda), zona media (imagen central) y extremo inferior (imagen derecha) de la cámara de aire, para el caso de $A=30$ en condiciones de verano cámara cerrada y con radiación solar.
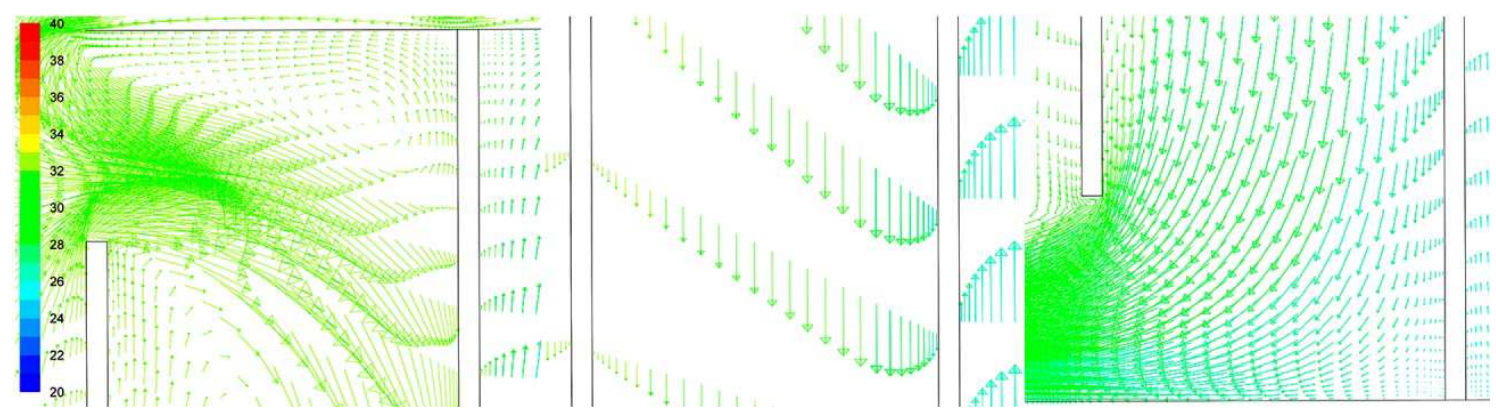

Figura 5.21. Vectores velocidad coloreados por temperatura $\left({ }^{\circ} \mathrm{C}\right)$ en el extremo superior (imagen izquierda), zona media (imagen central) y extremo inferior (imagen derecha) de la cámara de aire, para el caso de $A=30$ en condiciones de verano cámara abierta y sin radiación solar.
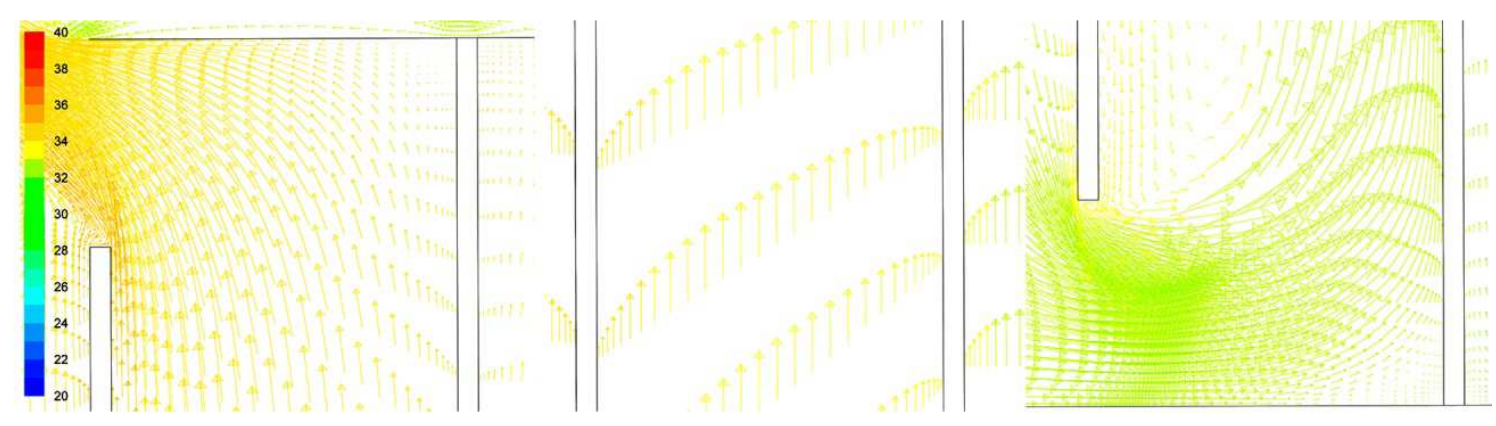

Figura 5.22. Vectores velocidad coloreados por temperatura $\left({ }^{\circ} \mathrm{C}\right.$ ) en el extremo superior (imagen izquierda), zona media (imagen central) y extremo inferior (imagen derecha) de la cámara de aire, para el caso de $A=30$ en condiciones de verano cámara abierta y con radiación solar.

Cuando la cámara está cerrada, se observan unos torbellinos de recirculación en los extremos superior e inferior de la cámara, y el movimiento del aire es cíclico.

En el caso de cámara abierta sin radiación solar, el aire entra por la abertura de salida, baja por la cámara y sale por la abertura de entrada. Esto es debido a que en condiciones de verano como el aire en la cámara está más frío que el exterior, ya que se enfría en contacto con el vidrio de la habitación que está a menor temperatura, el aire tiene mayor densidad que el exterior y por tanto baja por la cámara. También se observa un torbellino en el extremo superior de la cámara. 
En el caso de cámara abierta con radiación solar, el aire entra a través de la abertura inferior y sale por la abertura superior creando un flujo de aire mayor debido a una fuerza de convección natural mayor. Se observa un torbellino importante en el extremo inferior de la cámara.

En todas las situaciones, la temperatura media en la cámara es mayor que la temperatura media en el ambiente interior, y se observa un pico de temperatura en el extremo superior de la cámara.

En los casos con radiación solar, la temperatura media en la cámara es mayor en los casos sin radiación solar.

La Figura 5.23 representa el flujo de aire en cámaras abiertas, con radiación solar y sin ella, en relación con la esbeltez.

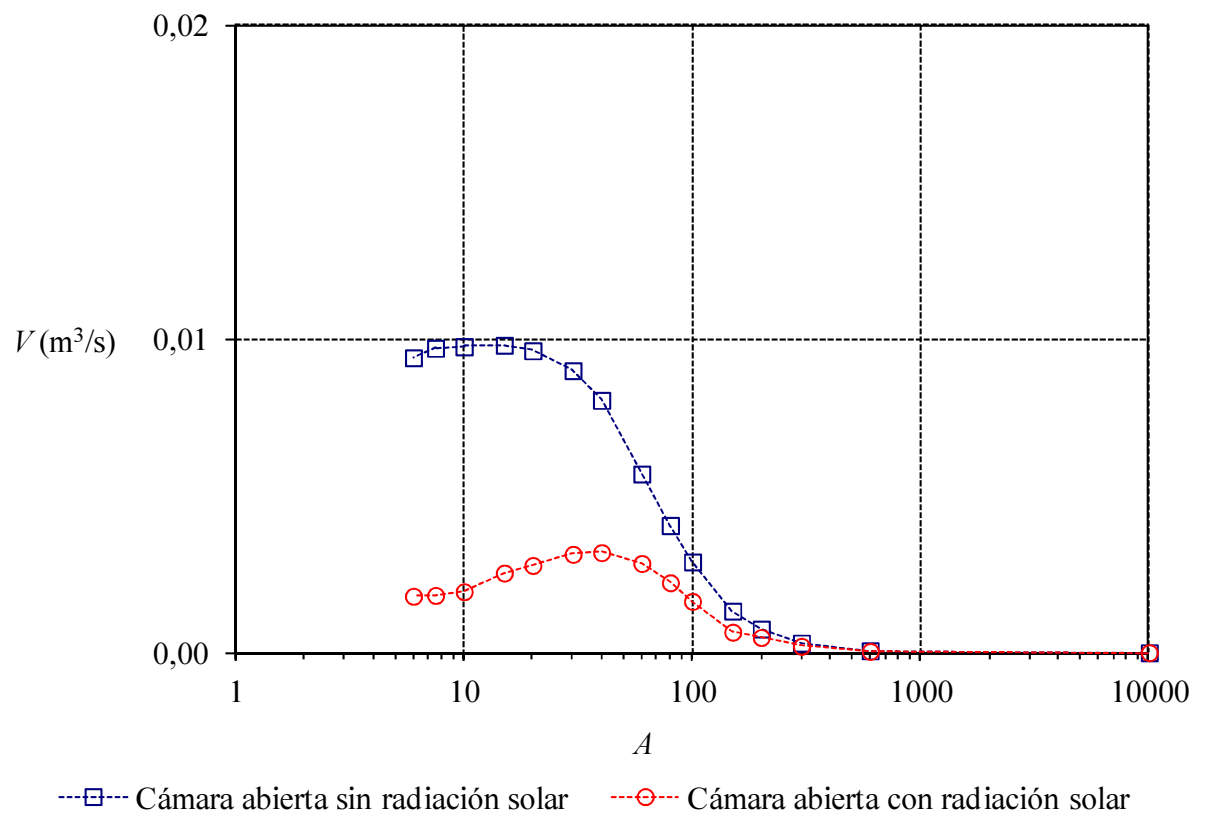

Figura 5.23. Flujo de ventilación en el escenario de verano para el caso de cámara abierta.

De los resultados obtenidos se pueden extraer las siguientes conclusiones:

- Sin radiación solar:

- El caudal de ventilación en la cámara de aire aumenta ligeramente de $A=6 \mathrm{a}$ $A=20$. A partir de ahí, disminuye de forma importante hasta $A=300$.

- El caudal de ventilación es mayor para los casos de sin radiación solar, del orden del $190 \%$ respecto a los casos con radiación solar.

- Con radiación solar:

- El caudal de ventilación aumenta de $A=6$ a $A=40$. A partir de ahí disminuye con la esbeltez hasta $A=300$. 
- En cámaras con altas esbelteces $(A>500)$, el aire apenas se mueve, domina la conducción.

\subsubsection{Cámara de aire óptima}

Se concluye que el ancho óptimo para la cámara de aire es del orden de $A=30$ porque en el escenario de verano a partir de $A=30$ comienza a aislar menos incluso en el caso de cámara cerrada.

Ahora se calcula el flujo de calor que es necesario extraer para el caso de $A=30$, de manera que la temperatura en la habitación sea de $26{ }^{\circ} \mathrm{C}$. La Figura 5.24 muestra los resultados obtenidos.

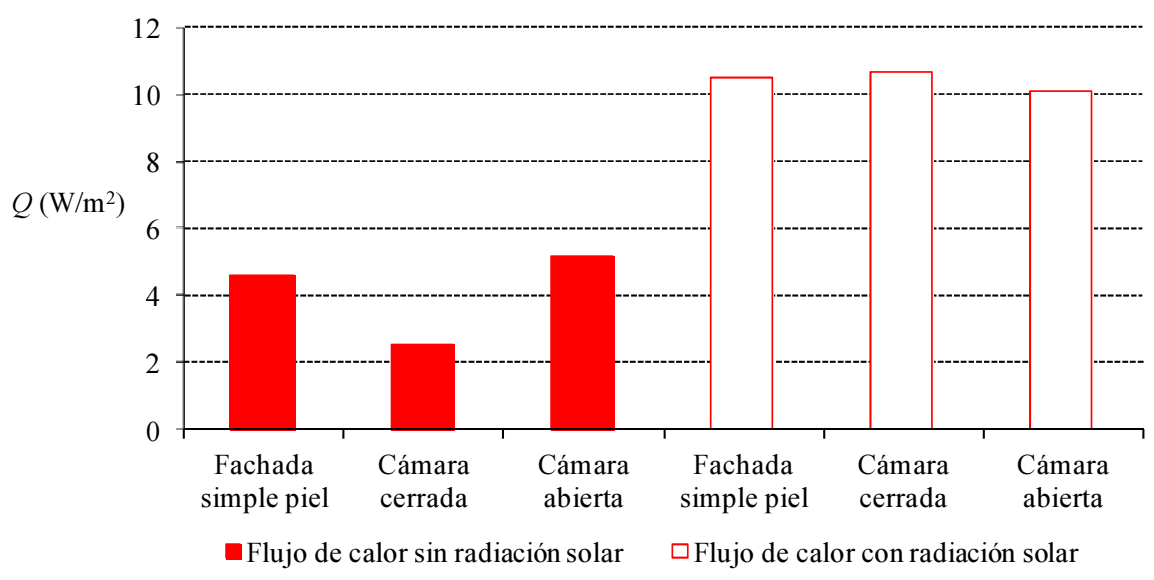

Figura 5.24. Flujo de calor para la fachada simple piel y $A=30$ para mantener la temperatura de la habitación a $26^{\circ} \mathrm{C}$ en verano.

Por un lado, se agrupan los casos con radiación solar, y por otro, los casos sin radiación solar. Se observa que en ausencia de radiación solar, el flujo de calor que se necesita extraer con el sistema de fachada doble piel es menor que el necesario para la fachada simple piel, excepto en los casos de cámara abierta; y en presencia de radiación solar es justo al contrario. Por lo que interesa mantener la cámara cerrada sin radiación solar y abrirla con radiación solar.

\subsubsection{Optimización de las aberturas}

Una vez obtenido el ancho de cámara óptimo, se decidió estudiar la dimensión de la abertura óptima. Hasta ahora todas las simulaciones se habían realizado con una abertura de tamaño igual a $h_{v}=0,06 \mathrm{~m}$. El objetivo es estudiar qué tamaño de abertura es el óptimo que mejore las condiciones del ambiente interior sin más consumo de energía. El tamaño de la abertura de entrada será igual al tamaño de la abertura de salida en todos los casos.

Se estudia la optimización de las aberturas en el único caso en el que se ahorra energía teniendo las aberturas de la cámara abiertas, es decir, en condiciones de verano con cámara abierta y con radiación solar. En este caso, el calor que había que extraer de la habitación para que se quedara a la temperatura de confort de $26{ }^{\circ} \mathrm{C}$ era de $Q=-10,08$ 
$\mathrm{W} / \mathrm{m}^{2}$ frente a los $-10,50 \mathrm{~W} / \mathrm{m}^{2}$ que se necesitan en el caso de fachada simple piel con sol. Abriendo las aberturas se produce un ahorro del $4 \%$.

Se decide estudiar la optimización de las aberturas en múltiplos de 3 , desde $0,01 \mathrm{~m}$ hasta $0,30 \mathrm{~m}$, porque la altura de la cámara es de $3 \mathrm{~m}$. También se estudian algunos casos extremos como el de $h_{v}=0,50 \mathrm{~m}$ y a $h_{v}=1 \mathrm{~m}$ para ver si se producía un cambio significativo en los resultados obtenidos. Esto hace un total de 12 casos de estudio.

Una vez realizadas las simulaciones, se analizan los resultados prestando especial atención a los resultados de la temperatura media de la habitación y al caudal de aire en la cámara. La Figuras 5.25 y 5.27 muestran la temperatura media en la habitación y el flujo de ventilación en la cámara en el escenario de verano con cámara abierta para los diferentes tamaños de aberturas estudiadas, respectivamente.

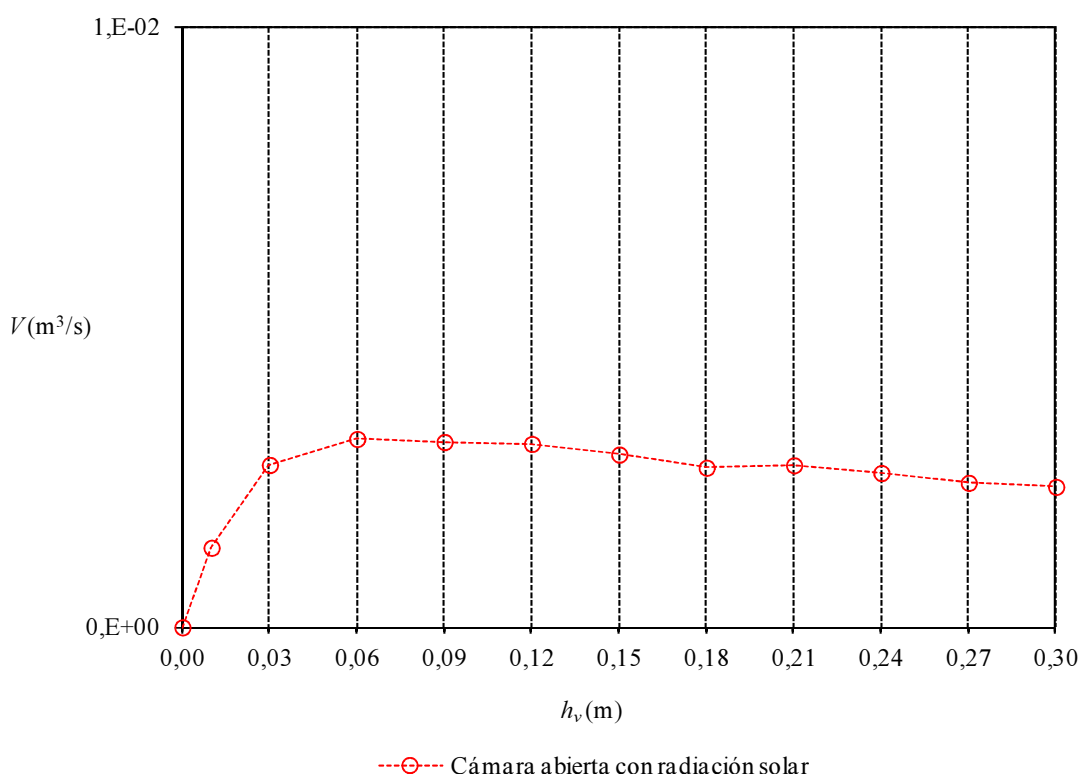

Figura 5.25. Flujo de ventilación en el escenario de verano para el caso de cámara abierta.

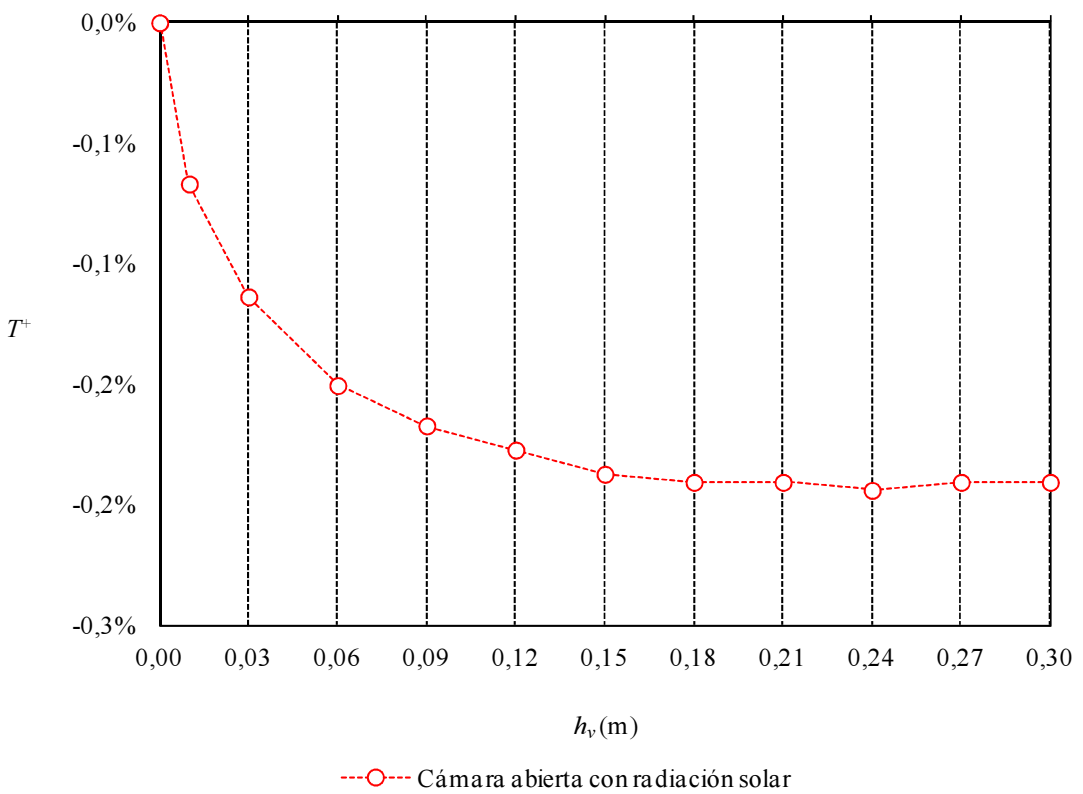

Figura 5.26. Temperatura media adimensional en la habitación en el escenario de verano para el caso de cámara abierta. 


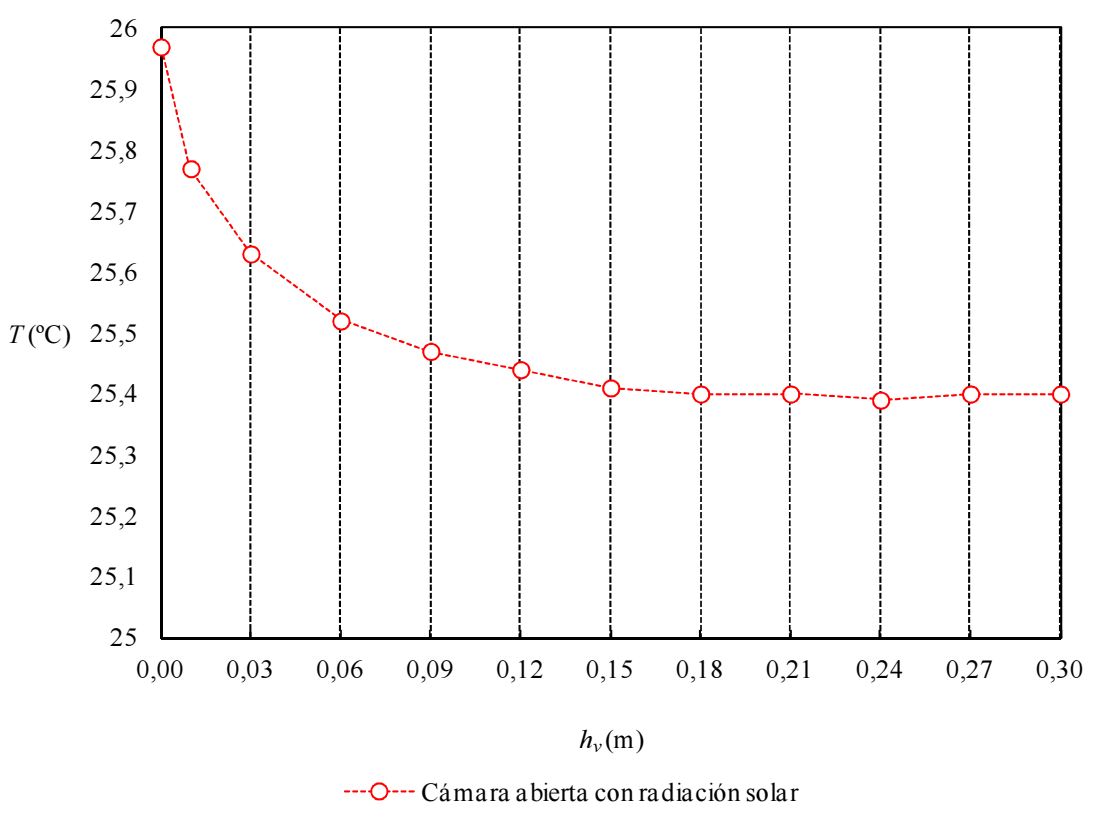

Figura 5.27. Temperatura media en la habitación en el escenario de verano para el caso de cámara abierta.

Los resultados obtenidos reflejan que interesa más elegir la dimensión de las aberturas en función del caudal de ventilación en la cámara de aire porque es una variable más significativa que la temperatura media en la habitación ya que ésta sólo varía alrededor de medio grado entre las aberturas más pequeñas y las más grandes estudiadas.

En vista de los resultados obtenidos, se ha comprobado que la abertura óptima para el caso de la cámara óptima $A=30$ es el de $h_{v}=0,06 \mathrm{~m}$ ya que es el tamaño de abertura que produce mayor caudal de ventilación.

Como ha resultado que la cámara óptima es de la misma dimensión que la utilizada en las simulaciones ya realizadas, ahorró el tener que volver a hacer más cálculos.

\subsubsection{Análisis de eficiencia energética}

En este apartado de la presente tesis, se compara el comportamiento térmico de una fachada doble piel respecto a una fachada simple piel de una habitación situada en la zona centro de España, en particular en Madrid, teniendo en cuenta solamente el movimiento del aire producido por convección natural. El objetivo es alcanzar o identificar una configuración de fachada más eficiente que mejore la eficiencia energética del edificio permitiendo unas condiciones de confort óptimas en el interior de la habitación. Se define el concepto de eficiencia energética como la cantidad de energía suministrada para mantener unas condiciones dadas con el menor consumo energético posible. Se ha utilizado el modelo de cámara correspondiente a $A=30$, y a continuación, se analiza y se discute el índice de eficiencia energética obtenido en todos los escenarios.

Las Figuras 5.28 y 5.29 representan el índice de eficiencia energética en los escenarios de invierno y verano respectivamente. Muestran el ahorro de energía (valores positivos) o el gasto de energía (valores negativos) para cada situación. Para ello, se calcula el 
flujo de calor que se necesita aportar o extraer para que la habitación permanezca a la temperatura de confort para el caso de fachada doble piel con una cámara de aire de $A=30$, que se corresponde con el ancho de cámara óptimo alcanzado en las simulaciones. De esta forma, se calcula el porcentaje de ahorro o gasto obtenido en comparación con la fachada simple piel, caso de referencia. Para ello, el índice de eficiencia energética $(\eta)$ se ha definido utilizando la siguiente fórmula:

$$
\eta=\left(Q-Q_{r e f}\right) / Q_{r e f}
$$

donde $Q$ es el flujo de calor obtenido; y $Q_{\text {ref }}$ es el flujo de calor de referencia.

En el escenario de invierno, los flujos de calor de referencia son $17,9 \mathrm{~W} / \mathrm{m}^{2}$ y $22 \mathrm{~W} / \mathrm{m}^{2}$ con y sin radiación solar, respectivamente. En el escenario de verano, los flujos de calor de referencia son $-10,5 \mathrm{~W} / \mathrm{m}^{2}$ y $-4,6 \mathrm{~W} / \mathrm{m}^{2}$ con y sin radiación solar respectivamente.

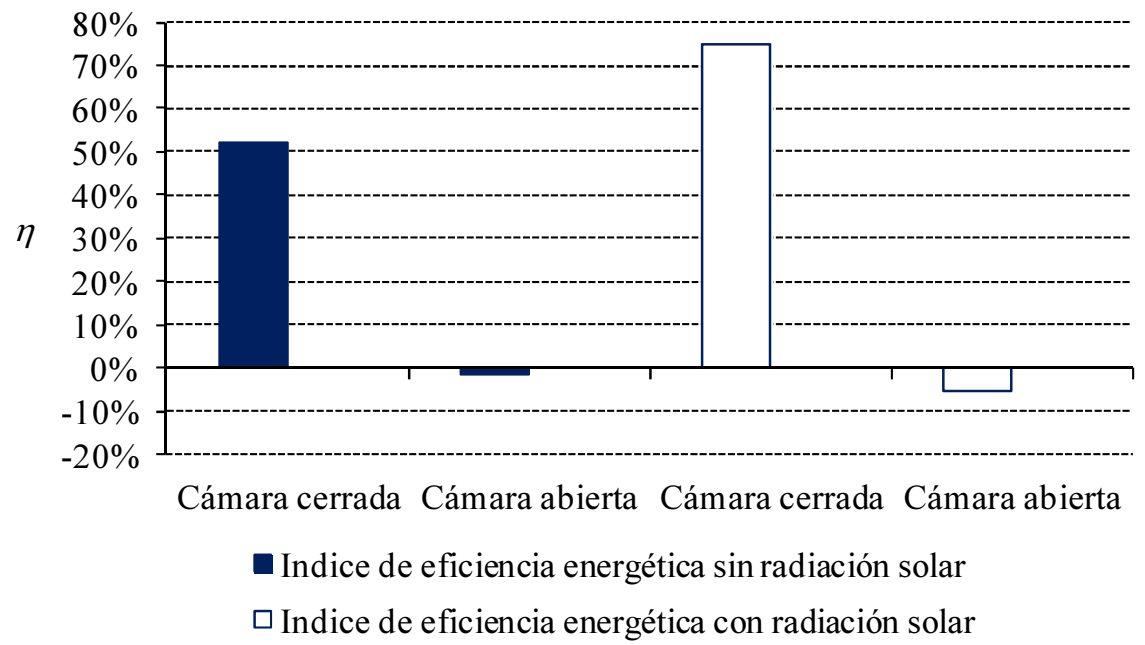

Figura 5.28. Índice de eficiencia energética en el escenario de invierno.

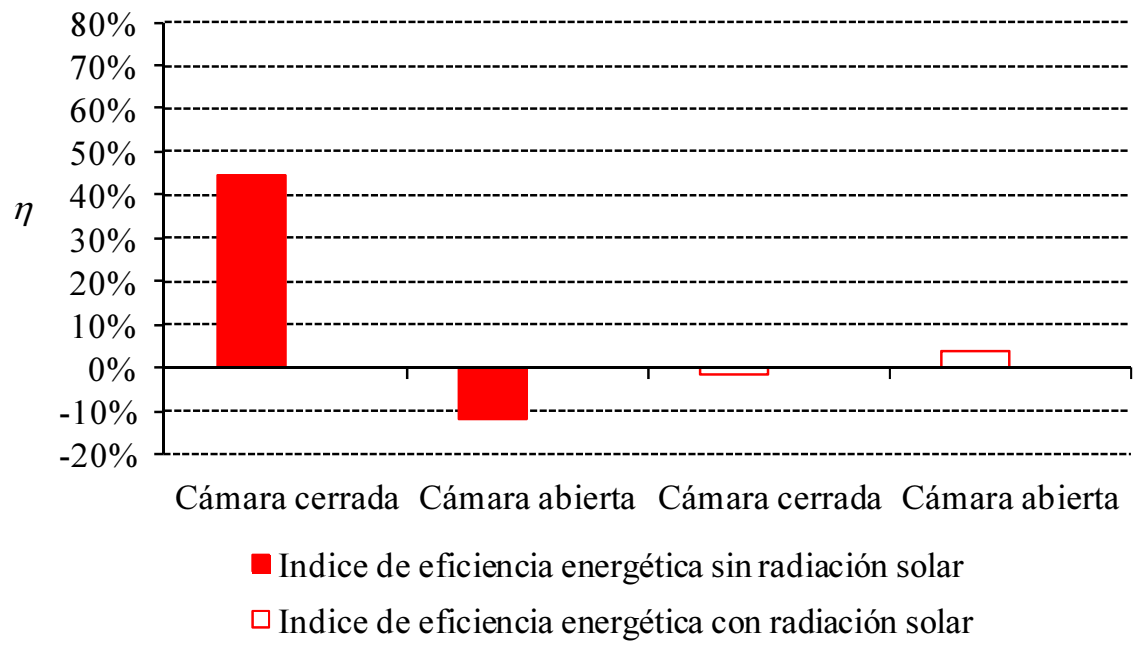

Figura 5.29. Índice de eficiencia energética en el escenario de verano. 
La Tabla 5.1 muestra los resultados obtenidos para los escenarios de invierno y verano:

\begin{tabular}{|c|c|c|c|c|}
\hline Escenario & Radiación Solar & Aberturas & $\begin{array}{c}\text { Ahorro de Energía } \\
(\%)\end{array}$ & $\begin{array}{c}\text { Gasto de Energía } \\
(\%)\end{array}$ \\
\hline \multirow{4}{*}{ Invierno } & \multirow{2}{*}{ No } & Cerrado & 52,3 & \\
\hline & & Abierto & & 1,5 \\
\hline & \multirow{2}{*}{$\mathrm{Si}$} & Cerrado & 75,1 & \\
\hline & & Abierto & & 5,1 \\
\hline \multirow{4}{*}{ Verano } & \multirow{2}{*}{ No } & Cerrado & 44,3 & \\
\hline & & Abierto & & 12 \\
\hline & \multirow{2}{*}{$\mathrm{Si}$} & Cerrado & & 1,4 \\
\hline & & Abierto & 4 & \\
\hline
\end{tabular}

Tabla 5.1. Porcentaje de ahorro o gasto de energía en los escenarios de invierno y de verano en comparación con la fachada simple piel.

\subsubsection{Conclusiones}

Después de analizar los resultados obtenidos a partir de las simulaciones, se discuten las configuraciones de fachada más eficientes para ambos escenarios:

- En el escenario de invierno siempre es más eficiente cerrar la cámara, tanto en presencia de radiación solar como sin ella. De estos, el más favorable siempre es el caso en que hay radiación solar. La ventilación en la cámara de aire no es beneficiosa en ninguna circunstancia porque aumentan las pérdidas por transmisión.

- En el escenario de verano, cerrar la cámara de aire en ausencia de la radiación solar es siempre más eficiente. En presencia de radiación solar, abrir la cámara es eficiente, ya que favorece el efecto chimenea. La ventilación reduce la ganancia de calor por transmisión y, por lo tanto, la carga de refrigeración.

Se puede concluir que:

- El sistema de fachada doble piel es mejor que el sistema de fachada simple piel en los cuatro escenarios: en invierno con la cámara cerrada y con radiación solar y sin ella, en verano con la cámara cerrada y sin radiación solar, y en verano con la cámara abierta y con radiación solar.

- Cerrar la cámara de aire es más eficiente en tres de los cuatro escenarios.

- Abrir la cámara sólo es eficiente en verano con radiación solar.

- Abrir la cámara en el escenario de verano con radiación solar supone menos ahorro del que se esperaba. 
- La fachada doble piel reduce la carga de calefacción en invierno y la carga de refrigeración en verano.

- El peor escenario en condiciones de invierno es abrir la cámara en presencia de radiación solar, porque aumenta la carga de calefacción.

- El peor escenario en condiciones de verano es abrir la cámara cuando no hay radiación solar, porque aumenta la carga de refrigeración.

- El tamaño de las aberturas $h_{v}=0,06 \mathrm{~m}$ es el óptimo ya que es el que produce mayor caudal de ventilación para los casos en los que abrir la cámara es más eficiente, es decir, en el escenario de verano con radiación solar.

Se consultó el registro histórico de temperaturas en la zona centro de España, en particular en Madrid, en la base de datos de AEMET (Agencia Estatal de Meteorología Española) con el fin de determinar si la solución de fachada doble piel era más eficiente en comparación con la solución de fachada simple piel. Tal y como se ha explicado en el apartado 3.3 del Capítulo 3, el sistema de calefacción se utiliza durante 5 meses al año, el sistema de refrigeración durante 4 meses, y durante 3 meses no es necesario utilizar ningún sistema de acondicionamiento térmico.

De acuerdo con la información presentada anteriormente en las Figuras 5.28 y 5.29 y en la Tabla 5.1, se concluye que el sistema de fachada doble piel proporciona mejores resultados en términos de ahorro en comparación con el sistema de fachada simple piel tanto en el escenario de invierno como en el de verano. Es particularmente notable, que el ahorro de energía alcanza el $75 \%$ en el escenario de invierno con la cámara cerrada y en presencia de radiación solar; y hasta un $4 \%$ en el escenario de verano con la cámara abierta y con radiación solar.

La fachada doble piel mejora el rendimiento térmico de los edificios, reduce el consumo de energía para calefacción y para refrigeración en todos los escenarios estudiados, y puede ayudar a producir unas condiciones interiores confortables.

En la primera parte de este capítulo, se ha estudiado el sistema de fachada doble piel cuando la ventilación natural en la cámara está dominada por convección natural. En los siguientes apartados se analiza el comportamiento de la fachada doble piel cuando la ventilación natural está dominada por viento.

\subsection{RESULTADOS DEL FLUJO DOMINADO POR VIENTO}

El objetivo de este apartado es estudiar la influencia de la dirección y de la velocidad del viento en la ventilación natural de la cámara de aire de una fachada doble piel en comparación con una fachada convencional.

Se realiza una investigación completa que analiza el modelo de una forma más amplia: el ambiente exterior, la cámara de aire y el ambiente interior; sin variar la geometría; con las aberturas abiertas y cerradas; y bajo diferentes condiciones: condiciones de invierno y de verano con y sin radiación solar, y con viento sobre la fachada de barlovento y de sotavento con diferentes velocidades. Como en el estudio de convección 
natural se ha llegado a la conclusión de que el modelo más eficiente de cámara de aire es el de $A=30$ con unas aberturas superior e inferior de $h_{v}=0,06 \mathrm{~m}$, sólo se hacen simulaciones con esta configuración de fachada. Los resultados obtenidos se presentan mediante gráficos adimensionales.

En todas las situaciones se estudian y analizan los fenómenos que tienen lugar desde el punto de vista de la distribución de temperaturas, los regímenes del flujo, la transferencia de calor y el comportamiento del flujo de aire.

Posteriormente, se compararán los resultados obtenidos con los obtenidos en los casos de flujo dominado por convección natural.

\subsubsection{Condiciones de invierno}

\subsubsection{Temperatura media en la habitación}

El escenario de invierno se simula con cámara abierta y cerrada, con radiación solar y sin ella, y con viento en la fachada de barlovento y de sotavento. Con el fin de estudiar en profundidad el efecto del viento en la fachada doble piel, se simulan todas las situaciones con 5 velocidades distintas $v=1 ; 2,5 ; 5 ; 10 ;$ y $20 \mathrm{~m} / \mathrm{s}$.

Se utiliza la fachada simple piel como caso de referencia con el que comparar los resultados obtenidos.

El escenario de invierno se simula con un flujo de calor en el suelo de $17,9 \mathrm{~W} / \mathrm{m}^{2}$ para los casos con radiación solar, y con un flujo de calor de $22 \mathrm{~W} / \mathrm{m}^{2}$ para los casos sin radiación solar. Este es el calor que se necesita aportar para que la temperatura de la habitación se mantenga a $20{ }^{\circ} \mathrm{C}$ (temperatura de confort para las condiciones de invierno) para el caso de fachada de simple piel.

Las siguientes figuras muestran el incremento de la temperatura media en la habitación en relación con la velocidad $v$ y la dirección del viento (fachada de barlovento y de sotavento), en los casos de sin y con radiación solar. Cada caso se expresa de forma adimensional $T^{+}=\left(T-T_{r e f}\right) / T_{r e f}$, y dimensional. 
Optimización de la fachada de doble piel acristalada con ventilación natural. Metodología de diseño para el análisis de la eficiencia energética del sistema.

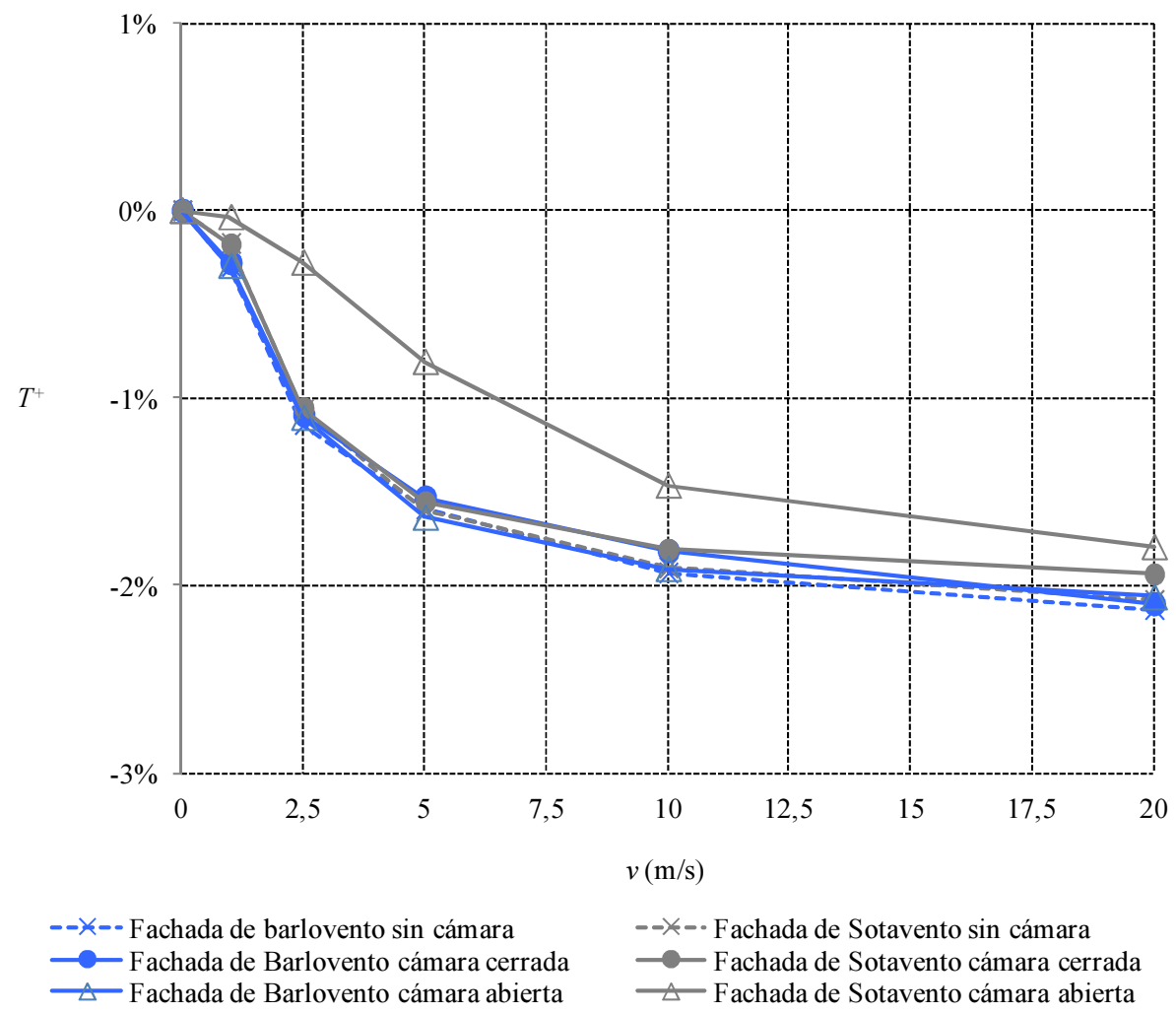

Figura 5.30. Temperatura media adimensional en la habitación para $A=30$ en el escenario de invierno y sin radiación solar.

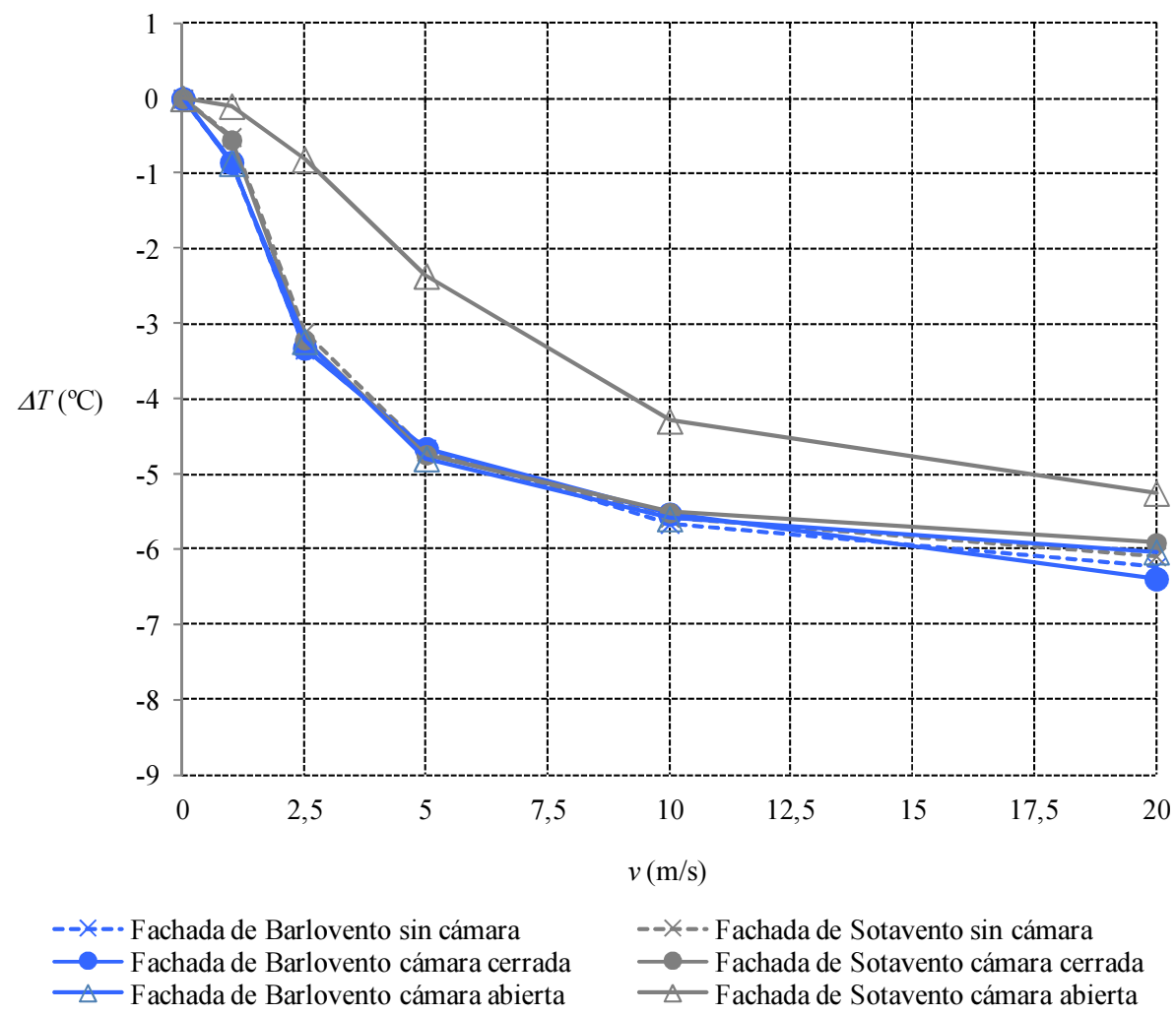

Figura 5.31. Incremento de la temperatura media en la habitación respecto del caso sin viento para $A=30$ en el escenario de invierno y sin radiación solar. 


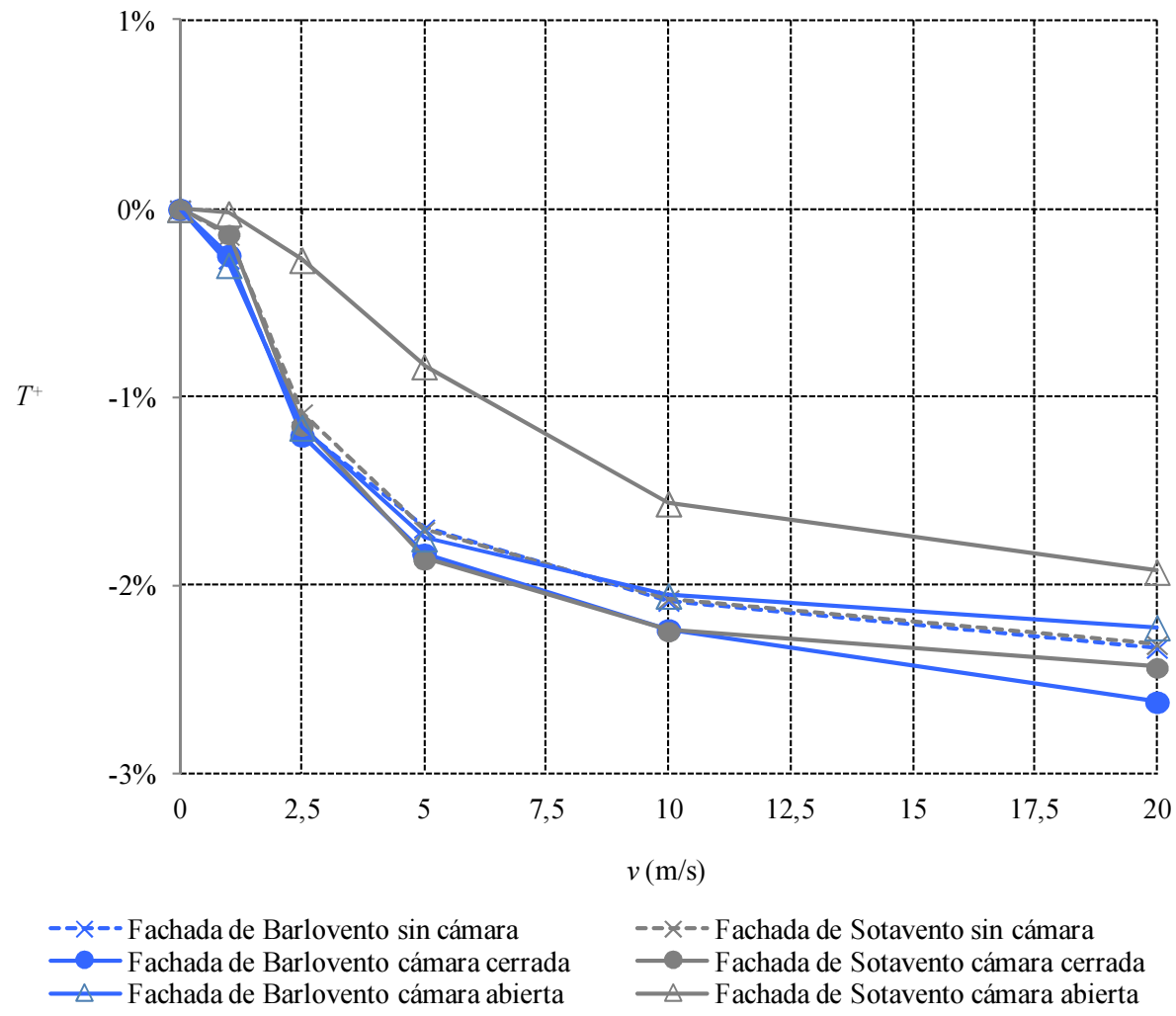

Figura 5.32. Temperatura media adimensional en la habitación para $A=30$ en el escenario de invierno y con radiación solar.

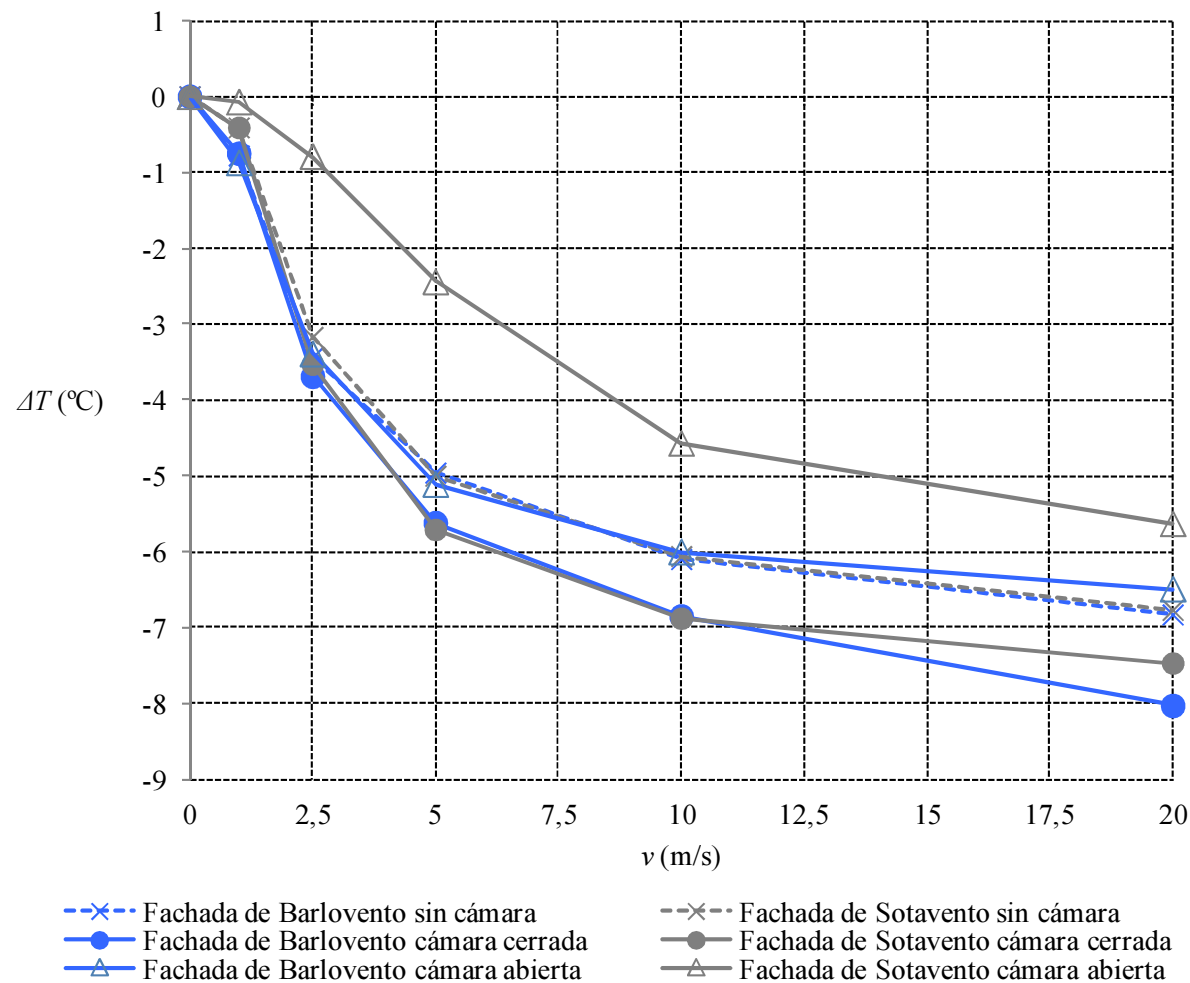

Figura 5.33. Incremento de la temperatura media en la habitación respecto del caso sin viento para $A=30$ en el escenario de invierno y con radiación solar. 
Se observa que:

- En todos los casos el viento tiene un efecto negativo en la temperatura media de la habitación, ya que la hace disminuir alejándose de la temperatura de confort $\left(20^{\circ} \mathrm{C}\right)$ conforme aumenta la velocidad del viento.

- De $v=0 \mathrm{~m} / \mathrm{s}$ a $v=10 \mathrm{~m} / \mathrm{s}$, la temperatura disminuye de forma rápida hasta alrededor de un $2 \%$.

- A partir de $v=10 \mathrm{~m} / \mathrm{s}$, la temperatura disminuye de forma más lenta.

- En el caso de cámara abierta con viento en la fachada de sotavento, el comportamiento es similar pero más lento.

\subsubsection{Distribución de temperatura en la cámara de aire}

Al igual que en los casos de flujo dominado por convección natural, se realiza un análisis de la relación entre la tasa de flujo de aire y la diferencia de temperatura entre los paños de vidrio para diferentes velocidades del viento y condiciones de contorno. Los dos paños de vidrio de la fachada doble piel separan dos ambientes a diferente temperatura, por lo tanto, se produce la transferencia de calor entre el paño caliente y el frío. Como ya se ha explicado anteriormente, el modo en el que se produce el intercambio de calor depende del número de Rayleigh.

Las Figuras 5.34 a 5.37 muestran la distribución de temperatura adimensional $T^{*}=\left(T-T_{f}\right) /\left(T_{c}-T_{f}\right)$, en función de la distancia horizontal adimensional en la cámara $\left(X^{*}=\right.$ $x / H)$, desde la pared caliente de la cámara hasta la pared fría, para la esbeltez de $A=30 \mathrm{y}$ con velocidades del viento en la fachada de barlovento y de sotavento de 1,5 y $20 \mathrm{~m} / \mathrm{s}$ y para los casos sin y con radiación solar. Se traza el perfil de temperatura adimensional en la cámara de aire para una sección horizontal dada para diferentes posiciones verticales adimensionales en la cámara $\left(Y^{*}=y / H\right)$, que son $\mathrm{Y}^{*}=0,0065 ; 0,0374 ; 0,5$; 0,9681 ; y 0,9935 . 

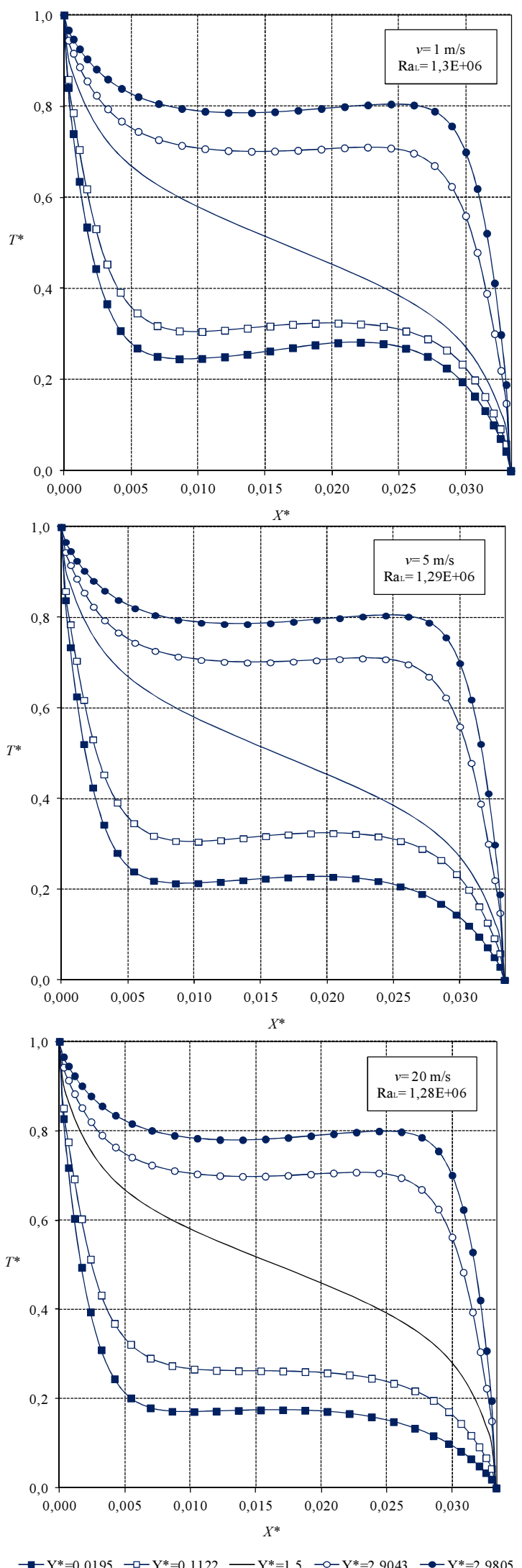

Figura 5.34. Perfil de temperatura en la cámara de aire para una sección horizontal dada para diferentes posiciones verticales: $A=30$, Régimen de Transición. En condiciones de invierno, cámara cerrada y sin radiación solar, para velocidades del viento en la fachada de barlovento de $v=1,5$ y $20 \mathrm{~m} / \mathrm{s}$ respectivamente. 
Optimización de la fachada de doble piel acristalada con ventilación natural. Metodología de diseño para el análisis de la eficiencia energética del sistema.
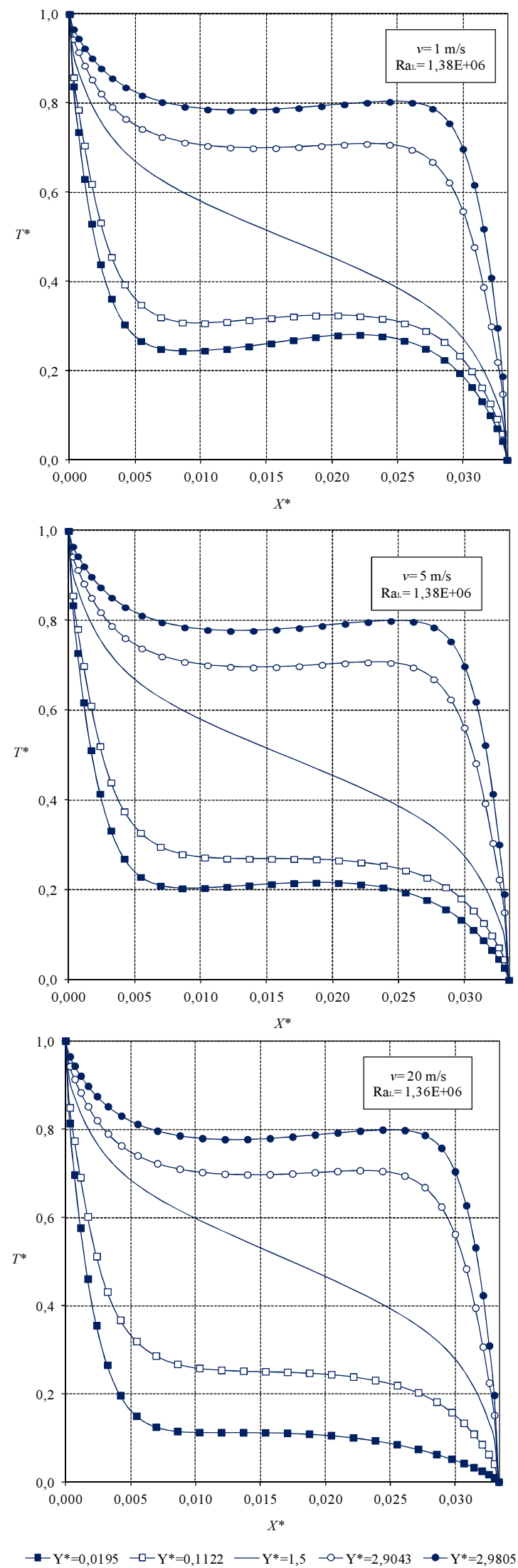

Figura 5.35. Perfil de temperatura en la cámara de aire para una sección horizontal dada para diferentes posiciones verticales: $A=30$, Régimen de Transición. En condiciones de invierno, cámara cerrada y con radiación solar, para velocidades del viento en la fachada de barlovento de $v=1,5$ y $20 \mathrm{~m} / \mathrm{s}$ respectivamente. 

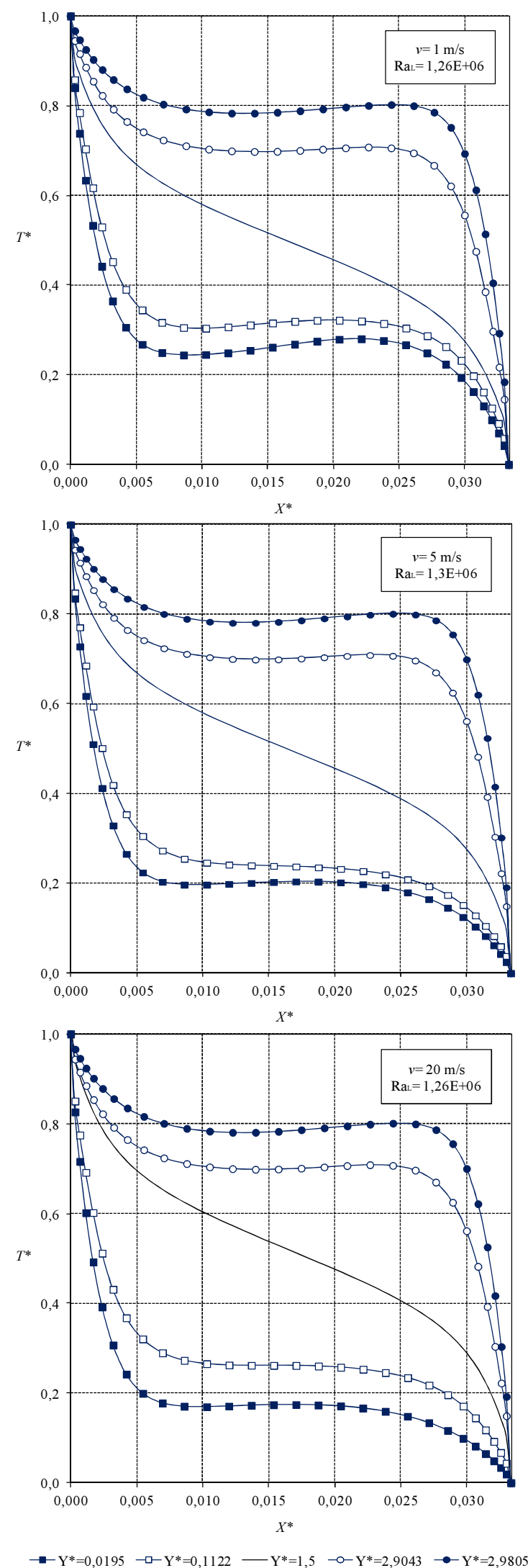

Figura 5.36. Perfil de temperatura en la cámara de aire para una sección horizontal dada para diferentes posiciones verticales: $A=30$, Régimen de Transición. En condiciones de invierno, cámara cerrada y sin radiación solar, para velocidades del viento en la fachada de sotavento de $v=1,5$ y $20 \mathrm{~m} / \mathrm{s}$ respectivamente. 
Optimización de la fachada de doble piel acristalada con ventilación natural. Metodología de diseño para el análisis de la eficiencia energética del sistema.
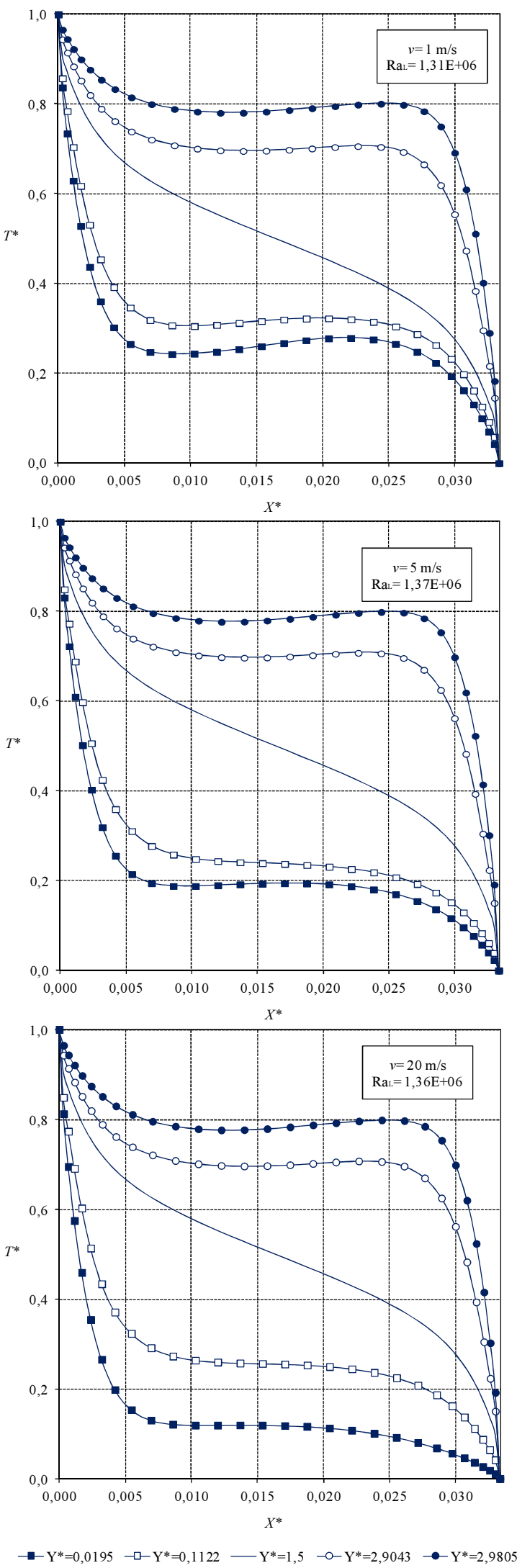

Figura 5.37. Perfil de temperatura en la cámara de aire para una sección horizontal dada para diferentes posiciones verticales: $A=30$, Régimen de Transición. En condiciones de invierno, cámara cerrada y con radiación solar, para velocidades del viento en la fachada de sotavento de $v=1$, 5 y $20 \mathrm{~m} / \mathrm{s}$ respectivamente. 
De acuerdo con los resultados obtenidos, en el caso de cámara cerrada para una esbeltez de $A=30$ y para velocidades del viento de $v=1,5$, y $20 \mathrm{~m} / \mathrm{s}$ se da el régimen de transición en términos de la esbeltez y del número de Rayleigh comprendido entre $10^{4} \mathrm{y}$ $10^{7}$, tanto para los casos con radiación solar como sin ella.

Los gráficos muestran que la distribución de temperatura en la cámara de aire es muy similar para los casos de viento en la fachada de barlovento como de sotavento.

En todas las situaciones, la temperatura media en la cámara de aire siempre es menor que la temperatura media en la habitación.

Las siguientes figuras representan el incremento de la temperatura media en la cámara de aire en relación con la velocidad y la dirección del viento, respecto a los casos sin viento.

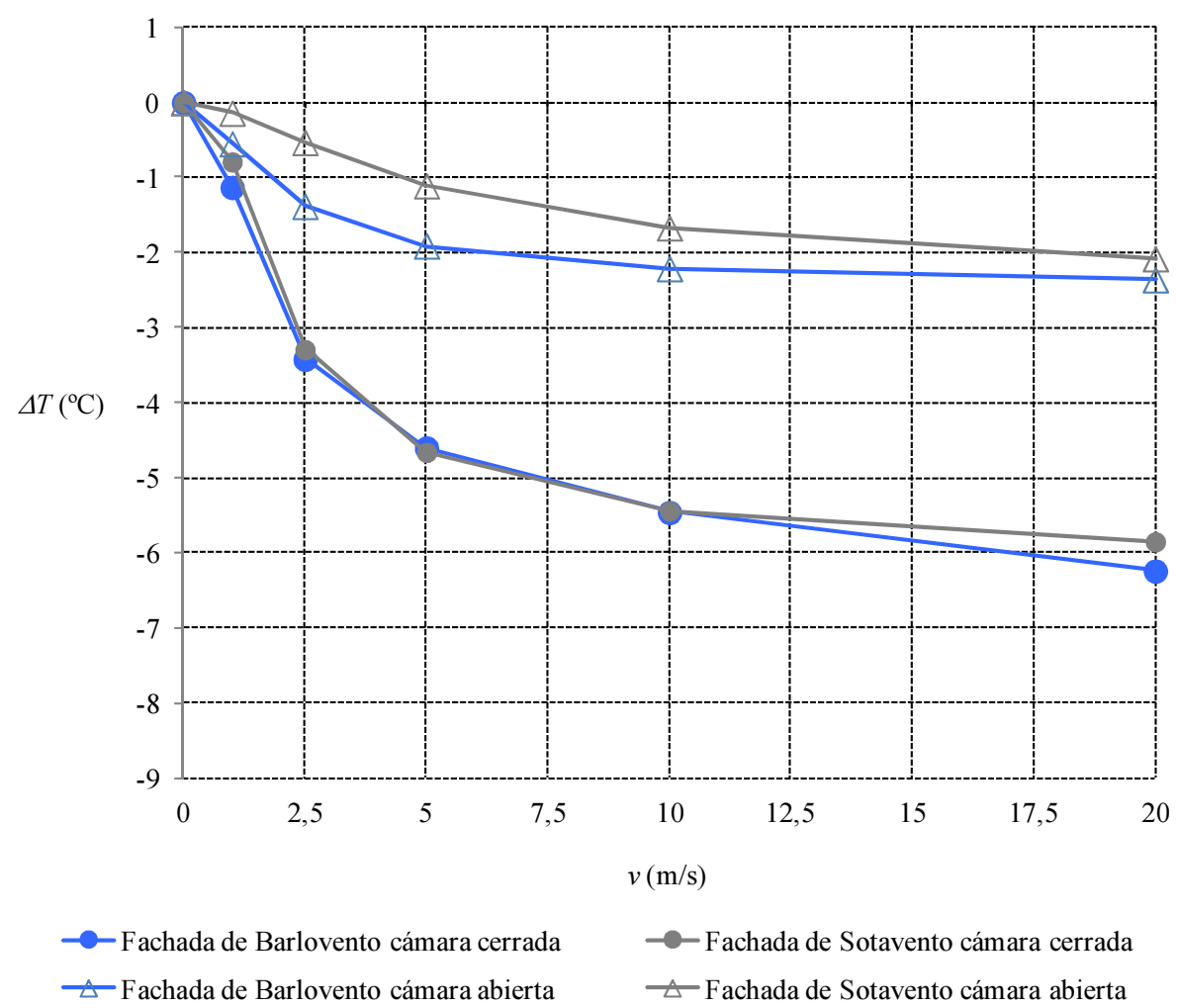

Figura 5.38. Incremento de la temperatura media en la cámara de aire respecto del caso sin viento para $A=30$ en el escenario de invierno y sin radiación solar. 


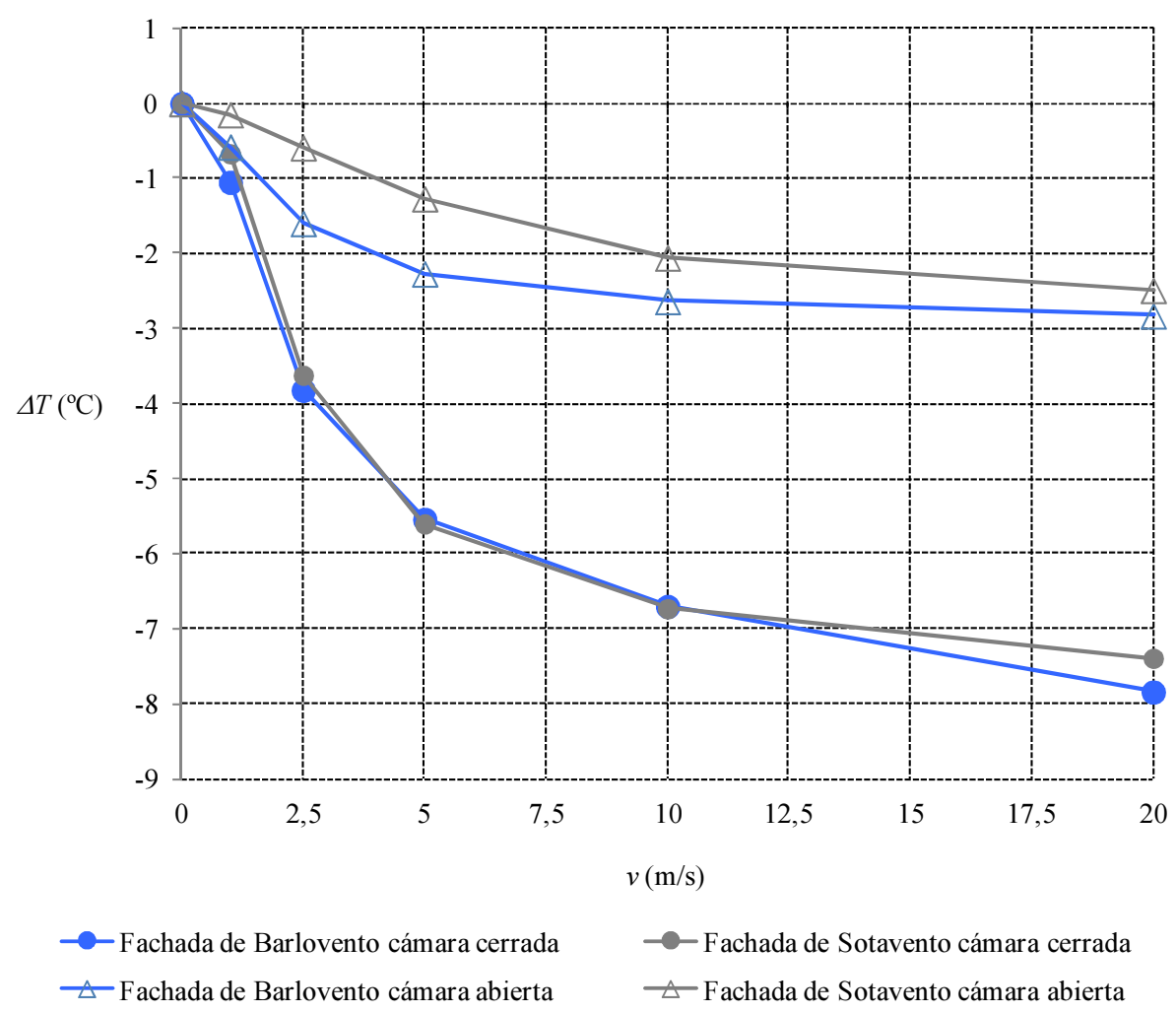

Figura 5.39. Incremento de la temperatura media en la cámara de aire respecto del caso sin viento para $A=30$ en el escenario de invierno y con radiación solar.

En todos los casos se observa una disminución de la temperatura media en la cámara conforme aumenta la velocidad del viento.

\subsubsection{Comportamiento del flujo de aire en el ambiente exterior}

Las siguientes figuras muestran las líneas de corriente coloreadas por velocidad para el escenario de invierno, cámara cerrada, con radiación solar y velocidad de $5 \mathrm{~m} / \mathrm{s}$, para el viento en la fachada de barlovento y sotavento, respectivamente. 


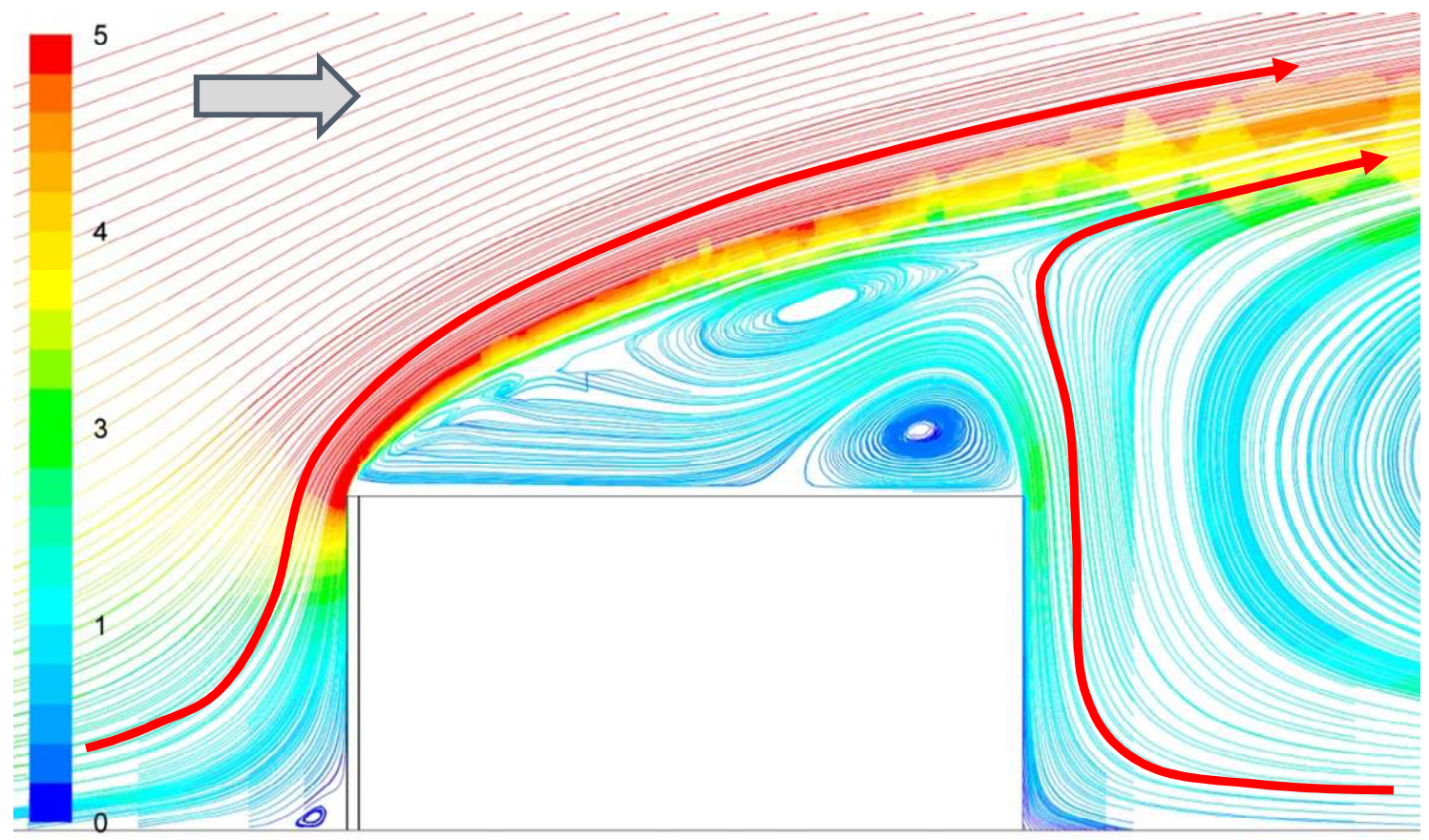

Figura 5.40. Líneas de corriente coloreadas por velocidad en el escenario de invierno, cámara cerrada, con radiación solar y viento en la fachada de barlovento $v=5 \mathrm{~m} / \mathrm{s}$.

En la fachada de barlovento el aire se encuentra con el obstáculo por lo que recorre la fachada de forma ascendente hasta alcanzar la esquina superior del edificio, donde la corriente se desprende. En la fachada de barlovento, el aire llega a mayor velocidad que en la fachada de sotavento para un mismo caso.

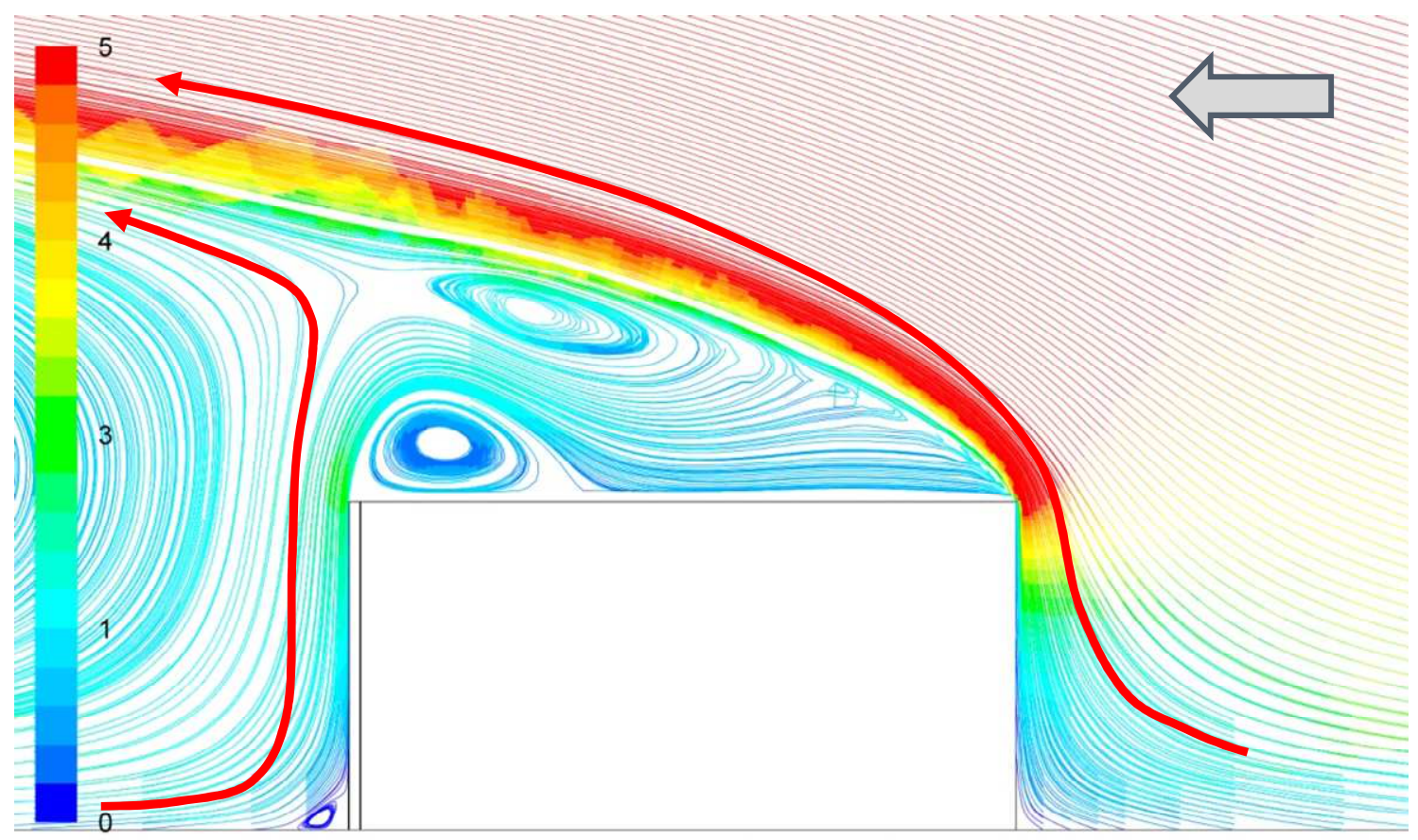

Figura 5.41. Líneas de corriente coloreadas por velocidad en el escenario de invierno, cámara cerrada, con radiación solar y viento en la fachada de sotavento $v=5 \mathrm{~m} / \mathrm{s}$. 
En la fachada de sotavento el comportamiento del aire es parecido que en la fachada de barlovento, es decir, el aire va desde la parte inferior hacia la parte superior de la fachada pero a menor velocidad que cuando hay un viento con la misma intensidad pero en la fachada de barlovento.

\subsubsection{Comportamiento del flujo de aire en el interior de la cámara}

Las Figuras 5.42 y 5.43 muestran el movimiento del flujo de aire en el interior de la cámara representado mediante vectores velocidad coloreados por velocidad para el caso de $A=30$ en el escenario de invierno con cámara abierta sin radiación solar y con viento en la fachada de barlovento.
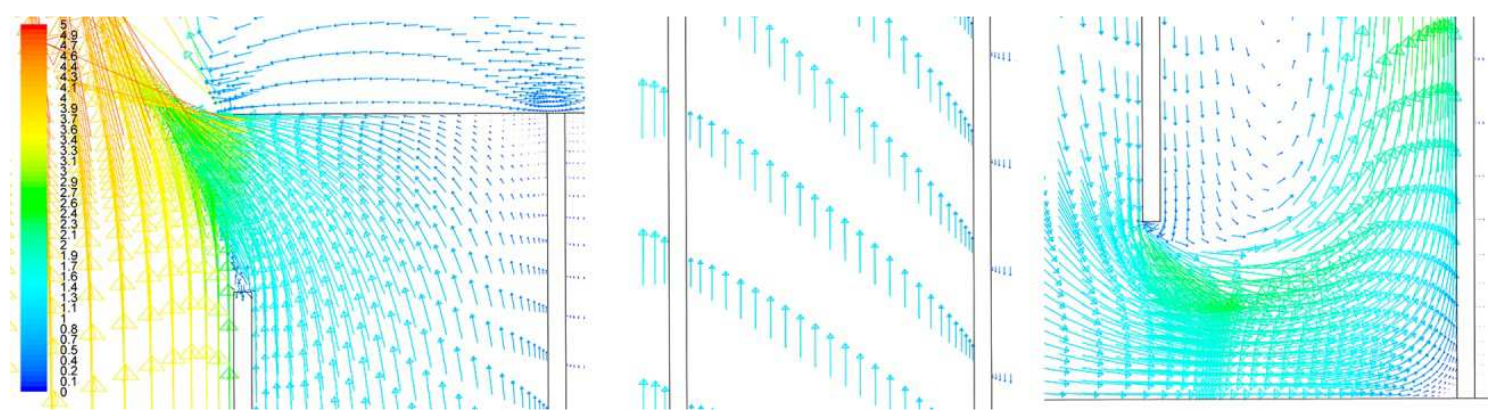

Figura 5.42. Vectores velocidad coloreados por velocidad $(\mathrm{m} / \mathrm{s})$ en el extremo superior (imagen izquierda), zona media (imagen central) y extremo inferior (imagen derecha) de la cámara de aire, para el caso de $A=30$ en condiciones de invierno cámara abierta, sin radiación solar y viento en la fachada de barlovento de $v=5 \mathrm{~m} / \mathrm{s}$.
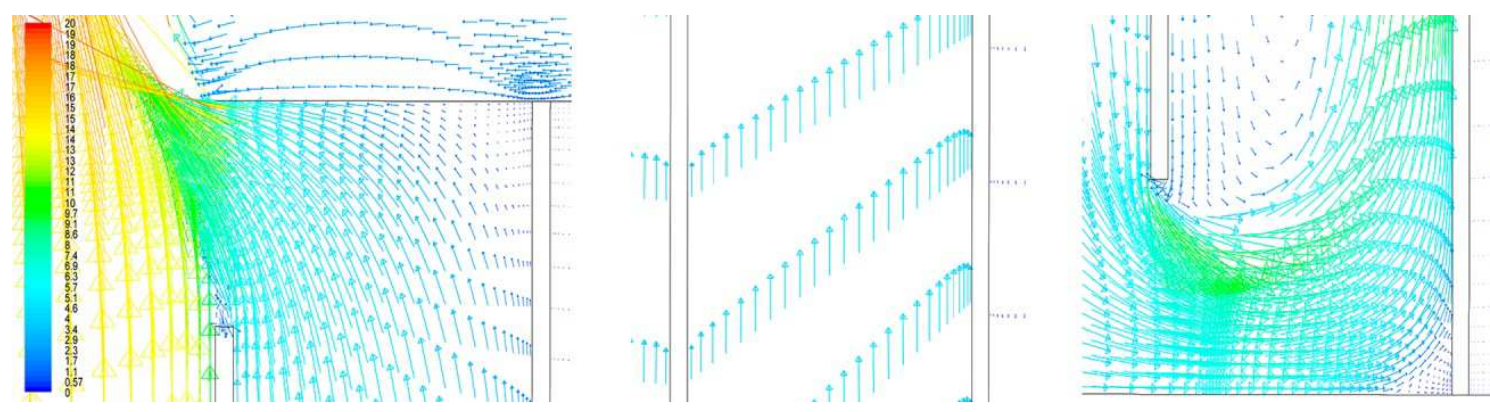

Figura 5.43. Vectores velocidad coloreados por velocidad $(\mathrm{m} / \mathrm{s})$ en el extremo superior (imagen izquierda), zona media (imagen central) y extremo inferior (imagen derecha) de la cámara de aire, para el caso de $A=30$ en condiciones de invierno cámara abierta, sin radiación solar y viento en la fachada de barlovento de $v=20 \mathrm{~m} / \mathrm{s}$.

El aire entra a través de la abertura inferior y sale por la abertura superior. La velocidad del aire en la cámara aumenta con el incremento de la velocidad del viento. Se observa un importante torbellino de recirculación de aire en el extremo inferior de la cámara.

A continuación se analiza la influencia de la velocidad y dirección del viento en el interior de la cámara de la fachada doble piel para el caso de cámara abierta y $A=30$. 
Las Figuras 5.44 y 5.45 muestran el caudal de aire $(V)$ en la cámara para las 5 velocidades del viento estudiadas en las fachadas de barlovento y de sotavento para los casos de sin y con radiación solar, respectivamente.

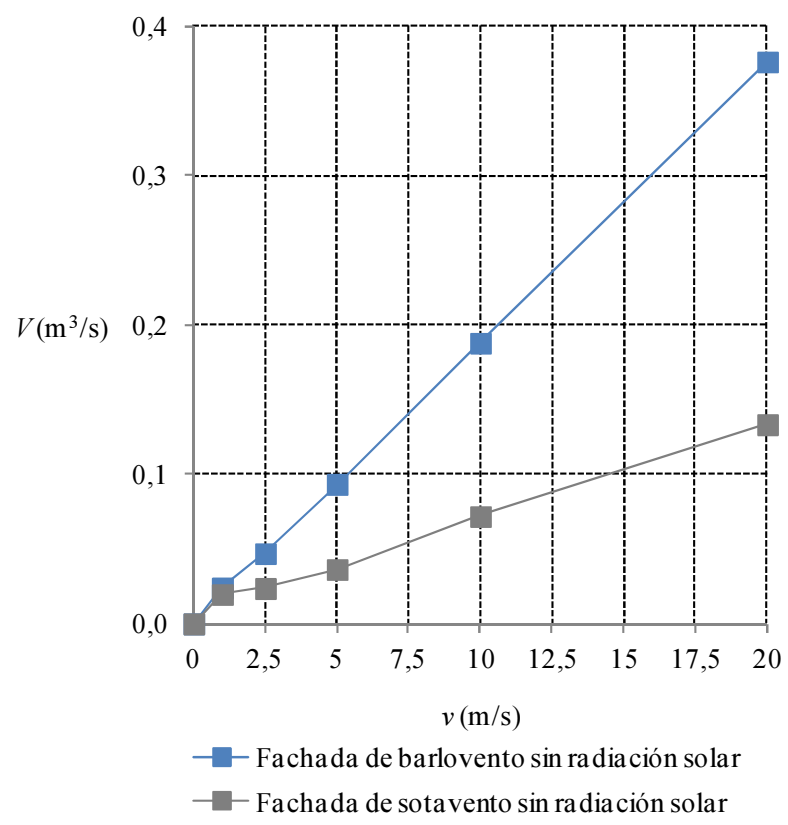

Figura 5.44. Caudal de aire en la cámara en el escenario de invierno, cámara abierta, sin radiación solar, $A=30$ y viento en las fachadas de barlovento y sotavento de $v=1 ; 2,5 ; 5 ; 10$ y $20 \mathrm{~m} / \mathrm{s}$.

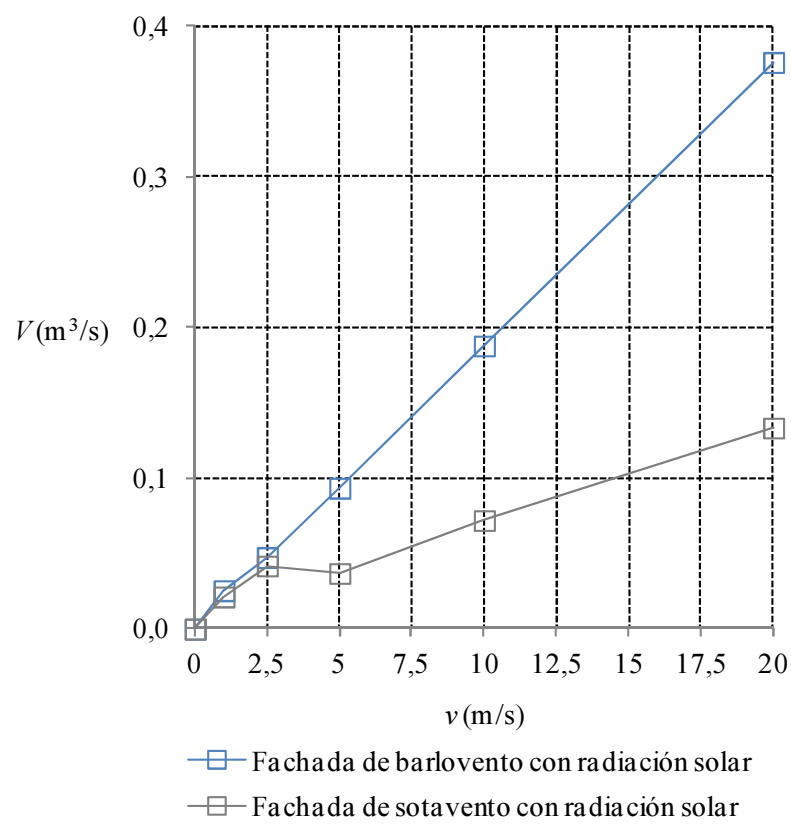

Figura 5.45. Caudal de aire en la cámara en el escenario de invierno, cámara abierta, con radiación solar, $A=30$ y viento en las fachadas de barlovento y sotavento de $v=1 ; 2,5 ; 5 ; 10$ y $20 \mathrm{~m} / \mathrm{s}$. 
De los resultados obtenidos se extraen las siguientes conclusiones relativas al caudal de aire:

- Aumenta con el incremento de la velocidad del viento, tanto para viento en la fachada de barlovento como de sotavento.

- Siempre es mayor para los casos de viento en la fachada de barlovento.

- Es prácticamente el mismo en los casos con y sin radiación solar.

- La radiación solar tiene poca influencia en el comportamiento del aire en la cámara.

\subsubsection{Flujo de calor}

Para poder calcular posteriormente el índice de eficiencia energética, hay que conocer el flujo de calor que hay que aportar o extraer con el objetivo mantener la habitación a la temperatura de confort, tanto en condiciones de invierno como de verano.

Para poder comparar los resultados, es necesario calcular la velocidad media $\left(v_{m}\right)$ del viento para los meses de invierno y de verano respectivamente. Para ello, se toman los datos de las velocidades medias del viento de la base de datos de MeteoPozuelo. Los datos empleados son las velocidades medias máximas mensuales del viento entre los años 2009 y 2014.

La Tabla 5.2 muestra los datos de velocidades medias del viento recogidas para los 5 meses de invierno:

VELOCIDAD MEDIA MÁXIMA DEL VIENTO $(\mathrm{km} / \mathrm{h})$

\begin{tabular}{|c|c|c|c|c|c|c|c|}
\hline Meses invierno & 2014 & 2013 & 2012 & 2011 & 2010 & 2009 & $\begin{array}{c}\text { velocidad media } \\
\qquad\left(v_{m}\right)\end{array}$ \\
\hline Enero & 26,30 & 25,20 & 13,70 & 13,70 & 21,70 & 20,40 & 20,17 \\
\hline Febrero & 29,00 & 27,00 & 23,50 & 22,40 & 21,60 & 19,60 & 23,85 \\
\hline Marzo & 25,10 & 25,70 & 19,70 & 22,60 & 20,90 & 21,50 & 22,58 \\
\hline Noviembre & 18,90 & 20,80 & 19,10 & 16,00 & 20,10 & 24,80 & 19,95 \\
\hline Diciembre & 22,20 & 16,00 & 15,20 & 14,40 & 15,60 & 19,70 & 17,18 \\
\hline $\begin{array}{l}\text { velocidad media de } \\
\text { referencia } \\
\left(v_{m, r e f}\right)\end{array}$ & & & & & & & 20,75 \\
\hline
\end{tabular}

Tabla 5.2. Velocidad media del viento para el escenario de invierno (km/h). Fuente: www.meteopozuelo.es

La velocidad media del viento de referencia $\left(v_{m, r e f}\right)$ obtenida para el escenario de invierno a lo largo de 6 años es de $20,75 \mathrm{~km} / \mathrm{h}$, es decir, $5,8 \mathrm{~m} / \mathrm{s}$. Este valor se utiliza como velocidad del viento en las simulaciones CFD para los casos de invierno. 
Se calcula en cada situación el flujo de calor que hay que aportar para el caso de $A=30$ para que la temperatura en la habitación se mantenga en $20^{\circ} \mathrm{C}$, temperatura de confort en condiciones de invierno, con una temperatura exterior de $4{ }^{\circ} \mathrm{C}$. La Figura 5.46 muestra los resultados obtenidos para los casos de viento en la fachada de barlovento y de sotavento.

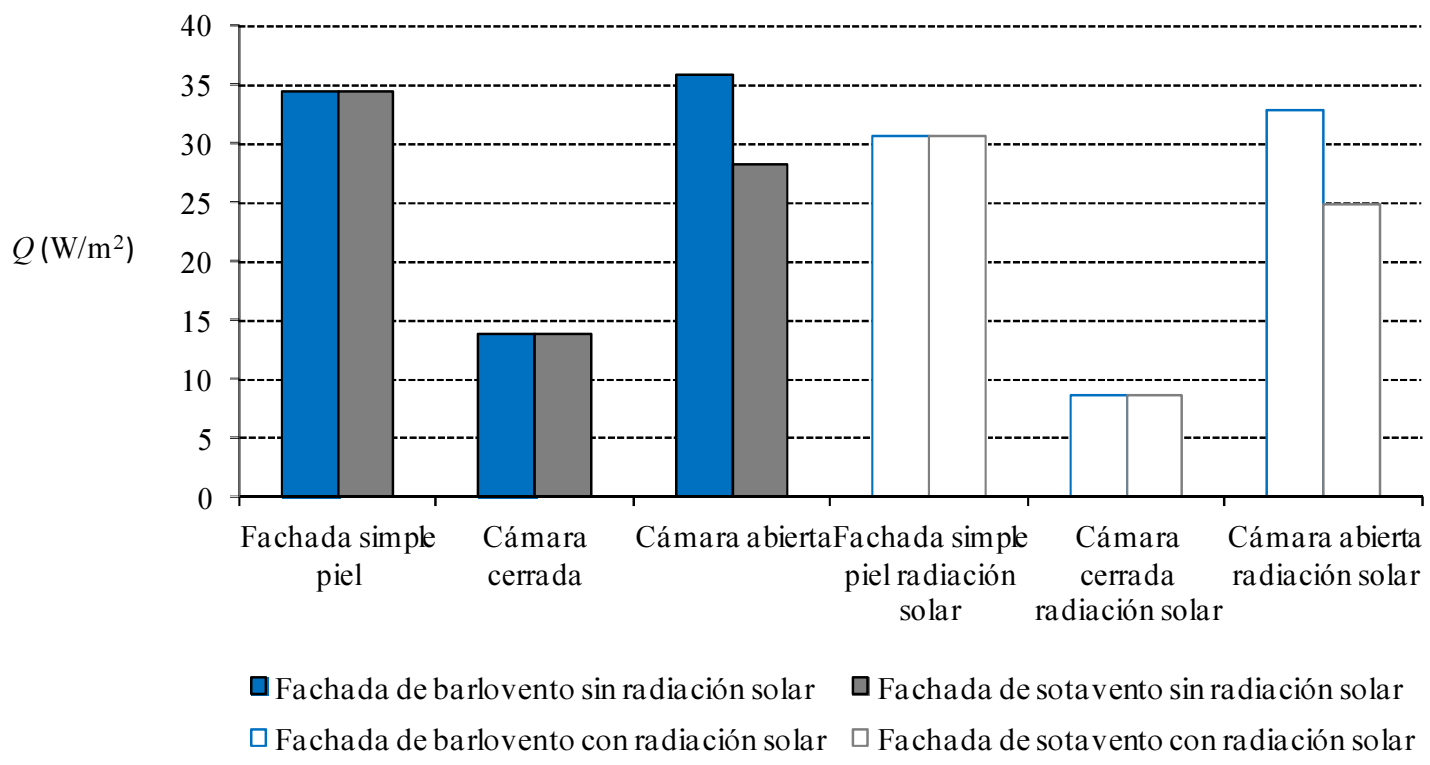

Figura 5.46. Flujo de calor para mantener la temperatura en la habitación a $20{ }^{\circ} \mathrm{C}$ con fachada simple piel y con fachada doble piel $A=30$, en condiciones de invierno con viento en las fachadas de barlovento y sotavento de velocidad $v_{m, r e f}=5,8 \mathrm{~m} / \mathrm{s}$.

Tras el análisis de los resultados obtenidos en las condiciones de invierno tanto en presencia de radiación solar como sin ella, se observa que:

- En los casos de fachada simple piel como en los de fachada doble piel con cámara cerrada no influye la dirección del viento, el flujo de calor que hay que aportar para que la habitación se mantenga a la temperatura de confort es prácticamente el mismo.

- El único caso en el que hay mayor diferencia entre el flujo de calor aportado con el viento, es en el caso de cámara abierta, que en la fachada de sotavento hay que aportar 7,55 W/m $\mathrm{m}^{2}$ menos en ausencia de radiación solar, y 7,90 W/m $\mathrm{m}^{2}$ menos en su presencia.

- Con la cámara cerrada, la fachada doble piel se comporta mejor que la fachada simple piel en presencia de viento. Interesa cerrar la cámara siempre, tanto en la fachada de barlovento como de sotavento. Incluso en presencia de radiación solar se produce un mayor ahorro de energía, hay que aportar aproximadamente $5,2 \mathrm{~W} / \mathrm{m}^{2}$ menos que en el mismo caso sin radiación solar.

- Interesa abrir la cámara en el caso de la fachada de sotavento, ya que se produce un pequeño ahorro de energía respecto a la fachada simple piel.

- Entre abrir o cerrar la cámara, siempre interesa cerrar la cámara para los casos de invierno porque se produce un mayor ahorro de energía. 


\subsubsection{Condiciones de verano}

\subsubsection{Temperatura media en la habitación}

Se simula el escenario de verano para las situaciones de cámara abierta y cerrada, con y sin radiación solar, y con viento en la fachada de barlovento y sotavento. Todas las situaciones se simulan con velocidades del viento de $v=1 ; 2,5 ; 5 ; 10 ;$ y $20 \mathrm{~m} / \mathrm{s}$.

Se utiliza la fachada simple como caso de referencia con el que comparar los resultados obtenidos.

El escenario de verano se simuló con un flujo de calor en el techo de $-10,50 \mathrm{~W} / \mathrm{m}^{2}$, para los casos con radiación solar, y con un flujo de $-4,6 \mathrm{~W} / \mathrm{m}^{2}$, para los casos sin radiación solar. Este es el calor que se necesita extraer para que la temperatura de la habitación se mantenga a $26^{\circ} \mathrm{C}$ (temperatura de confort para las condiciones de verano) tanto para los casos con radiación solar como para los casos sin radiación solar.

Las siguientes figuras muestran el incremento de la temperatura media en la habitación en relación con la velocidad $v$ y la dirección del viento (fachada de barlovento $\mathrm{y}$ de sotavento), en los casos de sin y con radiación solar. Cada caso se expresa de forma adimensional $T^{+}=\left(T-T_{r e f}\right) / T_{r e f}$, y dimensional.

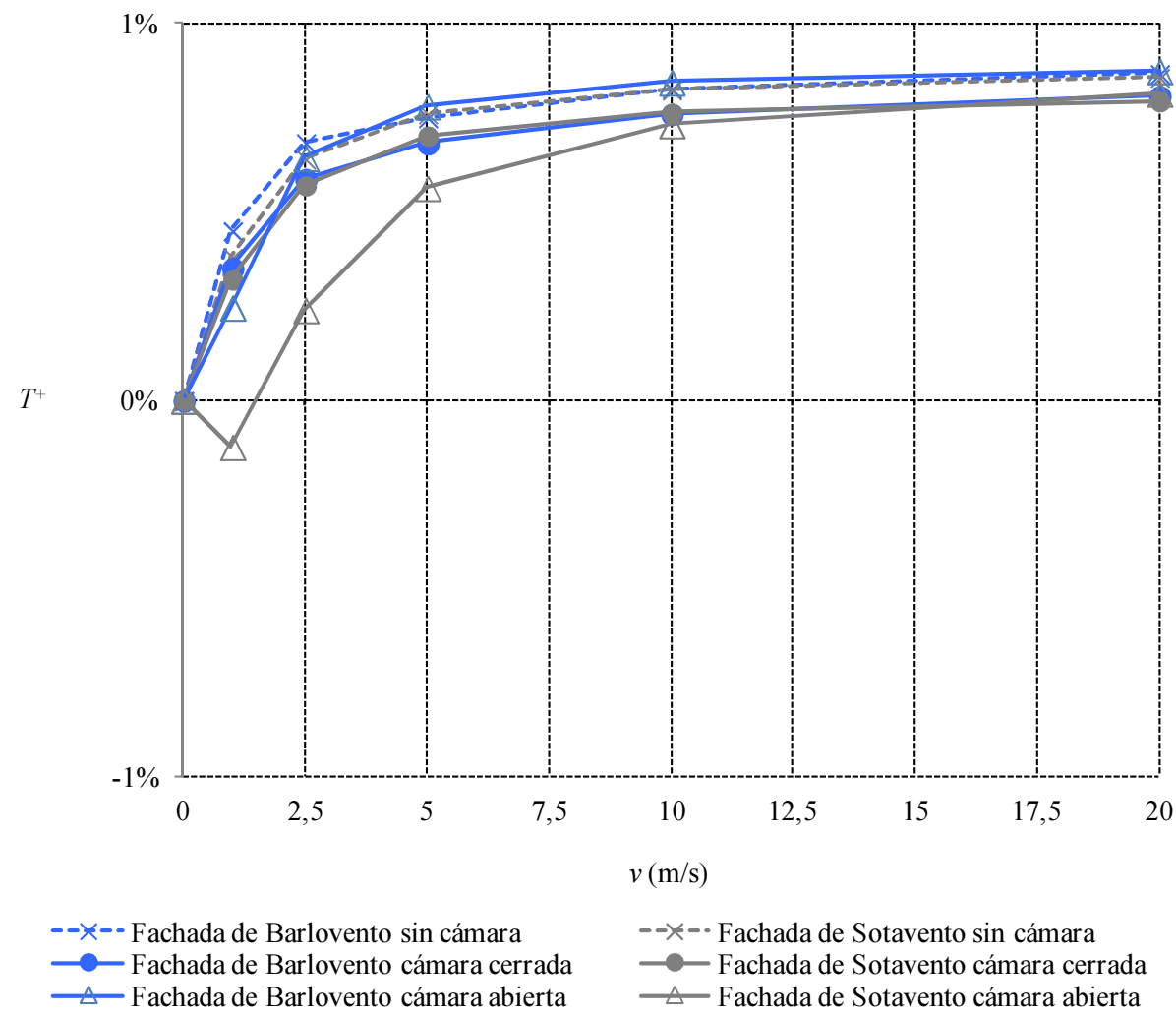

Figura 5.47. Temperatura media adimensional en la habitación para $A=30$ en el escenario de verano y sin radiación solar. 


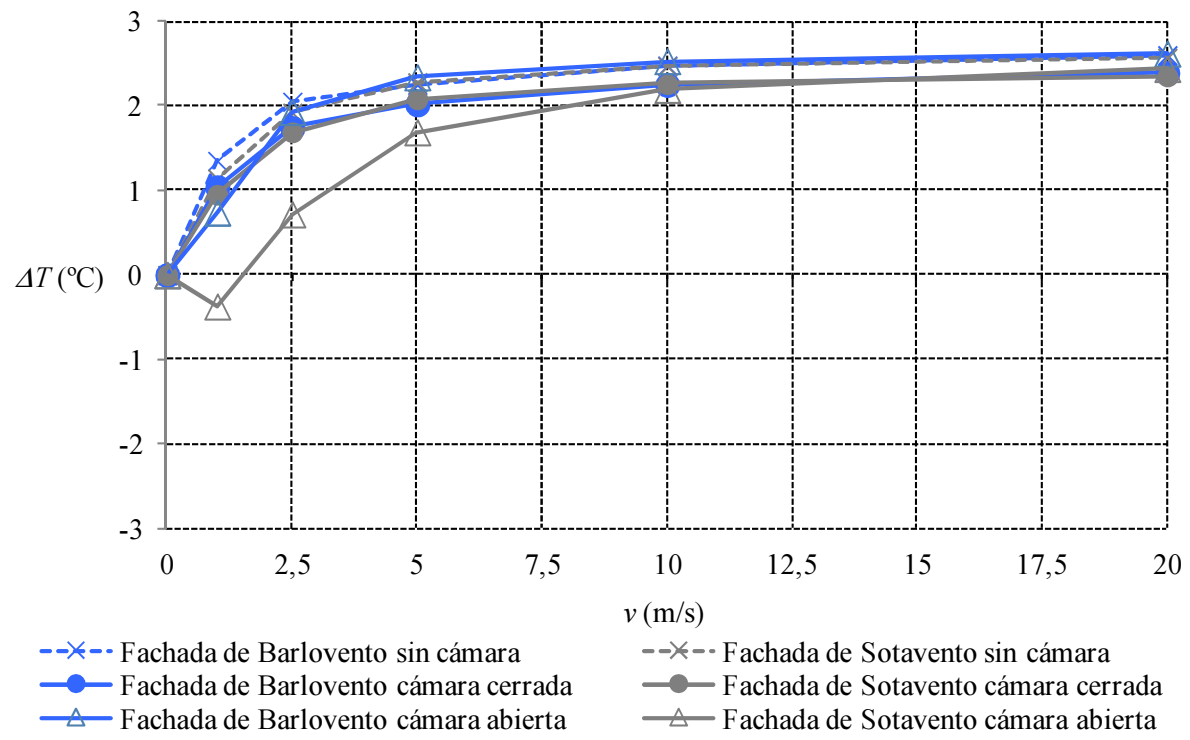

Figura 5.48. Incremento de la temperatura media en la habitación respecto del caso sin viento para $A=30$ en el escenario de verano y sin radiación solar.

Para los casos sin radiación solar se observa que:

- La temperatura media en la habitación aumenta conforme aumenta la velocidad del viento, alejándose de la temperatura de confort $\left(26^{\circ} \mathrm{C}\right)$.

- De $v=0 \mathrm{~m} / \mathrm{s}$ a $v=10 \mathrm{~m} / \mathrm{s}$, la temperatura aumenta de forma rápida hasta alrededor de un $1 \%$.

- A partir de $v=10 \mathrm{~m} / \mathrm{s}$, la temperatura aumenta de forma más lenta.

- En el caso de cámara abierta con viento en la fachada de sotavento, el comportamiento es similar pero más lento. 
Optimización de la fachada de doble piel acristalada con ventilación natural. Metodología de diseño para el análisis de la eficiencia energética del sistema.

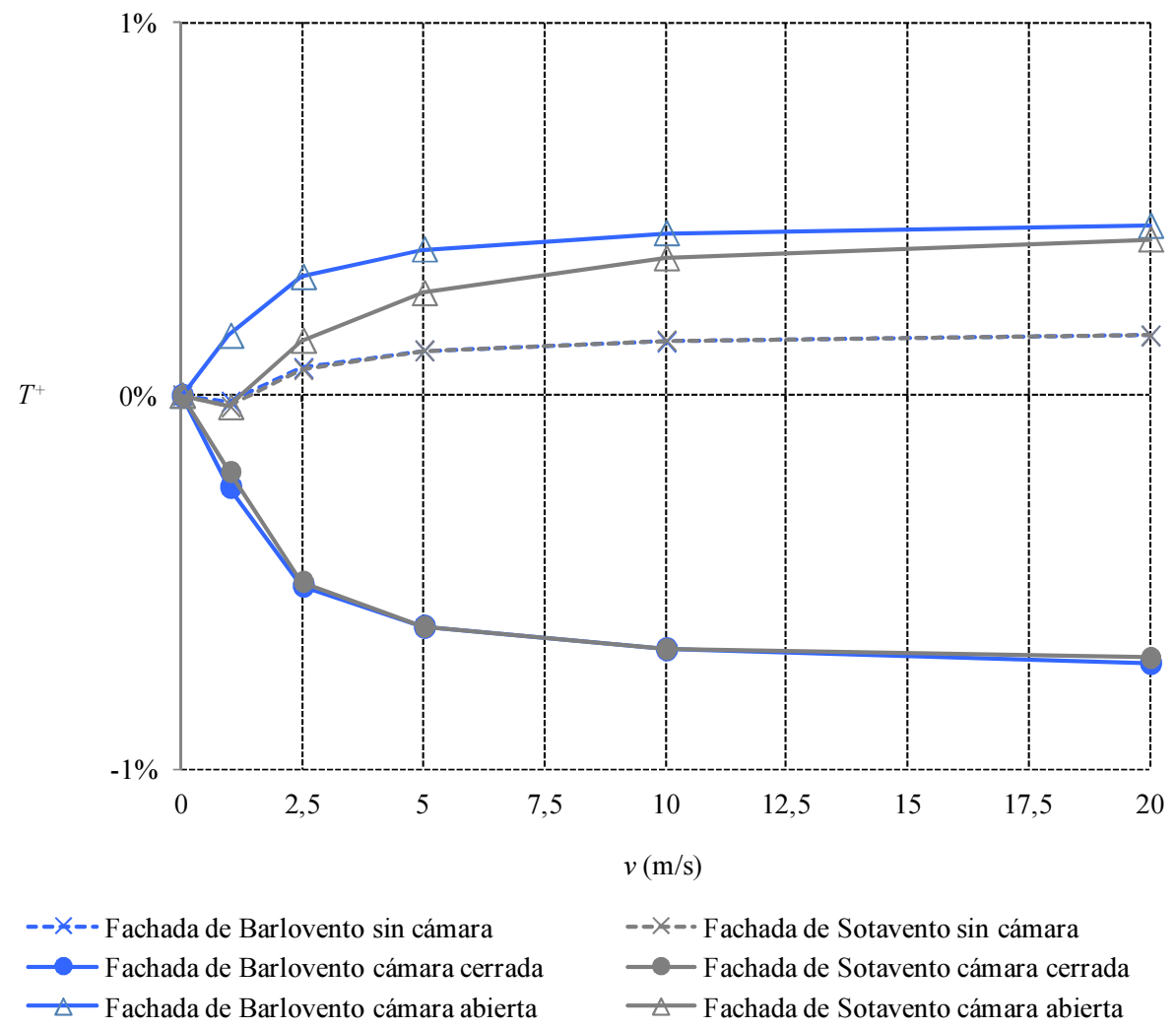

Figura 5.49. Temperatura media adimensional en la habitación para $A=30$ en el escenario de verano y con radiación solar.

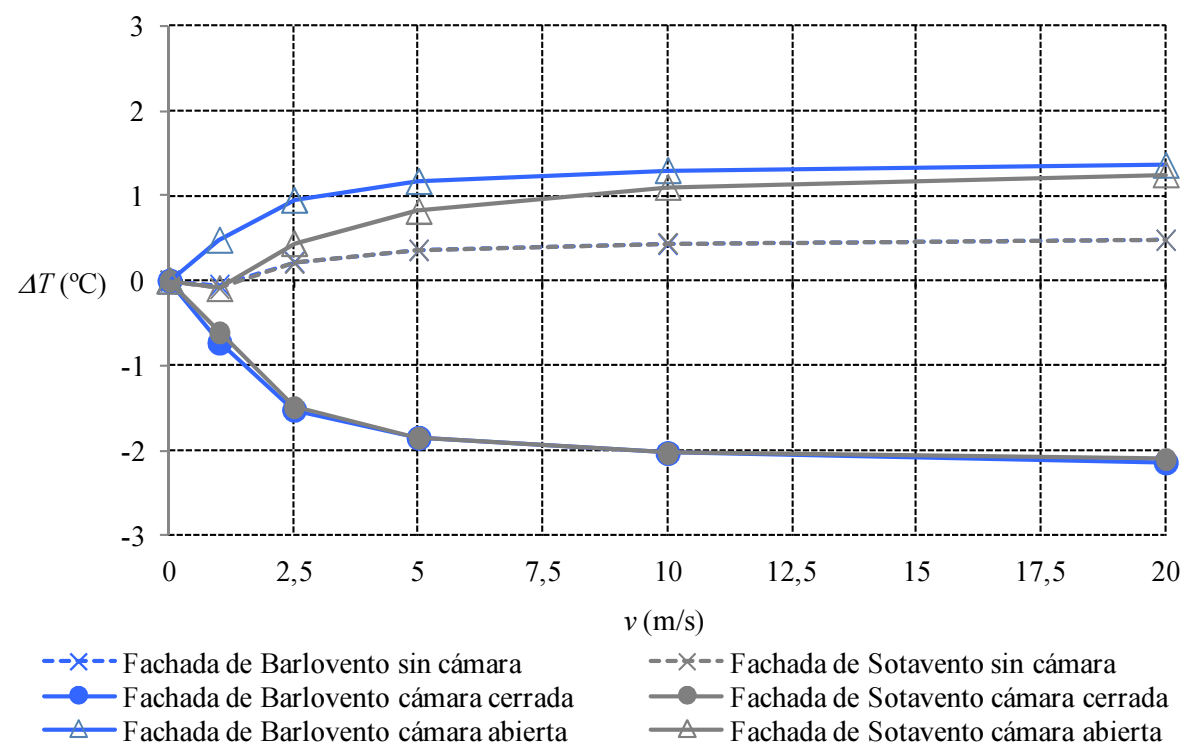

Figura 5.50. Incremento de la temperatura media en la habitación respecto del caso sin viento para $A=30$ en el escenario de verano y con radiación solar. 
Para los casos con radiación solar se observa que:

- Con cámara cerrada el viento tiene un efecto beneficioso, la temperatura media en la habitación disminuye conforme aumenta la velocidad. Esto es debido a que en los casos sin viento, la temperatura en la cámara es más alta que la temperatura en el exterior, y al soplar el viento, éste enfría el aire de la cámara y por tanto a la habitación.

- Con cámara abierta, la temperatura media en la habitación aumenta con el aumento de la velocidad.

\subsubsection{Distribución de temperatura en la cámara de aire}

Las Figuras 5.51 a 5.54 muestran la distribución de temperatura adimensional $T^{*}$, en función de la distancia horizontal adimensional en la cámara $\left(X^{*}=x / H\right)$, desde la pared caliente de la cámara hasta la pared fría, para la esbeltez de 30 y con velocidades del viento en la fachada de barlovento y de sotavento de 1,5 y $20 \mathrm{~m} / \mathrm{s}$ y para los casos sin y con radiación solar. Se traza el perfil de temperatura adimensional en la cámara de aire para una sección horizontal dada para diferentes posiciones verticales adimensionales en la cámara $\left(Y^{*}=y / H\right)$, que son $Y^{*}=0,0065 ; 0,0374 ; 0,5 ; 0,9681 ; y 0,9935$. 
Optimización de la fachada de doble piel acristalada con ventilación natural. Metodología de diseño para el análisis de la eficiencia energética del sistema.
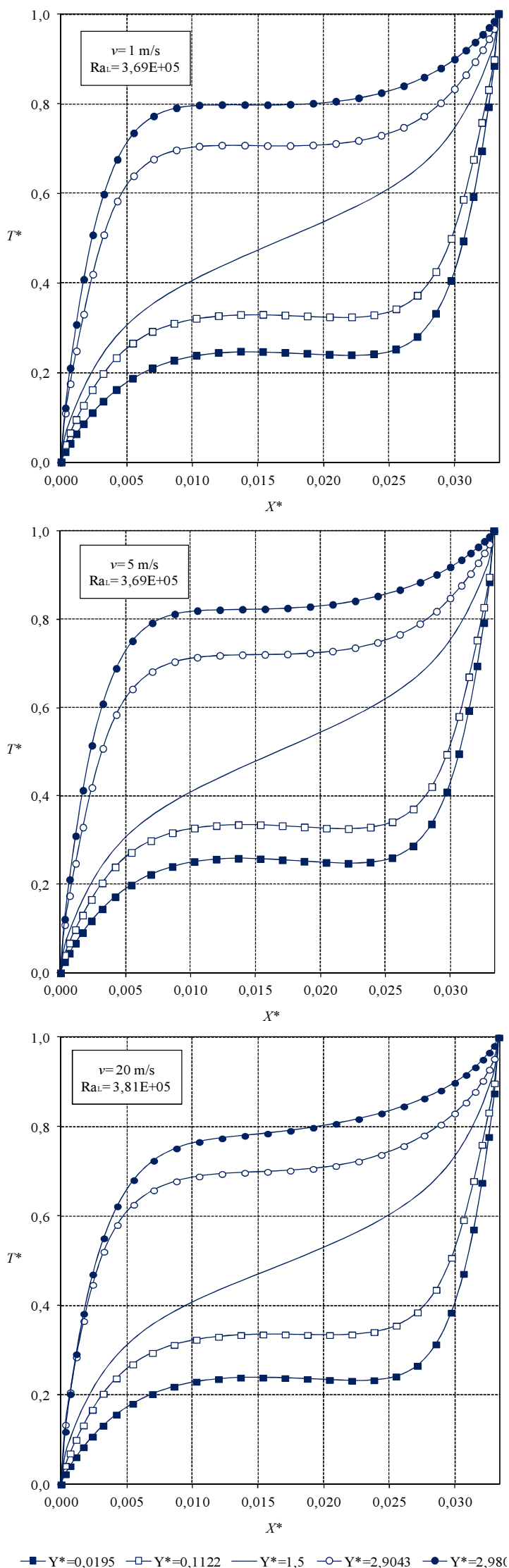

Figura 5.51. Perfil de temperatura en la cámara de aire para una sección horizontal dada para diferentes posiciones verticales: $A=30$, Régimen de Transición. En condiciones de verano, cámara cerrada y sin radiación solar, para velocidades del viento en la fachada de barlovento de $v=1,5$ y $20 \mathrm{~m} / \mathrm{s}$ respectivamente. 

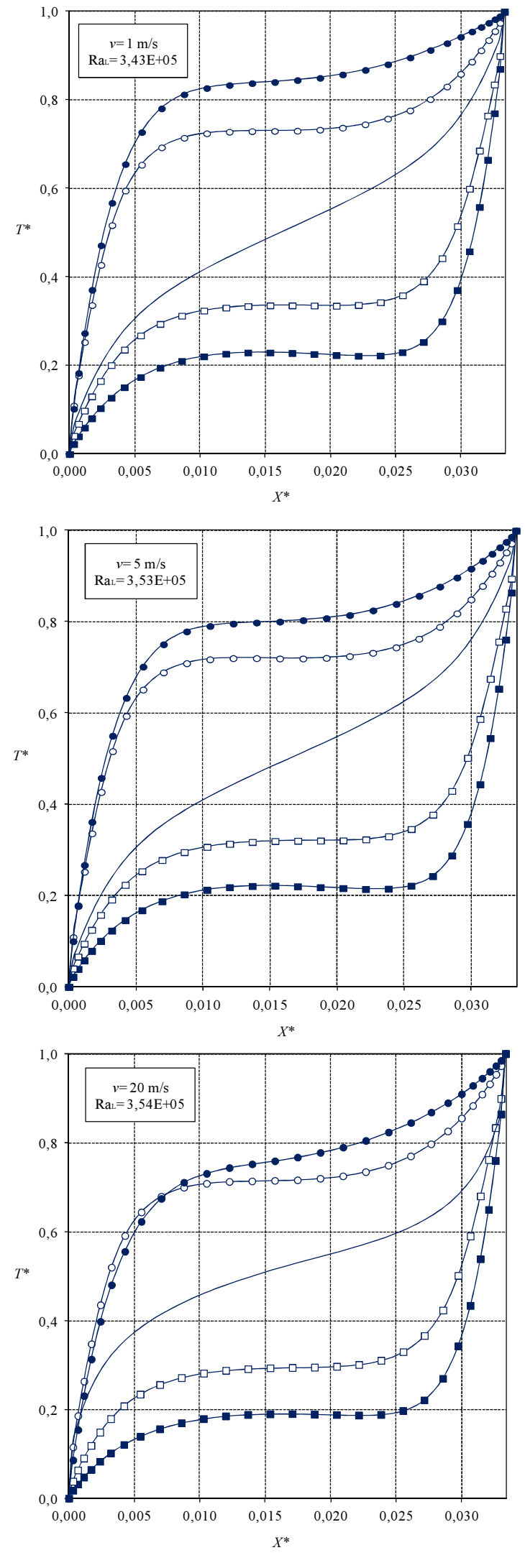

Figura 5.52. Perfil de temperatura en la cámara de aire para una sección horizontal dada para diferentes posiciones verticales: $A=30$, Régimen de Transición. En condiciones de verano, cámara cerrada y con radiación solar, para velocidades del viento en la fachada de barlovento de $v=1,5$ y $20 \mathrm{~m} / \mathrm{s}$ respectivamente. 
Optimización de la fachada de doble piel acristalada con ventilación natural. Metodología de diseño para el análisis de la eficiencia energética del sistema.
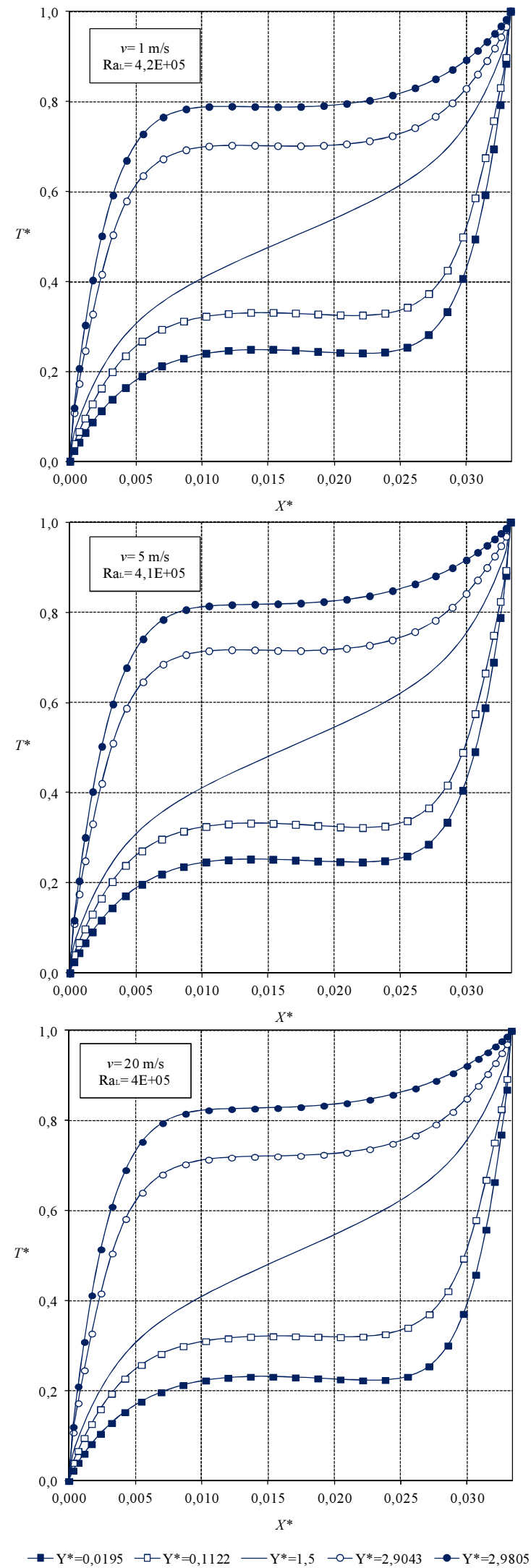

Figura 5.53. Perfil de temperatura en la cámara de aire para una sección horizontal dada para diferentes posiciones verticales: $A=30$, Régimen de Transición. En condiciones de verano, cámara cerrada y sin radiación solar, para velocidades del viento en la fachada de sotavento de $v=1,5$ y $20 \mathrm{~m} / \mathrm{s}$ respectivamente. 

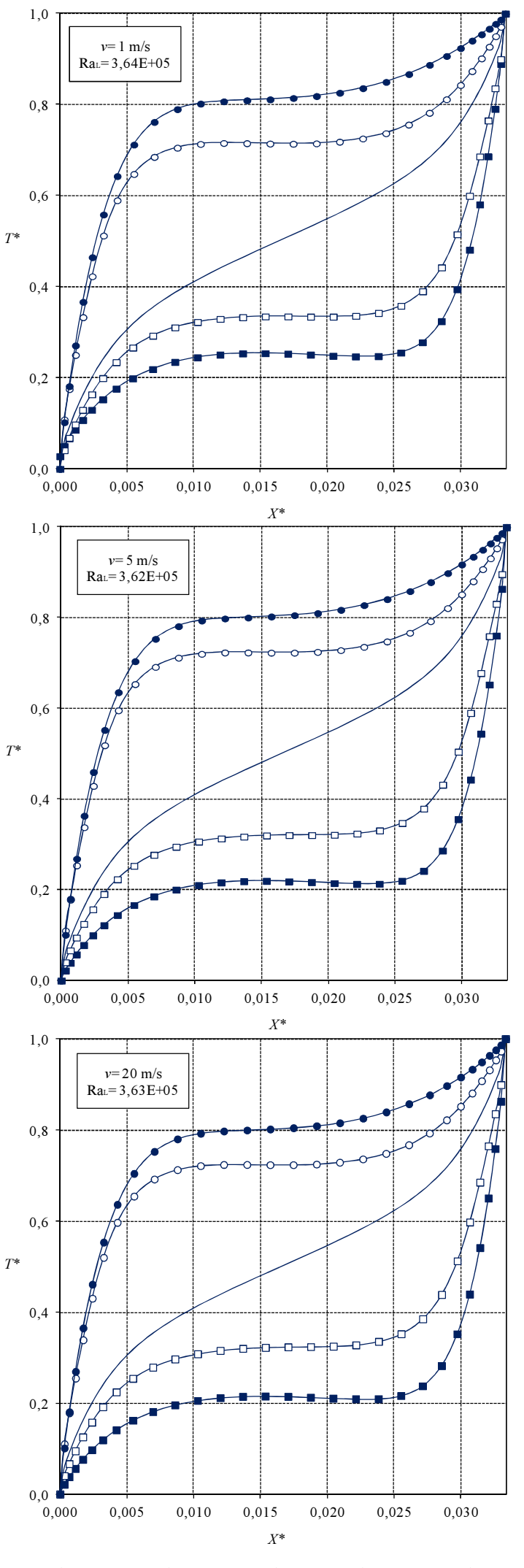

Figura 5.54. Perfil de temperatura en la cámara de aire para una sección horizontal dada para diferentes posiciones verticales: $A=30$, Régimen de Transición. En condiciones de verano, cámara cerrada y con radiación solar, para velocidades del viento en la fachada de sotavento de $v=1,5$ y $20 \mathrm{~m} / \mathrm{s}$ respectivamente. 
En el caso de cámara cerrada para una esbeltez de $A=30$ y para velocidades del viento de $v=1,5$, y $20 \mathrm{~m} / \mathrm{s}$ se da el régimen de transición en términos de la esbeltez y del número de Rayleigh, tanto para los casos con radiación solar como sin ella.

Los gráficos muestran que la distribución de temperatura en la cámara de aire es muy similar para los casos de viento en la fachada de barlovento como de sotavento. En todas las situaciones, con radiación solar y sin ella, la temperatura en la cámara de aire siempre es mayor que la temperatura media en la habitación. La temperatura media en la cámara de aire aumenta por la radiación solar absorbida. Las siguientes figuras representan el incremento de la temperatura en la cámara de aire en relación con la velocidad y la dirección del viento, respecto a los casos sin viento.

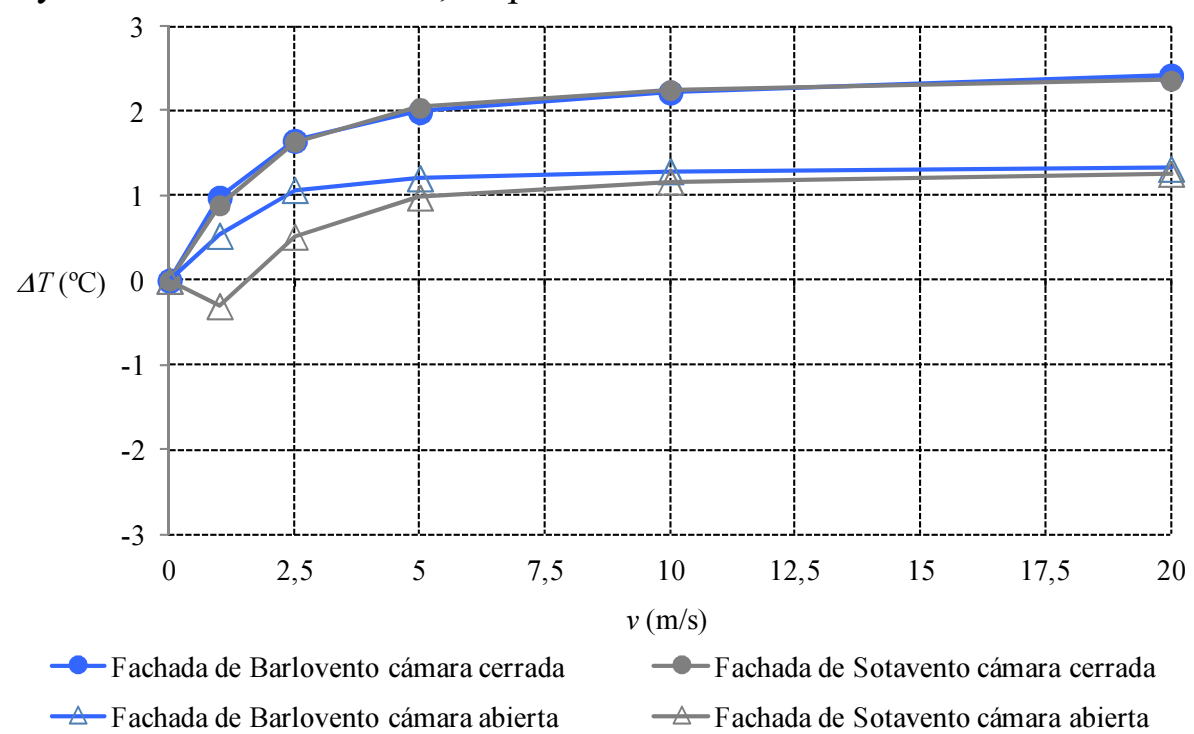

Figura 5.55. Incremento de la temperatura media en la cámara de aire respecto del caso sin viento para $A=30$ en el escenario de verano y sin radiación solar.

En todas las situaciones se observa un aumento de la temperatura media en la cámara conforme aumenta la velocidad del viento.

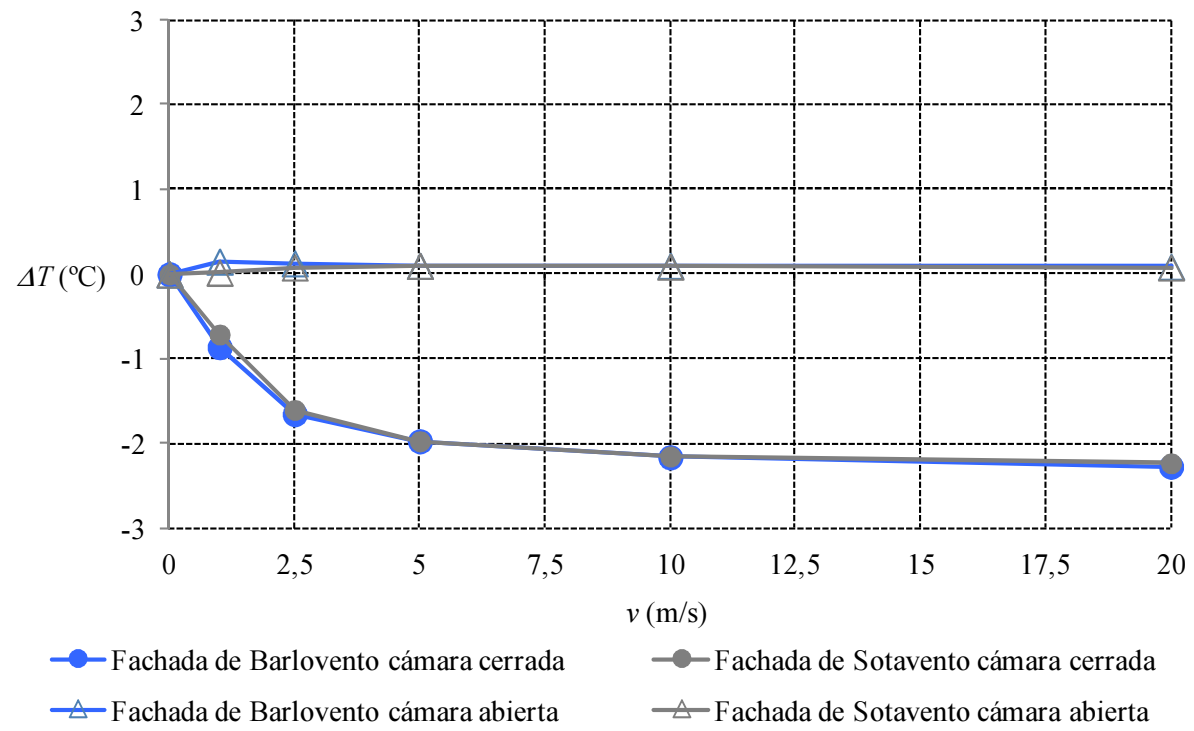

Figura 5.56. Incremento de la temperatura media en la cámara de aire respecto del caso sin viento para $A=30$ en el escenario de verano y con radiación solar. 
En los casos con cámara cerrada, la temperatura media en la cámara disminuye conforme aumenta la velocidad del viento; y en los casos con cámara abierta, la temperatura media en la cámara permanece constante y prácticamente igual que en los casos sin viento.

\subsubsection{Comportamiento del flujo de aire en el ambiente exterior}

Las siguientes figuras muestran las líneas de corriente coloreadas por velocidad para el escenario de verano, cámara cerrada, con radiación solar y velocidad de $5 \mathrm{~m} / \mathrm{s}$, para el viento en la fachada de barlovento y sotavento, respectivamente.

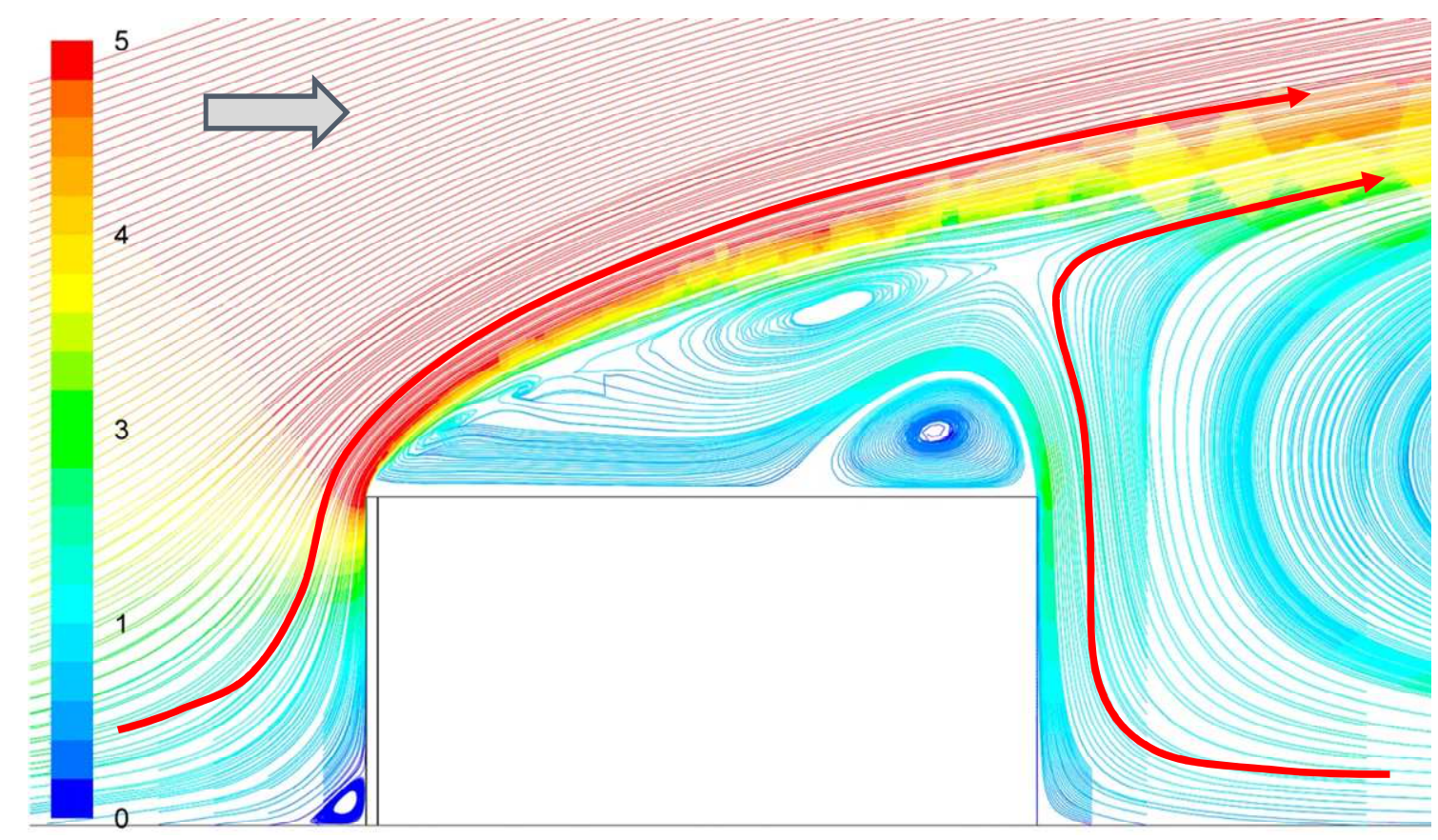

Figura 5.57. Líneas de corriente coloreadas por velocidad en el escenario de verano, cámara cerrada, con radiación solar y viento en la fachada de barlovento $v=5 \mathrm{~m} / \mathrm{s}$.

Al igual que en condiciones de invierno, en la fachada de barlovento el aire se encuentra con el obstáculo por lo que recorre la fachada de forma ascendente hasta alcanzar la esquina superior del edificio, donde la corriente se desprende. En la fachada de barlovento, el aire llega a mayor velocidad que en la fachada de sotavento para un mismo caso. 


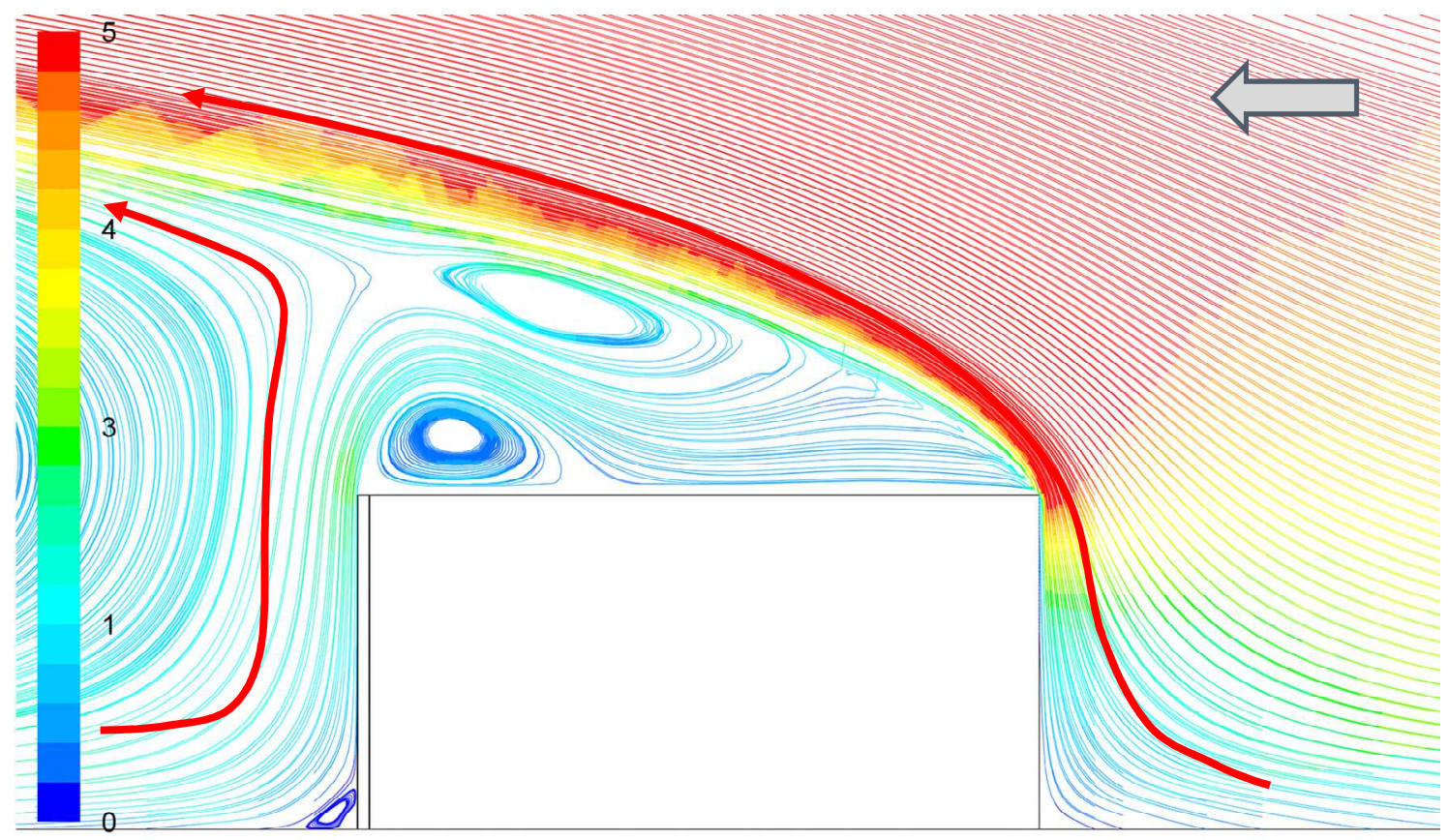

Figura 5.58. Líneas de corriente coloreadas por velocidad en el escenario de verano, cámara cerrada, con radiación solar y viento en la fachada de sotavento $v=5 \mathrm{~m} / \mathrm{s}$.

En la fachada de sotavento el comportamiento del aire es parecido que en la fachada de barlovento, es decir, el aire va desde la parte inferior hacia la parte superior de la fachada pero a menor velocidad que cuando hay un viento con la misma intensidad pero en la fachada de barlovento.

\subsubsection{Comportamiento del flujo de aire en el interior de la cámara}

Las Figuras 5.59 y 5.60 muestran el movimiento del flujo de aire en el interior de la cámara representado mediante vectores velocidad coloreados por velocidad para el caso de $A=30$ en el escenario de verano con cámara abierta sin radiación solar y con viento en la fachada de sotavento.

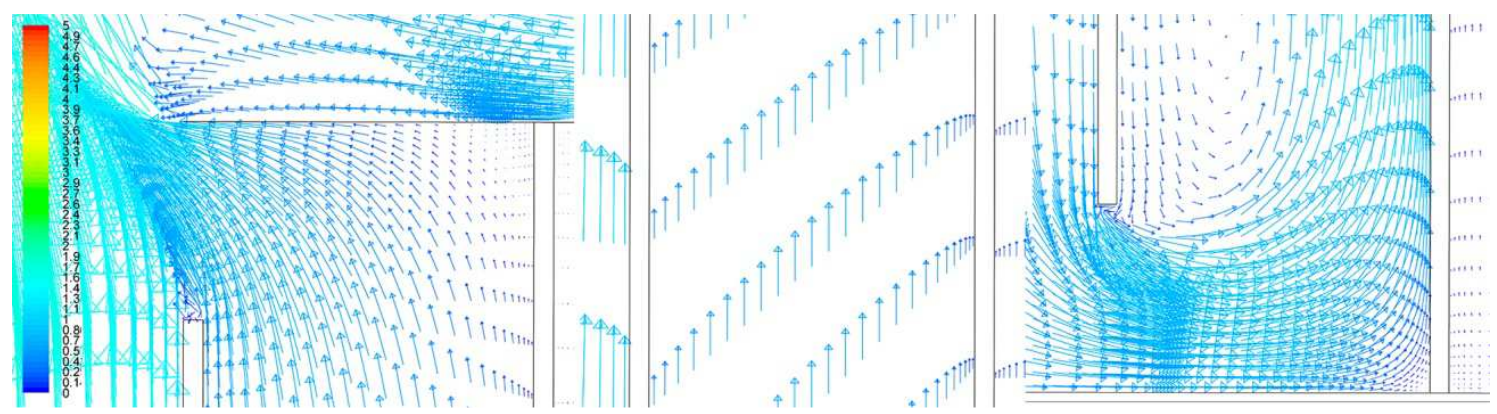

Figura 5.59. Vectores velocidad coloreados por velocidad $(\mathrm{m} / \mathrm{s})$ en el extremo superior (imagen izquierda), zona media (imagen central) y extremo inferior (imagen derecha) de la cámara de aire, para el caso de $A=30$ en condiciones de verano, cámara abierta, sin radiación solar y viento en la fachada de sotavento de $v=5 \mathrm{~m} / \mathrm{s}$. 


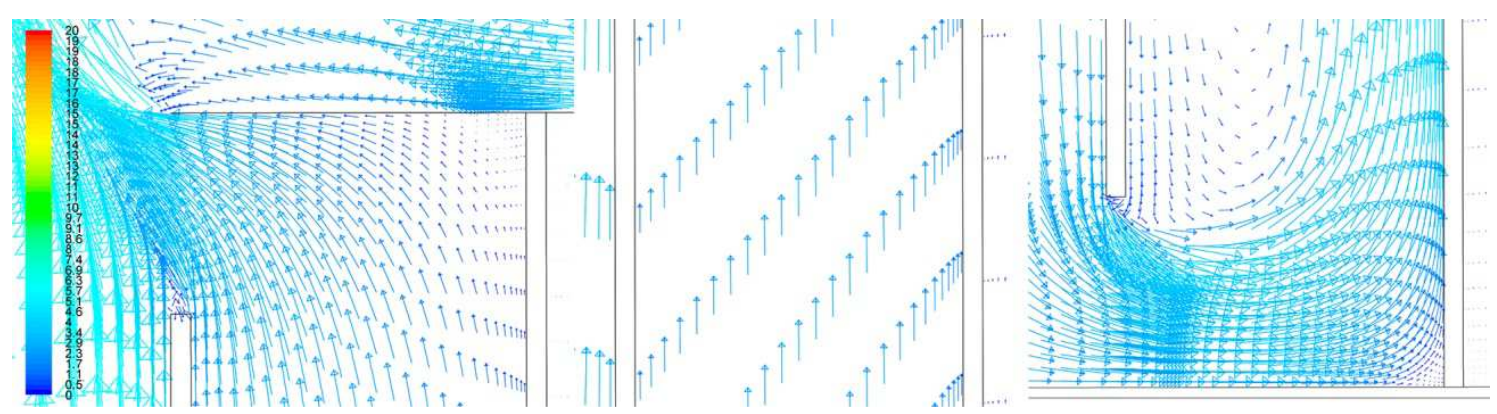

Figura 5.60. Vectores velocidad coloreados por velocidad $(\mathrm{m} / \mathrm{s})$ en el extremo superior (imagen izquierda), zona media (imagen central) y extremo inferior (imagen derecha) de la cámara de aire, para el caso de $A=30$ en condiciones de verano, cámara abierta, sin radiación solar y viento en la fachada de sotavento de $v=20 \mathrm{~m} / \mathrm{s}$.

El comportamiento del aire en el interior de la cámara es el mismo que en el escenario de invierno, la velocidad del aire en la cámara aumenta al aumentar la velocidad del viento y se observa un torbellino de recirculación en el extremo inferior de la cámara.

A continuación se analiza la influencia de la velocidad y dirección del viento en el interior de la cámara de la fachada doble piel para el caso de cámara abierta y $A=30$.

Las Figuras 5.61 y 5.62 muestran el caudal de aire $(V)$ en la cámara para las 5 velocidades del viento estudiadas en las fachadas de barlovento y de sotavento para los casos de sin y con radiación solar, respectivamente.

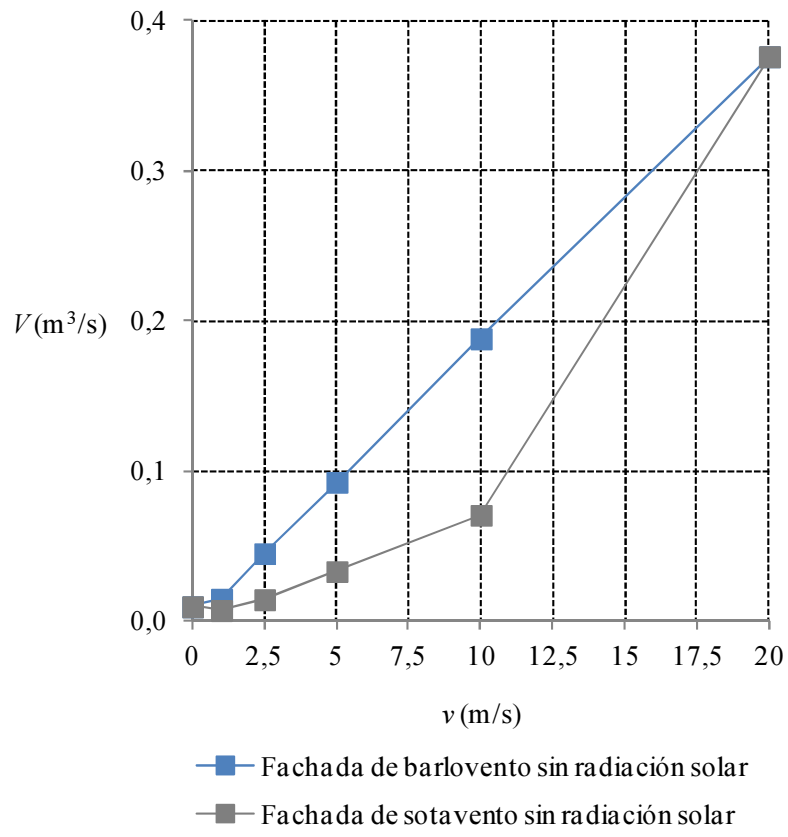

Figura 5.61. Caudal de aire en la cámara en el escenario de verano, cámara abierta, sin radiación solar, $A=30$ y viento en las fachadas de barlovento y sotavento de $v=1 ; 2,5 ; 5 ; 10$ y $20 \mathrm{~m} / \mathrm{s}$. 


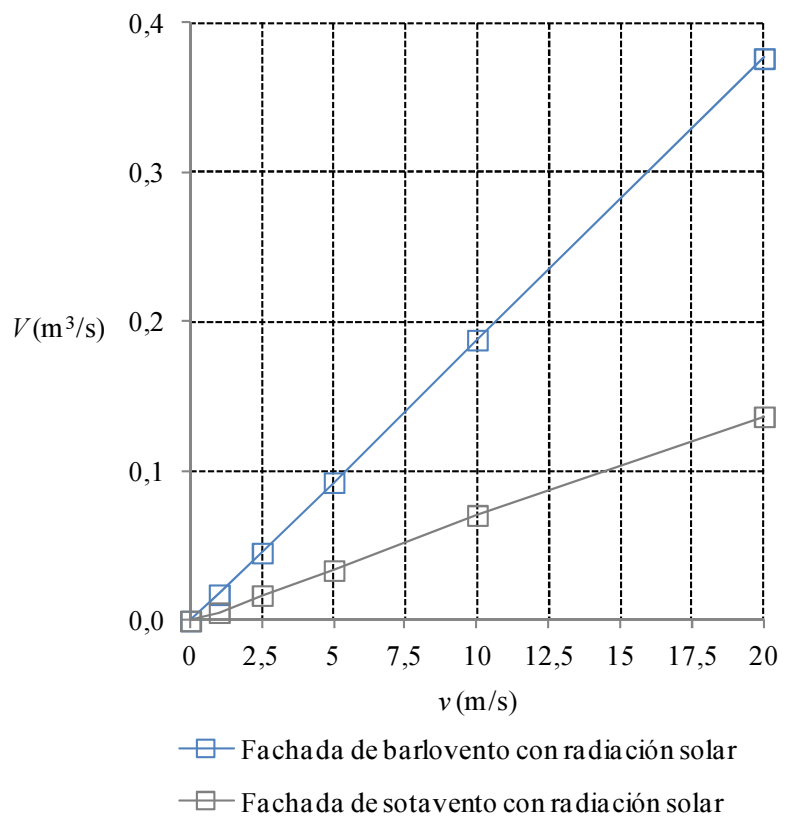

Figura 5.62. Caudal de aire en la cámara en el escenario de verano, cámara abierta, con radiación solar, $A=30$ y viento en las fachadas de barlovento y sotavento de $v=1 ; 2,5 ; 5 ; 10$ y $20 \mathrm{~m} / \mathrm{s}$.

De los resultados obtenidos se extraen las mismas conclusiones que para el escenario de invierno.

\subsubsection{Flujo de calor}

Se calcula la velocidad media $\left(v_{m}\right)$ del viento para los meses de verano. Para ello, se toman los datos de las velocidades medias del viento de la base de datos de MeteoPozuelo entre los años 2009 y 2014. La Tabla 5.3 muestra los datos de velocidades medias del viento recogidas para los 4 meses de verano:

VELOCIDAD MEDIA MÁXIMA DEL VIENTO $(\mathrm{km} / \mathrm{h})$

\begin{tabular}{lccccccc}
\hline Meses verano & $\mathbf{2 0 1 4}$ & $\mathbf{2 0 1 3}$ & $\mathbf{2 0 1 2}$ & $\mathbf{2 0 1 1}$ & $\mathbf{2 0 1 0}$ & $\mathbf{2 0 0 9}$ & $\begin{array}{c}\text { velocidad media } \\
\left(v_{m}\right)\end{array}$ \\
\hline Junio & 24,20 & 23,50 & 25,10 & 22,00 & 22,60 & 25,70 & 23,85 \\
Julio & 23,20 & 21,70 & 25,00 & 23,40 & 21,10 & 24,80 & 23,20 \\
Agosto & 23,80 & 19,90 & 24,50 & 22,70 & 21,60 & 21,50 & 22,33 \\
Septiembre & 21,00 & 19,80 & 18,90 & 31,70 & 21,50 & 19,90 & 22,13 \\
\hline $\begin{array}{l}\text { velocidad media de } \\
\text { referencia }\end{array}$ & & & & & & \\
$\left(v_{m, r e f}\right)$ & & & & & & \\
\hline
\end{tabular}

Tabla 5.3. Velocidad media del viento para el escenario de verano $(\mathrm{km} / \mathrm{h})$. Fuente: www.meteopozuelo.es

La velocidad media del viento de referencia obtenida para el escenario de verano a lo largo de 6 años es de $2,88 \mathrm{~km} / \mathrm{h}$, es decir, $6,3 \mathrm{~m} / \mathrm{s}$. Este valor utiliza como velocidad del viento en las simulaciones CFD para los casos de verano. 
Se calcula el flujo de calor que hay que extraer para el caso de $A=30$ en cada una de las situaciones para que la temperatura en la habitación se mantenga en $26^{\circ} \mathrm{C}$, temperatura de confort en condiciones de verano, con una temperatura exterior de $32{ }^{\circ} \mathrm{C}$.

La Figura 5.63 muestra los resultados obtenidos para los casos de viento en las fachadas de barlovento y de sotavento.

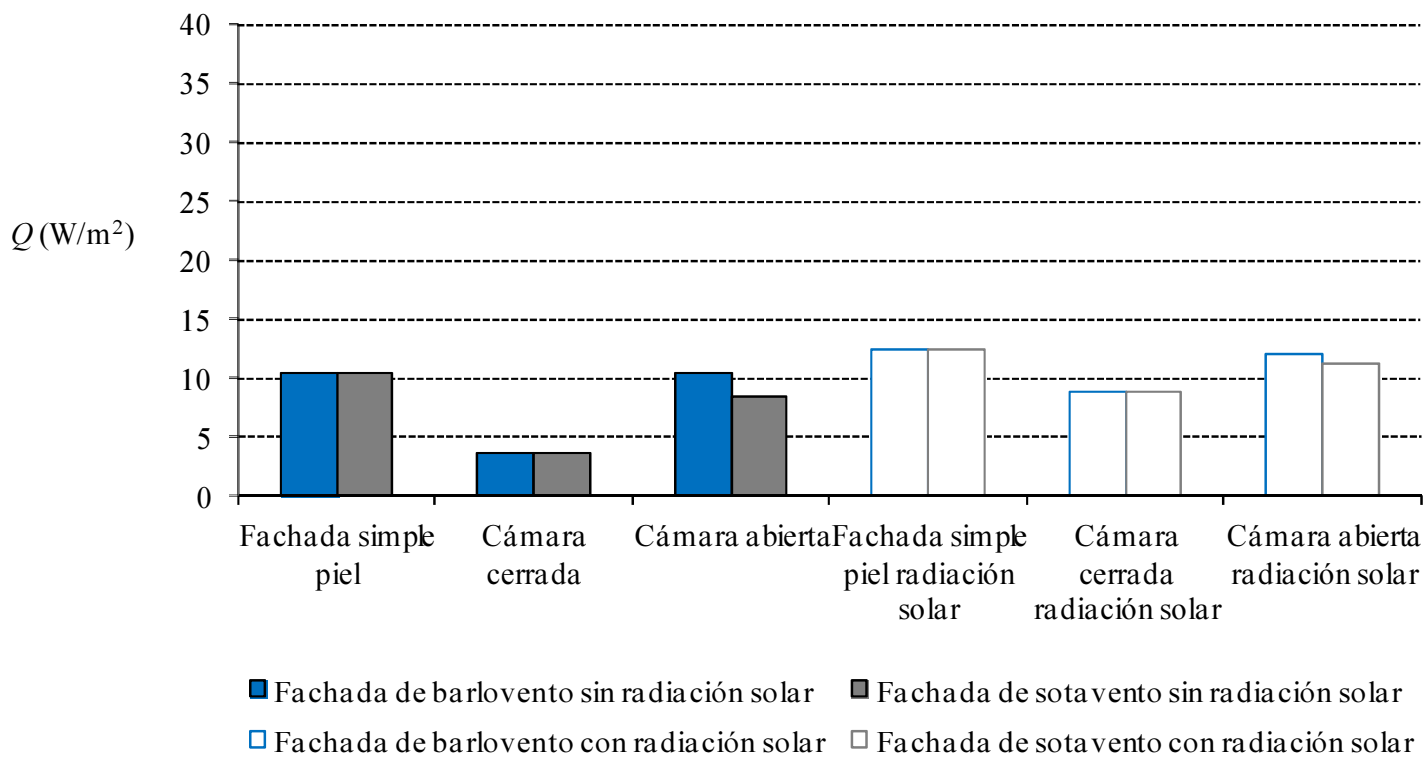

Figura 5.63. Flujo de calor para mantener la temperatura en la habitación a $26{ }^{\circ} \mathrm{C}$ con fachada simple piel y con fachada doble piel $A=30$, en condiciones de verano con el viento en las fachadas de barlovento y de sotavento de velocidad $v_{m, r e f}=6,3 \mathrm{~m} / \mathrm{s}$.

Tras el análisis de los resultados obtenidos en las condiciones de verano tanto en presencia de radiación solar como sin ella, se observa que:

- Tanto en los casos de fachada simple piel como en los de fachada doble piel con cámara cerrada no influye la dirección del viento, el flujo de calor que hay que extraer para que la habitación se mantenga a la temperatura de confort es prácticamente el mismo.

- El único caso en el que hay mayor diferencia entre el flujo de calor aportado con el viento en la fachada de barlovento o sotavento, es en el caso de cámara abierta, que con el viento en la fachada de sotavento hay que aportar $2 \mathrm{~W} / \mathrm{m}^{2}$ menos en ausencia de radiación solar, y $0,80 \mathrm{~W} / \mathrm{m}^{2}$ menos en presencia de radiación solar.

- Con la cámara cerrada, la fachada doble piel se comporta mejor que la fachada simple piel en presencia de viento. Interesa cerrar la cámara siempre, tanto con el viento en la fachada de barlovento como de sotavento. En ausencia de radiación solar, la fachada doble piel se comporta mejor porque se produce un ahorro de energía de aproximadamente $5,3 \mathrm{~W} / \mathrm{m}^{2}$ respecto al mismo caso pero con radiación solar. 
- Interesa abrir la cámara en el caso de viento en la fachada de sotavento, ya que se produce un pequeño ahorro de energía respecto a la fachada simple piel.

- Entre abrir o cerrar la cámara, siempre interesa cerrar la cámara para los casos de verano porque se produce un mayor ahorro de energía.

\subsubsection{Análisis de eficiencia energética}

En este apartado se compara el comportamiento térmico de una fachada simple piel respecto a una fachada doble piel de una habitación situada en la zona centro de España, en particular en Madrid, teniendo en cuenta la ventilación natural producida por viento. El objetivo es estudiar la influencia de la dirección y de la velocidad del viento en la configuración de fachada de doble piel más eficiente, la correspondiente a $A=30$. A continuación se analiza y se discute el índice de eficiencia energética obtenido en todos los escenarios estudiados.

Las Figuras 5.64 y 5.65 representan el índice de eficiencia energética en los escenarios de invierno y verano con el viento en la fachada de barlovento y de sotavento respectivamente. Muestran el ahorro (valores positivos) o el incremento del gasto de energía (valores negativos) para cada situación respecto al mismo caso con fachada simple piel. Para ello, se utiliza el valor del flujo de calor, obtenido anteriormente en los apartados 5.2.1.5 y 5.2.2.5, que se necesita aportar o extraer para mantener la habitación dentro de la temperatura de confort para el caso de fachada doble piel con una cámara de aire de $A=30$.

El porcentaje de ahorro o gasto obtenido se ha calculado en comparación con la fachada simple piel, caso de referencia. Para ello, se define el índice de eficiencia energética $(\eta)$ mediante la siguiente fórmula: $\eta=\left(Q_{\text {ref }} Q\right) / Q_{r e f}$, donde $Q$ es el flujo de calor obtenido; y $Q_{r e f}$ es el flujo de calor de referencia.

En el escenario de invierno, los flujos de calor de referencia que hay que aportar son de $30,6 \mathrm{~W} / \mathrm{m}^{2}$ y de $34,4 \mathrm{~W} / \mathrm{m}^{2}$ con viento en la fachada de barlovento y de sotavento, con y sin radiación solar, respectivamente.

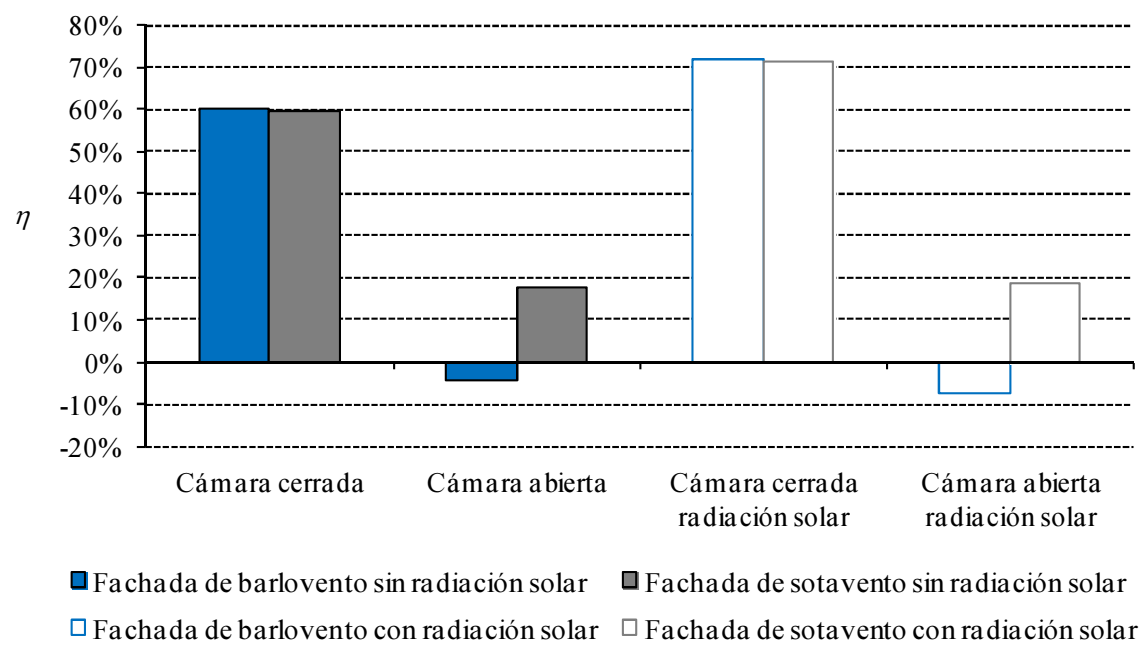

Figura 5.64. Índice de eficiencia energética en el escenario de invierno con el viento en la fachada de barlovento y de sotavento de velocidad $v=5,8 \mathrm{~m} / \mathrm{s}$. 
En el escenario de verano, los flujos de calor de referencia que hay que extraer son de $-12,5 \mathrm{~W} / \mathrm{m}^{2}$ y $-10,5 \mathrm{~W} / \mathrm{m}^{2}$ con viento en la fachada de barlovento y de sotavento, con y sin radiación solar, respectivamente.

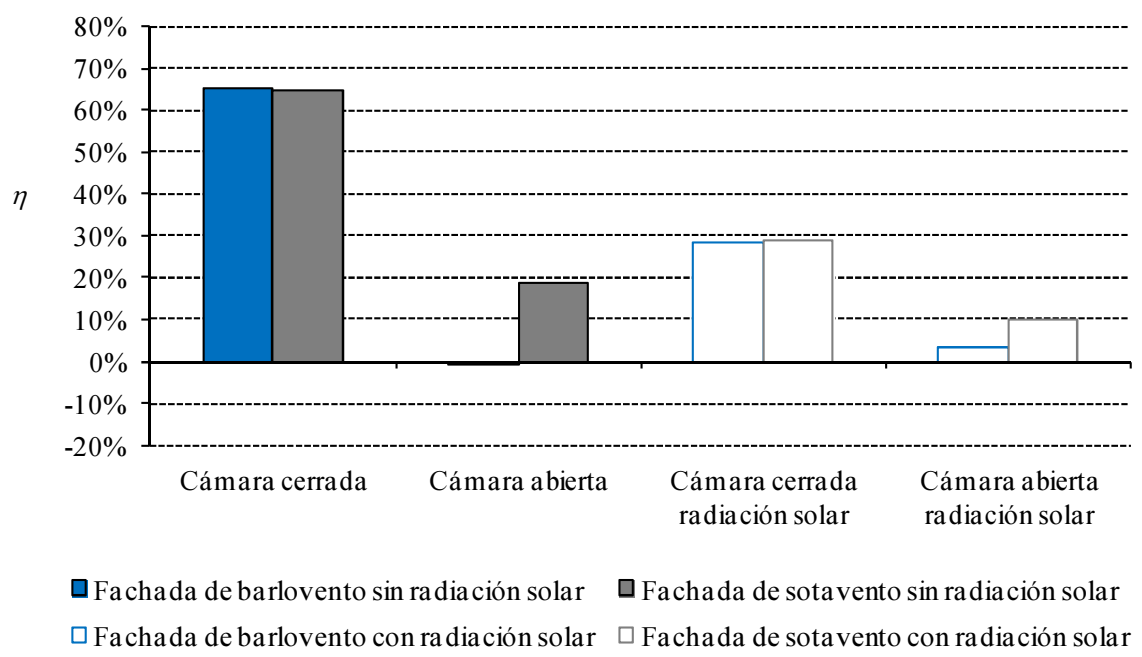

Figura 5.65. Índice de eficiencia energética en el escenario de verano con el viento en la fachada de barlovento y de sotavento de velocidad $v=6,3 \mathrm{~m} / \mathrm{s}$.

La Tabla 5.4 presenta los resultados obtenidos para los escenarios de invierno y verano:

\begin{tabular}{|c|c|c|c|c|c|}
\hline Escenario & Radiación Solar & Aberturas & $\begin{array}{l}\text { Viento } \\
\text { Fachada }\end{array}$ & $\begin{array}{c}\text { Ahorro de } \\
\text { Energía } \\
(\%)\end{array}$ & $\begin{array}{c}\text { Gasto de } \\
\text { Energía } \\
(\%)\end{array}$ \\
\hline \multirow{8}{*}{ Invierno } & \multirow{4}{*}{ No } & \multirow{2}{*}{ Cerrado } & Barlovento & 59,9 & \\
\hline & & & Sotavento & 59,7 & \\
\hline & & \multirow{2}{*}{ Abierto } & Barlovento & & 4,2 \\
\hline & & & Sotavento & 17,9 & \\
\hline & \multirow{4}{*}{$\mathrm{Si}$} & \multirow{2}{*}{ Cerrado } & Barlovento & 71,9 & \\
\hline & & & Sotavento & 71,5 & \\
\hline & & \multirow{2}{*}{ Abierto } & Barlovento & & 7,2 \\
\hline & & & Sotavento & 18,9 & \\
\hline \multirow{8}{*}{ Verano } & \multirow{4}{*}{ No } & \multirow{2}{*}{ Cerrado } & Barlovento & 65,1 & \\
\hline & & & Sotavento & 64,9 & \\
\hline & & \multirow{2}{*}{ Abierto } & Barlovento & & 0,5 \\
\hline & & & Sotavento & 18,7 & \\
\hline & \multirow{4}{*}{$\mathrm{Si}$} & \multirow{2}{*}{ Cerrado } & Barlovento & 28,4 & \\
\hline & & & Sotavento & 28,67 & \\
\hline & & \multirow{2}{*}{ Abierto } & Barlovento & 3,36 & \\
\hline & & & Sotavento & 9,98 & \\
\hline
\end{tabular}

Tabla 5.4. Porcentaje de ahorro o gasto de energía en los escenarios de invierno y de verano en comparación con la fachada simple piel. 


\subsubsection{Conclusiones}

Después de analizar los resultados obtenidos a partir de las simulaciones, se discuten las configuraciones de fachada más eficientes para cada escenario:

- En el escenario de invierno siempre es más eficiente cerrar la cámara, tanto en los casos de radiación solar como sin ella, ya que favorece el efecto invernadero. De todos ellos, el más favorable siempre es el caso en que hay radiación solar, tanto para el caso de viento en la fachada de barlovento como de sotavento. La ventilación sólo es beneficiosa en los casos de viento en la fachada de sotavento, aunque no recomendable ya que se ahorra más energía cerrando la cámara.

- En el escenario de verano la fachada doble piel es eficiente en todas las situaciones a excepción del caso de cámara abierta sin radiación solar y con viento en la fachada de barlovento. De todas ellas, la más favorable es el caso de cámara cerrada sin radiación solar, tanto para viento en la fachada de barlovento como de sotavento. En presencia de radiación solar, abrir la cámara siempre es eficiente, ya que favorece el efecto chimenea.

Se puede concluir que:

- El sistema de fachada doble piel es más beneficioso que el sistema de fachada simple piel en 13 escenarios. Solamente es desfavorable en 3 situaciones: en invierno con cámara abierta y viento en la fachada de sotavento, tanto con radiación como sin ella; y en verano sin radiación solar con cámara abierta.

- Cerrar la cámara siempre es más eficiente en todos los escenarios.

- Abrir la cámara es favorable en 5 escenarios. De estos, siempre es eficiente en verano con radiación solar, en las demás situaciones sólo con viento en la fachada de sotavento.

- La fachada doble piel reduce la carga de calefacción en invierno y la carga de refrigeración en verano.

- El peor escenario de invierno es abrir la cámara en presencia de radiación solar con viento en la fachada de barlovento porque aumenta la carga de calefacción.

- El peor escenario en condiciones de verano es abrir la cámara cuando no hay radiación solar y con viento en la fachada de barlovento porque aumenta la carga de refrigeración.

- Abrir la cámara en el escenario de verano con radiación solar supone menos ahorro del que se esperaba.

De acuerdo con la información presentada en las Figuras 5.64 y 5.65 y en la Tabla 5.4, se puede concluir que la fachada doble piel ofrece buenos resultados en términos de ahorro energético en comparación con la fachada simple piel en los escenarios de invierno y de verano tanto con radiación solar como sin ella. 
En condiciones de invierno, es particularmente notable el ahorro de hasta el $70 \%$ en el caso de cámara cerrada tanto con viento en la fachada de barlovento como de sotavento con radiación solar, y del 60\% sin radiación solar; e incluso hasta aproximadamente el $19 \%$ en el caso de cámara abierta con el viento en la fachada de sotavento con radiación solar.

En condiciones de verano, es particularmente notable el ahorro del 65,1\% en el caso de cámara cerrada tanto con viento en la fachada de barlovento como de sotavento sin radiación solar; y hasta el $18,7 \%$ en el caso de cámara abierta con viento en la fachada de sotavento y sin radiación solar.

Asimismo, comparando los resultados obtenidos en invierno y en verano con viento y sin radiación solar, se puede observar que la fachada doble piel es más eficiente en condiciones de verano, ya que se ahorra más energía. Sin embargo, en presencia de viento y de radiación solar la fachada doble piel es más eficiente en condiciones de invierno.

\subsection{ANÁLISIS COMPARATIVO}

En el siguiente apartado se realiza un análisis comparativo de los resultados obtenidos de la ventilación natural dominada tanto por convección natural como por viento en los escenarios de invierno y de verano con el objetivo de analizar la eficiencia energética de la fachada doble piel para el caso de $A=30$, cámara óptima, en comparación con la fachada simple piel convencional y poder alcanzar unas conclusiones.

\subsubsection{Condiciones de invierno}

\subsubsection{Flujo de calor}

La Figura 5.66 recoge los resultados obtenidos, tanto por convección natural como con viento, del flujo de calor que hay que aportar para el caso de $A=30$ en cada una de las situaciones, para que la temperatura en la habitación se mantenga en $20^{\circ} \mathrm{C}$, temperatura de confort en condiciones de invierno, y con una temperatura exterior de $4{ }^{\circ} \mathrm{C}$. 
Optimización de la fachada de doble piel acristalada con ventilación natural. Metodología de diseño para el análisis de la eficiencia energética del sistema.

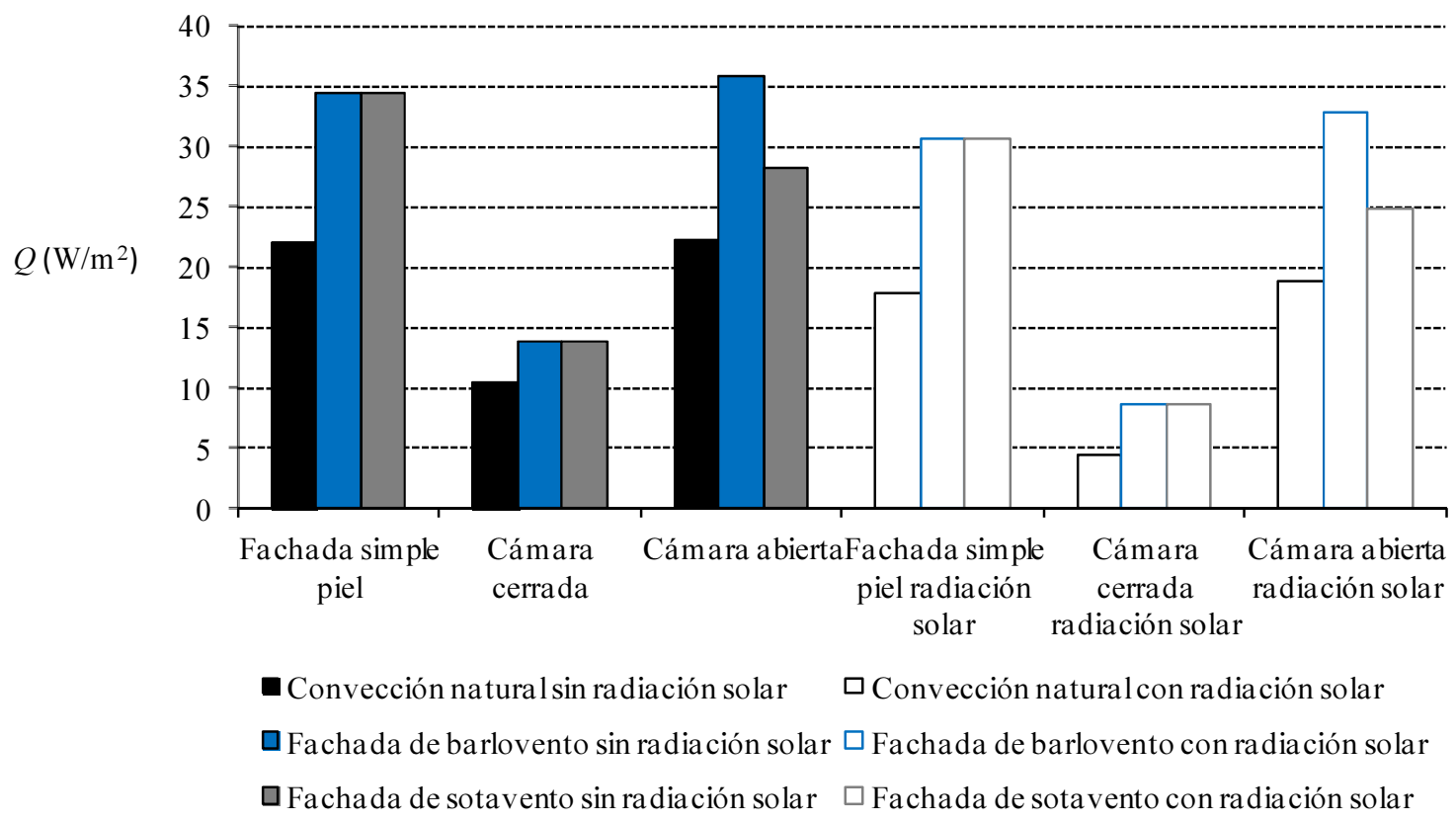

Figura 5.66. Flujo de calor para mantener la temperatura en la habitación a $20{ }^{\circ} \mathrm{C}$ con fachada simple piel y con fachada doble piel, en condiciones de invierno y temperatura exterior de $4{ }^{\circ} \mathrm{C}$ sin viento y con viento de velocidad $v=5,8 \mathrm{~m} / \mathrm{s}$.

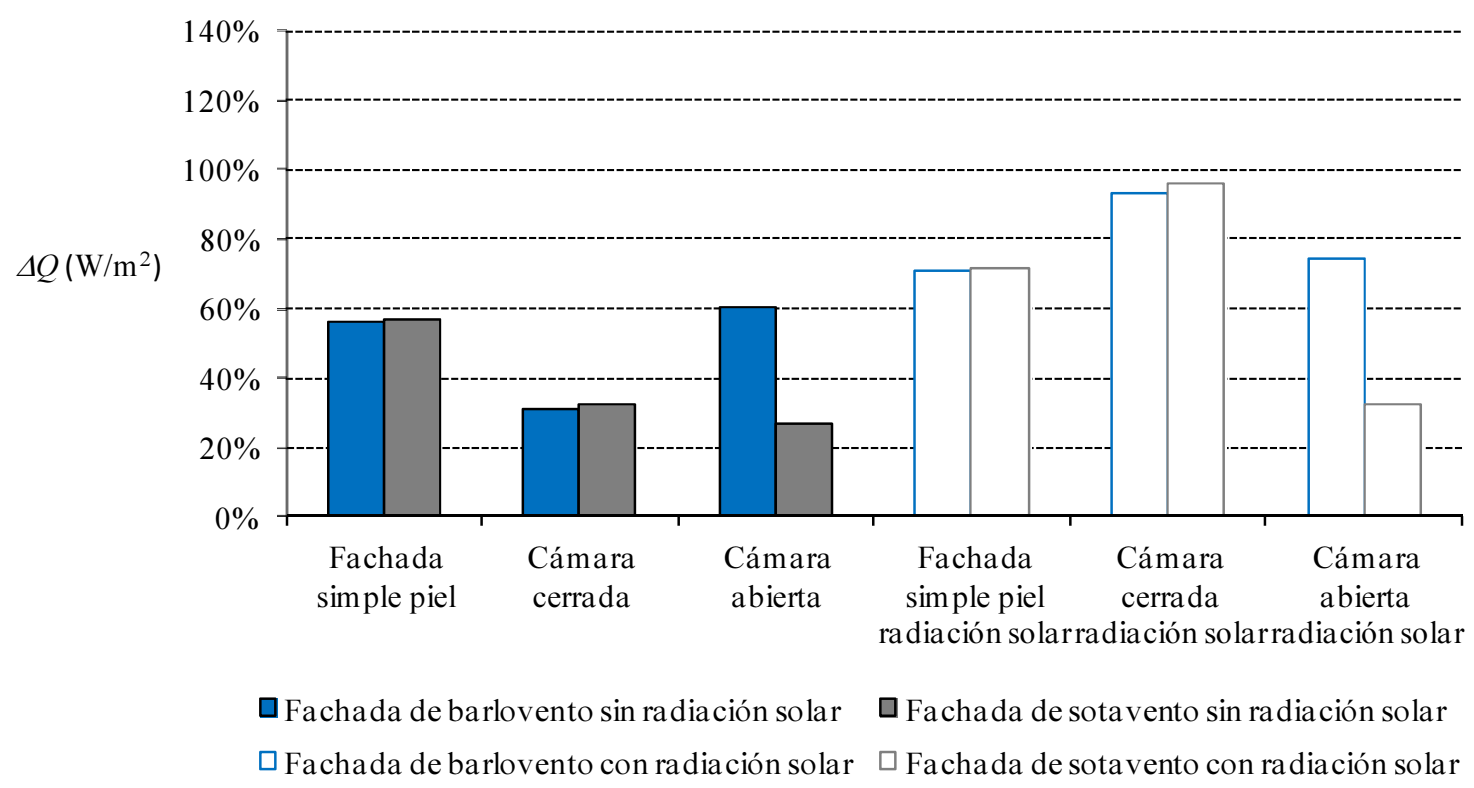

Figura 5.67. Incremento del flujo de calor que hay que aportar para mantener la temperatura en la habitación a $20^{\circ} \mathrm{C}$ con fachada simple piel y con fachada doble piel en los casos de ventilación producida por viento de velocidad $v=5,8 \mathrm{~m} / \mathrm{s}$ respecto al mismo caso de sin viento en condiciones de invierno y una temperatura exterior de $4{ }^{\circ} \mathrm{C}$.

Análisis de los resultados obtenidos:

- Hay que aportar mayor flujo de calor en los casos de flujo dominado por el viento que en los casos sin viento. 
- La dirección del viento sólo afecta en el caso de cámara abierta, especialmente en la fachada de barlovento.

- El viento afecta menos en el caso de cámara cerrada que en el resto de los casos.

- En todas las situaciones, el sistema que más interesa es el de fachada doble piel con cámara cerrada.

- Para todas las situaciones estudiadas, hay que aportar menos calor para los casos en los que la radiación solar está presente, y se produce un ahorro de energía.

- La situación que más interesa es la de cerrar la cámara en presencia de radiación solar, tanto para flujo dominado por convección natural como por viento. De estas, hay que aportar menor cantidad de calor cuando la ventilación natural se produce por convección natural, del orden de la mitad frente a la misma situación pero con ventilación natural producida por viento.

\subsubsection{Análisis de eficiencia energética}

La Figura 5.68 representa el índice de eficiencia energética en el escenario de invierno tanto de la ventilación natural dominada por convección natural como por viento. Muestran el ahorro o el incremento de gasto de energía para cada situación. Para ello, se utiliza el valor del flujo de calor, obtenido anteriormente, que se necesita aportar para mantener la habitación dentro de la temperatura de confort para el caso de fachada doble piel con una cámara de aire de $A=30$, esbeltez de cámara óptima alcanzada.

El porcentaje de ahorro o gasto obtenido se ha calculado en comparación con la fachada simple piel, caso de referencia, en las mismas condiciones de viento. Para ello, se define el índice de eficiencia energética $(\eta)$ mediante la siguiente fórmula: $\eta=\left(Q-Q_{r e f}\right) / Q_{\text {ref }}$, donde $Q$ es el flujo de calor obtenido; y $Q_{\text {ref }}$ es el flujo de calor de referencia.

En el escenario de invierno, el flujo de calor de referencia es de:

- 34,4 W/m ${ }^{2}$ con el viento en la fachada de barlovento y de sotavento sin considerar la radiación solar.

- 30,6 W/m $\mathrm{m}^{2}$ con el viento en la fachada de barlovento y de sotavento con radiación solar. 
Optimización de la fachada de doble piel acristalada con ventilación natural. Metodología de diseño para el análisis de la eficiencia energética del sistema.

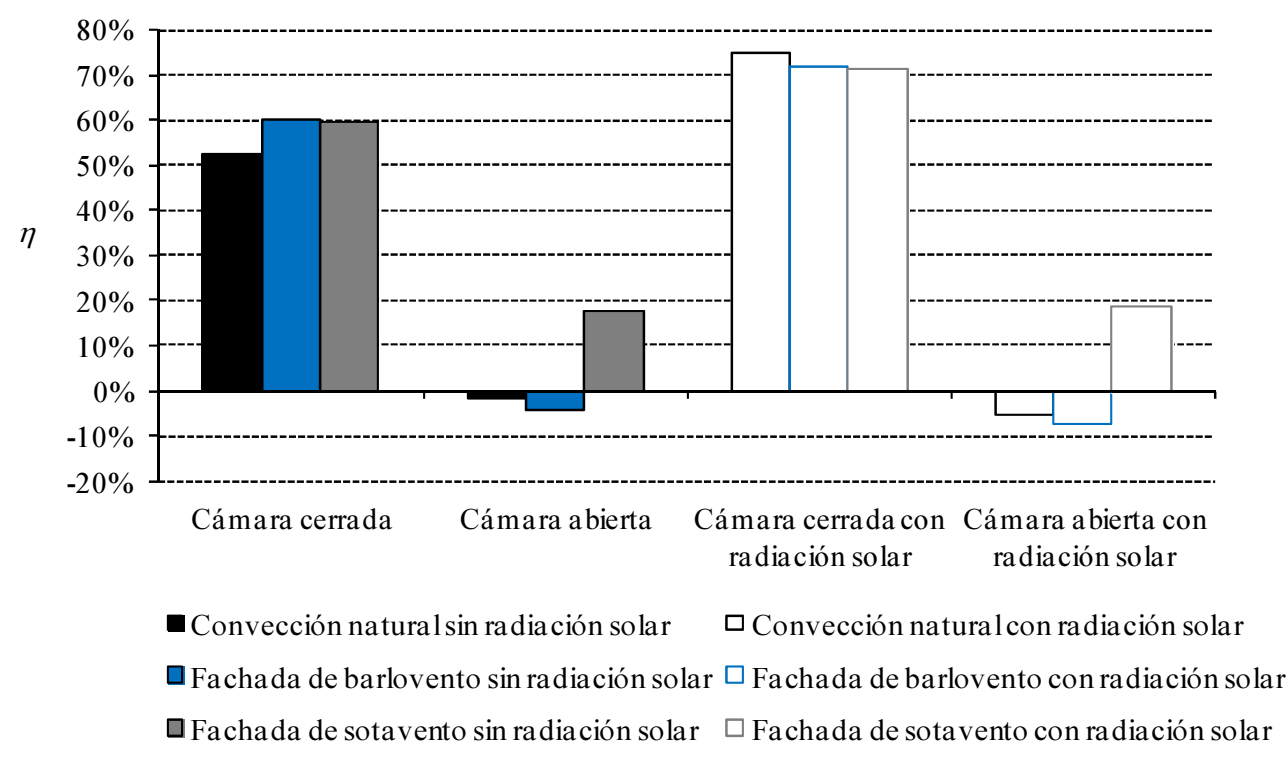

Figura 5.68. Índice de eficiencia energética para el escenario de invierno.

De acuerdo con la información presentada en la Figura 5.68, se puede concluir que la fachada doble piel con cámara cerrada ofrece mejores resultados en términos de ahorro energético en comparación con la fachada simple piel en el escenario de invierno. El ahorro es mayor para los casos en los que hay radiación solar, del orden de un $10 \%$ mayor sobre los casos sin radiación solar.

Es particularmente notable, el ahorro en el caso de cámara cerrada tanto con el flujo dominado por convección natural como por viento; e incluso el ahorro en el caso de cámara abierta con el viento en la fachada de sotavento.

\subsubsection{Condiciones de verano}

\subsubsection{Flujo de calor}

La Figura 5.69 recoge los resultados obtenidos, tanto por convección natural como con el viento, del flujo de calor que hay que extraer para el caso de $A=30$ en cada una de las situaciones, para que la temperatura en la habitación se mantenga en $26^{\circ} \mathrm{C}$, temperatura de confort en condiciones de verano, y con una temperatura exterior de $32{ }^{\circ} \mathrm{C}$. 


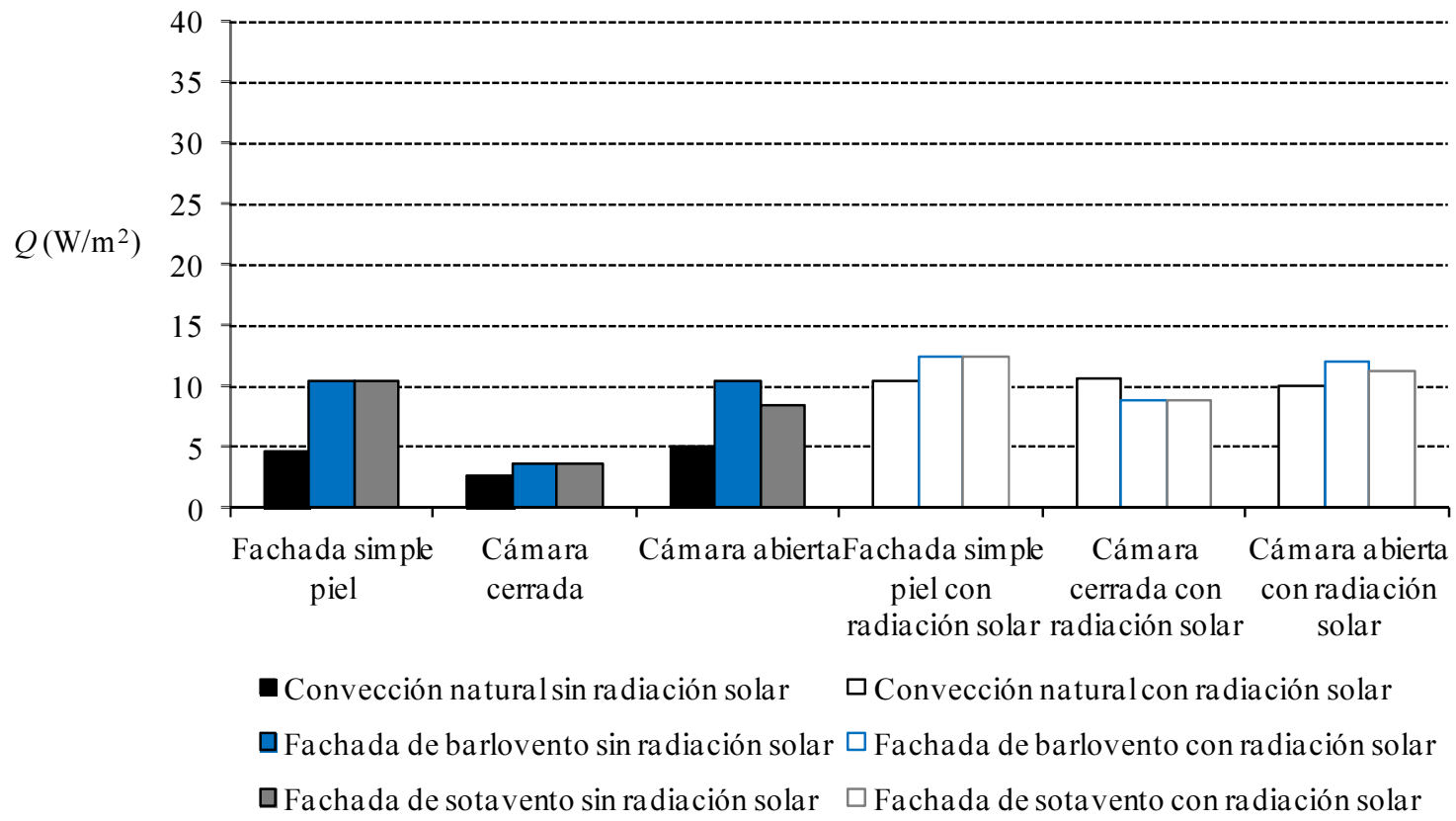

Figura 5.69. Flujo de calor para mantener la temperatura en la habitación a $26^{\circ} \mathrm{C}$ con fachada simple piel y con fachada doble piel, en condiciones de verano sin viento y con viento de velocidad $v=6,3 \mathrm{~m} / \mathrm{s}$ y una temperatura exterior de $32{ }^{\circ} \mathrm{C}$.

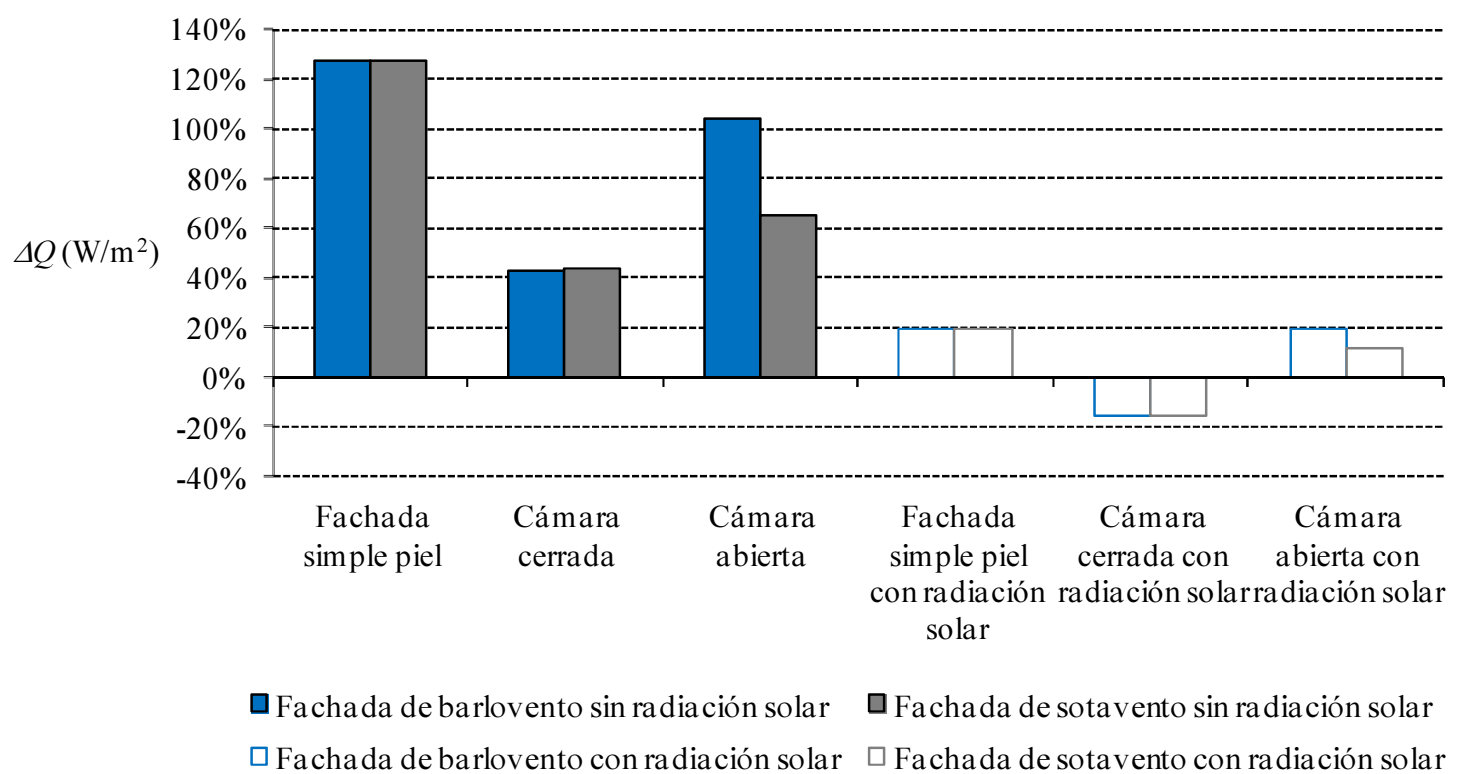

Figura 5.70. Incremento del flujo de calor que hay que extraer para mantener la temperatura en la habitación a $26{ }^{\circ} \mathrm{C}$ con fachada simple piel y con fachada doble piel en los casos de ventilación natural producida por viento de velocidad $v=6,3 \mathrm{~m} / \mathrm{s}$ respecto al mismo caso sin viento en condiciones de verano y una temperatura exterior de $32^{\circ} \mathrm{C}$. 
Análisis de los resultados obtenidos:

- Hay que extraer mayor flujo de calor en los casos de flujo dominado por el viento que en los casos de convección natural, a excepción del caso de cámara cerrada con radiación solar.

- La dirección del viento sólo afecta a los casos de cámara abierta, especialmente con el viento en la fachada de barlovento.

- El viento afecta menos en los casos de cámara cerrada con y sin radiación solar.

- En todas las situaciones, el sistema que más interesa es el de fachada doble piel con cámara cerrada sin radiación solar.

- De todas las situaciones, interesa más la cámara cerrada especialmente cuando no hay radiación solar porque hay que extraer menos calor para alcanzar la temperatura de confort. De estas, hay que extraer menor cantidad de calor cuando la ventilación natural se produce por convección natural, del orden de un tercio frente a la misma situación pero con ventilación natural producida por viento.

\subsubsection{Análisis de eficiencia energética}

La Figura 5.71 representa el índice de eficiencia energética en el escenario de verano tanto sin viento como con viento. Muestran el ahorro o el incremento de gasto de energía para cada situación. El porcentaje de ahorro o gasto obtenido se ha calculado en comparación con la fachada simple piel, caso de referencia, en las mismas condiciones de viento.

En el escenario de verano, el flujo de calor de referencia es de:

- $-10,5 \mathrm{~W} / \mathrm{m}^{2}$ con el viento en la fachada de barlovento y de sotavento sin considerar la radiación solar.

- $-12,5 \mathrm{~W} / \mathrm{m}^{2}$ con el viento en la fachada de barlovento y de sotavento con radiación solar. 


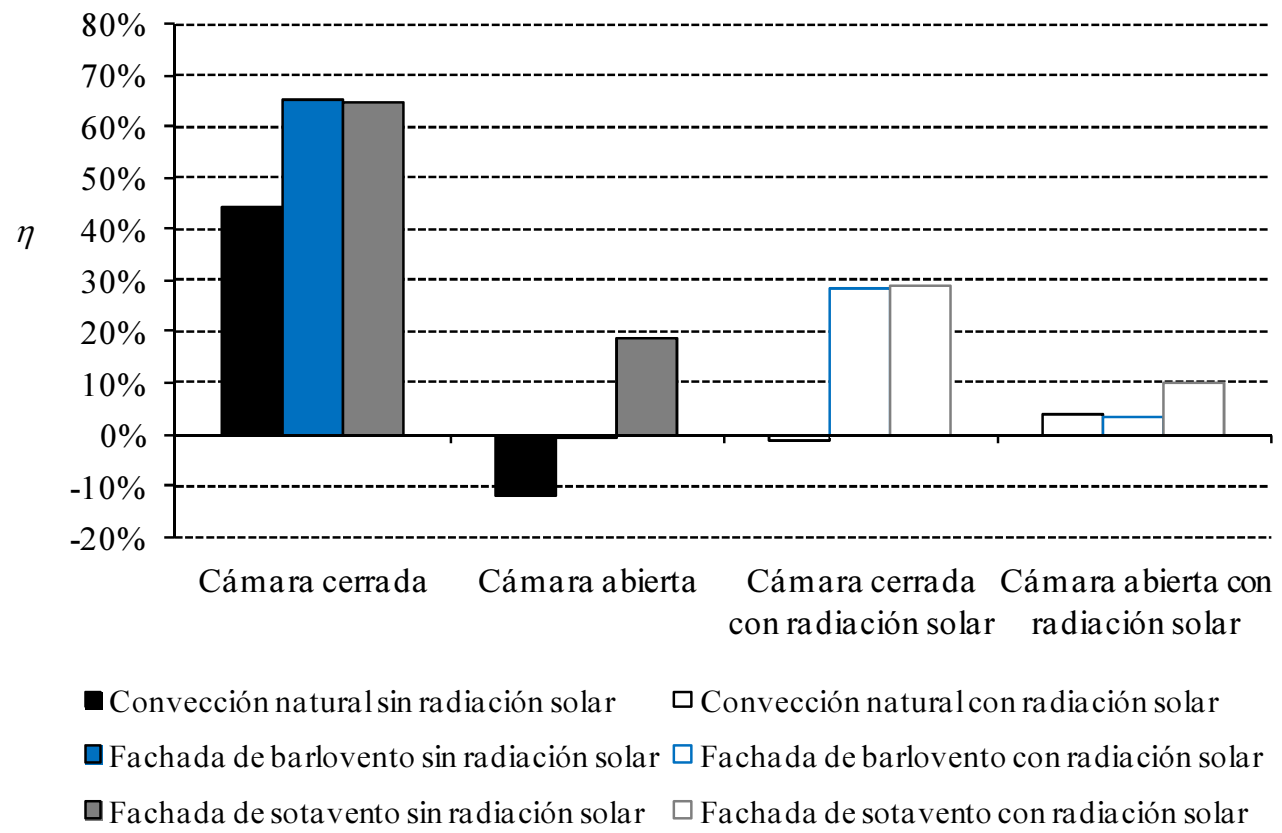

Figura 5.71. Índice de eficiencia energética para el escenario de verano.

De acuerdo con la información presentada en la Figura 5.71, se puede concluir que la fachada doble piel con la cámara cerrada ofrece mejores resultados en términos de ahorro energético en comparación con la fachada simple piel en el escenario de verano, especialmente para los casos de flujo dominado por viento. El ahorro es mayor para los casos en los que no hay radiación solar, del orden de un 37\% mayor sobre los casos con radiación solar.

Es particularmente notable, el ahorro en el caso de cámara cerrada tanto con el flujo dominado por convección natural como por viento; y el ahorro en el caso de cámara abierta con el viento en la fachada de sotavento.

Se observa que en el caso de flujo dominado por viento con radiación solar, es mejor cerrar la cámara ya que se ahorra más. En cambio, en el caso de flujo sin viento con radiación solar abrir la cámara es más eficiente energéticamente. Esto es debido a que el vidrio está más caliente que la temperatura exterior, y al haber viento, éste refrigera el cristal y pasa menos calor por conducción, pero por radiación sigue pasando el mismo calor aunque haya viento. 


\subsubsection{Conclusiones}

Del análisis comparativo entre la ventilación natural dominada por convección natural y la ventilación natural dominada por viento, se pueden extraer las siguientes conclusiones globales:

- Se concluye que tanto en invierno como en verano tanto con radiación solar como sin ella, la fachada doble piel es más eficiente que la fachada simple piel, sin importar que el flujo esté dominado por convección natural o por viento.

- La dirección del viento sólo afecta en los casos de cámara abierta, especialmente en la fachada de barlovento.

- Hay que aportar o extraer mayor flujo de calor en los casos de flujo dominado por el viento que en los casos de convección natural.

- El viento afecta menos en los casos de cámara cerrada.

- La situación que más interesa en condiciones de invierno es la de cerrar la cámara en presencia de radiación solar, tanto para flujo dominado por convección natural como por viento. De estas, se produce mayor ahorro energético cuando la ventilación natural se produce por convección natural.

- La situación que más interesa en condiciones de verano es la cámara cerrada cuando no hay radiación solar, tanto para flujo dominado por convección natural como por viento. De estas, se produce mayor ahorro energético cuando la ventilación natural se produce por viento. Sólo interesa abrir la cámara para el caso de flujo dominado por convección natural y en presencia de radiación solar.

- Abrir la cámara en el escenario de verano con radiación solar supone menos ahorro del que se esperaba. 


\section{CONCLUSIONES FINALES Y TRABAJOS FUTUROS}

En este capítulo se recogen las principales conclusiones de la aplicación del sistema de fachada doble piel acristalada como sistema pasivo para mejorar el rendimiento térmico y la eficiencia energética de los edificios frente al sistema de fachada simple piel, y se exponen las conclusiones finales de la integración del conjunto de esta investigación.

A continuación, se proponen futuras líneas de investigación en dos direcciones, la de dar continuidad y conclusión a los trabajos aquí realizados y la de abrir nuevos caminos.

Finalmente, se presentan los resultados científicos resultado de esta investigación. 
Optimización de la fachada de doble piel acristalada con ventilación natural. Metodología de diseño para el análisis de la eficiencia energética del sistema. 


\subsection{CONCLUSIONES DEL ANÁLISIS DE RESULTADOS}

\subsubsection{Conclusiones del flujo dominado por convección natural}

\subsubsection{Cámara de aire óptima}

Después de analizar los resultados obtenidos desde el punto de vista de la temperatura media en la habitación, la distribución de temperaturas en la cámara de aire, la tasa de transferencia de calor y el comportamiento del flujo de aire tanto en el ambiente interior como en la cámara; se concluye que la cámara de aire óptima es aquella que tiene una esbeltez de $A=30$ ya que:

- En el escenario de invierno valores menores no mejoran el aislamiento para el caso de cámara cerrada, que es la más eficiente, y valores más altos aíslan significativamente menos.

- En el escenario de verano a partir de $A=30$ comienza a aislar menos incluso en el caso de cámara cerrada.

- Además, esta esbeltez supone un ancho de cámara de aire moderado.

- La única situación en la que es más eficiente abrir la cámara de aire es en el escenario de verano con radiación solar, en el resto de situaciones aísla más la cámara de aire cerrada.

- En esta única situación en la que es más eficiente abrir la cámara de aire, el tamaño de las aberturas óptimo es de $0,06 \mathrm{~m}$, ya que tamaños menores reducen el caudal de ventilación en la cámara, y tamaños mayores no lo aumentan significativamente.

\subsubsection{Eficiencia energética}

El sistema de fachada doble piel proporciona mejores resultados en términos de ahorro energético en comparación con el sistema de fachada simple piel, tanto en el escenario de invierno como en el de verano. Es particularmente notable, que el ahorro de energía alcanza el $75 \%$ en el escenario de invierno con la cámara cerrada y en presencia de radiación solar; y hasta un $4 \%$ en el escenario de verano con la cámara abierta y con radiación solar. Abrir la cámara en el escenario de verano con radiación solar supone menos ahorro del que se podría esperar.

\subsubsection{Conclusiones del flujo dominado por viento}

En presencia de viento el sistema de fachada doble piel también ofrece mejores resultados en términos de ahorro energético en comparación con el sistema de fachada simple piel, tanto en los escenarios de invierno como de verano, con radiación solar y sin ella. 
En condiciones de invierno, es particularmente notable el ahorro de hasta el $70 \%$ en el caso de cámara cerrada y con radiación solar, tanto con viento en la fachada de barlovento como de sotavento, y del 60\% en el caso de que no haya radiación solar.

En condiciones de verano, es particularmente notable el ahorro del $65 \%$ en el caso de cámara cerrada y sin radiación solar, tanto con viento en la fachada de barlovento como de sotavento.

\subsubsection{Conclusiones del análisis comparativo con la fachada simple piel}

\subsubsection{Condiciones de invierno}

Se puede concluir que el sistema de fachada de doble piel con cámara cerrada ofrece mejores resultados en términos de ahorro energético en comparación con el sistema de fachada de simple piel. El ahorro es mayor en presencia de radiación solar (del orden de un $10 \%$ mayor sobre los casos sin radiación solar).

Es particularmente notable el ahorro en el caso de cámara cerrada, tanto con el flujo dominado por convección natural ( $75 \%$ de ahorro) como por viento ( $70 \%$ de ahorro), ambos casos con radiación solar.

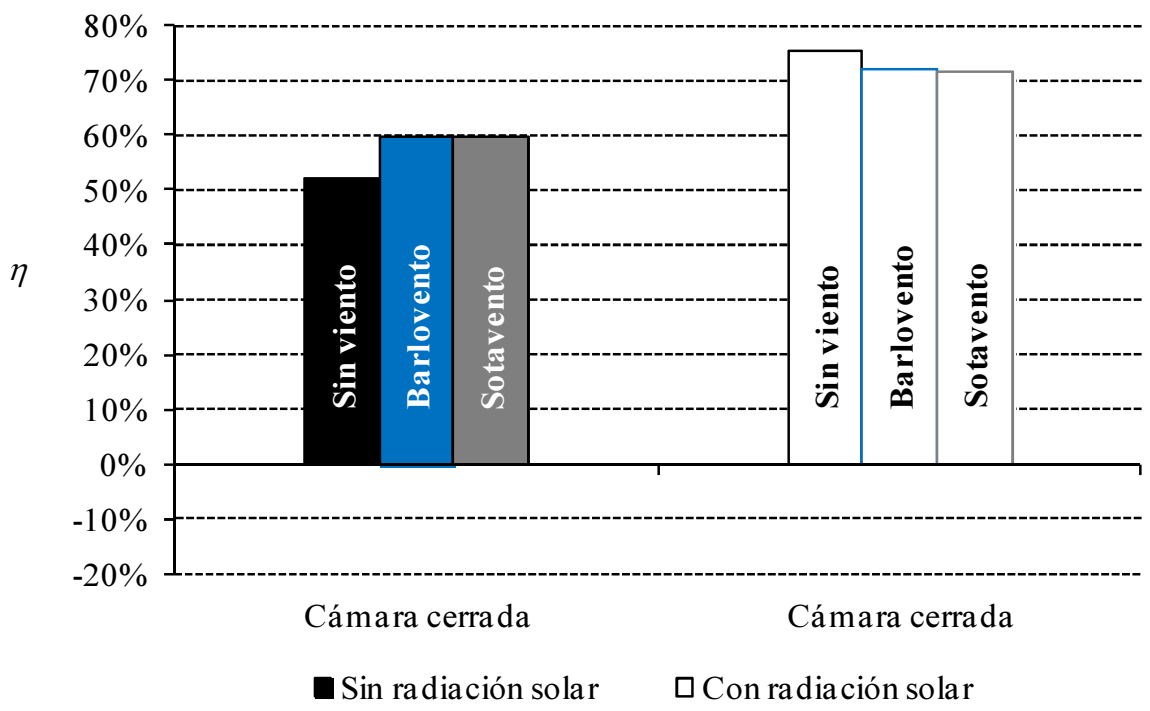

Figura 6.1. Mayor porcentaje de ahorro de energía en el escenario de invierno en comparación con la fachada simple piel.

\subsubsection{Condiciones de verano}

También se puede concluir que en estas condiciones el sistema de fachada de doble piel con la cámara cerrada ofrece mejores resultados en términos de ahorro energético en comparación con el sistema de fachada de simple piel, especialmente para los casos de flujo dominado por viento. El ahorro energético es mayor para los casos en los que no hay radiación solar (del orden de un 37\% mayor sobre los casos con de radiación solar). 
Es particularmente notable el ahorro energético en el caso de cámara cerrada tanto con el flujo dominado por convección natural (44\% de ahorro) como por viento $(65 \%$ de ahorro), ambos casos sin radiación solar.

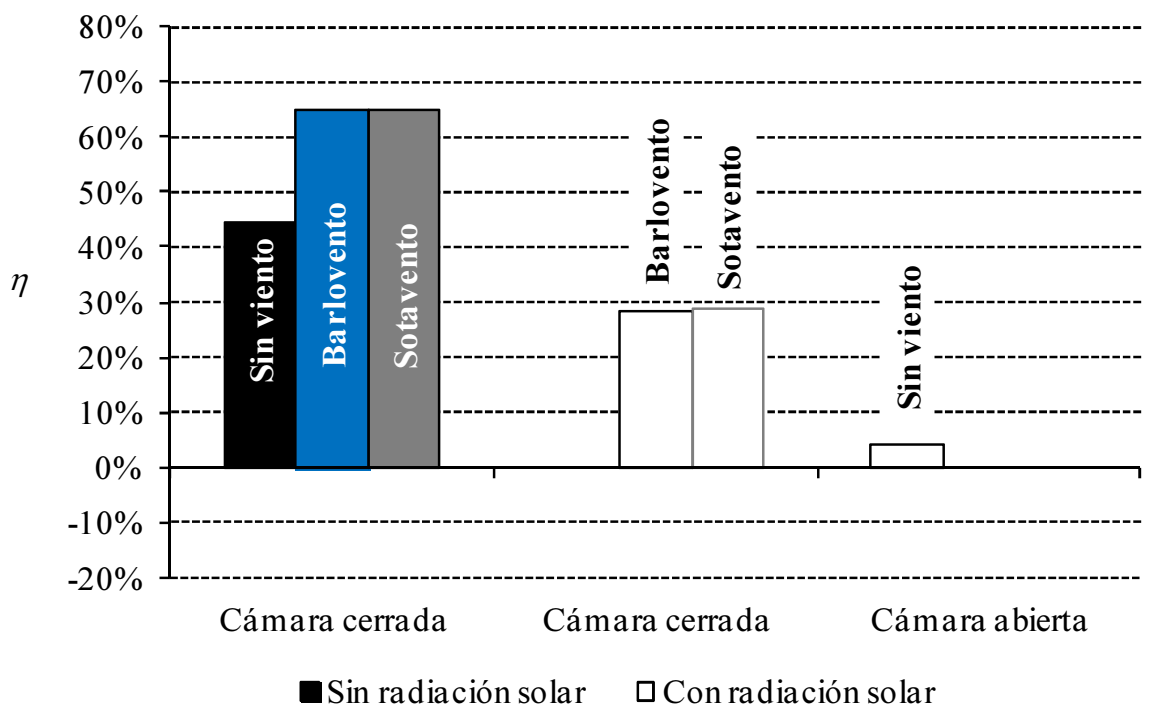

Figura 6.2. Mayor porcentaje de ahorro de energía en el escenario de verano en comparación con la fachada simple piel.

\subsubsection{Conclusiones generales}

Del análisis comparativo entre la ventilación natural dominada por convección natural y la ventilación natural dominada por viento, se pueden extraer las siguientes conclusiones globales:

- Tanto en invierno como en verano, y tanto en presencia de radiación solar como sin ella, el sistema de fachada de doble piel es más eficiente energéticamente que el sistema de fachada de simple piel, independientemente de que el flujo esté dominado por convección natural o por viento.

- El ahorro energético es mayor o igual en los casos de flujo dominado por viento que en los casos dominados por convección natural porque el viento afecta más a la fachada de simple piel que a la de doble piel.

- El viento afecta menos en los casos de cámara cerrada que en los de cámara abierta. La dirección del viento sólo afecta en los casos de cámara abierta, especialmente en la fachada de barlovento.

- En condiciones de invierno siempre lo más efectivo es, desde un punto de vista energético, mantener la cámara de aire cerrada, tanto para flujo dominado por convección natural como por viento, especialmente en presencia de radiación solar. 
- En condiciones de verano lo más efectivo es, en general, mantener la cámara de aire cerrada, tanto para flujo dominado por convección natural como por viento, especialmente cuando no hay radiación solar.

- Desde el punto de vista del ahorro energético, sólo es más eficiente abrir la cámara de aire en verano sin viento y en presencia de radiación solar.

\subsection{CONCLUSIONES DEL CONJUNTO DE LA INVESTIGACIÓN}

\section{En todas las situaciones el sistema de fachada de doble piel acristalada es más eficiente energéticamente que el sistema de fachada de simple piel.}

Cuanto mayor es la anchura de la cámara, mayor es su capacidad de aislamiento térmico, hasta alcanzar una esbeltez de $A=30$, a partir de la cual el aumentar su anchura no mejora su capacidad de aislamiento térmico. Además, esta esbeltez supone un ancho de cámara moderado con lo que se aumenta la superficie útil, lo cual es beneficioso económicamente para el promotor.

El efecto del viento sobre la fachada de doble piel, al igual que ocurre con la fachada de simple piel, es reducir su capacidad de aislamiento térmico. Sin embargo el ahorro de energía de la fachada de doble piel respecto de la fachada de simple piel es aún mayor en presencia de viento que en su ausencia.

En condiciones de invierno es más eficiente para el ahorro de energía cerrar la cámara en todos los casos para disminuir la carga de calefacción. Es particularmente notable el $\mathbf{7 5 \%}$ de ahorro de energía que se alcanza en el caso dominado por convección natural ( $\sin$ viento) y en presencia de radiación solar, para mantener unas condiciones interiores de confort óptimas.

En condiciones de verano generalmente es más eficiente energéticamente cerrar la cámara para disminuir la carga de refrigeración. Es particularmente notable el ahorro de energía del $65 \%$ para el caso dominado por viento en la fachada de barlovento y sin radiación solar, para mantener unas condiciones interiores de confort óptimas. El único caso en el que abrir la cámara es más eficiente para el ahorro de energía, es cuando no hay viento y además hay radiación solar, que se produce un ahorro del $4 \%$ respecto a la fachada de simple piel y un $5,4 \%$ de ahorro frente a la fachada de doble piel manteniendo la cámara de aire cerrada.

Habrá que valorar si es económicamente rentable la inversión de incorporar un mecanismo para abrir la cámara de aire, ya que sólo es favorable energéticamente en un caso y proporciona un ahorro bajo en comparación con el resto de escenarios.

Se ha desarrollado una metodología de diseño para analizar la eficiencia energética del sistema de fachada de doble piel acristalada con ventilación natural para el caso de un edificio de una planta, en dos dimensiones, con un tipo de vidrio concreto y en la zona centro de España, en particular en Madrid; pero esta metodología es extrapolable a un edificio de mayor altura, en tres dimensiones, con otros tipos de vidrios y en diferentes localizaciones. 


\subsection{FUTURAS LÍNEAS DE INVESTIGACIÓN}

Evaluar los resultados obtenidos en las simulaciones numéricas con experimentos a pequeña escala en túnel de viento o con modelos experimentales a escala real.

Estudiar la configuración de fachada doble piel acristalada óptima en las diferentes zonas climáticas de España.

Investigar la influencia del tipo de vidrio en la eficiencia energética del sistema, comparando entre distintas tipologías de vidrios, buscando el valor de esbeltez óptima en cada caso.

Influencia del elemento de sombreamiento en el interior de la cámara de aire o en el exterior de la fachada.

Estudiar el efecto de incluir aberturas en el ambiente interior para estudiar su efecto en la temperatura media y en el flujo de aire.

\subsection{INDICIOS DE CALIDAD}

\subsubsection{Contribuciones a congresos internacionales}

Autores: Edurne Sánchez Salcedo*, Antonio Rolando Ayuso.

Título: "Ventilation and sealing in the current envelopes in architecture".

Tipo de participación: Ponencia

Congreso: 2nd International Conference on Construction and Building Research. Universidad Politécnica de Valencia. Noviembre 2012.

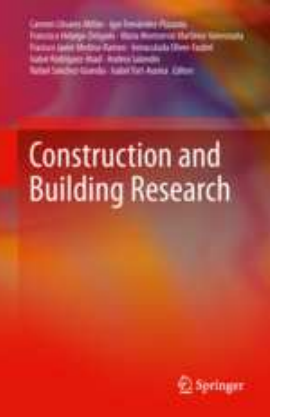

Editorial: Springer

ISBN 978-94-007-7789-7

\subsubsection{Artículo científico}

Autores: Edurne Sánchez Salcedo*, Antonio Rolando Ayuso, Rodolfo Sant Palma, Luis Ayuso Moreno.

Título: "Influence of natural ventilation due to buoyancy and heat transfer in the energy efficiency of a double skin facade building".

Revista: Energy for Sustainable Development Editorial: Elsevier, 2016.

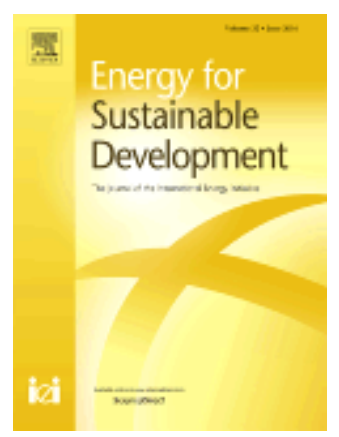

DOI: 10.1016/j.esd.2016.02.002 
Optimización de la fachada de doble piel acristalada con ventilación natural. Metodología de diseño para el análisis de la eficiencia energética del sistema. 


\section{REFERENCIA BIBIOGRÁFICAS}

\subsection{MONOGRAFÍAS}

Saint-Gobain Cristalería S.A. (2001). Manual del vidrio. Madrid: Saing-Gobain Glass.

\subsection{REVISTAS CIENTÍFICAS}

Allocca, C.; Quingyan, C.; Glicksman, L. (2003). Design analysis of single-sided natural ventilation, Energy and Buildings 35, pp. 785-795.

Asfour, O.; Gadi, M. (2007). A comparison between CFD and Network models for predicting wind-driven ventilation in buildings, Building and Environment 42, pp. 4079-4085.

Baldinelli, G. (2009). Double skin façades for warm climate regions: analysis of a solution with an integrated movable shading system, Building and Environment 44, pp. 1107-1118.

Ballestini, G.; De Carli, M.; Masiero, N.; Tombola, G. (2005). Possibilities and limitations of natural ventilation in restored industrial archaeology buildings with a double-skin facade in Mediterranean climates, Building and Environment 40, pp. 983995.

Balocco, C. (2002). A simple model to study ventilated facades energy performance, Energy and Buildings 34, pp. 469-475.

Balocco, C. (2004). A non-dimensional analysis of a ventilated double facade energy performance, Energy and Buildings 36, pp. 35-40.

Batchelor, G.K.; (1954). Heat transfer by free convection across a closed cavity between vertical boundaries at different temperatures, Quarterly of Applied Mathematics 12, pp. 209-233.

Cen, X.; Zhan, J.; Yang, S.; Ma, Y. (2008). CFD simulation and optimization design of double skin facade, Acta Scientiarum Natralium Universitatis Sunyatseni 47 (11), pp. 18-21.

Cetiner, I.; Özkan, E. (2005). An approach for the evaluation of energy and cost efficiency of glass façades, Energy and Buildings 37, pp. 673-684.

Chan, A.L.S.; Chow, T.T.; Fong, K.F.; Lin, Z. (2009). Investigation on energy performance of double skin facade in Hong Kong, Energy and Buildings 41, pp. 11351142 .

Chan, C.L.; Yu, Y.; Chen, C.F. (2004). Instability of convection of an ethanol-water solution in a vertical tank, J. Journal of Fluid Mechanics 510, pp. 243-265. 
Chen, Q. (2009). Ventilation performance prediction for buildings: A method overview and recent applications, Building and Environment 44, pp. 848-858.

Chou, S.K.; Chua, K.J.; Ho, J.C. (2009). A study on the effects of double skin façades on the energy management in buildings, Energy Conversion and Management 50, pp. $2275-2281$.

Chow, W.K.; Hung, W.Y.; Gao, Y.; Zou, G.; Dong, H. (2007). Experimental study on smoke movement leading to glass damages in double-skinned facade, Construction and Building Materials 21, pp. 556-566.

Coussirat, M.; Guardo, A.; Jou, E.; Egusquiza, E.; Cuerva, E.; Alavedra, P. (2008). Performance and influence of numerical sub-models on the CFD simulation of free and forced convection in double-glazed ventilated facades, Energy and Buildings 40, pp. $1781-1789$.

Da Silva, F.; Gomes, G. (2008). Gap inner pressures in multi-storey double skin facades, Energy and Buildings 40, pp. 1553-1559.

Ding, W.; Hasemi, Y.; Yamada, T. (2005). Natural ventilation performance of a doubleskin facade with a solar chimney, Energy and Buildings 37, pp. 411-418.

Eckertf, E.G.; Carlson, W.O. (1961). Natural convection in an air layer enclosed between two vertical plates with different temperatures, International Journal of Heat and Mass Transfer 2, pp. 106-120.

Eftekhari, M.M.; Marjanovic, L.D.; Pinnock, D.J. (2003). Air flow distribution in and around a single-sided naturally ventilated room, Building and Environment 38, pp. 389397.

Eicker, U.; Fux, V.; Bauer, U.; Mei, L.; Infield, D. (2008). Façades and summer performance of buildings, Energy and Buildings 40, pp. 600-611.

Elder, J.W. (1965). Laminar free convection in a vertical slot, Trans. ASME Journal of Heat Transfer 23, pp. 77-98.

Elder, J.W. (1965). Turbulent free convection in a vertical slot, J. Journal of Fluid Mechanics 23, pp. $98-107$.

ElSherbiny, S.M.; Raithby, G.D.; Hollands, K.G. (1982). Heat transfer by natural convection across vertical and inclined air layers, Journal of Heat Transfer 104, pp. 96102.

Etheridge, D.W. (2002). Nondimensional methods for natural ventilation design, Building and Environment 37, pp. 1057-1072.

Faggembauu, D.; Costa, M.; Soria, M.; Oliva, A. (2003). Numerical analysis of the thermal behavior of ventilated glazed facades in Mediterranean climates. Part I: development and validation of a numerical model, Solar Energy 75, pp. 217-228. 
Faggembauu, D.; Costa, M.; Soria, M.; Oliva, A. (2003). Numerical analysis of the thermal behaviour of glazed ventilated facades in Mediterranean climates. Part II: applications and analysis of results, Solar Energy 75, pp. 229-239.

Ganguli, AA.; Pandit, A.B.; Joshi, J.B. (2007). Numerical predictions of flow patterns due to natural convection in a vertical slot, Chemical Engineering Science 62, pp. 4479 -4495 .

Ganguli, AA.; Pandit, A.B.; Joshi, J.B. (2009). CFD simulation of heat transfer in a two-dimensional vertical enclosure, Chemical Engineering Research and Design 87, pp. 711-727.

Gill, A.E. (1966). The boundary layer regime for convection in a rectangular cavity, J. Journal of Fluid Mechanics 64, pp. 515-536.

Gratia, E.; De Herde, A. (2004). Guidelines for improving natural daytime ventilation in an office building with a double-skin facade, Solar Energy 36, pp. 367-372.

Gratia, E.; De Herde, A. (2004). Is day natural ventilation still possible in office buildings with a double-skin façade?, Building and Environment 39, pp. 399-409.

Gratia, E.; De Herde, A. (2004). Natural cooling strategies efficiency in an office building with a double-skin facade, Energy and Buildings 36, pp. 1139-1152.

Gratia, E.; De Herde, A. (2004). Natural ventilation in a double-skin facade, Energy and Buildings 36, pp. 137-146.

Gratia, E.; De Herde, A. (2004). Optimal operation of a south double-skin facade, Energy and Buildings 36, pp. 41-60.

Gratia, E.; De Herde, A. (2007). Are energy consumptions decreased with the addition of a double-skin?, Energy and Buildings 39, pp. 605-619.

Gratia, E.; De Herde, A. (2007). Greenhouse effect in double-skin facade, Energy and Buildings 39, pp. 199-211.

Gratia, E.; De Herde, A. (2007). The most efficient position of shading devices in a double-skin facade, Energy and Buildings 39, pp. 364-373.

Hanby, V.I.; Cook, M.J.; Infield, D.G.; Ji, Y.; Loveday, D.L.; Mei, L. (2008). Nodal network and CFD simulation of airflow and heat transfer in double skin facades with blinds, Building Services Engineering Research \& Technology, Vol. 29, nº 1, pp. 4559.

He, G.; Shu, L.; Zhang, S. (2011). Double skin facades in the hot summer and cold winter zone in China: Cavity open or closed?, Building Simulation 4, pp. 283-291. 
Hien, W.N.; Liping, W.; Chandra, A.N.; Pandey, A.R.; Xiaolin, W. (2005). Effects of double glazed facade on energy consumption, thermal comfort and condensation for a typical office building in Singapore, Energy and Buildings 37, pp. 563-572.

Høseggen, R.; Wachenfeldt, B.J.; Hanssen, S.O. (2008). Building simulation as an assisting tool in decision making: case study: with or without a double-skin facade, Energy and Buildings 40, pp. 821-827.

Ismail, K.R.; Henríquez, J.R. (2005). Two-dimensional model for the double glass naturally ventilated window, International Journal of Heat and Mass Transfer 48, pp. $461-475$.

Jiru, T.E.; Haghighat, F. (2008). Modeling ventilated double skin façade-A zonal approach, Energy and Buildings 40, pp. 1567-1576.

Kim, K.; Kim, B.S.; Park, S. (2007). Analysis of design approaches to improve the comfort level of a small glazed-envelope building during summer, Solar Energy 81, pp. $39-51$.

Kim, S.Y.; Song, K.D. (2007). Determining Photosensor Conditions of a Daylight Dimming Control System Using Different Double-skin Envelope Configurations, Indoor and Built Environment 16, pp. 411-425.

Kim, Y.M.; Kim, S.Y.; Shin, S.W.; Sohn, J.Y. (2009). Contribution of natural ventilation in a double skin envelope to heating load reduction in winter, Building and Environment 44, pp. 2236-2244.

Korpela, S.A.; Lee, Y.; Drummond, J.E. (1982). Heat transfer through a double pane window, ASME Journal of Heat Transfer 104, pp. 539 - 544.

Larsen, T.; Heiselberg, P.; Sawachi, T. (2003). Analysis and design of single-sided natural ventilation, Proceedings of ISHVAC 1.

Lartigue, B.; Lorente, S.; Bourret, B. (2000). Multicellular natural convection in a high aspect ratio cavity: experimental and numerical results, International Journal of Heat and Mass Transfer 43, pp. 3157-3170.

Le Quéré, P. (1990). A note on multiple and unsteady solutions in two dimensional convection in a tall cavity, Trans. ASME Journal of Heat Transfer 112, pp. 965-973.

Lee, Y.; Korpela, S. (1983). Multicellular natural convection in a vertical slot, J. Journal of Fluid Mechanics 126, pp. 91-124.

Li, R.; Pitts, A.; Li, Y. (2007). Buoyancy-driven natural ventilation of a room with large openings, Building Simulation, pp. 984-991.

Lou, W.J.; Li, H.; Wei, K.Z.; Chen, Y.; Li, H.L. (2008). Wind tunnel test study on wind pressure distribution on double-skin facades of high-rise buildings with typical shapes, Journal of Harbin Institute of Technology 40, pp. 296-301. 
Lou, W.; Jin, H.; Chen, Y.; Cao, L.; Yao, J. (2005). Wind tunnel test study on wind load characteristics for double-skin facade building with rectangular shape, Journal of Building Structures 26, pp. 65-70.

Manz, H. (2003). Numerical simulation of heat transfer by natural convection in cavities of facade elements, Energy and Buildings 35, pp. 305-311.

Manz, H. (2004). Total solar energy transmittance of glass double façades with free convection, Energy and Buildings 36, pp. 127-136.

Manz, H.; Frank, T. (2005). Thermal simulation of buildings with double-skin façades, Energy and Buildings 37, pp. 1114-1121.

Newel, M.E.; Schmidt, F.W. (1970). Heat transfer by laminar natural convection within rectangular enclosures, Trans. ASME C Journal of Heat Transfer 92, pp. 159-167.

Pappas, A.; Reilly, S. (2006). Energy performance of a double skin. In: International Solar Energy Conference.

Pappas, A.; Zhai, Z. (2008). Numerical investigation on thermal performance and correlations of double skin façade with buoyancy-driven airflow, Energy and Buildings 40, pp. 466-475.

Pasquay, T. (2004). Natural ventilation in high-rise buildings with double facades, saving or waste of energy, Energy and Buildings 36, pp. 381-389.

Pérez-Grande, I.; Meseguer, J.; Alonso, G. (2005). Influence of glass properties on the performance of double-glazed facades, Applied Thermal Engineering 25, pp. 31633175 .

Poirazis, H.; Blomsterberg, A.; Wall, M. (2008). Energy simulations for glazed office buildings in Sweden, Energy and Buildings 40, pp. 1161-1170.

Roth, K.; Lawrence, T.; Brodrick, J. (2007). Double-skin façades, ASHRAE J. 49, pp. 70-73.

Saelens, D.; Roels, S.; Hens, H. (2004). The inlet temperature as a boundary condition for multiple-skin facade modelling, Energy and Buildings 36, pp. 825-835.

Safer, N.; Woloszyn, M.; Roux, J.J. (2005). Three-dimensional simulation with a CFD tool of the airflow phenomena in single floor double-skin facade equipped with a venetian blind, Solar Energy 79, pp. 193-203.

Sánchez, E.; Rolando, A. (2014). Ventilation and sealing in the current envelopes in architecture, in: Construction and Building Research, Springer Netherlands, pp. 103110.

Seki, N.; Fukusako, S.; Inaba, H. (1978). Heat transfer of natural convection in a rectangular cavity with vertical walls of different temperatures, Journal of Fluid Mechanics 21, pp. $246-253$. 
Seki, N.; Fukusako, S.; Inaba, H. (1978). Visual observation of natural convective flow in a narrow vertical cavity, Journal of Fluid Mechanics 84, pp. $695-704$.

Stec, W.J.; Paassen, V. (2005). Symbiosis of the double skin facade with the HVAC system, Energy and Buildings 37, pp. 461-469.

Von Grabe, J. (2002). A prediction tool for the temperature field of double facades, Energy and Buildings 34, pp. 891-899.

Wakitani, S. (1994). Experiments on convective instability of large Prandtl number fluids in a vertical slot, Journal of Heat Transfer 116, pp. $120-126$.

Wakitani, S. (1996). Formation of cells in natural convection in a vertical slot at large Prandtl number, J. Journal of Fluid Mechanics 314, pp. 299-314.

Wakitani, S. (1997). Development of multicellular solutions in natural convection in air-filled vertical cavity, ASME Journal of Heat Transfer 119, pp. $97-101$.

Wright, J.L. (1996). A correlation to quantify convective heat transfer between vertical window glazings, ASHRAE Transactions 102, pp. 940 - 946.

Wright, J.L.; Sullivan, H.F. (1989). Natural convection in sealed glazing units: a review, ASHRAE Transactions 95, pp. 592-603.

Xamán, J.; Álvarez, G.; Lira, L.; Estrada, C. (2005). Numerical study of heat transfer by laminar and turbulent natural convection in tall cavities of façade elements, Energy and Buildings 37, pp. 787-794.

Xu, L.; Ojima, T. (2007). Field experiments on natural energy utilization in a residential house with a double skin facade system, Building and Environment 42, pp. 2014-2023.

$\mathrm{Xu}$, X.L.; Yang, Z. (2008). Natural ventilation in the double skin facade with venetian blind, Energy and Buildings 40, pp. 1498-1504.

Yakhot, V.; Orzag, S.A.; Thangam, S.; Gatski, T.B.; Speziak, C.G. (1992). Development of turbulence models for shear flows by a double expansion technique, Physics of Fluids 4, pp. 1510-1520.

Yilmaz, Z.; Cetintas, F. (2005). Double skin facade's effects on heat losses of office buildings in Istanbul, Energy and Buildings 37, pp. 691-697.

Yin, S.H.; Wung, T.Y.; Chen, K. (1978). Natural convection in an air layer enclosed within rectangular cavities, International Journal of Heat and Mass Transfer 21, pp. $307-315$.

Yoon, J.; Lee, E.; Hensen, J. (1997). Integrated thermal analysis of a three story experimental building with a three story experimental building with a double-skin and a ground-coupled heat exchanger, Proceedings of International Solar Energy Conference SOLAR 97: Energy for Sustainable Prosperity, pp. 7-13. 
Zerefos, S.C. (2007). On the performance of double skin facades in different environmental conditions, International Journal of Sustainable Energy 26, pp. 221-229.

Zhai, Z.; Zhang, W.; Zhang, Z.; Chen, Q. (2007). Evaluation of various turbulence models in predicting airflow and turbulence in enclosed environments by CFD: Part 1Summary of prevalent turbulence models, HVAC \& R Research 13, n 6, pp. 853.

Zhao, Y.; Curcija, D.; Gross, W.P.; (1997). Prediction of the multicellular flow regime of natural convection in fenestration glazing cavities, ASHRAE Transactions 103, pp. $1-12$.

Zhao, Y.; Curcija, D.; Power, J.P.; Goss, W.P. (1998). Improved heat transfer correlations for quantifying laminar natural convection across fenestration glazing cavities, ASHRAE Transactions, pp. 397-403.

Zhou, J.; Chen, Y. (2010). A review on applying ventilated double-skin facade to buildings in hot-summer and cold-winter zone in China, Renewable \& Sustainable Energy Reviews 14, pp. 1321-1328.

Zöllner, A.; Winter, E.R.F.; Viskanta, R. (2002). Experimental studies of combined heat transfer in turbulent mixed convection fluid flows in double-skin-façades, International Journal of Heat and Mass Transfer 45, pp. 4401-4408.

\subsection{NORMATIVA}

EN 410 (2011). Vidrio para la edificación. Determinación de las características luminosas y solares de los acristalamientos. Comité Europeo de Normalización (CEN).

EN 572-1 (2012). Vidrio para la edificación. Productos básicos de vidrio de silicato sodocálcico. Parte 1: Definiciones y propiedades generales físicas y mecánicas. Comité Europeo de Normalicación (CEN).

EN 673 (2011). Vidrio en la construcción. Determinación del coeficiente de transmisión térmica (valor U). Método de cálculo. Comité Europeo de Normalización (CEN).

EN 717-1 (2013). Acústica. Evaluación del aislamiento acústico en los edificios y de los elementos de construcción. Parte 1: Asilamiento a ruido aéreo.

EN 1096-4 (2005). Vidrio para la edificación. Vidrio de capa. Parte 4: Evaluación de la conformidad / Norma de producto. Comité Europeo de Normalización (CEN).

EN 1991-1-1 (2003). Eurocódigo 1: Acciones en estructuras. Parte 1-1. Acciones generales. Pesos específicos, pesos propios, y sobrecargas de uso en edificios. Comité Europeo de Normalización (CEN).

EN 1364-3 (2015). Ensayos de resistencia al fuego de elementos no portantes. Parte 3: Fachadas ligeras. Configuración completa (conjunto completo). Comité Europeo de Normalización (CEN). 
EN 1364-4 (2015). Ensayos de resistencia al fuego de elementos no portantes. Parte 4: Fachadas ligeras. Configuración parcial. Comité Europeo de Normalización (CEN).

EN ISO 10140-2 (2011). Acústica. Medición en laboratorio del aislamiento acústico de los elementos de construcción. Parte 2: Medición del aislamiento acústico al ruido aéreo.

EN ISO 10456 (2012). Materiales y productos para la edificación. Propiedades higrotérmicas. Valores tabulados de diseño y procedimientos para la determinación de los valores térmicos declarados y de diseño. Comité Europeo de Normalización (CEN).

EN 12152 (2002). Fachadas ligeras. Permeabilidad al aire. Requisitos de funcionamiento y clasificación. Comité Europeo de Normalización (CEN).

EN 12153: 2000. Fachadas ligeras. Permeabilidad al aire. Método de ensayo. Comité Europeo de Normalización (CEN), (2000).

EN 12154 (2000). Fachadas ligeras. Estanquidad al agua. Requisitos y clasificación. Comité Europeo de Normalización (CEN).

EN 12155 (2000). Fachadas ligeras. Estanquidad al agua. Ensayo de laboratorio bajo presión estática. Comité Europeo de Normalización (CEN).

EN 12179 (2000). Fachadas ligeras. Resistencia a la carga de viento. Método de ensayo. Comité Europeo de Normalización (CEN).

EN 12600 (2003). Vidrio para la edificación. Ensayo pendular. Método de ensayo al impacto y clasificación para vidrio plano. Comité Europeo de Normalización (CEN).

EN 12631 (2015). Prestaciones térmicas de las fachadas ligeras. Cálculo de la transmitancia térmica. Comité Europeo de Normalización (CEN).

EN 13050 (2011). Fachadas ligeras. Estanquidad al agua. Ensayo de baboratorio bajo presión dinámica de aire y proyección de agua. Comité Europeo de Normalización (CEN).

EN 13051 (2001). Fachadas ligeras. Estanquidad al agua. Ensayo "in situ". Comité Europeo de Normalización (CEN).

EN 13116 (2001). Fachadas ligeras. Resistencia a la carga de viento. Requisitos de prestaciones. Comité Europeo de Normalización (CEN).

EN 13119 (2007). Fachadas ligeras. Terminología. Comité Europeo de Normalización (CEN).

EN 13501-1 (2007). Clasificación en función del comportamiento frente al fuego de los productos de construcción y elementos para la edificación. Parte 1: Clasificación a partir de datos obtenidos en ensayos de reacción al fuego. Comité Europeo de Normalización (CEN). 
EN 13501-2 (2009). Clasificación en función del comportamiento frente al fuego de los productos de construcción y elementos para la edificación. Parte 2: Clasificación a partir de datos obtenidos de los ensayos de resistencia al fuego excluidas las instalaciones de ventilación. Comité Europeo de Normalización (CEN).

EN 13830 (2004). Fachadas ligeras. Norma de producto. Comité Europeo de Normalización (CEN).

EN 14019 (2004). Fachadas ligeras. Resistencia al impacto. Requisitos de comportamiento. Comité Europeo de Normalización (CEN).

EN 15251 (2008). Parámetros del ambiente interior a considerar para el diseño y la evaluación de la eficiencia energética de edificios incluyendo la calidad del aire interior, condiciones térmicas, iluminación y ruido. Comité Europeo de Normalización (CEN).

\subsection{PÁGINAS WEB}

es.saint-gobain-glass.com

www.aemet.es

www.aenor.es

www.ashrae.org

www.meteopozuelo.es

www.passivehouse.com

\subsection{OTROS}

ANSYS Fluent 15.0.7. (2014). Guía del usuario.

ANSYS Fluent 15.0.7. (2014). Guía teórica.

Guía de la herramienta Passivhaus. PHPP 7. (2012). Passivhaus Institut (PHI) 
Optimización de la fachada de doble piel acristalada con ventilación natural. Metodología de diseño para el análisis de la eficiencia energética del sistema. 


\section{Lista de Figuras}

Figura 1.1. Esquema de metodología.

Figura 2.1. Geometría y composición esquemática del sistema de fachada doble piel de vidrio. 13

Figura 2.2. Modelo de pequeña escala. Tanque lleno de agua para la visualización del flujo en un edificio de dos plantas con un atrio. "Ventilation performance prediction for buildings: A method overview and recent applications". Chen, 2009. 20

Figura 2.3. Experimento a escala real de un edificio de dos plantas con fachada doble piel. "Field experiments on natural energy utilization in a residential house with a double skin façade system". Xu et al., 2007.

Figura 2.4. Proporción de los diferentes modelos utilizados en 2007 para la predicción de la ventilación en edificios. "Ventilation performance prediction for buildings: A method overview and recent applications". Chen, 2009. 23

Figura 2.5. Comportamiento de la radiación solar en el paño de vidrio. Manual vidrio Saint-Gobain Glass.

Figura 2.6. Esquema de proceso de transferencia de calor en el sistema de fachada doble

piel acristalada con cámara cerrada. 30

Figura 2.7. Esquema de proceso de transferencia de calor en el sistema de fachada doble piel acristalada con cámara abierta. 31

Figura 2.8. Esquema de una cámara rectangular cerrada con paredes a diferente temperatura.

Figura 2.9. Esquema de las diferentes estructuras celulares: A) células primarias, B) células secundarias, C) células terciarias. "Numerical predictions on flow patterns due to natural convection in a vertical slot" Ganguli et al., 2007. 38 Figura 2.10. Patrones de flujo de diferentes autores. A) $A=16, \mathrm{Ra}=12.000$ : i) Le Quéré (1990), ii) Ganguli (2009). B) $A=16, \mathrm{Ra}=20.000$ : i) Le Quéré (1990), ii) Ganguli (2009). C) $\mathrm{A}=25, \mathrm{Ra}=10.100$ : i) Zhao et al. (1997), ii) Ganguli (2009). D) $A=40, \mathrm{Ra}=$ 3.550: i) Lartigue et al. (2000), ii) Ganguli (2009). E) $A=16, \mathrm{Ra}=14.200$ : i) Lartigue et al. (2000), ii) Ganguli (2009). "CFD simulation of heat transfer in a two dimensional vertical enclosure" Ganguli et al., 2009. 39

Figura 2.11. Experimento de un edificio en túnel de viento. "Gap inner pressures in multi-storey double skin facades". Da Silva et al., 2008. 45 
Figura 2.12. Modelo CFD. "A comparison between CFD and Network models for predicting wind-driven ventilation in buildings". Asfour et al., 2006. 46 Figura 3.1. Sección esquemática de la cámara de aire con aberturas cerradas. Dimensiones en metros $(\mathrm{m})$.

Figura 3.2. Sección esquemática de la cámara de aire con aberturas abiertas. Dimensiones en metros $(\mathrm{m})$. 59

Figura 3.3. Sección esquemática del dominio computacional y de la geometría utilizada para la simulación CFD de los casos de flujo dominado por convección natural. Dimensiones en metros $(\mathrm{m})$.

Figura 3.4. Sección esquemática del dominio computacional y de la geometría utilizada para la simulación CFD de los casos de flujo dominado por viento. Dimensiones en metros $(\mathrm{m})$.

Figura 3.5. Factores energéticos del vidrio sencillo. Calumen ${ }^{\circledR}$ II (versión 1.2.5). SaintGobain Glass. 65

Figura 3.6. Factores energéticos del vidrio doble. Calumen ${ }^{\circledR}$ II (versión 1.2.5). SaintGobain Glass.

Figura 4.1. Distribución de la presión en el interior y en el exterior de una habitación con grandes aberturas (a: modo de flujo I; b: modo de flujo II; c: modo de flujo III). "Buoyancy-driven natural ventilation of a room with large openings". Li et al., 2007. 84 Figura 4.2. Ilustración esquemática de los tres modos de flujo según la posición del plano neutro y el movimiento del aire en cada uno de ellos. (a: plano neutro interseca con la abertura inferior; b: plano neutro no interseca con ninguna abertura; c:plano neutro interseca con la abertura superior). "Buoyancy-driven natural ventilation of a room with large openings". Li et al., 2007.

Figura 4.3. Detalle del dominio computacional y de la geometría utilizada para la simulación CFD. "Buoyancy-driven natural ventilation of a room with large openings". Li et al., 2007.

Figura 4.4. Figura esquemática del modelo físico considerado en el estudio. "Buoynacydriven natural ventilation of a room with large openings". Li et al., 2007.

Figura 4.5. Caudal calculado mediante modelo analítico y por simulación CFD. "Buoyancy-driven natural ventilation of a room with large openings". Li et al., 2007. 87 Figura 4.6. Plano neutro calculado mediante modelo analítico y por simulación CFD. "Buoyancy-driven natural ventilation of a room with large openings". Li et al., 2007. 87

Figura 4.7. Caso de estudio mallado con la malla del tipo 1 89 
Figura 4.8. Detalle de la malla tipo 1.

Figura 4.9. Caso de estudio mallado con la malla del tipo 2 ....................................... 90

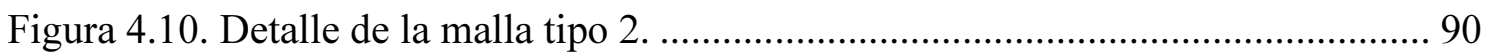

Figura 4.11. Caso de estudio mallado con la malla del tipo 3 .................................... 91

Figura 4.12. Detalle de la malla tipo 3 ................................................................. 91

Figura 4.13. Caudal de aire $V\left(\mathrm{~m}^{3} / \mathrm{s}\right)$ que entra en el modelo calculado por diferentes

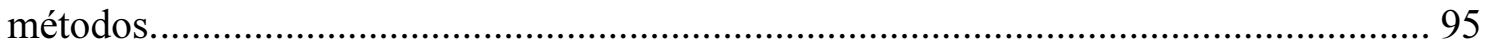

Figura 4.14. Altura del plano neutro $h_{n}(\mathrm{~m})$ calculado por distintos métodos................ 95

Figura 4.15. Caudal de aire $V\left(\mathrm{~m}^{3} / \mathrm{s}\right)$ que sale del modelo calculado por diferentes métodos.

Figura 4.16. Altura del plano neutro $h_{n}(\mathrm{~m})$ calculado por distintos métodos................ 97

Figura 4.17. Contorno de presión manométrica $(\mathrm{Pa})$ del caso 2.4 ................................ 99

Figura 4.18. Vectores velocidad coloreados por velocidad $(\mathrm{m} / \mathrm{s})$ del caso 2.4 ............ 99

Figura 4.19. Líneas de corriente coloreadas por velocidad (m/s) del caso 2.4 ............ 100

Figura 4.20. Líneas de corriente coloreadas por temperatura $\left({ }^{\circ} \mathrm{C}\right)$ del caso $2.4 \ldots \ldots \ldots . . .100$

Figura 4.21. Presión manométrica $(\mathrm{Pa})$ en la sección central de la habitación del caso 2.4 .

Figura 4.22. Esquema de procedimiento de trabajo en CFD...................................... 103

Figura 4.23. Diseño de la geometría del dominio computacional............................... 104

Figura 4.24. Detalle del diseño de la geometría de la habitación y de la fachada doble

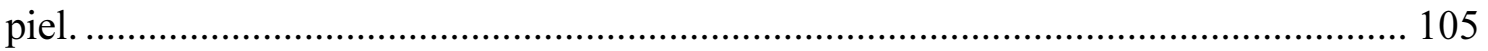

Figura 4.25. Mallado del volumen de control. ......................................................... 107

Figura 4.26. Detalle del mallado de los vidrios y de la cámara de aire........................ 108

Figura 4.27. Visualización por colores de las condiciones de contorno en Fluent en el escenario de invierno: verde (interior), azul (entrada de presión), rojo (salida de presión), y blanco (pared).

Figura 4.28. Fuente de calor uniformemente distribuida en el suelo (condiciones de invierno) y en el techo (condiciones de verano), respectivamente, donde $\mathrm{T}_{\mathrm{f}}$ es la

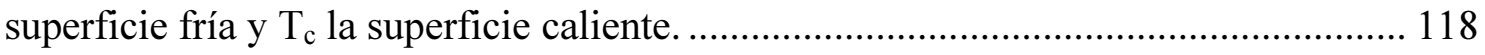

Figura 4.29. Detalle del vidrio como pared de dos lados. ........................................ 120

Figura 4.30. Diseño de la geometría del dominio computacional................................ 124

Figura 4.31. Mallado del volumen de control. .......................................................... 125

Figura 4.32. Visualización por colores de las condiciones de contorno en Fluent: verde (interior), azul (entrada de velocidad), rojo (salida de presión), y blanco (pared)....... 128 
Figura 4.33. Esquema de la ventana doble. "Double skin facades in the hot summer and cold winter zone in China: cavity open or closed?". He et al., 2011.

Figura 4.34. Vectores velocidad coloreados por temperatura $\left({ }^{\circ} \mathrm{C}\right)$

Figura 4.35. Vectores velocidad coloreados por velocidad $(\mathrm{m} / \mathrm{s})$.

Figura 5.1. Temperatura media en la habitación en el escenario de invierno.

Figura 5.2. Temperatura media adimensional en la habitación en el escenario de invierno

Figura 5.3. Perfil de temperatura en la cámara de aire para una sección horizontal dada para diferentes posiciones verticales: $A=150$, Régimen de Conducción; $A=30$, Régimen de Transición; $A=7,5$, Régimen de la Capa Límite, en condiciones de invierno, cámara cerrada y sin radiación solar.

Figura 5.4. Perfil de temperatura en la cámara de aire para una sección horizontal dada para diferentes posiciones verticales: $A=150$, Régimen de Conducción; $A=30$, Régimen de Transición; $A=7,5$, Régimen de la Capa Límite, en condiciones de invierno, cámara cerrada y con radiación solar. 146

Figura 5.5. Tasa de transferencia de calor en el escenario de invierno. 148 Figura 5.6. Contorno de distribución de temperatura y líneas de corriente coloreadas por temperatura en el escenario de invierno. 148 Figura 5.7. Vectores velocidad coloreados por temperatura $\left({ }^{\circ} \mathrm{C}\right)$ en el extremo superior (imagen izquierda), zona media (imagen central) y extremo inferior (imagen derecha) de la cámara de aire, para el caso de $A=30$ en condiciones de invierno cámara cerrada y sin radiación solar.

Figura 5.8. Vectores velocidad coloreados por temperatura $\left({ }^{\circ} \mathrm{C}\right)$ en el extremo superior (imagen izquierda), zona media (imagen central) y extremo inferior (imagen derecha) de la cámara de aire, para el caso de $A=30$ en condiciones de invierno cámara cerrada y con radiación solar.

Figura 5.9. Vectores velocidad coloreados por temperatura $\left({ }^{\circ} \mathrm{C}\right)$ en el extremo superior (imagen izquierda), zona media (imagen central) y extremo inferior (imagen derecha) de la cámara de aire, para el caso de $A=30$ en condiciones de invierno cámara abierta y sin radiación solar.

Figura 5.10. Vectores velocidad coloreados por temperatura $\left({ }^{\circ} \mathrm{C}\right)$ en el extremo superior (imagen izquierda), zona media (imagen central) y extremo inferior (imagen derecha) de la cámara de aire, para el caso de $A=30$ en condiciones de invierno cámara abierta y con radiación solar. 
Figura 5.11. Flujo de ventilación en el escenario de invierno para el caso de cámara abierta. 150

Figura 5.12. Flujo de calor para la fachada simple piel y para $A=30$ para mantener la temperatura de la habitación a $20^{\circ} \mathrm{C}$ en invierno.

Figura 5.13. Temperatura media en la habitación en el escenario de verano. 152

Figura 5.14. Temperatura media adimensional en la habitación en el escenario de verano.

Figura 5.15. Perfil de temperatura en la cámara de aire para una sección horizontal dada para diferentes posiciones verticales: $A=150$, Régimen de Conducción; $A=30$, Régimen de Transición; $A=7,5$, Régimen de la Capa Límite, en condiciones de verano, cámara cerrada y sin radiación solar.

Figura 5.16. Perfil de temperatura en la cámara de aire para una sección horizontal dada para diferentes posiciones verticales: $A=150$, Régimen de Conducción; $A=30$, Régimen de Transición; $A=7,5$, Régimen de la Capa Límite, en condiciones de verano, cámara cerrada y con radiación solar. 156

Figura 5.17. Tasa de transferencia de calor en el escenario de verano. 157 Figura 5.18. Contorno de distribución de temperatura y líneas de corriente coloreadas por temperatura en el escenario de verano. 158 Figura 5.19. Vectores velocidad coloreados por temperatura $\left({ }^{\circ} \mathrm{C}\right)$ en el extremo superior (imagen izquierda), zona media (imagen central) y extremo inferior (imagen derecha) de la cámara de aire, para el caso de $A=30$ en condiciones de verano cámara cerrada y sin radiación solar. 158

Figura 5.20. Vectores velocidad coloreados por temperatura $\left({ }^{\circ} \mathrm{C}\right)$ en el extremo superior (imagen izquierda), zona media (imagen central) y extremo inferior (imagen derecha) de la cámara de aire, para el caso de $A=30$ en condiciones de verano cámara cerrada y con radiación solar.

Figura 5.21. Vectores velocidad coloreados por temperatura $\left({ }^{\circ} \mathrm{C}\right)$ en el extremo superior (imagen izquierda), zona media (imagen central) y extremo inferior (imagen derecha) de la cámara de aire, para el caso de $A=30$ en condiciones de verano cámara abierta y sin radiación solar.

Figura 5.22. Vectores velocidad coloreados por temperatura $\left({ }^{\circ} \mathrm{C}\right)$ en el extremo superior (imagen izquierda), zona media (imagen central) y extremo inferior (imagen derecha) de la cámara de aire, para el caso de $A=30$ en condiciones de verano cámara abierta y con radiación solar. 
Figura 5.23. Flujo de ventilación en el escenario de verano para el caso de cámara abierta. 160

Figura 5.24. Flujo de calor para la fachada simple piel y $A=30$ para mantener la temperatura de la habitación a $26{ }^{\circ} \mathrm{C}$ en verano.

Figura 5.25. Flujo de ventilación en el escenario de verano para el caso de cámara abierta.

Figura 5.26. Temperatura media adimensional en la habitación en el escenario de verano para el caso de cámara abierta.

Figura 5.27. Temperatura media en la habitación en el escenario de verano para el caso de cámara abierta.

Figura 5.28. Índice de eficiencia energética en el escenario de invierno. 164

Figura 5.29. Índice de eficiencia energética en el escenario de verano. 164

Figura 5.30. Temperatura media adimensional en la habitación para $A=30$ en el escenario de invierno y sin radiación solar. 168

Figura 5.31. Incremento de la temperatura media en la habitación respecto del caso sin viento para $A=30$ en el escenario de invierno y sin radiación solar. 168 Figura 5.32. Temperatura media adimensional en la habitación para $A=30$ en el escenario de invierno y con radiación solar

Figura 5.33. Incremento de la temperatura media en la habitación respecto del caso sin viento para $A=30$ en el escenario de invierno y con radiación solar. 169 Figura 5.34. Perfil de temperatura en la cámara de aire para una sección horizontal dada para diferentes posiciones verticales: $A=30$, Régimen de Transición. En condiciones de invierno, cámara cerrada y sin radiación solar, para velocidades del viento en la fachada de barlovento de $v=1,5$ y $20 \mathrm{~m} / \mathrm{s}$ respectivamente.

Figura 5.35. Perfil de temperatura en la cámara de aire para una sección horizontal dada para diferentes posiciones verticales: $A=30$, Régimen de Transición. En condiciones de invierno, cámara cerrada y con radiación solar, para velocidades del viento en la fachada de barlovento de $v=1,5$ y $20 \mathrm{~m} / \mathrm{s}$ respectivamente.

Figura 5.36. Perfil de temperatura en la cámara de aire para una sección horizontal dada para diferentes posiciones verticales: $A=30$, Régimen de Transición. En condiciones de invierno, cámara cerrada y sin radiación solar, para velocidades del viento en la fachada de sotavento de $v=1,5$ y $20 \mathrm{~m} / \mathrm{s}$ respectivamente.

Figura 5.37. Perfil de temperatura en la cámara de aire para una sección horizontal dada para diferentes posiciones verticales: $A=30$, Régimen de Transición. En condiciones de 
invierno, cámara cerrada y con radiación solar, para velocidades del viento en la fachada de sotavento de $v=1,5$ y $20 \mathrm{~m} / \mathrm{s}$ respectivamente

Figura 5.38. Incremento de la temperatura media en la cámara de aire respecto del caso sin viento para $A=30$ en el escenario de invierno y sin radiación solar

Figura 5.39. Incremento de la temperatura media en la cámara de aire respecto del caso sin viento para $A=30$ en el escenario de invierno y con radiación solar. 176

Figura 5.40. Líneas de corriente coloreadas por velocidad en el escenario de invierno, cámara cerrada, con radiación solar y viento en la fachada de barlovento $v=5 \mathrm{~m} / \mathrm{s} \ldots 177$ Figura 5.41. Líneas de corriente coloreadas por velocidad en el escenario de invierno, cámara cerrada, con radiación solar y viento en la fachada de sotavento $v=5 \mathrm{~m} / \mathrm{s}$... 177 Figura 5.42. Vectores velocidad coloreados por velocidad $(\mathrm{m} / \mathrm{s})$ en el extremo superior (imagen izquierda), zona media (imagen central) y extremo inferior (imagen derecha) de la cámara de aire, para el caso de $A=30$ en condiciones de invierno cámara abierta, sin radiación solar y viento en la fachada de barlovento de $v=5 \mathrm{~m} / \mathrm{s}$. 178 Figura 5.43. Vectores velocidad coloreados por velocidad $(\mathrm{m} / \mathrm{s})$ en el extremo superior (imagen izquierda), zona media (imagen central) y extremo inferior (imagen derecha) de la cámara de aire, para el caso de $A=30$ en condiciones de invierno cámara abierta, sin radiación solar y viento en la fachada de barlovento de $v=20 \mathrm{~m} / \mathrm{s}$. 178 Figura 5.44. Caudal de aire en la cámara en el escenario de invierno, cámara abierta, sin radiación solar, $A=30 \mathrm{y}$ viento en las fachadas de barlovento y sotavento de $v=1 ; 2,5$; $5 ; 10$ y $20 \mathrm{~m} / \mathrm{s}$.

Figura 5.45. Caudal de aire en la cámara en el escenario de invierno, cámara abierta, con radiación solar, $A=30 \mathrm{y}$ viento en las fachadas de barlovento y sotavento de $v=1$; 2,$5 ; 5 ; 10$ y $20 \mathrm{~m} / \mathrm{s}$. 179

Figura 5.46. Flujo de calor para mantener la temperatura en la habitación a $20{ }^{\circ} \mathrm{C}$ con fachada simple piel y con fachada doble piel $A=30$, en condiciones de invierno con viento en las fachadas de barlovento y sotavento de velocidad $v_{m, r e f}=5,8 \mathrm{~m} / \mathrm{s}$. 181 Figura 5.47. Temperatura media adimensional en la habitación para $A=30$ en el escenario de verano y sin radiación solar.

Figura 5.48. Incremento de la temperatura media en la habitación respecto del caso sin viento para $A=30$ en el escenario de verano y sin radiación solar.

Figura 5.49. Temperatura media adimensional en la habitación para $A=30$ en el escenario de verano y con radiación solar. 184 
Figura 5.50. Incremento de la temperatura media en la habitación respecto del caso sin viento para $A=30$ en el escenario de verano y con radiación solar.

Figura 5.51. Perfil de temperatura en la cámara de aire para una sección horizontal dada para diferentes posiciones verticales: $A=30$, Régimen de Transición. En condiciones de verano, cámara cerrada y sin radiación solar, para velocidades del viento en la fachada de barlovento de $v=1,5$ y $20 \mathrm{~m} / \mathrm{s}$ respectivamente. 186 Figura 5.52. Perfil de temperatura en la cámara de aire para una sección horizontal dada para diferentes posiciones verticales: $A=30$, Régimen de Transición. En condiciones de verano, cámara cerrada y con radiación solar, para velocidades del viento en la fachada de barlovento de $v=1,5$ y $20 \mathrm{~m} / \mathrm{s}$ respectivamente.

Figura 5.53. Perfil de temperatura en la cámara de aire para una sección horizontal dada para diferentes posiciones verticales: $A=30$, Régimen de Transición. En condiciones de verano, cámara cerrada y sin radiación solar, para velocidades del viento en la fachada de sotavento de $v=1,5$ y $20 \mathrm{~m} / \mathrm{s}$ respectivamente. 188

Figura 5.54. Perfil de temperatura en la cámara de aire para una sección horizontal dada para diferentes posiciones verticales: $A=30$, Régimen de Transición. En condiciones de verano, cámara cerrada y con radiación solar, para velocidades del viento en la fachada de sotavento de $v=1,5$ y $20 \mathrm{~m} / \mathrm{s}$ respectivamente.

Figura 5.55. Incremento de la temperatura media en la cámara de aire respecto del caso sin viento para $A=30$ en el escenario de verano y sin radiación solar. 190

Figura 5.56. Incremento de la temperatura media en la cámara de aire respecto del caso $\sin$ viento para $A=30$ en el escenario de verano y con radiación solar. 190 Figura 5.57. Líneas de corriente coloreadas por velocidad en el escenario de verano, cámara cerrada, con radiación solar y viento en la fachada de barlovento $v=5 \mathrm{~m} / \mathrm{s} \ldots 191$ Figura 5.58. Líneas de corriente coloreadas por velocidad en el escenario de verano, cámara cerrada, con radiación solar y viento en la fachada de sotavento $v=5 \mathrm{~m} / \mathrm{s}$... 192 Figura 5.59. Vectores velocidad coloreados por velocidad $(\mathrm{m} / \mathrm{s})$ en el extremo superior (imagen izquierda), zona media (imagen central) y extremo inferior (imagen derecha) de la cámara de aire, para el caso de $A=30$ en condiciones de verano, cámara abierta, sin radiación solar y viento en la fachada de sotavento de $v=5 \mathrm{~m} / \mathrm{s}$. Figura 5.60. Vectores velocidad coloreados por velocidad $(\mathrm{m} / \mathrm{s})$ en el extremo superior (imagen izquierda), zona media (imagen central) y extremo inferior (imagen derecha) de la cámara de aire, para el caso de $A=30$ en condiciones de verano, cámara abierta, sin radiación solar y viento en la fachada de sotavento de $v=20 \mathrm{~m} / \mathrm{s}$ 193 
Figura 5.61. Caudal de aire en la cámara en el escenario de verano, cámara abierta, sin radiación solar, $A=30$ y viento en las fachadas de barlovento y sotavento de $v=1 ; 2,5$; $5 ; 10$ y $20 \mathrm{~m} / \mathrm{s}$.

Figura 5.62. Caudal de aire en la cámara en el escenario de verano, cámara abierta, con radiación solar, $A=30 \mathrm{y}$ viento en las fachadas de barlovento y sotavento de $v=1 ; 2,5$; $5 ; 10$ y $20 \mathrm{~m} / \mathrm{s}$.

Figura 5.63. Flujo de calor para mantener la temperatura en la habitación a $26{ }^{\circ} \mathrm{C}$ con fachada simple piel y con fachada doble piel $A=30$, en condiciones de verano con el viento en las fachadas de barlovento y de sotavento de velocidad $v_{m, r e f}=6,3 \mathrm{~m} / \mathrm{s}$.

Figura 5.64. Índice de eficiencia energética en el escenario de invierno con el viento en la fachada de barlovento y de sotavento de velocidad $v=5,8 \mathrm{~m} / \mathrm{s}$. 196 Figura 5.65. Índice de eficiencia energética en el escenario de verano con el viento en la fachada de barlovento y de sotavento de velocidad $v=6,3 \mathrm{~m} / \mathrm{s}$. 197 Figura 5.66. Flujo de calor para mantener la temperatura en la habitación a $20{ }^{\circ} \mathrm{C}$ con fachada simple piel y con fachada doble piel, en condiciones de invierno y temperatura exterior de $4{ }^{\circ} \mathrm{C}$ sin viento y con viento de velocidad $v=5,8 \mathrm{~m} / \mathrm{s}$. 200 Figura 5.67. Incremento del flujo de calor que hay que aportar para mantener la temperatura en la habitación a $20^{\circ} \mathrm{C}$ con fachada simple piel y con fachada doble piel en los casos de ventilación producida por viento de velocidad $v=5,8 \mathrm{~m} / \mathrm{s}$ respecto al mismo caso de sin viento en condiciones de invierno y una temperatura exterior de $4{ }^{\circ} \mathrm{C}$.

Figura 5.68. Índice de eficiencia energética para el escenario de invierno. 202

Figura 5.69. Flujo de calor para mantener la temperatura en la habitación a $26{ }^{\circ} \mathrm{C}$ con fachada simple piel y con fachada doble piel, en condiciones de verano sin viento y con viento de velocidad $v=6,3 \mathrm{~m} / \mathrm{s}$ y una temperatura exterior de $32{ }^{\circ} \mathrm{C}$.

Figura 5.70. Incremento del flujo de calor que hay que extraer para mantener la temperatura en la habitación a $26{ }^{\circ} \mathrm{C}$ con fachada simple piel y con fachada doble piel en los casos de ventilación natural producida por viento de velocidad $v=6,3 \mathrm{~m} / \mathrm{s}$ respecto al mismo caso sin viento en condiciones de verano y una temperatura exterior de $32{ }^{\circ} \mathrm{C}$.

Figura 5.71. Índice de eficiencia energética para el escenario de verano. 205 Figura 6.1. Mayor porcentaje de ahorro de energía en el escenario de invierno en comparación con la fachada simple piel. 210 
Figura 6.2. Mayor porcentaje de ahorro de energía en el escenario de verano en

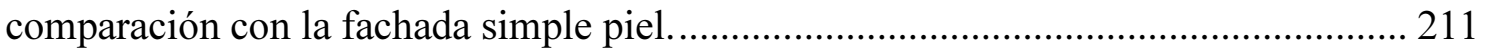




\section{Lista de Tablas}

Tabla 2.1. Requisitos básicos y características técnicas de las fachadas ligeras. (UNE

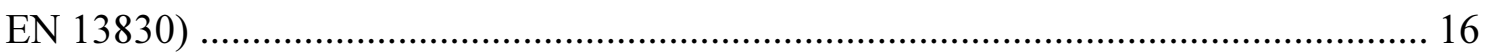

Tabla 2.2. Clases de permeabilidad al aire (A) basada en la superficie total. (UNE EN 12152)

Tabla 2.3. Clases de permeabilidad al aire (A) basada en la longitud de junta fija. (UNE EN 12152)

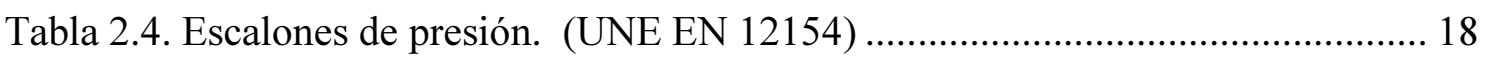

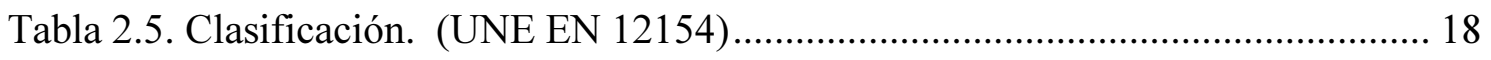

Tabla 2.6. Evaluación de diferentes modelos turbulentos para predecir el flujo de aire en ambientes cerrados. "Evaluation of various turbulence models in predicting airflow and turbulence in enclosed environments by CFD: Part 1-Summary of prevalent turbulence models" Zhai et al., 2007.

Tabla 2.7. Investigaciones realizadas por diferentes autores. Hipótesis, conclusiones, limitaciones y correlaciones propuestas. "Numerical predictions of flow patterns due to natural convection in a vertical slot" A. A. Ganguli et al., 2007; "CFD simulation of heat transfer in a two-dimensional vertical enclosure" A. A. Ganguli et al., 2009. ...... 41 Tabla 3.1. Propiedades físicas, ópticas y térmicas de los paños de vidrio sodocálcico. (UNE-EN ISO 10456, UNE-EN 410, UNE-EN 673).

Tabla 3.2. Características geográficas correspondientes a la zona climática de Madrid.69

Tabla 3.3. Radiación global anual por orientación. Passive House Institute.

Tabla 3.4. Radiación global mensual para la orientación sur. Passive House Institute. 69

Tabla 3.5. Número total de casos estudiados en función de las alternativas de geometría y de configuraciones de fachada posibles para los casos de flujo dominado por convección natural.

Tabla 3.6. Número total de casos estudiados en función de las alternativas de geometría y de configuraciones de fachada posibles para la optimización de las aberturas. 75

Tabla 3.7. Número total de casos estudiados en función de las alternativas de geometría y de configuraciones de fachada posibles para los casos de flujo dominado por viento.76 Tabla 3.8. Resumen de parámetros de estudio de la fachada doble piel acristalada. ..... 79

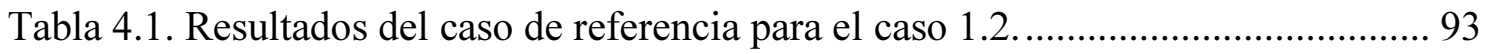

Tabla 4.2. Resultados mediante diferentes métodos de cálculo para el caso 1.2 .......... 93

Tabla 4.3. Propiedades físicas del aire. 113 
Tabla 4.4. Propiedades físicas del vidrio. (UNE-EN ISO 10456).

Tabla 4.5. Resumen de parámetros utilizados para la modelización fluidodinámica y para el cálculo numérico de la fachada doble piel acristalada. 138

Tabla 5.1. Porcentaje de ahorro o gasto de energía en los escenarios de invierno y de verano en comparación con la fachada simple piel. 165

Tabla 5.2. Velocidad media del viento para el escenario de invierno $(\mathrm{km} / \mathrm{h})$. Fuente: www.meteopozuelo.es 180

Tabla 5.3. Velocidad media del viento para el escenario de verano $(\mathrm{km} / \mathrm{h})$. Fuente: www.meteopozuelo.es. 194

Tabla 5.4. Porcentaje de ahorro o gasto de energía en los escenarios de invierno y de verano en comparación con la fachada simple piel. 


\section{ANEXO I. HISTÓRICO DE TEMPERATURAS EN MADRID}

El siguiente anexo recoge el registro histórico de temperaturas en la zona centro de España, en particular en Madrid. La fuente es la base de datos de AEMET (Agencia Estatal de Meteorología) consultada en su página web www.aemet.es. Recoge el histórico de temperaturas $\left({ }^{\circ} \mathrm{C}\right)$ en Madrid en la estación meteorológica de cuatro vientos entre los años 1945 y 2012.

Para los meses de invierno se toma el valor de la temperatura mínima media, y para los meses de verano el valor de la temperatura máxima media. 


\section{I.I HISTÓRICO DE TEMPERATURAS EN EL MES DE ENERO}

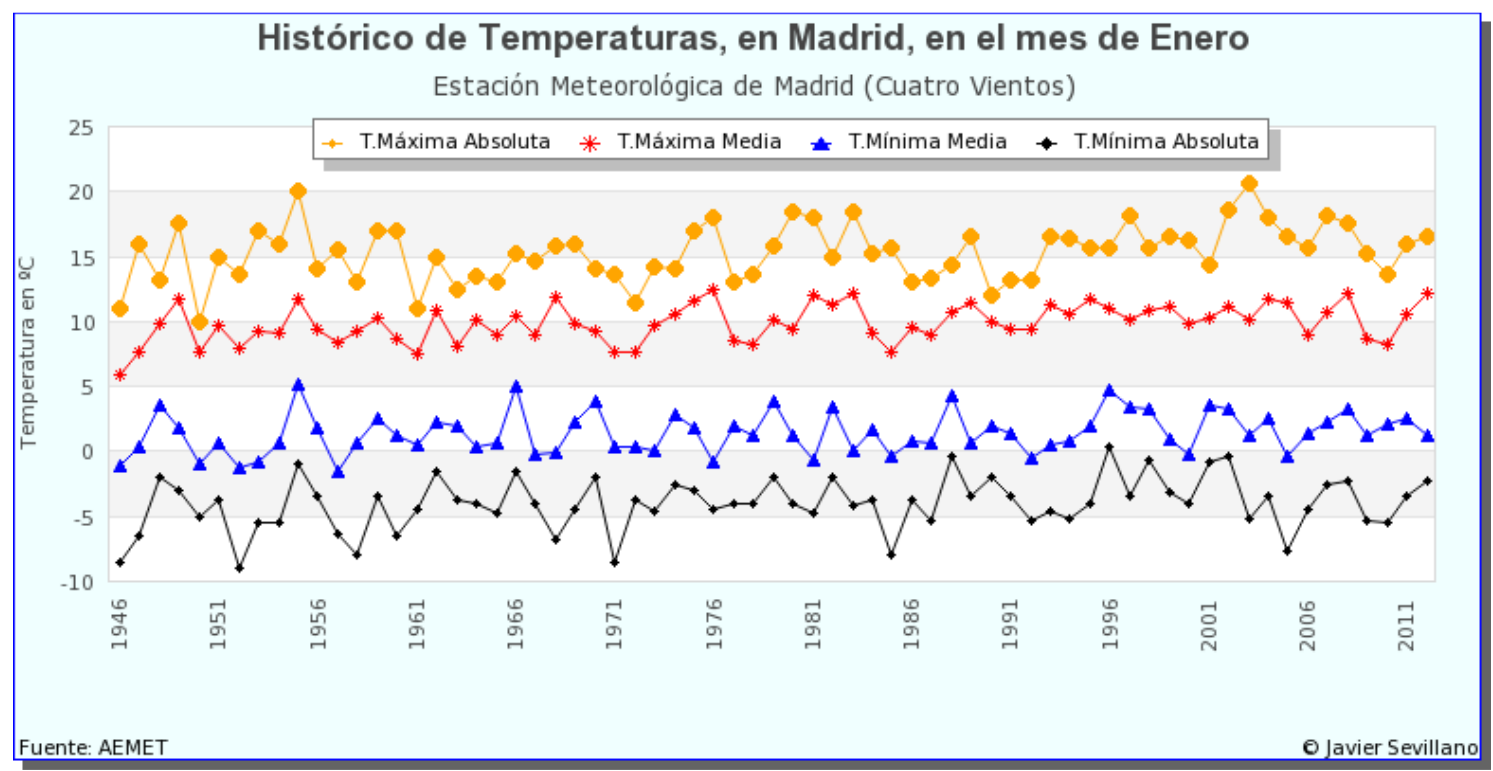

Figura I.1. Histórico de temperaturas en Madrid en el mes de enero $\left({ }^{\circ} \mathrm{C}\right)$.

\begin{tabular}{|c|c|c|c|c|c|c|c|c|c|c|c|c|c|c|c|}
\hline \multicolumn{16}{|c|}{ Temperaturas en Enero, en Madrid } \\
\hline 16.2 & 14.4 & 18.6 & 20.6 & 18.0 & 16.6 & 15.6 & 18.1 & 17.6 & 15.2 & 13.6 & 16.0 & 16.5 & & & T.Măxima Absoluta \\
\hline 9.9 & 10.2 & 11.1 & 10.1 & 11.8 & 11.5 & 8.9 & 10.7 & 12.2 & 8.6 & 8.3 & 10.5 & 12.2 & & & T.Măxima Media \\
\hline-0.3 & 3.5 & 3.3 & 1.2 & 2.5 & -0.4 & 1.4 & 2.3 & 3.2 & 1.3 & 2.1 & 2.6 & 1.2 & & & T.Mínima Media \\
\hline-4.0 & -0.8 & -0.4 & -5.2 & -3.4 & -7.6 & -4.4 & -2.6 & -2.2 & -5.4 & -5.5 & -3.4 & -2.2 & & & T.Mínima Absoluta \\
\hline 1985 & 1986 & 1987 & 1988 & 1989 & 1990 & 1991 & 1992 & 1993 & 1994 & 1995 & 1996 & 1997 & 1998 & 1999 & \\
\hline 15.6 & 13.0 & 13.4 & 14.4 & 16.6 & 12.0 & 13.2 & 13.2 & 16.6 & 16.4 & 15.6 & 15.6 & 18.2 & 15.6 & 16.6 & T.Mắxima fbsoluta \\
\hline 7.6 & 9.6 & 8.9 & 10.7 & 11.5 & 10.0 & 9.4 & 9.4 & 11.3 & 10.6 & 11.7 & 11.0 & 10.1 & 10.8 & 11.1 & T.Măxima Media \\
\hline-0.4 & 0.8 & 0.6 & 4.3 & 0.7 & 1.9 & 1.4 & -0.5 & 0.5 & 0.8 & 1.9 & 4.7 & 3.4 & 3.3 & 1.0 & T.Mínima Media \\
\hline-8.0 & -3.8 & -5.4 & -0.4 & -3.4 & -2.0 & -3.4 & -5.4 & -4.6 & -5.2 & -4.0 & 0.4 & -3.4 & -0.6 & -3.2 & T.Mínima Absoluta \\
\hline 1970 & 1971 & 1972 & 1973 & 1974 & 1975 & 1976 & 1977 & 1978 & 1979 & 1980 & 1981 & 1982 & 1983 & 1984 & \\
\hline 14.0 & 13.6 & 11.4 & 14.2 & 14.0 & 17.0 & 18.0 & 13.0 & 13.6 & 15.8 & 18.4 & 18.0 & 15.0 & 18.4 & 15.2 & T.Măxima Absoluta \\
\hline 9.2 & 7.7 & 7.7 & 9.7 & 10.5 & 11.6 & 12.4 & 8.5 & 8.3 & 10.1 & 9.4 & 12.0 & 11.3 & 12.2 & 9.1 & T.Măxima Media \\
\hline 3.8 & 0.4 & 0.3 & 0.0 & 2.9 & 1.8 & -0.8 & 1.9 & 1.2 & 3.9 & 1.3 & -0.6 & 3.4 & 0.1 & 1.6 & T.Mínima Media \\
\hline-2.0 & -8.6 & -3.8 & -4.6 & -2.6 & -3.0 & -4.4 & -4.0 & -4.0 & -2.0 & -4.0 & -4.8 & -2.0 & -4.2 & -3.8 & T.Mínima Absoluta \\
\hline 1955 & 1956 & 1957 & 1958 & 1959 & 1960 & 1961 & 1962 & 1963 & 1964 & 1965 & 1966 & 1967 & 1968 & 1969 & \\
\hline 20.0 & 14.0 & 15.5 & 13.0 & 17.0 & 17.0 & 11.0 & 15.0 & 12.5 & 13.5 & 13.0 & 15.2 & 14.6 & 15.8 & 16.0 & T.Măxima Absoluta \\
\hline 11.7 & 9.4 & 8.4 & 9.2 & 10.2 & 8.7 & 7.5 & 10.8 & 8.1 & 10.1 & 8.9 & 10.4 & 9.0 & 11.9 & 9.9 & T.Mâxima Media \\
\hline 5.2 & 1.8 & -1.5 & 0.7 & 2.5 & 1.2 & 0.5 & 2.2 & 1.9 & 0.3 & 0.6 & 5.0 & -0.2 & -0.1 & 2.2 & T.Mínima Media \\
\hline-1.0 & -3.5 & -6.4 & -8.0 & -3.5 & -6.5 & -4.5 & -1.5 & -3.8 & -4.0 & -4.8 & -1.6 & -4.0 & -6.8 & -4.5 & T.Mínima Absoluta \\
\hline & & & & & & 1946 & 1947 & 1948 & 1949 & 1950 & 1951 & 1952 & 1953 & 1954 & \\
\hline & & & & & & 11.0 & 15.9 & 13.2 & 17.6 & 10.0 & 15.0 & 13.6 & 17.0 & 16.0 & T.Măxima Absoluta \\
\hline & & & & & & 5.9 & 7.6 & 9.8 & 11.8 & 7.6 & 9.7 & 7.9 & 9.3 & 9.1 & T.Măxima Media \\
\hline & & & & & & -1.1 & 0.4 & 3.5 & 1.8 & -1.0 & 0.6 & -1.2 & -0.8 & 0.7 & T.Mínima Media \\
\hline & & & & & & -8.5 & -6.5 & -2.0 & -3.0 & -5.0 & -3.8 & -9.0 & -5.5 & -5.5 & T.Mínima Absoluta \\
\hline
\end{tabular}

Tabla I.1. Histórico de temperaturas en Madrid en el mes de enero $\left({ }^{\circ} \mathrm{C}\right)$. 


\section{I.II HISTÓRICO DE TEMPERATURAS EN EL MES DE FEBRERO}

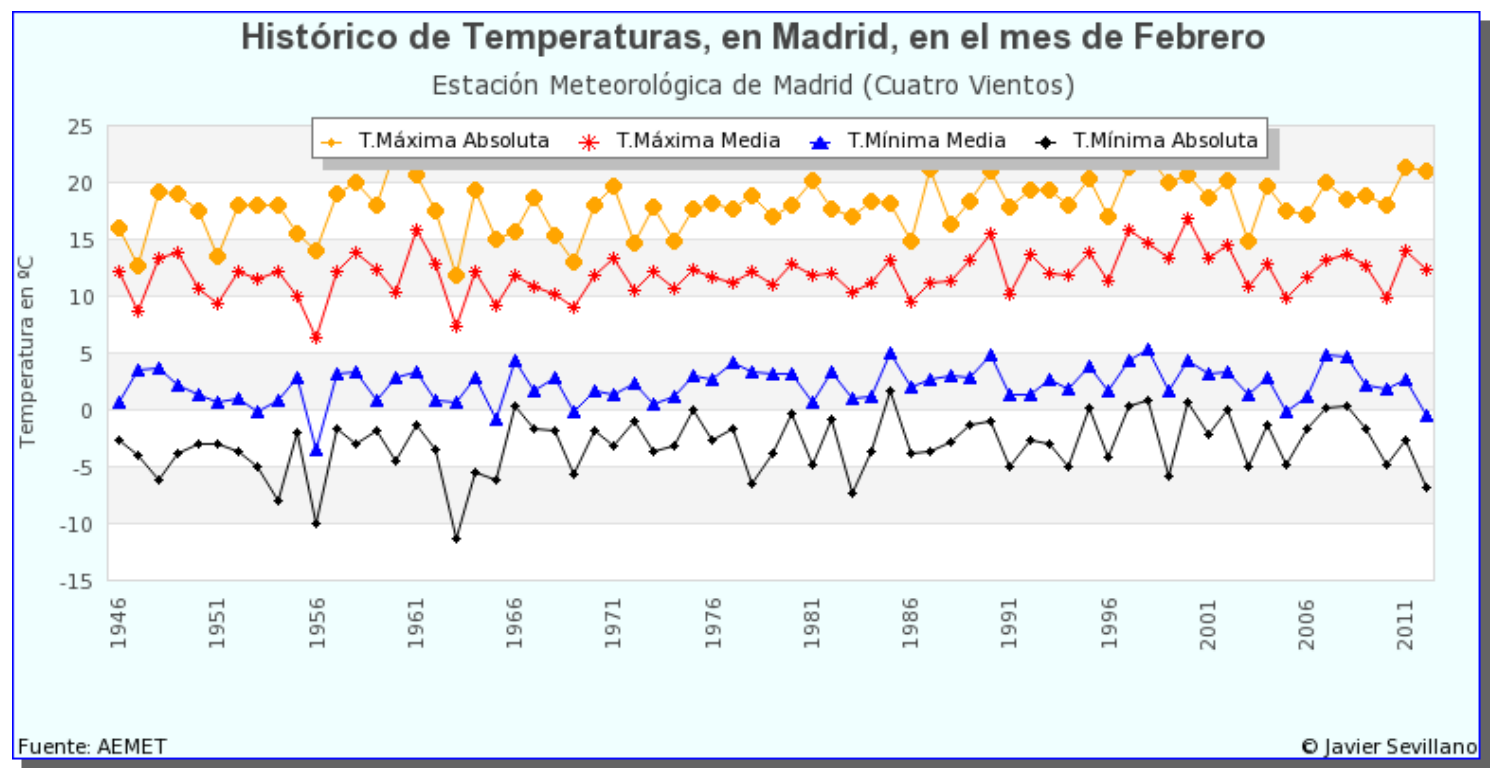

Figura I.2. Histórico de temperaturas en Madrid en el mes de febrero $\left({ }^{\circ} \mathrm{C}\right)$

\begin{tabular}{|c|c|c|c|c|c|c|c|c|c|c|c|c|c|c|c|}
\hline \multicolumn{16}{|c|}{ Temperaturas en Febrero, en Madrid } \\
\hline 20.6 & 18.6 & 20.2 & 14.8 & 19.6 & 17.5 & 17.2 & 20.0 & 18.5 & 18.8 & 18.0 & 21.3 & 21.0 & & & T.Măxima Absoluta \\
\hline 16.8 & 13.3 & 14.5 & 10.9 & 12.8 & 9.9 & 11.7 & 13.1 & 13.7 & 12.7 & 9.9 & 14.0 & 12.4 & & & T.Măxima Media \\
\hline 4.4 & 3.1 & 3.4 & 1.4 & 2.8 & -0.1 & 1.1 & 4.9 & 4.6 & 2.2 & 1.8 & 2.7 & -0.5 & & & Mínima Media \\
\hline 0.6 & -2.2 & 0.0 & -5.0 & -1.4 & -4.8 & -1.6 & 0.2 & 0.4 & -1.6 & -4.8 & -2.6 & -6.8 & & & T.Mínima Absoluta \\
\hline 1985 & 1986 & 1987 & 1988 & 1989 & 1990 & 1991 & 1992 & 1993 & 1994 & 1995 & 1996 & 1997 & 1998 & 1999 & \\
\hline 18.2 & 14.8 & 21.2 & 16.4 & 18.4 & 21.0 & 17.8 & 19.4 & 19.4 & 18.0 & 20.4 & 17.0 & 21.4 & 22.4 & 20.0 & T.Mấxima Absoluta \\
\hline 13.1 & 9.5 & 11.2 & 11.4 & 13.1 & 15.5 & 10.2 & 13.7 & 12.0 & 11.8 & 13.9 & 11.4 & 15.8 & 14.7 & 13.4 & T.Măxima Media \\
\hline 5.0 & 2.0 & 2.7 & 3.0 & 2.9 & 4.9 & 1.3 & 1.4 & 2.6 & 1.8 & 3.8 & 1.7 & 4.3 & 5.4 & 1.6 & T.Mínima Media \\
\hline 1.6 & -3.8 & -3.6 & -2.8 & -1.4 & -1.0 & -5.0 & -2.6 & -3.0 & -5.0 & 0.2 & -4.2 & 0.4 & 0.8 & -5.8 & T.Mínima Absoluta \\
\hline 1970 & 1971 & 1972 & 1973 & 1974 & 1975 & 1976 & 1977 & 1978 & 1979 & 1980 & 1981 & 1982 & 1983 & 1984 & \\
\hline 18.0 & 19.6 & 14.6 & 17.8 & 14.8 & 17.6 & 18.2 & 17.6 & 18.8 & 17.0 & 18.0 & 20.2 & 17.6 & 17.0 & 18.4 & T.Măxima fbsoluta \\
\hline 11.8 & 13.4 & 10.5 & 12.1 & 10.7 & 12.4 & 11.7 & 11.2 & 12.1 & 11.0 & 12.8 & 11.9 & 12.0 & 10.3 & 11.2 & T.Măxima Media \\
\hline 1.6 & 1.3 & 2.4 & 0.5 & 1.1 & 3.0 & 2.7 & & 3.4 & & & 0.6 & & & 1.1 & T.Mínima Media \\
\hline-1.8 & -3.2 & -1.0 & -3.6 & -3.2 & 0.0 & -2.6 & -1.6 & -6.5 & -3.8 & -0.4 & -4.8 & -0.8 & -7.4 & -3.6 & T.Mínima Absoluta \\
\hline 1955 & 1956 & 1957 & 1958 & 1959 & 1960 & 1961 & 1962 & 1963 & 1964 & 1965 & 1966 & 1967 & 1968 & 1969 & \\
\hline 15.5 & 14.0 & 19.0 & 20.0 & 18.0 & 23.0 & 20.6 & 17.5 & 11.9 & 19.4 & 15.0 & 15.6 & 18.6 & 15.4 & 13.0 & T. Măxima Absoluta \\
\hline 10.0 & 6.4 & 12.2 & 13.8 & 12.3 & 10.3 & 15.9 & 12.9 & 7.4 & 12.1 & 9.2 & 11.9 & 10.8 & 10.2 & 9.0 & T.Măxima Media \\
\hline 2.8 & -3.5 & 3.2 & 3.3 & 0.8 & 2.8 & 3.3 & 0.8 & 0.6 & 2.9 & -0.8 & 4.3 & 1.7 & 2.9 & -0.2 & T.Mínima Media \\
\hline-2.0 & -10.0 & -1.6 & -3.0 & -1.8 & -4.5 & -1.4 & -3.5 & -11.4 & -5.5 & -6.2 & 0.3 & -1.6 & -1.8 & -5.6 & T.Mínima Absoluta \\
\hline & & & & & & 1946 & 1947 & 1948 & 1949 & 1950 & 1951 & 1952 & 1953 & 1954 & \\
\hline & & & & & & 16.0 & 12.6 & 19.2 & & & 13.5 & 18.0 & 18.0 & 18.0 & T. Măxima Absoluta \\
\hline & & & & & & 12.1 & 8.6 & 13.4 & 13.9 & 10.7 & 9.3 & 12.2 & 11.5 & 12.1 & T.Măxima Media \\
\hline & & & & & & 0.7 & 3.5 & 3.7 & 2.2 & 1.3 & 0.7 & 1.0 & -0.1 & 0.9 & T.Mínima Media \\
\hline & & & & & & -2.6 & -4.0 & -6.2 & -3.8 & -3.0 & -3.0 & -3.6 & -5.0 & -8.0 & T.Mínima Absoluta \\
\hline
\end{tabular}

Tabla I.2. Histórico de temperaturas en Madrid en el mes de febrero $\left({ }^{\circ} \mathrm{C}\right)$. 


\section{I.III HISTÓRICO DE TEMPERATURAS EN EL MES DE MARZO}

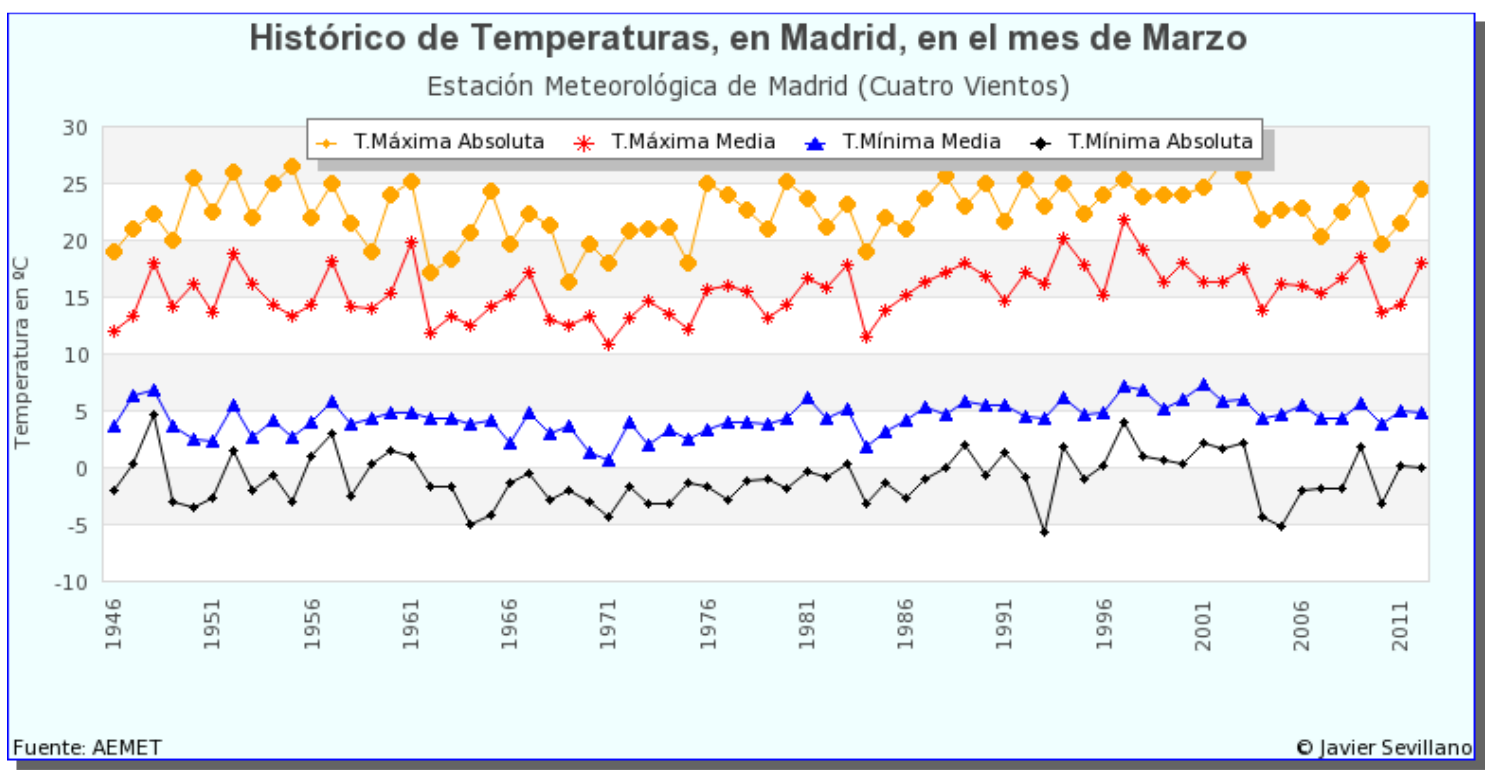

Figura I.3. Histórico de temperaturas en Madrid en el mes de marzo $\left({ }^{\circ} \mathrm{C}\right)$.

\begin{tabular}{|c|c|c|c|c|c|c|c|c|c|c|c|c|c|c|c|}
\hline & & & & & & & & & & & & & & & \\
\hline 2000 & 2001 & 2002 & 2003 & 2004 & 2005 & 2006 & 2007 & 2008 & 2009 & 2010 & 2011 & 2012 & & & \\
\hline 24.0 & 24.6 & 26.8 & 25.6 & 21.8 & 22.6 & 22.8 & 20.4 & 22.5 & 24.5 & 19.6 & 21.5 & 24.5 & & & T.Măxima Absoluta \\
\hline 18.0 & 16.4 & 16.4 & 17.5 & 13.8 & 16.2 & 16.0 & 15.4 & 16.6 & 18.5 & 13.6 & 14.4 & 18.0 & & & T.Măxima Media \\
\hline 6.0 & 7.3 & 5.8 & 6.0 & 4.3 & 4.6 & 5.5 & 4.3 & 4.4 & 5.6 & 3.8 & 5.0 & 4.8 & & & T.Mínima Media \\
\hline 0.4 & 2.2 & 1.6 & 2.2 & -4.4 & -5.2 & -2.0 & -1.8 & -1.8 & 1.8 & -3.2 & 0.1 & 0.0 & & & T.Mínima Absoluta \\
\hline 1985 & 1986 & 1987 & 1988 & 1989 & 1990 & 1991 & 1992 & 1993 & 1994 & 1995 & 1996 & 1997 & 1998 & 1999 & \\
\hline 22.0 & 21.0 & 23.6 & 25.6 & 23.0 & 25.0 & 21.6 & 25.4 & 23.0 & 25.0 & 22.4 & 24.0 & 25.4 & 23.8 & 24.0 & T.Máxima Absoluta \\
\hline 13.8 & 15.2 & 16.3 & 17.1 & 18.0 & 16.9 & 14.6 & 17.1 & 16.2 & 20.1 & 17.8 & 15.2 & 21.9 & 19.1 & 16.3 & T.Măxima Media \\
\hline 3.1 & 4.2 & 5.4 & 4.6 & 5.8 & 5.5 & 5.5 & 4.5 & 4.3 & 6.1 & 4.7 & 4.9 & 7.2 & 6.9 & 5.1 & T.Mínima Media \\
\hline-1.4 & -2.6 & -1.0 & 0.0 & 2.0 & -0.6 & 1.4 & -0.8 & -5.6 & 1.8 & -1.0 & 0.2 & 4.0 & 1.0 & 0.6 & T.Mínima Absoluta \\
\hline 1970 & 1971 & 1972 & 1973 & 1974 & 1975 & 1976 & 1977 & 1978 & 1979 & 1980 & 1981 & 1982 & 1983 & 1984 & \\
\hline 19.6 & 18.0 & 20.8 & 21.0 & 21.2 & 18.0 & 25.0 & 24.0 & 22.6 & 21.0 & 25.2 & 23.6 & 21.2 & 23.2 & 19.0 & T.Máxima Absoluta \\
\hline 13.3 & 10.8 & 13.1 & 14.7 & 13.5 & 12.1 & 15.7 & 16.0 & 15.5 & & & 16.6 & & 17.8 & 11.5 & T.Măxima Media \\
\hline 1.4 & 0.7 & 4.0 & 2.0 & 3.4 & 2.5 & 3.4 & 4.0 & 4.0 & 3.8 & 4.4 & 6.2 & 4.4 & 5.2 & 1.8 & T.Mínima Media \\
\hline-3.0 & -4.4 & -1.6 & -3.2 & -3.2 & -1.4 & -1.6 & -2.8 & -1.2 & -1.0 & -1.8 & -0.4 & -0.8 & 0.4 & -3.2 & T.Mínima Absoluta \\
\hline 1955 & 1956 & 1957 & 1958 & 1959 & 1960 & 1961 & 1962 & 1963 & 1964 & 1965 & 1966 & 1967 & 1968 & 1969 & \\
\hline 26.5 & 22.0 & 25.0 & 21.5 & 19.0 & 24.0 & 25.2 & 17.1 & 18.3 & 20.6 & 24.3 & 19.6 & 22.3 & 21.4 & 16.4 & T.Máxima Absoluta \\
\hline 13.4 & 14.4 & 18.2 & 14.1 & 14.0 & 15.4 & 19.8 & 11.8 & 13.3 & 12.5 & 14.1 & 15.1 & 17.2 & 13.0 & 12.5 & T.Măxima Media \\
\hline 2.6 & 4.0 & 5.9 & 3.8 & 4.4 & 4.9 & 4.8 & 4.3 & 4.4 & 3.9 & 4.1 & 2.2 & 4.9 & 3.0 & 3.7 & T.Mínima Media \\
\hline-3.0 & 1.0 & 3.0 & -2.5 & 0.4 & 1.5 & 1.0 & -1.7 & -1.6 & -5.0 & -4.2 & -1.4 & -0.5 & -2.8 & -2.0 & T.Mínima Absoluta \\
\hline & & & & & & 1946 & 1947 & 1948 & 1949 & 1950 & 1951 & 1952 & 1953 & 1954 & \\
\hline & & & & & & 19.0 & 21.0 & 22.4 & 20.0 & 25.5 & 22.5 & 26.0 & 22.0 & 25.0 & T.Máxima Absoluta \\
\hline & & & & & & 12.0 & 13.4 & 18.0 & 14.1 & 16.2 & 13.6 & 18.8 & 16.1 & 14.4 & T.Măxima Media \\
\hline & & & & & & 3.7 & 6.4 & 6.8 & 3.7 & 2.5 & 2.4 & 5.5 & 2.6 & 4.1 & T.Mínima Media \\
\hline & & & & & & -2.0 & 0.3 & 4.6 & -3.0 & -3.5 & -2.7 & 1.5 & -2.0 & -0.7 & T.Mínima Absoluta \\
\hline
\end{tabular}

Tabla I.3. Histórico de temperaturas en Madrid en el mes de marzo $\left({ }^{\circ} \mathrm{C}\right)$. 


\section{I.IV HISTÓRICO DE TEMPERATURAS EN EL MES DE ABRIL}

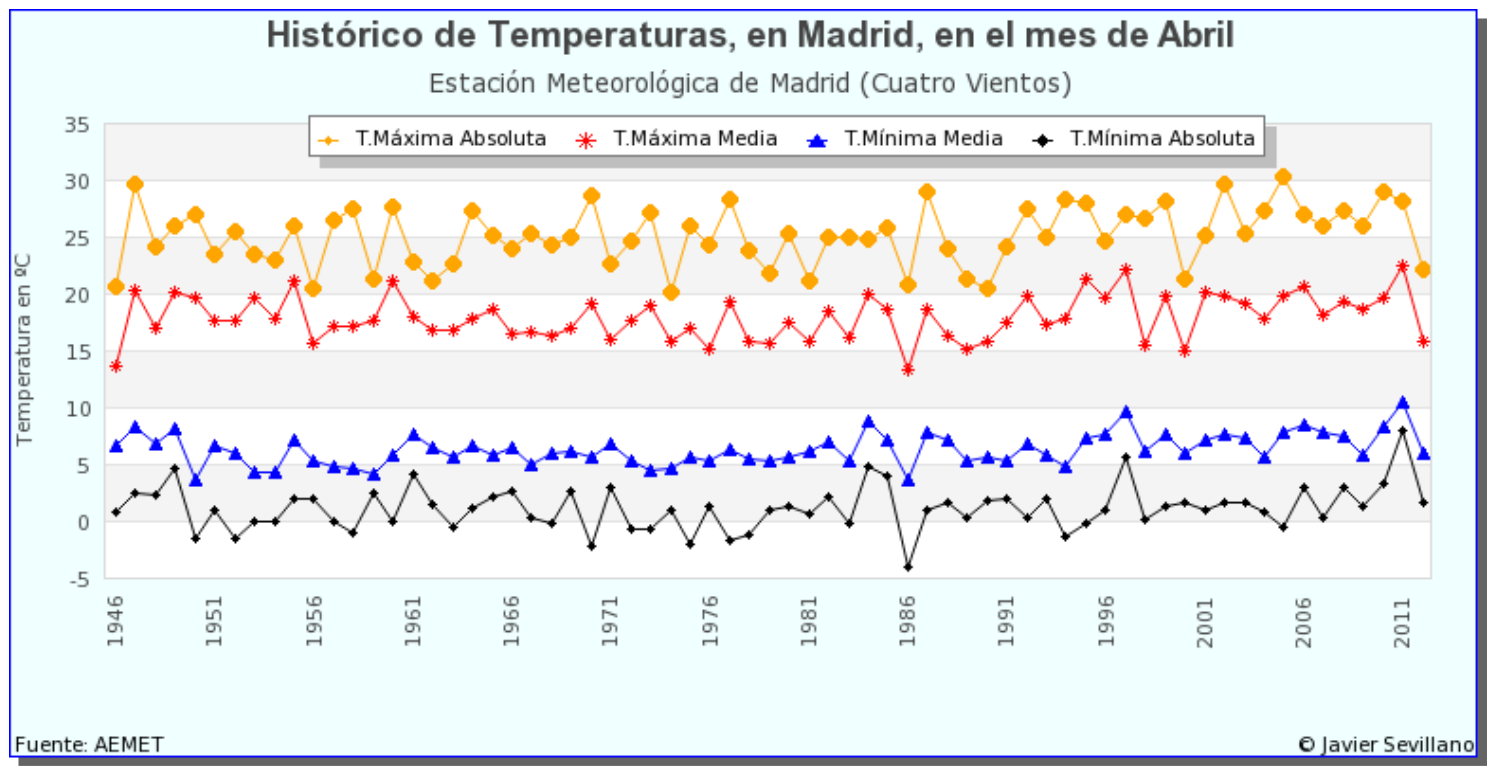

Figura I.4. Histórico de temperaturas en Madrid en el mes de abril $\left({ }^{\circ} \mathrm{C}\right)$.

\begin{tabular}{|c|c|c|c|c|c|c|c|c|c|c|c|c|c|c|c|}
\hline \multicolumn{16}{|c|}{ Temperaturas en Abril, en Madrid } \\
\hline 21.4 & 25.2 & 29.6 & 25.4 & 27.4 & 30.4 & 27.0 & 26.0 & 27.4 & 26.0 & 29.0 & 28.2 & 22.2 & & & T.Mắxima Absoluta \\
\hline 15.0 & 20.1 & 19.9 & 19.1 & 17.9 & 19.9 & 20.6 & 18.2 & 19.4 & 18.6 & 19.7 & 22.5 & 15.8 & & & T.Máxima Media \\
\hline 6.0 & 7.1 & 7.6 & 7.3 & 5.7 & 7.8 & 8.5 & 7.9 & 7.5 & 5.8 & 8.4 & 10.5 & 6.0 & & & T.Mínima Media \\
\hline 1.6 & 1.0 & 1.6 & 1.6 & 0.8 & -0.5 & 3.0 & 0.4 & 3.0 & 1.4 & 3.4 & 8.0 & 1.6 & & & T.Mínima Absoluta \\
\hline 1985 & 1986 & 1987 & 1988 & 1989 & 1990 & 1991 & 1992 & 1993 & 1994 & 1995 & 1996 & 1997 & 1998 & 1999 & \\
\hline 25.8 & 20.8 & 29.0 & 24.0 & 21.4 & 20.5 & 24.2 & 27.5 & 25.0 & 28.4 & 28.0 & 24.6 & 27.0 & 26.6 & 28.2 & T.Mắxima Absoluta \\
\hline 18.7 & 13.4 & 18.6 & 16.4 & 15.1 & 15.8 & 17.5 & 19.9 & 17.3 & 17.9 & 21.3 & 19.7 & 22.2 & 15.5 & 19.8 & T.Mâxima Media \\
\hline 7.2 & 3.6 & 7.9 & 7.1 & 5.4 & 5.7 & 5.4 & 6.8 & 5.9 & 4.9 & 7.3 & 7.7 & 9.7 & 6.1 & 7.7 & T.Mínima Media \\
\hline 4.0 & -4.0 & 1.0 & 1.6 & 0.4 & 1.8 & 2.0 & 0.4 & 2.0 & -1.4 & -0.2 & 1.0 & 5.6 & 0.2 & 1.4 & T.Mínima Absoluta \\
\hline 1970 & 1971 & 1972 & 1973 & 1974 & 1975 & 1976 & 1977 & 1978 & 1979 & 1980 & 1981 & 1982 & 1983 & 1984 & \\
\hline 28.6 & 22.6 & 24.6 & 27.2 & 20.2 & 26.0 & 24.4 & 28.4 & 23.8 & 21.8 & 25.4 & 21.2 & 25.0 & 25.0 & 24.8 & T.Măxima Absoluta \\
\hline 19.1 & 16.0 & 17.7 & 19.0 & 15.8 & 17.0 & 15.2 & 19.4 & 15.9 & 15.7 & 17.5 & 15.9 & 18.5 & 16.1 & 20.0 & T.Mâxima Media \\
\hline 5.7 & 6.8 & 5.4 & 4.5 & 4.7 & 5.7 & 5.3 & 6.4 & 5.5 & 5.3 & 5.6 & 6.1 & 7.0 & 5.4 & 8.9 & T.Mínima Media \\
\hline-2.2 & 3.0 & -0.6 & -0.6 & 1.0 & -2.0 & 1.4 & -1.6 & & 1.0 & 1.4 & 0.6 & 2.2 & -0.2 & 4.8 & T.Mínima Absoluta \\
\hline 1955 & 1956 & 1957 & 1958 & 1959 & 1960 & 1961 & 1962 & 1963 & 1964 & 1965 & 1966 & 1967 & 1968 & 1969 & \\
\hline 26.0 & 20.5 & 26.5 & 27.5 & 21.4 & 27.6 & 22.8 & 21.2 & 22.6 & 27.4 & 25.2 & 24.0 & 25.4 & 24.3 & 25.0 & T.Mắxima Absoluta \\
\hline 21.2 & 15.6 & 17.1 & 17.2 & 17.6 & 21.1 & 18.0 & 16.8 & 16.8 & 17.9 & 18.6 & 16.5 & 16.6 & 16.3 & 17.0 & T.Măxima Media \\
\hline 7.1 & 5.4 & 4.8 & 4.6 & 4.2 & 5.9 & 7.6 & 6.5 & 5.7 & 6.6 & 5.9 & 6.5 & 5.0 & 6.0 & 6.2 & T.Mínima Media \\
\hline 2.0 & 2.0 & 0.0 & -1.0 & 2.5 & 0.0 & 4.1 & 1.5 & -0.5 & 1.2 & 2.2 & 2.6 & 0.4 & -0.2 & 2.6 & T.Mínima Absoluta \\
\hline & & & & & & 1946 & 1947 & 1948 & 1949 & 1950 & 1951 & 1952 & 1953 & 1954 & \\
\hline & & & & & & 20.7 & 29.6 & 24.2 & 26.0 & 27.0 & 23.5 & 25.5 & 23.5 & 23.0 & T.Mắxima Absoluta \\
\hline & & & & & & 13.6 & 20.3 & 17.0 & 20.1 & 19.7 & 17.6 & 17.6 & 19.7 & 17.9 & T.Măxima Media \\
\hline & & & & & & 6.6 & 8.3 & 6.9 & 8.1 & 3.6 & 6.7 & 6.0 & 4.4 & 4.4 & T.Mínima Media \\
\hline & & & & & & 0.8 & 2.5 & 2.4 & 4.6 & -1.5 & 1.0 & -1.5 & 0.0 & 0.0 & T.Mínima Absoluta \\
\hline
\end{tabular}

Tabla I.4. Histórico de temperaturas en Madrid en el mes de abril $\left({ }^{\circ} \mathrm{C}\right)$. 


\section{I.V HISTÓRICO DE TEMPERATURAS EN EL MES DE MAYO}

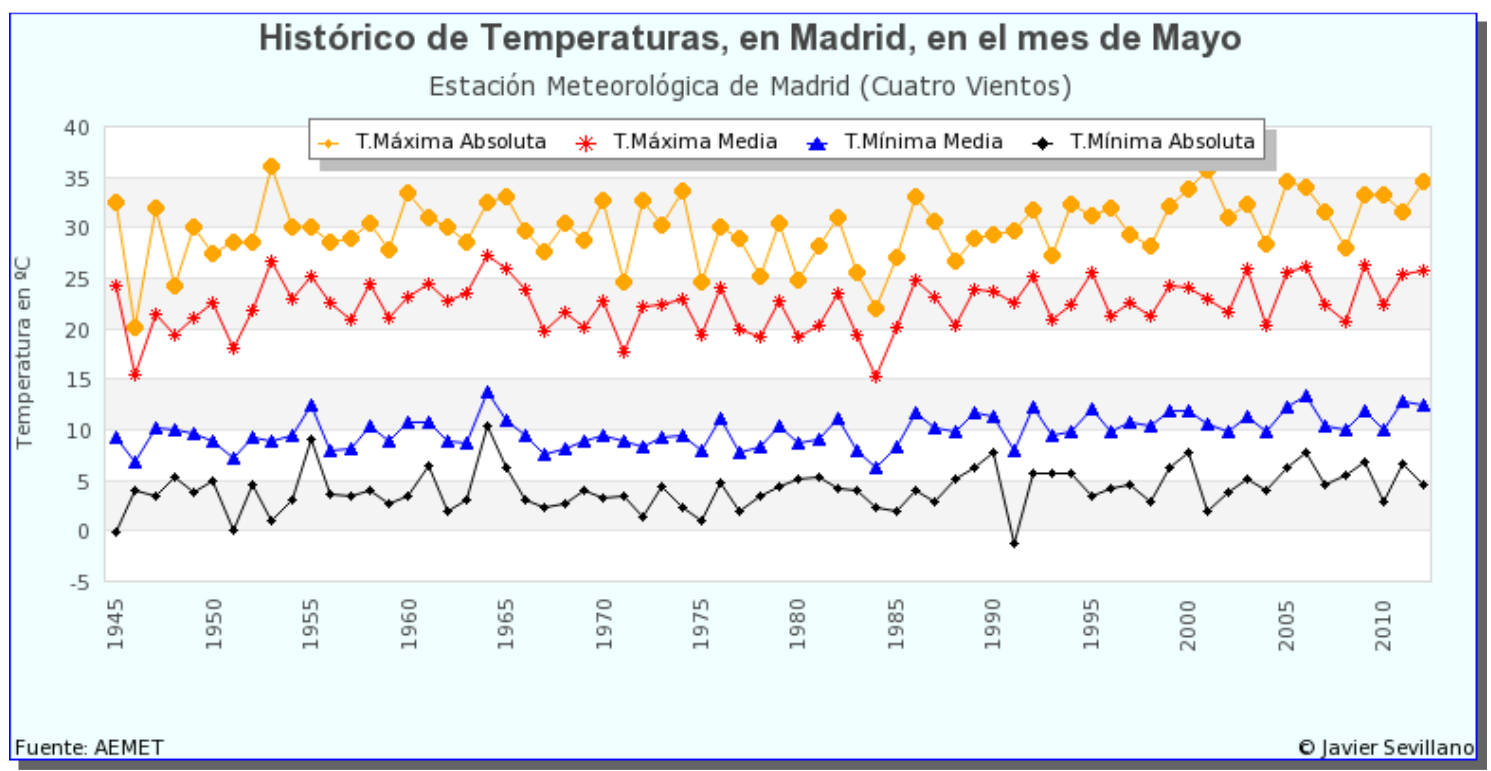

Figura I.5. Histórico de temperaturas en Madrid en el mes de mayo $\left({ }^{\circ} \mathrm{C}\right)$.

\begin{tabular}{|c|c|c|c|c|c|c|c|c|c|c|c|c|c|c|c|}
\hline 2000 & 2001 & 2002 & 2003 & 2004 & 2005 & 2006 & 2007 & 2008 & 2009 & 2010 & 2011 & 2012 & & & \\
\hline 33.8 & 35.6 & 31.0 & 32.4 & 28.4 & 34.6 & 34.0 & 31.5 & 28.0 & 33.2 & 33.2 & 31.5 & 34.6 & & & T.Măxima Absoluta \\
\hline 24.1 & 23.0 & 21.6 & 26.0 & 20.4 & 25.6 & 26.1 & 22.4 & 20.7 & 26.3 & 22.4 & 25.4 & 25.7 & & & T.Măxima Media \\
\hline 11.8 & 10.6 & 9.9 & 11.3 & 9.8 & 12.3 & 13.4 & 10.3 & 10.0 & 11.9 & 10.0 & 12.9 & 12.4 & & & T.Mínima Media \\
\hline 7.8 & 2.0 & 3.8 & 5.2 & 4.0 & 6.2 & 7.8 & 4.6 & 5.5 & 6.8 & 2.8 & 6.7 & 4.5 & & & T.Mínima Absoluta \\
\hline 1985 & 1986 & 1987 & 1988 & 1989 & 1990 & 1991 & 1992 & 1993 & 1994 & 1995 & 1996 & 1997 & 1998 & 1999 & \\
\hline 27.0 & 33.0 & 30.6 & 26.6 & 29.0 & 29.4 & 29.6 & 31.8 & 27.2 & 32.4 & 31.2 & 32.0 & 29.4 & 28.2 & 32.2 & T.Măxima Absoluta \\
\hline 20.2 & 24.9 & 23.1 & 20.3 & 23.9 & 23.7 & 22.6 & 25.1 & 20.8 & 22.3 & 25.6 & 21.2 & 22.5 & 21.2 & 24.3 & T.Mấxima Media \\
\hline 8.4 & 11.6 & 10.1 & 9.9 & 11.7 & 11.4 & 8.0 & 12.2 & 9.5 & 9.9 & 12.0 & 9.9 & 10.8 & 10.4 & 11.9 & T.Mínima Media \\
\hline 2.0 & 4.0 & 2.8 & 5.2 & 6.2 & 7.8 & -1.2 & 5.6 & 5.6 & 5.6 & 3.4 & 4.2 & 4.6 & 2.8 & 6.2 & T.Mínima Absoluta \\
\hline 1970 & 1971 & 1972 & 1973 & 1974 & 1975 & 1976 & 1977 & 1978 & 1979 & 1980 & 1981 & 1982 & 1983 & 1984 & \\
\hline 32.6 & 24.6 & 32.6 & 30.2 & 33.6 & 24.6 & 30.0 & 29.0 & 25.2 & 30.4 & 24.8 & 28.2 & 31.0 & 25.6 & 22.0 & T.Măxima Absoluta \\
\hline 22.7 & 17.7 & 22.1 & 22.4 & 23.0 & 19.4 & 24.1 & 19.9 & 19.1 & 22.7 & 19.2 & 20.4 & 23.5 & 19.4 & 15.2 & T.Máxima Media \\
\hline 9.5 & 8.9 & 8.3 & 9.2 & 9.4 & 7.9 & 11.1 & 7.8 & 8.4 & 10.4 & 8.6 & 9.0 & 11.2 & 7.9 & 6.3 & T.Mínima Media \\
\hline 3.2 & 3.4 & 1.4 & 4.4 & 2.4 & 1.0 & 4.8 & 2.0 & 3.4 & 4.4 & 5.2 & 5.4 & 4.2 & 4.0 & 2.4 & T.Mínima Absoluta \\
\hline 1955 & 1956 & 1957 & 1958 & 1959 & 1960 & 1961 & 1962 & 1963 & 1964 & 1965 & 1966 & 1967 & 1968 & 1969 & \\
\hline 30.0 & 28.5 & 29.0 & 30.5 & 27.8 & 33.5 & 31.0 & 30.0 & 28.5 & 32.5 & 33.0 & 29.6 & 27.6 & 30.4 & 28.8 & T.Măxima Absoluta \\
\hline 25.1 & 22.5 & 20.9 & 24.4 & 21.1 & 23.1 & 24.4 & 22.7 & 23.5 & 27.3 & 25.9 & 23.8 & 19.7 & 21.6 & 20.1 & T.Măxima Media \\
\hline 12.4 & 8.0 & 8.1 & 10.3 & 8.8 & 10.7 & 10.7 & 8.9 & 8.7 & 13.7 & 11.0 & 9.5 & 7.5 & 8.1 & 8.9 & T.Mínima Media \\
\hline \multirow[t]{6}{*}{9.0} & 3.7 & 3.5 & 4.0 & 2.6 & 3.5 & 6.4 & 2.0 & 3.0 & 10.3 & 6.2 & 3.0 & 2.4 & 2.6 & 4.0 & T.Mínima Absoluta \\
\hline & & & & & 1945 & 1946 & 1947 & 1948 & 1949 & 1950 & 1951 & 1952 & 1953 & 1954 & \\
\hline & & & & & 32.5 & 20.2 & 32.0 & 24.2 & 30.0 & 27.5 & 28.5 & 28.5 & 36.0 & 30.0 & T.Măxima Absoluta \\
\hline & & & & & 24.3 & 15.5 & 21.4 & 19.4 & 21.0 & 22.6 & 18.1 & 21.8 & 26.7 & 23.0 & T.Măxima Media \\
\hline & & & & & 9.2 & 6.8 & 10.2 & 10.0 & 9.7 & 8.8 & 7.1 & 9.2 & 8.9 & 9.4 & T.Mínima Media \\
\hline & & & & & -0.2 & 4.0 & 3.5 & 5.4 & 3.9 & 5.0 & 0.0 & 4.5 & 1.0 & 3.0 & T.Mínima Absoluta \\
\hline
\end{tabular}

Tabla I.5. Histórico de temperaturas en Madrid en el mes de mayo $\left({ }^{\circ} \mathrm{C}\right)$. 


\section{I.VI HISTÓRICO DE TEMPERATURAS EN EL MES DE JUNIO}

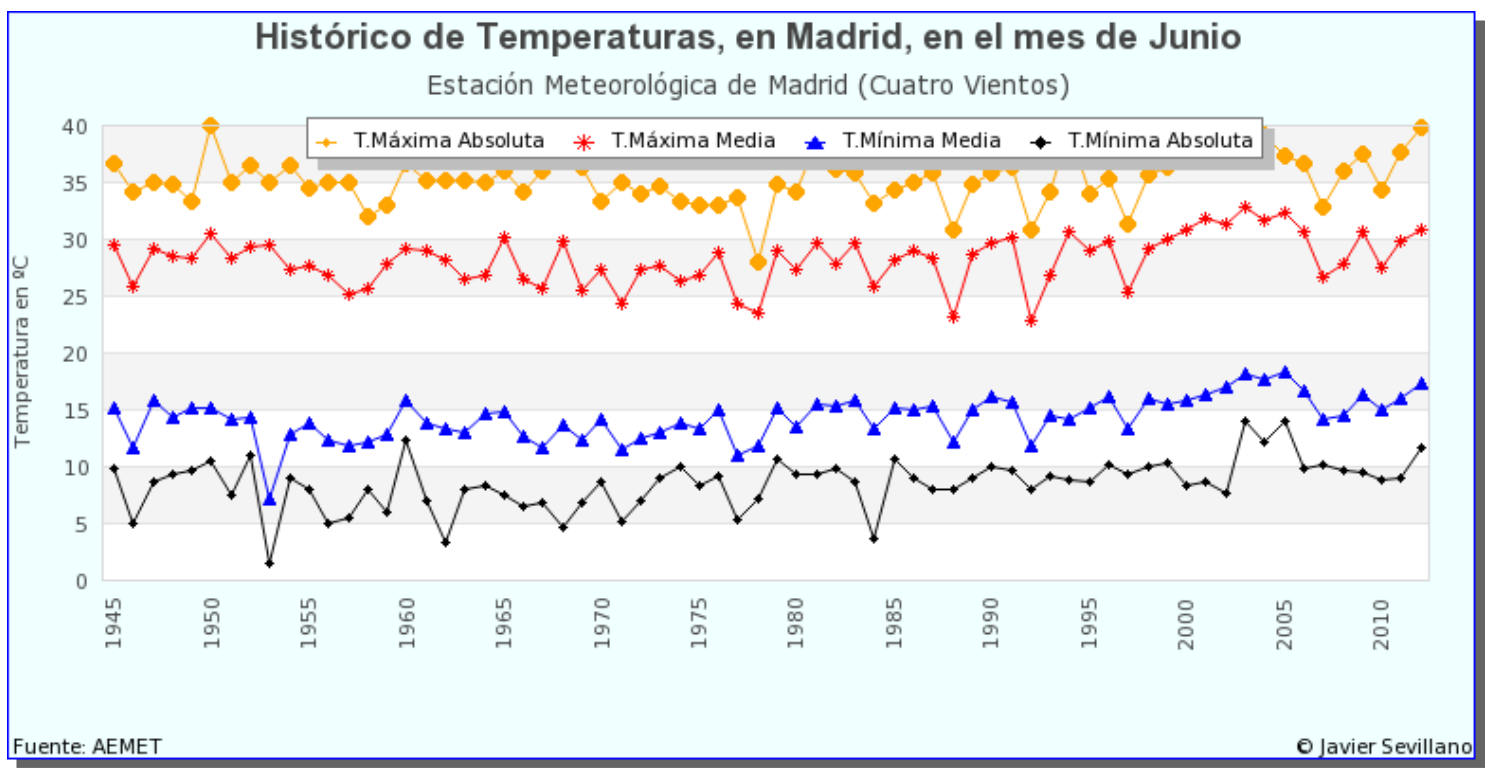

Figura I.6. Histórico de temperaturas en Madrid en el mes de junio $\left({ }^{\circ} \mathrm{C}\right)$.

\begin{tabular}{|c|c|c|c|c|c|c|c|c|c|c|c|c|c|c|c|}
\hline \multicolumn{16}{|c|}{ Temperaturas en Junio, en Madrid } \\
\hline 2000 & 2001 & 2002 & 2003 & 2004 & 2005 & 2006 & 2007 & 2008 & 2009 & 2010 & 2011 & 2012 & & & \\
\hline 37.2 & 38.8 & 38.8 & 37.0 & 39.2 & 37.4 & 36.6 & 32.8 & 36.0 & 37.5 & 4.4 & 37.6 & 39.8 & & & T.Măxima fbsoluta \\
\hline 30.8 & 31.8 & 31.4 & 32.8 & 31.6 & 32.4 & 30.7 & 26.6 & 27.8 & 30.7 & 27.5 & 29.8 & 30.8 & & & T.Măxima Media \\
\hline 15.8 & 16.3 & 17.0 & 18.2 & 17.6 & 18.4 & 16.7 & 14.2 & 14.5 & 16.4 & 15.0 & 16.0 & 17.3 & & & T.Mínima Media \\
\hline 8.4 & 8.6 & 7.6 & 14.0 & 12.2 & 14.0 & 9.8 & 10.1 & 9.6 & 9.5 & 8.9 & 9.0 & 11.7 & & & Mínima Absoluta \\
\hline 1985 & 1986 & 1987 & 1988 & 1989 & 1990 & 1991 & 1992 & 1993 & 1994 & 1995 & 1996 & 1997 & 1998 & 1999 & \\
\hline 34.4 & 35.0 & 35.8 & 30.8 & 34.8 & 35.8 & 36.4 & 30.8 & 34.2 & 39.6 & 34.0 & 35.4 & 31.4 & 35.6 & 36.4 & T.Măxima Absoluta \\
\hline 28.1 & 29.0 & 28.3 & 23.2 & 28.6 & 29.6 & 30.1 & 22.8 & 26.8 & 30.6 & 29.0 & 29.8 & 25.4 & 29.1 & 30.0 & T.Máxima Media \\
\hline 15.2 & 15.0 & 15.3 & 12.2 & 15.0 & 16.1 & 15.7 & 11.9 & 14.5 & 14.1 & 15.2 & 16.1 & 13.3 & 16.0 & 15.5 & T.Mínima Media \\
\hline 10.6 & 9.0 & & 8.0 & 9.0 & & & & & & & & & & 10.4 & \\
\hline 1970 & 1971 & 1972 & 1973 & 1974 & 1975 & 1976 & 1977 & 1978 & 1979 & 1980 & 1981 & 1982 & 1983 & 1984 & \\
\hline 33.4 & 35.0 & 34.0 & 34.6 & 33.4 & 33.0 & 33.0 & 33.6 & 28.0 & 34.8 & 34.2 & 38.6 & 36.2 & 35.8 & 33.2 & T.Măxima Absoluta \\
\hline 27.4 & 24.3 & 27.4 & 27.6 & 26.3 & 26.8 & 28.9 & 24.3 & 23.5 & 29.0 & 27.4 & 29.6 & 27.9 & 29.7 & 25.8 & T.Máxima Media \\
\hline 14.1 & 11.5 & 12.5 & 13.0 & 13.8 & 13.4 & 15.0 & 11.0 & 11.8 & 15.1 & 13.5 & 15.5 & 15.3 & 15.8 & 13.3 & T.Mínima Media \\
\hline 8.6 & 5.2 & 7.0 & 9.0 & 10.0 & 8.4 & 9.2 & & 7.2 & & & & & 8.6 & 3.6 & T.Mínima Absoluta \\
\hline 1955 & 1956 & 1957 & 1958 & 1959 & 1960 & 1961 & 1962 & 1963 & 1964 & 1965 & 1966 & 1967 & 1968 & 1969 & \\
\hline 34.5 & 35.0 & 35.0 & 32.0 & 33.0 & 36.7 & 35.2 & 35.2 & 35.2 & 35.0 & 36.0 & 34.2 & 36.0 & 38.0 & 36.4 & T.Măxima Absoluta \\
\hline 27.7 & 26.9 & 25.1 & 25.6 & 27.8 & 29.1 & 29.0 & 28.2 & 26.5 & 26.9 & 30.2 & 26.5 & 25.6 & 29.9 & 25.5 & T.Măxima Media \\
\hline 13.8 & 12.4 & 11.9 & 12.1 & 12.8 & 15.9 & 13.8 & 13.3 & 13.0 & 14.6 & 14.9 & 12.6 & 11.7 & 13.7 & 12.3 & T.Mínima Media \\
\hline 8.0 & 5.0 & 5.5 & 8.0 & 6.0 & 12.4 & 7.0 & 3.4 & 8.0 & 8.4 & 7.5 & 6.5 & 6.8 & 4.6 & 6.8 & T.Mínima Absoluta \\
\hline & & & & & 1945 & 1946 & 1947 & 1948 & 1949 & 1950 & 1951 & 1952 & 1953 & 1954 & \\
\hline & & & & & 36.7 & 34.1 & 35.0 & 34.8 & 33.4 & 40.0 & 35.0 & 36.5 & 35.0 & 36.5 & T.Mắxima Absoluta \\
\hline & & & & & 29.5 & 25.9 & 29.2 & 28.5 & 28.4 & 30.5 & 28.3 & 29.3 & 29.5 & 27.4 & T.Măxima Media \\
\hline & & & & & 15.2 & 11.7 & 15.8 & 14.3 & 15.2 & 15.1 & 14.2 & 14.4 & 7.2 & 12.9 & T.Mínima Media \\
\hline & & & & & 9.9 & 5.0 & 8.7 & 9.4 & 9.6 & 10.5 & 7.5 & 11.0 & 1.5 & 9.0 & T.Mínima Absoluta \\
\hline
\end{tabular}

Tabla I.6. Histórico de temperaturas en Madrid en el mes de junio $\left({ }^{\circ} \mathrm{C}\right)$. 


\section{I.VII HISTÓRICO DE TEMPERATURAS EN EL MES DE JULIO}

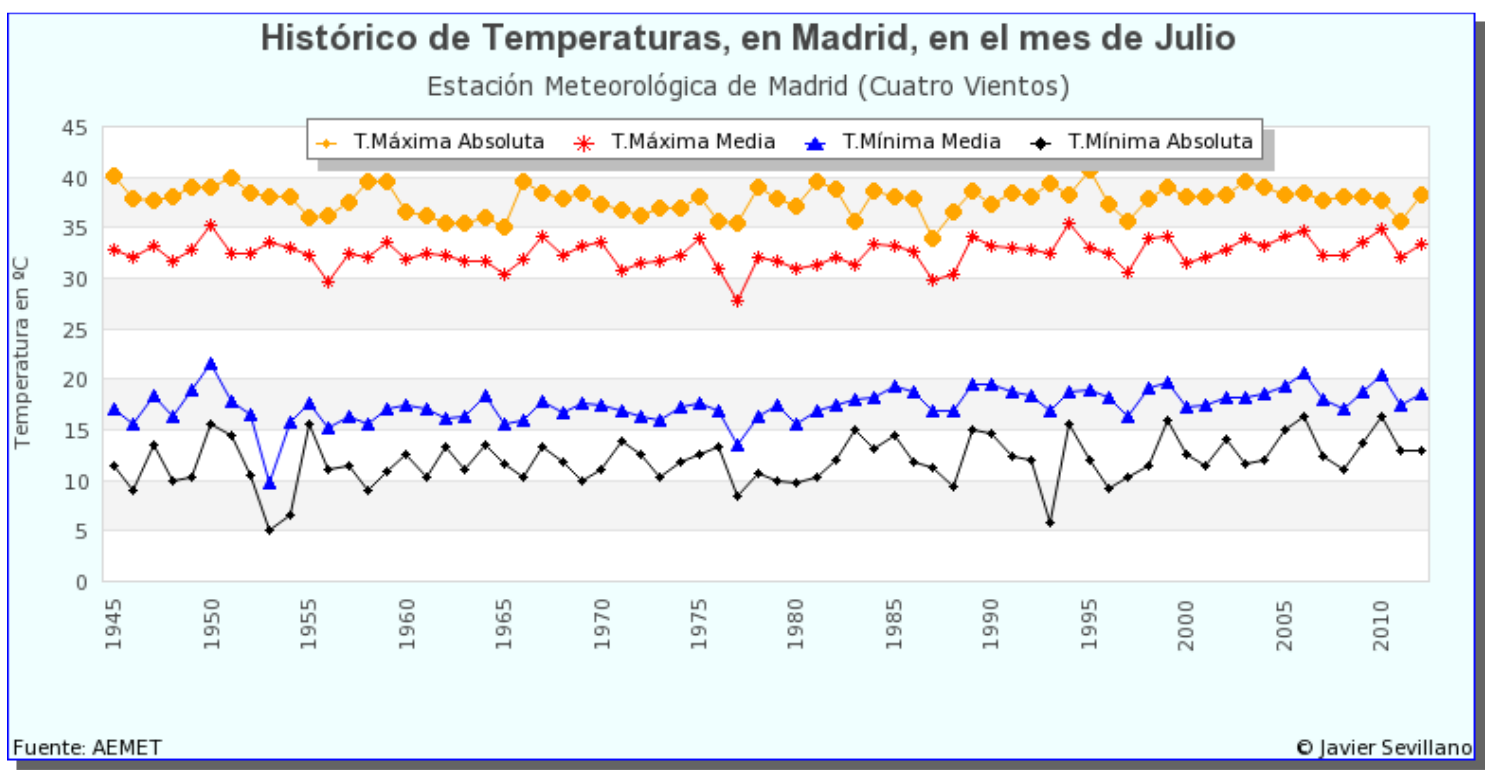

Figura I.7. Histórico de temperaturas en Madrid en el mes de julio $\left({ }^{\circ} \mathrm{C}\right)$.

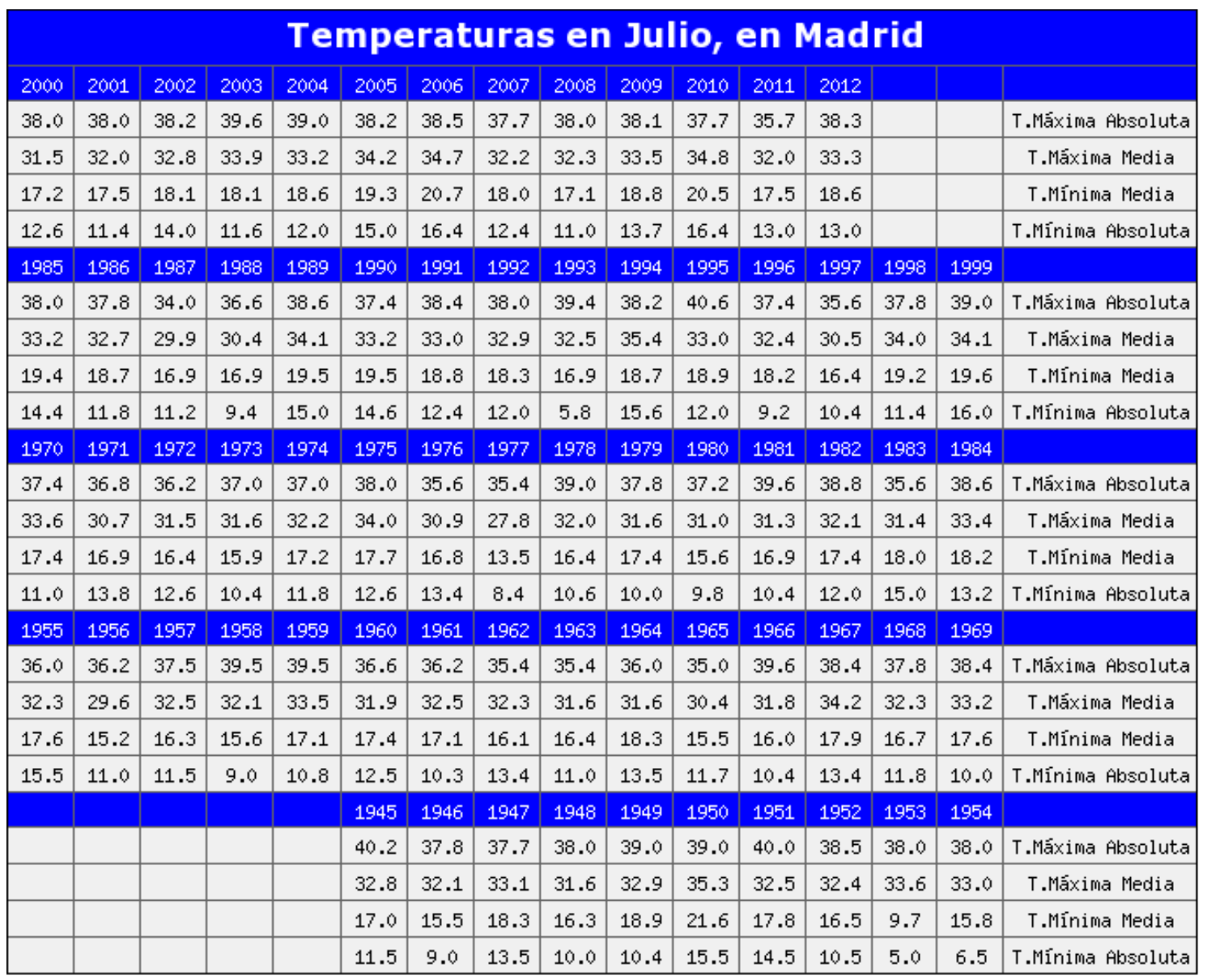

Tabla I.7. Histórico de temperaturas en Madrid en el mes de julio $\left({ }^{\circ} \mathrm{C}\right)$. 


\section{I.VIII HISTÓRICO DE TEMPERATURAS EN EL MES DE AGOSTO}

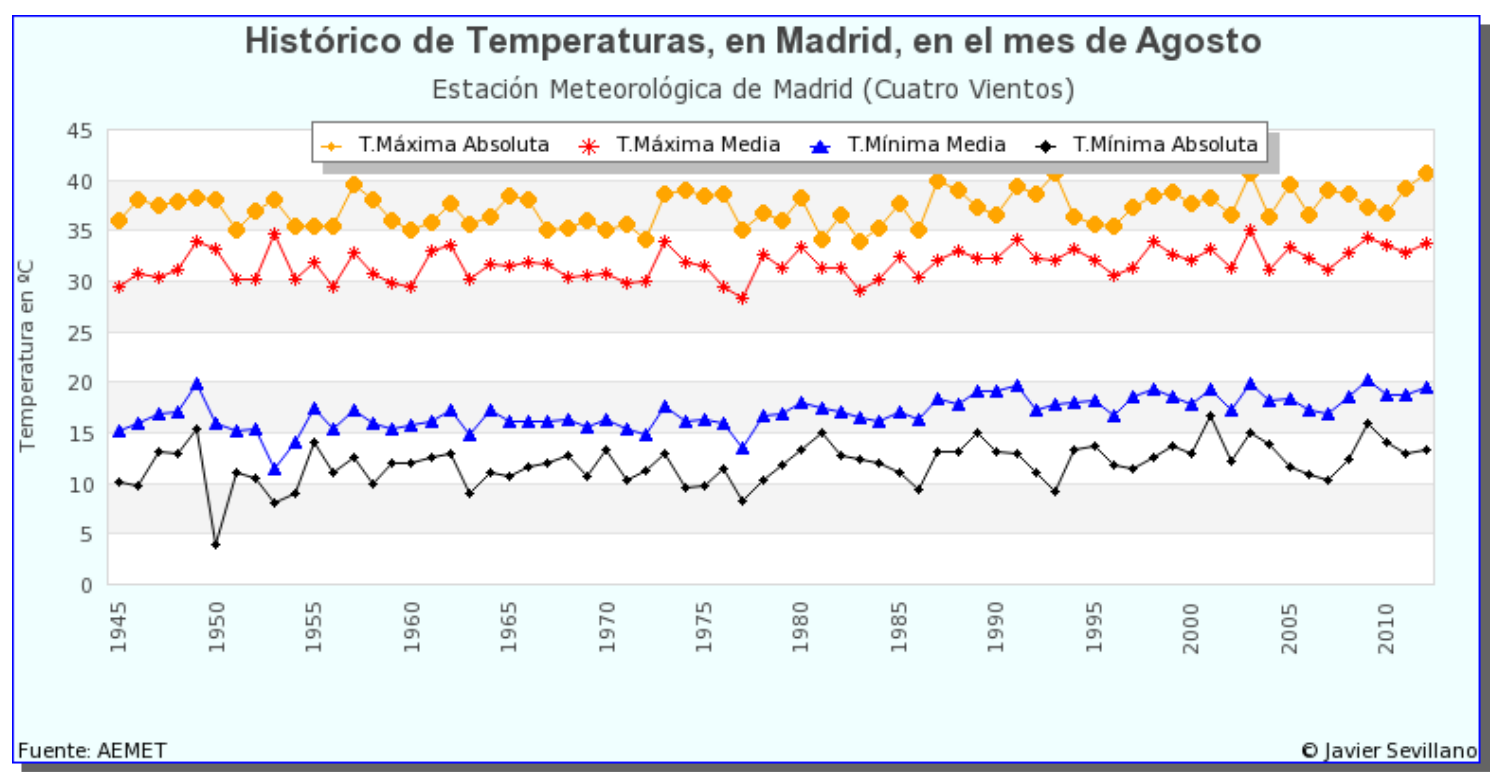

Figura I.8. Histórico de temperaturas en Madrid en el mes de agosto $\left({ }^{\circ} \mathrm{C}\right)$.

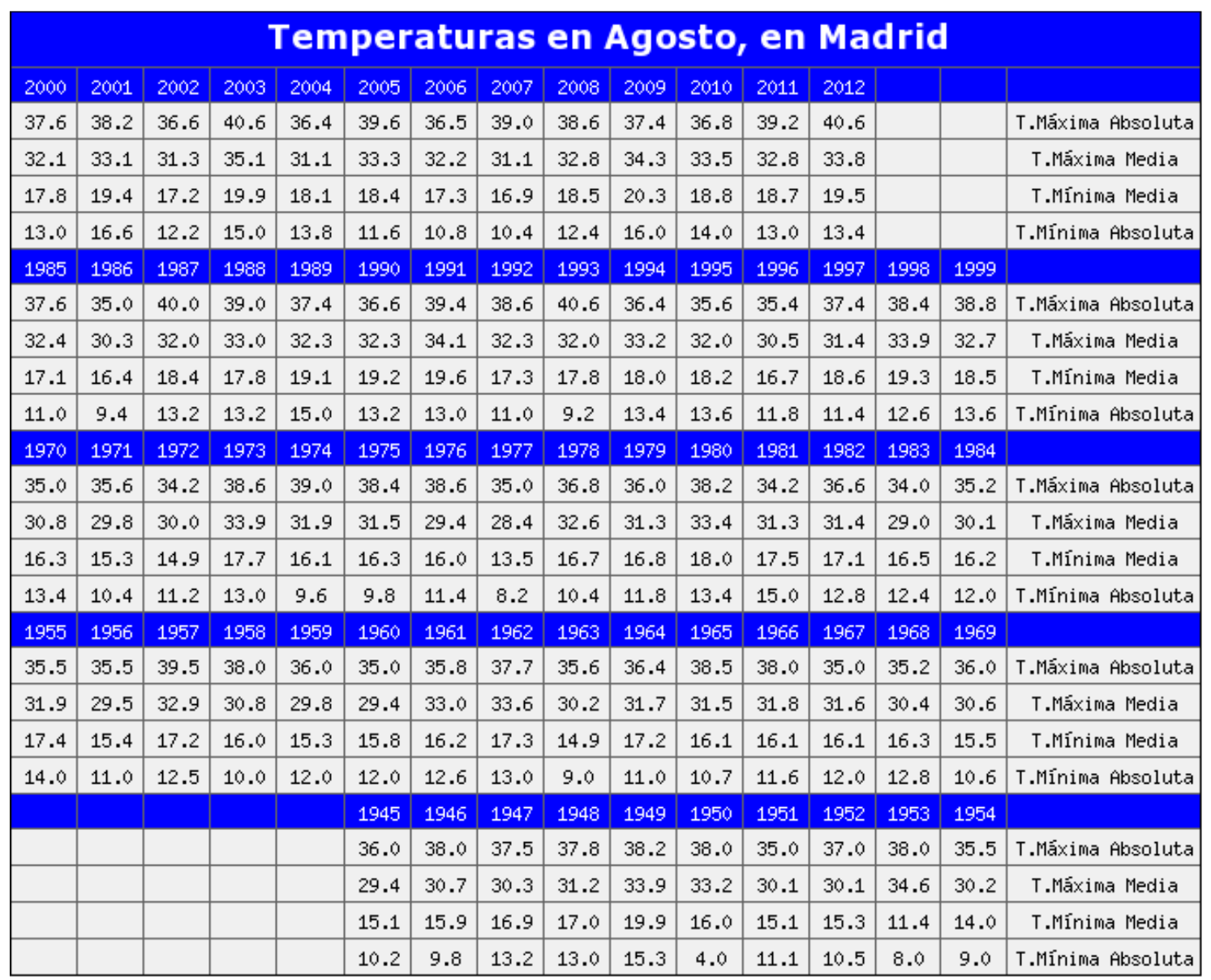

Tabla I.8. Histórico de temperaturas en Madrid en el mes de agosto $\left({ }^{\circ} \mathrm{C}\right)$. 


\section{I.IX HISTÓRICO DE TEMPERATURAS EN EL MES DE SEPTIEMBRE}

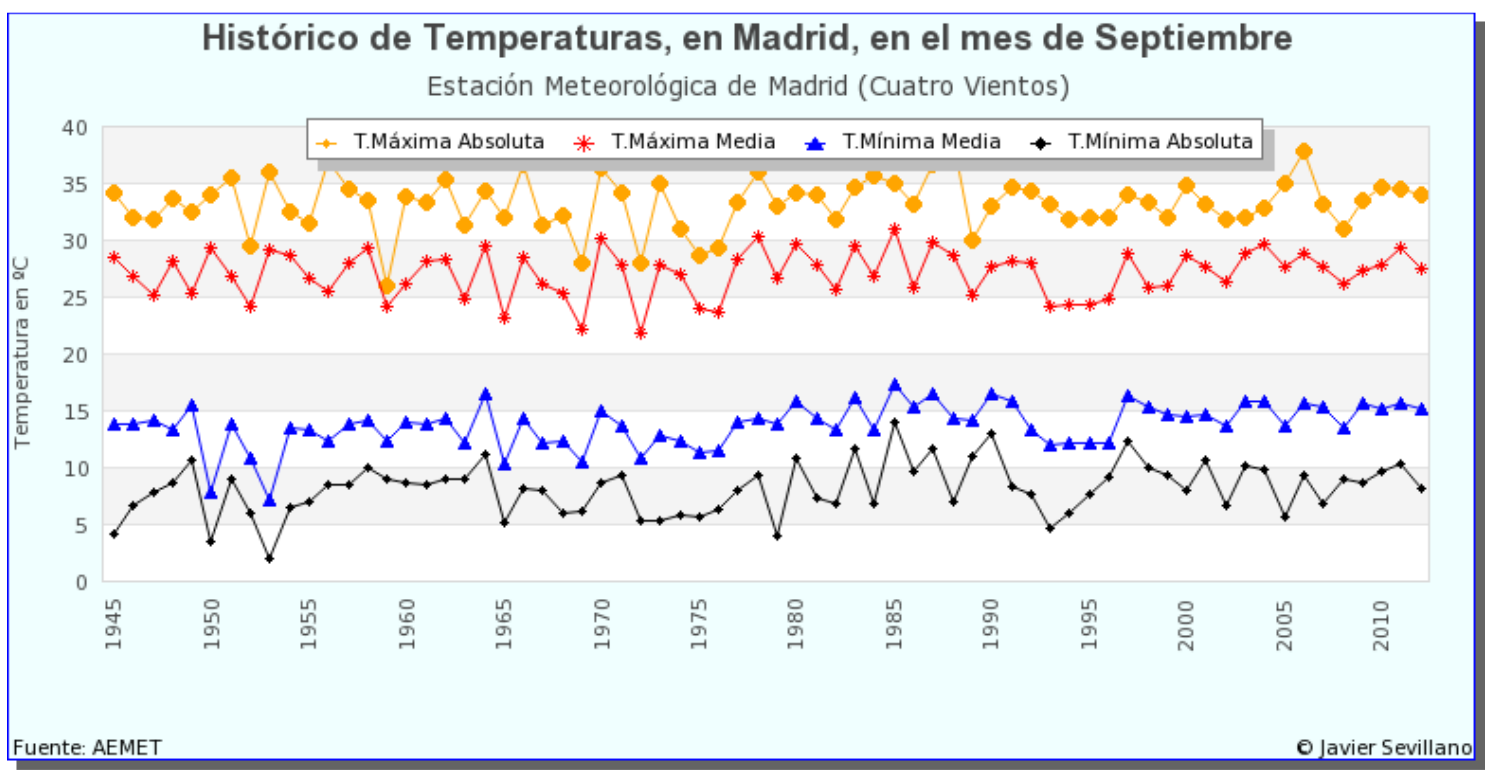

Figura I.9. Histórico de temperaturas en Madrid en el mes de septiembre $\left({ }^{\circ} \mathrm{C}\right)$.

\begin{tabular}{|c|c|c|c|c|c|c|c|c|c|c|c|c|c|c|c|}
\hline \multicolumn{16}{|c|}{ Temperaturas en Septiembre, en Madrid } \\
\hline 2000 & 2001 & 2002 & 2003 & 2004 & 2005 & 2006 & 2007 & 2008 & 2009 & 2010 & 2011 & 2012 & & & \\
\hline 34.8 & 33.2 & 31.8 & 32.0 & 32.8 & 35.0 & 37.8 & 33.2 & 31.0 & 33.5 & 34.6 & 34.5 & 34.0 & & & T.Măxima Absoluta \\
\hline 28.6 & 27.6 & 26.3 & 28.8 & 29.7 & 27.6 & 28.8 & 27.7 & 26.2 & 27.3 & 27.9 & 29.3 & 27.5 & & & T.Máxima Media \\
\hline 14.5 & 14.7 & 13.7 & 15.9 & 15.8 & 13.7 & 15.6 & 15.3 & 13.5 & 15.6 & 15.1 & 15.7 & 15.1 & & & T.Mínima Media \\
\hline 8.0 & 10.6 & 6.6 & 10.2 & 9.9 & 5.6 & 9.4 & 6.8 & 9.0 & 8.6 & 9.6 & 10.4 & 8.2 & & & T.Mínima Absoluta \\
\hline 1985 & 1986 & 1987 & 1988 & 1989 & 1990 & 1991 & 1992 & 1993 & 1994 & 1995 & 1996 & 1997 & 1998 & 1999 & \\
\hline 35.0 & 33.2 & 36.6 & 38.6 & 30.0 & 33.0 & 34.6 & 34.4 & 33.2 & 31.8 & 32.0 & 32.0 & 34.0 & 33.4 & 32.0 & T.Máxima fbsoluta \\
\hline 31.0 & 25.8 & 29.9 & 28.7 & 25.2 & 27.6 & 28.1 & 28.0 & 24.2 & 24.3 & 24.3 & 24.8 & 28.9 & 25.9 & 26.0 & T.Măxima Media \\
\hline 17.3 & 15.4 & 16.5 & 14.4 & 14.1 & 16.5 & 15.8 & 13.3 & 12.0 & 12.1 & 12.2 & 12.2 & 16.3 & 15.4 & 14.7 & T.Mínima Media \\
\hline 14.0 & 9.6 & 11.6 & 7.0 & 11.0 & 13.0 & 8.4 & 7.6 & 4.6 & 6.0 & 7.6 & 9.2 & 12.4 & 10.0 & 9.4 & T.Mínima Absoluta \\
\hline 1970 & 1971 & 1972 & 1973 & 1974 & 1975 & 1976 & 1977 & 1978 & 1979 & 1980 & 1981 & 1982 & 1983 & 1984 & \\
\hline 36.4 & 34.2 & 28.0 & 35.0 & 31.0 & 28.6 & 29.4 & 33.4 & 36.0 & 33.0 & 34.2 & 34.0 & 31.8 & 34.6 & 35.6 & T.Măxima Absoluta \\
\hline 30.2 & 27.8 & 21.9 & 27.9 & 27.0 & 24.0 & 23.6 & 28.3 & 30.4 & 26.6 & 29.7 & 27.8 & 25.6 & 29.5 & 26.8 & T.Mäxima Media \\
\hline 15.0 & 13.6 & 10.8 & 12.8 & 12.3 & 11.3 & 11.5 & 14.0 & 14.4 & 13.8 & 15.8 & 14.4 & 13.4 & 16.2 & 13.3 & T.Mínima Media \\
\hline 8.6 & 9.4 & 5.4 & 5.4 & 5.8 & 5.6 & 6.4 & 8.0 & 9.4 & 4.0 & 10.8 & 7.4 & 6.8 & 11.6 & 6.8 & T.Mínima Absoluta \\
\hline 1955 & 1956 & 1957 & 1958 & 1959 & 1960 & 1961 & 1962 & 1963 & 1964 & 1965 & 1966 & 1967 & 1968 & 1969 & \\
\hline 31.5 & 37.0 & 34.5 & 33.5 & 26.0 & 33.8 & 33.4 & 35.3 & 31.4 & 34.4 & 32.0 & 36.6 & 31.4 & 32.2 & 28.0 & T. Măxima Absoluta \\
\hline 26.6 & 25.5 & 28.0 & 29.3 & 24.1 & 26.2 & 28.1 & 28.4 & 24.9 & 29.5 & 23.1 & 28.5 & 26.1 & 25.4 & 22.1 & T.Măxima Media \\
\hline 13.4 & 12.4 & 13.9 & 14.1 & 12.4 & 14.0 & 13.8 & 14.3 & 12.2 & 16.5 & 10.3 & 14.3 & 12.1 & 12.4 & 10.5 & T.Mínima Media \\
\hline 7.0 & 8.5 & 8.5 & 10.0 & 9.0 & 8.6 & 8.5 & 9.0 & 9.0 & 11.2 & 5.2 & 8.2 & 8.0 & 6.0 & 6.2 & T.Mínima Absoluta \\
\hline & & & & & 1945 & 1946 & 1947 & 1948 & 1949 & 1950 & 1951 & 1952 & 1953 & 1954 & \\
\hline & & & & & 34.1 & 32.0 & 31.9 & 33.6 & 32.5 & 34.0 & 35.5 & 29.5 & 36.0 & 32.5 & T. Máxima Absoluta \\
\hline & & & & & 28.5 & 26.8 & 25.2 & 28.2 & 25.3 & 29.4 & 26.9 & 24.1 & 29.2 & 28.7 & T.Măxima Media \\
\hline & & & & & 13.9 & 13.9 & 14.1 & 13.4 & 15.5 & 7.9 & 13.8 & 10.8 & 7.2 & 13.5 & T.Mínima Media \\
\hline & & & & & 4.2 & 6.7 & 7.8 & 8.6 & 10.7 & 3.5 & 9.0 & 6.0 & 2.0 & 6.5 & T.Mínima Absoluta \\
\hline
\end{tabular}

Tabla I.9. Histórico de temperaturas en Madrid en el mes de septiembre $\left({ }^{\circ} \mathrm{C}\right)$. 


\section{I.X HISTÓRICO DE TEMPERATURAS EN EL MES DE OCTUBRE}

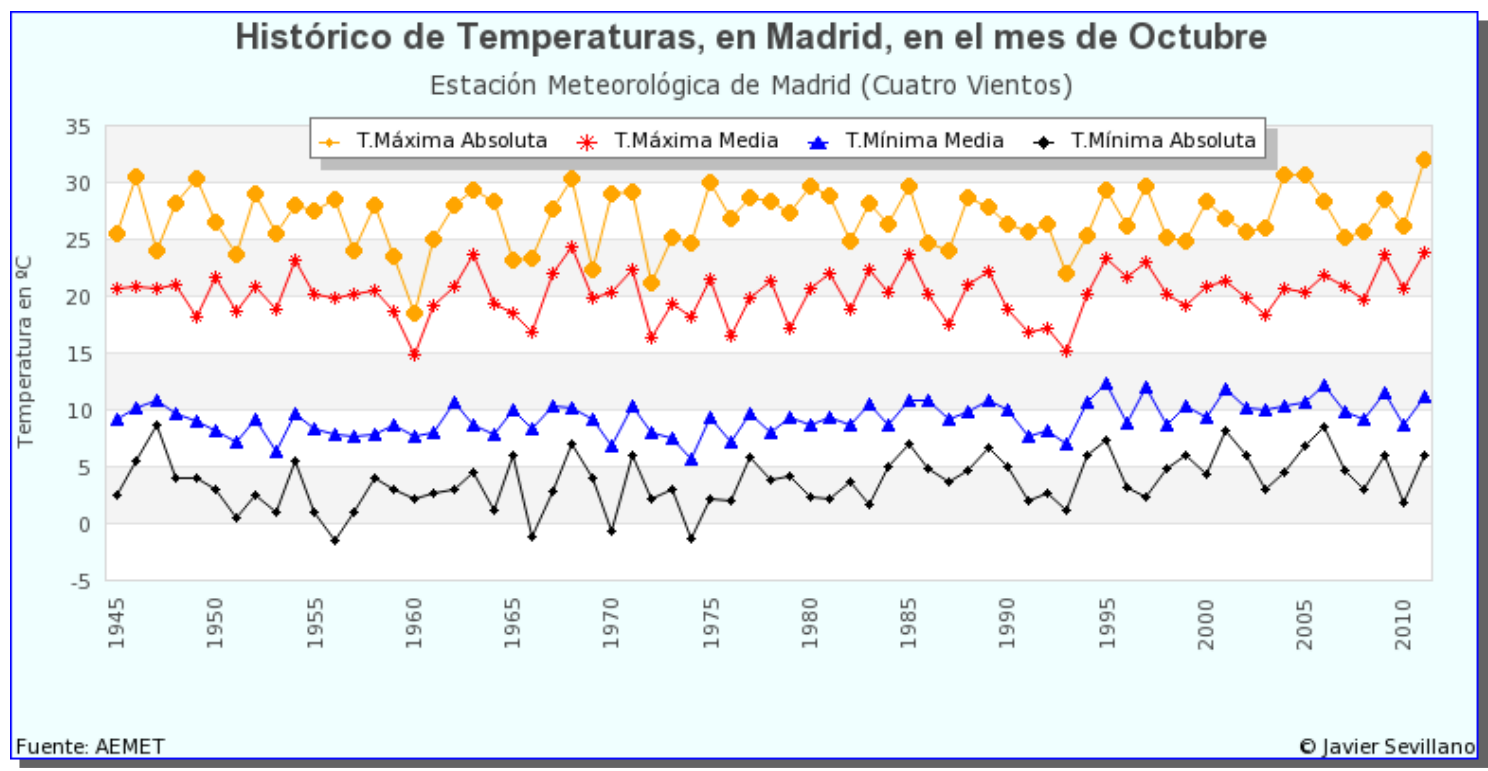

Figura I.10. Histórico de temperaturas en Madrid en el mes de octubre $\left({ }^{\circ} \mathrm{C}\right)$.

\begin{tabular}{|c|c|c|c|c|c|c|c|c|c|c|c|c|c|c|c|}
\hline \multicolumn{16}{|c|}{ Temperaturas en Octubre, en Madrid } \\
\hline 28.4 & 26.8 & 25.6 & 26.0 & 30.7 & 30.6 & 28.4 & 25.2 & 25.6 & 28.5 & 26.2 & 32.0 & & & & T.Măxima fbsoluta \\
\hline 20.8 & 21.3 & 19.9 & 18.4 & 20.6 & 20.3 & 21.8 & 20.9 & 19.6 & 23.6 & 20.6 & 23.9 & & & & T.Măxima Media \\
\hline 9.4 & 11.8 & 10.1 & 10.0 & 10.4 & 10.7 & 12.2 & 9.9 & 9.2 & 11.5 & 8.6 & 11.1 & & & & T.Mínima Media \\
\hline 4.4 & 8.2 & 6.0 & 3.0 & 4.5 & 6.8 & 8.5 & 4.6 & 3.0 & 6.0 & 1.8 & 6.0 & & & & T.Mínima Absoluta \\
\hline 1985 & 1986 & 1987 & 1988 & 1989 & 1990 & 1991 & 1992 & 1993 & 1994 & 1995 & 1996 & 1997 & 1998 & 1999 & \\
\hline 29.6 & 24.6 & 24.0 & 28.6 & 27.8 & 26.4 & 25.6 & 26.4 & 22.0 & 25.4 & 29.4 & 26.2 & 29.6 & 25.2 & 24.8 & T.Măxima fbsoluta \\
\hline 23.6 & 20.2 & 17.5 & 21.0 & 22.2 & 18.9 & 16.9 & 17.2 & 15.2 & 20.1 & 23.4 & 21.6 & 23.0 & 20.1 & 19.2 & T.Măxima Media \\
\hline 10.9 & 10.9 & 9.2 & 9.9 & 10.8 & 10.0 & 7.7 & 8.2 & 7.0 & 10.7 & 12.3 & 8.8 & 12.0 & 8.6 & 10.4 & T.Mínima Media \\
\hline 7.0 & 4.8 & 3.6 & 4.6 & 6.7 & 5.0 & 2.0 & 2.6 & 1.2 & 6.0 & 7.4 & 3.2 & 2.4 & 4.8 & 6.0 & T.Mínima Absoluta \\
\hline 1970 & 1971 & 1972 & 1973 & 1974 & 1975 & 1976 & 1977 & 1978 & 1979 & 1980 & 1981 & 1982 & 1983 & 1984 & \\
\hline 29.0 & 29.2 & 21.2 & 25.2 & 24.6 & 30.0 & 26.8 & 28.6 & 28.4 & 27.4 & 29.6 & 28.8 & 24.8 & 28.2 & 26.4 & T.Măxima fbsoluta \\
\hline 20.4 & 22.3 & 16.4 & 19.4 & 18.1 & 21.5 & 16.5 & 19.8 & 21.3 & 17.2 & 20.6 & 22.0 & 18.9 & 22.4 & 20.3 & T.Máxima Media \\
\hline 6.9 & 10.4 & 8.0 & 7.5 & 5.6 & 9.3 & 7.1 & 9.6 & 8.0 & 9.4 & 8.6 & 9.3 & 8.6 & 10.5 & 8.6 & T.Mínima Media \\
\hline-0.6 & 6.0 & 2.2 & 3.0 & -1.4 & 2.2 & 2.0 & 5.8 & 3.8 & 4.2 & 2.4 & 2.2 & 3.6 & 1.6 & 5.0 & T.Mínima Absoluta \\
\hline 1955 & 1956 & 1957 & 1958 & 1959 & 1960 & 1961 & 1962 & 1963 & 1964 & 1965 & 1966 & 1967 & 1968 & 1969 & \\
\hline 27.5 & 28.5 & 24.0 & 28.0 & 23.5 & 18.5 & 25.0 & 28.0 & 29.4 & 28.4 & 23.2 & 23.4 & 27.6 & 30.4 & 22.4 & T.Măxima fbsoluta \\
\hline 20.1 & 19.9 & 20.1 & 20.5 & 18.6 & 14.8 & 19.1 & 20.9 & 23.6 & 19.3 & 18.5 & 16.8 & 22.0 & 24.4 & 19.8 & T.Măxima Media \\
\hline 8.3 & 7.8 & 7.7 & 7.9 & 8.7 & 7.6 & 8.0 & 10.7 & 8.6 & 7.8 & 10.0 & 8.3 & 10.4 & 10.2 & 9.1 & T.Mínima Media \\
\hline 1.0 & -1.5 & 1.0 & 4.0 & 3.0 & 2.2 & 2.6 & 3.0 & 4.5 & 1.2 & 6.0 & -1.2 & 2.8 & 7.0 & 4.0 & T.Mínima Absoluta \\
\hline & & & & & 1945 & 1946 & 1947 & 1948 & 1949 & 1950 & 1951 & 1952 & 1953 & 1954 & \\
\hline & & & & & 25.5 & 30.5 & 24.0 & 28.2 & 30.4 & 26.5 & 23.7 & 29.0 & 25.5 & 28.0 & T.Măxima fbsoluta \\
\hline & & & & & 20.7 & 20.9 & 20.7 & 21.0 & 18.2 & 21.7 & 18.6 & 20.8 & 18.8 & 23.2 & T.Măxima Media \\
\hline & & & & & 9.2 & 10.2 & 10.9 & 9.6 & 9.0 & 8.2 & 7.2 & 9.2 & 6.3 & 9.6 & T.Mínima Media \\
\hline & & & & & 2.5 & 5.5 & 8.6 & 4.0 & 4.0 & 3.0 & 0.5 & 2.5 & 1.0 & 5.5 & T.Mínima Absoluta \\
\hline
\end{tabular}

Tabla I.10. Histórico de temperaturas en Madrid en el mes de octubre $\left({ }^{\circ} \mathrm{C}\right)$. 


\section{I.XI HISTÓRICO DE TEMPERATURAS EN EL MES DE NOVIEMBRE}

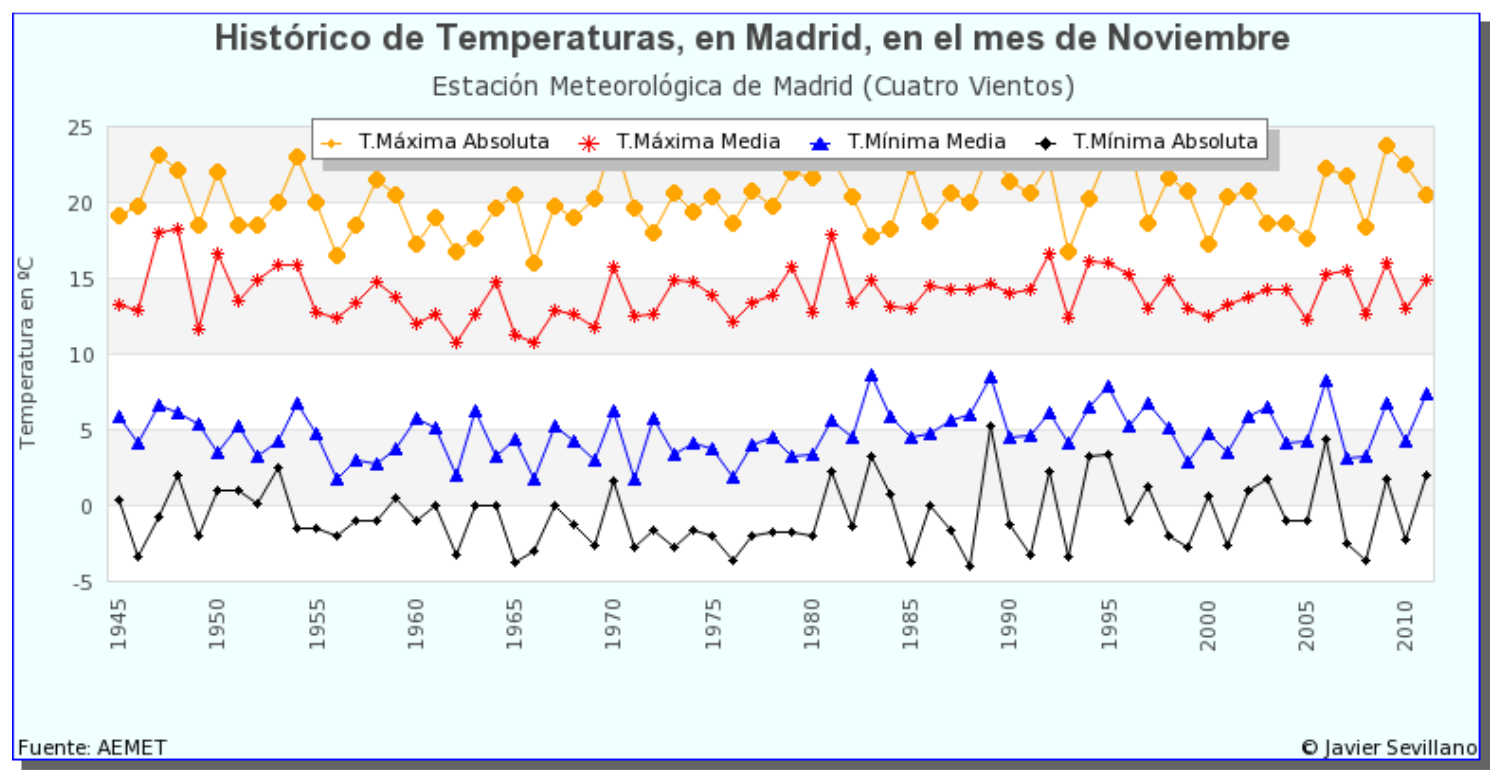

Figura I.11. Histórico de temperaturas en Madrid en el mes de noviembre $\left({ }^{\circ} \mathrm{C}\right)$.

\begin{tabular}{|c|c|c|c|c|c|c|c|c|c|c|c|c|c|c|c|}
\hline \multicolumn{16}{|c|}{ Temperaturas en Noviembre, en Madrid } \\
\hline 17.2 & 20.4 & 20.8 & 18.6 & 18.6 & 17.6 & 22.2 & 21.8 & 18.4 & 23.8 & 22.5 & 20.5 & & & & T.Măxima fbsoluta \\
\hline 12.5 & 13.3 & 13.7 & 14.2 & 14.3 & 12.3 & 15.3 & 15.5 & 12.6 & 16.0 & 13.0 & 14.9 & & & & T.Măxima Media \\
\hline 4.8 & 3.5 & 5.9 & 6.5 & 4.1 & 4 & 8.3 & 3.1 & 3.2 & 6.7 & 4.2 & 7.4 & & & & Mínima Media \\
\hline 0.6 & -2.6 & 1.0 & 1.8 & -1.0 & -1.0 & 4.4 & -2.5 & -3.6 & 1.8 & -2.2 & 2.0 & & & & T.Mínima Absoluta \\
\hline 1985 & 1986 & 1987 & 1988 & 1989 & 1990 & 1991 & 1992 & 1993 & 1994 & 1995 & 1996 & 1997 & 1998 & 1999 & \\
\hline 22.4 & 18.8 & 20.6 & 20.0 & 23.6 & 21.4 & 20.6 & 22.6 & 16.8 & 20.2 & 23.2 & 24.0 & 18.6 & 21.6 & 20.8 & T.Máxima Absoluta \\
\hline 13.0 & 14.5 & 14.2 & 14.2 & 14.6 & 14.0 & 14.2 & 16.6 & 12.4 & 16.1 & 16.0 & 15.3 & 13.0 & 14.9 & 13.0 & T.Măxima Media \\
\hline 4.5 & 4.7 & 5.6 & 6.0 & 8.5 & 4.5 & 4.6 & 6.1 & 4.1 & 6 & 9 & 5.2 & & & 2.9 & \\
\hline-3.8 & 0.0 & -1.6 & -4.0 & 5.2 & -1.2 & -3.2 & 2.2 & -3.4 & 3.2 & 3.4 & -1.0 & 1.2 & -2.0 & -2.8 & T.Mínima Absoluta \\
\hline 1970 & 1971 & 1972 & 1973 & 1974 & 1975 & 1976 & 1977 & 1978 & 1979 & 1980 & 1981 & 1982 & 1983 & 1984 & \\
\hline 24.2 & 19.6 & 18.0 & 20.6 & 19.4 & 20.4 & 18.6 & 20.8 & 19.8 & 22.0 & 21.6 & 23.0 & 20.4 & 17.8 & 18.2 & T.Măxima fbsoluta \\
\hline 15.7 & 12.5 & 12.6 & 14.9 & 14.7 & 13.9 & 12.1 & 13.4 & 13.9 & 15.7 & 12.7 & 17.9 & 13.4 & 14.9 & 13.1 & T.Măxima Media \\
\hline 6.2 & 1.8 & 5.7 & 3.4 & 4.1 & 3.8 & 1.9 & 4.0 & 4.5 & 3.3 & 3.4 & 5.6 & 4.5 & 8.6 & 5.9 & T.Mínima Media \\
\hline 1.6 & -2.8 & -1.6 & -2.8 & -1.6 & -2.0 & -3.6 & -2.0 & -1.8 & -1.8 & -2.0 & 2.2 & -1.4 & 3.2 & 0.8 & T.Mínima Absoluta \\
\hline 1955 & 1956 & 1957 & 1958 & 1959 & 1960 & 1961 & 1962 & 1963 & 1964 & 1965 & 1966 & 1967 & 1968 & 1969 & \\
\hline 20.0 & 16.5 & 18.5 & 21.5 & 20.5 & 17.2 & 19.0 & 16.8 & 17.6 & 19.6 & 20.5 & 16.0 & 19.8 & 19.0 & 20.2 & T.Măxima Absoluta \\
\hline 12.8 & 12.4 & 13.4 & 14.7 & 13.8 & 12.0 & 12.6 & 10.8 & 12.6 & 14.8 & 11.3 & 10.8 & 12.9 & 12.6 & 11.8 & T.Măxima Media \\
\hline 4.7 & 1.7 & 3.0 & 2.7 & 3.8 & 5.8 & 5.1 & 2.0 & 6.2 & 3.3 & 4.4 & 1.8 & 5.2 & 4.2 & 3.0 & T.Mínima Media \\
\hline-1.5 & -2.0 & -1.0 & -1.0 & 0.5 & -1.0 & 0.0 & -3.2 & 0.0 & 0.0 & -3.7 & -3.0 & 0.0 & -1.2 & -2.6 & T.Mínima Absoluta \\
\hline & & & & & 1945 & 1946 & 1947 & 1948 & 1949 & 1950 & 1951 & 1952 & 1953 & 1954 & \\
\hline & & & & & 19.1 & 19.7 & 23.1 & 22.1 & 18.5 & 22.0 & 18.5 & 18.5 & 20.0 & 23.0 & T.Măxima Absoluta \\
\hline & & & & & 13.2 & 12.9 & 18.0 & 18.2 & 11.6 & 16.6 & 13.5 & 14.9 & 15.9 & 15.9 & T.Măxima Media \\
\hline & & & & & 5.9 & 4.1 & 6.6 & 6.1 & 5.4 & 3.5 & 5.3 & 3.2 & 4.2 & 6.8 & T.Mínima Media \\
\hline & & & & & 0.4 & -3.4 & -0.8 & 2.0 & -2.0 & 1.0 & 1.0 & 0.1 & 2.5 & -1.5 & T.Mînima Absoluta \\
\hline
\end{tabular}

Tabla I.11. Histórico de temperaturas en Madrid en el mes de noviembre $\left({ }^{\circ} \mathrm{C}\right)$. 


\section{I.XII HISTÓRICO DE TEMPERATURAS EN EL MES DE DICIEMBRE}

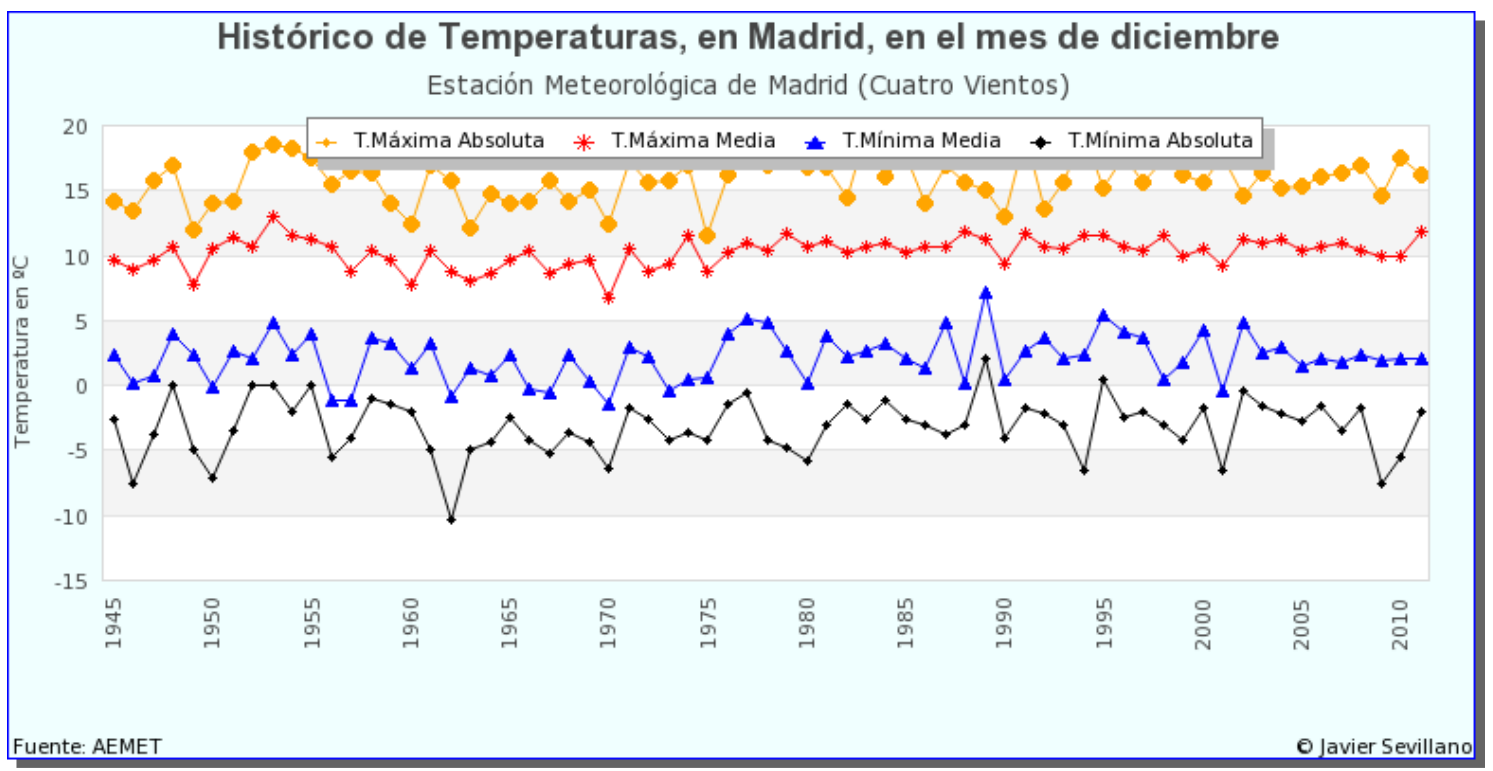

Figura I.12. Histórico de temperaturas en Madrid en el mes de diciembre $\left({ }^{\circ} \mathrm{C}\right)$.

\begin{tabular}{|c|c|c|c|c|c|c|c|c|c|c|c|c|c|c|c|}
\hline \multicolumn{16}{|c|}{ Temperaturas en diciembre, en Madrid } \\
\hline 2000 & 2001 & 2002 & 2003 & 2004 & 2005 & 2006 & 2007 & 2008 & 2009 & 2010 & 2011 & & & & \\
\hline 15.6 & 17.6 & 14.6 & 16.4 & 15.2 & 15.4 & 16.0 & 16.4 & 17.0 & 14.6 & 17.5 & 16.2 & & & & T.Măxima Absoluta \\
\hline 10.5 & 9.2 & 11.3 & 10.9 & 11.2 & 10.4 & & 11.0 & 10.4 & & & 11.9 & & & & T.Măxima Media \\
\hline 4.2 & -0.4 & 4.9 & 2.5 & 3.0 & 1.5 & & 1.8 & 2.3 & 1.9 & 2.1 & 2.1 & & & & T.Mínima Media \\
\hline-1.8 & -6.6 & -0.4 & -1.6 & -2.2 & -2.8 & -1.6 & -3.5 & -1.8 & -7.5 & -5.5 & -2.0 & & & & T.Mínima Absoluta \\
\hline 1985 & 1986 & 1987 & 1988 & 1989 & 1990 & 1991 & 1992 & 1993 & 1994 & 1995 & 1996 & 1997 & 1998 & 1999 & \\
\hline 17.6 & 14.0 & 17.0 & 15.6 & 15.0 & 13.0 & 19.2 & 13.6 & 15.6 & 19.4 & 15.2 & 17.6 & 15.6 & 17.4 & 16.2 & T.Măxima Absoluta \\
\hline 10.2 & 10.6 & 10.7 & 11.9 & 11.3 & 9.4 & 11.7 & 10.7 & 10.5 & 11.6 & 11.5 & 10.6 & 10.4 & 11.5 & 9.9 & T.Măxima Media \\
\hline 2.1 & 1.3 & 4.9 & 0.2 & 7.2 & 0.5 & 2.7 & 3.6 & 2.1 & 2.3 & 5.4 & 4.1 & 3.7 & 0.5 & 1.8 & T.Mínima Media \\
\hline-2.6 & -3.0 & -3.8 & -3.0 & 2.0 & -4.0 & -1.8 & -2.2 & -3.0 & -6.6 & 0.4 & -2.4 & -2.0 & -3.0 & -4.2 & T.Mínima Absoluta \\
\hline 1970 & 1971 & 1972 & 1973 & & & & & 1978 & 1979 & 980 & 1981 & 1982 & 983 & 1984 & \\
\hline 12.4 & 17.2 & 15.6 & 15.8 & 17.0 & 11.6 & 16.2 & 17.4 & 17.0 & 19.4 & 16.8 & 16.8 & 14.4 & 19.6 & 16.0 & T.Mắxima Absoluta \\
\hline 6.8 & 10.5 & 8.8 & 9.4 & 11.6 & 8.8 & 10.2 & 11.0 & 10.4 & 11.7 & 10.6 & 11.1 & 10.2 & 10.7 & 11.0 & T.Măxima Media \\
\hline-1.5 & 3.0 & 2.2 & -0.4 & 0.5 & 0.6 & 3.9 & 5.1 & 4.8 & 2.6 & 0.1 & 3.8 & 2.2 & 2.7 & 3.2 & T.Mínima Media \\
\hline-6.4 & -1.8 & -2.6 & -4.2 & -3.6 & -4.2 & -1.4 & -0.6 & -4.2 & -4.8 & -5.8 & -3.0 & -1.4 & -2.6 & -1.2 & T.Mínima Absoluta \\
\hline 1955 & 1956 & 1957 & 1958 & 1959 & 1960 & 1961 & 1962 & 1963 & 1964 & 1965 & 1966 & 1967 & 1968 & 1969 & \\
\hline 17.5 & 15.5 & 16.5 & 16.3 & 14.0 & 12.4 & 17.0 & 15.8 & 12.1 & 14.8 & 14.0 & 14.2 & 15.8 & 14.2 & 15.0 & T.Măxima Absoluta \\
\hline 11.2 & 10.6 & 8.8 & 10.4 & 9.6 & 7.8 & 10.4 & 8.8 & 8.0 & & & 10.4 & 8.6 & 9.3 & 9.6 & T.Măxima Media \\
\hline 4.0 & -1.1 & -1.2 & 3.7 & 3.3 & 1.3 & & -0.8 & 1.4 & 0.8 & 2.4 & -0.2 & -0.6 & 2.4 & 0.3 & T.Mínima Media \\
\hline 0.0 & -5.5 & -4.0 & -1.0 & -1.5 & -2.0 & -5.0 & -10.3 & -5.0 & -4.4 & -2.5 & -4.2 & -5.2 & -3.6 & -4.4 & T.Mínima Absoluta \\
\hline & & & & & 1945 & 1946 & 1947 & 1948 & 1949 & 1950 & 1951 & 1952 & 1953 & 1954 & \\
\hline & & & & & 14.1 & 13.5 & 15.8 & 17.0 & 12.0 & 14.0 & 14.2 & 18.0 & 18.5 & 18.2 & T.Măxima Absoluta \\
\hline & & & & & 9.6 & 8.9 & 9.7 & 10.6 & 7.8 & 10.5 & 11.4 & 10.7 & 13.0 & 11.6 & T.Măxima Media \\
\hline & & & & & 2.4 & 0.1 & 0.7 & 3.9 & 2.3 & -0.1 & 2.7 & 2.0 & 4.9 & 2.3 & T.Mínima Media \\
\hline & & & & & -2.6 & -7.5 & -3.8 & 0.0 & -5.0 & -7.1 & -3.5 & 0.0 & 0.0 & -2.0 & T.Mínima Absoluta \\
\hline
\end{tabular}

Tabla I.12. Histórico de temperaturas en Madrid en el mes de diciembre $\left({ }^{\circ} \mathrm{C}\right)$. 
Optimización de la fachada de doble piel acristalada con ventilación natural. Metodología de diseño para el análisis de la eficiencia energética del sistema. 


\section{Lista de Figuras Anexo I}

Figura I.1. Histórico de temperaturas en Madrid en el mes de enero $\left({ }^{\circ} \mathrm{C}\right)$.................. 238

Figura I.2. Histórico de temperaturas en Madrid en el mes de febrero $\left({ }^{\circ} \mathrm{C}\right)$................ 239

Figura I.3. Histórico de temperaturas en Madrid en el mes de marzo $\left({ }^{\circ} \mathrm{C}\right)$. ................. 240

Figura I.4. Histórico de temperaturas en Madrid en el mes de abril $\left({ }^{\circ} \mathrm{C}\right)$...................... 241

Figura I.5. Histórico de temperaturas en Madrid en el mes de mayo $\left({ }^{\circ} \mathrm{C}\right)$. .................. 242

Figura I.6. Histórico de temperaturas en Madrid en el mes de junio $\left({ }^{\circ} \mathrm{C}\right)$.................... 243

Figura I.7. Histórico de temperaturas en Madrid en el mes de julio $\left({ }^{\circ} \mathrm{C}\right)$...................... 244

Figura I.8. Histórico de temperaturas en Madrid en el mes de agosto $\left({ }^{\circ} \mathrm{C}\right)$.................. 245

Figura I.9. Histórico de temperaturas en Madrid en el mes de septiembre $\left({ }^{\circ} \mathrm{C}\right)$. ......... 246

Figura I.10. Histórico de temperaturas en Madrid en el mes de octubre $\left({ }^{\circ} \mathrm{C}\right)$.............. 247

Figura I.11. Histórico de temperaturas en Madrid en el mes de noviembre $\left({ }^{\circ} \mathrm{C}\right)$......... 248

Figura I.12. Histórico de temperaturas en Madrid en el mes de diciembre $\left({ }^{\circ} \mathrm{C}\right)$.......... 249 


\section{Lista de Tablas Anexo I}

Tabla I.1. Histórico de temperaturas en Madrid en el mes de enero $\left({ }^{\circ} \mathrm{C}\right)$.................... 238

Tabla I.2. Histórico de temperaturas en Madrid en el mes de febrero $\left({ }^{\circ} \mathrm{C}\right)$.................. 239

Tabla I.3. Histórico de temperaturas en Madrid en el mes de marzo $\left({ }^{\circ} \mathrm{C}\right)$. .................. 240

Tabla I.4. Histórico de temperaturas en Madrid en el mes de abril $\left({ }^{\circ} \mathrm{C}\right)$. ..................... 241

Tabla I.5. Histórico de temperaturas en Madrid en el mes de mayo $\left({ }^{\circ} \mathrm{C}\right)$..................... 242

Tabla I.6. Histórico de temperaturas en Madrid en el mes de junio $\left({ }^{\circ} \mathrm{C}\right)$.................... 243

Tabla I.7. Histórico de temperaturas en Madrid en el mes de julio $\left({ }^{\circ} \mathrm{C}\right)$. ...................... 244

Tabla I.8. Histórico de temperaturas en Madrid en el mes de agosto $\left({ }^{\circ} \mathrm{C}\right)$................... 245

Tabla I.9. Histórico de temperaturas en Madrid en el mes de septiembre $\left({ }^{\circ} \mathrm{C}\right)$............ 246

Tabla I.10. Histórico de temperaturas en Madrid en el mes de octubre $\left({ }^{\circ} \mathrm{C}\right)$. .............. 247

Tabla I.11. Histórico de temperaturas en Madrid en el mes de noviembre $\left({ }^{\circ} \mathrm{C}\right)$.......... 248

Tabla I.12. Histórico de temperaturas en Madrid en el mes de diciembre $\left({ }^{\circ} \mathrm{C}\right)$........... 249 
